UNIVERSIDAD POLITÉCNICA DE VALENCIA

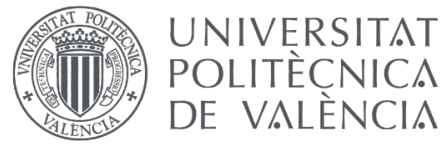

Departamento de Proyectos Arquitectónicos

\title{
SISTEMAS COMPLEJOS DE FACHADAS LA ADAPTABILIDAD DE LAS ENVOLVENTES DE VIDRIO
}

María Palencia Muro

Diciembre, 2015, Valencia

\author{
Director: \\ Dr. Jorge Torres Cueco \\ UNIVERSIDAD POLITÉCNICA DE VALENCIA
}



SISTEMAS COMPLEJOS DE FACHADAS. LA ADAPTABILIDAD DE LAS ENVOLVENTES DE VIDRIO

UNIVERSIDAD POLITÉCNICA DE VALENCIA 

ÍNDICE DE CONTENIDOS

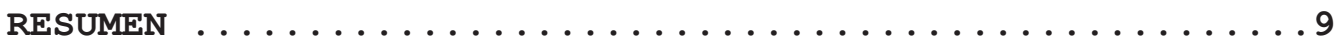

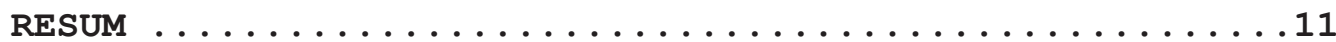

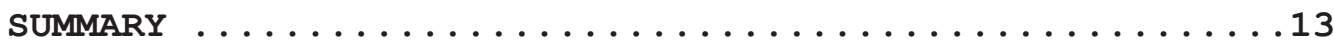

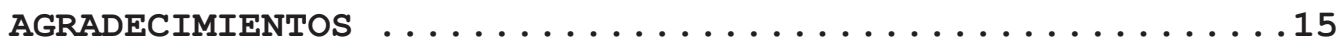

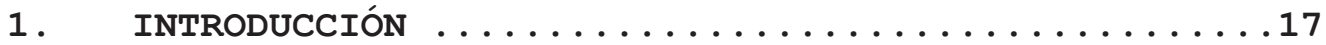

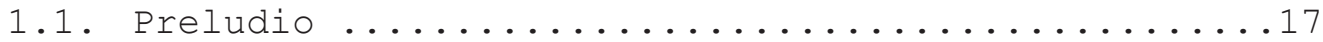

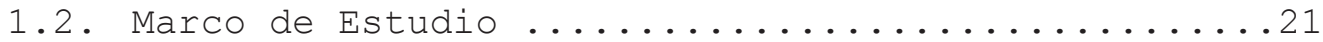

1.2.1 Técnica. Concepto ................23

1.2.2 Eficiencia Energética. Concepto ..........25

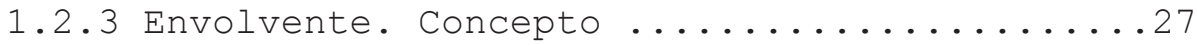

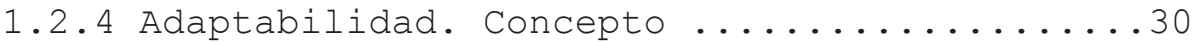

1.3. Hipótesis y Objetivos de la Investigación ........33

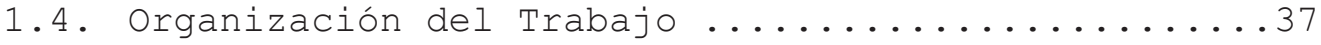

2. LA TÉCNICA. INICIOS DE LAS ENVOLVENTES .......41

2.1. Prototipo de Técnica. El Modelo Arquitectónico en

Altura. Chicago .....................41

2.2. La Envolvente como superficie continua.

Mies van der Rohe, Chicago. ...............51

2.2.1 Lake Shore Drive (MVdR, Chicago 1951) .....57

2.2.2 One IBM Plaza (MVdR, Chicago 1970) .......62

2.2 .3 Consideraciones .................66

2.3. La Envolvente como superficie intercambiadora.

Schipporeit \& Heinrich, Chicago ............67

2.3.1 Lake Point Tower (GS\& JH, Chicago 1969) ...70

2.3 .2 Consideraciones .................76

3. LA ENERGÍA. EVOLUCIÓN DE LAS ENVOLVENTES .......79

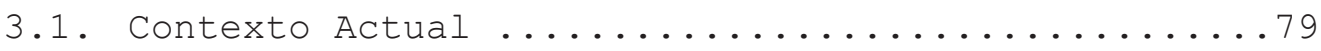

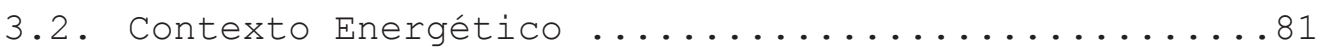

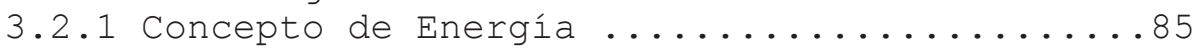

3.2.2 Concepto de Epidermis ..............87

3.2.3 Concepto de Envolvente

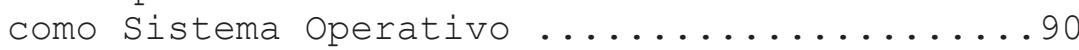



3.2.4 Barreras Existentes ................93

3.3. La Envolvente como superficie de adaptabilidad.

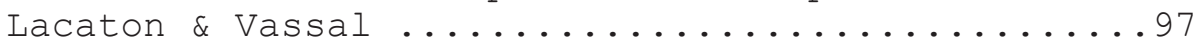

3.3.1 Proyecto de Transformación de

Tour Bois le Petre (París, 2005 - 2011) ........100

3.3.2 Proyecto de Transformación de una torre de

viviendas en Saint-Nazaire

(Saint-Nazaire, 2006 - 2012) ...............104

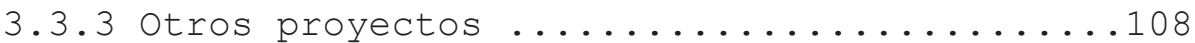

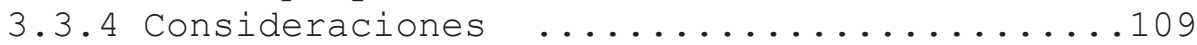

4. LA ENVOLVENTE. COMPONENTES Y COMPORTAMIENTO ....113

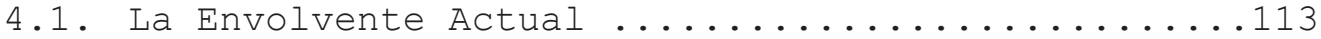

4.2. Componentes y Principios de la Envolvente de Vidrio.

La Piel Simple vs. La Piel Multi-capa .........115

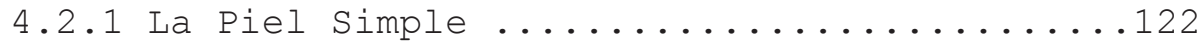

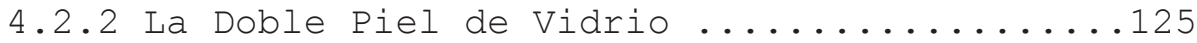

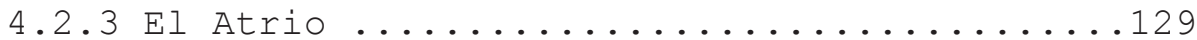

4.3. La Envolvente como superficie de evolución.

SCB, Chicago; Krueck \& Sexton, Chicago ..........131

4.3.1 340 on the Park (SCB, Chicago 2007) ......131

4.3.2 Spertus Building (K\&S, Chicago 2007) .....138

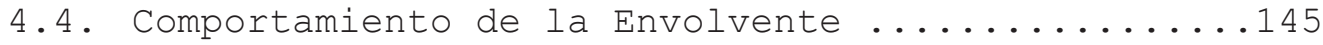

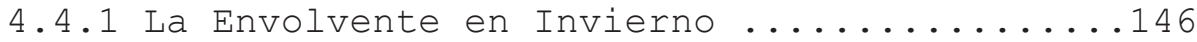

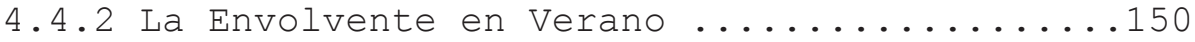

5. LA ADAPTABILIDAD. PROYECTO DE TRANSFORMACIÓN DE LA

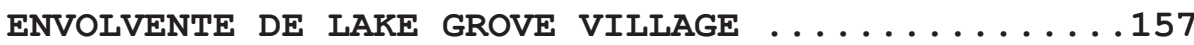

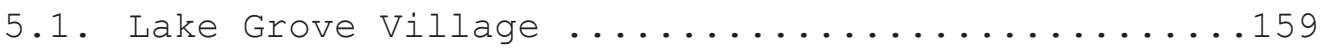

5.1.1 Paul DePondt. El Arquitecto .....................

5.1.2 Lake Grove Village. La Arquitectura ......170

5.2. Objetivos del Diseño y Campo de Trabajo .........179

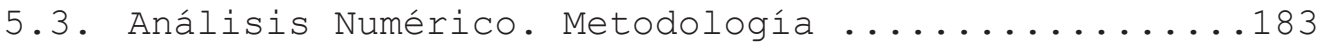

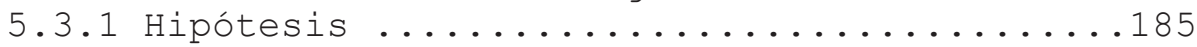

5.3.2 Características del Prototipo de Estudio ..187

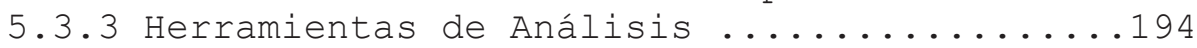

5.3.4 Descripción del Proceso ..............204

5.4. Evaluación de los componentes para una Envolvente de

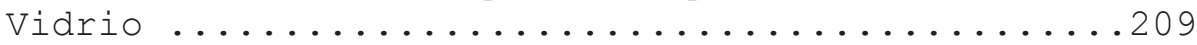

5.4.1 Estudio del Vidrio ................211 



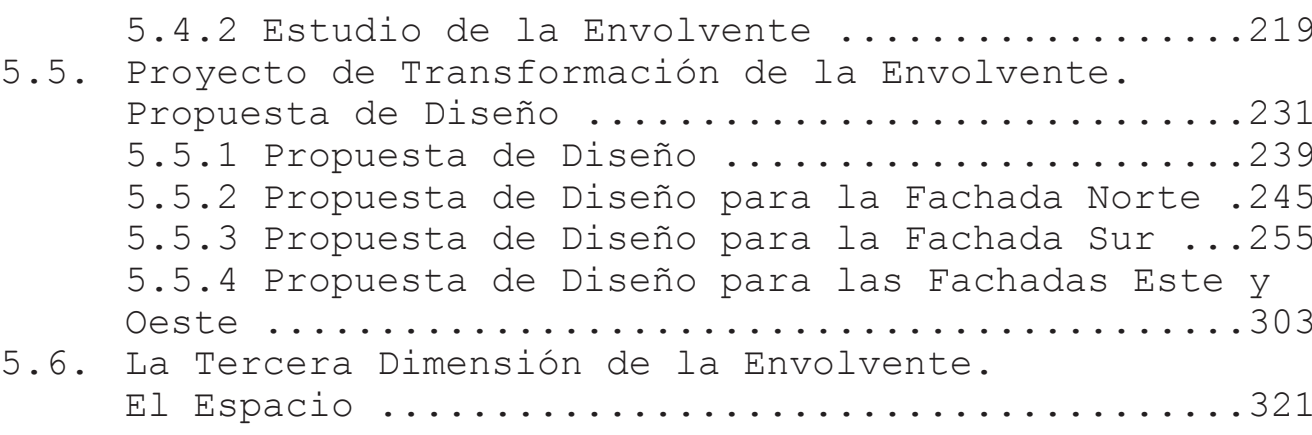

6. CONCLUSTONES: LA ADDPTABIIIDAD

7. BIBLIOGRAFÍA

8. ANEXOS 



\section{RESUMEN}

La profundidad de la envolvente permite establecer la unión entre el espacio interior y el exterior, convirtiéndose así en una superficie capaz de controlar, permitir y adaptar, es decir, controlar los intercambios, permitir la fluidez y adaptarse a las necesidades. De esta forma introducimos la investigación: la integración de las envolventes en el proceso de transformación de la fachada de Lake Grove Village. Construido en la década de los 60, estos edificios residenciales en chicago se caracterizan por un sistema modular y prefabricado, con posibilidades de transformación. Para ello, son cuatro los conceptos que hilan el trabajo.

En primer lugar, la técnica. La técnica aparece como una herramienta de estudio, lo que permite reflexionar acerca de su uso en el prototipo de construcción en altura en Chicago y comprender las posibilidades que ofrece para el proyecto de transformación propuesto. La elección del modelo en altura obedece a que representa un ejemplo de materialización de nuevos escenarios de las envolventes, y presenta retos y posibilidades para el diseño. Se establecen así las bases sobre las que estudiar la envolvente, su adaptabilidad y evolución hacia unas energéticamente más eficientes: los tres conceptos restantes.

En segundo lugar, la eficiencia energética. La eficiencia energética aparece como objetivo del diseño, y se entiende como una actitud por parte de la arquitectura que permite dar respuesta a las necesidades de hoy, sin mermar las futuras. En el proyecto, ha supuesto el talante con el que se ha diseñado hacia la reducción energética, la mejora en la calidad del espacio interior y la adaptabilidad de la propuesta. De esta manera, se habla de eficiencia en el consumo, en los espacios y en el diseño.

En tercer lugar, la envolvente. El concepto de la envolvente se entiende como aquélla que, mediante la tercera dimensión, permite entender la interrelación entre el espacio interior, el espacio exterior y la superficie que los delimita. Los parámetros que definen las envolventes, así como sus mecanismos de comportamiento, servirán para esta- 
blecer las bases sobre las que parte el diseño del proyecto de transformación de la envolvente de Lake Grove Village. Mediante la identificación, la definición y el análisis, el proyecto se centra en una envolvente que apuesta por la eficiencia y ofrece la adaptabilidad.

Por último, la adaptabilidad. La adaptabilidad de las envolventes es una herramienta y también una premisa del diseño que se encuentra ya en el edificio original de Lake Grove Village. La adaptabilidad de las posibilidades técnicas, la adaptabilidad ante los requerimientos energéticos, la adaptabilidad ante las necesidades de los usuarios, la adaptabilidad de los espacios y, por último, la adaptabilidad de las envolventes. De esta manera, este concepto, tal y como se entiende en este proyecto, se traslada al presente, teniendo en cuenta que pueda variar en un futuro. Se unifican así los conceptos de técnica, eficiencia energética, envolvente y adaptabilidad. 


\section{RESUM}

La profunditat de l'envoltant permet establir la unió entre l'espai interior i l'exterior, convertint-se així en una superfície capaç de controlar, permetre i adaptar, és a dir, controlar els intercanvis, permetre la fluidesa i adaptar-se a les necessitats. D'esta manera introduim la investigació: la integració de les envoltants en el procés de transformació de la façana de Lake Grove Village. Constrüt en la dècada dels 60, estos edificis residencials a Chicago es caracteritzen per un sistema modular i prefabricat, amb possibilitats de transformació. Per a això, són quatre els conceptes que filen el treball.

En primer lloc, la tècnica. La tècnica apareix com una ferramenta d'estudi, la qual permet reflexionar sobre el seu ús en el prototip de construcció en altura a Chicago i comprendre les possibilitats que oferix per al projecte de transformació proposat. L'elecció del model en altura obeix a que representa un exemple de materialització de nous escenaris de les envoltants, i presenta reptes i possibilitats per al disseny. S'establixen així les bases sobre les quals estudiar l'envoltant, la seua adaptabilitat i evolució cap a unes energèticament més eficients: els tres conceptes restants.

En segon lloc, l'eficiència energètica. L'eficiència energètica apareix com a objectiu del disseny, i s'entén com una actitud per part de l'arquitectura que permeteix donar resposta a les necessitats de hui, sense minvar les futures. En el projecte, ha suposat l'actitud amb què s'ha dissenyat cap a la reducció energètica, la millora en la qualitat de l'espai interior i l'adaptabilitat de la proposta. D'esta manera, es parla d'eficiència en el consum, en els espais i en el disseny.

En tercer lloc, l'envoltant. El concepte de l'envoltant s'entén com aquella que, mitjçant la tercera dimensió, permet entendre la interrelació entre l'espai interior, l'espai exterior i la superfície que els delimita. Els paràmetres que definixen les envoltants, així com els seus mecanismes de comportament, serviran per a establir les bases sobre 
les què parteix el disseny del projecte de transformació de l'envoltant de Lake Grove Village. Mitjançant la identificació, la definició i l'anàlisi, el projecte se centra en una envoltant que aposta per l'eficiència i oferix adaptabilitat.

Finalment, l'adaptabilitat. L'adaptabilitat de les envoltants és una ferramenta i també una premissa del disseny, que es troba ja en l'edifici original de Lake Grove Village. L'adaptabilitat de les possibilitats tècniques, l'adaptabilitat davant dels requeriments energètics, l'adaptabilitat davant de les necessitats dels usuaris, l'adaptabilitat dels espais $i$, finalment, l'adaptabilitat de les envoltants. D'esta manera, este concepte, tal com s'entén en este projecte, es trasllada al present, tenint en compte que puga variar en un futur. S'unifiquen així els conceptes de tècnica, eficiència energètica, envoltant i adaptabilitat. 


\section{SUMMARY}

The depth of the building envelope allows you to set the connection between the inner and outer spaces, thus becoming a surface capable of controlling, enabling and adapting. In other words, controlling the energy movements through its surface, enabling the interchange, and adapting itself to different needs. By this means we introduce the main focus of this research: integrating the building envelope design within the transformation process for Lake Grove Village. Built in the 1960s, the Chicago-based residential buildings are characterized for the use of a prefabricated modular system that creates a scenario with possibilities for transformation. To do this, there are four concepts that drive this project.

In first place, the technique. The concept of technique appears as a study tool that allows us to think about its use within the prototype selected for the project - the tall building in Chicago - and also allows us to understand the possibilities its use offers for the renovation project proposed. Choosing the tall building as the prototype is due to the fact that it represents an example of new scenarios for the building envelope at different eras, as well as it presents challenges and possibilities for design. This establishes the basis upon which to study the three other concepts: the building envelope, its adaptability, and its development towards a more energy efficient scenario.

Secondly, the energy efficiency. The concept of energy efficiency appears as a goal of the design and it is understood as a manner in which the architecture is able to respond the needs of today without compromising future ones. In the project, energy efficiency has meant the spirit in which the project has been approached towards the following: energy reduction, interior space quality improvement, and adaptability of the proposed solution. By this means the project deals with efficiency in energy usage, efficiency in the space, and efficiency in the design.

Thirdly, the building envelope. The concept of the building envelope is understood as the element that allows 
the relationship between the interior space, the outdoor space and the intermediate surface the delineates these. The parameters that define these facades, as well as their behaviors are used to establish the basis on which the design for the transformation of Lake Grove Village grows from. By identifying, defining and analyzing the concepts proposed, the project focuses on a wrapper that is committed to efficiency and offers adaptability.

Finally, the adaptability. This concept is both a tool and a premise of the design that is present in the original project of Lake Grove Village. Adaptability of the technical possibilities, the adaptability towards the energy requirements, the adaptability to the needs of users, spaces and, finally, the adaptability of the building envelope. Therefore, the concept, as it is understood in this project, is translating to the present what could vary in the near future. Thus, technical concepts, energy efficiency, building envelope and its adaptability are unified in the project. 


\section{AGRADECIMIENTOS}

Este trabajo comienza a elaborarse en el año 2010 mientras cursaba el Master of Science in Architecture en el Illinois Institute of Technology de Chicago. Lo que comenzó siendo un trabajo de máster fue, poco a poco, convirtiéndose en un proyecto que combina el carácter de investigación junto con la aspiración proyectual. Nada de ello hubiese sido posible sin la contribución y el apoyo de tantos que han estado presentes a lo largo de este trayecto.

En primer lugar, mi más profundo agradecimiento al director de la tesis, el profesor Jorge Torres Cueco. Con su apoyo, flexibilidad y experiencia, me ha permitido explorar el campo de investigación en el que estaba interesada, al mismo tiempo que ha encaminado y guiado el desarrollo del trabajo. Su confianza y exigencia profesional han sido básicos para este proyecto. Gracias por el respaldo, las sugerencias y el esfuerzo por contribuir a un trabajo más íntegro y coherente.

Debo un especial reconocimiento también al centro donde esto se originó. Gracias a la Escuela de Arquitectura del Illinois Institute of Technology por brindarme la oportunidad de comenzar este trabajo. Agradezco también a aquéllos que formaron parte de esos comienzos: el profesor John Durbrow, el Sr. Helmut Meyer, de TRANSOLAR, y el ingeniero James Patterson por compartir material del proyecto original de Lake Grove Village para el desarrollo de la investigación.

Por último, un agradecimiento muy especial para mi familia y amigos, quienes, con su comprensión y aliento continuo, me han apoyado durante el desarrollo del proyecto y han alentado en mis estudios y proyectos. 



\subsection{PRELUDIO.}

"Eliminada ya cualquier dimensión teológica (...) la técnica adquiere hoy una condición básicamente instrumental al servicio de la subjetividad del proyecto". ${ }^{1}$

La integración de los diferentes componentes de un edificio añade cierta complejidad al proyecto arquitectónico aun cuando cada uno de los elementos esté bien reconocido y asimilado. El uso de nuevos avances tecnológicos en un proyecto puede ofrecer ventajas pero, al mismo tiempo, puede incorporar en la arquitectura nuevos conceptos que hay que resolver. Es el caso de las envolventes de vidrio de los edificios, donde tan importante es entender la relación que se produce entre la formalización estética que adquiere el proyecto y el (buen) uso de la técnica, protagonista en la composición de las fachadas especialmente desde finales del siglo XIX. 
En ocasiones, las ventajas que pueden traer consigo ciertos avances pueden verse obstaculizadas por diferentes factores. La falta de entendimiento, de tiempo, las limitaciones económicas, etc pueden afectar el proceso de diseño y, por tanto, el resultado. En contra, parece razonable entender los conceptos y funciones que residen detrás de los componentes de un edificio para interiorizar las opciones y obtener así el fin deseado: entender las posibilidades y condicionantes con el fin de proyectar Arquitectura...

Esto, que puede resultar un concepto básico en la Arquitectura, será el hilo conductor de este trabajo. A lo largo del mismo, y con el objetivo principal de presentar una propuesta de transformación para la fachada de un edificio residencial en Chicago, se llevará a cabo un estudio de los condicionantes y requerimientos existentes, una propuesta de integración y adaptabilidad en la solución, el análisis de la misma y, finalmente, la extracción de los resultados.

El trabajo consta de cuatro apartados diferenciados entre sí. El primero plantea las reflexiones teóricas estudiadas sobre el uso de la técnica en la construcción de edificios en altura. Partiendo de la base de las posibles ventajas mediante su uso, se analiza la evolución de las envolventes de vidrio en la arquitectura de Chicago desde los años 50 hasta nuestros días. Tomando como referencia una serie de proyectos pertenecientes a diferentes etapas, se analiza el papel que las envolventes han tenido para entender la situación actual. Es precisamente durante este estudio cuando el trabajo se va enriqueciendo y se identifican los parámetros que serán analizados posteriormente. A lo largo del proceso cuando se establece la relación entre la ciudad de Chicago, el prototipo del edificio en altura y la concepción de la envolvente.

En el segundo apartado se enmarca el concepto de la envolvente en la situación actual. Para ello, se analizan diferentes propuestas, exponiendo las barreras existentes así como las nuevas corrientes de investigación hacia una arquitectura energéticamente eficiente. Tanto los conceptos teóricos como los casos prácticos han ayudado a crear la base de los estudios posteriores y entender la evolución de 
las envolventes. El trabajo de los arquitectos franceses Lacaton \& Vasall destaca por su relevancia para esta investigación. El proyecto de transformación de la Torre Bois-le-Prêtre que estos arquitectos llevaron a cabo en el edificio residencial coincidió en el tiempo con el desarrollo de esta investigación. De manera similar, y sin ánimo de establecer comparación con este grupo de arquitectos, los proyectos presentan semejanzas tanto en el planteamiento como en los objetivos. A pesar de la diferencia que pueda existir en las estrategias planteadas, resulta casi imposible no citar y entender la similitud entre ambos proyectos, uno teórico y el otro real.

En el tercer apartado se estudian los conceptos tras la técnica de las envolventes de vidrio con el fin de entender y establecer los parámetros necesarios con los que se va a abordar el proyecto de transformación de la envolvente de Lake Grove Village.

Finalmente está el apartado que dota de mayor originalidad al trabajo al exponer la propuesta de transformación de la envolvente de Lake Grove Village, que dota de un enforque proyectual a esta investigación. Para ello, además se lleva a cabo el consiguiente estudio de las diferentes decisiones para proponer una solución de diseño que comprenda las posibilidades de hoy sin comprometer las de mañana.

En definitiva, en este documento se ofrece una propuesta de integración de una fachada de vidrio dentro en una construcción existente. Las opciones y las limitaciones se abordan desde una perspectiva de la adaptabilidad presente y futura. Se identifican los parámetros, se analizan las necesidades, se esbozan las propuestas, se evalúan y se define el proyecto. Aunque es sabido que normalmente las decisiones de mayor éxito son aquéllas que se consideran desde etapas iniciales, este proyecto es de intervención. con ello, las decisiones y propuestas se evalúan y se diseñan solamente hasta lo permitido. Aun así cabe destacar que, como se verá en los apartados en los que se explica el proyecto original, uno de los factores que permite realizar esta transformación es precisamente el planteamiento del 
arquitecto que en los años 60 diseñó un edificio en el que se consideró la posibilidad de remodelación posterior. Por tanto, se puede extraer la conclusión que los sistemas originales de los edificios en Lake Grove Village estaban, - parecían estar, diseñados para una posible adaptabilidad desde sus orígenes.

Este trabajo se centra en estudiar los principios que podrían aplicarse a un edificio en etapas iniciales, pero ya en la fase del diseño de la envolvente. La propuesta de re-diseño para una fachada de un edificio ya existente y la integración con la arquitectura ya levantada constituirán la esencia del trabajo.

Este trabajo comienza por definir el objeto de estudio e identificar las barreras encontradas en la arquitectura a este respecto. En primer lugar, se presenta el marco general de trabajo indicando los objetivos principales de la investigación, así como la metodología empleada y la organización general del proyecto. 
2. Norbert Lechner, Heating, Cooling, Lighting. Sustainable Design Methods for Architects (New Jersey: John Wiley \& Sons, 2009), pág. 2 .

3. Norbert Lechner, Heating, Cooling, Lighting. Sustainable Design Methods for Architects (New Jersey: John Wiley \& Sons, 2009).

\subsection{MARCO DE ESTUDIO.}

"Architecture has been called journalism in stone, since it has always reflected the culture, climate, and resources of the time and place". ${ }^{2}$

Los inicios de un proyecto consisten en analizar las condiciones locales, identificar los requisitos del programa y definir las necesidades de los usuarios. Los parámetros del diseño quedan definidos mediante esta primera etapa en la que, cada vez más, se tienden a establecer los cimientos de un proyecto. Al fin y al cabo, las decisiones iniciales acaban siendo las más determinantes en el proceso arquitectónico. ${ }^{3}$ Es precisamente éste, el concepto con el que comenzó este trabajo de investigación de carácter proyectual. Tras esta fase de análisis, identificación y definición de los parámetros, se establecen los conceptos definidos para su evaluación. Finalmente, el proyecto se formaliza a partir de lo que se ha ido definiendo conceptualmente a lo largo del proceso. 


\section{CAPÍTULO 01}

Sin embargo, antes de analizar las características de la investigación, este apartado define los conceptos que se consideran esenciales, y cuyas definiciones tienen una especial relevancia.

A continuación se explican los siguientes conceptos:

- Técnica

- Eficiencia Energética

- Envolvente

- Adaptabilidad 


\subsubsection{Técnica. Concepto}

"... Ia técnica, que podemos, desde luego, definir, como la reforma que el hombre impone a la naturaleza en vista de la satisfacción de sus necesidades. Éstas, hemos visto, eran imposiciones de la naturaleza al hombre. El hombre responde imponiendo a su vez un cambio a la naturaleza. Es, pues, la técnica, la reacción enérgica contra la naturaleza."4

Diferentes arquitectos y autores han tratado el concepto de la técnica y su significado en la arquitectura. Etimológicamente la palabra técnica proviene del griego techné, que significa arte u oficio, y que se empleaba para designar el conocimiento y la habilidad para organizar y planear libremente una creación. Esto en parte coincide con el discurso de Ortega y Gasset, quien en el texto La Meditación de la Técnica, sugiere que, a lo largo de la evolución, el acto de la técnica entiende el esfuerzo por llevar a cabo una acción:

"Acto técnico - decíamos - no son aquéllos en que hacemos esfuerzos para satisfacer directamente nuestras necesidades, sean éstas elementales o francamente superfluas, sino aquéllas en que dedicamos el esfuerzo, primero, a inventar y luego a ejecutar u plan de actividad que nos permita:

4. José Ortega y Gaset. Meditación de la Técnica. Filosofía Hoy. (Madrid: Edición de la Revista Occidente, 1977), pág.324. $5 \& 6$. José Ortega y Gaset. Meditación de la Técnica. Filosofía Hoy. (Madrid: Edición de la Revista Occidente, 1977), pág.333. 7. Iñaki Ábalos \& Juan Herreros, Técnica y Arquitectura en la Ciudad Contemporánea (Guipúzcoa: Editorial Nerea,1992), contraportada.

8. Ignasi de Solà-Morales, Marta Llorente, Josep M. Montaner, Antoni Ramón, Jordi Oliveras, Introducción a la Arquitectura. Conceptos Fundamentales. (Barcelona: UPC, 2000).
1. Asegurar la satisfacción de las necesidades, por lo pronto, elementales.

2. Lograr esa satisfacción con el mínimo esfuerzo.

3. Crearnos posibilidades completamente nuevas produciendo objetos que no hay en la naturaleza del hombre."5

Tras ello incide: "...la técnica es, por lo pronto, el esfuerzo para ahorrar el esfuerzo." 6 En lo que a este trabajo se refiere, esa acepción tiene gran interés puesto que, como se ha señalado al inicio de esta investigación y apuntan Ábalos y Herreros - ". . la técnica adquiere hoy una condición básicamente instrumental al servicio de la subjetividad del proyecto"7- lo que para este trabajo sugiere el uso de la técnica como instrumento.

Por otro lado, en Introducción a la Arquitectura. Conceptos Fundamentales se sugiere que el espacio, y por tanto la arquitectura, es posible gracias a la técnica. ${ }^{8}$ Y 
añade: "La arquitectura requiere del esfuerzo técnico, pero también impulsa su desarrollo: acapara en este gesto las fuerzas disponibles y las modifica".9

Y es que, la técnica, no sólo ha permitido la evolución del espacio arquitectónico, sino que ésta se ha visto obligada a desarrollar e innovar para dar respuesta a los diferentes requerimientos del espacio arquitectónico.

En una tercera instancia, Sigfried Giedion, narró su visión de la concepción del espacio a lo largo de la historia de la arquitectura, entre otros en Architecture and the Phenomena of Transition, The Three Space Conception in Architecture. En el texto presenta la historia de la arquitectura como una sucesión de concepciones del espacio arquitectónico agrupadas en tres etapas.

La primera hasta Grecia, y la segunda desde Roma hasta la Revolución Industrial. Según el autor, la primera etapa se caracteriza por el espacio exterior, las relaciones entre volúmenes y su capacidad de relación. Por otro lado, la segunda se caracteriza por el espacio interior como contenedor de objetos, desapareciendo la libre disposición de volúmenes en favor del orden y la perforación del perímetro. A ella se atribuye la apertura de huecos en el cerramiento, para una posterior desintegración de la pared en favor del cerramiento de vidrio (que ocurre en la tercera etapa).

Finalmente, en la tercera concepción espacial se considera la arquitectura como volumen y como espacio, y es aquí donde comienza la interacción del espacio interior con el exterior. Esto es, en parte, gracias al uso y desarrollo de nuevos materiales y nuevas técnicas constructivas que desembocan en un lenguaje estético. Aparece el acero y el vidrio plano; la desmaterialización de los cerramientos, la transparencia y la luz integrada en el espacio interior.

\footnotetext{
Al fin y al cabo, uno de los objetivos de la arquitectura es el bienestar de sus usuarios y, según el texto de Ortega y Gasset, "Hombre, técnica y bienestar son, en última instancia, sinónimos."10
}

9. Ignasi de Solà-Morales, Marta Llorente, Josep M. Montaner, Antoni Ramón, Jordi Oliveras, Introducción a la Arquitectura. Conceptos Fundamentales. (Barcelona: UPC, 2000). pág. 29.

10. José Ortega y Gaset. Meditación de la Técnica. Filosofía Hoy. (Madrid: Edición de la Revista Occidente, 1977), pág.329. 


\subsubsection{Eficiencia Energética. Concepto}

"... energy efficient architecture must be understood as a combination of minimal energy consumption, optimum indoor climate conditions and architectural quality". ${ }^{11}$

La situación energética actual obliga a la arquitectura, considerada una de las principales causas de las emisiones de gases nocivos al medio ambiente, ${ }^{12}$ a adoptar medidas responsables que ayuden a la conservación de su entorno. La industria y la profesión arquitectónica pueden unir esfuerzos y desarrollar soluciones en las que las prioridades de unos y otros se acerquen, y así la arquitectura pueda contribuir al bienestar y a diluir los límites entre las distintas atmósferas utilizando los recursos del propio entorno.

Un ejemplo de ello son las envolventes de vidrio, cuyo comportamiento puede, entre otros, reducir el uso de los sistemas mecánicos. El abuso que en la actualidad se hace de los sistemas climáticos artificiales, además de provocar consecuencias negativas en el medio natural, trae consigo un deterioro de la percepción de confort por parte del usuario. Como superficies delimitadoras de ambos medios, las envolventes juegan un papel importante a la hora de determinar el comportamiento energético del proyecto y, en definitiva, influir en el confort interior del espacio.

Cada vez son más numerosos los edificios que optan por incorporar en sus diseños medidas de conservación de la energía. Sin embargo, pese al desarrollo de nuevas tecnologías, y en especial, las destinadas a optimizar las fachadas de vidrio, todavía hay ciertas barreras que deben ser superadas para que estas medidas tecno-arquitectónicas se conviertan en una práctica habitual.

En primer lugar, existen barreras relacionadas con el propio diseño del proyecto. El temor por parte de ciertos sectores de la profesión a que medidas técnicas acaben comprometiendo la formalización final del proyecto hace que, en una primera instancia, se rechacen parte de estas estrategias. La técnica que hay detrás de las envolventes de vidrio no tiene como objetivo anular la idea formal 
del proyecto sino ayudar a mejorar la respuesta de los espacios. La apuesta por incorporar estrategias avanzadas en la concepción de los envolventes puede suponer un paso para conjugar las solución formal buscada con una solución energéticamente eficiente $y$, por tanto, mayor confort para los usuarios.

En segundo lugar, parece existir todavía escepticismo a la hora de emplear de ciertos avances. Pese a que se hayan probado más eficientes energéticamente, creen climas interiores de mayor calidad, ofrezcan posibilidades de integración con el resto del edificio que permiten no supeditar los deseos de diseño y puedan suponer un recorte económico para los usuarios, la poca oferta de contraste provoca que, en ocasiones, no sean consideradas por los arquitectos y clientes.

En tercer lugar, no todas las medidas están al alcance de cualquier proyecto arquitectónico. La faceta económica acaba jugando un papel igualmente relevante debido a que los costes iniciales de las medidas más avanzadas suelen ser mayores que las más tradicionales. Por ello, puede resultar ventajoso para el proceso que cada una de las partes involucrada entienda las consecuencias y posibilidades de dichas medidas y la implicación no sólo a corto plazo sino en un periodo de tiempo más duradero.

En resumen, para el desarrollo de este proyecto se entiende el concepto de eficiencia energética como aquél que apuesta por la combinación de la reducción del consumo energético, el confort interior $y$ la adaptabilidad del espacio, mediante el diseño arquitectónico. Así, se habla de eficiencia en el consumo, eficiencia en el espacio $y$ eficiencia en el diseño. 


\subsubsection{Envolvente. Concepto}

"The skin performs an important function in the body's response to a range of climatic information and regulates its emission of heat with the help of heat control receptors, blood vessels, sweat glands and hairs. (...) As our third skin, the outside of the building fullfills tasks similar to those of human skin or clothing. It creates an interior and an exterior; it separates but is also permeable, this allowing exchage to take place". ${ }^{12}$

El símil de la envolvente arquitectónica a la piel del edificio ha sido un término muy sugerente durante la arquitectura moderna. Durante el movimiento moderno, Le Corbusier estableció la separación entre la fachada y la estructura, introduciendo la ventana corrida. La piel y la estructura se separan enmarcando las vistas al exterior y estableciendo una relación inmediata entre el medio construido y el medio natural. Así, la ventilación e iluminación natural por medio de la "fenêtre en longeur", el control solar por medio del "brise soleil", la envolvente inteligente y activa por medio del "mur neutralizant", o la incorporación de aire acondicionado mediante la "respiration exacte", son ejemplos de cómo el arquitecto trasladó a la teoría y a la práctica sus inquietudes hacia una arquitectura moderna y avanzada.

Más adelante se introdujo el concepto de envolvente como superficie continua de vidrio, que se convertiría en protagonista indiscutible en la era de la construcción en altura. Además de poseer una cualidad de ligereza y transparencia que permitía desmaterializar la misma tecnología, su empleo obligó a una reconsideración de los espacios destinados al acondicionamiento de las estancias interiores. Como una superficie hermética que independizaba el espacio interior del exterior, aparecieron las cuestiones que se debían resolver, especialmente en lo que a los sistemas de ventilación de espacios se referían. Para garantizar

12. Hausladen, G., de Saldanha, M., Liedl, P. Climate Skin: Building-skin concepts that can do more with less energy. (Basel: Birkhäuser-Publishers for Architecture, 2008), pág. $12 \& 14$. el confort de los espacios interiores, era necesario sustituir la inercia de los muros másicos por el desarrollo de los sistemas de climatización mecánicos. Fue éste uno de los factores que más determinaron y caracterizaron la 
arquitectura de vidrio de mitad de siglo, especialmente aquélla destinada a las construcciones en altura.

Unos de los arquitectos que explotó al máximo el uso del muro continuo de vidrio fue Mies Van der Rohe, quien, en edificios como Lake Shore Drive (Chicago, 1951), el Seagram Building (Nueva York, 1954) o el One IBM Plaza (Chicago, 1970), experimentó con las posibilidades que este material podría llegar a alcanzar y cuyas investigaciones todavía hoy son modelos de referencia. El concepto de piel había escalado a un nuevo nivel de interacción entre la envolvente y la técnica.

Posteriormente se introducen nuevos conceptos que hablan de la confluencia de los dos anteriores: la posibilidad de una superficie continua que deja de lado la hermética y pasa a albergar nuevas funciones y cobrar una posición más activa. La superficie de vidrio continua, inerte y poco eficiente energéticamente debía ser sustituida por otra en la que el vidrio tomase un papel activo en el clima interior. El desarrollo de nuevas formas de trabajar la piel, los materiales, las carpinterías y la conexión con el espacio interior ayudan a esta evolución, combinando las funciones estéticas y ligeras con otras de ventilación, aislamiento, control solar y por último y, como objetivo final, mayor confort.

La complejidad de la envolvente de vidrio, aun cuando se trata de una piel inerte e ineficaz, es ya de por sí considerable. Si a ello añadimos sistemas avanzados, al menos en una primera instancia, la complejidad aumenta de forma relevante. Sin embargo, debido a los beneficios que pueden obtenerse al incorporar envolventes de vidrio responsables ante las necesidades de los usuarios y los requerimientos energéticos, las dificultades o inversiones iniciales pueden convertirse en ventajas a largo plazo. Por ejemplo, el vidrio es el principal material que se emplea en las fachadas de los edificios en altura. La selección del tipo de vidrio, de sus propiedades físicas, o de las opciones que éste tiene no sólo para aumentar al máximo la visión sino también el control de la entrada de calor y de luz, son características que afectarán el planteamiento del 
proyecto en su conjunto. Es decir, las dimensiones de los espacios, las orientaciones del volumen en general e incluso los acabados de los suelos y particiones interiores. Si a ello añadimos el estudio de sistemas de protección solar y su localización, la imagen y, por tanto, las intenciones del proyecto, variarán. Por ello, cobra especial importancia ser conocedor de las posibilidades que existen para que los proyectos sean coherentes en función, forma y técnica. Las incertidumbres técnicas iniciales pueden ser corregidas si se posee la información necesaria, y los usuarios, arquitectos y clientes deben esforzarse por implicarse en las opciones y posibilidades que ofrece el desarrollo de la técnica para la optimización de las envolventes de vidrio.

En resumen, para este trabajo se entiende la envolvente como aquélla superficie activa que es capaz de iluminar, ventilar, mirar $y$ habitar para una mejora del espacio interior. 


\subsubsection{Adaptabilidad. Concepto}

"Adaptabilidad: dicho de un ser vivo: acomodarse a las condiciones de su entorno". 13

A lo largo de este trabajo aparece el concepto de "adaptabilidad" de una manera u otra. Ya sea directa o indirectamente, los métodos y propuestas llevadas a cabo han apostado por la adaptabilidad como solución que cabría estudiar. De las diferentes acepciones del término, aquélla que sugiere mayor interés por la naturaleza del tema a tratar es la referente a un ser vivo, ya que se ha vinculado a la capacidad por parte de la envolvente de dar respuesta y a acomodarse a diferentes entornos y requerimientos.

Los inicios de este trabajo residen en el interés por proponer un proyecto de transformación mediante la envolvente. Una de las características de dicha envolvente es la adaptabilidad. El proyecto original de Lake Grove Village y la forma en la que se diseñó y construyó, fue uno de los detonadores del interés hacia la adaptabilidad. Por ejemplo, y como se verá posteriormente, la modulación de las fachadas y su sistema modular, la independencia de la estructura, o la tabiquería en seco, han permitido que sea factible proponer la transformación de la envolvente sin prácticamente intervenir en el espacio interior, a no ser que así se desee. De esta manera se podrán proponer diferentes tipos de envolvente que creen diversos espacios y permitan la adaptabilidad según las necesidades. Fue durante la etapa de análisis del proyecto existente cuando se sugirió el concepto de adaptabilidad como propuesta y método: la adaptabilidad como método de trabajo, como solución, y como flexibilidad.

Ahora bien, para definir el proyecto y explicar el concepto es necesario acotar el término. Para el objeto de esta investigación, se entiende la adaptabilidad como herramienta a las posibilidades de la técnica, a los condicionantes del entorno y situaciones medioambientales, y como herramienta a las necesidades cambiantes por parte de los usuarios.

13. Real Academia Española. (2001). Diccionario de la lengua española (22.a ed.), Madrid. 
En definitiva: la adaptabilidad de la arquitectura. Ello se estudia a través de conceptos teóricos y el estudio de casos prácticos. Determinados aspectos, y no todos debido entre otros a limitaciones, podrán ser aplicados en el proyecto de transformación.

Primero, en lo referente a los aspectos más técnicos de la arquitectura, este trabajo se refiere a la adaptabilidad a incorporar, por ejemplo, medidas sin dejar de lado las necesidades primarias de confort de los usuarios.

Segundo, en lo referente a las respuestas al medio ambiente, este proyecto busca soluciones que puedan adaptarse a diferentes orientaciones y requisitos de las mismas. Esto se verá mediante sistemas móviles, materiales de construcción o, por ejemplo, mediante un mayor control por parte del usuario.

Tercero, en el aspecto socio-cultural, la adaptabilidad de los edificios para dar respuesta a los usos cambiantes, la adaptabilidad de los espacio como solución a modos de vida y familiares variables.

En resumen, para el desarrollo de esta investigación se entiende la adaptabilidad como medio y opción hacia una arquitectura capaz de entender el presente sin olvidar el futuro. 

14. The Burndtland Report. (World Commision on Environment and Development, 1987), pág. 43.

\subsection{HIPÓTESIS Y OBJETIVOS DE LA INVESTIGACIÓN.}

"Sustainable development is development that meets the needs of the present without compromising the ability of future generations to meet their own needs". ${ }^{14}$

Esta acepción, que fue plasmada en el documento elabroado por el WCED y aceptada por las Naciones Unidas, recoge parte de los conceptos con los que se trabaja en este proyecto. En primer lugar, hace referencia a las necesidades de hoy. En este referente, el trabajo reconoce los retos actuales para un diseño energéticamente eficiente. En segundo lugar, destaca el hecho de que estos requerimientos no comprometan la habilidad de generaciones futuras hacia sus necesidades. En lo que se refiere a ello, esta investigación apuesta por la adaptabilidad, concretamente, de las evolventes. El proyecto original de Lake Grove Village ya presentaba una fachada con unas características que podían sugerir la posibilidad de adaptación o cambio. En el proyecto de transformación de la envolvente, el trabajo se "aprovecha" 
de ello para sugerir una intervención en lugar de una reconstrucción, y así sacar partido de la arquitectura ya proyectada. Al mismo tiempo, la nueva propuesta -aun a pesar de ser teórica- apuesta por la construcción modular y destaca la posible adaptación en tiempos futuros. Los conceptos de la técnica y la envolvente no son más que la herramienta y objeto, respectivamente, de dicho ejercicio de investigación proyectual.

La hipótesis principal de este trabajo explora la integración de las envolventes en el proceso arquitectónico mediante un proyecto de transformación de la fachada de un edificio en Chicago, con el fin de poder dar respuesta a las variaciones del entorno $y$, por tanto, la adaptabilidad del mismo.

Para ello se establecen los siguientes objetivos:

En primer lugar, estudiar y repasar el prototipo de construcción en altura en Chicago, como modelo arquitectónico y para el desarrollo del proyecto de tranformación que se desallora en el trabajo. Para ello, se lleva a cabo una reflexión acerca del uso de la técnica en los edificios en altura de la arquitectura estadounidense. La elección de la construcción en altura obedece a que representa un ejemplo de materialización de nuevos escenarios y, al mismo tiempo, donde aparecen retos que requieren una solución. Esta primera reflexión establece las bases sobre las que se desarrolla el concepto de la envolvente como superficie intercambiadora; se estudia la evolución de la envolventes de vidrio, y se analizan cómo distintas generaciones de arquitectos enfocaron el desarrollo del muro cortina.

En segundo lugar, entender el concepto de eficiencia energética; comprendiendo el contexto, identificando las barreras y analizando las propuestas para el diseño de la propuesta de tranformación de la envolvente. Para ello, se centra en el estudio de la envolvente como sistema operativo y su interrelación con otros conceptos del proyecto. Este análisis presenta las conexiones (existentes o no) entre los distintos conceptos que hay tras las fachadas de vidrio, en el que los condicionantes locales, las intenciones del 
proyecto, las necesidades de los usuarios y los avances y posibilidades técnicas, tendrán que ser consideradas para obtener un resultado conjunto y responsable. Más que establecer los logros de la arquitectura a este respecto, el trabajo de estudio destaca las líneas potenciales de mejora que en la actualidad diversos equipos están desarrollando.

En tercer lugar, establecer y definir los conceptos y principios de las envolventes de vidrio en la construcción en altura. Parámetros que vendrán determinados por cómo el análisis exhaustivo de los condicionantes locales y las necesidades de los usuarios crean oportunidades para distintos tipos de cerramientos, y cómo éstos tendrán una influencia inevitable en la concreción del proyecto. Para ello, se estudian los mecanismos principales de los mismos; es decir, las funciones, los conceptos y las interacciones de las fachadas en el conjunto del proyecto de arquitectura. La identificación de las ventajas que ofrece la evolución técnica de las fachadas pretenderá sugerir la necesaria vinculación e implicación de la técnica del cerramiento con el valor del proyecto.

Por último, y como parte central del trabajo, procedemos a plasmar en un ejercicio de carácter proyectual lo estudiado, introduciendo los conceptos extraídos en el diseño de una fachada de vidrio para un edificio existente en Chicago. Para ello, y establecidos ciertos requerimientos, se evalúan los diferentes componentes que integran la fachada propuesta para diseñar para evaluar los beneficios obtenidos y las limitaciones de las propuestas con el fin de mejorar, posteriormente, los diseños. Las decisiones técnicas y de proyecto se evalúan en favor del clima exterior e interior con el objetivo de corroborar la conveniencia de relacionar la subjetividad formal y la formulación técnica. 



\subsection{ORGANIZACIÓN DEL TRABAJO.}

El trabajo está organizado en una serie de capítulos, cada uno de los cuales está dirigido a primero identificar, segundo analizar y por último evaluar el aspecto específico sobre el que se esté tratando en lo referente a las envolventes de vidrio de los edificios en altura.

El primer capítulo ha ofrecido una introducción del objeto de estudio explicando los conceptos principales en los que se basa el trabajo, identificando la hipótesis del mismo y sus objetivos, y adelantando un guión de lo que se desarrollará posteriormente.

El segundo capítulo analiza la evolución de la técnica en la arquitectura de la construcción en altura, especialmente aquélla referida a las envolventes de vidrio. Con un breve análisis del rascacielos como prototipo de la vida moderna, este apartado explicará parte de la herencia que perdura de la arquitectura de los años cincuenta. Este 
segundo capítulo entra en el análisis de casos prácticos de estudio, concentrándose en los edificios levantados en las décadas de los años cincuenta, sesenta y setenta para entender el porqué de ciertas decisiones llevadas a cabo en aquél entonces.

El tercer capítulo estudia el contexto actual de la arquitectura de fachadas. Se identifican las posibilidades que existen hoy en día y se exponen las barreras que se consideran se deben reforzar estableciendo el necesario contraste entre el clima artificial que ha persistido en este tipo de construcciones y la conservación natural que hoy en día se persigue.

El cuarto capítulo estudia, establece y define los parámetros que concretan los principios de las envolventes de vidrio de la construcción en altura. Para ello, este apartado se centra en analizar las diferentes funciones, conceptos e interacciones de las fachadas en el conjunto del proyecto de arquitectura. En este tercer apartado, se justifica la explicación literaria con el estudio de casos prácticos, concentrándose éstos en aquéllos construidos en la última década en Chicago.

El quinto capítulo supone el grueso del trabajo. Es en esta sección en la que se desarrolla el proyecto en sí y se plasman los conceptos aprehendidos en el proyecto de transformación de la envolvente de Lake Grove Village. A lo largo de este capítulo se desarrolla el contexto, el objetivo, la metodología y las herramientas que se emplean para el trabajo. Posteriormente, se evalúa la propuesta de diseño para entender los beneficios y limitaciones de la misma y poder ser refinada. El apartado acaba proponiendo sistemas que permitan la adaptabilidad de la envolvente a diferentes contextos.

El último capítulo recoge las conclusiones y abre las puertas a establecer las bases para futuras líneas de investigación, con la intención de que la arquitectura venidera cree modelos de nuevas tecnologías para una arquitectura comprometida con la sociedad, la innovación y el entorno. 




\section{CAPÍTULO 02 \\ LA TÉCNICA. INICIOS DE LA ENVOLVENTE}

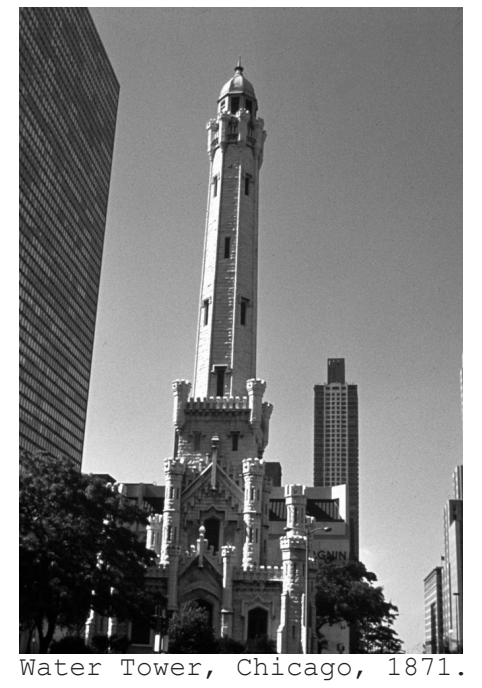

Fotografía del Digital Collection de UIC, C. William Brubacker, 1977 .

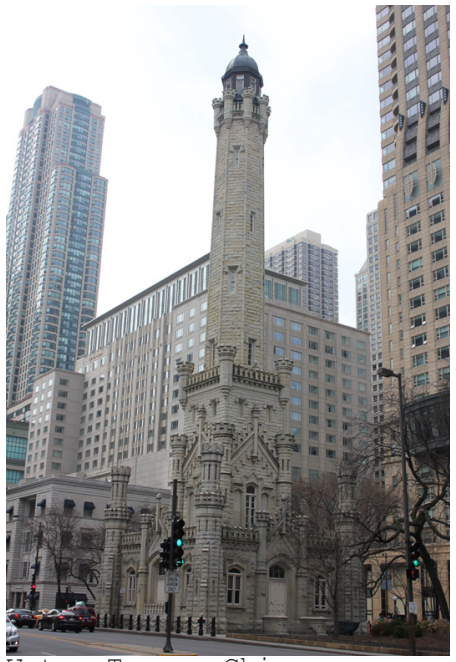

Water Tower, Chicago. Fotografía año 2015.

1. Ramón Araujo, Construir en Altura (Barcelona: Editorial Reverté, 2012), página 25 .

\subsection{PROTOTIPO DE TÉCNICA. EL MODELO ARQUITECTÓNICO EN AL- TURA. CHICAGO.}

"La construcción vertical ya existió en la Antigüedad; y desde Roma a la ciudad del siglo XIX la construcción con muros de carga permitió la superposición de planos de uso hasta cierta altura". ${ }^{1}$

La experimentación americana de finales del siglo XIX desarrolló la concreción de nuevos conceptos arquitectónicos que supusieron un impulso decisivo en el desarrollo de nuevas propuestas tecnológicas de las que fueron testigo ciudades como Chicago. Tras el "Great Chicago Fire", incendio que redujo a cenizas prácticamente toda la ciudad en 1871, la arquitectura de chicago sufrió una transformación que la hizo destacar por su originalidad e innovación, más que por su carácter clásico y antiguo. Mientras en otras ciudades norteamericanas se estaba imponiendo el estilo neoclásico con la construcción de muchos de los edificios federales, Chicago optó por una nueva forma de expresión que incluía la 
experimentación con nuevos materiales en la arquitectura. Posteriormente, el desarrollo del ascensor o las técnicas de aire acondicionado, entre otros, generalizaron este tipo de construcción a lo largo del Movimiento Moderno.

En torno a 1880, los impulsores de la "Chicago School" comenzaron a explorar las posibilidades de materiales como el acero, aplicados a la construcción. ${ }^{2}$ Así, Colin Rowe explica en "La Estructura de Chicago" ${ }^{3}$ la relación entre la estructura y los materiales empleados en la arquitectura, definiendo la estructura como el "catalizador de una arquitectura: pero debe advertirse que la propia estructura también se ha convertido en arquitectura"." Este hecho cobra especial relevancia en la arquitectura de Chicago, particularmente con la experimentación de nuevos materiales en el diseño y en la construcción de lo que entonces fueron los primeros rascacielos. De la arquitectura llevada a cabo en la ciudad en las décadas de 1880 y 1890 cabe resaltar ejemplos como el Home Insurance Building (William Le Baron Jenney, Chicago, 1884), la Columbian Exposition (Chicago, 1893) para la que se construyeron diversos edificios que todavía hoy constituyen hitos en la ciudad como el science Museeum (Daniel Burnham, Chicago, 1982), y de los planes urbanísticos para grandes urbes como el de Daniel Burnham para Chicago. Frank Lloyd Wright, Louis Sullivan o Wellborn Root entre otros, ayudaron a crear el chicago que hemos heredado.

De éstos destaca la evolución de la estructura. La superposición de planos que anteriormente venían dados por el uso de los muros de carga, pasa a necesitar del empleo de estructuras reticulares, estructuras mixtas, etc. La masividad del elemento convierte a la inercia térmica en la principal ventaja de los sistemas de muro tradicionales. Sin embargo, el principal problema de estos sistemas en los edificios en altura es la estabilidad y la necesaria regularidad para su funcionamiento óptimo. A pesar de que los avances de la técnica hayan permitido que se construyan edificios de cierta altura con sistemas de muro, la arquitectura vertical apostó por el desarrollo del sistema reticular, en parte gracias a los avances de materiales como el acero.

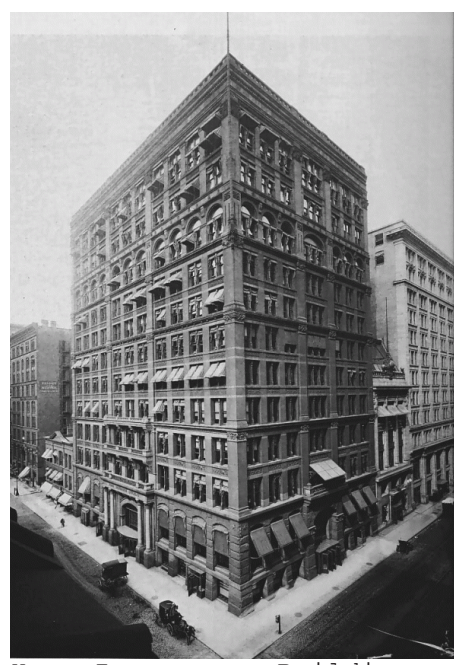

Home Insurrance Building, Chicago, 1884, William LeBaron Janay. Considerado uno de los primeros edificios en altura.

2. Colin Rowe, Manierismo y Arquitectura Moderna y Otros Ensayos (Barcelona: Gustavo Gili, 1978).

3. Colin Rowe, Architectural Review, 1956.

4. Colin Rowe,

Architectural Review, 1956. 


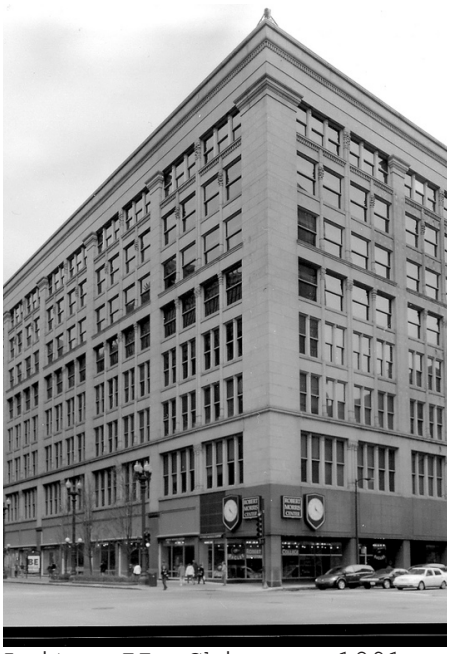

Leiter II, Chicago, 1891 , William Le Baron Janay.

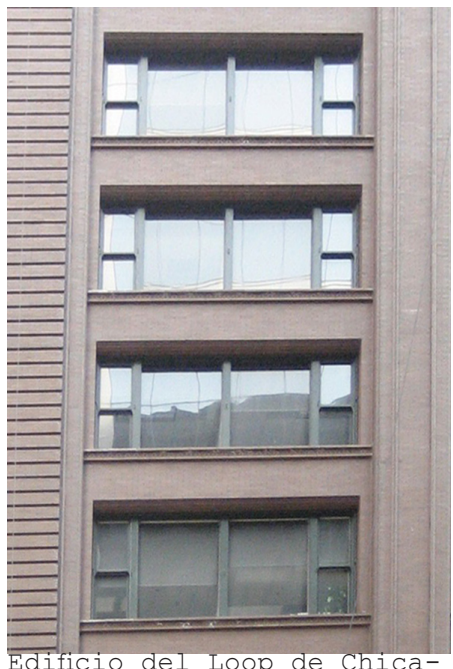
go con la conocida "ventana de Chicago".

Fotografía año 2008.

5. Colin Rowe, Manierismo y Arquitectura Moderna y Otros Ensayos (Barcelona: Gustavo Gili, 1978).

6. Architecture: The Second Chicago School. www. encyclopedia.chicagohistory.
El sistema reticular ha sido la solución más generalizada en la construcción en altura, permitiendo una planta diáfana gracias también a la acción de los núcleos de comunicación verticales rígidos. Sin embargo, la arquitectura de Chicago de finales del siglo XIX se caracteriza por un sistema estructural mixto en el que una serie de pórticos paralelos quedan atados entre sí mediante un muro perimetral en la fachada. Edificios como el Leiter II, también del arquitecto William Le Baron Jenney, representan un claro ejemplo de la "arquitectura vertical" de entonces caracterizada por un sistema mixto de marcos reticulares. Considerado uno de los edificios emblemáticos de la ciudad que vio nacer los "rascacielos", esta construcción fue una de las primeras obras comerciales llevadas a cabo mediante la estructura reticular.

La construcción y estructura empleada había logrado, como hacía referencia Rowe en sus texto, "crear arquitectura". ${ }^{5}$ y es que, con el tipo de construcción los diseños de la arquitectura vertical, llegaron también las "Ventanas de Chicago". Éstas se caracterizaron por tener un vano central fijo y dos laterales móviles con el objetivo de incrementar la zona de entrada de luz y aumentar la ventilación natural y cruzada. Ya entonces se tenía en consideración la mejora del clima interior de los espacios. Aun hoy, muchos de los edificios construidos por aquel entonces siguen respetándolas. Tanto las estructuras mixtas como las fachadas con grandes acristalamientos siguen siendo de actualidad.

Tras la Segunda Guerra Mundial, la construcción de arquitectura residencial, que había estado algo ralentizada, comenzó a reaparecer en chicago especialmente en forma de torres de apartamentos. Una década después fue también el turno de la arquitectura de uso comercial. Eran las décadas de los 40 y los 50, y estas dos tipologías arquitectónicas representaron lo que algunos sectores denominaron la "Second Chicago School", que incluye arquitectura hasta mediados de los 70. ${ }^{6}$ Uno de los principales protagonistas de esta etapa fue el arquitecto Mies van der Rohe que, tras emigrar de Alemania en 1938, pasó a dirigir el departamento de Arquitectura del entonces Armour Insititute of Technology, 
posteriormente Illinois Institute of Technology. ${ }^{7}$ En 1939, fue comisionado para llevar a cabo el proyecto del actual Illinois Institute of Technology (IIT). Edificios como el Crown Hall se conviertieron en construcciones emblemáticas de esta segunda etapa de la arquitectura de Chicago, entre otros por su construcción con acero y vidrio.

El campus del IIT fue un proyecto de larga duración. En él participaron otros arquitectos como Skidmore Owings \& Merrill (SOM) o Holabird \& Root y, posteriormente, Murphy / Jahn o Rem Koolhaas. El diseño del campus universitario se llevó a cabo durante un periodo extenso de tiempo, comenzando en 1939 y finalizando en $1946 .{ }^{8}$ El proyecto del campus crea un orden, y secuencia espacios construídos y espacios al aire libre estableciendo un diálogo entre lo ocupado y el vacío. Durante este tiempo, el diseño dirigido por el arquitecto alemán evolucionó de una arquitectura enfocada en expresar la función a otra centrada en expresar la estructura. De sus edificios se denotan distinas maneras de expresar la estructura en la arquitectura. En primer lugar, edificios como el Perlstein Building o Siegel Hall se caracterizan por el empleo de marcos reticulares cuya fachada está envuelta por paneles de ladrillo y vidrio. En segundo lugar, los tres bloques residenciales que construyó en el IIT se caracterizan por una estructura de hormigón que se relaciona con la de edificios en altura. En tercer lugar, emplea una estructura de muros de carga en la capilla. Por último, probablemente el edificio más emblemático, el S.R. Crown Hall, se caracteriza por un esqueleto de acero que envuelve la fachada de vidrio y deja ver una planta diáfana, libre y flexible.

El protagonismo de la estructura en la arquitectura se verá reflejada en gran parte de las construcciones comerciales - y también residenciales - que arquitectos como Mies Van der Rohe llevaron a cabo en Chicago. Esta etapa fue dominada por el concepto de "innovación", que pasó a estar concebido como la confluencia de varias tecnologías y a expresarse mediante un lenguaje práctico y funcional; las experimentaciones con las nuevas posibilidades de los materiales y los desarrollos constructivos permitieron esta evolución. La década de 1950 se convirtió, por tanto, en un

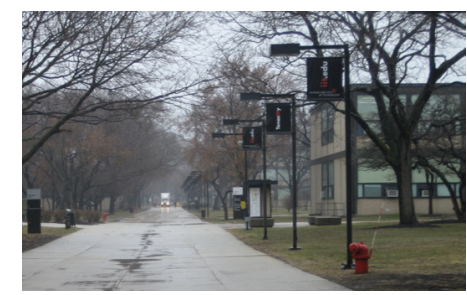

Illinois Institute Technology, 1942-1946, Mies Van der Rohe.

Fotografía año 2008.
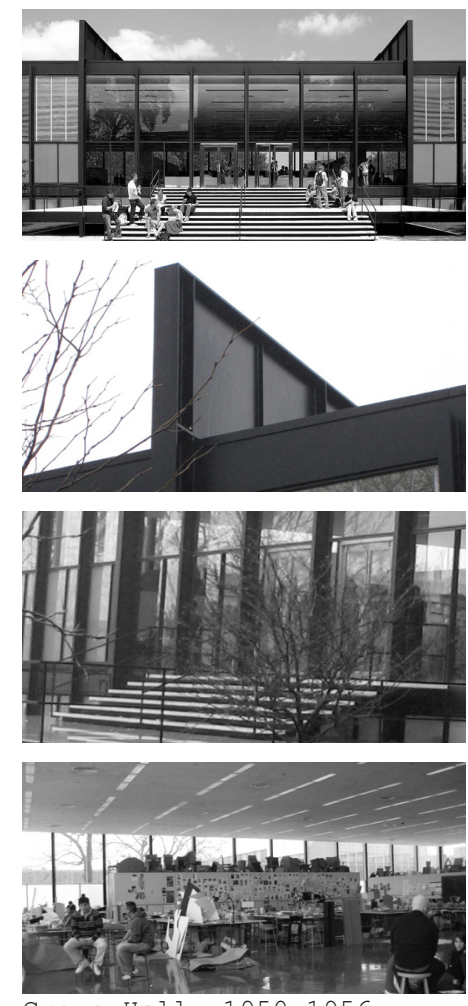

Crown Hall, 1950-1956, Mies Van der Rohe.

Fotografías año 2008-2009.

7. http://arch.iit.edu/ about/mies-van-der-rohe. 8. Franz Schulze \& Kevin Harrington, Chicago's Famous Buildings (Chicago: The University Chicago Press, 2003). 


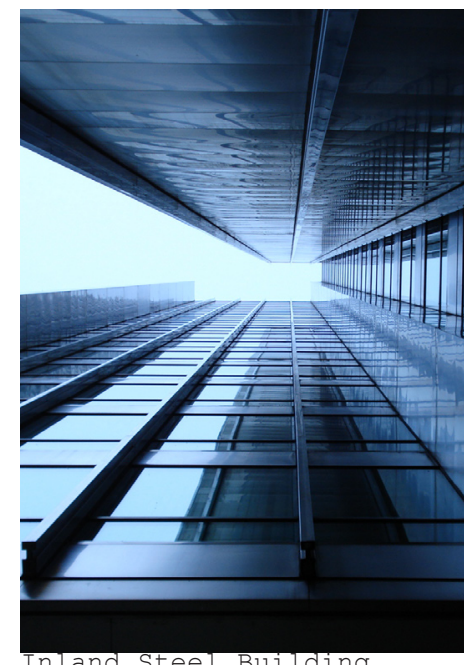

1958, SOM.

Fotografía de Timothy Brown, 2010.
9. Ramón Araujo, Construir en Altura (Barcelona: Editorial Reverté, 2012). 10. Franz Schulze \& Kevin Harrington, Chicago's Famous Buildings (Chicago: The University Chicago Press, 2003). periodo crucial en la evolución de los edificios en altura. ${ }^{9}$ El resultado que mejor ejemplifica este proceso tecnocientífico en la arquitectura fue sin duda el resultado del rascacielos estadounidense, protagonista en los "downtown" de ciudades norteamericanas desde hace varias décadas. No sólo Mies fue precursor de este tipo de arquitectura. Skidmore Owings \& Merril (SOM) fue una de las primeras grandes firmas de arquitectura estadounidense en diseñar y construir un edificio que reflejaba las características principales de la "Second Architecture School" en Chicago. El edificio de oficinas se convierte casi en el principal tema de experimentación, ya que es donde la técnica juega un papel importante debido a los temas relacionados con la climatización de los espacios y los núcleos de comunicación. Los ascensores y las instalaciones son, por tanto, una de las principales preocupaciones.

Un ejemplo es el edificio Inland Steel Building (SOM, Chicago, 1958), el primer edificio en altura construido en el Loop tras la Gran Depresión americana. ${ }^{10}$ El edificio de 20 pisos se caracteriza por el desplazamiento del núcleo de comunicación vertical y las instalaciones fuera de la planta de la torre. Al mismo tiempo, la estructura de acero inoxidable sale de la envolvente, permitiendo un vano de $18 \mathrm{~m}$ de planta libre. El muro cortina, situado entre los soportes verticales, está dominado por los montantes verticales, cuya profundidad permite a estos elementos verticales hacer de protección solar. El canto del forjado, solado y falso techo -de $1.5 \mathrm{~m}$ de altura aproximadamente- se cierra con áreas opacas que contrastan con el acristalamiento doble de las áreas de visión. Es en este edificio donde se puede observar también la improtancia del forjado que, junto con el desarrollo de los edificios en altura y la trascendencia de las instalaciones, comienza a tener un espesor considerable en los edificios de oficinas. A partir de aquí, la construcción en altura se convirtió en el prototipo de experimentación y desarrollo, y las envolventes de los mismos fueron la imagen de la ciudad y el progreso.

Ábalos y Herreros sugieren en Técnica y Arquitectura en la Ciudad Contemporánea que las dos cualidades que convirtieron el rascacielos en el prototipo tecno-arquitectónico fueron, 
por un lado, el hecho de que era el resultado de un proceso de elaboración científico e industrializado y, por otro, el hecho de que era el resultado de un análisis funcional o sociológico que representaba las actividades que en él se iban a desarrollar; actividades propias de la era de la industrialización."1 A finales del siglo XIX los "downtown" estadounidenses se convirtieron en zonas meramente destinadas al trabajo. Las sedes de las empresas más poderosas se trasladaban a los centros de las ciudades y eran estos edificios nuevos, resultados de la industrialización, los que mayoritariamente albergarían el centro de operaciones de estas industrias. Por tanto, la "industria" parecía estar buscando edificios "industrializados" donde crear sus centros neurálgicos; se estableció una relación entre el proceso por el que se concebía el rascacielos y la actividad que en él se iba a desempeñar, obteniendo así un prototipo que vinculaba la producción industrial con la concepción de la misma.

La construcción en altura sigue siendo una de las protagonistas principales de la arquitectura. Ya sea con el fin de albergar sedes de oficinas corporativas, o con el de alojar apartamentos u hoteles de lujo en las ciudades norteamericanas, lo cierto es que sigue siendo "el prototipo" de un estilo de vida marcado por el poder y la urbanidad. Esto ha mantenido activa la discusión acerca de la evolución de este modelo arquitectónico, y sus componentes se ven envueltas en constantes fases de evolución. La estructura, los sistemas mecánicos y la relación entre el espacio interior y exterior, son factores que han influenciado la concreción de las construcciones en altura de maneras muy dispares desde su nacimiento. A ello hay que añadir la persistente discusión de la piel exterior del rascacielos, cuya manera de relacionarse con el interior y el exterior del edificio ha sido y es protagonista en los círculos afines.

En primer lugar, la estuctura evoluciona con las necesidades; la estructura reticular, que para arquitectos como Mies Van der Rohe había sido un elemento inseparable en la construcción en altura, pasa a un segundo plano cuando comienzan a considerarse otros elementos tales como las ac-

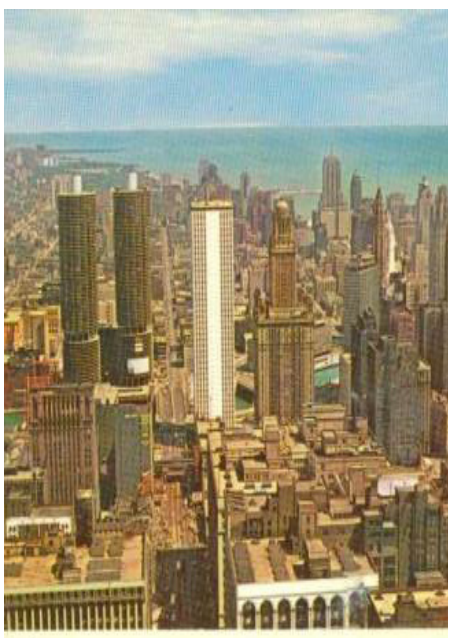

Imagen de Chicago de la década de los 60's.

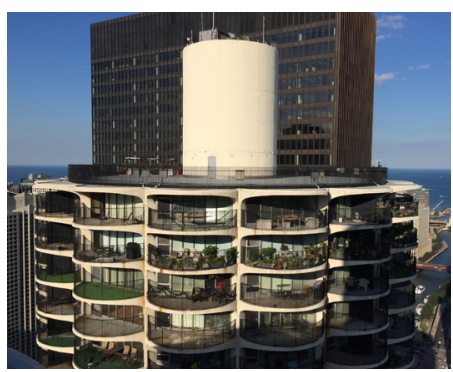

Marina City Towers, 1964, Beltrand Goldberg.

Fotografías año 2014

11. Iñaki Ábalos \& Juan Herreros, Técnica y Arquitectura en la Ciudad Contemporánea (Guipúzcoa: Editorial Nerea, 1992). 

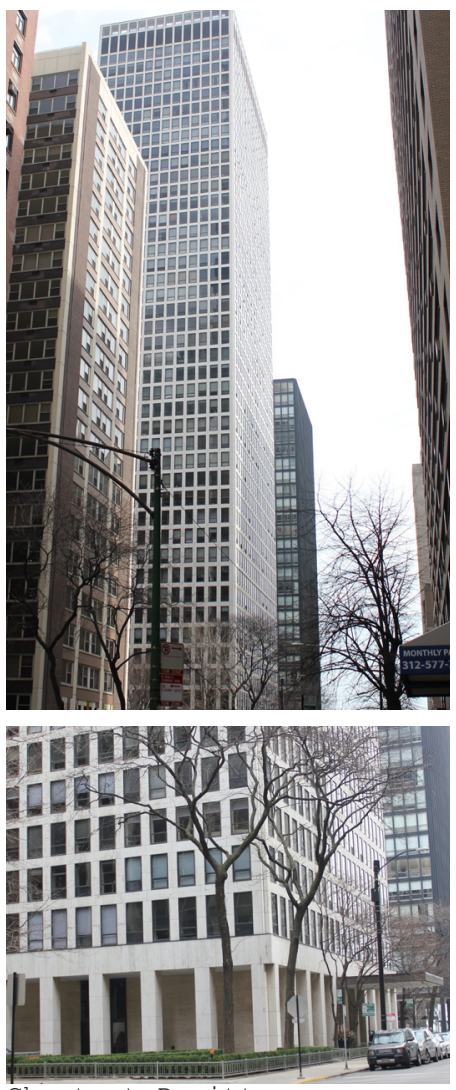

Chestnut-Dewitt

Apartments, 1964, SOM.

Fotografías año 2015.

12. Iñaki Ábalos \& Juan Herreros, Técnica y Arquitectura en la Ciudad Contemporánea (Guipúzcoa: Editorial Nerea,1992), página 49.

13. Iñaki Ábalos \& Juan Herreros, Técnica y Arquitectura en la Ciudad Contemporánea (Guipúzcoa: Editorial Nerea,1992), página 61.

14. Dr. Fazlur R. Khan: Engineering Pioneer of Modern Architecture: http://www.lehigh. edu/ infrk/2011.08. article.html. ciones del viento. Ábalos y Herreros lo describen como "el fin de la retícula". ${ }^{12}$ La ciudad de Chicago, caracterizada por sus fuertes vientos, empieza a ver en sus edificaciones en altura tipologías estructurales diferentes a los marcos reticulares. Por ejemplo, en las torres de apartamentos que Bertrand Goldberg diseña para Chicago en 1964: Marina City. En este caso, se emplea una estructura en la que se concentra la masa en el centro de las torres, así como el empleo de mecanismos de arcos en el exterior para amortiguar las cargas horizontales. La relación entre los elementos estructurales y los planos de cierre del edificio varía así según el tratamiento, estando en unos casos conectado y en otros sin establecer conexiones.

Las aportaciones de SOM en lo referente a la estructura de los edificios en altura se debe, entre otros, al trabajo de Fazlur Khan (1929-1982). ${ }^{13}$ Durante su carrera, llevó a la práctica lo que hasta entonces eran estudios teóricos. Cuando se unió a Skidmore en la década de los 60, los diseños estructurales empleados para edificios en altura se limitaban al empleo de un esqueleto formado esencialmente por vigas y columnas: estructuras de marcos reticulares. Al mismo tiempo, aparecían muros de carga de hormigón, o sistemas de cerchas, que los ingenieros empleaban para la estabilidad frente a las acciones laterales como el viento. ${ }^{14}$ Estos tipos estructurales, aptos para edificios con una altura máxima de entre 20-30 alturas, no sólo no eran los más eficientes para edificios de mayor altura sino que también resultaban significativamente más costosos.

Así, por ejemplo el edificio de apartamentos chestnut-Dewit, se convirtió en el primer intento de estructura tubular. Debido a las acciones del viento que se preveían para el edificio, el equipo de ingenieros y arquitectos de SOM que trabajaban en este proyecto, propuso un nuevo sistema en el que la estructura se traslada del núcleo central al perímetro del edificio, resistiendo así las acciones horizontales de viento. Las columnas, espaciadas a pocos metros entre sí, crean una jaula estructural que dota de resistencia lateral y soporte de cargas de gravedad.Las vigas de canto dotan de inercia al sistema que permite la libertad de los espacios interiores. El cerramiento del 
edificio conforma un sistema tubular estructural que actúa, junto con las vigas, como una ménsula empotrada. Con ésto, SOM permite optimizar el sistema estructural y su eficacia. El tipo de fachada está en este caso directamente relacionado con la estructura, ya que los paneles quedan empotrados entre la misma. ${ }^{15}$ Compositivamente, la relación entre la estructura y la fachada es directa.

En segundo lugar, la complejidad de los sistemas energéticos de los que se abastece la construcción en altura aumentó con la evolución de los rascacielos. Junto con el diseño estructural, el control ambiental es determinante en la organización de los edificios en altura. Con ello, la definición de un espacio donde alojar los sistemas energéticos fue un punto en el que los arquitectos e ingenieros centraron sus esfuerzos. ${ }^{16}$ Las respuestas de los arquitectos a los deseos de ligereza y transparencia no daban solución a problemas y cuestiones de tipo energético. Los ideales de fachadas que se establecieron en la arquitectura moderna trajeron consigo contradicciones y situaciones que era preciso resolver, algunas de las cuales la arquitectura actual sigue sin haber resuelto. Por ejemplo, la desnudez de las fachadas de vidrio, características en la arquitectura de Mies, trae consigo necesidades de climatización artificial en las que el confort interior se relega a los equipamientos mecánicos, cuyo uso excesivo complica energética y económicamente el proyecto. Lo que parecía tener una solución más o menos sencilla en las construcciones de menor altura, se complicaba con los rascacielos. El elevado número de los empleados en las oficinas y el equipamiento necesario para tal, incrementaban las cargas internas y complicaba el poder alcanzar un confort interior. A esto se añade el hecho de que las envolventes de vidrio no estaban pensadas para asumir estos controles reguladores.

Por tanto, las construcciones en altura llevaron consigo un desarrollo necesario de los sistemas de suministro energético para climatización, ventilación, transporte o iluminación. Los forjados, cuyo espesor aumenta considerablemente, albergan no sólo las losas de forjado y otros elementos estructurales, sino, entre otros elementos, las instalaciones de aire. Se convierte, por tanto, en el es-

15. Iñaki Ábalos \& Juan Herreros, Técnica y Arquitectura en la Ciudad Contemporánea (Guipúzcoa: Editorial Nerea, 1992).

16. Ramón Araujo,

Construir en Altura

(Barcelona: Editorial Reverté, 2012). 


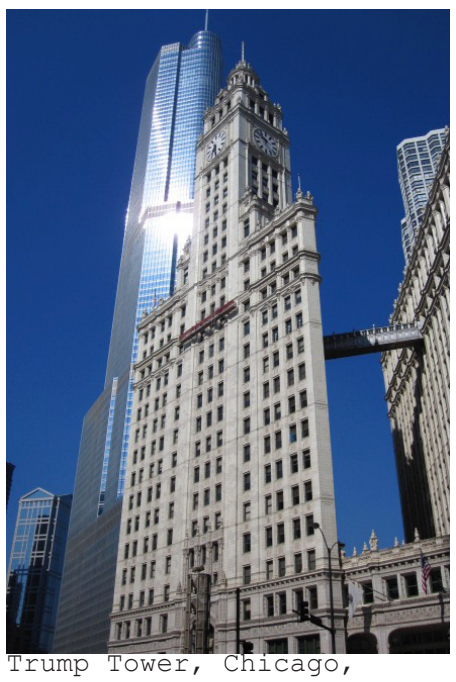

2010, SOM.

Fotografía de Trump Tower \& Wrigley Building año 2009 . pacio destinado a las instalaciones. Un ejemplo de ello se puede ver en el Manufacturers Hanover Trust en Nueva York, edificio diseñado por SOM en 1954.

Por último, se establece una separación física entre usuario del medio exterior. Esto se representa mediante el distanciamiento del plano del suelo y del plano de fachada. Un ejemplo de ello es la Lever House (SOM, Nueva York, 1967), donde los arquitectos elevan el edificio de la cota de la calle, y crean un espacio de transición entre el usuario y el viandante. Esta separación se repite en distintos edificios a lo largo de la historia. En la actualidad se emplea, de manera similar, en proyectos en los que se delegan ciertas actividades a los planos inferiores. Un ejemplo de ello es el recientemente terminado Trump Hotel (SOM, Chicago, 2010), donde las plantas destinadas a los aparcamientos sirven de aislamiento entre el interior y el exterior del edificio. Dejando de lado las diferencias entre ambos modelos de proyecto, se emplean elementos estratégicos para independizar diferentes atmósferas.

Por consiguiente, la evolución técnica de la construcción en altura ha atravesado distintas etapas a lo largo del tiempo. En la mayoría de los casos estos elementos se caracterizaron por la dispar relación, incluso su ausencia, con la envolvente del edificio. Sin embargo, en la actualidad existen opciones para que estos sistemas energéticos estén relacionados con los elementos de cierre: la envolvente.

Las propuestas actuales de vidrios de respuesta energética variable, la aparición de los dobles muros cortina o la evolución de las envolventes de manera pasiva a un elemento activo en el edificio, son estrategias que apuntan en esta dirección. Sin embargo, el máximo aprovechamiento de estos mecanismos en la práctica general de la arquitectura, especialmente la residencial, está todavía por resolver. Y lo que es más, la arquitectura de hoy en día debe amoldarse a las condiciones y requisitos actuales, tanto técnicos como energéticos $y$, entre otras consideraciones, asumir un posible cambio en el espesor de "la envolvente", que puede llegar a la dimensión del atrio. Los modelos actuales deben 


\section{CAPÍTULO 02}

considerar las opciones que actualmente existen y no basarse únicamente en imitaciones del pasado cuando las premisas y condicionantes eran distintos.

La evolución de la técnica en la construcción en altura exige que hoy en día se revisen los principios de formalización del proyecto, estableciendo conexiones entre las posibilidades de la técnica y la concepción del edificio. ¿Las envolventes?... Son el punto clave en el que comenzar a establecer el análisis, ofreciendo múltiples posibilidades en el uso de la técnica e influyendo en la definición tipológica del modelo desde los nuevos procedimientos constructivos a los que se tiene acceso. 


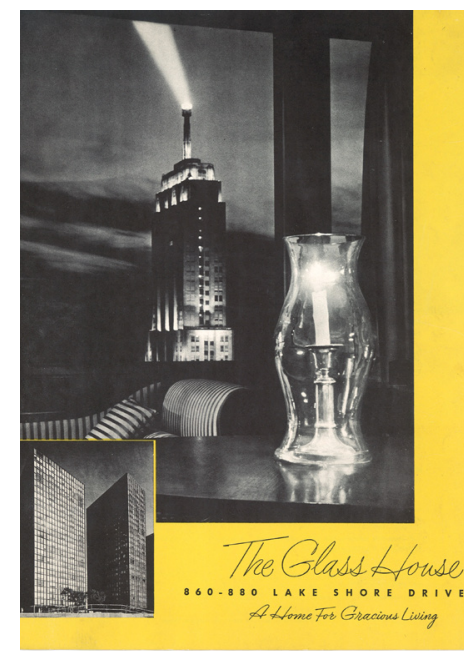

The Glass House. 860-880 Lake Shore Drive, Chicago, 1957.

\subsection{LA ENVOLVENTE COMO SUPERFICIE CONTINUA. MIES VAN DER ROHE, CHICAGO.}

La evolución del cerramiento de vidrio a lo largo del siglo $\mathrm{XX}$ ha ido modificando las condiciones de proyecto y se ha visto relacionada con el desarrollo de diferentes técnicas constructivas. Lo que en las etapas iniciales se materializaba dando prioridad a la transparencia y visibilidad de los espacios interiores sin considerar otros problemas derivados de las mismas, dio paso a tener en cuenta otros aspectos relacionados con el clima interior. De esta forma, el desarrollo de nuevas técnicas, así como los cambios en las preocupaciones por parte de la sociedad, se han visto reflejados en la arquitectura de fachadas de vidrio de las construcciones en altura a lo largo de su historia.

Durante el Movimiento Moderno se desarrollaron técnicas que ayudaron a construcciones antes irrealizables. Esto, junto con la experimentación de materiales y procesos industrializados, supuso un perfeccionamiento en el tra- 
tamiento de las envolventes de los edificios, que tendían a alejarse de los artesanales muros masivos y optaban por una pared ligera, reticular y prefabricada. ${ }^{17}$ Esta transformación fue fruto de una industrialización científica que ha ido dando respuesta de manera más o menos acertada a las distintas propiedades y requerimientos que se exige a los cerramientos. Su concepción, formación y montaje recuerda a los procesos industriales empleados en otras áreas de fabricación, como por ejemplo el sector del automóvil.

A comienzos del siglo xx, la experimentación con los materiales y los procedimientos industriales trajeron consigo un desplazamiento significativo en la concepción de los cerramientos. Por ejemplo, estudiando los principios que conforman los tipos de pared ligera, se observa que éstos se basan en una simplificación de los componentes de cerramientos anteriormente empleados: los muros de ladrillo con cámara de aire se simplifican en paneles de vidrio con o sin cámara o se introduce paneles opacos con aislamiento, persiguiendo comportamientos parecidos a los muros.

En Europa, las aportaciones de Le Corbusier a este respecto fueron resultado de distintas formas de investigación. Así, la ventilación e iluminación natural por medio de la "fenêtre en longeur", el control solar mediante el "brise soleil", la envolvente inteligente y activa a través del "mur neutralizant", o la incorporación de aire acondicionado mediante la "respiration exacte", son ejemplos de cómo el arquitecto llevó a la teoría y a la práctica sus inquietudes hacia una arquitectura moderna y avanzada.

En el texto que el arquitecto suizo redacta tras conocer la sentencia por parte del jurado para el concurso de la Sociedad de Naciones de 1927-29 para Ginebra se hace referencia al desarrollo de un sistema de cerramiento basado en su característica "fenêtre en longueur". ${ }^{18}$ El sistema de muro cerámico doble incorpora los distintos elementos de un muro tradicional tales como las hornacinas para los radiadores, el canal de condensaciones e incluso los mecanismos exteriores de limpieza. A la propuesta del cerramiento en la que las superficies opacas y transparentes ejercen papeles significantes y característicos, se añade la voluntad

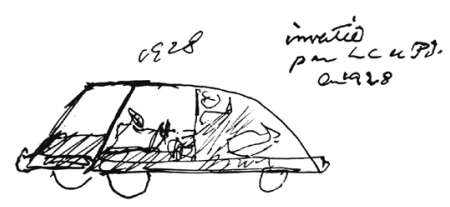

Diagramas de Voiture Minimum: Le Corbusier and the Automovile

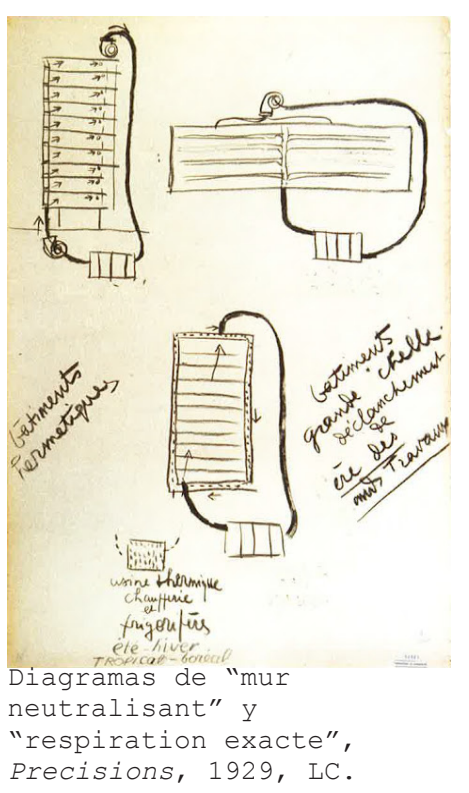

17. Iñaki Ábalos \& Juan Herreros, Técnica y Arquitectura en la Ciudad Contemporánea (Guipúzcoa: Editorial Nerea, 1992). 18. Le Corbusier, Une Maison, Un Palais. A la Recherche d'une unité architecturale (París: Editions Connivences, 1989). 

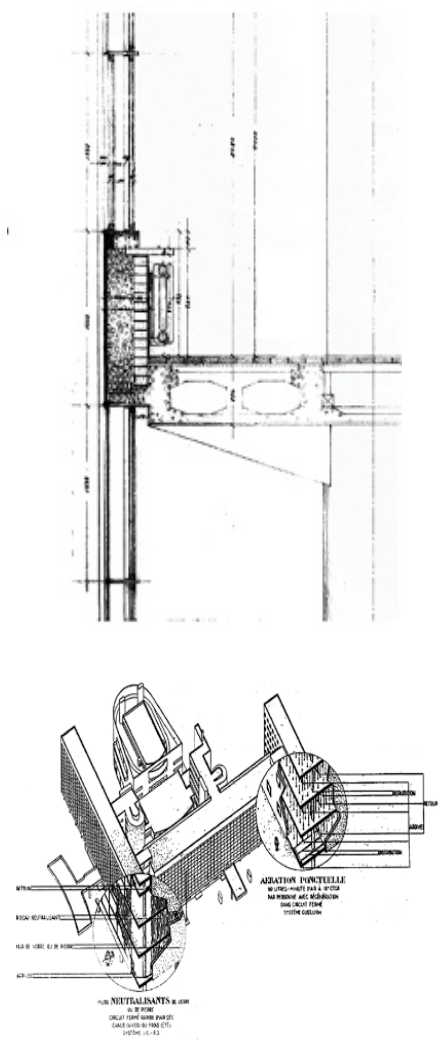

Diagramas de Le Corbusier para el Centrosoyuz, Moscú, 1928, LC.

19. Le Corbusier, Une Maison, Un Palais. A la Recherche d'une unité architecturale (París: Editions Connivences, 1989).

20. Iñaki Ábalos \& Juan Herreros, Técnica y Arquitectura en la Ciudad Contemporánea (Guipúzcoa: Editorial Nerea, 1992). del arquitecto por utilizar la inercia de la masa del muro como retardador de intercambios energéticos, una de las principales desventajas del vidrio y las carpinterías metálicas empleadas por aquél entonces. Se recalca, por tanto, la necesidad de establecer una barrera entre el exterior y el interior, y la masa del muro sirve para asegurar cierta estabilidad en el espacio interior. Estabilidad que, cómo no, pasa por relegar las funciones de acondicionamiento a los sistemas mecánicos artificiales.

En una segunda propuesta de dicho muro, el arquitecto habla ya de sustituir el muro másico tradicional por hojas ligeras que supuestamente optimicen la respuesta al problema interior-exterior. ${ }^{19}$ En el texto Técnica y Arquitectura en la Ciudad Contemporánea, los autores explican otra de las propuestas introducidas en el proyecto de sociedad de Naciones, que consistía en estudiar la posibilidad de desarrollar un sistema de ventilación que asegurase la entrada de aire sin contaminar la temperatura y humedad regulada en la cámara entre los vidrios. ${ }^{20}$ Le Corbusier proponía incluir un sistema de renovación de aire con retorno al sistema central. En este proyecto, la cámara que rodea al edificio debía reducir la energía necesaria para calentar el volumen del edificio, aunque no tuvo en consideración otros aspectos tales como los efectos derivados de la radiación directa del sol, los problemas de estratificación de corrientes de aire (la cámara iba a ser continua) o las posibles condensaciones. A pesar de que no tuvo un éxito inmediato, sirve de precedente al desarrollo teórico de los sistemas artificiales de ventilación para el clima interior.

En el proyecto Centrosoyuz en Moscú (1928), el concepto del "mur neutralisant" y de "respiration exacte" fueron aplicados con los siguientes conceptos. Por un lado, se crea un espacio aislado y sellado del exterior, tratando de evitar la transmisión de energía (y por tanto de aire caliente y frío) del exterior al interior y viceversa. Aquí entra el concepto del "mur neutralizant". Por otro lado, el concepto de "respiration exacte" se persigue mediante un sistema de ventilación controlada con efecto en la temperatura del aire y la humedad. Podría ser la introducción del aire acondicionado a sistemas de fachada avanzados. 
Europa no era el único punto en el que arquitectos como Le Corbusier dedicaban sus esfuerzos a estudiar las posibilidades de las envolventes. En Chicago, junto con el desarrollo del "balloon-frame", arquitectos como Frank Lloyd Wright o Walter Gropius estudiaban las posibilidades de emplear materiales industrializados en los muros ligeros. En estos casos, los cerramientos se convertirían en un conjunto de hojas acabadas exterior e interiormente, dotados de elementos impermeabilizantes, con aislante térmico e incluso acústico, y que se montarían en seco y se conectarían a los forjados mediante un marco de acero.

Pero la propuesta más ambiciosa fue sin duda el cerramiento continuo de vidrio, que se convertiría en el cerramiento protagonista de la era del rascacielos. Además de ser concebido con una cualidad de ligereza y transparencia que permitía desmaterializar los aspectos técnicos que se albergaban detrás de este material, el empleo del vidrio obligó a una reconsideración de los espacios destinados al acondicionamiento de las estancias interiores. Al entender el cerramiento de vidrio como una superficie hermética que independizaba el espacio interior del exterior, aparecieron las cuestiones que se debían resolver, especialmente en lo que a los sistemas de ventilación de espacios se referían. Para garantizar el confort de los espacios interiores, era necesario sustituir la inercia de los muros másicos por el desarrollo de los sistemas de climatización mecánicos. Fue éste uno de los factores más determinantes y característicos de la arquitectura de vidrio de mitad de siglo, especialmente aquélla destinada a las construcciones en altura.

La introducción de este nuevo sistema de cerramiento potenció el papel de relación entre la técnica y la estética, especialmente mediante el uso de dos materiales tan aparentemente antagónicos como el acero y el vidrio. La expresión formal de las estructuras en la arquitectura no era nada nuevo por aquél entonces; en la Edad Media se había llevado a cabo en su máxima expresión en las catedrales góticas. Desde entonces, distintas evoluciones constructivas habían incorporado esta manera de unir la estructura y la expresión formal. Sin embargo, fue especialmente notable en 
la arquitectura de los años 50, en la que se producía una doble paradoja. Por un lado, el uso del vidrio exigía un esqueleto que enmarcase y asegurase la sustentación del material y, en consecuencia, requería del uso de la técnica. Por otro lado, inevitablemente, la ingravidez de este material sugería una imagen de piel casi efímera que justificaba el deseo existente por conseguir una imagen de material libre, flotante en el espacio y que configurase el volumen interior. Parecía haber una idea común en la arquitectura de fachadas del movimiento internacional: sólo mediante el uso de una piel de vidrio se aseguraba que tanto la técnica como la expresión libre arquitectónica pudiesen ser conjugadas. Y éste parecía ser el fin principal de un gran número de los edificios que se diseñaron: una piel de vidrio transparente en la que se deja ver el marco estructural y el uso de la técnica requerida (o no) para su construcción. Por tanto, el desarrollo de los vidrios y de las estructuras de acero impulsaron dichas experimentaciones, y se han convertido en aportaciones de gran valor para la arquitectura de siguientes generaciones.

Otra de las premisas principales de la construcción en altura fue potenciar la libertad de los espacios interiores. La presencia de una piel que en nada compromete el espacio interior, su distribución y su funcionamiento, hace que los proyectos, sobre todo aquéllos destinados a oficinas, cobren especial flexibilidad. Los espacios interiores no estaban vinculados al cerramiento, sino que se abrían y se unían con el entorno exterior para optimizar y maximizar el contacto visual, ya sea con la ciudad o la inmensidad de un lago. Sin embargo, esta premisa trajo consigo grandes inconvenientes que los arquitectos de este periodo no tuvieron en cuenta. El hecho de que la superficie de cierre fuese una fina piel de vidrio simple, que no permitía ningún punto de conexión entre el espacio interior y el espacio exterior más allá del visual, hizo que las ventajas obtenidas del aprovechamiento de la luz solar quedasen mermadas por los problemas derivados de la radiación directa del sol sobre el vidrio y, en consecuencia, del excesivo calentamiento del espacio interior. A esto se añadían las pérdidas de calor con el uso de un vidrio simple. Por tanto, a pesar del indiscutible desarrollo tecnológico que supuso la 
experimentación que se llevó a cabo en lo referente a las fachadas de muros cortina, quedaban sin resolver factores que hoy resultan determinantes para el buen funcionamiento de las fachadas y del edificio en su conjunto.

Unos de los arquitectos que explotó al máximo el uso del muro continuo de vidrio fue Mies Van der Rohe, quien, en edificios como Lake Shore Drive (Chicago, 1951), el Seagram Building (Nueva York, 1954) o el One IBM Plaza (Chicago, 1970), experimentó con las posibilidades que este material podría llegar a alcanzar y cuyas investigaciones todavía hoy son modelos de referencia. Los dos ejemplos que se explican a continuación: Lake Shore Drive Apartments, y One IBM Plaza, forman parte de la obra americana característica de Mies Van Der Rohe en Chicago. Como sugiere Ignacio Paricio en el artículo para AV, fue precisamente a lo largo de su obra americana donde Mies dio rumbos distintos a la sinceridad constructiva de la que hacía halago según el edificio en cuestión. ${ }^{21}$ La exposición de los perfiles verticales estructurales que había potenciado en edificios de una sola planta (S.R. Crown Hall), fue vetado al tratar edificios en altura debido principalmente a la protección contra incendios. Así, por ejemplo, en edificios como Lake Shore Drive, la imagen se conserva introduciendo la repetición de montantes verticales que se ha explicado con anterioridad. Posteriormente, estos perfiles verticales de acero pasaron a ser en bronce y aluminio, tomando caminos cada vez menos estructurales y más formales. Al mismo tiempo, los pilares estructurales llegan a la planta baja creando una especie de porches en los que el lobby se retranquea del perímetro de fachada como se verá en los apartamentos Lake Shore Drive. Posteriormente, sin embargo, cuando la estructura debía estar protegida y en un plano interior al de la piel de vidrio, el traspaso de la misma fue inevitable.
21. Ignacio Paricio, Tres observaciones Inconvenientes sobre la construcción Americana, A\&V, n6, 1986. 


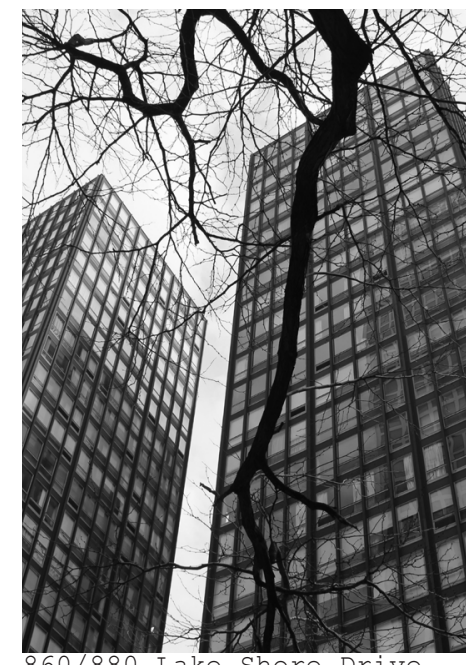

$860 / 880$ Lake Shore Drive, Chicago, 1951, MVdR. Fotografía año 2015.

\subsubsection{Lake Shore Drive (Mies van der Rohe, Chicago 1951)}

Las torres residenciales de vidrio y acero 860/880 Lake Shore Drive se sitúan en una de las zonas más privilegiadas de la ciudad de Chicago. A orillas del Lago Michigan y a escasos pasos del centro de la ciudad, ambas torres se colocan en ángulo recto respecto a la trama urbana de la ciudad, y se conectan entre sí mediante una marquesina que une la cara norte del número 860 con la sur del número 880. El núcleo central, alineado a los pilares y favoreciendo una planta libre y estructura modular, permite la relación entre la estructura y la fachada. La solución de fachada de estas torres se caracterizan por los perfiles en I que, sin ninguna función estructural, están soldados a las vigas y pilares con una separación de $1.60 \mathrm{~m}$ que dotan de una trama vertical a la fachada de vidrio. La estructura de acero, organizada en módulos de $3.50 \mathrm{~m}$ de altura, carga con una estructura secundaria que a la vez hace de soporte de los paneles de fachada, a excepción de los perfiles en I, que quedan adosados a los pilares. Las ventanas luego quedan divididas por montantes de aluminio de suelo a techo y que delimitan de esta manera las áreas de los pilares y las jácenas creando una zona de sombras frente a la luz de las superficies de acristalamiento.

El proyecto establece una distinción entre las capas primarias y secundarias de la construcción, entre el esqueleto y lo superpuesto o entre el tronco y la piel. Esto hará que proyectos posteriores estén resueltos con una imagen similar basada en los contrastes. En el caso del muro cortina proyectado por Mies para estas dos torres de apartamentos, el arquitecto hizo coincidir el vidrio con la cara exterior de la estructura, y los detalles de fachada muestran una intención de enfatizar así la idea de transparencia continua y plana. Sin embargo, esta decisión incorpora problemas constructivos y energéticos ya que se debía asegurar la independencia de movimientos entre la estructura y la envolvente para los movimientos diferenciales. Para ello fue necesario contar con juntas de expansión, lo que energéticamente ocasiona puentes térmicos que causan problemas de pérdidas de energía e infiltración. En justificación a la expresión de la técnica, en este caso a la estructura, y 
contradiciendo el axioma planteado por Sullivan "form follows function", Mies hace suya esta expresión introduciendo el término "estructura" en lugar de "función". De esta manera da a entender que aunque la función del edificio cambie, la forma será la misma debido a la independencia de la estructura y la piel, característica que fue desarrollando en los sucesivos proyectos.

Uno de los objetivos del proyecto fue la conexión del espacio interior con el exterior, permitiendo así una planta libre y acristalada. La distribución de las plantas y los distintos estudios que se llevaron a cabo dejaron entrever dicha voluntad. Así, en las plantas de 860/880 Lake Shore Drive, las esquinas se destinan a los salones y las estancias principales. En el proyecto de los apartamentos Algonquin, Mies ya establece su voluntad de buscar el enmarque de las vistas de la ciudad y el Lago Michigan. En el caso de LSD (unos meses después), el arquitecto establece un juego entre las superficies de vidrio y los perfiles de acero, creando espacios visuales que relacionan el interior con el exterior de las viviendas, aun sin establecer ningún tipo de conexión física. De esta manera, no sólo logra enmarcar las vistas desde las unidades de viviendas con estampas del Lago Michigan o del "skyline" del "downtown" de Chicago, sino que resalta la construcción sobre los edificios vecinos debido principalmente al contraste producido entre el negro del acero estructural y las superficies continuas de vidrio detrás de las cuales se entrevén las cortinas grisáceas y las carpinterías. Consigue así trasladar el concepto de la terraza o porche típico de la vivienda suburbana americana a la vivienda en altura.

Fue precisamente en la ciudad que vio nacer el prototipo de construcciones en altura donde Mies se declina por el uso de un esqueleto de acero no sólo estructural sino también interior. Con un fin que podría decirse prácticamente estético, el arquitecto se vio en la necesidad de solventar los problemas térmicos y de prevención de incendios para llevar al límite la máxima que él mismo se había impuesto. El cerramiento de 860 Lake Shore Drive marcó un punto de inflexión en las posibilidades del vidrio en las fachadas de las construcciones en altura. Lo que antes podía ser un 


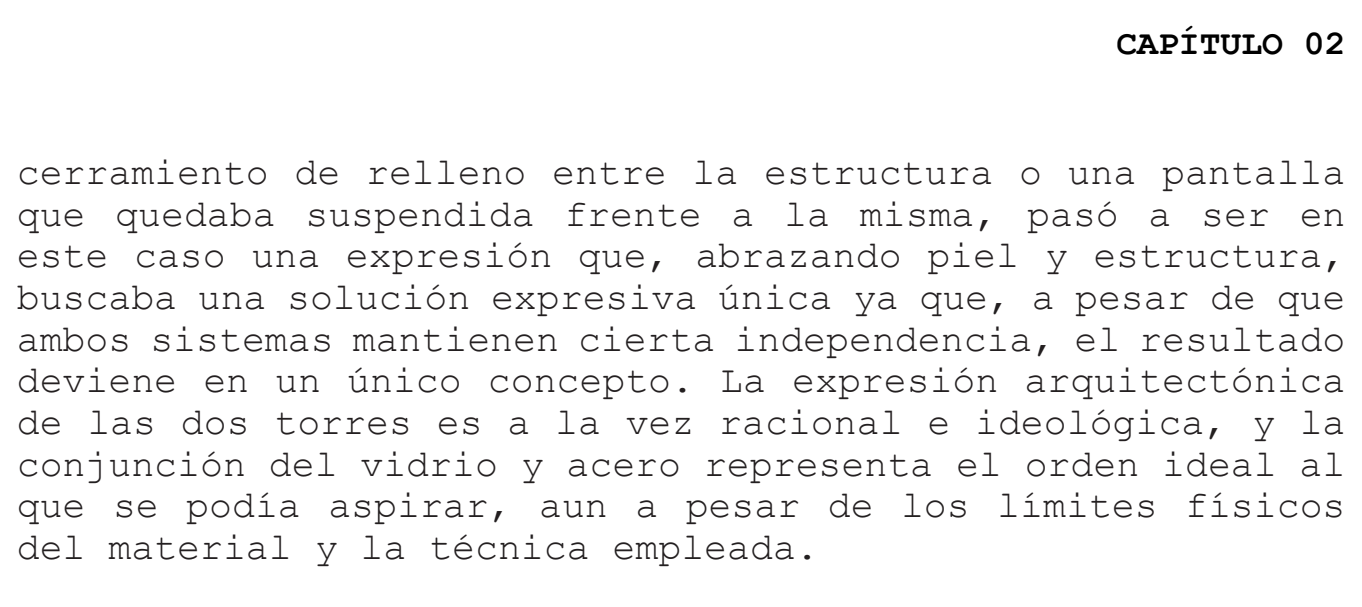




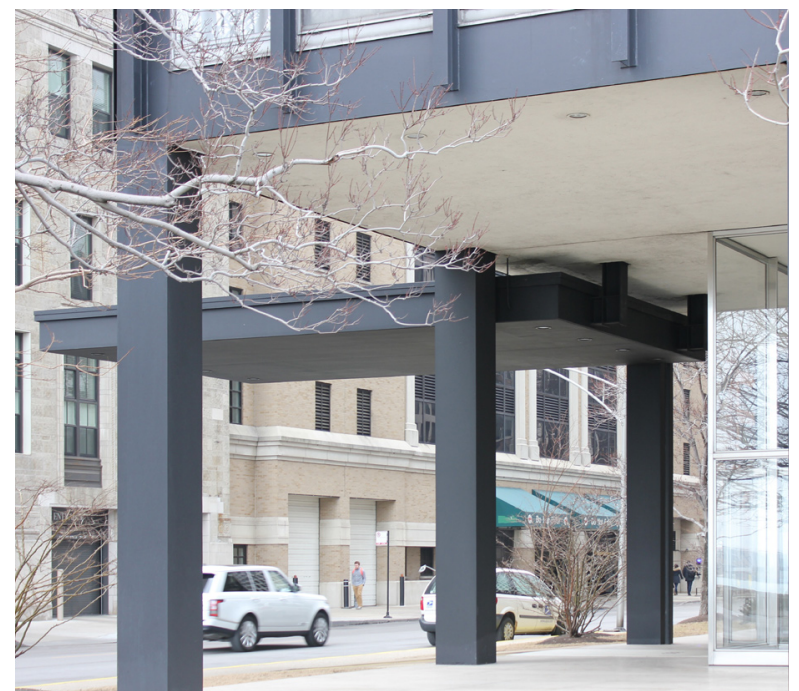

Marquesina de entrada de la torre sur. Fotografía año 2015.

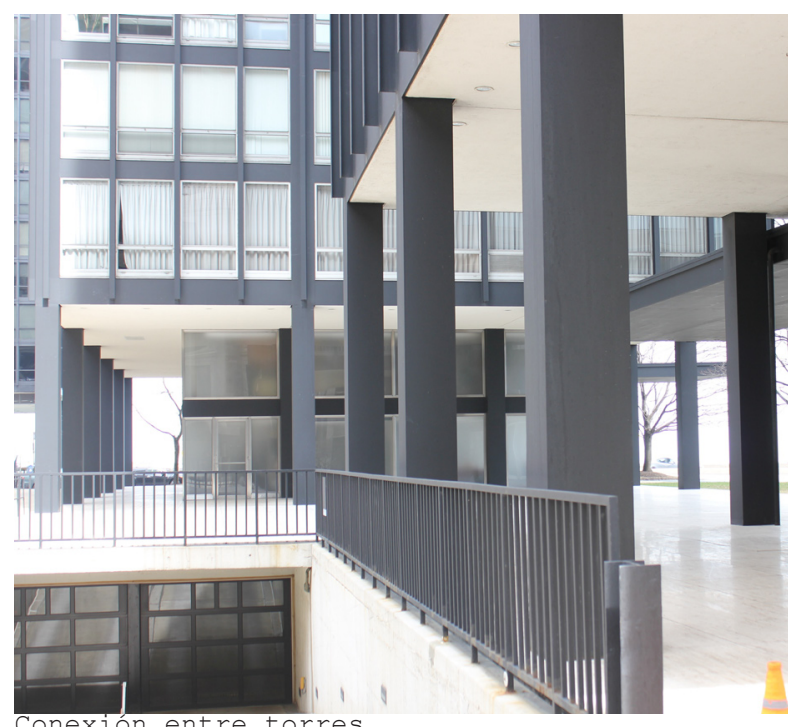

Conexión entre torres.

Fotografía año 2015.

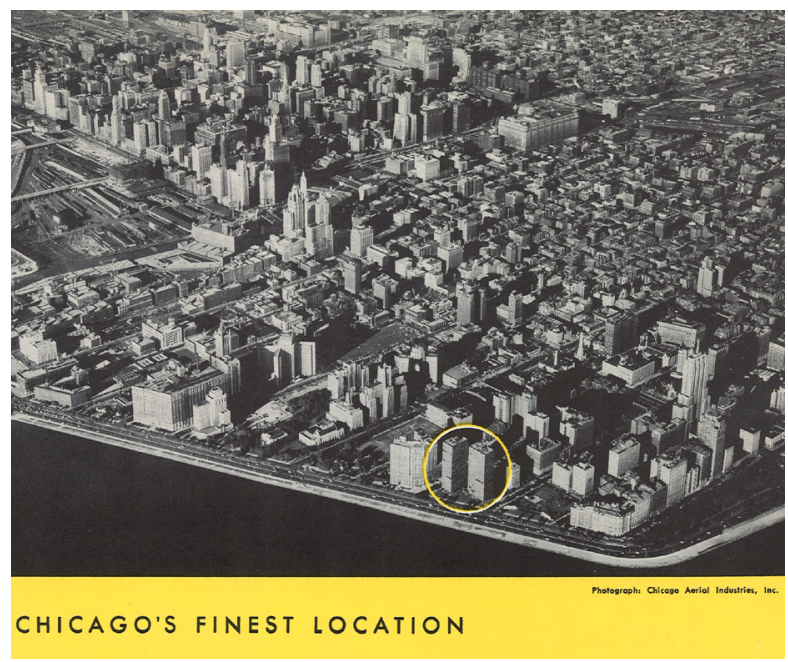

Fotografía aérea de una parte de la ciudad con la localización de las torres a orillas de Lago Michigan.

La imagen servía de presentación para la pu-

blicación del folleto The Glass House. 860-880 Lake Shore Drive, 1957.

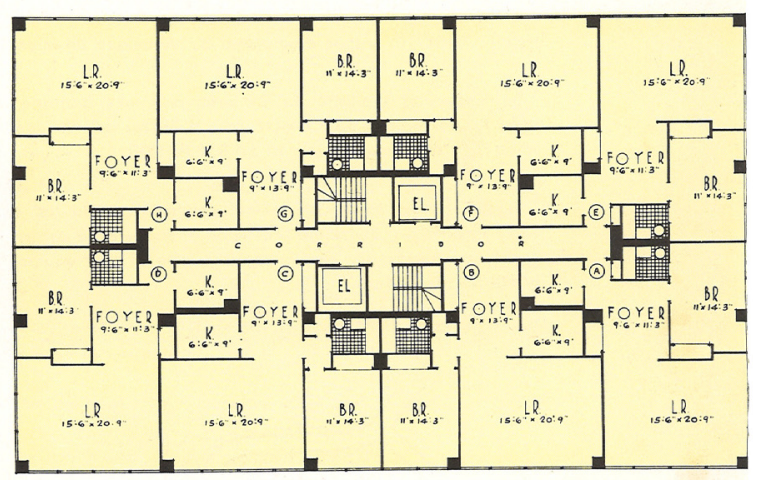

TYPICAL FLOOR PLAN

Ilustración de una de las plantas tipo de The Glass House. 860-880 Lake Shore Drive, 1957. 


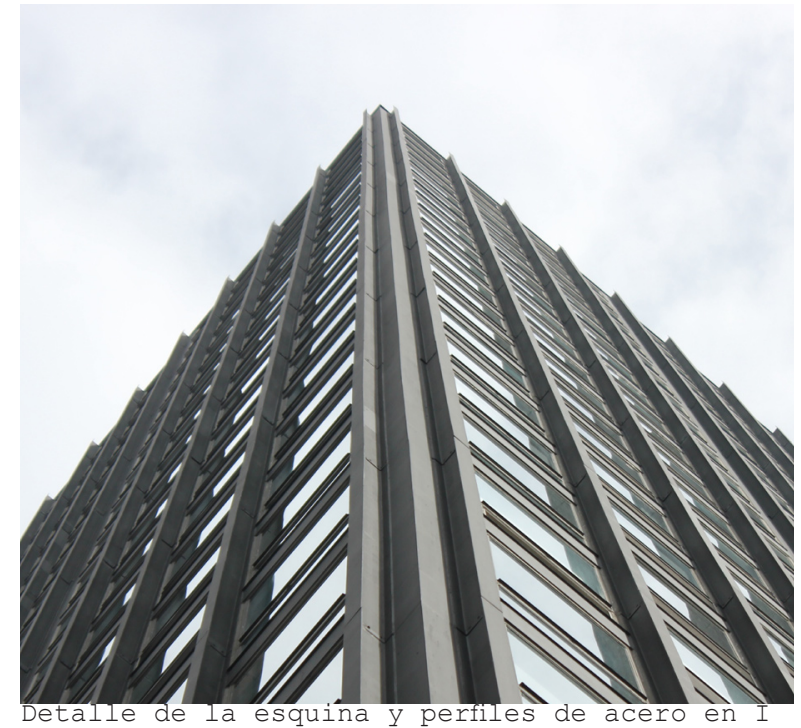

de las torres en la zona superior.

Fotografía año 2015.

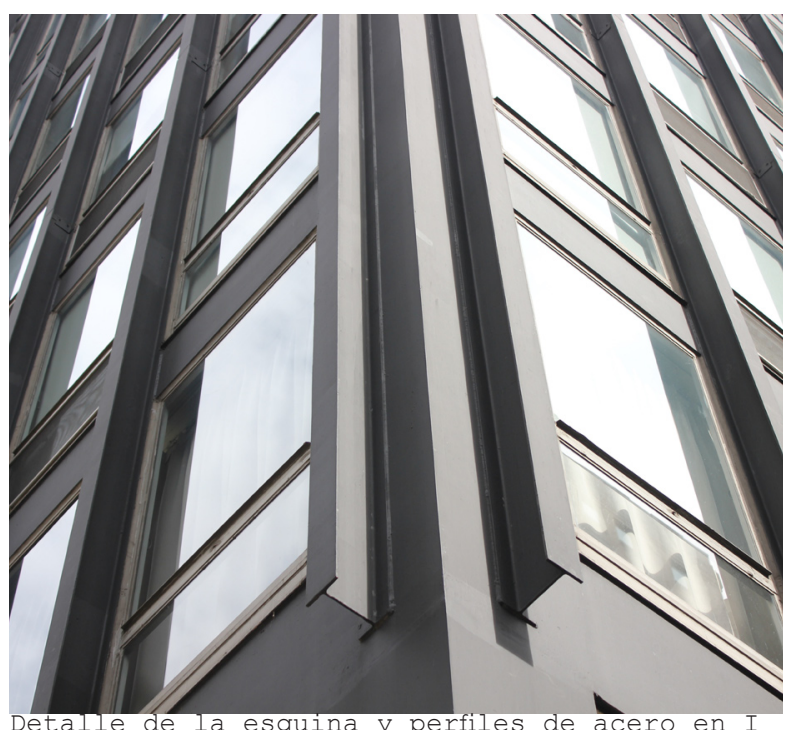

de las torres en la zona inferior.

Fotografía año 2015.

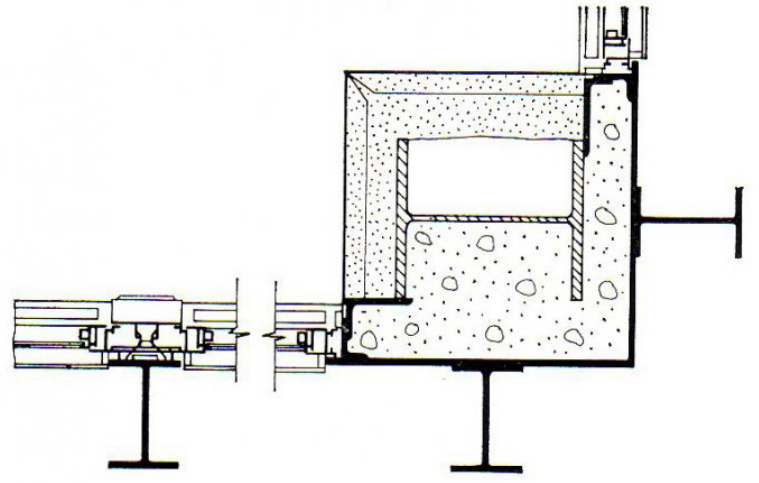

Detalle en planta de la envolvente de Lake Shore Drive Apartments.

La ilustración se llevó a cabo para la publicación de The Architectural Review de 1972 en la que el profesor John Winter estudió los detalles en esquina de varios de los edificios de Mies

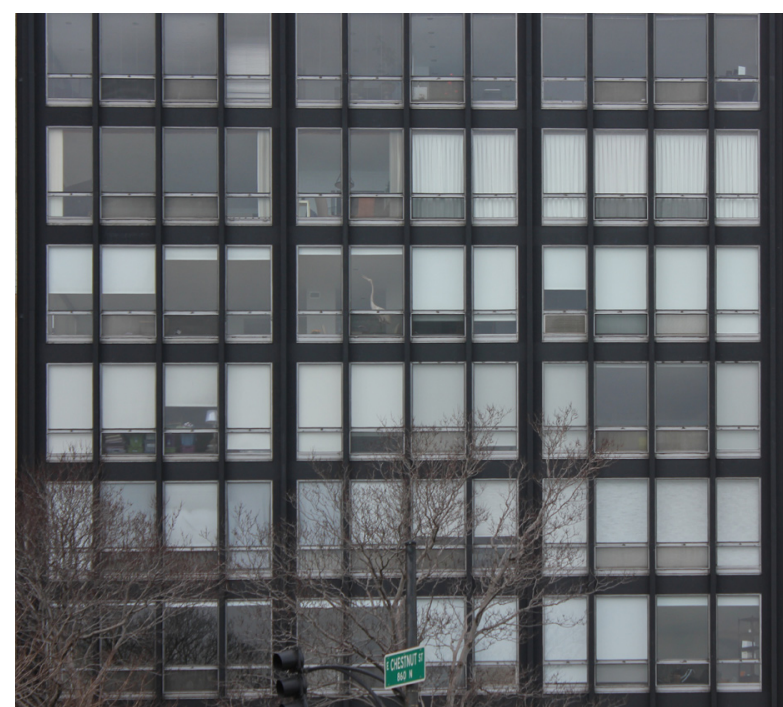

Muro cortina de las torres caracterizado por

la modulación, y los perfiles de acero. Fotografía año 2015. 


\subsubsection{One IBM Plaza (Mies van der Rohe, Chicago 1970)}

En el edificio destinado a albergar las oficinas de la empresa multinacional IBM, Mies opta por una solución que había introducido en el Seagram Building (Nueva York, 1954) y que hará que se distancie en parte del proyecto anterior: el retranqueo de la estructura respecto al plano de fachada. Este hecho, que inicialmente puede parecer un detalle sin importancia, acaba caracterizando la arquitectura de Mies y otorga una definición más congruente técnicamente a sus proyectos. Con este cambio sutil el arquitecto logra eliminar gran parte de los problemas de puentes térmicos que surgían cuando el plano entre ambos sistemas era el mismo. Por consiguiente, en este edificio, los montantes están dispuestos en una posición avanzada respecto a la estructura y están unidos a ellos mediante cartelas, permitiendo que la construcción se lleve a cabo con mayor perfección técnica. Al eliminarse gran parte de las juntas se reducen los puentes térmicos y, por tanto, las infiltraciones de agua y aire al interior de la estructura del muro cortina.

Otro de los cambios que se pueden observar en este proyecto respecto al anterior es la dimensión de los sistemas; la superficie casi inmaterializada que actúa como piel del edificio incorpora sistemas de inducción de aire y de climatización para evitar la condensación del agua en el muro cortina. Esto hace que el espesor del conjunto empiece a tener cierta envergadura, en contra de lo que había sido hasta entonces.

Ábalos y Herreros destacan en su texto la situación problemática que se da en el punto de separación entre el vidrio y los montantes. ${ }^{22}$ Al estudiar los detalles de fachada, se observa que el empleo de los perfiles en $\mathrm{T}$ en One IBM Plaza, crea una superficie expuesta al exterior en la que el riesgo de condensación de agua es considerable. El estrangulamiento que se produce entre el vidrio y los montantes crea una zona de pérdidas de energía y puente térmico que hace que el muro cortina se convierta en un elemento completamente vulnerable al ambiente exterior. Este esquema, que comenzó utilizando con vidrios simples en proyectos anteriores, se reproduce como solución formal aun cuando

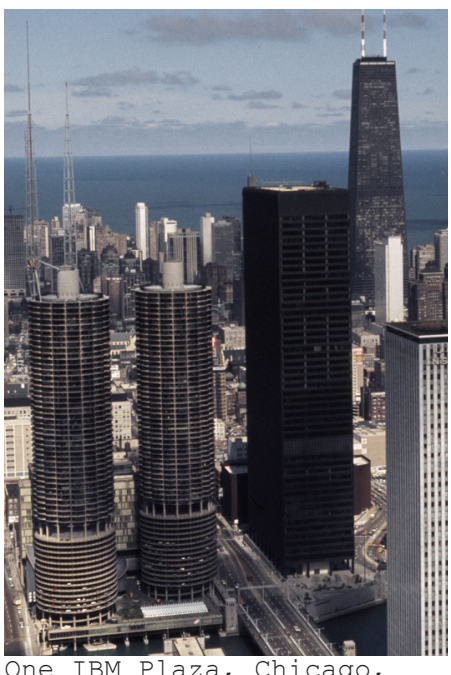

1970, MVdR junto a Marina City de Goldberg y John Hancock de SOM.

Fotografía del Digital

Collection de UIC, William Brubacker, 1972 .

22. Iñaki Ábalos \& Juan Herreros, Técnica y Arquitectura en la Ciudad Contemporánea (Guipúzcoa: Editorial Nerea, 1992). 
ésta debía ser adaptada a los vidrios de mayores espesores como en el caso de los vidrios dobles con cámara de aire. El detalle del encuentro entre el vidrio y los montantes prevalece como si fuese su símbolo de identidad, más incluso que el material de las carpinterías (que varía de acero, aluminio o bronce), el ritmo de las fachadas o el dimensionado de los montantes (que ya se ha indicado que ha variado sustancialmente). La decisión de esta separación, ya sea por crear sombras en la fachada o por no unir directamente distintos materiales, está condicionando el comportamiento del muro cortina y perdiendo así parte de las cualidades de las que podría gozar.

A pesar de los problemas térmicos y constructivos que posteriormente se extraen de ciertos aspectos de las fachadas de Mies, parece justo afirmar que, gracias a las aportaciones de este arquitecto alemán, las posibilidades alcanzadas por el uso del vidrio en las construcciones en altura se multiplicaron. El contexto en el que se desarrollaron difiere al actual, y las principales preocupaciones tampoco lo eran; la ingravidez del material, los juegos de sombras, la flexibilidad interior debido a la independencia de las fachadas y la experimentación del material al unir lo subjetivo con la técnica, caracterizaban la arquitectura que aquéllos años se estaba desarrollando en los prototipos de construcciones en altura. Las capacidades proyectuales que actualmente tenemos a nuestra disposición son herencia del desarrollo indiscutible de la arquitectura norteamericana de la segunda mitad de siglo. 


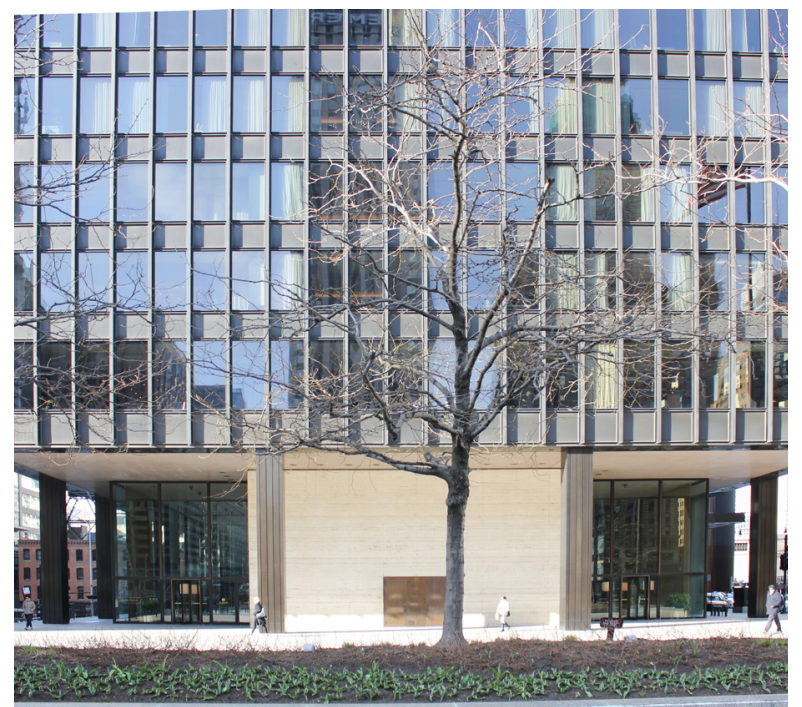

Encuentro de la torre con la plaza peatonal. Fotografía año 2015.

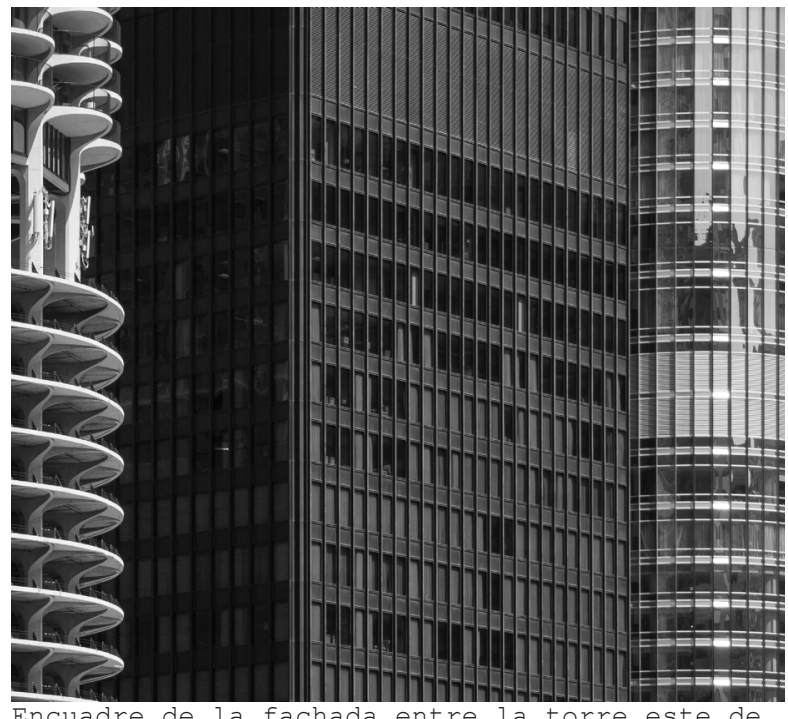

Encuadre de la fachada entre la torre este de Marina City y Trump Tower.

Fotografía de Kevin Zolkiewicz año 2014.

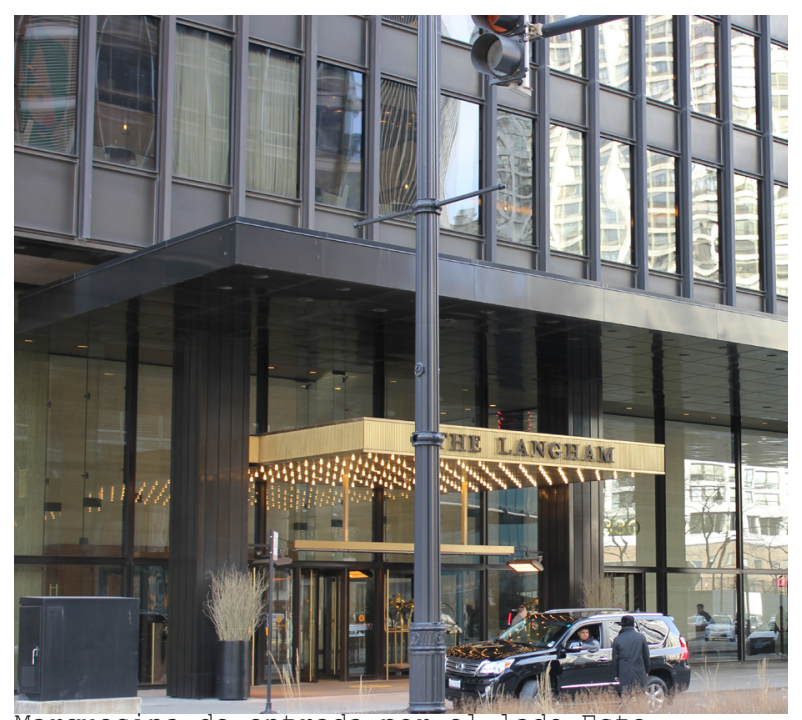

Marquesina de entrada por el lado Este.

Fotografía año 2015.

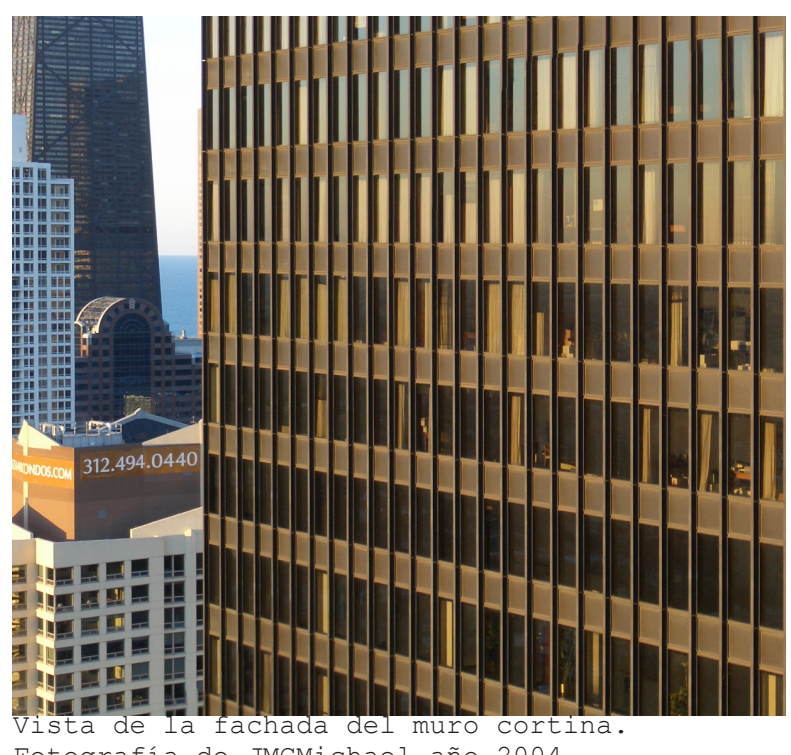

Fotografía de JMCMichael año 2004. 


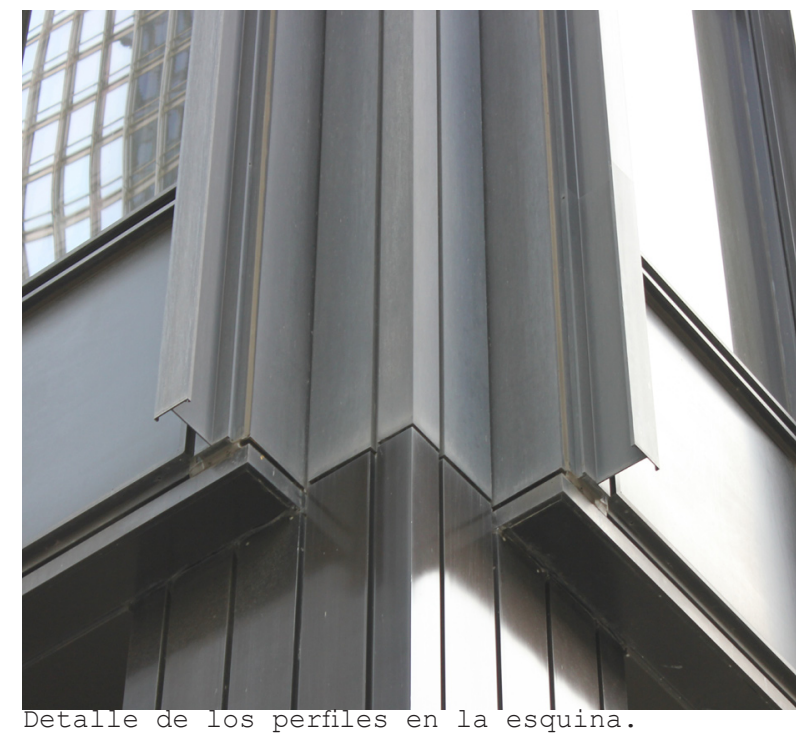
Fotografía año 2015.

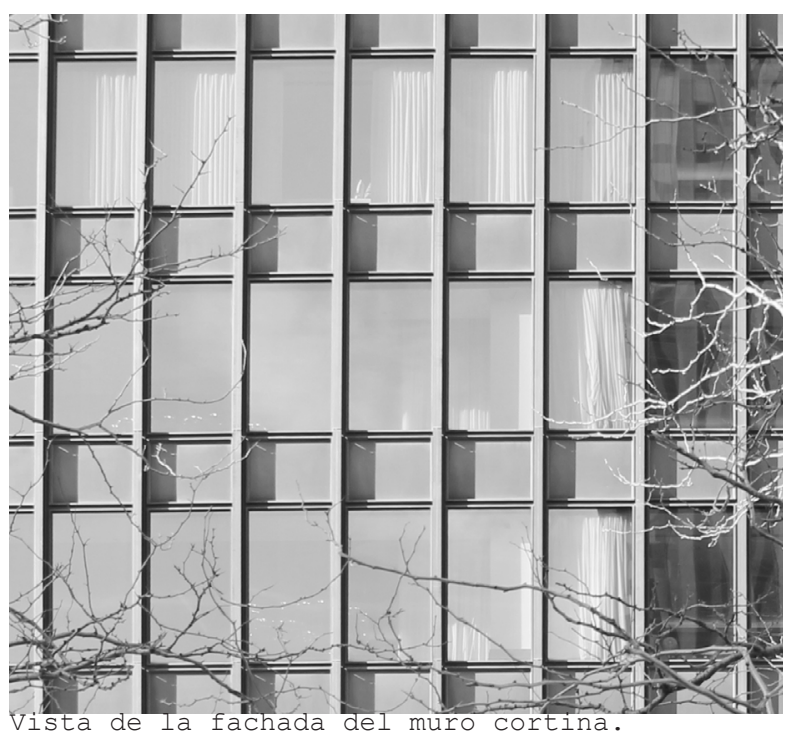

Fotografía año 2015.

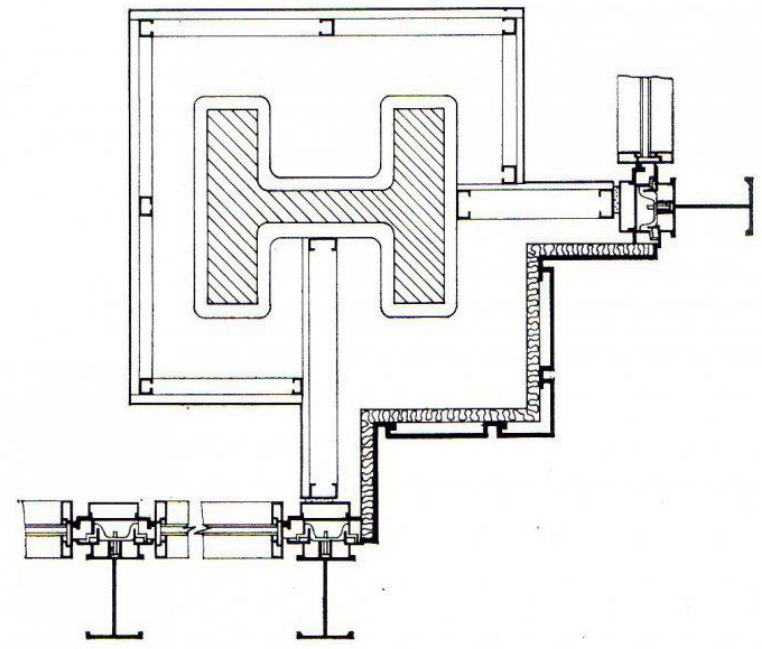

Detalle en planta de la envolvente de IBM Building.

La ilustración se llevó a cabo para la publicación de The Architectural Review de 1972 en la que el profesor John Winter estudió los detalles en esquina de varios de los edificios de Mies

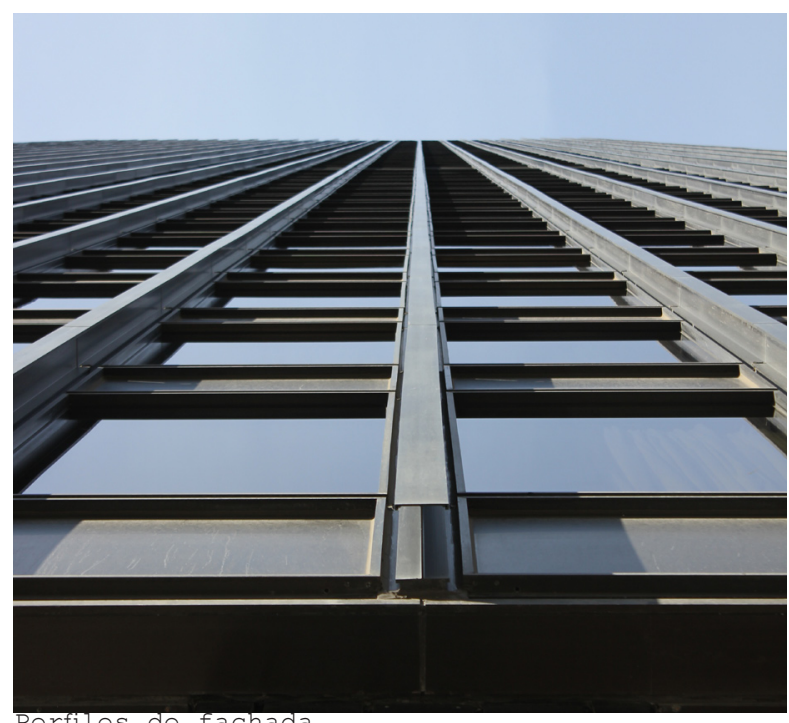

Fotogra die tachada. 


\subsubsection{Consideraciones}

Los primeros ejemplos de muro cortina muestran una indiferencia energética inicial debido en parte a la aplicación del clima artificial que se instauró en la arquitectura, especialmente en los edificios de oficinas. Este clima artificial interior independizaba el comportamiento del espacio habitable de las condiciones exteriores, trasladando la responsabilidad de relación y confort a los suelos y techos técnicos. De esta manera, la profundidad de los espacios interiores podía ampliarse sin verse condicionado por la ineficacia del cerramiento de fachada. Los primeros casos de pieles continuas de vidrio así lo muestran, y sirvieron de antesala a un posterior desarrollo de la técnica que se debía emplear en los muros cortina.

Las posibilidades del vidrio como material aislante al mismo tiempo que como elemento de control energético y de aprovechamiento de la luz del sol son incalculables, siempre y cuando se conozca la técnica y se identifiquen los parámetros que hay detrás del mismo. De lo contrario, el inaduecuado uso del vidrio supone un aumento en el consumo energético no asumible por la sociedad actual. El gasto mantenido por la incomodidad de una piel inerte, que no ejerce ningún fin mas que el de separar atmósferas distintas, obligó a adoptar medidas en las que la arquitectura dejase de distanciarse del medio natural y, por el contrario, empezase a establecer relaciones e intercambios para un mejor funcionamiento. Fue en aquél momento cuando la arquitectura, especialmente aquélla enfocada en las fachadas, empezó a tomar decisiones encaminadas a la importancia de la optimización de energías y recursos.

La incorporación de mecanismos y materiales que apostaban por intentar establecer un clima de confort interior sin tener que desvincular esto de los deseos arquitectónicos, fue una de las principales premisas de las siguientes generaciones de arquitectos, especialmente en proyectos de muros cortina de edificios en altura. El vidrio no tenía porqué quedar comprometido, pero sí debía ser estudiado para obtener un funcionamiento adecuado de la envolvente. 


\subsection{LA ENVOLVENTE COMO SUPERFICIE INTERCAMBIADORA. SCHIPPOREIT \& HEINRICH, CHICAGO.}

La evolución de las fachadas de vidrio se ha producido mediante un proceso continuo de evaluación y experimentación, a lo que hay que añadir los avances técnicos y las posibilidades de los materiales. La disminución de la conductividad térmica del vidrio y, por tanto, la reducción de las pérdidas de energía a través de estas superficies, pasa a ser uno de los parámetros que precisan ser evaluados y con el que medir la conveniencia de un sistema u otro. El otro será controlar las ganancias de radiación solar en el espacio.

Por tanto, uno de los objetivos de las envolventes será reducir los intercambios entre el exterior y el interior para mejorar su comportamiento y favorecer el control ambiental. Dos procesos mediante los que esto se lleva a cabo son la incorporación de cámaras de aire entre los vidrios y el revestimiento en las superficies del vidrio. 
La piel continua, inerte y energéticamente poco eficiente debía ser sustituida por otra en la que el vidrio adopte un papel activo en el confort o clima interior. Por ejemplo, los primeros vidrios dobles con cámara de aire supusieron un gran paso hacia delante. Respecto a los vidrios de una sola hoja, los dobles se aproximan más al concepto de muro de capa múltiple, ya que la cámara de aire reduce las transferencias energéticas de zonas de menor temperatura a otras de temperaturas más elevadas. Otro ejemplo es el uso de superficies de vidrio reflectantes (cuya absorción de radiación es muy inferior a los transparentes), que supone un avance especialmente para climas u orientaciones en los que las ganancias de energía solar son el principal factor a controlar. Desde un punto de vista energético, pueden reducir las cargas de aire acondicionado. Desde un punto de vista compositivo, permitió controlar la transparencia de los espacios y, como se verá en alguno de los casos que se estudian más adelante, dejar los interiores a la imaginación del peatón. La superficie de fachada pasa de ser una opción que deja entrever el interior a otra que refleja el contexto exterior. ${ }^{23}$

Por tanto, los paneles flotantes de vidrio, la comercialización de los vidrios dobles con cámara de aire al vacío, así como la comercialización de los vidrios reflectantes y coloreados, serán factores que facilitarán que el uso del material se adecue a las condiciones del clima artificial interior $y$, al mismo tiempo, no reniegue de las posibles ventajas del clima exterior.

Por otro lado, las carpinterías, que deben garantizar el hermetismo al aire y a los agentes exteriores, quedan medianamente resueltas mediante una simple junta entre vidrios. Además, la subestructura o los sistemas de marcos del muro cortina se ven sometidos a un replanteamiento respecto a las posiciones que se les asignaba en situaciones anteriores. La solución que parece más eficaz, y que sigue considerándose hoy en día como una buena opción, consiste en evitar la sobreexposición de esta subestructura. Es decir, se traslada la carpintería al interior intercalándola entre los forjados y la superficie de cerramiento, disminuyendo así las superficies expuestas $y$, por tanto, evitan-
23. Agrest, D., Arquitecture from Without. Theoretical framing for a critic (Cambridge: MIT Press, 1991). 
do los puentes térmicos ya que se favorece la continuidad del cerramiento. A esto hay que añadir el hecho de que se simplifican los detalles en la construcción y montaje del vidrio. Esto se puede hacer en gran medida gracias al desarrollo del aluminio como material de enmarque. Posteriormente, el desarrollo de la silicona estructural supone un gran avance, ya que fija el vidrio por adherencia y permite que puedan eliminarse las carpinterías exteriores.

Por último, son varios los arquitectos que se inclinan por la experimentación con fachadas ligeras que no son únicamente de vidrio. El concepto tras el que se desarrollan estos sistemas sigue siendo el del muro cortina, y los sistemas son prefabricados y montados en seco en las obras. Aunque de mucha menos proyección y uso, se proyectan fachadas en las que la posición del vidrio está estratégicamente concebida, dejando la principal función de aislar a paneles multicapas opacos que vienen a tomar el mismo contacto con los marcos y carpinterías que el vidrio.

En resumen, las generaciones posteriores a los primeros estudios del muro cortina de vidrio toman conciencia de la importancia de solventar preocupaciones de confort interior que antes no se habían tenido en cuenta. Ahora bien, los conceptos que emplean no son nuevos, y están basados en desarrollos de los maestros anteriores. La arquitectura en altura de Chicago así lo recoge: nuevas expresiones y formalizaciones basadas en modelos anteriores. 


\subsubsection{Lake Point Tower (Schipporeit \& Heinrich, Chicago 1969)}

El solar en el que desde 1969 emerge el edificio Lake Point Tower solía estar ocupado por agua del Lago Michigan. Las formaciones de terreno que en el presente hay en la desembocadura del río Chicago, incluyendo el solar de Lake Point Tower, fueron consecuencia del desarrollo industrial y la actividad de ingeniería que ha caracterizado la ciudad de Chicago. En 1962, como respuesta a la decadencia que el transporte fluvial y ferroviario estaba sufriendo, se ideó un plan de re-calificación de los solares pertinentes para, entre otros, llevar a cabo un proyecto que revitalizase una zona de la ciudad que entonces no era excesivamente atractiva.

La conexión con Mies van der Rohe, quien había llegado al IIT (entonces Armour Institute of Technology) en 1938, fue evidente desde que se mostró la imagen del edificio. Fue a través del arquitecto alemán que Greenwald (empresa constructora de Lake Shore Drive y Lake Point Tower) se puso en contacto con George Schipporeit, antiguo estudiante del IIT y trabajador de la oficina de Mies. Junto con su compañero de estudio y trabajo, John Heinrich, llevaron a cabo este icono de la arquitectura de Chicago. Aunque los artífices del proyecto afirman que el resultado final es obra de un largo recorrido de diseño y planeamiento, parece que las influencias de Mies Van der Rohe eran inevitables. Es más, los primeros esbozos fueron dibujados a partir de un vocabulario gráfico que Mies había compuesto entre 1940 y 1950. Se dice incluso que la imagen del Seagram (NY, 1958) sirvió como modelo de referencia para el exterior de Lake Point Tower, cuya composición se basó en perfiles de bronce y superficies de vidrio continuas que daban al edificio una imagen de elegancia e inmaterialidad.

No sólo se conectó la imagen de Lake Point Tower con su vecino neoyorkino, sino que tan pronto como el proyecto fue anunciado y presentado, los críticos se abalanzaron a afirmar que había sido proyectada en base a la nunca construida torre de vidrio de Mies. Era muy sencillo establecer conexiones entre dos estudiantes de Mies. Carl Condit, un

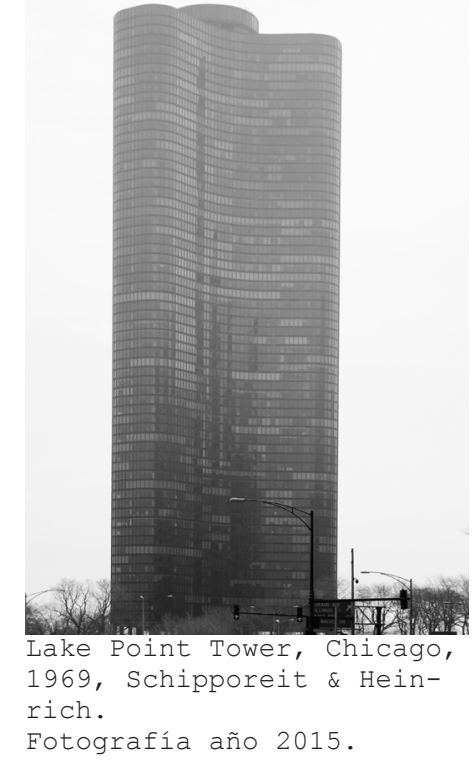

Fotografía año 2015. 
24. Carl Condit, Building Planning and Urban Technology (Chicago: Chicago University Press, 1974). respetable historiador y crítico de arquitectura en los Estados Unidos afirmó en uno de sus escritos: "the three-lobed shape of the tower was derived from a celebrated skyscraper Project that Mies van der Rohe proponed for Berlin in 1921. The young architects who created the Lake Point (Tower) design were students of Mies at IIT and members of his office staff, and they were the first to adapt the Berlin concept to an executed building" ${ }^{24}$. Aun así, los arquitectos negaron las afirmaciones y aseguraron que el resultado vino dado por los requerimientos del programa, el planeamiento, las necesidades estructurales y la situación económica.

Ahora bien, la torre de apartamentos al borde del Lago Michigan supo avanzar en el tratamiento de las fachadas de vidrio y, hoy día, la envolvente de la torre sigue empleándose como modelo de estudio. No sólo fue la primera fachada en incorporar una doble curvatura en el vidrio, sino que las inquietudes por parte de los arquitectos por dar respuesta - no sólo estética, sino también técnica y energética - a los diferentes requerimientos interiores y exteriores, marcaron un antes y un después en la arquitectura de fachadas. Durante su carrera junto a Mies, Schipporeit fue el encargado, entre otros, de llevar a cabo los detalles para el exterior de una torre de apartamentos en Detroit (Michigan), para los que incluso preparó los documentos necesarios para su fabricación. Tras esto, el arquitecto alemán le encargó trabajar en los detalles para un sistema de fachada que por primera vez integraría sistemas de aire acondicionado. Es decir, Schipporeit, artífice de la fachada de muro cortina de Lake Point Tower y profesor del IIT hasta poco antes de su fallecimiento, tuvo la oportunidad y la voluntad de estudiar distintos sistemas de cerramientos de vidrio desde una temprana edad, y su destreza en esta materia pudo verse reflejada en la fachada para Lake Point Tower.

La envolvente de vidrio consta de perfiles verticales de aluminio, superficies de vidrio tintado del mismo color y frentes de forjado de plástico recubiertos por una pintura de bronce. Los vidrios, continuos en toda la longitud visible, son vidrios dobles con cámara de aire que amortigua las transferencias de calor. Su color reduce la radiación directa de calor en verano, ayudando así a reducir 
las cargas de aire acondicionado ya que refleja gran parte de la energía solar. Las carpinterías, de espesor reducido para la altura total del sistema, no estaban pensadas como elementos principales en las fachadas, y los arquitectos quisieron que la sombra que proyectaban se redujese a un elemento secundario. En este caso, las juntas entre los sistemas se ven reducidas; la estructura funciona independiente del cerramiento ayudando a absorber los movimientos diferenciales de ambos. El único problema de puentes térmicos se vería en los puntos situados sobre los forjados de hormigón. Es en estos lugares donde los espacios interiores reciben aire del exterior.

Quizás ésta fue la gran novedad del sistema planteado por Schipporeit: una parrilla situada sobre el forjado que daba paso a la entrada de aire a una cabina de apertura superior eliminando la necesidad de proyectar ventanas operables, reduciendo así la posibilidad de puentes térmicos. Con ello también se logra la imagen de superficie continua que se buscaba. Además, esta cabina albergaría los aparatos de aire acondicionado y calefacción necesarios para el clima interior, y estaba cerrada con una rejilla que evitaba la entrada de insectos en los conductos y espacios interiores.

Los arquitectos no tuvieron en cuenta únicamente los deseos de imagen, sino también la comodidad de los usuarios y la posibilidad de ejecución de los detalles planteados. Con esta finalidad, el equipo de arquitectos e ingenieros trabajó conjuntamente para simplificar los distintos detalles; las conexiones al forjado eran simples anclajes que quedaban cubiertos por la cabina de ventilación y los elementos que desde el exterior se percibían de la fachada eran aquéllos necesarios para su ejecución y montaje. Parecía un lenguaje claro y limpio, sin entresijos. A esto hay que añadir el hecho de que consideraran el mantenimiento de las superficies de vidrio. Para ello, los arquitectos idearon un sistema en la cubierta integrado con el muro cortina para que unas plataformas pudiesen deslizarse en vertical a través de las guías de las carpinterías de aluminio para la limpieza de la fachada. 
Lake Point Tower fue y sigue siendo un icono de la arquitectura de Chicago y un punto de atracción de muchos turistas. Pese a que quizás la arquitectura no le haya otorgado todo el reconocimiento que se merece, Lake Point Tower destaca por la innovación, la originalidad y la apuesta por conectar la envolvente de vidrio con el clima interior. 


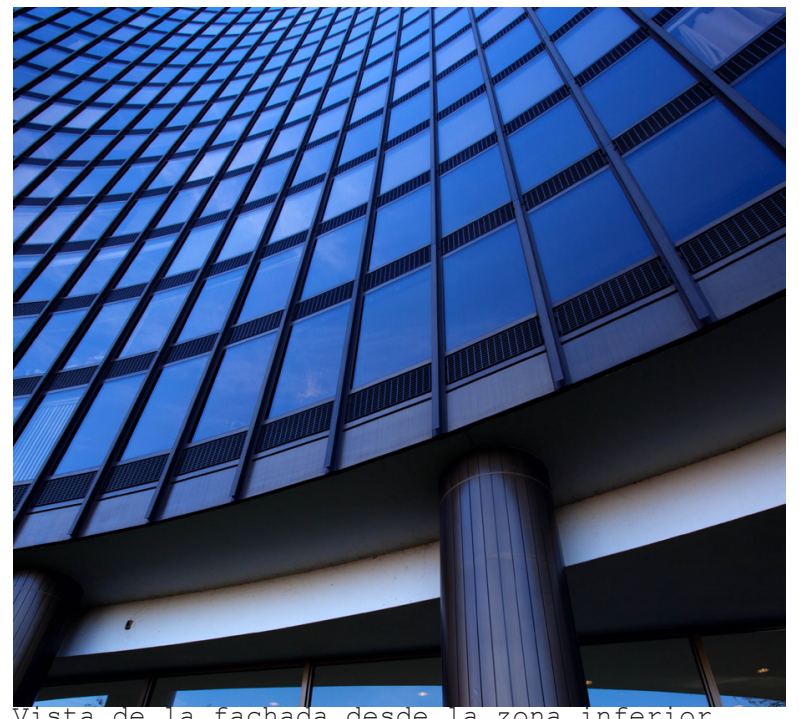

Vista de la fachada desde la zona inferior. Fotografía de Chris Smith año 2011.

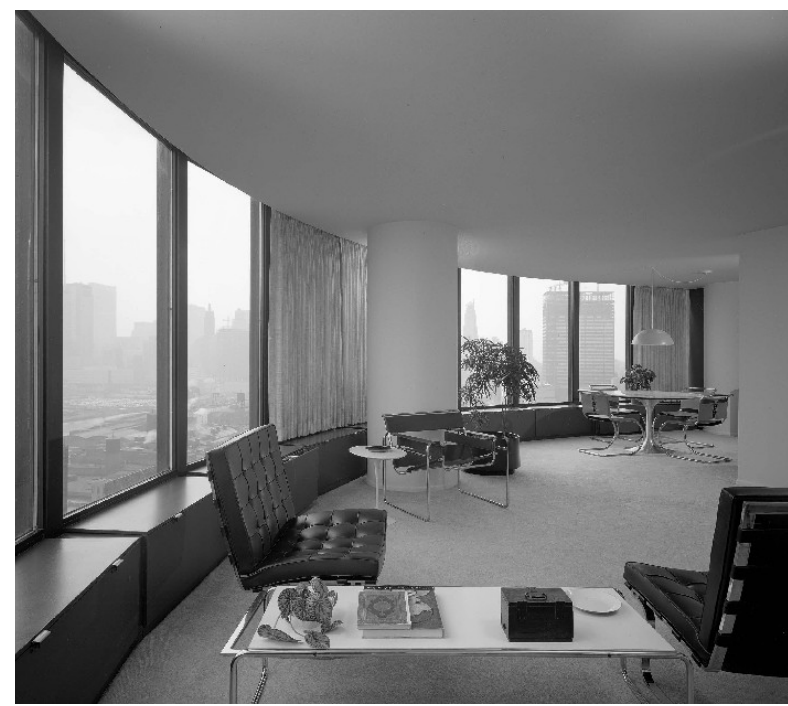

Vista del interior de uno de los apartamentos. Fotografía en lakepointtower.org.

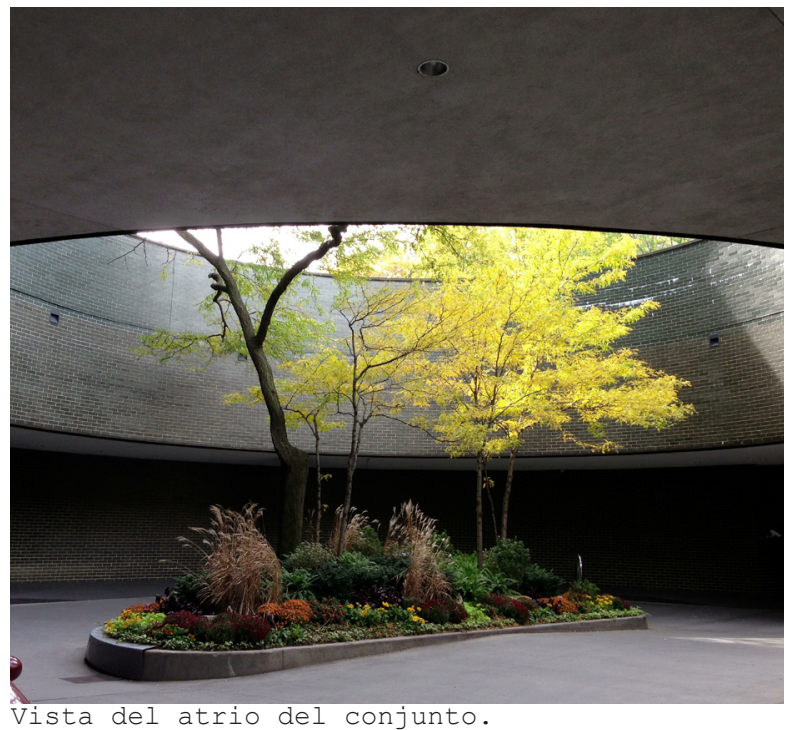

Fotografía de Photophile2012 año 2012.

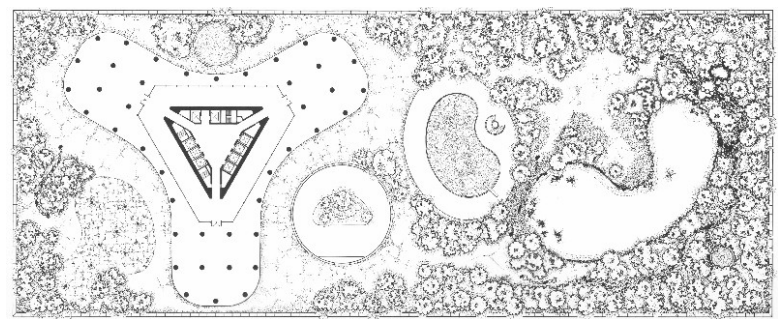

Planta tipo de la torre de apartamentos.

Planta de Alfred Caldwell. lakepointtower.org. 
CAPÍTULO 02

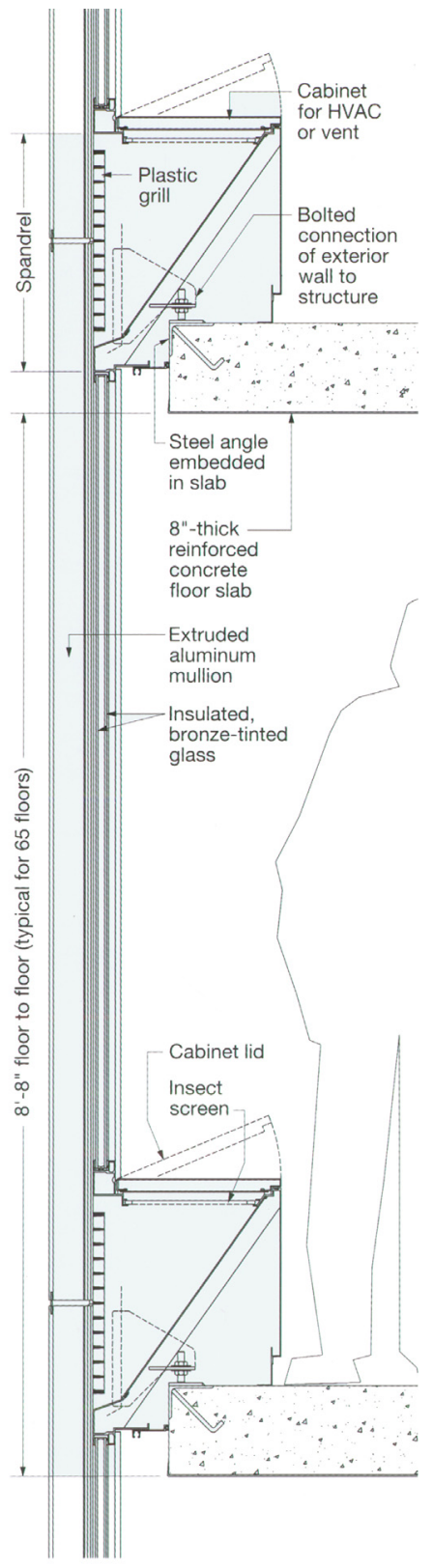

Sección de la fachada de la torre. Elemento de ventilación natural incorporado en la piel.

Imagen de Lake Point Tower. A Design History, Edward Windhorst, CAF, Chicago, 2009.

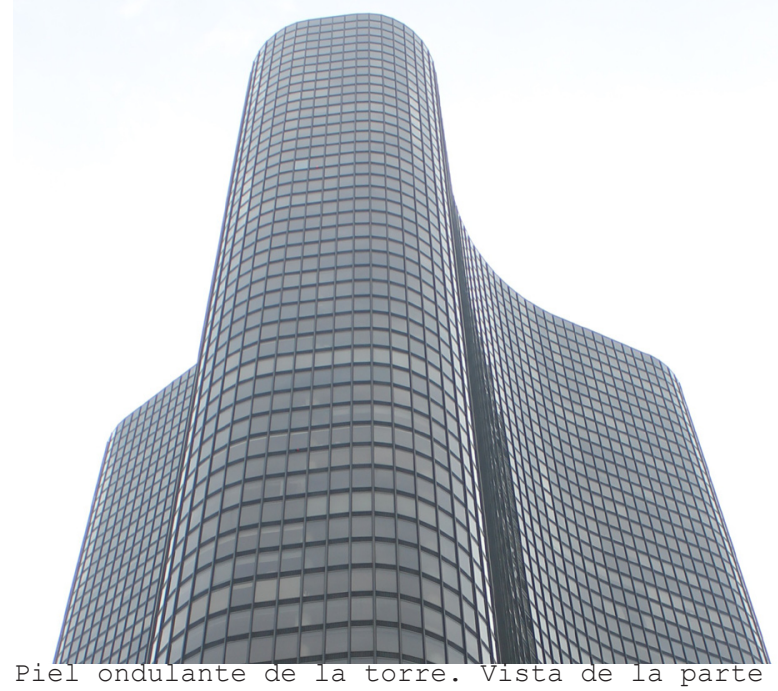
superior.

Fotografía año 2015.

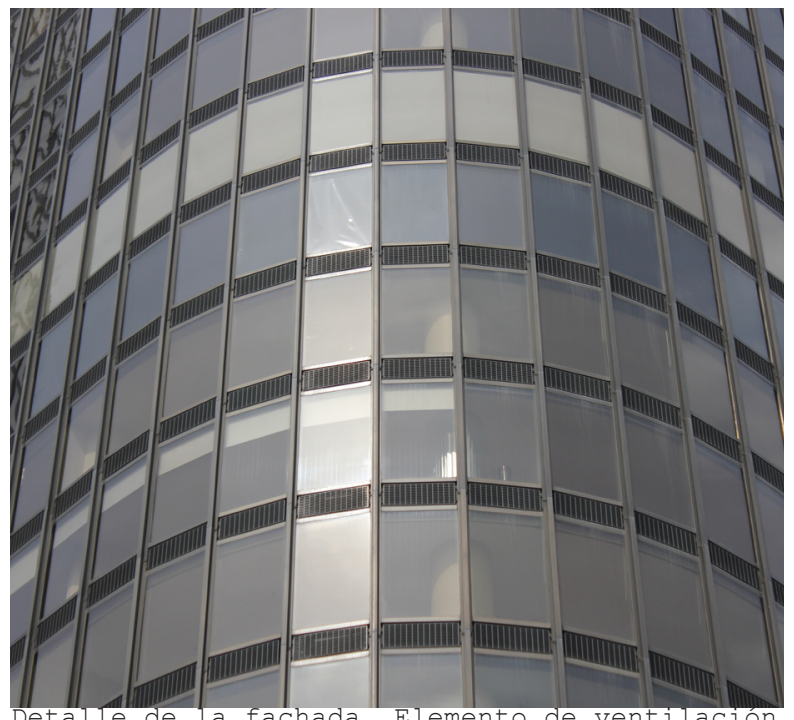

natural en el perímetro.

Fotografía año 2015. 


\subsubsection{Consideraciones}

Hoy en día el cerramiento de vidrio, que aspira a la más absoluta ingravidez, sigue siendo el principal material en las construcciones en altura que respetadas firmas arquitectónicas desarrollan en las principales ciudades del mundo. Aun a pesar de las contradicciones con las que la arquitectura se ha encontrado a lo largo del tiempo en las fachadas de vidrio de las construcciones en altura, el concepto del muro cortina sigue manteniendo una postura viva y activa en la profesión. Pero, mientras que hasta fechas no muy lejanas sólo la deseada transparencia justificaba su comprobada ineficiencia térmica, todavía hoy continúan las investigaciones para poder abordar los requisitos energéticos que el medio ambiente exige.

El uso de una piel inerte en el muro cortina junto con el desarrollo de los espacios de clima artificial interior se probaron ineficaces en lo referente al comportamiento energético de los cerramientos. La conductividad térmica del vidrio debía ser el elemento que había que controlar mediante la incorporación de la vidrios y carpinterías de mayor capacidad. Evitando el uso de vidrios simples, aun sin aumentar excesivamente la masa del cerramiento, podía disminuirse significativamente. La disminución de la conductividad térmica del vidrio permitió evaluar la eficacia del cerramiento y de los sistemas que neutralizasen los intercambios energéticos entre el espacio interior y el exterior. Siguiendo este razonamiento, tanto las propiedades del vidrio utilizado como las características de las carpinterías de los muros cortina eran los dos elementos principales que debían ser estudiados y tenidos en cuenta a la hora de determinar el comportamiento de la envolvente en su conjunto. Hoy en día, éstos siguen siendo los dos factores principales que determinarán el comportamiento de la fachada, de ahí que sea preciso prestarles especial atención.

Por tanto, serán las siguientes generaciones de arquitectos quienes estudiarán el desarrollo de los principios constructivos implícitos en los conceptos del muro cortina para dar una respuesta energética adecuada en contra del clima artificial. Las soluciones apuestan por diseños que 
se alejan de lo inerte de los muros cortina iniciales y en cambio se acercan a elementos activos en el funcionamiento energético del edificio climatizado. 

CAPÍTULO 03

LA ENERGÍA. EVOLUCIÓN DE LAS ENVOLVENTES

1. Iñaki Ábalos \& Juan Herreros, Técnica y Arquitectura en la Ciudad Contemporánea (Guipúzcoa: Editorial Nerea, 1992).
3.1 CONTEXTO ACTUAL.

La segunda mitad del siglo XX ha sido testigo de un cambio en el papel de la envolvente del edificio: de una piel inerte inicial, sin más valor que el de ser una superficie de conexión visual, a una más activa que se integra con otros sistemas del edificio. Además, estos cambios en la comprensión de la envolvente del edificio han dado lugar a modificaciones en la percepción y las necesidades del espacio interior. ${ }^{1}$

Lo que en las etapas iniciales se materializaba dando prioridad a la transparencia y la visibilidad de los espacios interiores, fue luego abordado desde una perspectiva de mejora y priorización ambiental interior y de regulación de la energía. Los autores de Técnica y Cultura en la Ciudad Contemporánea se refieren a la posible conexión entre las preocupaciones de la sociedad y el desarrollo de las expresiones arquitectónicas. En su texto revisan la influencia que, por ejemplo, la situación energética de los años 30 y

79 
los años 70 tuvo en la formalización del edificio de vidrio. ${ }^{2}$ En esos mismos términos, Compagno relaciona el desarrollo de nuevas técnicas de acristalamiento con la crisis energética de la década de los 70.3 Hasta 1973, el consumo de energía fue aumentando*, sin embargo, los estudios indican que las preocupaciones posteriores hacen que la curva de consumo energético se estabilice. ¿Cómo se refleja esto en el diseño del edificio, y más concretamente en el relacionado con cerramientos de vidrio? ¿Ha sido el papel de la envolvente intencionalmente considerado en función de los condicionantes ambientales, energéticos o culturales? Las siguientes secciones tienen la intención de analizar la posible relación entre la materialización del diseño de la fachada de vidrio y el contexto en el que fueron creados.

En este apartado se exponen los distintos conceptos arquitectónicos que se ven afectados por decisiones en torno a la envolvente, ya sean energéticos o espaciales. El capitulo concluye con el estudio de arquitectura francés liderado por Anne Lacaton \& Jean Phillippe Vassal y, concretamente, con el proyecto de la Torre Bois. Sin conocer la existencia de dicho proyecto, pero casi simultáneamente, el proyecto de los arquitectos franceses y este trabajo de investigación presentan grandes similitudes en cuanto al proceso de creación y a los conceptos de la envolvente. Por ello, se ha considerado de interés presentar el proyecto de Lacaton \& Vassal en este trabajo.
2. Iñaki Ábalos \& Juan Herreros, Técnica y Arquitectura en la Ciudad Contemporánea (Guipúzcoa: Editorial Nerea, 1992). 3. Andrea Compagno, Intelligent Glass Facades (Berlína: Editorial Brikhäuser, 2002) . 4. Norbert Lechner, Heating, Cooling, Lighting. Sustainable Design Methods for Architects (New Jersey: John Wiley \& Sons, 2009). 


\subsection{CONTEXTO ENERGÉTICO.}

Diferentes entidades internacionales están llevando a cabo apuestas por reducir el consumo energético. Éstas parecen apuntar hacia un compromiso de la arquitectura hacia el medio ambiente en el que las envolventes adquieren un papel protagonista y activo, conectadas con otros sistemas operativos del edificio.

Una de las apuestas a la que se están sumando diferentes estudios de arquitectura es el concepto "Architecture 2030". "Architecture 2030" es una organización sin ánimo de lucro que se formó en el año 2002 como respuesta al calentamiento global. ${ }^{5}$ El fundador de la organización es Edward Mazria, experto en estudiar soluciones arquitectónicas que apuestan por procesos responsables hacia el espacio interior y el exterior. Uno de sus libros de alcance es the Passive Solar Energy Book, en el que presenta, en forma de guía, una serie de soluciones y propuestas hacia un diseño caracterizado por las medidas pasivas de conservación de la 
energía. ${ }^{6}$ Sus esfuerzos van encaminados a reducir el calentamiento global y las emisiones de gases nocivos procedentes de la arquitectura, mediante estrategias que intentan influir en los procesos de diseño y en el planteamiento de los proyectos. Los objetivos, entre otros, incluyen que edificios de nueva construcción y aquéllos que requieran una rehabilitación sustancial rebajen el consumo de energía a, como máximo, un 50\% del consumo medio para la zona y el tipo de edificio del que se trate. ${ }^{7}$ Para ello, establece unos plazos: 60\% de reducción en el 2010, 70\% en 2015, 80\% en 2020, $90 \%$ en 2025 y la eliminación total del consumo de energía no renovable en el 2030.8 Aun a pesar de que la apuesta sea ambiciosa, las propuestas que se llevan a cabo para intentar lograr el "2030 Challenge" pueden, por lo menos, traer consigo una mayor conciencia y posibles beneficios. Tener en cuenta factores como, por ejemplo, la situación geográfica del edificio, la orientación de las envolventes, el área de superficie de vidrio, o el entorno desde etapas iniciales, puede ayudar a mitigar los efectos de la energía.

Otra de las propuestas es la desarrollada por Werner Sobek, arquitecto e ingeniero alemán que dirigió el "Institute for Lightweight Structures", en Sttutgart, sucediendo a Frei Otto. Sobek menciona en su artículo "Sustainable Tall Buildings" otra de las propuestas que existen actualmente para reducir el consumo energético y las emisiones al medio ambiente. Se trata del "Triple Zero Concept", que trata de dar respuesta a todos los aspectos ecológicos de la sostenibilidad. ${ }^{9}$

El "Triple Zero Concept" consta de tres premisas. En primer lugar "zero energy", en la que se exige la reducción del consumo de energía en los sistemas operativos de un edificio (calefacción, aire acondicionado, electricidad o ventilación). Además, propone emplear únicamente energías renovables. En segundo lugar, "zero emission" supondría que los materiales empleados no emitan sustancias nocivas al medio ambiente, que se diseñen sistemas flexibles y reutilizables o reciclables y que se tenga en cuenta la duración de los sistemas empleados a lo largo de la vida útil del edificio. Por último, "triple zero concept" se basa en asumir "zero waste" es decir, que los materiales empleados pue-

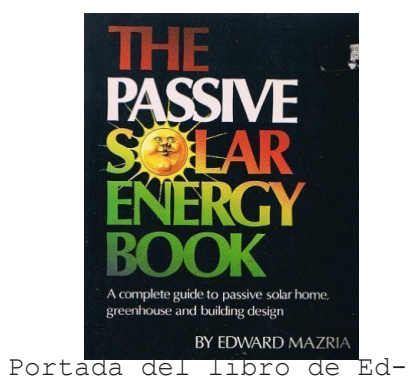

ward Mazria.

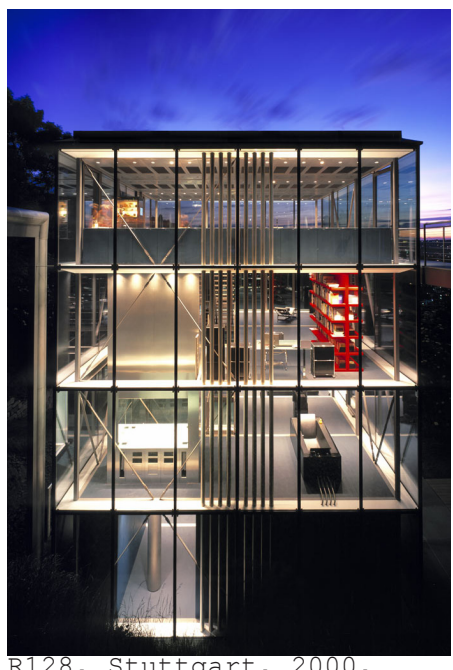

R128, Stuttgart, 2000, Werner Sobek.

Fotografía de Roland Halbe, www. werenersobek. de

6. Edward Mazria, The Passive Solar Energy Book (Rodale Press, 1979).

7. "WWW.AIA2030.org".

8. "WWW.AIA2030.org".

9. Werner Sobek,

"Sustainable Tall Buildings. Some

Introductory Remarks". CTBUH, 8th World

Conference, (2008). 
dan ser reciclables o los sistemas de construcción puedan ser desmontables sin necesidad de derribar un edificio. Por tanto, este concepto trata de reconducir la arquitectura hacia un compromiso con el medio natural, pero también con el social. ${ }^{10}$

Con objetivos dirigidos a controlar el consumo energético, países como Estados Unidos, Gran Bretaña, Japón o Francia han incorporado en su práctica habitual sistemas de certificación para proyectos de arquitectura. Son muchos los estudios y profesionales que se implican en prácticas de este tipo, y que reconducen su arquitectura para que ésta esté comprometida con el entorno y sea consciente del mismo. Estas acreditaciones acaban siendo una herramienta empleada para evaluar el grado de compromiso que, como arquitectos, estamos llevando a cabo. También ofrecen estrategias y opciones con las que potencialmente mejorar el comportamiento del proyecto o al menos minimizar su efecto. Las estrategias abarcan campos desde el número de aparcamientos para bicicletas, como en los materiales empleados.

Por otro lado, el Departamento de Energía de Estados Unidos, junto con el Laboratorio Nacional Lawrence Berkley, está haciendo una labor considerable al promocionar el uso de programas que permiten a los arquitectos evaluar, entre otras facetas, las decisiones adoptadas en la composición de las fachadas. Estos programas están conectados a unas bases de datos que recogen los productos existentes. En definitiva, se trata de propuestas que apuestan por una arquitectura que adopta una postura activa en respuesta a los condicionantes medioambientales y al confort interior durante el diseño.

Ahora bien, estos mecanismos no representan modelos únicos a seguir, pero sí son organismos que desde diferentes lugares están apostando por un diseño inteligente y un compromiso entre el medio natural y el construido.

10. Werner Sobek

"Sustainable Tall Buildings. Some

Introductory Remarks". CTBUH, 8th World

Conference, (2008). 



\subsubsection{Concepto de Energía}

El consumo energético por parte de la arquitectura hace que sea necesario un replanteamiento en el diseño de la envolvente de vidrio de los edificios en altura. El término "sostenibilidad", tan frecuentemente empleado, parece no estar siempre definido de la misma manera. Para acotar posibles variaciones, este trabajo entiende el término sostenibilidad como el indicado en el Capítulo 1:

"Sustainable development is development that meets the needs of the present without compromising the ability of future generations to meet their own needs". ${ }^{11}$

A pesar de que cada vez se es más consciente de ello, parece aún existir la necesidad de entender y aprehender el impacto de la arquitectura en el medio natural y, por tanto, en el campo energético. La arquitectura es considerada uno de los principales responsables de dos de los factores que más preocupan cuando hablamos de medio ambiente: la emisión de gases nocivos y uno de sus efectos, el cambio climático. ${ }^{12}$ Esto no se debe tan sólo a la contaminación ambiental durante los procesos de construcción o ensamblaje, sino también a las sustancias nocivas que los edificios emiten al medio ambiente durante su vida útil. Las implicaciones se traducen en términos energéticos, económios y de confort. Para poder entender la situación en la que se encuentra la arquitectura hoy en día es necesario entender el contexto en el que nos estamos moviendo.

En el año 2001, la comisión de las Naciones Unidas estimó que en 2030 el número de personas que estaría viviendo en áreas urbanas sería de aproximadamente cinco billones. El crecimiento de habitantes en áreas urbanas ha sido de un $30 \%$ en 1950 y un 47\% en el año 2000. Los cinco billones corresponderían a un 60\% de la población, según las estadísticas de las Naciones Unidas. ${ }^{13}$ La escasez de energía, el calentamiento global o la contaminación pueden determinar la calidad de vida de sus habitantes.

Con el objetivo de aportar posibles soluciones a un contexto particualar - pero que pueda ser trasladado a uno 


\section{CAPÍTULO 03}

más global- este trabajo analiza las condiciones que, en el contexto energético y medioambiental actual, permiten establecer las relaciones entre la envolvente y los factores energéticos. La conciencia por la conservación del medio ambiente y por la reducción energética ha sido tratada en diversos periodos de la historia. Sin embargo, la situación contemporánea exige nuevas medidas, y las envolventes de vidrio pueden tener un papel protagonista en el proceso. 


\subsubsection{Concepto de Epidermis}

"The key is light, and light illuminates forms. And those forms have the power to excite through the play of proportions, through the play of relationships of the unexpected, of the amazing. But also through spiritual play of its reason to be; its honest birth, its ability to last, structure, mobility, boldness, yes daring, play - of creations, which are the important creations - the basis of architecture."14

La envolvente de un edificio tiene un comportamiento que, aunque metafóricamente, podría asemejarse al de la epidermis del cuerpo humano. Como elementos de protección a la vez que de regulación, estas superficies trabajan para aislar el medio interior de los agentes exteriores y, al mismo tiempo, controlar los flujos de intercambio. En el caso de la epidermis, este tejido trabaja con otros sistemas del cuerpo humano para poder llevar a cabo los mecanismos de protección y regulación automáticamente. Éste es precisamente el aspecto que pretende conseguir la envolvente que se estudia en este trabajo.

Inicialmente, el sentido primordial de los edificios era satisfacer el sentimiento humano de protección; buscar un refugio frente a los agentes externos, ya fuesen animales salvajes o fenómenos medioambientales. El hombre buscó refugio en cuevas, cobertizos o simples tiendas hechas con restos naturales, lo que dependía en gran medida de las condiciones climatológicas y geográficas del lugar en el que se encontraban. Por tanto, desde que el hombre comenzó a sentir la necesidad de tener un espacio que lo aislase del medio exterior, el contexto climatológico en el que se desarrollaba ha jugado un papel relevante, y prueba de ello son las soluciones arquitectónicas que han ido dando respuesta a los diferentes requerimientos climatológicos y geográficos. Sin embargo, los distintos movimientos y tendencias arquitectónicas parecen haber diluido la apuesta por una arquitectura que atienda a las necesidades concre-

14 Nicholas Fox Weber, Le Corbusier. A Life. (New York: Random House, 2008), pág. 689. tas derivadas de factores tales como la ubicación o las condiciones climatológicas. 
Cada vez son más los edificios, especialmente las construcciones en altura, que parecen estar marcados por la intemporalidad y la internacionalidad. Gran parte de la responsabilidad recae sobre el tratamiento de la envolvente.

Ahora bien, en el contexto actual, en el que en ocasiones se proyecta sin estar in situ, en el que tanto las necesidades de los usuarios y las funciones de los edificios varían y en el que las condiciones climatológicas tienden a ser imprevisibles -incluso extremas-, sería interesante dotar a las envolventes de características de adaptabilidad. Tan importante es que la epidermis responda activamente a los condicionantes externos por medio de conexiones con otros sistemas, como que la piel cerramiento esté conectada con otros mecanismos para poder dar respuesta a diferentes condicionantes. En este sentido, este proyecto se refiere a la "inteligencia" de la fachada ya no en términos de la tecnología que la define, sino en cuánto que es capaz de beneficiarse de los recursos naturales tales como la radiación solar, la ventilación natural y la luz solar, para adaptarse.

En el marco actual - en el que los deseos de transparencia, la dependencia en el clima artificial interior y las exigencias del medio natural tienen pesos específicos equivalentes - la apuesta de la arquitectura por sistemas que diluyan los límites entre el espacio interior y el exterior puede tener consecuencias beneficiosas para el medio ambiente y la economía. La apuesta por unas fachadas responsables energéticamente ayudará, por un lado, a reducir el efecto invernadero al limitar las emisiones de gases nocivos y, por otro, a limitar los costes de funcionamiento. El gasto principal de consumo de energía en edificios cuya fachada está compuesta principalmente de vidrio no se limita sólo a las pérdidas de energía, sino también a la energía empleada en la ventilación e iluminación de los espacios. Una utilización óptima del aire natural, un aprovechamiento de la luz incidente en la superficie de vidrio, así como disponer de energía almacenada para su reutilización, pueden ayudar a reducir los costes. 
Debido a que los condicionantes y exigencias hacia las envolventes han variado a lo largo del tiempo, la arquitectura se amolda para dar respuesta a las decisiones de diseño, los condicionantes externos, la confortabilidad de los usuarios, las repercusiones económicas y los requerimientos energéticos. 


\subsubsection{Concepto de Envolvente como Sistema Operativo}

"Designing the ecoskyscraper involves configuring its built form and operational systems so that they integrate with nature in a benign and seamless way over its lifecycle, by imitating the structure, processes and properties of ecosystems, an approach referred to here as ecomimesis.". ${ }^{15}$

Ken Yeang, arquitecto nacido en China en 1948, es conocido fundamentalmente por sus estudios acerca de la importancia de que la arquitectura adopte una posición activa frente a los problemas que sufre el medio ambiente. Adelantado a su tiempo, hace ya cuarenta años que reconoció públicamente que el calentamiento global y el incremento de la contaminación medioambiental acarrearían efectos desastrosos en el balance de la biodiversidad y los ecosistemas. ${ }^{16}$ Desde entonces, sus proyectos se basan en aplicar teorías y conceptos fundamentados en el "ecodesign" para concienciar a la sociedad de la responsabilidad que tiene la arquitectura sobre el medio natural. El principal objetivo que trata de conseguir es la reducción (o en el mejor de los casos la eliminación total) de la actual dependencia que la arquitectura tiene de las energías no renovables. Para ello hace una apuesta definida por unos diseños involucrados con el medio natural para así crear el confort interior. Esto se traduce en una reducción de las emisiones al medioambiente.

Por idealistas que estas teorías puedan parecer, el marco teórico que se extrae de ellas ha sido aplicado en diversos estudios con el objetivo de identificar los mecanismos que hay detrás de la arquitectura de fachadas. Éstos se agrupan en cinco sistemas diferenciados entre sí: el pasivo, el mixto, el completo, el productivo y el compuesto.

El primero de ellos corresponde con la situación ideal. En el sistema pasivo los diseños son consecuencia de estrategias bioclimáticas donde las condiciones locales y los recursos naturales son los principales elementos que entran en juego. Este enfoque se basa en estudiar el clima local, sus variaciones en las distintas estaciones del año, la presencia de fuentes naturales y la situación geográfica.
TOWER AS VERTICAL URBAN DESIGN

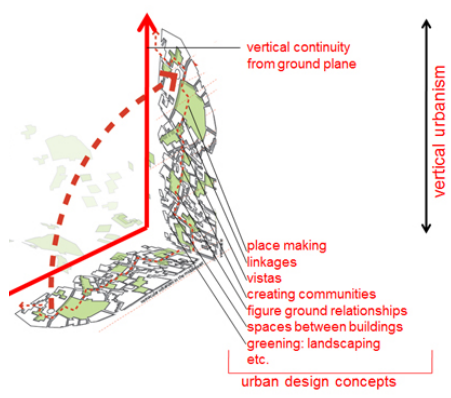

Diagrama del concepto de torrec omo un diseño urbano vertical. Tower as a Vertical Urban Design, Ken Yeang.
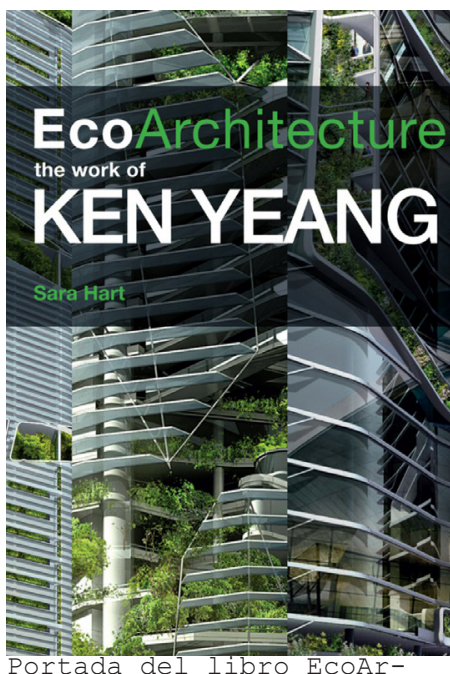

chtitecture, the work of Ken Yeang.

15. Ken Yeang,

"Ecoskyscrapers and Ecomimesis: New tall building typologies". CTBUH, 8th World Conference, (2008), Abstract.

16. "www.iaa-ngo.com". 


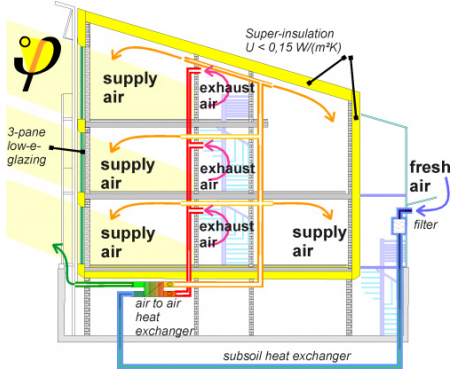

Passive House, Darmstadt, 1991.

Diagrama del Passivhause Institute, www.passiv.de

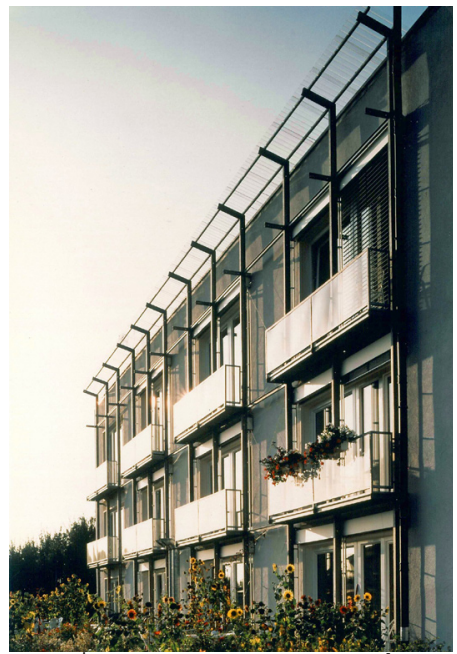

Passive House, Darmstadt, 1991.

Fotografía de H.G. Esch, www.passiv.de.

17."passivehouseinternational.org". 18. "Designing the Nearly Zero Energy Building. Passive House and renewables". Passive House Institute, Darmstadt.
Como las combinaciones de los distintos factores concluyen en múltiples casos, este tipo de estrategia se centrará en analizar cada situación de forma autónoma. La esencia del sistema pasivo es no incluir en sus diseños ningún tipo de sistema o equipamiento electromecánico. Por el contrario, lo supliría atendiendo a las orientaciones y a los condicionantes locales. Las envolventes de los edificios estarán diseñadas en función de las distintas condiciones que se dan en cada una de las orientaciones, y así se definirán los aislamientos, los tipos de vidrio y sus componentes, el porcentaje óptimo de opacidad para cada una de ellas, la cantidad o el tipo de ventilación natural necesaria. Por lo tanto, es recomendable que este tipo de estrategia sea definida desde los estados iniciales del proyecto, ya que el diseño estará condicionado por ellas. En cuanto a las envolventes, éstas mantendrían una relación de funcionamiento con los otros sistemas operativos del edificio, y activamente respondería a diferentes condiciones. Son estrategias que se individualizan para cada caso y que tratan de sacar provecho de los recursos naturales para crear un confort interior óptimo.

La primera vivienda diseñada en Alemania siguiendo estas premisas se construyó 1991. ${ }^{17}$ "The Passive House Insitute", centro de investigación alemán con sede en los Estados Unidos, llevó a cabo una serie de estudios para comparar la energía que necesitaba una vivienda pasiva con otras de construcción tradicional. Mediante los estándares de "Passive House" y el uso de energía renovable, atendiendo a los requerimientos del lugar, las orientaciones, y los materiales, podía obtenerse lo que se denomina "Nearly Zero Energy". ${ }^{18}$ Por lo tanto, se ha comprobado que los métodos pasivos pueden ofrecer posibilidades para mejorar el diseño de las construcciones y reducir así los gastos energéticos. Aunque no todas las construcciones puedan aplicar cada una de las estrategias, existen otros métodos que combinan elementos y permiten reducir también el consumo.

Los otros cuatro modos de actuación son: el sistema mixto, el sistema completo, el sistema productivo y el sistema compuesto. El primero de ellos, el sistema mixto, utilizará los equipamientos electromecánicos para adquirir 
el confort interior que no se ha podido conseguir a través de las estrategias del sistema pasivo. En segundo lugar, el sistema completo, el más común hoy en día, se basa en relegar el total de las necesidades interiores a los sistemas electromecánicos. La mayor ventaja es que el usuario siempre obtiene lo que desea, algo poco usual con los métodos anteriores. Sin embargo, los costos energéticos pueden ser mayores. En tercer lugar, el sistema productivo se basa en que el edificio genera su propia energía para su uso y, a pesar de las ventajas que este sistema tendría si pudiese implementarse completamente, la realidad es que cuenta con dificultades técnicas que todavía han de resolverse. Por último tenemos el sistema compuesto, que utiliza estrategias de los diferentes sistemas y los combina.

Es decir, los mecanismos por los que las envolventes de los edificios son capaces de estar integrados con el resto del proyecto son considerables. Cada paso que la práctica de la arquitectura dirije hacia un diseño energéticamente eficiente y reconociendo las posiblidades de una arquitectura responsable puede trabajar hacia un mayor equilibrio entre el medio natural y el construido. 


\subsubsection{Barreras Existentes}

"Building design is the keystone of architectural practice. Translating needs and aspirations, theories and technologies, and schedules and budgets into appropriate and exciting places and buildings requires great skill as well as attention to broader public concerns"19

A pesar de los beneficios encontrados en un diseño eficiente, existen ciertas barreras a sobrepasar para que las estrategias y apuestas por envolventes energéticamente eficientes puedan generalizarse. Para efectos de este trabajo, éstas se han clasificado en tres grupos: las limitaciones económicas, los requerimientos técnicos y el proceso arquitectónico.

\section{Barreras económicas}

Las barreras económicas o limitaciones de mercado son quizás las que presentan mayores dificultades porque su solución abarca un campo que desborda al de la arquitectura.

Al evaluar las posibilidades y los potenciales de llevar a cabo un diseño de un cerramiento integrado con el resto del edificio y que participe de manera activa en la reducción de los gastos energéticos, entran en juego diversos factores. Los gastos iniciales del sistema, su diseño, fabricación, transporte o montaje son factores que hay que considerar. A pesar de los costes elevados que inicialmente puede suponer la inversión en estrategias de esta índole, el ahorro a largo plazo también debe ser tenido en cuenta.

Los costes de las envolventes de vidrio son ya de por sí elevados en proporción al resto del proyecto. Cuando a esto se suman sistemas en los que entran en juego, no sólo materiales y productos, sino también mecanismos de funcionamiento que requieren de otros sistemas, por ejemplo móviles, los costes pueden incrementar sustancialmente. Estos factores pueden hacer que algunos clientes expresen cierta reticencia. La posible reducción en el consumo de ener-

19. David Haviland, Architect's Handbook of Professional Practice, (New York, American Insititute of Architects: 1994). pag.631. gía, en el mantenimiento, en el cuidado y en la reparación de los sistemas, puede hacer que las decisiones adoptadas atendiendo a factores como la localización o la orienta- 
ción, puedan ser ventajosas a largo plazo ya que la energía necesaria para mantener un confort interior podría ser menor. Sin embargo, todo ello requiere un planeamiento más detallado del proyecto desde los estados iniciales.

Diversos estudios de investigación en Inglaterra han concluido que, aunque el coste de un sistema avanzado y responsable con el medio ambiente fuese el mismo que el de mantener, reparar y usar los equipamientos mecánicos, los usuarios adquieren un mayor grado de confort y la productividad en los espacios interiores aumenta considerablemente. ${ }^{20}$

La propuesta que este grupo de investigadores hizo tras obtener los resultados, se caracterizó por el que parte del presupuesto inicial de los proyectos se destinase hacia estrategias y diseños avanzados de sistemas de fachadas.

Tampoco hay que obviar los límites que el propio mercado impone sobre los usuarios. Cuanto mayor es el desconocimiento, mayor es la inseguridad y, en consecuencia, menor es el consumo. Esto hace que los precios y costes se alejen de los posibles usuarios, quienes deberían poder familiarizarse con los productos para poder sacar el máximo provecho.

El papel de ayudar e informar también lo tienen las instituciones, como por ejemplo las educativas. Las universidades están llevando a cabo un papel importante al incluir en sus programas asignaturas sobre el papel que tiene la arquitectura en el mundo global y sus respuestas ante problemas existentes, además de investigar nuevos conceptos de envolventes y su implicación con "lo natural".

Por tanto, las barreras de mercado, el coste o la difusión son las primeras que habría que vencer para que la arquitectura en su conjunto pueda apostar por diseños que se nutran de las nuevas tecnologías existentes y emergentes para dar una respuesta responsable a la sociedad.
20. Michael Wigginton, Jude Harris. Intelligent skins. (Oxford: Elsevier Ltd, 2002) . 


\section{Barreras técnicas}

En segundo lugar, la arquitectura se enfrenta a los límites de carácter técnico. La escasez de ejemplos en los que basar la experiencia, y los altos costes iniciales de los sistemas, hace que exista cierto escepticismo a la hora de apostar por sistemas avanzados. La complejidad de los mismos, el desconocimiento de los conceptos que hay detrás de ellos, e incluso de las respuesta de estos sistemas, son factores que impiden su difusión. A esto se añade la complejidad de ensamblaje o funcionamiento que en algunos casos existe. Los vidrios de repuesta variable o sistemas de recuperación de energía para un uso posterior incorporados en las envolventes, así como la introducción de tecnologías tales como los PCM ("phase change materials"), que al pasar de un estado a otro almacenan energía para luego desprenderla cuando sea necesario, para aumentar el confort interior, son sólo ejemplos de hasta qué punto la técnica está dispuesta a evolucionar al servicio de la arquitectura. Sin embargo, el desconocimiento por parte de amplios sectores relacionados con la profesión, puede llevar a la desconfianza. El mismo vidrio es capaz de cumplir múltiples funciones si se conocen los mecanismos que subyacen en él.

Compañías como Schücco, de origen alemán y especializada en la tecnología del aluminio, han llevado a cabo estudios en los que han presentado sus propuestas para un vidrio que cumpla los requisitos necesarios para el confort interior. En este caso, la compañía hace referencia al concepto del que se ha hablado anteriormente: la piel del camaleón, en el que la superficie de vidrio tiene incorporados sistemas de células fotovoltaicas, sistemas de control solar, películas que filtren las longitudes de onda de la energía solar o gases con comportamiento controlable. Pese a que la idea no sea nueva y haya sido propuesta teóricamente con anterioridad, el producto presentado constituye un ejemplo de la relevancia del vidrio en las fachadas de los edificios.

Okalux es otra compañía también de origen alemán que introduce la posibilidad de incorporar elementos de protección solar de respuesta variable y selectiva en las cavidades de los vidrios multicapas. En este caso, el aspecto 
del vidrio cambia según las condiciones exteriores, de tal forma que la respuesta de dichos elementos varía en un sentido u otro. Sea como fuere, el uso de la técnica en general no es un fin en sí mismo, sino un mecanismo que, en última instancia, puede ayudar en el proceso arquitectónico. Si se potencia el conocimiento, será más fácil decidiry, quizás, diluir los límites.

\section{Barreras en el proceso de diseño arquitectónico}

La arquitectura comienza a implementar un proceso en el que el periodo del diseño inicial se convierte en la etapa principal de desarrollo. De esta manera se dota de mayor peso a estas etapas iniciales en las que las decisiones son menos difíciles de variar y el coste derivado de las mismas es también menor. Sin embargo, sigue siendo habitual que las etapas posteriores sean las que predominan en los métodos tradicionales de producción.

En lo que a las envolventes de los edificios respecta, esto supone un problema, ya que las decisiones que les afectan inciden en el conjunto del edificio. Es decir, tradicionalmente, las decisiones sobre la materialización de las envolventes se han relegado a etapas posteriores del proceso. Esto no sólo ha elevado su coste final sino que ha dificultado la coordinación entre los diferentes equipos participantes, pues en muchos casos se presta atención a las envolventes cuando las decisiones de organización de los espacios interiores y sobre la relación entre lo opaco y el vacío ya son casi totalmente inamovibles.

La falta de integración hace que ambos recorran en caminos paralelos. El reto puede consistir en introducir los conceptos de las envolventes en la práctica de la arquitectura general para que los mismos que llevan a cabo los diseños preliminares sean los que estén teniendo en cuenta estas cuestiones. De lo contrario, los equipos acaban por relegar a terceros estos aspectos y su participación siempre se da en estados avanzados. La integración plena puede llevarse a cabo mediante el conocimiento por parte de los profesionales de cuáles son los elementos que deben definir los estados iniciales del proyecto. 


\subsection{ENVOLVENTE COMO SUPERFICIE DE ADAPTABILIDAD. LACATON Y VASSAL .}

El desarrollo de este proyecto ha permitido la toma de contacto con diversos proyectos que, en cierta medida, recuerdan a algunos estudios llevados a cabo para este mismo ejercicio. Por ejemplo, la obra de los arquitectos franceses Anne Lacaton y Jean Pierre Vassal, y específicamente el estudio de sus proyectos de rehabilitación de viviendas y transformación de espacios, han permitido entender cómo la práctica de la arquitectura también está tomando conciencia de la importancia del reciclaje y la transformación para dar respuesta a las necesidades de la sociedad actual.

Inevitablemente, la confluencia de la búsqueda por respuestas medioambientales, el compromiso social, así como la actual y ya duradera crisis económica, ha abierto la posibilidad de nuevas propuestas que apuestan por una arquitectura social y cultural ligadas a la transformación y la flexibilidad. La exposición custodiada en el MOMA de "Nueva 
York Small Scale, Big Change: New Architectures of Social Engagement" (octubre 2010 - enero, 2011) presentó once proyectos en construcción en distintos continentes caracterizados por la apuesta por una arquitectura innovadora en comunidades marginales. Los arquitectos que participaron en esta exposición no sólo abordan las necesidades funcionales de los espacios diseñados, sino que tienen como objetivo común ejercer un efecto de transformación social dentro de las particularidades de cada una de las comunidades en las que han trabajado, más allá del ámbito del proyecto en sí.

Además, los proyectos expuestos tienen en común la incorporación de medidas pioneras energéticamente sostenibles con el estudio de materiales locales tradicionales junto con otros innovadores. El compromiso renovador de los arquitectos que participan en este proyecto recuerda, en parte, a aquéllos de la segunda mitad del siglo XX, aunque se concentran en proyectos específicos con el fin de tener un efecto globalizador. La exposición es tan sólo una selección de proyectos dentro de un grupo mayor de iniciativas similares en diversos lugares. Arquitectos como Lacaton y Vassal han priorizado proyectos de influencia social y cultural siendo a la vez conscientes de los costes, el programa y el diseño del proyecto. De esta manera, los arquitectos han logrado ofrecer a la comunidad espacios físicos con fines determinados a la vez que una oportunidad de autodeterminación y sentido de identidad e integración.

Distintos medios (dentro y fuera del mundo arquitectónico) analizaron el efecto tras la exposición. El New York Times, por citar uno, en un artículo publicado en octubre del 2010 titula: "Real-Life Design: Erecting Solutions to Social Problems". ${ }^{21}$ En el artículo, el columnista Nicolai Ouroussoff comienza diciendo que la arquitectura está reencontrando su conciencia social. Y es que en un mundo y un tiempo donde también las sociedades desarrolladas están sufriendo las consecuencias de la crisis económica, la arquitectura por fin ha decidido actuar, aunque sea a pequeña escala.

La arquitectura, criticada en ocasiones por la excesiva tendencia a la experimentación estética y la belleza,

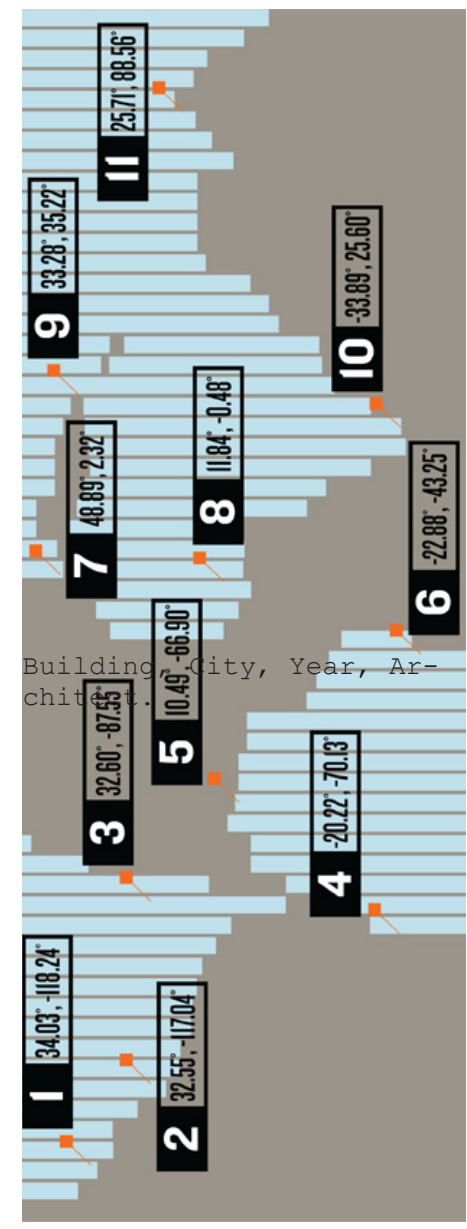

Mapa de actuación de Small Scale, Big Change para la exposición del MOMA, octubre 2010-enero 2011.

21. Nicolai Ouroussoff, "Real-Life Design: Erecting Solutions to Social Problems", New York Times, (New York: Oct 14, 2014). 


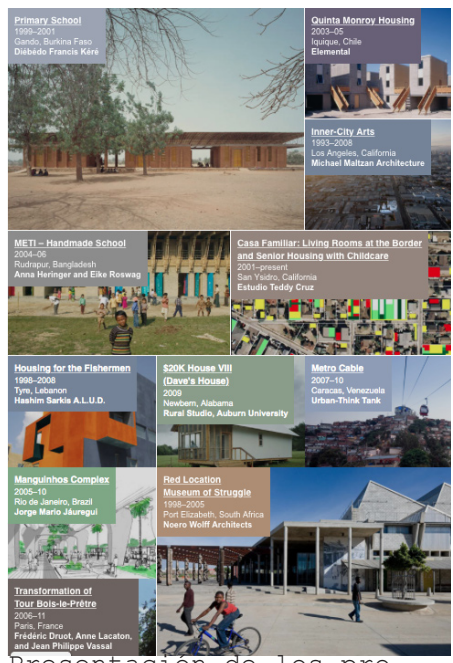

Presentacion de los proyectos para el MOMA Small Scale, Big Change

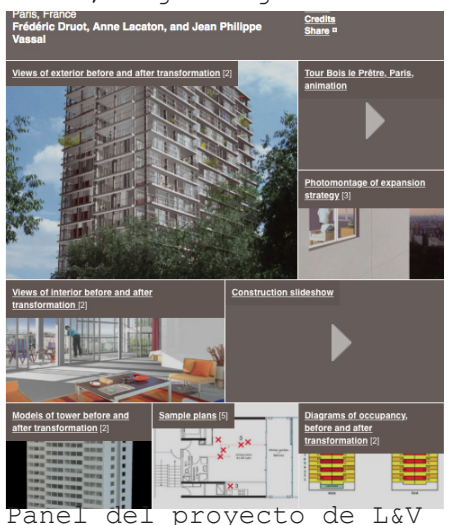

para la exposición del MOMA Small Scale, Big Change, octubre 2010 enero 2011.

22. Nicolai Ouroussoff, "Real-Life Design: Erecting Solutions to Social Problems", New York Times, (New York: Oct 14, 2014).

23. Andres Lepik, "Building on Society", Small Scale Big Change: New Architectures of Social Engagement, (New York: MOMA 2010 - 2011) se hace partícipe del valor de la belleza en la arquitectura social. En dicho artículo, se realza especialmente el valor de la arquitectura de Lacaton y Vassal en el proyecto de Transformación de Tour Bois le Petre y la manera en la que los arquitectos destinan sus esfuerzos a reciclar y rediseñar un edificio existente, evitando el revuelo social de demoler un edificios de viviendas ocupado y, por contra, dotarlo de una calidad y cualidad arquitectónica y social que sirve como ejemplo a muchos otros proyectos de arquitectura. Me siento especialmente identificada con este proyecto, ya que, entre otras cuestiones, existe una coincidencia en los objetivos de esta investigación, y en las fechas en las que proyecto y tesis se estaba diseñando.

"But it also had symbolic meaning: The act of ripping off the facades is a reaction against our tendency to keep the poor and their problems hidden away. The balconies are a visible means of pushing back against the escalating costs of urban space." 22

"The recent global economic crisis has heightened the perception that architecture of the past decades has placed itself too much in the service of economic and political interests and has too little regard for social concerns... ". ${ }^{23}$ 


\subsubsection{Proyecto de Transformación de Tour Bois le Prêtre (París, 2005 - 2011)}

El proyecto de transformación que Lacaton \& Vassal llevan a cabo en la Tour Bois-le-Prêtre de París supone un ejemplo de arquitectura experimental en un edificio existente. La construcción original, finalizado en la década de los años 60, formaba parte de un conjunto de edificios de aproximadamente $50 \mathrm{~m}$ de altura situado en un barrio periférico de la capital francesa. Como alternativa a la política existente en la mayor parte de las ciudades de demoler y reconstruir, los arquitectos proponen reutilizar aquello que se considere pertinente y proponer alternativas a lo que deba ser reemplazado. Con ello, no sólo se estudian nuevas vías de arquitectura, sino que los arquitectos logran demostrar que, en ocasiones, este proceso puede ser menos costoso, más rápido y mantener e incluso mejorar la calidad de la obra.

De manera similar a lo que posteriormente observaremos en el edificio de Lake Grove Village en Chicago, la fachada de la Tour-le-Prêtre ofrece un gran potencial para la transformación. La arquitectura original presentaba una independencia constructiva entre las grandes superficies de vidrio, balcones o galerías, de la estructura de forjados de hormigón. La primera renovación de este edificio fue en la década de los 80. La renovación incluyó un revestimiento aislante delante de las fachadas que cerró los balcones, reduciendo las aberturas de las ventanas y, por consiguiente, disminuyendo en gran medida la entrada de luz natural en los espacios. La planta baja, originalmente elevada sobre pilotis, creaba una entrada falta de luz, por lo que parte de los objetivos de la intervención de los arquitectos franceses era devolver la luz y la ventilación natural a los espacios. Al mismo tiempo, y respetando la estructura original de los edificios, la intervención pretendió otorgar mayor calidad y cualidad espacial a las viviendas.

El proyecto de Lacaton y Vassal reúne otra semejanza con el de Lake Grove Village que se propone en este estudio, y es el diseño y aprovechamiento de una doble capa en la fachada. En este caso, los espacios considerados "de

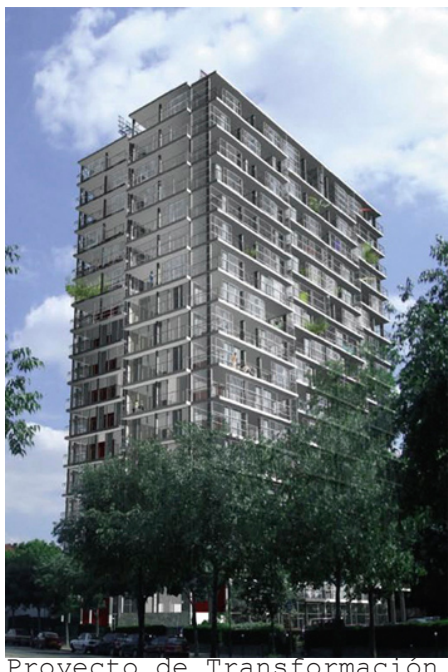

de Tour Bois le Prêtre, París, 2005-2011, Lacaton \& Vassal.

Fotografía del proyecto extraída de la publicación $2 \mathrm{G}$ No. 60 . 
transición exterior-interior" crean una doble envolvente transparente y habitable que rodea casi la totalidad del perímetro del edificio y permite crear estancias de ambiente intermedios entre el interior y el exterior. La primera fachada (desde el interior) sustituye a la existente y se compone de una piel corredera y acristalada que da paso a una galería o espacio intermedio que sirve de regulador de temperatura. Este espacio de transición está separado del exterior por una segunda piel translúcida que otorga un carácter de espacio privado interior. Como veremos posteriormente, en Lake Grove Village, los balcones no rodean el edificio pero crean estancias de control ambiental. Sin embargo, en ambos casos la habitabilidad de la fachada es un aspecto fundamental. De la misma manera, el proyecto de la Tour-le-Prêtre estudia el efecto de esta nueva piel sobre el consumo de energía, y posteriormente permite reducir a la mitad tanto el consumo energético como la contaminación acústica. 


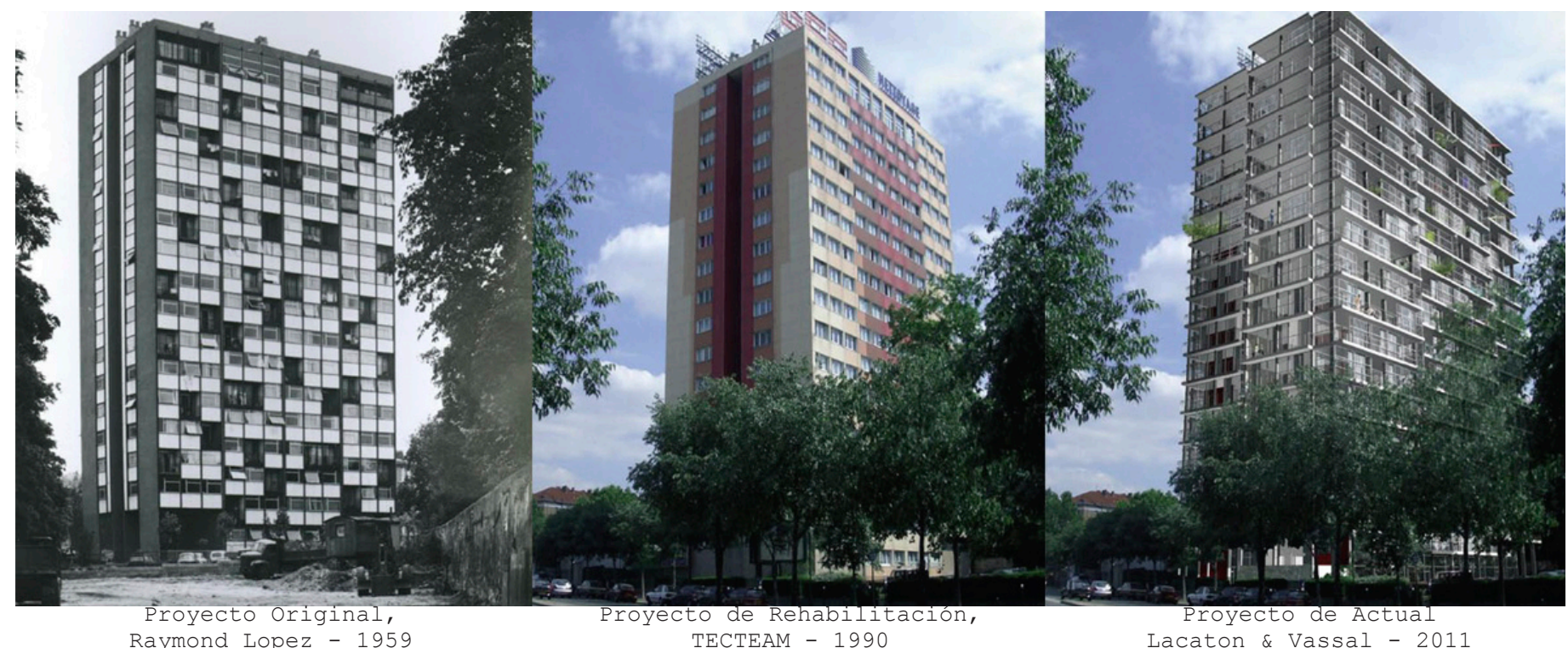

Fotografías del proyecto original, el de rehabilitación y el actual, extraídas de la publicación 2G No.60.
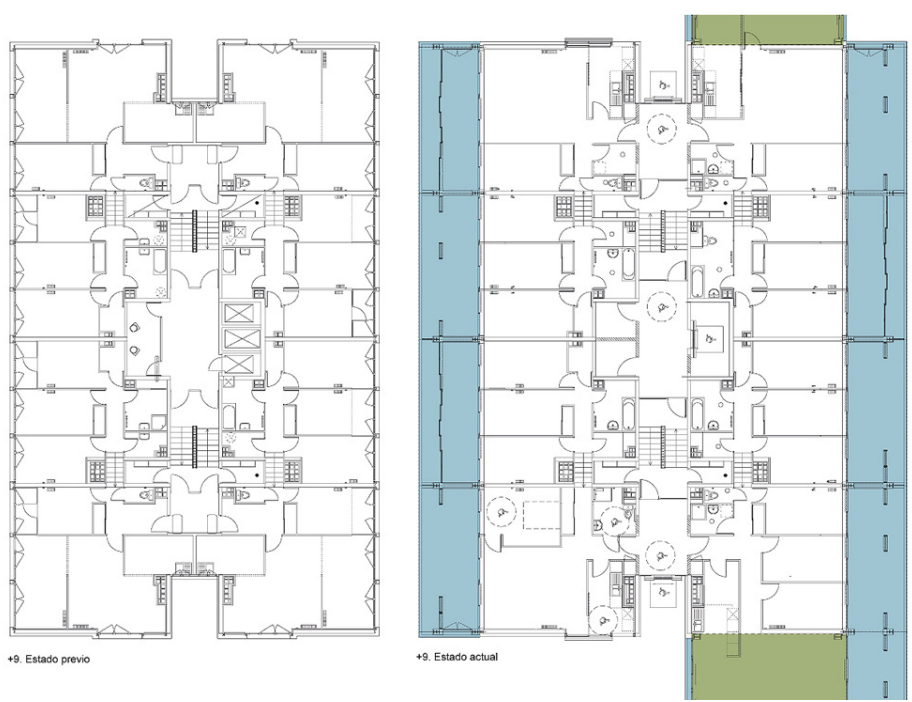

Plantas del edificio - estado previo y proyecto.

Diagramas de las plantas extraídas de la publicación El Croquis $177 / 178$.

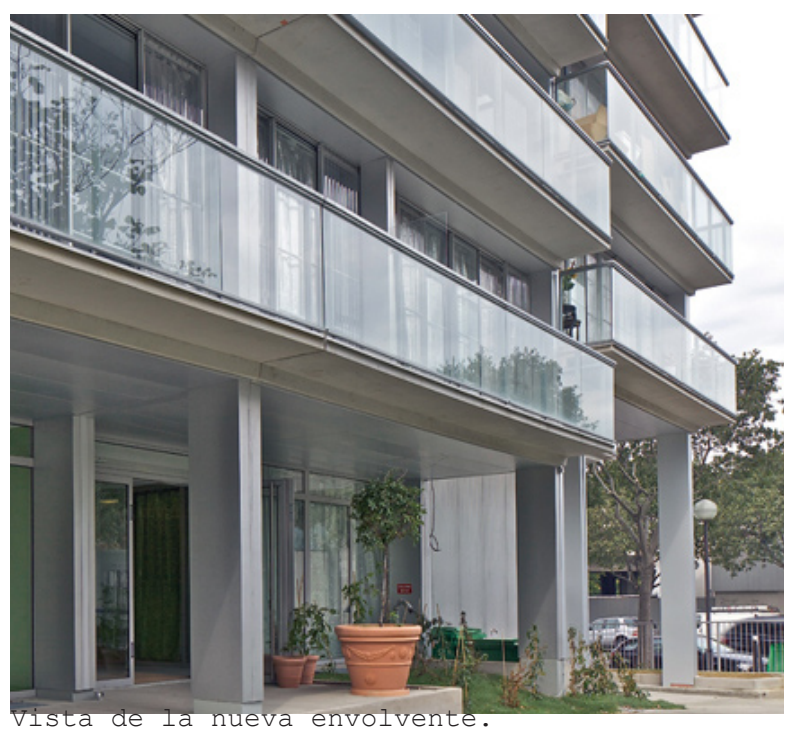

Fotografía extraída de la publicación 2G No. 60 . 


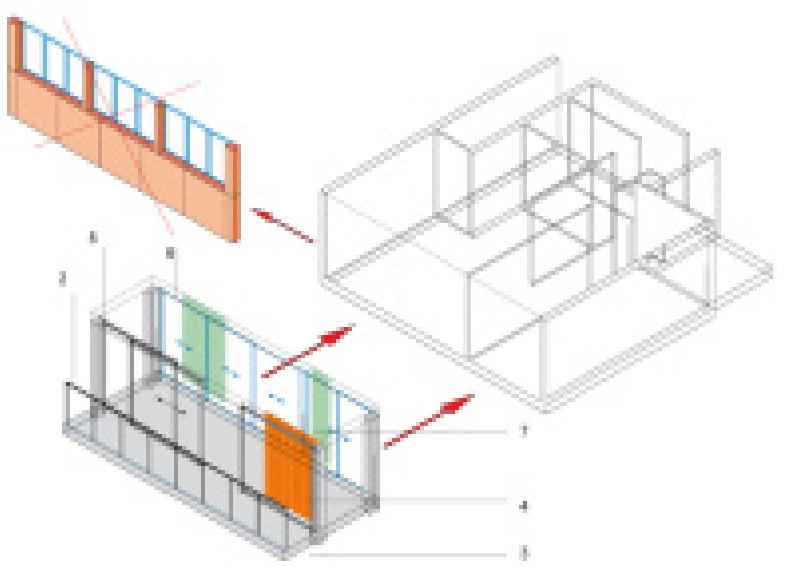

Ampliación de la zona de vivienda.

Diagramas axonométricos y en sección extraídos de la publicación 2G No.60.

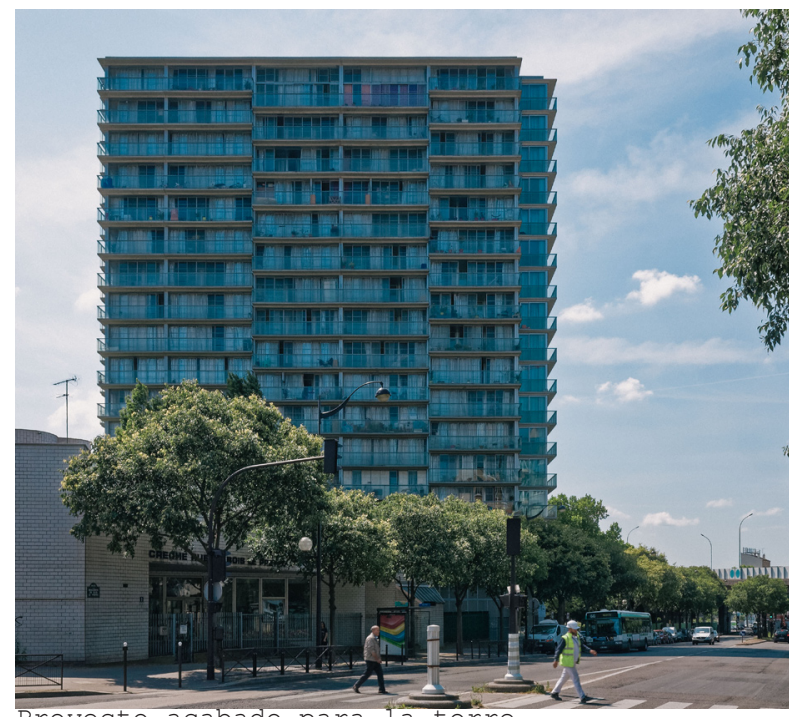

Proyecto acabado para la torre. Fotografía de Victortsu, 2014.
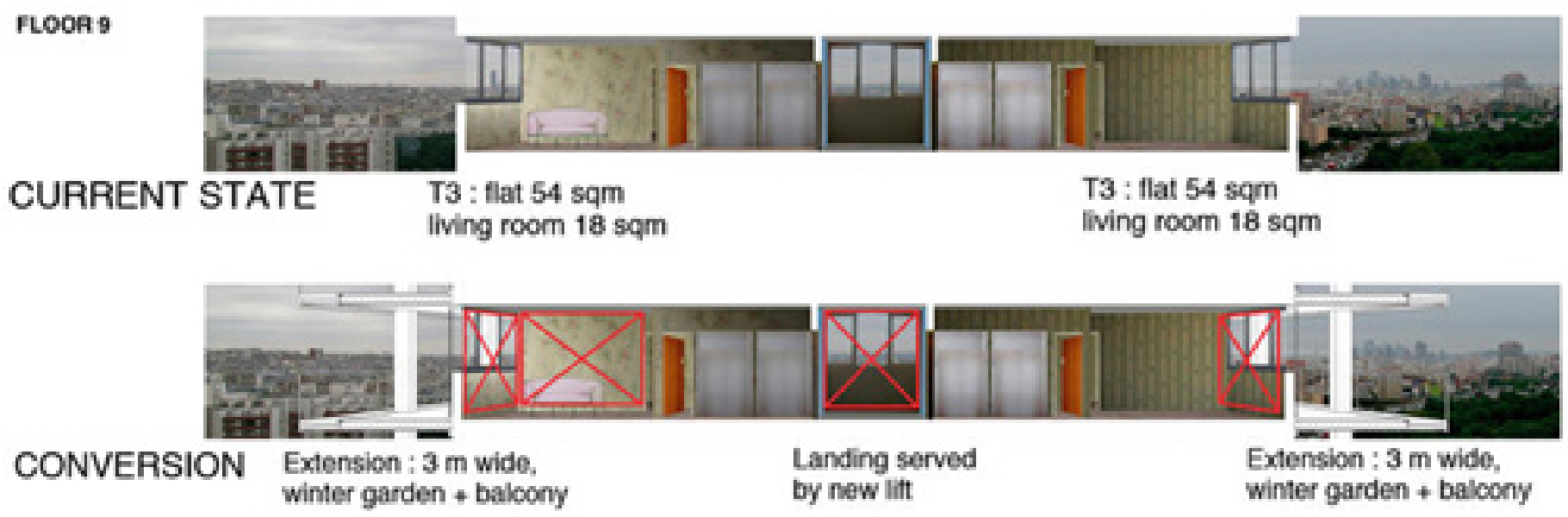

living room 18 sqm

PROJECT

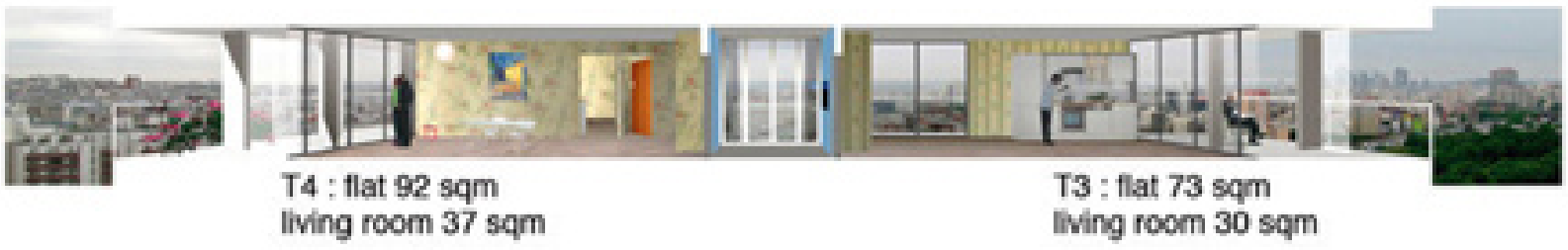




\subsubsection{Proyecto de Transformación de una torre de viviendas en Saint-Nazaire (Saint-Nazaire, 2006 - 2012)}

La reconstrucción de la torre de viviendas en el barrio de La Chesnaie (Saint-Nazaire, Francia) es otro de los proyectos en los que Lacaton \& Vassal apuestan por la transformación en lugar de la demolición y reconstrucción. En este caso, el edificio de viviendas se encuentra en un lugar privilegiado por su cercanía tanto al centro urbano como al mar, lo que permite estar rodeado de zonas verdes, espacios abiertos y zonas de equipamientos y de recreo. Sin embargo, la realidad a la que se enfrentan los arquitectos en el momento de intervenir en la zona es la de una disminución del aparente atractivo. El plan del proyecto contempla la transformación de la zona no mediante la destrucción sino mediante la transformación de 40 viviendas de una de las torres y la construcción de otras 40 nuevas adheridas a la torre existente. Por tanto, este nuevo proyecto presenta una doble operación: transformación y densificación para tratar de revalorizar una zona con grandes potenciales de entorno. Una vez más, los ideales de reciclaje y aprovechamiento que estos arquitectos han mostrado en obra nueva se observan en esta doble actuación.

El espacio de la galería o la logia cobra un especial protagonismo, una vez más, en la arquitectura de Lacaton \& Vassal. Cada vivienda ve aumentada su habitabilidad mediante la adición de una galería y un balcón que se adoptan en la fachada sin grandes cambios estructurales. La galería o logia comprende unos dispositivos de paneles móviles transparentes que se asocian a un balcón que se añade delante de la fachada. La galería se convierte en el espacio de control solar y térmico y sirve, una vez más, como estancia de relación entre el interior y el exterior.

Una vez completado el proyecto, y de manera similar al proyecto de transformación de la Tour-le-Pêtre, el conjunto es más económico que si hubiese requerido el derribo y reconstrucción del mismo número de viviendas. A esto hay que añadir que el proyecto sirve de lanzadera para una transformación de barrio, permitiendo la construcción de nuevas viviendas y la transformación de otras existentes con el

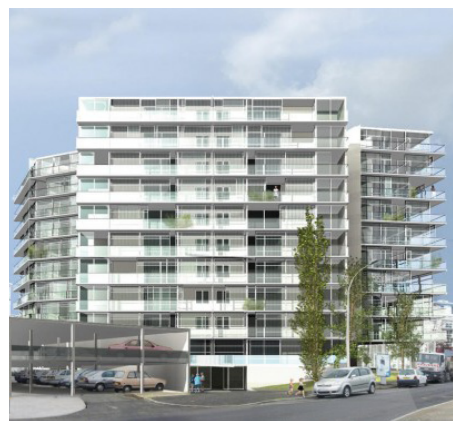

Proyecto de Transformación de torre de viviendas en Saint Nazaire, 2006-2012, Lacaton \& Vassal. Fotografía del proyecto extraída de la publicación 2G No. 60 . 


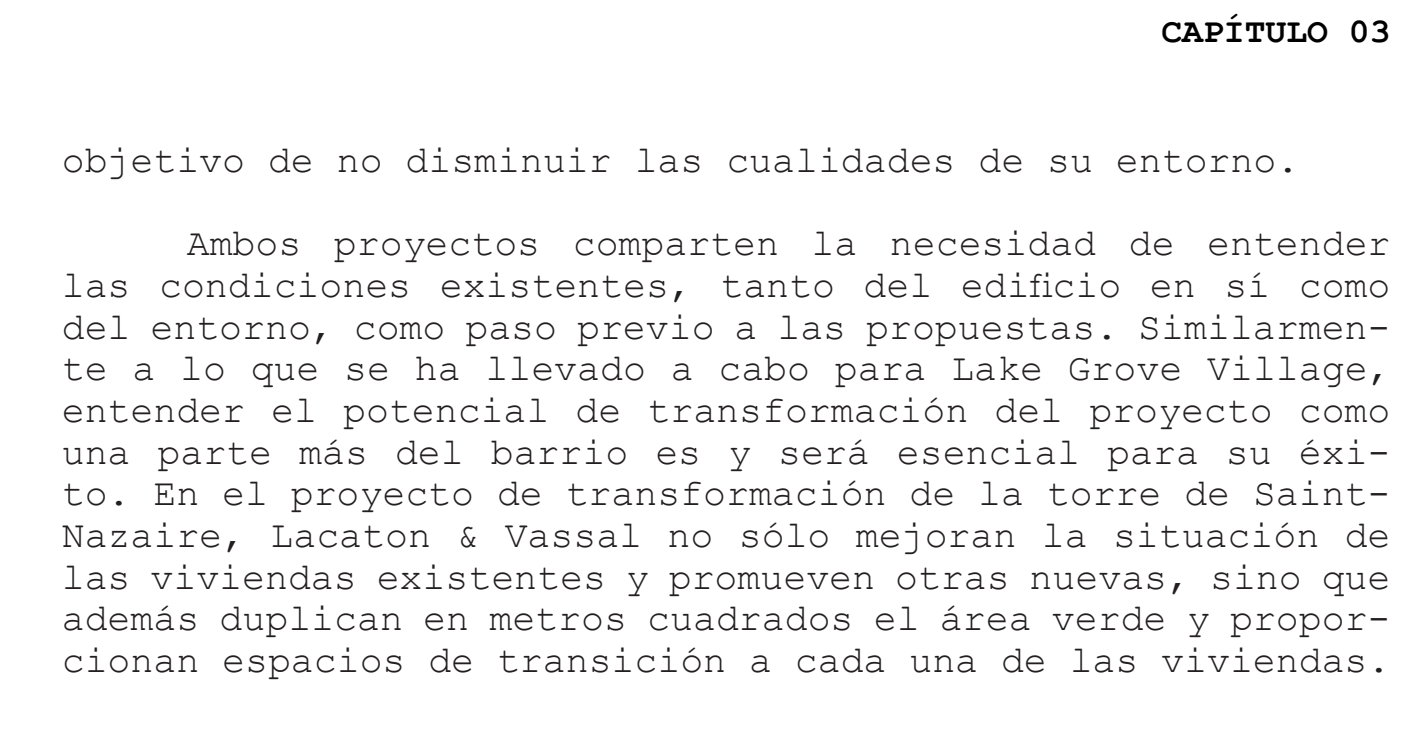

105 


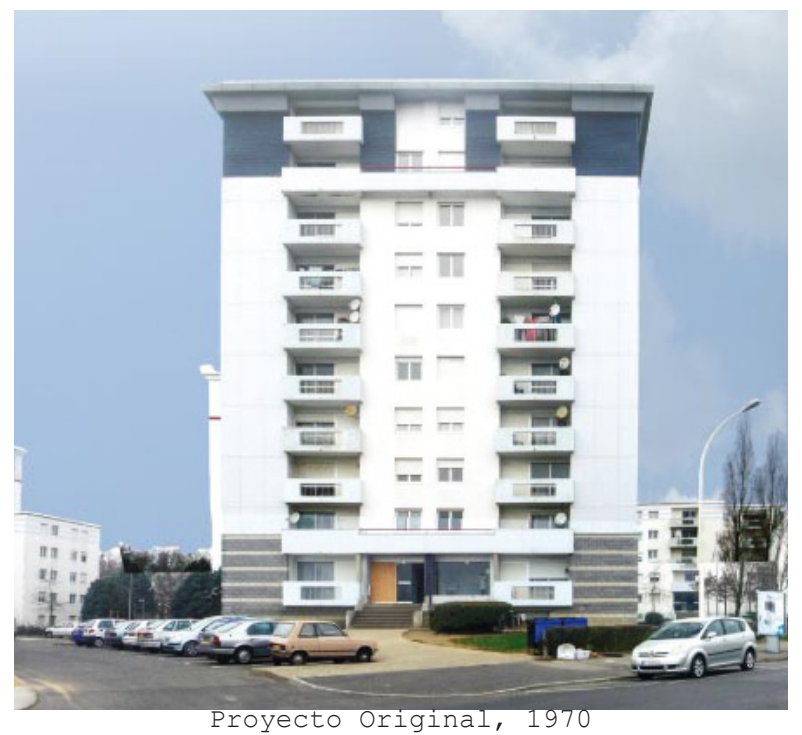

Fotografías del proyecto original y el actual, extraídas de la publicación 2G No.60.

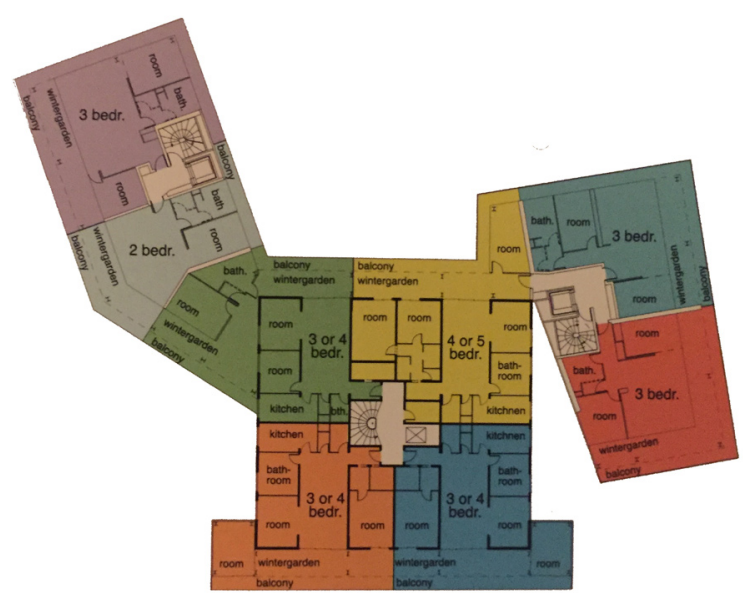

Diagrama en planta del conjunto.

Diagrama extraído de la publicación El Croquis $177 / 178$.

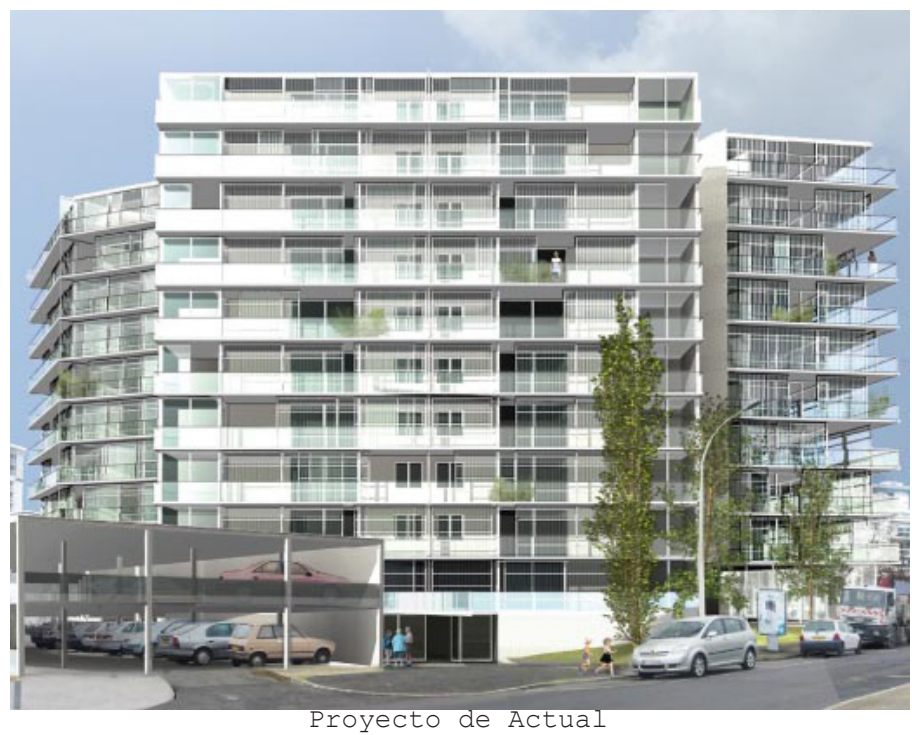

Tacaton \& Vassal - 2012

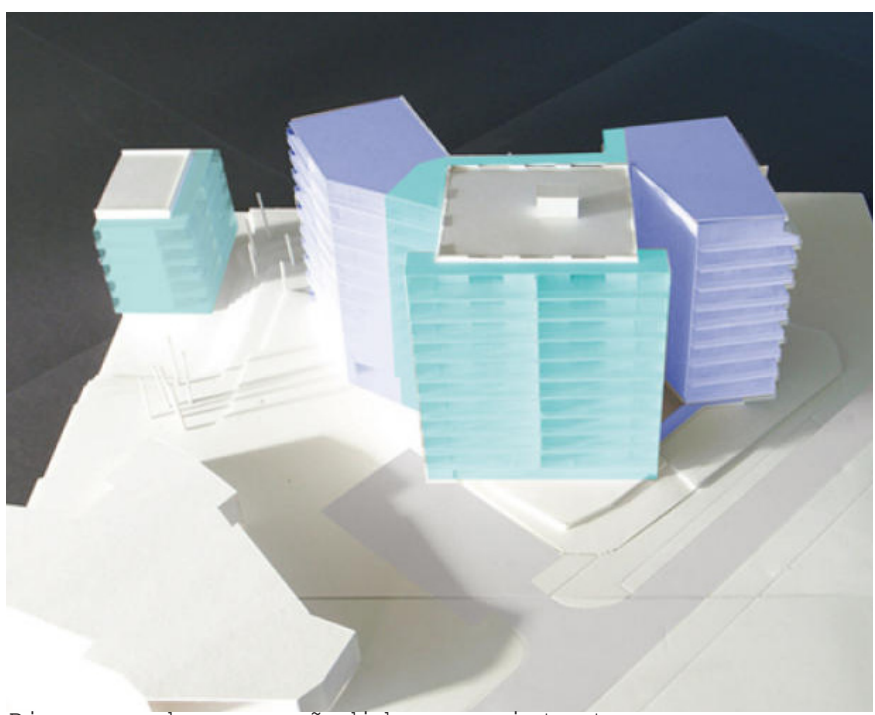

Diagrama de usos añadidos y existentes.

Fotografía extraída de la publicación 2G No.60. 
CAPÍTULO 03

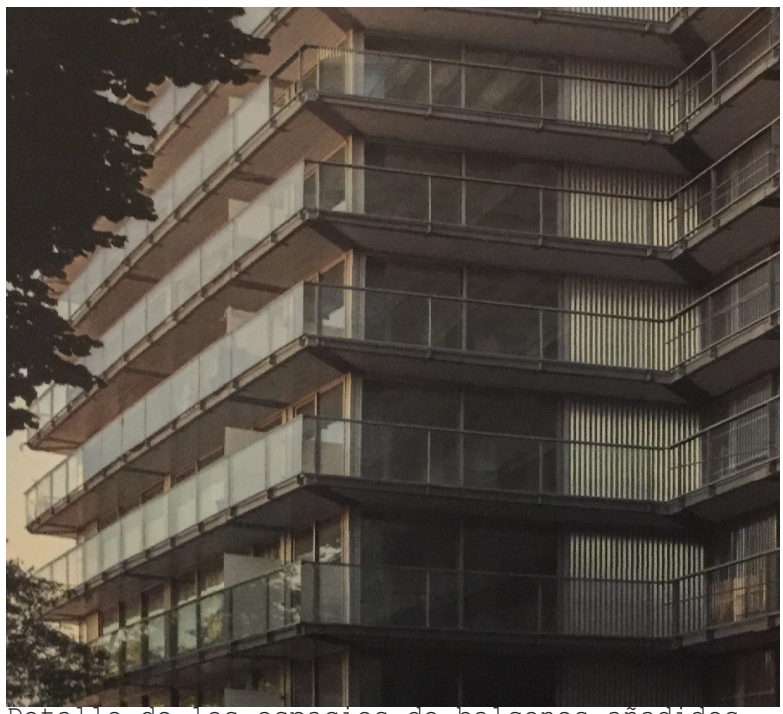

Detalle de los espacios de balcones añadidos. Fotografía extraída de la publicación El Croquis $177 / 178$.

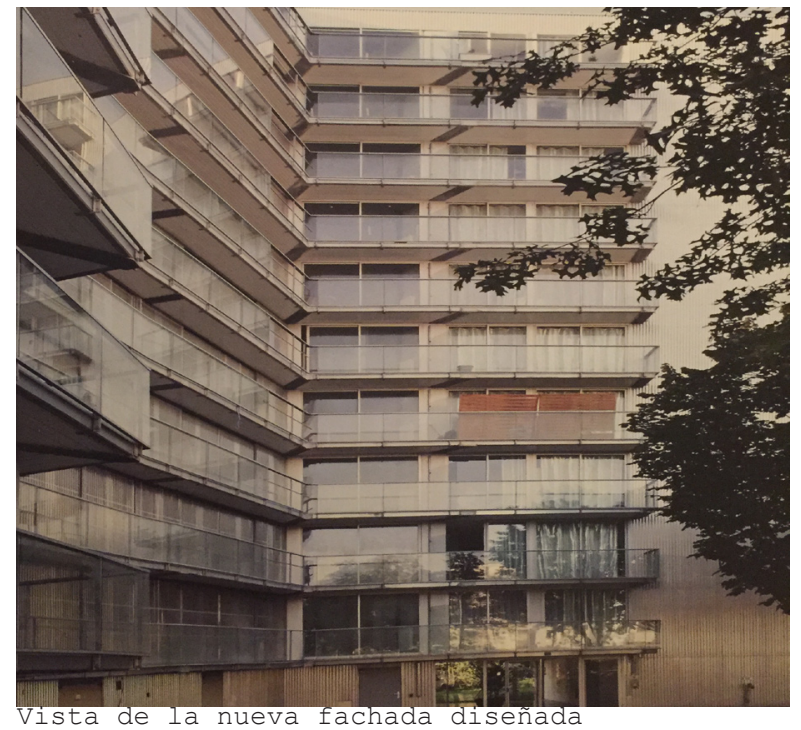

Fotografía extraída de la publicación El Croquis $177 / 178$.

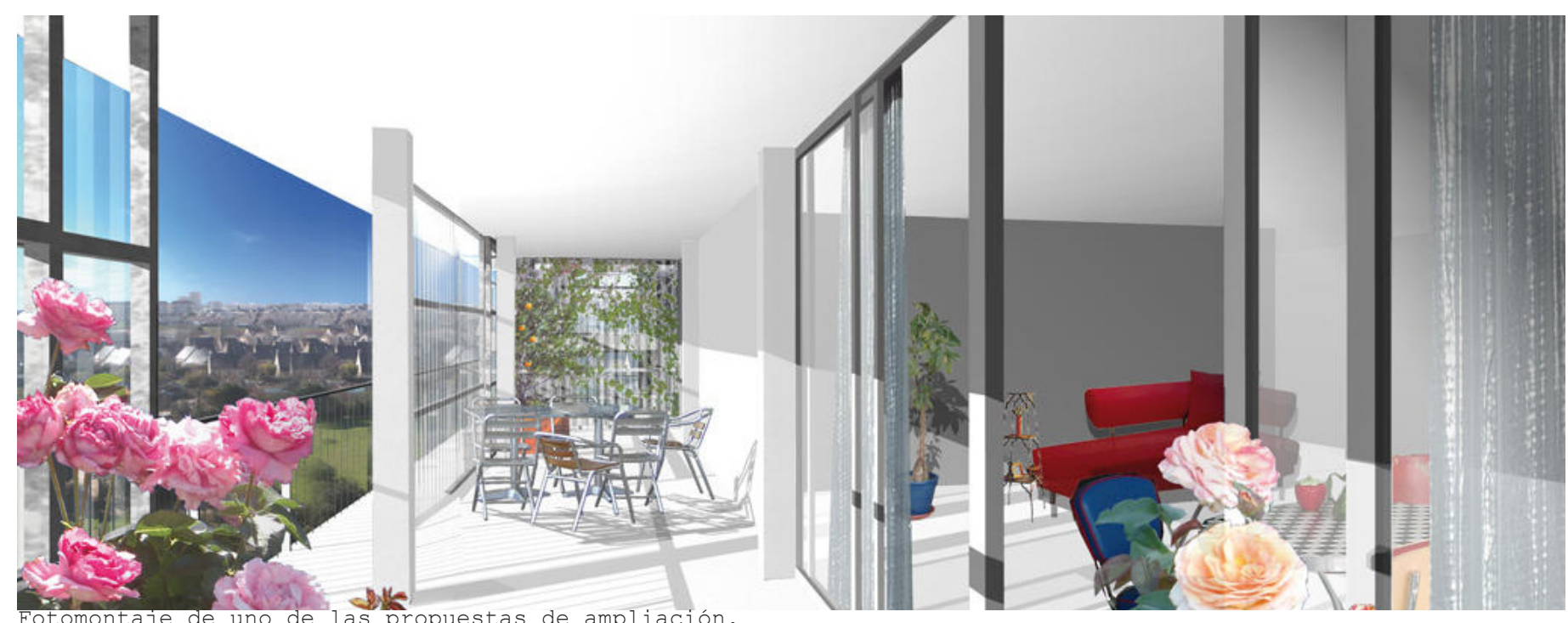

Fotografía extraída de la publicación 2G No.60. 


\subsubsection{Otros proyectos}

Lacaton \& Vassal no sólo son pioneros en los proyectos de transformación de viviendas existentes. Si se estudia su obra, se observa su intención y su interés en la investigación y en proponer nuevas soluciones a problemas ya existentes en la mayor parte de las grandes ciudades.

Así, por ejemplo, los arquitectos llevaron a cabo un proyecto de plan urbanístico para un barrio de Dublín (2007). En él, se enfrentan al reto de abordar la reforma de una zona industrial obsoleta e inutilizada en la que deben proponer la construcción de zonas residenciales, oficinas, equipamientos y espacios públicos. Una vez más, el análisis de lo existente lleva a ensalzar características y potenciales de la zona $y$, con una actitud de renovación y transformación, se lleva a cabo la superposición de usos, espacios y funciones. La teoría de la reutilización y la renovación vuelve a estar presente en esta propuesta y, una vez más, también los espacios residenciales se caracterizan por la luz, la ventilación y la calidad espacial con lo básico.

También en 2007 los arquitectos son comisionados para llevar a cabo una investigación con el objetivo de examinar la posibilidad de aumentar ocasionalmente la altura máxima permitida en París, analizando las consecuencias potenciales en aspectos como el trabajo o el consumo energético. Este proyecto teórico les permite situar una cuadrícula de 130 x 55m sobre un barrio de París superponiéndolo a las redes urbanas existentes y estudiando las transformaciones que el barrio debería llevar a cabo para la densificación y la inclusión de torres de mayor altura que los $37 \mathrm{~m}$ permitidos actualmente. Una vez más, el objetivo de los arquitectos no es la demolición y reconstrucción de la zona, sino ver qué edificios existen, cuáles se conservan, cuáles se reutilizany, por último, cuáles se añaden.

Un ejemplo más de la importancia de la investigación y el análisis. 


\subsubsection{Consideraciones}

Anne Lacaton \& Jean-Philippe Vassal han demostrado a lo largo de los años un interés y una pasión por comprender la importancia de lo existente y las posibilidades que otorga la superposición en lugar de la demolición. Los proyectos que hemos estudiado en este apartado son sólo un ejemplo de la intención por parte de los arquitectos por alejarse de la imposición y, por el contrario, de superponer lo nuevo a lo existente en favor de un producto que nace de la combinación de ambos. De esta manera, por ejemplo, hemos visto cómo las fachadas de edificios existentes se complementan con espacios de transición, o cómo los barrios en decadencia aprovechan los recursos existentes para potenciar nuevas oportunidades. Ya sea en la escala de las viviendas o en la del tejido urbano, los proyectos de Lacaton \& Vassal se decantan por una retícula estructural abierta que genera espacios nuevos en tejidos existentes. Del estudio de sus proyectos y las respuestas a sus propuestas encontramos como característica común la convivencia, la mezcla y la simbiosis. Y son términos no carentes de significados en los proyectos de estos arquitectos, logrando establecer como suyas estas cualidades.

La concepción de la arquitectura descrita anteriormente coincide con la que se identifica en este trabajo. Desarrollada simultáneamente en el tiempo, se comparte el interés por la renovación y la apuesta por la mezcla y la transformación.

El producto nacido de la confluencia de dos espacios y tiempos, de dos arquitecturas, se caracteriza por la aparición de nuevos usos, no siempre previstos en los comienzos del proceso de diseño. Los arquitectos franceses resaltan la importancia de identificar las diferencias entre las distintas estructuras o tramas en lugar de ahogar una con la otra. Sólo de esa manera, describen, la libertad estructural se convertirá en condición de milagro.

En el terreno constructivo, existe otra característica que se asemeja a la aquí planteada: la flexibilidad de los espacios. Por tanto, la flexibilidad de las construccio- 
nes. De esta manera, los proyectos de transformación se han caracterizado por el uso de fachadas ligeras independientes de la estructura y con posibilidad de adaptación. Ello se relaciona también con las necesidades cambiantes de los usuarios, ya sea por motivos socio-familiares o climatológicos. De esta manera, los arquitectos conciben la vivienda y los espacios como un lugar que permita el cambio, un espacio en el que se pueda controlar y crear climas nuevos dependiendo de las necesidades. Del estudio de varios de sus proyectos se ha destacado el uso de la galería, la logia, o ese espacio de transición que permite el control del clima de los espacios interiores. Esto, relacionado también con el tipo de construcción ligera y la independencia de la estructura, es otro ejemplo de superposición, en este caso de espacios. El diseño de estas estructuras abiertas permite no sólo el incremento de luz y energía solar, sino que el usuario, como si de una vestimenta se tratase, pueda fabricar de algún modo el clima que le convenga en cada momento. El uso de cortinas, brise-soleis, vidrios de diferente opacidad e incluso diferentes tipos de superficies transparentes (no sólo vidrio) permiten esta adaptabilidad y transformación en el día a día. Otro gesto más hacia el concepto de adaptabilidad.

La situación actual parece ligada a las necesidades de transformación e interpretación. Como hemos visto en este capítulo, el contexto energético, el contexto social y el contexto espacial (con las limitaciones derivadas respectivamente de factores medioambientales, crisis económica y aspectos constructivos) ofrecen desafíos que pueden convertirse en atractivas oportunidades para la arquitectura. Oportunidades para la innovación, para la reconstrucción, para la transformación y la optimización. De igual manera que las ciudades sufren procesos de rehabilitación de barrios y mejora de sus instalaciones, los edificios tienen potencial para ser mejorados y adaptados a las nuevas necesidades sin que ello conlleve la destrucción.

Como citan Lacaton \& Vassal : "lo existente se erige como un soporte poderoso de la imaginación". 



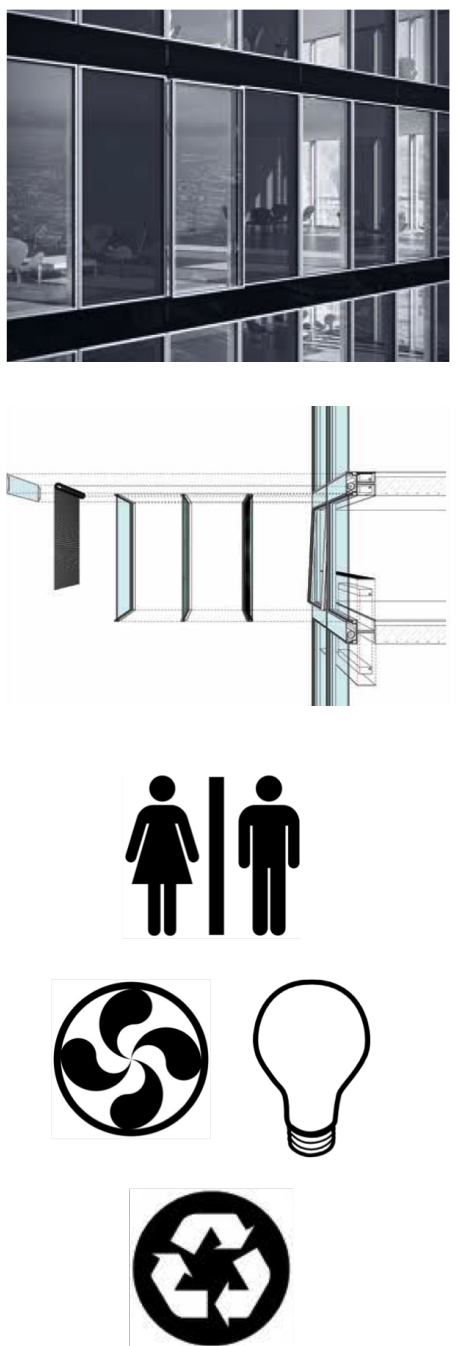

Diagrama de la Envolvente: combinación de elementos que apuestan por una eficiencia energética y un clima interior confortable mediante la expresión arquitectónica.

Los esquemas muestran los componentes de la envolvente $\mathrm{E}^{2}$ de Shüco en la publicación Profile.
CAPÍTULO 04

LA ENVOLVENTE. COMPONENTES Y COMPORTAMIENTO

\subsection{LA ENVOLVENTE ACTUAL.}

Hoy en día, la arquitectura tiende a trabajar con periodos más cortos y costes de producción que también tienden a reducirse. Los equipos de trabajo concentran sus esfuerzos en proponer conceptos y diseños que aumenten el confort y reduzcan los gastos tanto del consumo energético como de los sistemas mecánicos de los que se abastecen. Para tratar de compensar esta situación se requieren herramientas y sistemas adicionales que ayuden en el proceso arquitectónico; es aquí donde entran en juego elementos como los programas de simulación.

Sin embargo, el nivel de detalle que éstos exigen es muy superior a lo que en muchas ocasiones se puede esperar de un proyecto en una fase inicial, y resulta difícil evaluar las estrategias del diseño consideradas si no se poseen los conocimientos necesarios para tomar las decisiones. 
Son muchos los estudios que dedican esfuerzos al diseño de proyectos energéticamente eficientes que crean climas interiores sin comprometer los requerimientos del medio ambiente. Sin que la escala del proyecto sea un condicionante en este caso, existe una tendencia por delegar en las envolventes de los edificios las funciones de control y regulación del espacio interior, y que éstas se conviertan en protagonistas en la formalización del proyecto. Para ello, es necesaria la identificación y definición de los componentes tras las envolventes de vidrio, y establecer los requerimientos en cada caso.

En primer lugar, conocer los movimientos que se producen en las superficies de vidrio de un edificio -siendo este material uno de los más empleados-; entender cómo se transporta la energía, cuáles son las decisiones que pueden evitar la pérdida excesiva de la misma, etc.

En segundo lugar, y tras conocer las propiedades de los vidrios, definir los conceptos de las envolventes y entender las ventajas o inconvenientes según la función que deban desempeñar y la orientación a la que esté expuesta la superficie de fachada.

A continuación, estudiar el comportamiento de las envolventes al ser sometidas a variaciones climáticas o de orientación. Así entender en cada caso, el beneficio que obtienen de la ventilación natural, la energía solar o la iluminación.

En resumen, identificar las interacciones de las envolventes con el resto de mecanismos para que las soluciones arquitectónicas estén lo más integradas posibles. La definición de 'integración' de las envolventes hace mención a aquéllas diseñadas, analizadas y resueltas como un sistema funcional que influye y se influencia del entorno, a fin de establecer una situación de equilibrio.
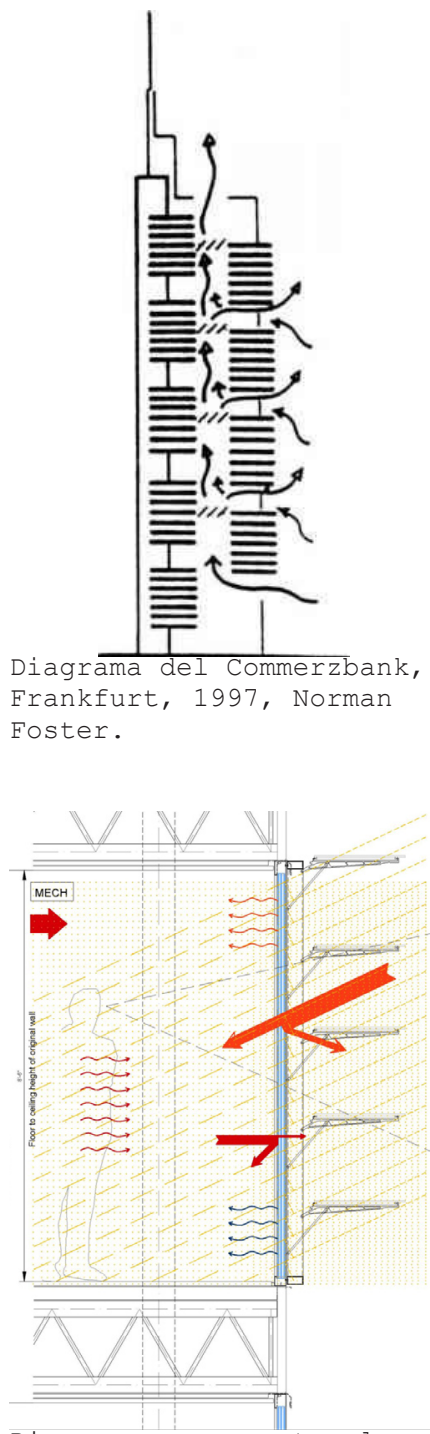

Diagrama que muestra los posibles movimientos a través de la envolvente 


\subsection{COMPONENTES Y PRINCIPIOS DE LA ENVOLVENTE DE VIDRIO. LA PIEL SIMPLE VS. LA PIEL MULTICAPA.}

Las fachadas de vidrio pueden cumplir con diferentes funciones que contribuyen a mejorar el confort interior, el control de la entrada de la iluminación natural, la protección solar, la generación y control de energía solar térmica, la ventilación y, por supuesto, permitir la visión al exterior. La manera en la que estas funciones se combinen dará como resultado distintos principios y tipologías de fachada.

Por lo que respecta a este trabajo, se definen tres tipos de envolvente dependiendo de sus componentes. Si la envolvente es una piel simple que alberga todas las funciones, la denominaremos envolvente elemental. Si las funciones se organizan en varias capas creando una alternancia de elementos estaremos refiriéndonos a envolventes de doble piel. Por último, la aparición del atrio ha adquirido una dimensión esencial como forma que profundiza en los concep- 
tos de la envolvente trasladando las funciones a una tercera dimensión.

Las envolventes de vidrio se dividen fundamentalmente en tres zonas en las que se acogen las distintas funciones. La zona de iluminación natural suele ocupar la parte superior del muro cortina para que la luz pueda entrar a mayor profundidad en el espacio. Si esta zona ocupa la totalidad de la anchura de la estancia, la iluminación será más homogénea y, en definitiva, mejor. En el caso de que se necesite una profundidad de entrada de luz considerable, esta zona quedaría fuera del alcance de los controles solares. Si se requiere un nivel de ventilación natural alto y aumentar el número de recambios de aire para el acondicionamiento térmico interior, entonces se emplearían estas zonas para proyectar huecos. La zona central de la unidad se caracteriza por permitir las vistas al exterior además de proporcionar iluminación natural. Esta zona será la que habitualmente acoja los sistemas de control solar para reducir las cargas térmicas en verano y el peligro de deslumbramiento en invierno. Normalmente, las aperturas al exterior se proyectan en este espacio central permitiendo las vistas y la ventilación natural. Por último, las zonas opacas compuestas por vidrios tintados, a los que se puede añadir o bien aislante térmico en el interior, o bien paneles opacos de algún material ligero. Obviamente esta zona no influye en la iluminación natural, pero sí que colabora en bloquear la entrada innecesaria de energía solar térmica en verano. A su vez, estas zonas opacas pueden albergar los sistemas de ventilación mecánicos o los de generación de energía.

El vidrio sigue siendo uno de los materiales principales en las envolventes de los edificos en altura, cuya técnica de producción en la década de los 50 supuso un punto de inflexión. ${ }^{2}$ Surgieron los vidrios flotados, que permitían la creación de superficies extremadamente planas, de grosor uniforme y con muy pocas deformidades visuales. El vidrio flotado es lo que se suele usar hoy en día en la arquitectura de fachadas y su relevancia estriba no sólo en sus cualidades físicas sino también en la posibilidad de aplicar películas y revestimientos a su superficie. El vidrio flotado es la base sobre la que se asentarán los desarrollos

1. G. Hausladen, M. De Saldanha, P. Liedl, Cliemate Skin: Building-skin concepts that can do more with less energy (Basel: Birkhäuser Publishers for Architecture, 2008.

2. Andrea Campodagno, Intelligent Glass Facades (Basel: Birkhäuser Publishers for Architecture, 2002 . 
futuros y, como tal, sus cualidades y posibilidades han ido evolucionando. Lo que se confeccionaba, anteriormente a 1965, con vidrios de una sola hoja, pasó a construirse, entre 1965 y 1980, con vidrios dobles con cámara de aire o triples, que surgieron eventualmente en los 70.3 El empleo de revestimientos y láminas de baja emisividad han hecho que estos últimos hayan tenido quizás menos éxito, especialmente en el mercado estadounidense. El desarrollo de dicha técnica ha permitido obtener resultados energéticamente sostenibles.

Dependiendo del tipo de vidrio, las estrategias para su confección varían según el producto. Por un lado, se altera el material cambiando la composición química o las propiedades físicas, como ocurre en los vidrios tintados. Por otro, se pueden aplicar revestimientos en la superficie del material, como los revestimientos reflectivos o los de baja emisividad (Low-E) que se emplean para disminuir las ganancias de energía solar en verano. Por último, se consigue mejorar las propiedades del vidrio al crear unidades multicapa y controlar el espacio entre los paneles mediante películas, gases inertes, etc. Para obtener un resultado que suponga una mejora en la respuesta del vidrio y asegurar así una buena aclimatación interior, suelen combinarse al menos dos de dichas estrategias.

Los vidrios de espectro selectivo son vidrios que permiten que una parte del espectro solar sea absorbido por la superficie y penetre en el espacio, y la otra se refleje al exterior. Uno de los vidrios que mejor cumplen esta función es el VE1-2M, de la compañía estadounidense Viracon, que ha suscitado una revolución en el mundo del vidrio convencional. VE1-2M tiene la faz interior cubierta de un revestimiento Low-E selectivo en el espectro electromagnético. Su mayor ventaja es que, sin alterar prácticamente la visión y su imagen, este vidrio admite una gran cantidad de luz natural al mismo tiempo que bloquea una parte importante de la energía solar térmica, ayudando a mejorar el clima interior, sobre todo en épocas calurosas. La posición del revestimiento, según esté en la segunda o tercera superficie del vidrio doble, determinará su comportamiento. Es decir, si el revestimiento se encuentra en la tercera superficie (o 
primera cara del vidrio interior), el efecto será reducir el intercambio de energía entre los paneles del vidrio. Si se añade un gas inerte en la cámara entre paneles, la conductividad del vidrio disminuye $y$, por tanto, se reducen las pérdidas por transmisión, mejorando así el rendimiento térmico de la superficie. Este supuesto será apropiado para aquellas situaciones en que las demandas de calefacción sean dominantes, como ocurre en los climas fríos en invierno. Si por otro lado el panel de espectro selectivo se halla en el exterior y por tanto el revestimiento está en la segunda superficie del vidrio (es recomendable situarlas en las caras de la cámara y no en contacto con el ambiente exterior), la cantidad de energía solar que se transmite al interior se ve reducida. Esta solución será la adecuada para climas de calor dominante u orientaciones en las que la radiación solar sea cuantiosa. La decisión ha de ser meditada ya que lo que puede resultar beneficioso en los meses de calor puede ser perjudicial con la llegada del frío. Antes de entrar en los diferentes tipos de envolventes según la clasificación, es conveniente entender los mecanismos a través de los cuales se producen las transferencias de energía en las superficies de vidrio. Sin ánimo de realizar un estudio exhaustivo de los mismos, se ha considerado necesario entender los mecanismos para los estudios y la propuesta de transformación de la envolvente que se desarrolla en este trabajo.

El vidrio es especialmente sensible a las transferencias de energía. La transferencia de calor es un proceso físico en el que se intercambia energía en forma de calor entre distintos cuerpos o partes de un mismo cuerpo a temperatura distinta. Estos procesos sobrevienen por conducción, convección o radiación y, aunque en ocasiones se producen los tres al mismo tiempo, puede darse el caso que uno predomine sobre el resto.

La conducción es la transferencia de energía térmica en un elemento o entre cuerpos en contacto. ${ }^{4}$ Es consecuencia de una variación de temperatura. Es decir, el proceso tiende a igualar la temperatura dentro del cuerpo con la exterior trasladando la energía desde las regiones de mayor temperatura a las de menor. La conducción se produce en distintos

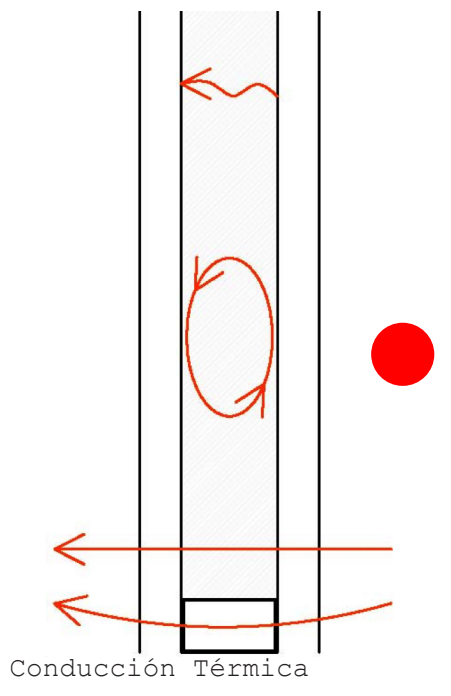

4. Conducción del Vidrio: uk.saint-gobain-glass.com 


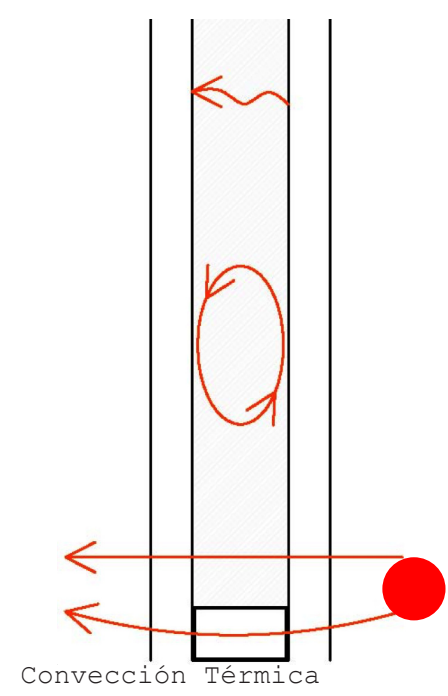

cuerpos, pero este proceso no requiere movimiento de las moléculas. La conductividad térmica es la propiedad de un material para transmitir calor aunque el tipo de material determinará en qué grado. Por ejemplo, la conductividad térmica en los metales es alta, razón por la que es tan importante la elección de las carpinterías en las fachadas. De la misma manera, los materiales de los que se componen los separadores situados en las cavidades de los vidrios serán determinantes a la hora de evaluar la conductividad térmica de la superficie. Por el contrario, la conductividad térmica es exigua en materiales como la fibra de vidrio, lo que lo convierte en un buen material aislante. Los gases se comportan de manera similar, aunque su conductividad es nula cuando se logra un vacío ideal. Dada la dificultad técnica de alcanzar un vacío completo, la cavidad suele estar rellena de aire o de algún gas inerte. La conductividad térmica del aire es superior a la de los gases inertes. Por este motivo, si el material relleno de la cavidad es argón, kriptón o xenón, la conductividad del vidrio puede reducirse y permitir que la respuesta a las transmisiones térmicas sea mejor. Este aspecto se desarrolla en el del Capítulo 5, numéricamente, el efecto que tiene el gas en las propiedades de transmisión térmica de un vidrio.

La convección por su parte, es la propagación de calor a través de líquidos 0 gases. ${ }^{5}$ La diferencia principal con la conducción es que en este caso la transferencia de energía está basada en el movimiento de moléculas. La convección transporta el calor entre zonas con diferentes temperaturas. El material (gas o el aire en el caso del vidrio) aumenta de volumen al calentarse disminuyendo su densidad. Las partículas del gas ascienden y desplazan el aire que se encuentra en la parte superior de la cámara provocando corrientes de movimiento ascendentes y descendentes. Los separadores incluidos en la cámara de aire determinarán la separación o distancia entre las unidades de vidrio, lo que definirá el ancho de la cámara. Es muy importante que el ancho de esta cámara esté controlado ya que de él dependerá en parte el comportamiento del vidrio. Si la cámara es demasiado ancha, las transferencias por convección serán más difíciles de evitar ya que se producirán movimientos de aire con mayor facilidad.

5. Convección del Vidrio: uk. saint-gobain-glass. com 
Por último, la radiación es la transmisión de energía térmica entre dos cuerpos a diferente temperatura. ${ }^{6} \mathrm{La}$ diferencia principal con la conducción y la convección es que las sustancias que intercambian calor no tienen porqué estar en contacto y pueden estar separadas por un vacío. Los valores que determinan la radiación solar que finalmente atraviesa una superficie de vidrio son la absorción, la reflexión y la transmisión. Los gases y los vidrios son capaces de transmitir grandes cantidades de radiación, cuyas propiedades vendrán determinadas por la longitud de onda con la que incidan. Éstos serán los parámetros que determinarán las ganancias de energía solar que atravesarán las superficies de vidrio. En el caso de la absorción, este fenómeno transforma la radiación en energía térmica, lo que hace que la temperatura de la superficie exterior del vidrio se vea considerablemente incrementada. La radiación en forma de longitudes de onda menor serán las responsables de la energía disipada en el espacio interior. En vidrios sin ningún tipo de tratamiento, la mayor parte de la energía transportada se produce por radiación. Sin embargo, la disposición de películas en las caras de los paneles de vidrio logran no sólo disminuir la radiación que atraviesa la superficie, sino controlar el tipo de onda que lo hace y eliminar prácticamente su efecto.

Además del vidrio, el otro componente principal por el que se define la envolvente para este trabajo son los mecanismos de control solar, recomendables en muchas ocasiones y necesarios en tantos otros. Los sistemas comprenderán una capa más en la envolvente y su localización dependerá de la función. A modo de resumen se repasan los conceptos básicos que servirán para los estudios consecutivos.

Primero, los sistemas de control solar externos que bloquean la radiación antes de que pueda entrar en contacto con la superficie de vidrio. Pese a tener en cuenta condicionantes atmosféricos como el viento, la nieve, la lluvia, - la alta intensidad de radiación solar en verano, en determinados climas estos sistemas requieren de un mantenimiento continuo $y$, en muchas ocasiones resultan dañados por los agentes externos.

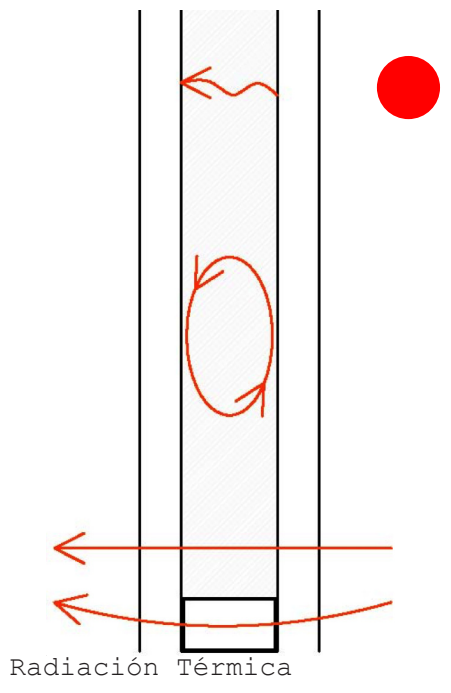

6. Radiación del Vidrio: uk. saint-gobain-glass. com 
Segundo, los situados en el interior están protegidos de los agentes externos. La eficacia es menor a la de los externos y, según el ángulo en que estén posicionados, pueden acabar actuando como un agente radiador, emitiendo energía al interior y condicionando el confort del espacio si no existe un medio de evacuación del aire caliente.

Tercero, los situados entre los paneles de vidrio han supuesto un gran avance ya que son eficientes a la vez que están protegidos de los agentes externos. Pueden ser fijos o móviles. Los primeros son texturas o impresos en la superficie del vidrio, que tienen el inconveniente de reducir la visibilidad al exterior en su afán por restringir la entrada de energía solar y controlar la luz admitida. Este tipo de solución es válida para espacios en los que la visión al exterior no sea una prioridad. Los móviles incluyen, por ejemplo, lamas situadas en la cavidad entre paneles que pueden controlarse manual o eléctricamente para dominar la entrada de la luz y de la energía solar. 


\subsubsection{La Piel Simple}

Las fachadas simples están normalmente compuestas por zonas transparentes y opacas distribuidas en el mismo plano. Tradicionalmente este método, ha sido el empleado a la hora de diseñar. En esta clase de fachadas una única superficie hace las funciones de ventilación, control solar y de admisión de energía solar térmica. Cada una de éstas estará posicionada en el lugar preciso para cumplir con su función. Normalmente, la zona inferior de la fachada se destinará a las zonas opacas, beneficiando así al clima interior y pudiendo, en todo caso, albergar los elementos de generación de energía si así se diseñan. Las superficies grandes de vidrio centrales deberán contar con alguno de los mecanismos de control solar que se han mencionado con anterioridad para no crear una sobreexposición del espacio. En este sentido, se debe tener en cuenta que, como las fachadas simples no tienen espacio para proteger los sistemas de control solar, será preciso utilizar los que no requieran de este mantenimiento o, en todo caso, emplear sistemas de control solar en las cavidades de los vidrios. Las funciones de control y direccionamiento de la luz se emplazarán en la parte superior para asegurar la entrada de luz en toda la profundidad del espacio.

La ventilación en esta clase de fachadas se producirá acorde con las necesidades del programa, ya sea en el espacio central o en los superiores. La principal desventaja de estos sistemas es que no están protegidos de agentes atmosféricos como el viento, lo que hace difícil la ventilación en el caso de las construcciones en altura. Otro de los inconvenientes es que en zonas especialmente ruidosas, una única piel no puede amortiguar el sonido, por lo que los espacios están más expuestos a problemas acústicos.

Las principales características y comportamiento de las pieles simples se podrían concretar en:

- Comportamiento en invierno o demanda de energía para calefacción: el rendimiento de la fachada dependerá del tipo de vidrio empleado, su conductividad térmica y la proporción de superficie acristalada frente a la opaca (suele ser elevada), así como de las carpinterías y soluciones

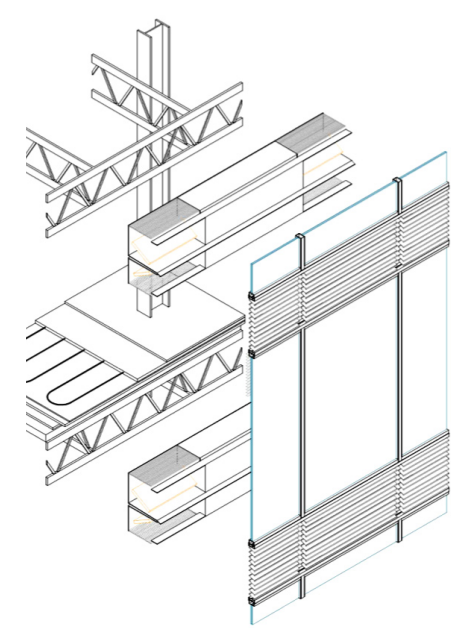

Esquema envolvente de piel simple 
para evitar los puentes térmicos.

- Comportamiento en verano: el rendimiento de la fachada dependerá del vidrio y los revestimientos empleados que reduzcan la radiación, la proporción de superficie acristalada frente a la opaca (suele ser elevada) y sobre todo de los sistemas de control solar empleados para reducir las ganancias en verano. La ventilación nocturna contribuirá al confort interior.

- Iluminación natural: las grandes superficies de acristalamiento ayudarán en la iluminación natural siempre y cuando se tengan en cuenta mecanismos que eviten el deslumbramiento. El tipo de vidrio empleado y su transmisión lumínica será otro factor a tener en cuenta para beneficiarse de esta clase de iluminación.

- Ventilación: la ventilación por infiltración en caso de construcciones en altura expuestas al viento, o la ventilación por las zonas superiores de iluminación para evacuar el aire caliente en verano, influirán en el clima interior. En zonas en las que se requiera una mayor cantidad de aire natural, se necesitarán proyectar huecos en las superficies centrales de los sistemas de muros cortina. 
CAPÍTULO 04
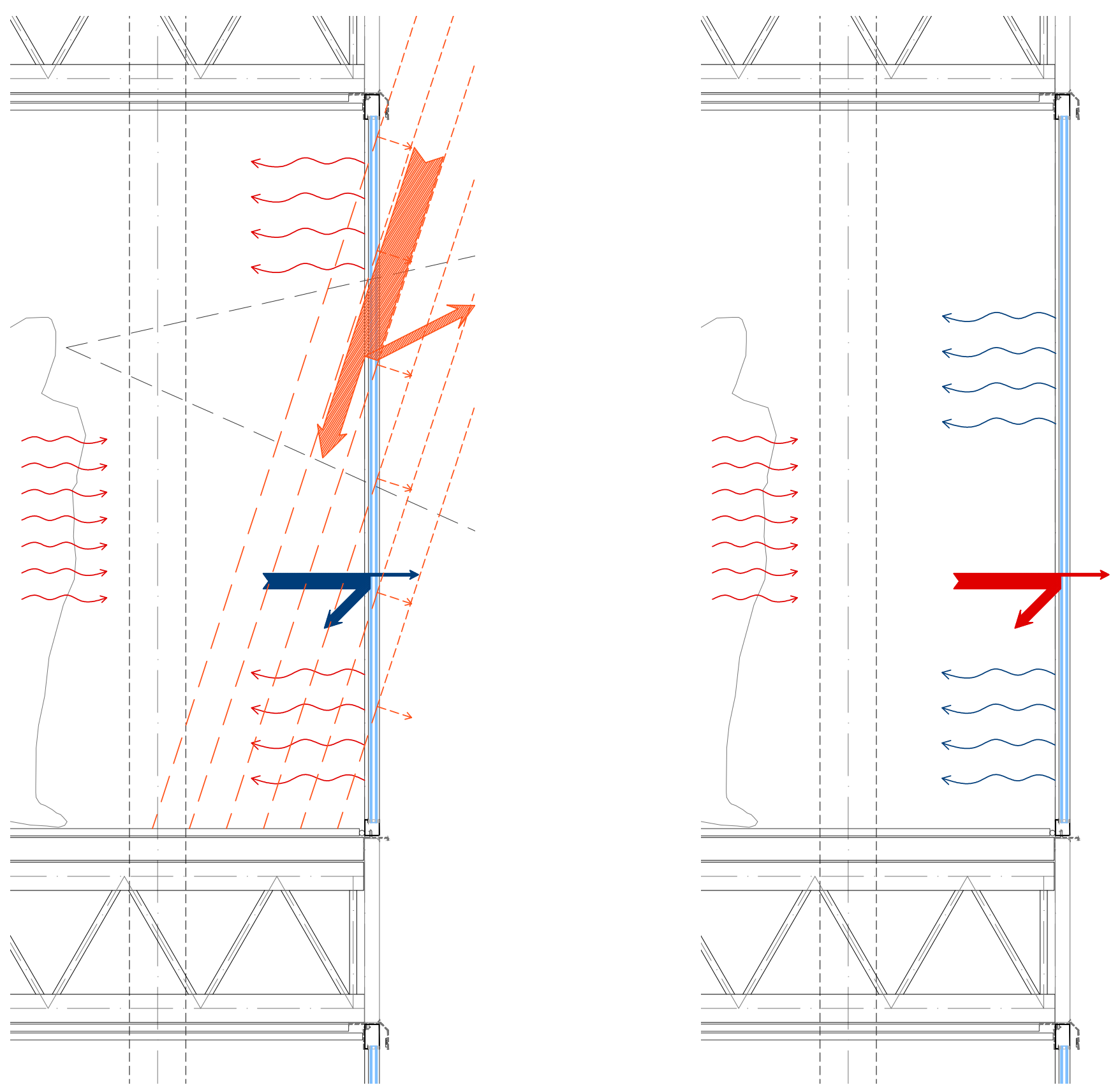


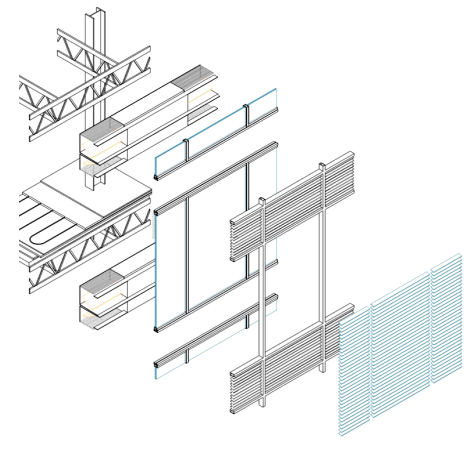

Esquema envolvente de doble piel de vidrio

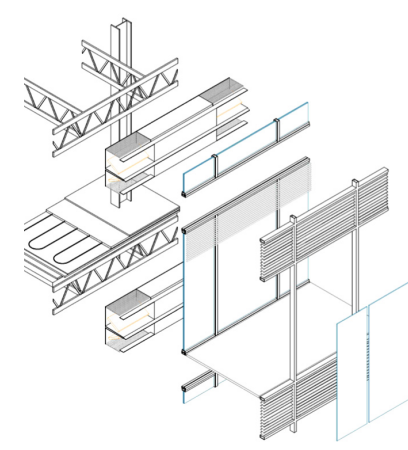

Esquema envolvente de doble piel de vidrio

\subsubsection{La Doble Piel de Vidrio}

En las fachadas compuestas por dos pieles de vidrio sus funciones se dividen en dos planos. Dependiendo de lo que se requiera, la fachada principal será la exterior o la interior. En este tipo de fachadas el espacio interior del edificio no estará recibiendo ventilación natural ni admitiendo iluminación o ganancias de energía solar de manera indiscriminada, debido al retranqueo del espacio como consecuencia del uso de las dos pieles. Por ejemplo, la entrada de energía solar térmica se verá reducida al tener que atravesar varias capas, y lo mismo ocurrirá con la ventilación natural directa. Los sistemas de protección solar pueden instalarse en el interior de la cavidad, evitando el peligro de que resulten dañados por los agentes externos. Si la piel externa es transparente, la visión al exterior no tiene porqué verse obstaculizada en estas fachadas. Las envolventes de doble piel de vidrio reducen la presión del viento en las superficies de fachada en contacto con el espacio interior permitiendo que las ventanas puedan abrirse libremente. Del mismo modo, si se diseñan aperturas en los extremos superiores e inferiores de la piel externa, la presión que podría generarse en el interior de la cavidad quedaría controlada.

El espacio entre las dos pieles será continuo o estará compartimentado según la función que vaya a desempeñar y las necesidades del espacio habitable interior. En la mayor parte de los casos, estas dobles pieles de vidrio han sido proyectadas para edificios de uso de oficinas. Sin embargo, cada vez son más los destinados a uso residencial que incorporan estas dobles pieles de vidrio para beneficio del espacio interior. En los edificios de uso residencial las cámaras entre la doble piel de vidrio suelen estar compartimentadas por unidad para aislar los diferentes usos. En estos casos la ventilación de la cámara suele hacerse en la altura correspondiente a los forjados horizontalmente, o en las esquinas de la cámara de forma vertical.

En el caso de que la cámara entre las dos pieles esté compartimentado, las características y el comportamiento de estas envolventes pueden resumirse en los siguientes: 
- Comportamiento en invierno o demanda de energía para calefacción: el rendimiento de la fachada en invierno dependerá de los recambios de aire establecidos y la capacidad aislante del sistema. A ello hay que añadir que el tipo de vidrio empleado en la piel principal también afectará el comportamiento, así como el aprovechamiento máximo de la energía solar térmica. En invierno el aire en la cámara puede calentarse durante el día y servirá de un espacio más de aislamiento del frío exterior.

- Comportamiento en verano: la posición de los sistemas de protección solar en la cavidad intermedia mejorará el rendimiento de la fachada en verano. La posibilidad de ventilar la fachada para evacuar el aire caliente y la opción de emplear aire fresco para la ventilación nocturna mejorarán el confort interior durante los meses de calor. La profundidad de la fachada ayudará a reducir las ganancias solares térmicas en verano.

- Iluminación natural: la iluminación de los espacios interiores se verá reducida con la profundidad de la fachada y con el paso a través de las diferentes capas. En estos casos lo habitual es emplear elementos de redireccionamiento de la luz para que ésta pueda entrar en la profundidad del espacio.

- Ventilación: la cámara ofrece la posibilidad de que, incluso durante el invierno, se pueda tener ventilación natural cuando sea necesario. El espacio interior ventilará a la cámara, lo que reduce el peligro del frío en invierno y del calor en verano.

En ocasiones, la piel exterior no será una superficie de vidrio continua sino que estará compuesta por elementos de protección solar que no cerrarán herméticamente la cavidad. Esto, aunque complica excesivamente el funcionamiento de la piel y su construcción, ofrece prestaciones que no ofrecen los otros sistemas, ya que se trata de llevar al campo de la piel exterior los mecanismos de control tanto de la cámara entre pieles como del espacio interior en sí. Estos sistemas suelen ser móviles y ajustables, con lo que permiten a los usuarios regular las opciones según los requerimientos climáticos a lo largo del año. Sin embargo, la situación más complicada la encontramos en verano debido a las necesidades de ventilación, y más aún cuando el edifi- 
cio se encuentra en una zona ruidosa. Las características de este tipo de doble piel controlable y ajustable son las siguientes:

- Comportamiento en invierno o demanda de energía para calefacción: el rendimiento de la fachada en invierno dependerá de la posibilidad de crear en la cámara un colchón térmico de aire caliente durante el día y de que la piel exterior no bloquee la entrada de energía solar térmica para calentar el espacio.

- Comportamiento en verano: el tipo de sistema de protección solar en la piel exterior determinará la entrada de energía solar en verano. Parte de ella quedará reducida a causa de la profundidad de situación del espacio interior. La posibilidad de ventilar la fachada para evacuar el aire caliente y la opción de emplear aire fresco para la ventilación nocturna mejorarán el confort interior durante los meses de calor.

- Iluminación natural: la iluminación de los espacios interiores se verá reducida con la profundidad de la fachada y con el paso a través de las diferentes capas. En estos casos lo habitual es emplear elementos de redireccionamiento de la luz para que ésta pueda entrar en la profundidad del espacio.

- Ventilación: como el espacio entre pieles está ventilado, habrá una renovación constante del aire que ayudará a que la superficie del vidrio no esté ni tan frío en invierno ni en verano tan caliente. Esto aumentará el confort interior. 
CAPÍTULO 04
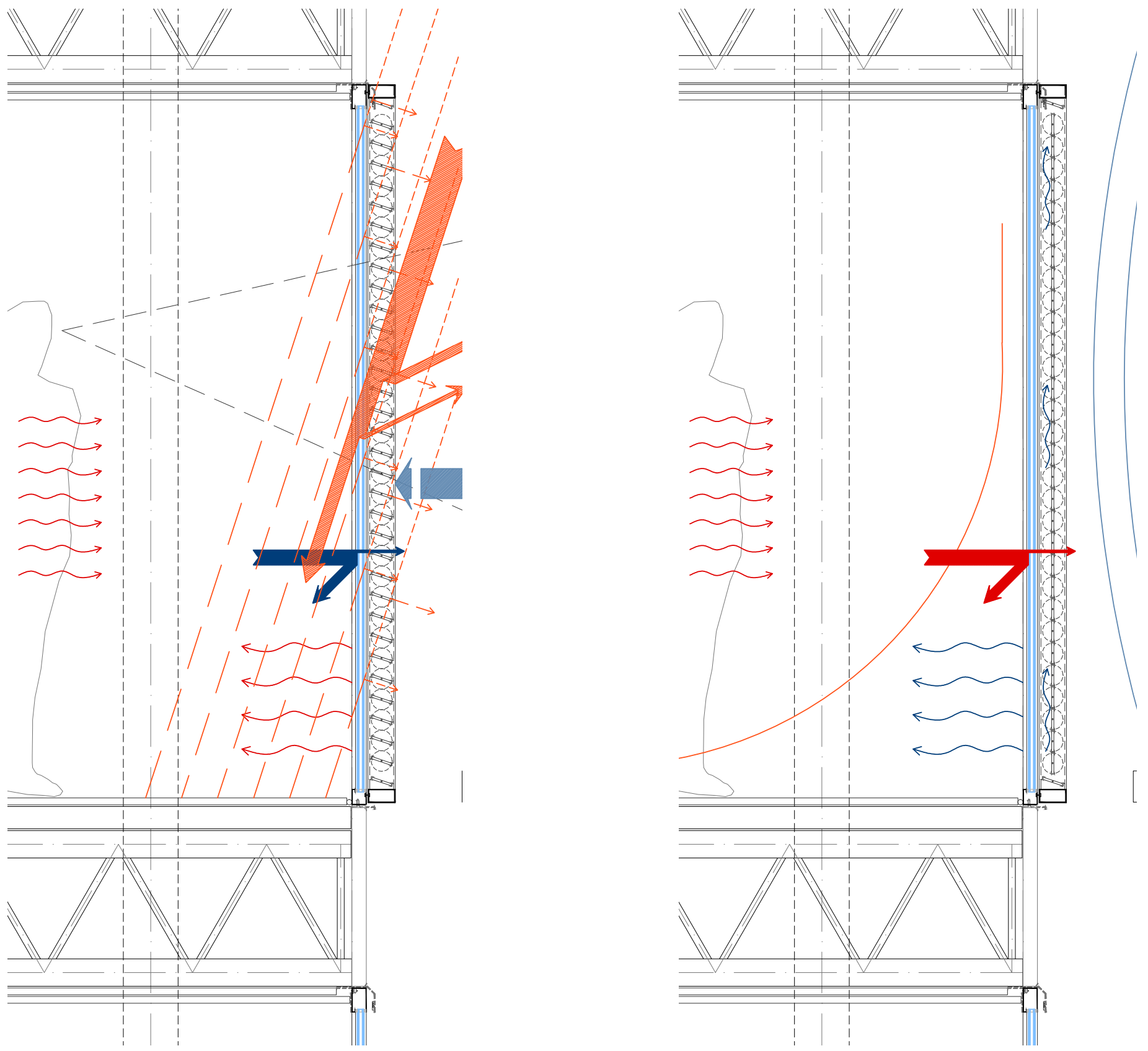

128 


\subsubsection{El Atrio}

El principal objetivo de la ventilación natural es que los usuarios puedan sacar provecho de las corrientes de viento que se originan en las superficies y que ayuden a equilibrar las temperaturas interiores para mejorar el confort del espacio, reduciendo así el uso del aire acondicionado. El diseño de edificios que apuestan por estrategias que incorporan mecanismos de ventilación natural se ha extendido en el sector, especialmente desde que se ha ido tomando conciencia del medio ambiente. Sin embargo, en la construcción en altura esto ocurre con menor frecuencia, ya que el proceso se complica proporcionalmente a la altura del edificio. Las complicaciones ocasionadas por los vientos y los espacios cada vez más reducidos que dificultan inducir una ventilación cruzada, hace que poder contar con ventilación natural se convierta en un reto.

La ventilación natural en los espacios dependerá principalmente de su conexión con el exterior. Si las estancias, en lo que al flujo de aire se refiere, están consideradas como compartimentos aislados, la falta de ventilación cruzada obliga a que todas las renovaciones de aire discurran por una misma superficie, sin que el resultado sea el deseado en la mayoría de los casos. En cambio, si en cada estancia se obtiene ventilación procedente de dos orientaciones opuestas, se puede lograr la ventilación cruzada y las renovaciones de aire resultarían más sencillas. Como se ha indicado anteriormente, esto no siempre es posible debido a la tendencia a diseñar espacios reducidos. La sección de los edificios en altura que hoy en día se llevan a cabo no permite que una misma estancia pueda gozar de ventilación cruzada en el edificio con tanta facilidad.

Para ello, la arquitectura en altura parece haber recobrado una idea que tradicionalmente se ha venido usando: el atrio o espacio central. Este modelo permite que los espacios de un edificio estén conectados con una apertura vertical por la que las corrientes de aire recorren el edificio desde las entradas, por la envolvente principal, hasta el espacio central. Esto asegura una renovación constante de aire, ya que el atrio se emplea para generar entrada de aire 
fresco en las estancias y salida del aire caliente. Uno de los problemas de esta clase de ventilación en los edificios en altura son las altas presiones diferenciales que pueden generarse por el mecanismo de succión del aire. Sin embargo, este inconveniente se puede solventar a través de segmentaciones o divisiones del edificio, aisladas unas de otras, que permitirán obtener las magnitudes y direcciones de aire necesarias. Estos espacios abiertos horizontales pueden estar destinados a terrazas comunitarias del proyecto y permiten que cada segmento del edificio sea estudiado de manera aislada.

Un ejemplo es el Commerzbank (Foster \& Partners, Frankfurt 1997) que ha servido de modelo de estudio para muchos de los edificios en altura posteriores. En este caso, el edificio se divide en diversas secciones con espacios abiertos entre ellos que permiten la circulación controlada del aire en movimiento. Otra de la ventaja obtenida mediante este esquema de edificio es que se asegura la entrada de luz natural en todas las estancias. El Commerzbank supuso un punto de inflexión en la arquitectura de fachadas de vidrio, ya que en su proceso de diseño se apostó por una optimización de los recursos naturales para lograr el confort interior y ofrecer una solución responsable y comprometida con el medio ambiente. 


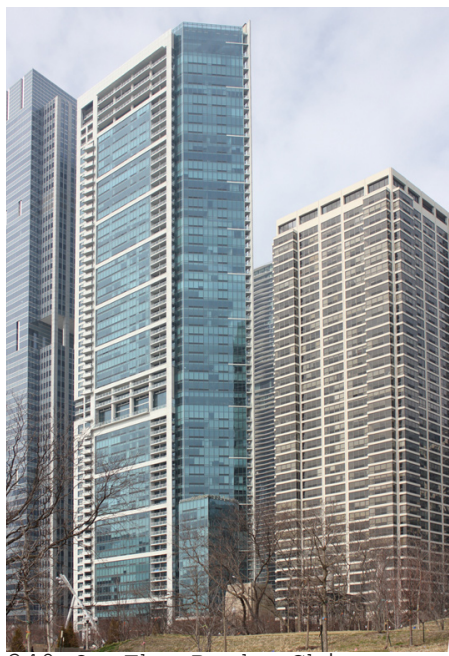

340 On The Park, Chicago, 2007, SCB.

Fotografía año 2015.

\subsection{LA ENVOLVENTE COMO SUPERFICIE DE EVOLUCIÓN. SCB, KRUECK \& SEXTON, CHICAGO.}

\subsubsection{On the Park (SCB, Chicago 2007)}

340 On the Park es un edificio residencial situado en la zona este de Chicago cuya construcción se finalizó en el 2007. Diseñado por la firma Solomon Cordwell Buenz, gozaba del prestigio de ser el edificio de uso residencial más alto de la ciudad con un total de 62 plantas y 205 metros de altura. Con la construcción de One Museum Park (Pappageorge Haymes, Ltd, Chicago 2010) de 224 metros de altura, actualmente ha pasado a ocupar el segundo puesto en el "ranking" de los edificios residenciales más altos de Chicago. Además de sobresalir en el ámbito de la arquitectura por su altura, fue el primer edificio residencial en la zona central del país en recibir la medalla plateada del sistema de certificación norteamericana LEED, lo que puso al edificio y a las estrategias que los arquitectos habían diseñado para su desarrollo en boca de todos los profesionales del 
país. Las propuestas de los arquitectos perseguían reducir sustancialmente el uso de energía y, así fue: la torre residencial se diseñó y se construyó usando un 10\% menos de energía de lo que habría necesitado un edificio convencional de las mismas proporciones.

Lo más destacable de este proyecto es la apuesta por una arquitectura comprometida con el medio ambiente y responsable ante los futuros usuarios, sin dejar de lado la utilidad de los conceptos. Para ello se lleva a cabo un planeamiento exhaustivo de cuáles son las funciones que cada parte del edificio debe desempeñar y cómo pueden éstas colaborar en el conjunto del proyecto. El edificio se compone de tres partes principales: una base de aparcamiento subterráneo, una planta baja destinada al uso de servicios terciarios o comercios para los residentes, y el desarrollo de la torre residencial en sí. El éxito de este conjunto es, entre otros, fruto de un trabajo conjunto de los diferentes equipos involucrados en el proceso, por lo que tanto los arquitectos e ingenieros, como el contratista, el cliente o el promotor fueron responsables de ir guiando el proyecto en función de las necesidades que cada equipo proponía. El resultado fue un edificio capaz de dar respuesta a los requerimientos energéticos y ofrecer un clima interior de confort dentro del marco de la viabilidad económica. A pesar de las ambiciosas estrategias y del empleo de un sistema de cerramiento complejo, los apartamentos se lograron vender a unos precios competitivos.

El éxito de este conjunto se debe en parte a la posición activa que se ha conferido a la envolvente del edificio, entendiéndose como tal no sólo la fachada, sino toda la superficie que envuelve el edificio en contacto del espacio interior con el exterior. La envolvente de 340 On the Park es un sistema complejo en el que se han combinado superficies de vidrio verticales, espacios de transición controlados, dobles pieles de vidrio y terrazas e invernaderos. Tanto la forma finalmente adoptada, como las decisiones en cuanto a la envolvente, tratan de dar respuesta al entorno de la ciudad. Por ejemplo, al contrario de lo que ocurría en otras construcciones aisladas en altura, la planta del edificio varía para un mejor aprovechamiento de los recursos 
naturales de su localización; cada fachada se adecua a la situación, la orientación y las vistas.

De esta manera, la fachada norte se curva ligeramente hacia el este para reducir la superficie expuesta a la orientación más fría y favorecer las vistas del lago que a su vez refleja grandes cantidades de luz a los espacios. En el lado sur ocurre algo similar; se inclina la fachada para favorecer una orientación sur-este que permita abrir vistas al este y disminuir la entrada de radiación solar en verano. Una de las premisas era maximizar la entrada controlada de luz en los apartamentos, por lo que las orientaciones compuestas ofrecían mayores ventajas que las exactas. Otra estrategia consiste en incluir en el diseño retranqueos de la fachada principal en forma de balcones o terrazas, calculando la profundidad necesaria para que se admita la totalidad de la energía solar térmica en invierno, pero que ayuden, sin embargo, a controlar su entrada durante los meses de calor. Estos espacios de transición permiten a su vez que se puedan abrir las ventanas y puertas en su totalidad sin peligro de que los fuertes vientos que afectan a esta ciudad incidan en el confort interior. Además de estos espacios, los arquitectos proyectaron una cubierta ajardinada sobre la base del aparcamiento que, junto con un sistema de almacenamiento, recoge el agua de la lluvia para reciclar su uso.

La cubierta de la última planta está revestida de un material de color claro y de alta reflexión que evita acumulaciones de energía en verano y minimiza las cargas de aire acondicionado. A esto hay que añadir que la envolvente hace un quiebro en la planta 25 para crear un espacio de iluminación o invernadero con vistas al parque en beneficio de los residentes. Este espacio se abre con un sistema de puertas de vidrio plegables de más de cuatro metros de altura que permiten la entrada de aire natural en el edificio. El vidrio de estas superficies está retranqueado respecto al plano de la fachada principal para admitir el sol en invierno pero no así en verano. Para alinear este espacio con el resto del volumen del edificio se proyectó una terraza continua con acceso al exterior. 
Capitalizando las vistas sobre Millenium Park, el Lago Michigan y la ciudad, los arquitectos se imaginaron una torre de vidrio desde la que poder tener acceso a todos estos escenarios. Por ello, el vidrio es el elemento principal que define el carácter del edificio, combinando superficies transparentes de suelo a techo con una estructura metálica que crea una retícula sobre la que van insertándose los diferentes elementos. Las decisiones sobre qué vidrio emplear se adoptaron en función de cuáles serían las necesidades de cada espacio. De esta manera, el vidrio empleado en el vestíbulo del edificio es un vidrio doble con cámara de aire que permite una transparencia total y conecta el espacio interior de acceso con el entorno exterior admitiendo una gran cantidad de luz.

En el resto del edificio, se emplea un vidrio de doble hoja con un revestimiento de baja emisividad, en el que el panel exterior está tintado para reflejar la radiación directa en verano. La cámara entre los dos paneles de vidrio está rellena por un gas inerte, lo que ayuda a reducir las pérdidas por conducción durante el invierno. Los controles solares, ya sean elementos aislados o los revestimientos incluidos en el vidrio, ayudan a disminuir la radiación directa en verano sin impedir la entrada de luz natural. Como la proporción de vidrio respecto a elementos opacos es muy superior, en invierno las estancias siguen recibiendo grandes cantidades de sol. Las zonas opacas y frentes de forjado son paneles de aluminio con material aislante que mejora la resistencia de la superficie a las pérdidas energéticas. Las carpinterías empleadas para este muro cortina son de aluminio y presentan rotura de puente térmico para reducir la conductividad térmica. Otra de las grandes incorporaciones es que los sistemas mecánicos integran la envolvente con el resto de componentes del edificio, haciendo que ésta pueda jugar un papel activo en el confort interior.

La envolvente de 340 On the Park se proyectó para que cumpliese las máximas funciones posibles y estuviese conectada con otros sistemas del edificio. Más allá de cuestiones estéticas el valor de este edificio es incuestionable en la medida en que cada decisión se ha adoptado conjugando los aspectos térmicos del edificio con los requerimientos de 
aclimatación interior de los usuarios. El éxito de un edificio de estas características reside en el hecho de que, desde los estados iniciales del proyecto, ha habido una apuesta por diversos campos y por emplear la técnica como instrumento para lograr el fin deseado, expresando una arquitectura con la que los arquitectos parecían estar plenamente convencidos. 


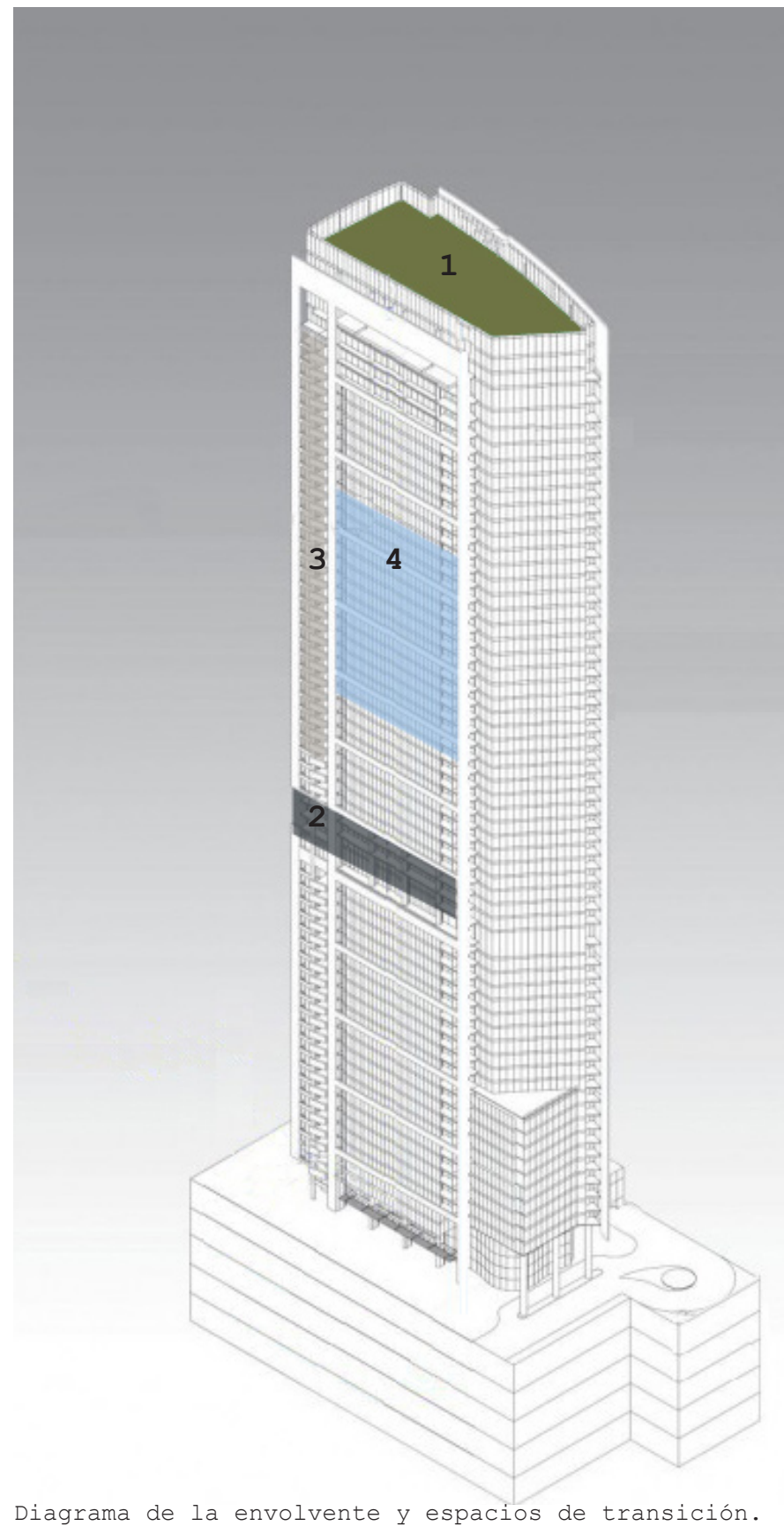

La Envolvente:

1 Cubierta jardín

2 Terraza invernadero

3 Balcones

4 Muro cortina

El Muro Cortina:

- Sistemas de ventilación natural controlada.

- Sistemas mecánicos integrados con la envolvente.

- Perfiles de aluminio con rotura de puente térmico.

- Vidrios de alto rendimiento energético. 


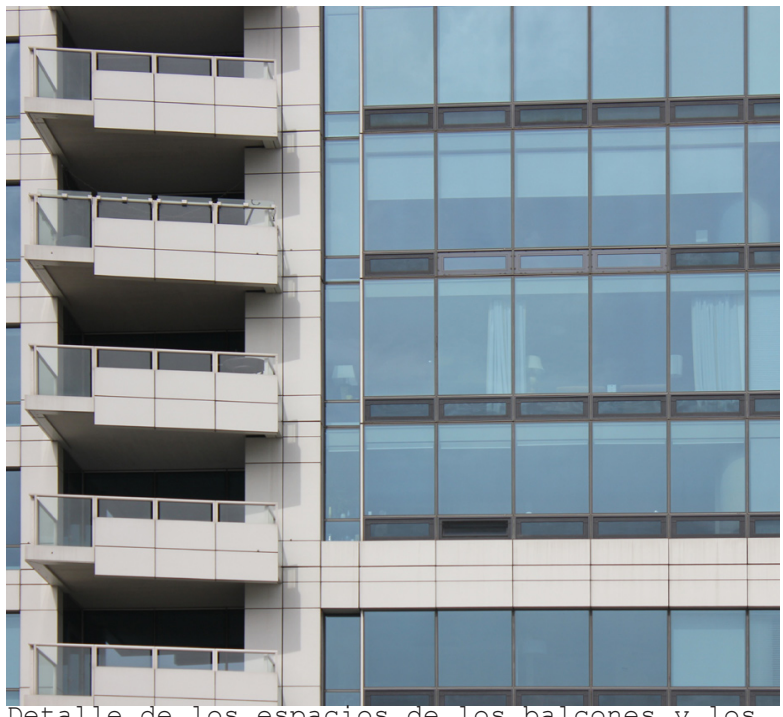
Detalle de los espacios de los balcones y los paneles de vidrio operables en la fachada Sur. Fotografía año 2015.

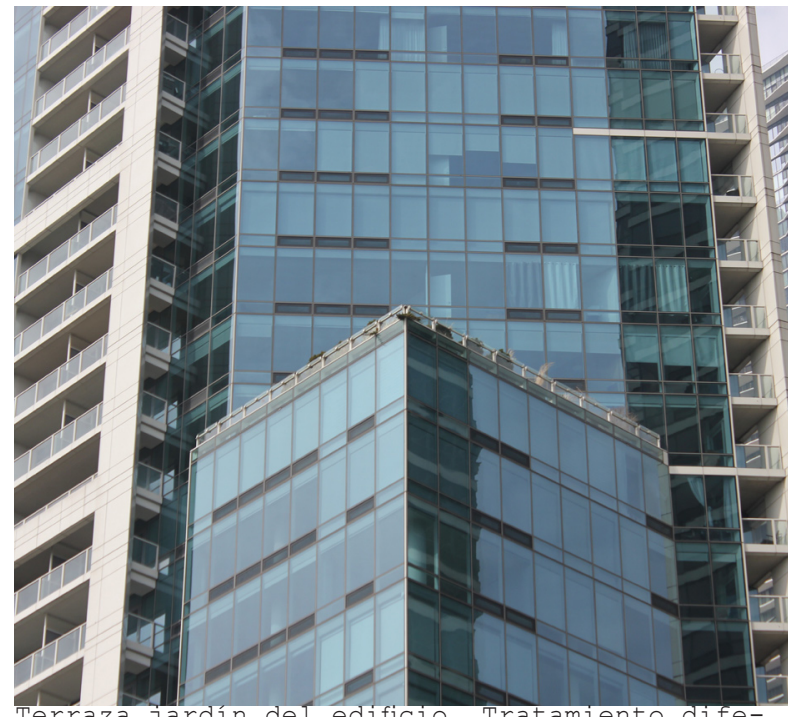

Terraza jardín del edificio. Tratamiento diferente según la orientación.

Fotografía año 2015.

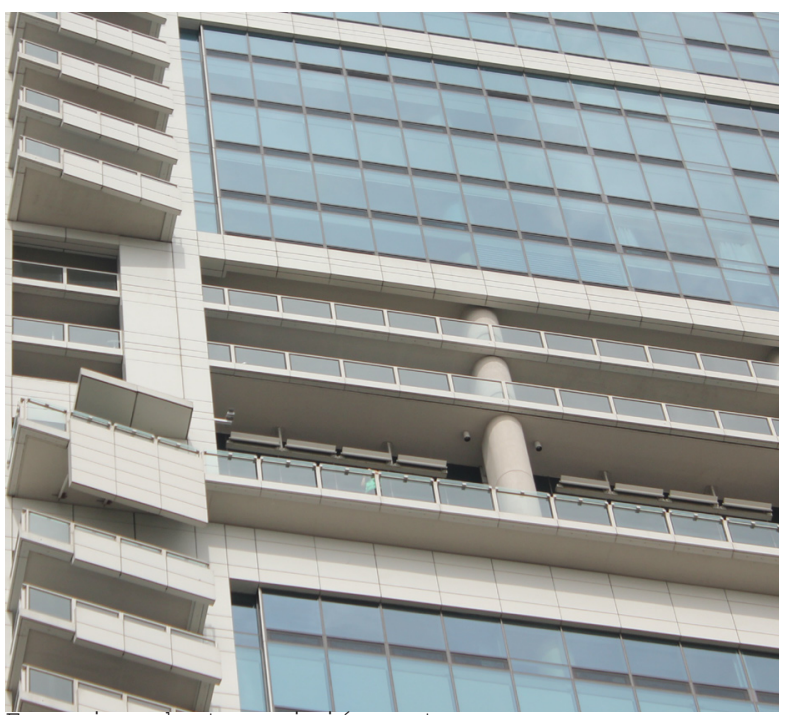

Espacios de transición y terrazas comunes.

Fotografía año 2015

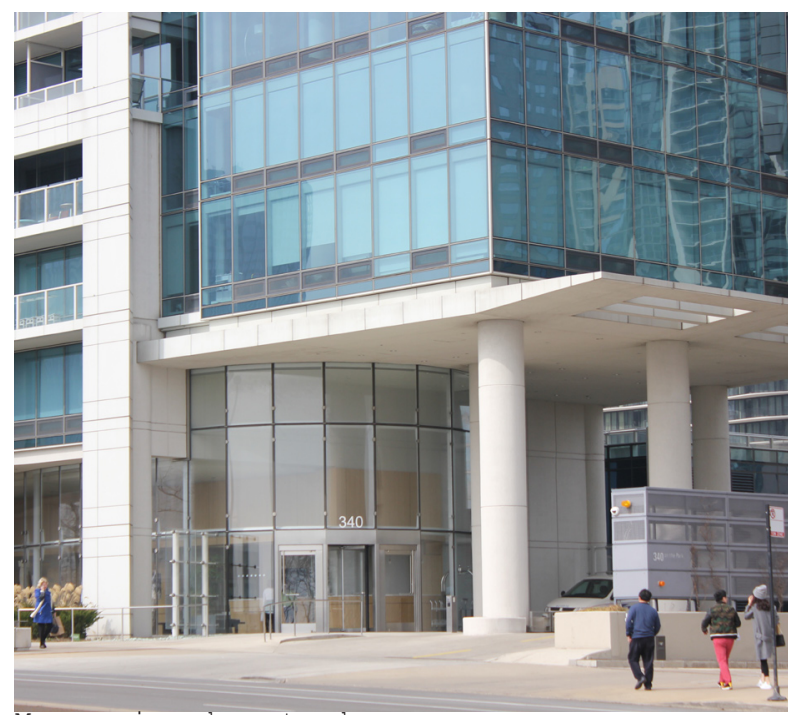

Marquesina de entrada.

Fotografía año 2015. 


\subsubsection{Spertus Building (Krueck \& Sexton Architects, Chicago 2007)}

El College of Jewish Studies, fundado en Chicago en 1924, fue el predecesor del spertus Building. En él se impartía historia, religión y hebreo. Si en sus orígenes constituyó un lugar de encuentro para las primeras generaciones de inmigrantes judíos, hoy se $h$ convertido en un centro de referencia en el Medio Oeste estadounidense; la organización y el número de visitantes fue incrementándose con el tiempo. Como respuesta a las demandas de la comunidad, se fueron añadiendo programas y actividades, e incluso logró transformarse en un centro acreditado por el sistema de universidades estadounidenses gracias a sus programas de postgrado sobre la cultura judía. En 1993 se convirtió oficialmente en el spertus Institute of Jewish Studies, cuyo nombre reflejaba su identidad multidisciplinar y las diversas formas de aproximar al ser humano a la cultura judía. Tras ocupar diversos edificios, entre ellos en el one IBM Plaza de Mies van der Rohe, la organización convino en la necesidad de un nuevo edificio, una nueva imagen acorde a la situación actual.

En el año 2007, tras años de planeamiento, discusiones y de organizar eventos para recaudar dinero, el spertus Building abrió sus puertas en el número 610 South Michigan Avenue. Diseñado por la firma de arquitectura asentada en Chicago, Krueck \& Sexton Architects, este edificio reclama la innovación y el compromiso con el medio ambiente, especialmente en lo referente a la concepción de la envolvente de vidrio, así como la relación con la comunidad. El edificio - que ha sido galardonado con diversos premios - consta, entre otros, de espacios para la comunidad, salas de eventos culturales y biblioteca. Está compuesto por espacios interiores interconectados que comparten una envolvente en movimiento continua de diez plantas de altura.

Las distintas plantas vuelcan sobre el espacio de entrada central, resaltando la idea de comunicación e interrelación entre las distintas actividades a modo de atrio. Al mismo tiempo, los espacios en cada planta están limitados por superficies de vidrio transparentes que permiten que 
se establezca contacto visual no sólo con el exterior del edificio, sino también entre espacios interiores. Así, el vidrio se convierte en el elemento principal del proyecto, y los arquitectos se benefician de ello al emplear distintos tipos de vidrio que permiten la iluminación natural directa e indirecta de las estancias reduciendo las necesidades de los sistemas mecánicos. El espacio interior adquiere dinamismo - reflejo de la variedad de programas que alberga, y con voluntad de innovación espacial y tecnológica, en la que además el confort interior se asegura mediante la introducción controlada de aire por infiltración.

Al contrario de lo que ocurre en otros edificos, este dinamismo interior se refleja en la concepción de la envolvente del edificio. La fachada de vidrio es el reflejo técnico, subjetivo y formal de la esencia del proyecto. Los arquitectos han logrado que las ideas que la comunidad judía deseaba promover en el edificio se vean plasmadas en la imagen que proyecta. Lo consiguen mediante una envolvente estudiada para que, al mismo tiempo que se cumplen los requisitos del programa, esté comprometida con su localización. Por ejemplo, la geometría de la fachada es una superficie que varía constantemente en tres dimensiones, al igual que el espacio interior. El resultado es una composición de piezas individuales en las que, entre las 726 piezas de vidrio que la componen, hay 556 formas distintas. Lo que, a simple vista, pueden parecer números sin importancia, revela en realidad la complejidad del sistema de cerramiento, el cual se ha podido llevar a cabo gracias al trabajo conjunto de los arquitectos e ingenieros del equipo.

Un estudio exhaustivo de las diferentes posibilidades para la fachada concluyó en el uso de juntas de silicona estructural de una pulgada $(2.54 \mathrm{~cm})$ entre los paneles de vidrio para evitar la entrada del viento y la humedad. Esto, además de conferir a la envolvente un comportamiento térmico excelente debido a la silicona estructural y ausencia de puentes térmicos, permite a los arquitectos potenciar la idea de ligereza y movimiento de la superficie de vidrio en toda la altura. Como soporte del vidrio, se proyectó un sistema de perfiles de aluminio en el interior del edificio que no entran en contacto con el ambiente exte- 
rior. La altura del sistema de envolvente es de 50 metros, y las distintas piezas tienen un tamaño medio de 1.3 por 2.3 metros con formas geométricas diferentes. La intención de crear una envolvente continua, además de relacionar la fachada con la interconexión del espacio interior, ofrece la posibilidad de que los usuarios establezcan una relación visual con el skyline de Chicago, Grant Park, Millenium Park y el Lago Michigan. Mediante el empleo de un vidrio transparente, la envolvente anuncia su accesibilidad y naturaleza pública del edificio, animando a los viandantes a entrar y disfrutar de las opciones culturales de su interior. El vidrio empleado es un vidrio doble de 1.375 pulgadas de grosor. La superficie exterior es un panel de vidrio transparente con un revestimiento Low-E que ayuda a reducir la radiación al interior del espacio y un revestimiento tipo "frit" que actúa de control solar cuando se necesita, puesto que es capaz de variar el patrón con la intensidad de la energía solar. El panel interior de vidrio es un vidrio laminado. Para poder asegurar un rendimiento óptimo y a merced de los usuarios, el proyecto incluye un sistema de control solar interior que ayuda a evitar deslumbramientos y exceso de energía térmica en los meses de mayor calor. De esta manera, los arquitectos apostaron por un vidrio capaz de cumplir los deseos subjetivos y funcionales del proyecto, atendiendo a los requisitos para un confort interior.

Además de una envolvente de vidrio extremadamente cuidada y en respuesta a las necesidades reales del medio ambiente, el estudio de Krueck \& Sexton tuvo en cuenta otros elementos de la envolvente, y no sólo la fachada, para el confort interior. En la cubierta se diseñó una terrazajardín de aproximadamente 6700sf en el que la vegetación plantada es autóctona. La cubierta cuenta con un sistema de reciclaje de agua de la lluvia, absorbe aire exterior y ayuda a mantener el edificio de vidrio aclimatado disminuyendo el efecto del calentamiento urbano.

Sin embargo, los arquitectos expresaron su deseo no sólo de asegurar un edificio que respondiese a las necesidades estéticas, técnicas y medioambientales, sino que fuera capaz de conectar con el barrio en el que se encuentra. Para ello, trataron de establecer relaciones entre el vi- 
drio dinámico y las fachadas de mampostería estáticas. Como otros muchos edificios en el Loop - muchos de los cuales se han ido construyendo en periodos de innovación arquitectónica tras el incendio de Chicago - el spertus Building toma conciencia de las posibilidades actuales. Los arquitectos proyectaron un diseño que incluyese el uso de nuevas tecnologías y materiales, al mismo tiempo que mantuviera un respeto por el lugar donde se asienta. Por ejemplo, la malla de piedra, ladrillo y terracota de la que se componen los edificios adyacentes, ejerce una presión simbólica sobre la piel de vidrio del spertus Building, cuya fachada se pliega hacia el exterior de una manera dinámica simbolizando el movimiento y la libertad del vidrio. Esto añade un punto de simbolismo al edificio, ya que el color del vidrio cambia según el ángulo de incidencia del sol, invitando al peatón a entrar en lo que los usuarios han denominado en ocasiones como "una ventana a la cultura judía". Al mismo tiempo, el tamaño medio de las piezas de vidrio de las que se compone la fachada del centro judío tiene unas dimensiones similares a las del resto de los edificios de Michigan Avenue. De la misma manera que los edificios adyacentes del siglo XIX y XX, la envolvente dinámica y cristalina del spertus Building intenta introducir la luz en toda la profundidad del edificio. Es más, el énfasis en el aprovechamiento de la luz natural está también relacionado con la frase bíblica "yehi", que en hebreo significa "hágase la luz". El edificio ha adoptado la imagen de una llama como emblema siguiendo esta misma idea de luz física y de iluminación como aprendizaje, algo a lo que la cultura judía ha dado siempre mucha importancia.

El resultado es un edificio capaz de transmitir sensaciones empleando la técnica, al mismo tiempo que asegura un clima interior confortable y controlable. 


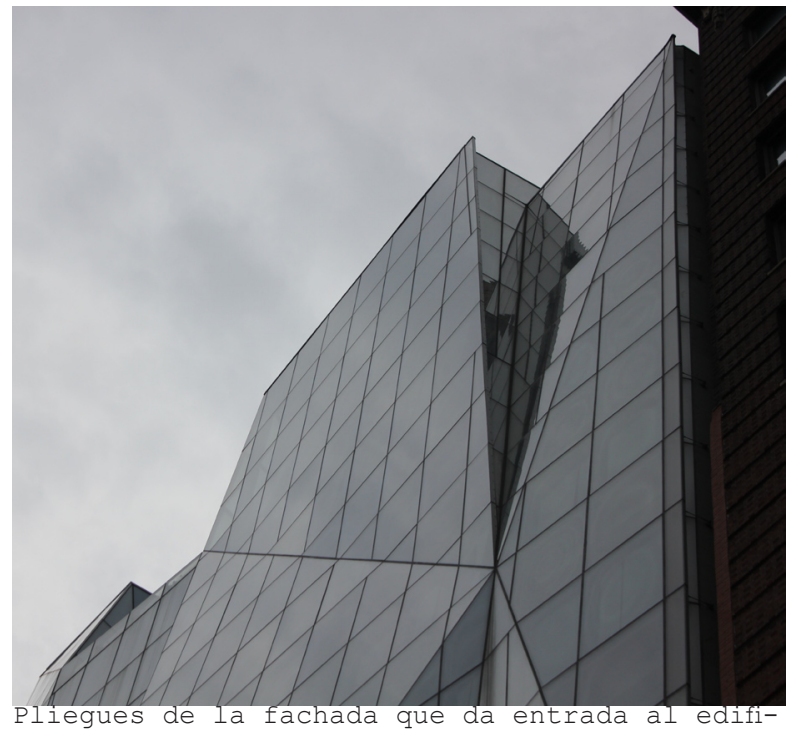
cio por Michigan Avenue.

Fotografía año 2015.

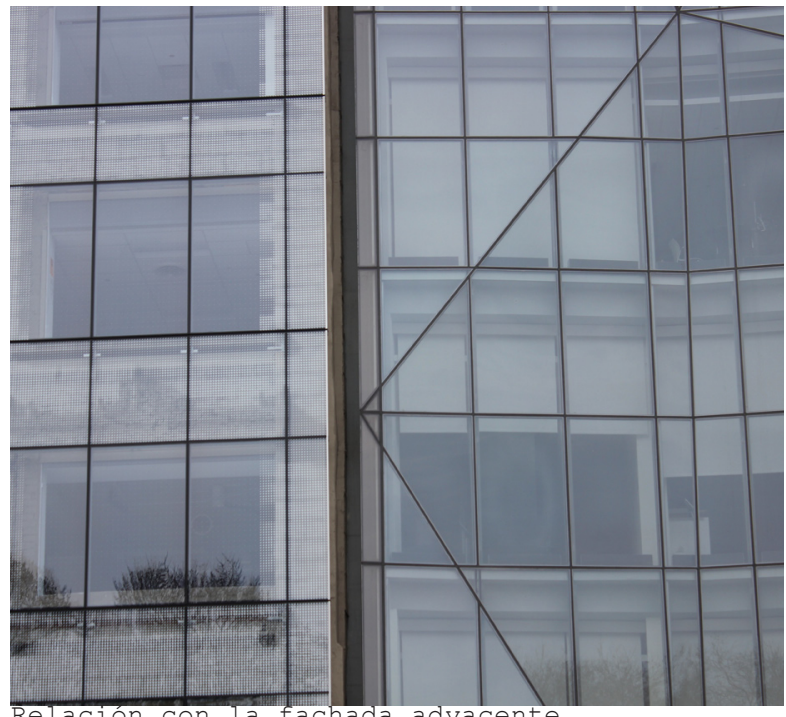

Relacion con la fachada adyacente. Fotografía año 2015.

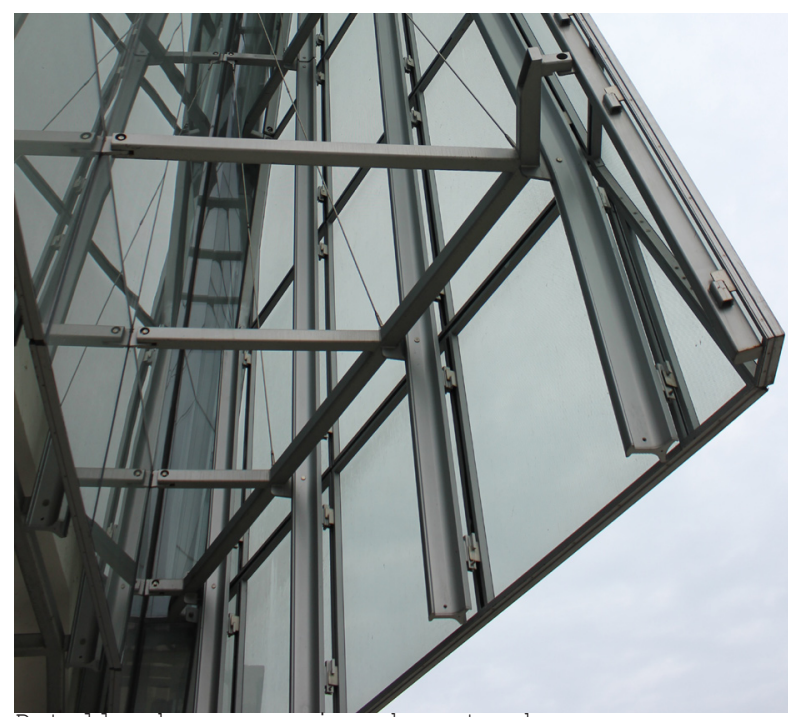

Detalle de marquesina de entrada.

Fotografía año 2015.

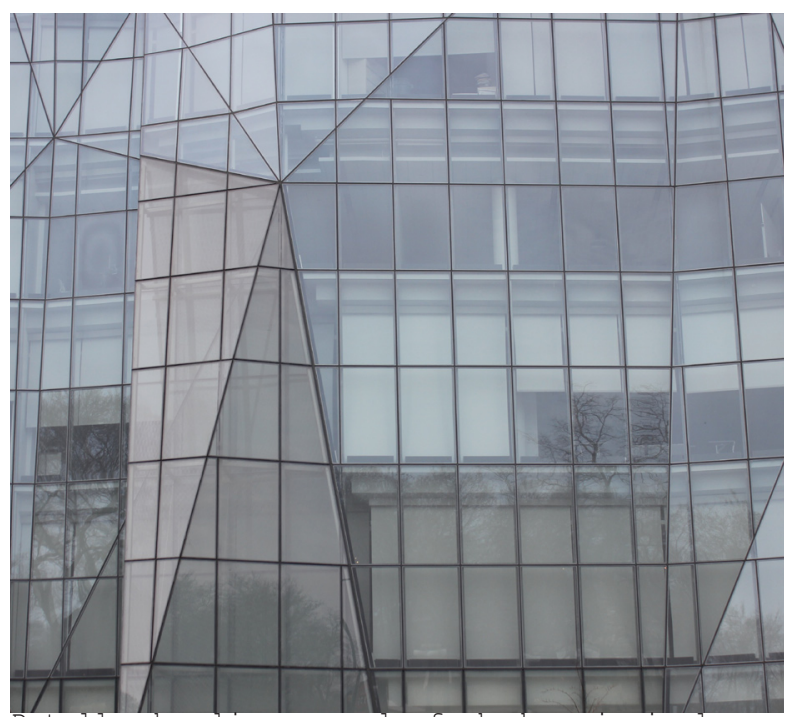

Detalle de pliegue en la fachada principal. Fotografía año 2015. 


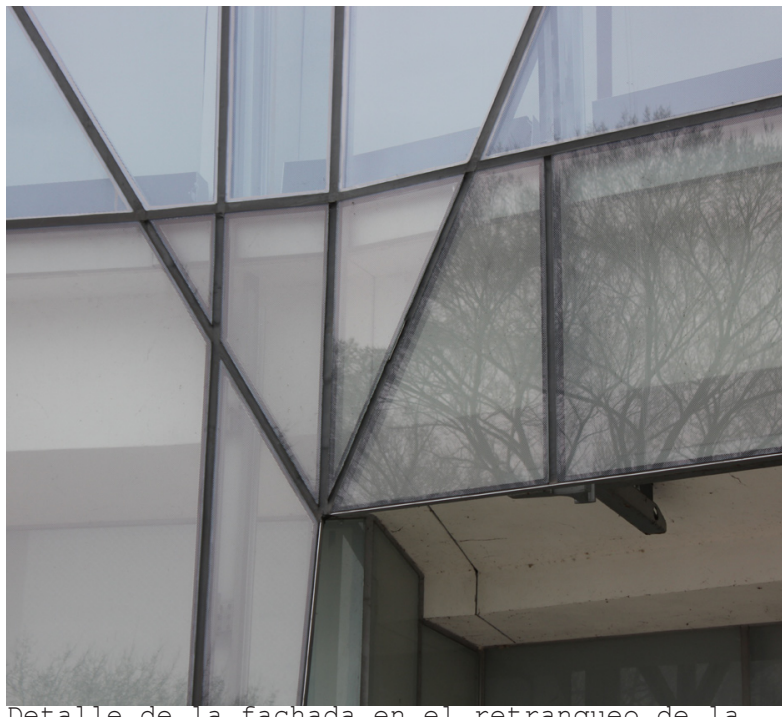

Detalle de la fachada en el retranqueo de la entrada y confluencia de paneles de diferente tamaño y ángulo.

Fotografía año 2015.

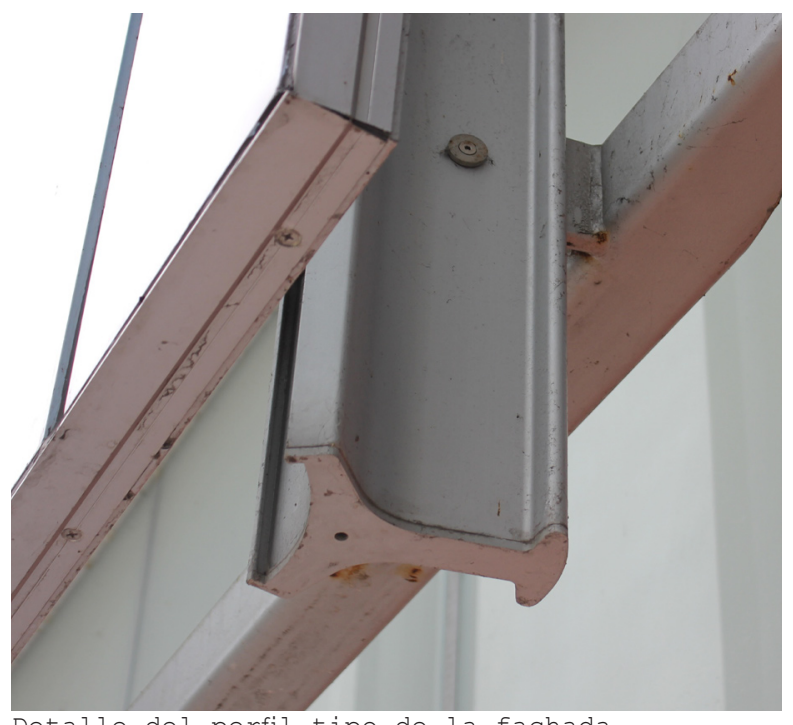

Detalle del perfil tipo de la fachada.

Fotografía año 2014.

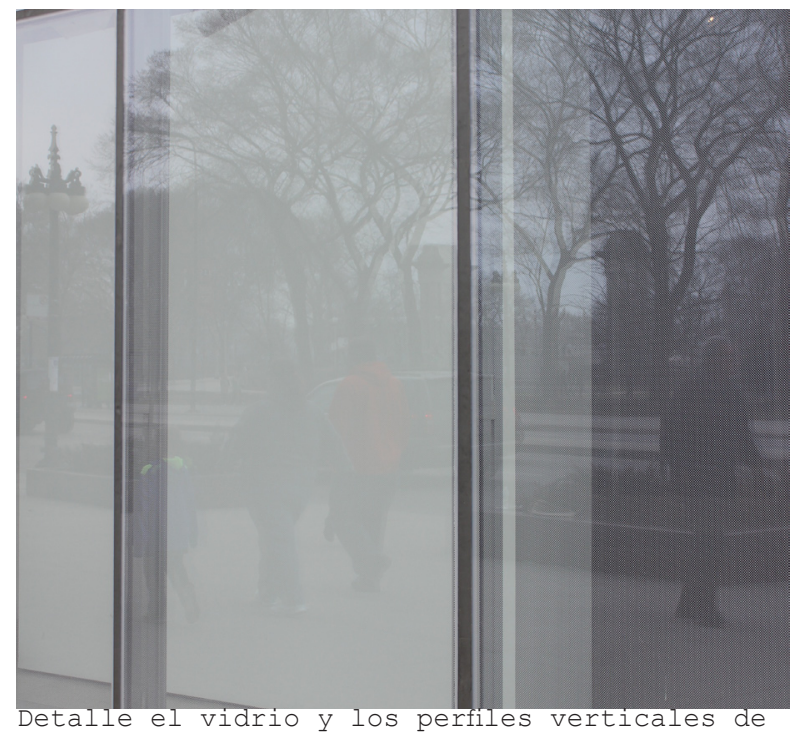

la fachada.

Fotografía año 2015.

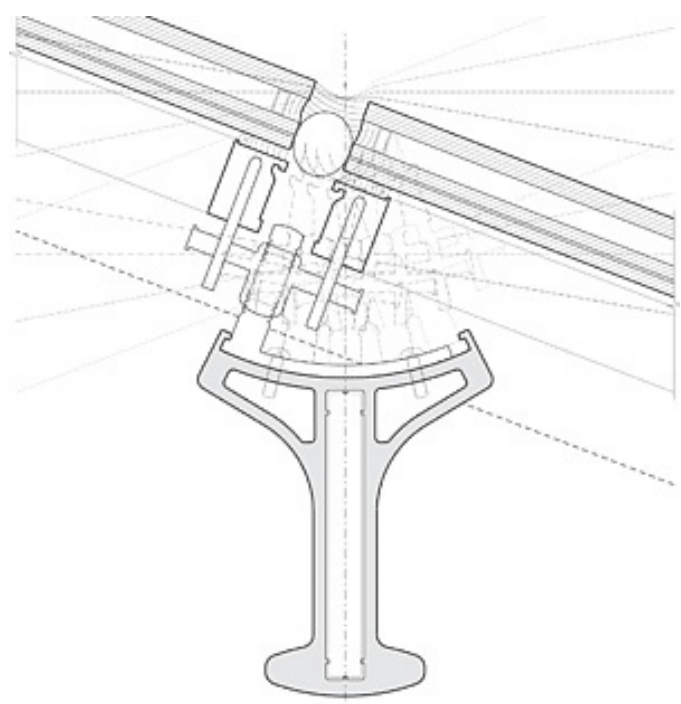

Detalle del perfil tipo de la fachada del sistema VS1. 

7. Norbert Lechner, Heating, Cooling, Lighting. Sustainable Design Methods for Architects (New Jersey: John Wiley \& Sons, 2009), pág.

\subsection{COMPORTAMIENTO DE LA ENVOLVENTE.}

Keeping warm and staying cool... minimize heat loss in the winter and heat gain in the summer. ${ }^{7}$

Las funciones de las envolventes de los edificios son múltiples y en ocasiones pueden resultar complejas de entender. Sin embargo, de una manera muy simple podemos afirmar que el principal objetivo del cerramiento es evitar las pérdidas de calor en invierno y reducir las ganancias en verano. El comportamiento que deben desempeñar las envolventes en una estación u otra no es el mismo. Para el desarrollo de este proyecto ha resultado imprescindible entender y, posteriormente analizar, el comportamiento de las mismas. Por ello, y por obvio que parezca, esta sección repasa aquéllos puntos que se consideran importantes para el análisis posterior. Éstas se estudiarán en las distintas estaciones, y ayudarán a entender el comportamiento de la envolvente. 


\subsubsection{La Envolvente en Invierno}

Los requerimientos energéticos para calentar un edificio han cambiado radicalmente durante los últimos años debido, en parte, al empleo de nuevos materiales y a las mejoras en las propiedades aislantes. El uso de vidrios con una o más cámaras de aire rellenas de gases como el argón, el kriptón o el xenón, han reducido las pérdidas energéticas. Sin embargo, a pesar de ello, en invierno hay que evitar las pérdidas energéticas causadas por la transmisión de la superficie del vidrio y por la ventilación. De lo contrario, las ganancias de energía solar que se obtienen mediante el uso del vidrio pueden verse mitigadas.

\section{Minimizar las pérdidas energéticas}

Las pérdidas energéticas por ventilación son uno de los elementos principales que deben ser controlados en las superficies de vidrio en invierno. Mediante la limitación de recambios de aire a los estrictamente necesarios según los estándares higiénicos se puede reducir el consumo de energía. La relevancia de las pérdidas por ventilación está relacionada con las cargas internas. Cuando las cargas internas son elevadas, la ventilación las disipa en parte y las compensa. Sin embargo, esto sólo puede llevarse a cabo en estaciones templadas o mediante mecanismos de recuperación de energía.

Por otra parte, se deben considerar las pérdidas energéticas producidas por transmisión de energía a través de la superficie del vidrio. Por un lado, los meses de invierno exigen que las pérdidas por transmisión se reduzcan al mínimo. La calidad del vidrio empleado y la temperatura de la cara interior del cerramiento serán determinantes. Hay diferentes factores que afectarán el grado de transmisión de un cerramiento, pero en las envolventes de vidrio pueden reducirse espacialmente a los puentes térmicos y al tipo de aislamiento en elementos opacos, y a la clase de vidrio empleado.

Por un lado, el efecto negativo de los puentes térmicos en las carpinterías de las fachadas hace que sea imprescindible prestar atención a los perfiles empleados. Como 
se ha estudiado en apartados anteriores, las carpinterías de los muros cortina han evolucionado tanto en los materiales empleados como en su composición. Con los mecanismos de rotura de puentes térmicos, el empleo de materiales de baja conductividad térmica, y mediante el desarrollo de la silicona estructural, las pérdidas por transmisión por los perfiles quedan mermadas. Por otro lado, los materiales empleados en los paneles opacos de las fachadas de vidrio han sufrido mejoras gracias al uso de materiales aislantes que se comportan mejor frente a las pérdidas de energía, como en el caso de la lana de roca mineral. El grosor, que será determinante en el comportamiento aislante del elemento, vendrá determinado por la oferta del mercado y por las limitaciones de espacio de estos sistemas, que no suelen ser excesivas.

Otro factor que determinará la transmisión térmica del cerramiento es el tipo de vidrio empleado. Hoy en día, el uso de vidrios simples ha sido prácticamente eliminado en la construcción de muros cortina debido a su mal comportamiento térmico, especialmente durante los meses de invierno. Un panel simple de vidrio convierte el espacio interior en uno vulnerable y prácticamente incapaz de mantener la energía generada. Por lo tanto, en general, el mercado ofrece vidrios de dos paneles y de tres, siendo éste último al que más se recurre en países pioneros en la tecnología de fachadas como Alemania o Suiza. El espacio entre los paneles de vidrio y el material empleado para su relleno determinará su comportamiento frente a las pérdidas energéticas. Se ha estimado que por cada cavidad rellena de uno de los gases existentes, se pueden reducir las pérdidas de energía aproximadamente un 10\%. El vidrio triple, que tiene un efecto doblemente aislante respecto al vidrio de dos paneles, presenta ciertos inconvenientes en invierno, puesto que las ganancias de energía solar necesaria también se ven reducidas. Lo mismo ocurre con la visibilidad total. En la práctica, el tipo de vidrio vendrá determinado por la superficie, la orientación de la fachada en cuestión y las cargas energéticas interiores. El empleo de unidades de vidrio triple puede ser beneficioso para ahorrar energía cuando se trate de grandes superficies de fachada orientadas al sur. 
En este caso, la diferencia entre un vidrio doble y uno triple es mayor. Por tanto, las superficies de la envolvente deben evitar las pérdidas energéticas en invierno para aumentar el confort interior y reducir las cargas adicionales de otros sistemas mecánicos. Sin embargo, tan importante es prevenir la pérdida de energía del espacio interior, como permitir la entrada de energía solar durante el día.

\section{Maximizar las ganancias energéticas}

El aprovechamiento de la energía solar - en climas como el de Chicago -en los que las bajas temperaturas son constantes y severas - ofrece posibilidades de mejoría del confort interior dificiles de alcanzar por otros medios. Es por ello que el uso del vidrio como material principal de las fachadas puede ser una buena solución si se emplea con responsabilidad y se tiene conocimiento de sus propiedades. La optimización de ganancias energéticas en invierno puede no sólo beneficiar psicológicamente y en términos de confort a los usuarios, sino que disminuirá el uso de los sistemas mecánicos de calefacción. Para ello, y para un tipo de clima determinado, las ganancias energéticas de una superficie vendrán determinadas por el área de transparencia de la superficie respecto al de las zonas opacas, la orientación de la fachada, la capacidad de admitir energía térmica solar del vidrio y el factor de reducción de energía de los elementos de control solar.

La proporción de superficies transparentes respecto a las zonas opacas es uno de los factores principales en el tema que nos ocupa, ya que las ganancias de energía solar térmica aumentan proporcionalmente a las de los elementos transparentes empleados. Sin embargo, se ha demostrado que en ocasiones los edificios no son capaces de aprovechar la totalidad de las ganancias solares. Por tanto, no se trata únicamente de admitir la máxima entrada de sol en invierno, sino de estudiar las posibilidades de almacenar para un uso futuro la energía que no se emplea inmediatamente.

Sin embargo, esto, aisladamente, no es un factor determinante. Para poder evaluar la conveniencia de una pro- 
porción u otra, se tendrá que tener en cuenta la orientación de la superficie de vidrio. Por ejemplo, las fachadas orientadas al norte no reciben energía solar directa durante los meses de invierno pero sí energía difusa. Debido a ello, las ganancias de energía solar se ven reducidas, lo que provoca que las cargas energéticas sean mayores. En el caso de grandes superficies de vidrio, las pérdidas a través del mismo pueden ser un problema. Además, la existencia de luz difusa en el norte incrementa las posibilidades de deslumbramiento. Por otro lado, si la superficie de vidrio es excesivamente reducida, el espacio puede no estar recibiendo la energía necesaria. Por ello, se tiende a limitar la superficie expuesta en el norte y se disponen elementos de regulación de la entrada de la luz y de redireccionamiento de la misma en conjunción con el empleo de vidrios de alto rendimiento.

Por el contrario, en las fachadas orientadas al sur, una mayor superficie de vidrio incrementará la entrada de energía solar directa aprovechable durante los meses de invierno. Como el factor de absorción de energía del vidrio estará relacionado no sólo con la superficie, sino también con el ángulo de inclinación del vidrio, será importante evaluar la posibilidad de que las fachadas orientadas al sur se diseñen para que admitan el mayor grado de energía solar térmica en invierno. Dado que en esta época del año la altura del sol es más baja que en verano, la entrada de luz estará asegurada en estas orientaciones. Los problemas de deslumbramiento deberán ser solucionados con medidas de control de entrada de luz. Si a estas superficies de fachada se añaden vidrios dobles o triples con cámaras rellenas de gases inertes que reduzcan las pérdidas de energía, las fachadas orientadas al sur tendrán un rendimiento apropiado durante los meses fríos. En resumen, el aprovechamiento de la energía solar térmica dependerá principalmente del clima local y la orientación. Cuando coincida que los requerimientos energéticos debido a las bajas temperaturas exteriores y la entrada de radiación solar sean considerables, se podrá aprovechar al máximo la energía solar térmica. 


\subsubsection{La Envolvente en Verano}

El rendimiento energético de las envolventes de vidrio en verano es uno de los puntos más conflictivos debido a la situación medioambiental actual. De unos años a esta parte, los veranos son cada vez más calurosos y la entrada de energía solar a través de las superficies de vidrio ha condicionado el confort de los espacios interiores, incluso en aquellos climas mayoritariamente fríos. A este hecho hay que añadir que cada vez son más numerosos y de mayor potencia los aparatos electrónicos en las estancias, lo que ha provocado que las cargas energéticas interiores hayan aumentado considerablemente, acarreando un incremento en el uso de sistemas de refrigeración mecánicos que condicionan el clima interior. Este escenario ha obligado a la arquitectura a prestar más atención al rendimiento de las envolventes - especialmente las de vidrio - para controlar, entre otros, la entrada de energía solar en verano. Los actuales requerimientos de las envolventes en lo que respecta al comportamiento energético en verano sugieren que éstas deben poder ofrecer una respuesta variable según las condiciones exteriores. Así, deberán considerarse factores como la radiación solar, la entrada de luz natural o la ventilación natural.

\section{Minimizar las ganancias energéticas}

Al contrario que en las estaciones frías, durante los meses de calor es preciso limitar la entrada de energía solar para evitar el sobrecalentamiento de los espacios interiores y disminuir las cargas derivadas de los equipos de refrigeración. Para ello, se atenderán distintas cuestiones tales como la influencia de la orientación o la incorporación de sistemas de control solar y su posición.

La orientación de las fachadas será el factor que determinará el resto de parámetros que se deben considerar para minimizar la entrada de energía solar no deseada en verano. La orientación definirá el ángulo de incidencia del sol en la envolvente así como la intensidad de la radiación solar. De esta manera, para cada orientación habrá unas horas determinadas en las que la superficie recibirá radiación solar directa. 
En las fachadas orientadas al norte se deben considerar los sistemas de protección solar para controlar la entrada de luz difusa. Una buena estrategia consiste en incorporar sistemas de protección solar interiores con una superficie reflectante a la luz. En las fachadas orientadas al este y oeste, el control de entrada de energía solar es esencial. Las fachadas al este reciben gran cantidad de radiación solar a un ángulo bajo durante las primeras horas de la mañana. Durante estas horas los sistemas de protección solar podrían estar completamente cerrados para evitar la entrada de energía al no requerir vistas al exterior. La ventilación natural ayudaría a reducir el calentamiento de las estancias, ya que la temperatura aumenta, por lo general, conforme avanza el día.

En el oeste ocurre prácticamente lo contrario. Durante los meses de verano y por la tarde, las fachadas orientadas al poniente reciben grandes cantidades de energía directa. Los sistemas de control de protección solar deberían estar cerrados durante las horas de máxima radiación, aunque en tal caso entrarían en conflicto con las horas de ocupación de las estancias. A esto se suma el hecho de que la radiación que penetra en las estancias durante la tarde debe ser disipada para el confort durante la noche. Sin embargo, en ocasiones las altas temperaturas en las tardes de verano lo imposibilitan. Por tanto, durante los meses de verano las fachadas orientadas al oeste son las más desfavorables. Una buena estrategia de control solar para las fachadas orientadas tanto al este como al oeste es la incorporación de lamas verticales, puesto que el bajo ángulo de incidencia del sol evita la radiación sin limitar la visión al exterior.

En última instancia, las fachadas orientadas al sur reciben radiación directa solar con un ángulo elevado. Esto hace que la penetración de la radiación sea mucho menor que en las anteriores y sea más fácil de controlar y evitar. Bajo estas condiciones, los sistemas de protección solar que se pueden aplicar son mayores y más eficientes, ya que pueden impedir la entrada de energía solar, controlar la entrada de luz y no limitar las vistas al exterior. A esto hay que añadir que la ventilación puede eliminar parte de 
la energía térmica almacenada. En caso de que se proyectasen envolventes con retranqueos, éstos pueden ser diseñados para que la radiación directa se evite en verano pero sea admitida en invierno. Sin embargo, la opción que mejores resultados ofrece para evitar el sobrecalentamiento de las fachadas orientadas al sur es la incorporación de lamas horizontales móviles con grados ajustables. Si se diseñan de manera responsable atendiendo a su tamaño, el material y su posición, así como al tipo y grado de control del sistema, pueden disminuir la entrada de energía solar térmica y controlar la entrada de luz, ya sea mediante la temperatura interior o por la intensidad de la radiación solar.

El tipo de vidrio y sus componentes son otros de los elementos principales que deben ser contemplados. De la misma manera que las cavidades entre paneles de vidrio y su relleno determinarán la conductividad térmica del vidrio y definirán su comportamiento frente a las pérdidas de energía en invierno, en verano la preocupación es reducir la transmisión de radiación al interior de los espacios. Este fenómeno puede limitarse mediante el uso de vidrios tintados o revestidos. En ambos casos se disminuye la entrada de energía solar, aunque el aspecto de la envolvente quede condicionado por el color del vidrio. Para mejorar el comportamiento del vidrio frente a su respuesta energética sin alterar significativamente su imagen, los vidrios de baja emisividad suponen una buena opción.

El revestimiento Low-E puede aplicarse en vidrios monolíticos o en vidrios laminados, aunque cuando se emplea en los primeros los valores son más positivos. Igualmente, aunque el revestimiento puede ser aplicados en cualquier cara del vidrio siempre y cuando el proceso de fabricación así lo permita, la aplicación de los revestimientos en las caras interiores de la cámara (superficie número 2 o número 3) suele ser la opción más empleada y beneficiosa.

Finalmente, y como se ha indicado anteriormente, la decisión de aplicarlos en una u otra cara vendrá determinada de lo que se pretenda obtener. Una última posibilidad de estas películas es la de incorporar revestimientos que puedan cambiar de función, e incluso de estado, según la 
radiación solar exterior, las necesidades del usuario o la temperatura.

Por tanto, la reducción de ganancias energéticas durante los meses de verano es uno de los elementos clave para asegurar el confort interior. Como se ha venido señalando, para ello se debe considerar fundamentalmente la orientación y los sistemas de control solar. En última instancia, estos dos parámetros determinarán la proporción de superficies transparentes que conviene tener en cuenta en cada una de las orientaciones en los distintos sistemas de control solar.

\section{Aprovechamiento de la ventilación natural}

La entrada de aire natural en las estancias durante el verano puede desahogar de calor los espacios. Los límites de una ventilación libre y sin control vendrán determinados por la permisibilidad de las temperaturas de los espacios interiores. Mientras las temperaturas exteriores sean inferiores a las interiores, la ventilación natural puede ser una ventaja que se debe tener en cuenta. Sin embargo, cuando las temperaturas exteriores excedan los valores interiores, es necesario que el aire caliente no penetre en las estancias, pues de lo contrario estaría disminuyendo el confort interior. Una posible solución es mantener las ventanas cerradas en las horas de más calor y abrirlas durante la noche para que el aire fresco entre en las estancias y mejore el clima interior. Las opciones para lograr ventilar una estancia en verano son diversas y el tipo de ventilación variará en función del objetivo que se persiga. Por ejemplo, la ventilación por medio de ventanas tradicionales es apropiada para lugares donde el sonido exterior no constituya un problema para el espacio interior, o en aquéllas situaciones en las que se requiera una cantidad de aire natural considerable, al tiempo que se deseen vistas al exterior.

Por otro lado, la ventilación por medio de las dobles pieles de vidrio puede resultar apropiada en lugares en los que el entorno sea excesivamente ruidoso o en climas en los que el viento juegue un factor determinante en el diseño de las envolventes. Sin embargo, durante el verano no es 
recomendable que la única ventilación provenga del espacio entre las dos pieles de vidrio ya que esta cámara habrá estado expuesta a altas temperaturas durante la mayor parte del día. Por ello, sería aconsejable que las dobles pieles de vidrio dispusiesen de ventilación directa al exterior. Otro método de ventilación es mediante los llamados "flaps" - superficies operables en la parte inferior y superior de la fachada, que permite no solo la ventilación natural del espacio, sino también la renovación de aire. Esta solución suele ser apropiada para edificios en altura donde los vientos no permitan las grandes aperturas al exterior. Otra de las ventajas de este sistema es que, en caso de lluvia, su tamaño, la posición y la dirección de apertura evitan que el agua entre en las estancias. La ventilación por infiltración de aire asegura un cambio básico de aire y la renovación del mismo. Este método no es apreciable por el usuario, por lo que psicológicamente puede no ser más aceptado y, aunque durante el verano constituye una buena opción, puede provocar pérdidas de energía durante los meses de invierno.

Todos los aquí descritos son mecanismos de ventilación natural a través de las envolventes de los edificios y, a grandes rasgos, influyen de manera considerable en el clima interior. Una de los objetivos es mejorar el confort interior, pero no hay que olvidar que por medio de la ventilación natural se puede disminuir el uso de sistemas mecánicos de acondicionamiento. Las posibilidades de aprovechar la ventilación natural como método de enfriamiento de los espacios vendrán determinadas por el rango o velocidad de recambios de aire y la diferencia de temperaturas entre el interior y el exterior. Por este motivo, una manera adecuada de reducir las cargas de calor en las estancias es mediante la ventilación purgada o la infiltración, ya que aunque la temperatura exterior supere a la interior sigue siendo factible eliminar el aire caliente del interior mediante corrientes de ventilación. 




\section{CAPÍTULO 05 \\ TÉCNICA Y PROYECTO. LAKE GROVE VILLAGE}

Este capítulo comprende el grueso de la investigación, cuyo proceso está basado en la teoría analizada previamente y en la experiencia adquirida en el transcurso de dicha investigación. Pese a la extensión del mismo, se ha optado por presentarlo en un solo capítulo con la finalidad de destacar y facilitar la integración de sus objetivos.

En primer lugar, ofrecer una visión global en la que se incluyen los distintos estudios teóricos y numéricos así como los resultados y conclusiones extraídos. En segundo lugar, evidenciar el carácter de la investigación en la que, al igual que en el proceso de diseño, las conclusiones y resultados derivan en estudios e iteraciones. En tercer lugar, este capítulo recalca la posibilidad de aplicar el proceso y conclusiones de manera autónoma en futuros trabajos y/o proyectos.

A tal efecto, en primer lugar ha sido preciso detallar el objeto de estudio: la arquitectura (Lake Grove Village), el arquitecto (Paul DePondt) y los motivos que han impulsado 


\section{CAPÍTULO 05}

su elección. A esto hay que añadir la explicación de conceptos relevantes que nos permiten perfilar el contexto teórico que influye en el objeto de esta investigación.

A continuación se establecen los objetivos del análisis y se define el campo de trabajo para, posteriormente, exponer el análisis numérico de los conceptos, incluyendo la hipótesis y metodología, la descripción del proceso y la interpretación de los resultados. Esto permitirá exponer los análisis llevados a cabo durante la investigación, relacionarlos con la base teórica anterior y presentar las posibilidades analíticas que podrás ser empleadas en el tercer y último apartado de este capítulo: el proyecto.

El proyecto consiste de una propuesta práctica fruto de las conclusiones extraídas de los análisis con el objetivo de poder validar la decisión de diseño y propuesta de adaptabilidad de la fachada. 
CAPÍTULO 05

5.1 LAKE GROVE VILLAGE.

Como se ha expuesto en capítulos anteriores, la investigación propone la intervención y propuesta de diseño del tránsito entre el exterior y el interior, es decir, la envolvente de un edificio en el sur de la ciudad de Chicago: Lake Grove Village. Dicha intervención parte de la idea de la renovación, la reutilización y el reciclaje. Teniendo en cuenta el gasto que acarrearía demoler el edificio y construir uno nuevo, se ha optado por aprovechar las características del edificio ya existente. La finalidad es optimizar tanto su comportamiento frente a condiciones climatológicas cambiantes, como el espacio interior, mejorando así las condiciones interiores y favoreciendo la adaptabilidad de las funciones gracias a la creación de dicho espacio de transición.

En los primeros estadios de este proyecto, cuyo embrión hay que situarlo entre 2009 y 2011 durante el Master of Science in Arquitecture en el Illinois Institute of Tecnology, se plantearon diversas posibilidades; entre ellas,

159 
el desarrollo de una envolvente para un edificio teórico de nueva construcción. Sin embargo, ésta pronto se descartó. El mercado inmobiliario estadounidense también ha hallado en la renovación de edificios una respuesta a la situación de la economía global. De hecho, ésta era una práctica habitual previa a la recesión económica. En ciudades como Nueva York, donde el mercado inmobiliario representa una industria tan potente, la renovación de las fachadas es una práctica frecuente que persigue incrementar el valor de los edificios. Éstos se revisten manteniendo su estructura y sus sistemas principales, lo que convierte a la envolvente, a su vez, en un elemento central de la nueva imagen que se desea proyectar.

Un ejemplo de ello es 1040 Avenue of the Americas. Construido en el año 1925, el edificio original se caracterizaba por su fachada de mampostería con aperturas ocasionales. En el año 2006, el equipo de arquitectos Iu + Bibliowicz, junto con la consultoría de fachadas Gilzanz Murray \& Steficek, llevó a cabo el proyecto de renovación de la envolvente del edificio. Hoy día, nada queda de la robustez de la fachada original. En su lugar se exhibe una piel de vidrio continua que da al cruce de la calle 42 con la Sexta Avenida. El proceso por el que se revistió el edificio permitió, además de modernizar su imagen y potencialmente incrementar su valor, seguir cumpliendo con sus funciones a lo largo del proceso de rehabilitación. En muchas ocasiones, los huecos originales del edificio se respetan, lo que permite al muro cortina deslizarse frente a la piel original.

La elección de un edificio ya existente no ha estado únicamente condicionada por las oportunidades de renovación, sino también por la preocupación por los efectos adversos de la arquitectura en el medio ambiente, el exceso de contaminación de la industria de la construcción, la exigencia de los usuarios sobre el control térmico de los espacios o el aumento de los requerimientos de confort. Todos estos factores han contribuido a plantear una propuesta de diseño de "lo ya existente" y facilitar una solución que diese respuesta a los distintos condicionantes: la envolvente adaptable.

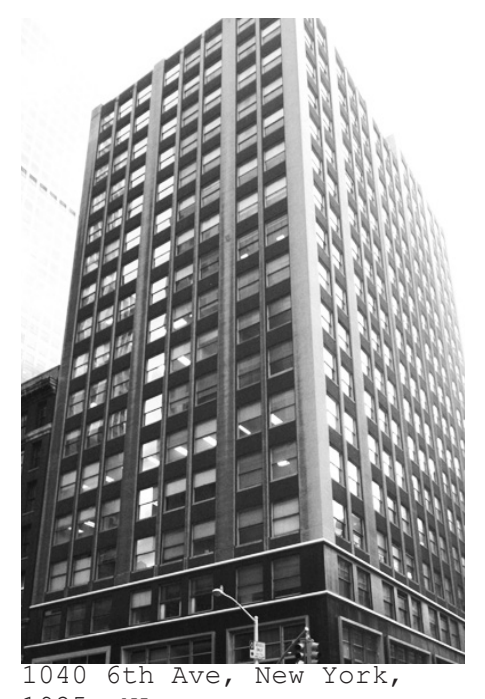

1925, NA.

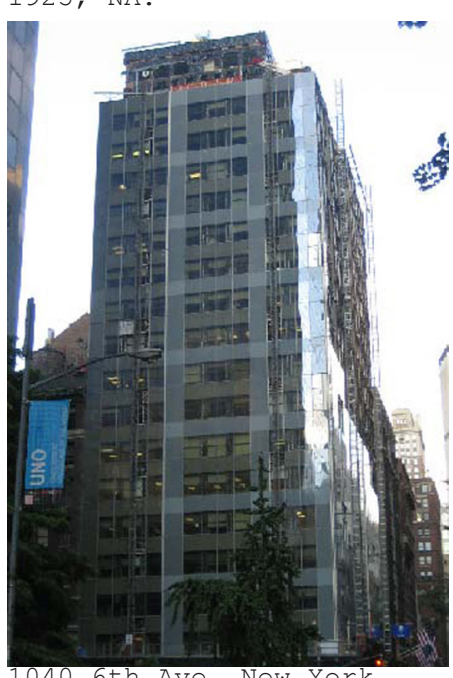

1040 6th Ave, New York, 2006, IU + Bibliowicz. Fotografía año 2008. 


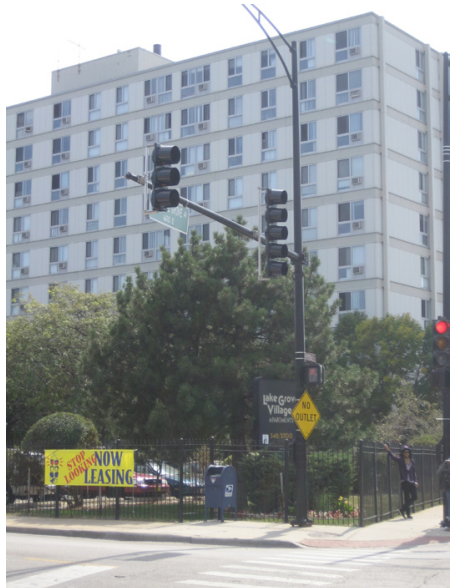

Lake Grove Village, Chicago, 1969, Paul De Pondt. Fotografía año 2009.
El edificio seleccionado para poner en práctica esta idea es Lake Grove Village, diseñado por el arquitecto francés Paul DePondt en 1962. El proyecto está basado en un sistema modular de fachada en seco. Éste es, precisamente, una de las contribuciones más importantes del arquitecto al proceso de diseño, ya que fue concebido con la intención de que la mayor parte de los componentes pudieran ser sustituidos en el futuro.

Pese a que no es un edificio célebre, la manera de entender la arquitectura por parte de su creador y los elementos que lo componen lo convierten en un objeto de estudio inmejorable. Paul Depondt plasma en este conjunto de edificios la voluntad de estudiar y comprender no sólo los espacios, sino también a sus usuarios y sus posibles usos. 


\subsubsection{Paul DePondt. El Arquitecto}

El arquitecto Paul DePondt debe su fama internacional fundamentalmente a su experiencia en el uso de materiales prefabricados. Nacido en Francia, adquirió su experiencia académica y profesional tanto en su país natal como en Estados Unidos. Inició sus estudios de Arquitectura en 1951 en el Illinois Institute of Tecnology (IIT) de Chicago. Posteriormente cursó sus estudios de máster en la Universidad de Harvard. ${ }^{1}$ Después de trabajar en distintos despachos de arquitectura en Nueva York, DePondt regresó a Francia con una idea clara de lo que la Arquitectura debía ser en aquel momento: "Las nuevas formas de arquitectura sólo se pueden lograr mediante un dominio total de los materiales y un entendimiento de las técnicas de construcción". ${ }^{2}$ A su regreso, DePondt diseñó numerosos proyectos en los que expresó su forma de entender la Arquitectura y en el que manifiesta su interés y apuesta por la utilización de materiales industrializados.

\section{Viviendas en Rouen}

Su primera contribución importante a este respecto llegó en 1968 con el diseño y la construcción de un edificio de 500 apartamentos de bajo coste en Rouen, Francia. Uno de los principales objetivos de este proyecto era la eliminación de materiales pesados. En Rouen, DePondt se sirvió del acero y otros materiales industrializados que proporcionaban una ventaja para las grandes luces que debía solventar. De esta manera, se lograba la flexibilidad del espacio interior que el arquitecto perseguía con el diseño. La experimentación y el estudio de los materiales de construcción le permitió ejecutar su propuesta de diseño mediante el uso de la técnica aplicada en los elementos prefabricados.

Mientras que otros países apostaban por paneles prefabricados de hormigón para las fachadas, DePondt lo hacía por el uso de un sistema de construcción industrializado basado en el empleo de paneles de acero y paneles sándwich de aluminio, experimentando así con la fachada ligera. Esto también trajo consigo el estudio de sistemas de ingeniería que permitiesen el montaje de los paneles en el menor tiem-

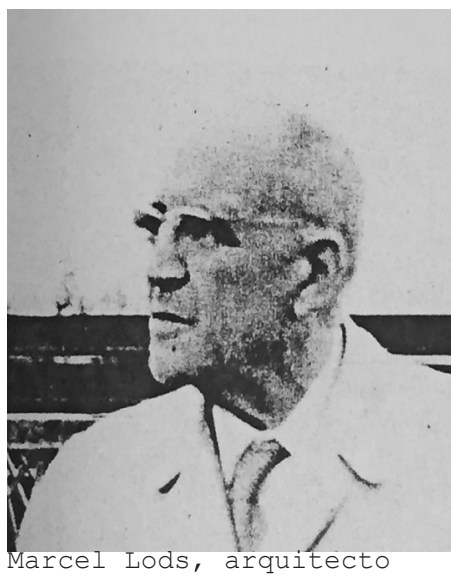

conocido en Francia como el "arcquitecto del mañana", con quien Paul DePondt trabajó.

Imagen extraída de la publicación Apartment.

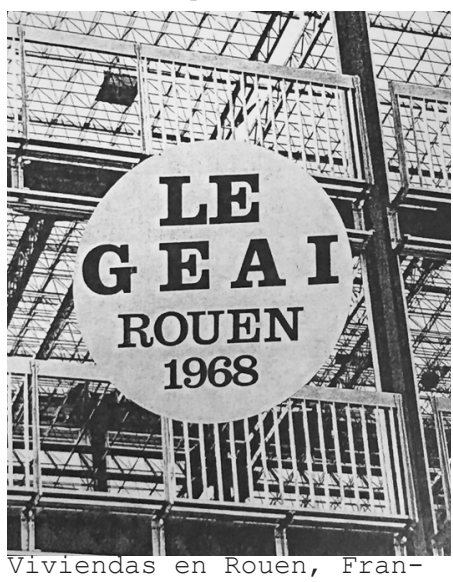

cia, 1968, Paul DePondt. Imagen extraída de la publicación Groupement pour l'etude d'une architecture industrialisée.

1. NA, Profil 13 (1976). 2. NA, Profil 13 (1976). 


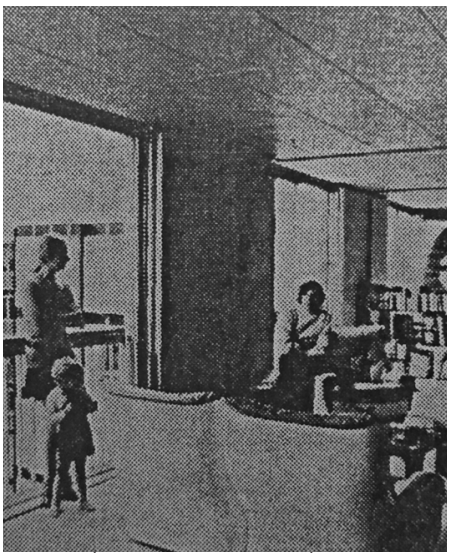

Interior del espacio con quías dispuestas para variar las particiones. Imagen extraída de la publicación HUD International, April 1972.
3. NA, "French total building system - steel and aluminum", Apartment. 4. NA, "French total building system - steel and aluminum", Apartment. 5. NA, "French total building system - steel and aluminum", Apartment. po posible. De esto se desprende que la eficiencia económica era otro de sus objetivos. ${ }^{3}$ El proyecto de viviendas en Rouen se convirtió así en un prototipo de experimentación que sería revisado posteriormente con el fin de mejorar la producción y calidad del tipo de arquitectura por la que apostaba.

A continuación se explican los aspectos singulates desarrollados para las viviendas de Rouen, cuyo sistema arquitectónico es la base de lo que posteriormente se aplicará en Lake Grove Village. Los principales objetivos de este nuevo sistema de diseño fueron: reducir significativamente los costes de construcción, establecer un diseño con un volumen predecible y controlable -las envolventes ligeras permitieron reducir el volumen de la fachada, obteniendo así un área mayor en los espacios interiores- e incrementar la flexibilidad del diseño y del espacio interior. Así lo explica Marcel Lods, el arquitecto francés responsable del diseño inicial de Rouen. ${ }^{4}$

A esto hay que añadir que, pese a que el sistema fue instalado en un edificio de uso residencial, su diseño perseguía su posible adaptación a otra clase de edificios, tales como oficinas. El artículo "French total building system - Steel and aluminum", publicado en la revista Apartment, explica las ideas que conducen a estos arquitectos franceses a diseñar este innovador sistema industrializado. ${ }^{5}$

Frente a otros diseños alternativos, estos arquitectos se vieron en la necesidad de explicar las motivaciones que les llevaron a elegir el acero para sus fachadas. Fundamentaron su decisión en que este material les había permitido dar solución a los problemas que surgieron tras la utilización de otros materiales como el hormigón.

En primer lugar, el uso de un material ligero facilitaba el manejo de las unidades prefabricadas in-situ. Consecuentemente, las grúas y la maquinaria necesarias para su instalación podrían ser de menor capacidad de carga. Esto permitía, asimismo, que las piezas pudieran transportarse a mayores distancias. 
En segundo lugar, debido a su naturaleza prefabricada, las unidades o módulos de fachada podrían ser construidos con mayor precisión, aumentando, por tanto, el control de calidad y posibilitando mejoras en la colocación de las sujeciones y los anclajes. Esto derivaría en una mayor rapidez de montaje y un menor margen de error. Lo que hoy en día puede parecer una obviedad, supuso un paso importante a la hora de reducir los tiempos, aumentar la eficiencia y mejorar la calidad. Además, al estudiar las propiedades y posibilidades del material, los arquitectos emplearon elementos de acero tratados con el objetivo de que fuesen resistentes a la intemperie, lo que evitaba los costes derivados de pintar el acero, incluso el que estaba situado en la estructura exterior.

Mediante revisiones, el sistema de las fachadas fue mejorando para asegurar así la idoneidad de los componentes de acero. En primer lugar, éstos tenían que poder transportarse sin envolturas para ahorrar costes, pero a su vez tenían que poder ser maniobrados y erguidos sin que las superficies sufriesen daños.

En segundo lugar, el sistema debía ser capaz de aislar acústicamente las viviendas y los demás espacios en una misma unidad. Dado que este sistema no podía servirse de la masa y la inercia de la fachada para aislar acústicamente, se diseñaron cámaras de aire y roturas de puentes acústicos dentro de los sistemas. El método de aislamiento acústico empleado en Rouen y en Lake Grove Village fue similar. En ambos casos, el aislamiento se consiguió mediante el uso de paredes dobles entre viviendas adyacentes, creando una separación entre ellas que permitiera albergar la estructura portante del edificio. Los pilares no debían estar en contacto con las paredes para evitar así un puente acústico.

En tercer lugar, estudiaron cuidadosamente los métodos de ensamblaje que permitirían reducir el tiempo de instalación de los paneles. La industrialización de todos los componentes de las fachadas y paredes interiores, la estandarización de los componentes, la fabricación en masa y la simplificación de las secuencias de montaje hicieron posible un sistema y una estructura eficientes y relativa-

\section{4}


6. NA, "French total building system - steel and aluminum", Apartment. 7. NA, "French total building system - steel and aluminum", Apartment. mente rápidos. En las viviendas de Rouen, cada uno de los edificios principales se compone de cuatro sub-edificios independientes. El estudio detallado y la planificación del diseño permitió, por ejemplo, erigir cada uno de estos subedificios en tan sólo ocho días, una vez que los cimientos ya estaban construidos. ${ }^{6}$ Posteriormente, la instalación de las puertas, los cerramientos, las paredes, los suelos y los techos requirieron de tan sólo 52 días más. ${ }^{7}$ Por 10 tanto, Rouen ejemplifica como pocos cómo el equipo de arquitectos franceses perfiló un plan inteligente y detallado del proceso arquitectónico en su conjunto, pensando no sólo en el diseño y resultado final, sino también en el proceso de construcción tanto de los componentes como del conjunto de las 500 viviendas.

\section{Evolución en Francia \& Estados Unidos}

En 1969, Paul DePondt regresó a Chicago para ahondar en las posibilidades del uso del acero en la construcción, en un momento en el que el uso de este material, a excepción de en las viviendas residenciales, estaba en pleno auge. De una parte, podía servirse de la experiencia que había acumulado gracias a los distintos proyectos que desarrolló en Francia y, de otra, embeberse de las posibilidades de mejora técnicas que ofrecía Estados Unidos.

A DePondt se le brindó la oportunidad de poner en práctica los conocimientos adquiridos en Estados Unidos cuando en 1973 la compañía 3M le propuso que construyera su futura sede en Francia. El punto de partida fue la construcción de una pequeña oficina en la que parte del personal pudiera instalarse temporalmente. Esto le permitió mejorar los sistemas industrializados que había ido perfeccionando a lo largo de los últimos años a ambos lados del Atlántico. Uno de los elementos más sustanciales que desarrolló para este proyecto fue el sistema de suelo en seco. El edificio de 3M le otorgó la oportunidad de profundizar en los sistemas previamente utilizados. Pudo ahondar, entre otros, en el uso de materiales ligeros y de baja inercia como, por ejemplo, el vidrio de doble capa; evaluar el aumento de la flexibilidad del espacio interior mediante el replanteo de la posición de la estructura respecto a las fachada, o ana- 
lizar las ventajas que aportan las vigas de canto. El proyecto 3M proporcionó a DePondt un abanico de posibilidades no sólo en lo que se refiere a las fachadas ligeras, sino también a las propiedades que ofrecían otros materiales y elementos constructivos a la hora, una vez más, de mejorar la calidad del espacio interior.

Pero no todos los aspectos estaban directamente vinculados con la ingeniería; al fin y al cabo estamos ante un arquitecto preocupado por el diseño que, eso sí, supo aprovechar las posibilidades técnicas que tenía a su alcance para el diseño general del edificio. El proyecto consistía básicamente en una estructura de acero construida alrededor de un jardín. Debido a la gran presencia de este espacio exterior en el conjunto, se optó por vincularlo a las oficinas interiores. A tal fin, abrió un hueco en el centro del edificio con un jardín interior cubierto con cúpulas de plástico de peso ligero a modo de atrio. Esto permitía controlar la luminosidad de los espacios de las oficinas y crear una doble fachada, una exterior y otra interior al atrio.

En 1976, con Depondt de vuelta en los EE.UU., el Estado de Missouri convocó un concurso para la construcción de un espacio de oficinas de 27.000 pies cuadrados que debía consolidar varios departamentos. Pese a que el pliego de condiciones contemplaba la posibilidad tanto de rehabilitación como de nueva construcción, existían factores relativos al tiempo de ejecución y al coste presupuestado que desaconsejaban la aplicación de métodos de construcción tradicionales. Paul Depondt se presentó al concurso con una propuesta cuyo principal enfoque consistía en el diseño de una estructura que consolidase el área necesaria en una máximo de cinco pisos de altura, con un tiempo de ejecución y presupuesto limitados. A su entender, la integración completa de los diferentes componentes del edificio entre sí permitiría reducir el tiempo y el coste significativamente en comparación a los métodos convencionales.

Uno de los aspectos más singulares de este sistema fue la incorporación y extensión de los paneles de cerramiento en el frente de los forjados. Éstos no sólo ayudaban a transmitir las cargas a la estructura y la resistencia a

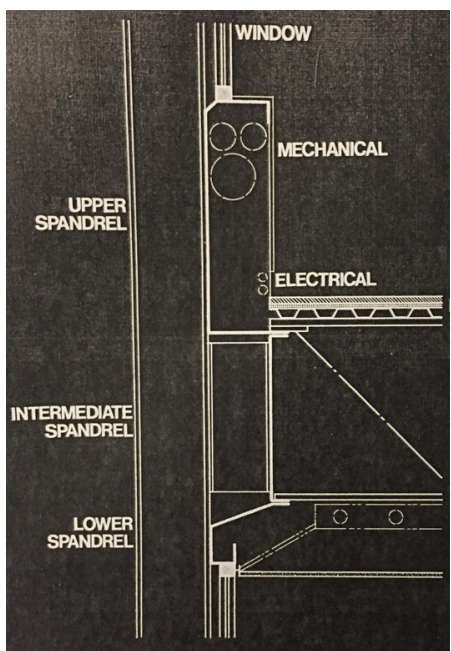

Office Space, Missouri, 1976, Paul DePondt. Imagen extraída de la publicación del equipo de Architects International (A/I-Chicago).

\section{6}


esfuerzos laterales, sino que proporcionaban continuidad a la envolvente, pasando ésta a formar parte del cerramiento. Los paneles se ensamblaron con láminas de acero que luego se atornillaban y se recubrían con un material que proporcionase aislamiento térmico para evitar así la transmisión directa. Otro aspecto interesante de este sistema fue el montaje en seco del suelo, que consistía en una cubierta de acero con aislamiento que a la postre permitiría a los inquilinos decidir el tipo de acabado. En aras de una mayor eficiencia, los distintos componentes (elementos horizontales, paneles frente a los forjados y sistema de suelo) se ensamblan entre sí y se anclan a la estructura. En un primer momento, los paneles estaban diseñados para actuar a modo de colectores solares que, unidos al sistema de aguas, podrían trabajar conjuntamente para bombear agua caliente o fría en el edificio. Una vez más, el diseño de DePondt nos permite observar la apuesta de su equipo por una arquitectura activa y adaptable.

Por todo ello, el arquitecto encargado de diseñar y construir en 1962 Lake Grove Village en Chicago, demostró una visión única de la arquitectura, moderna e innovadora. El uso de suelo estandarizado, el empleo de paneles ligeros de fachada, la industrialización y prefabricación, la estandarización, la flexibilidad, la investigación de sistemas estructurales flexibles y la incorporación y combinación de funciones en un mismo sistema fueron sus principales contribuciones a la arquitectura tal y como la conocemos hoy en día. Estas contribuciones facilitaron, como hemos señalado anteriormente, el desarrollo de un sistema fácil de instalar y que reduce los tiempos y los costes de construcción, a la vez que permite su remplazo en un futuro si fuera necesario. Como hemos podido comprobar, la adaptabilidad estaba ya instalada en la mente de este arquitecto de los años 60 . 


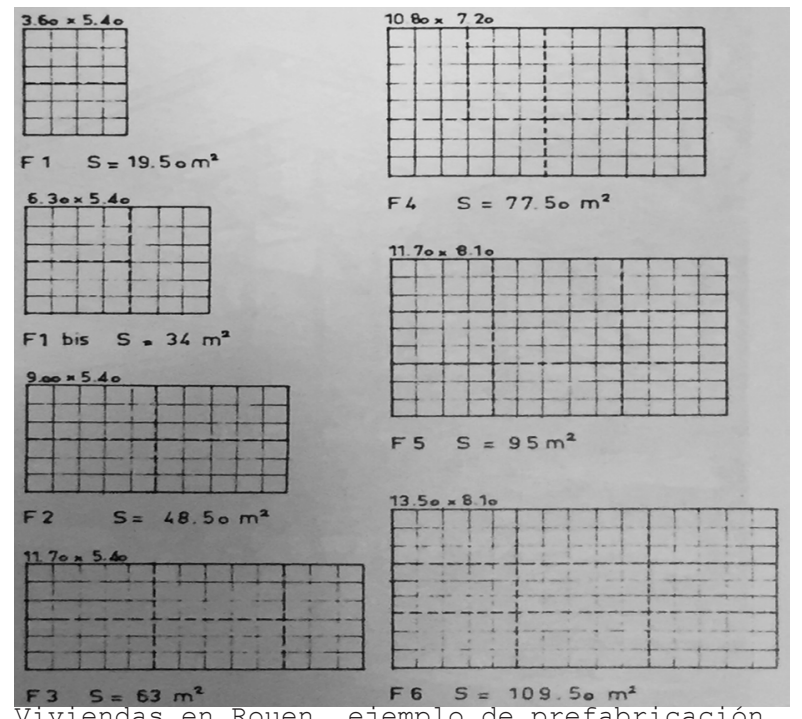

Fiviendas en Rouen, ejemplo de prefabricación de los elementos de forjado de acero.
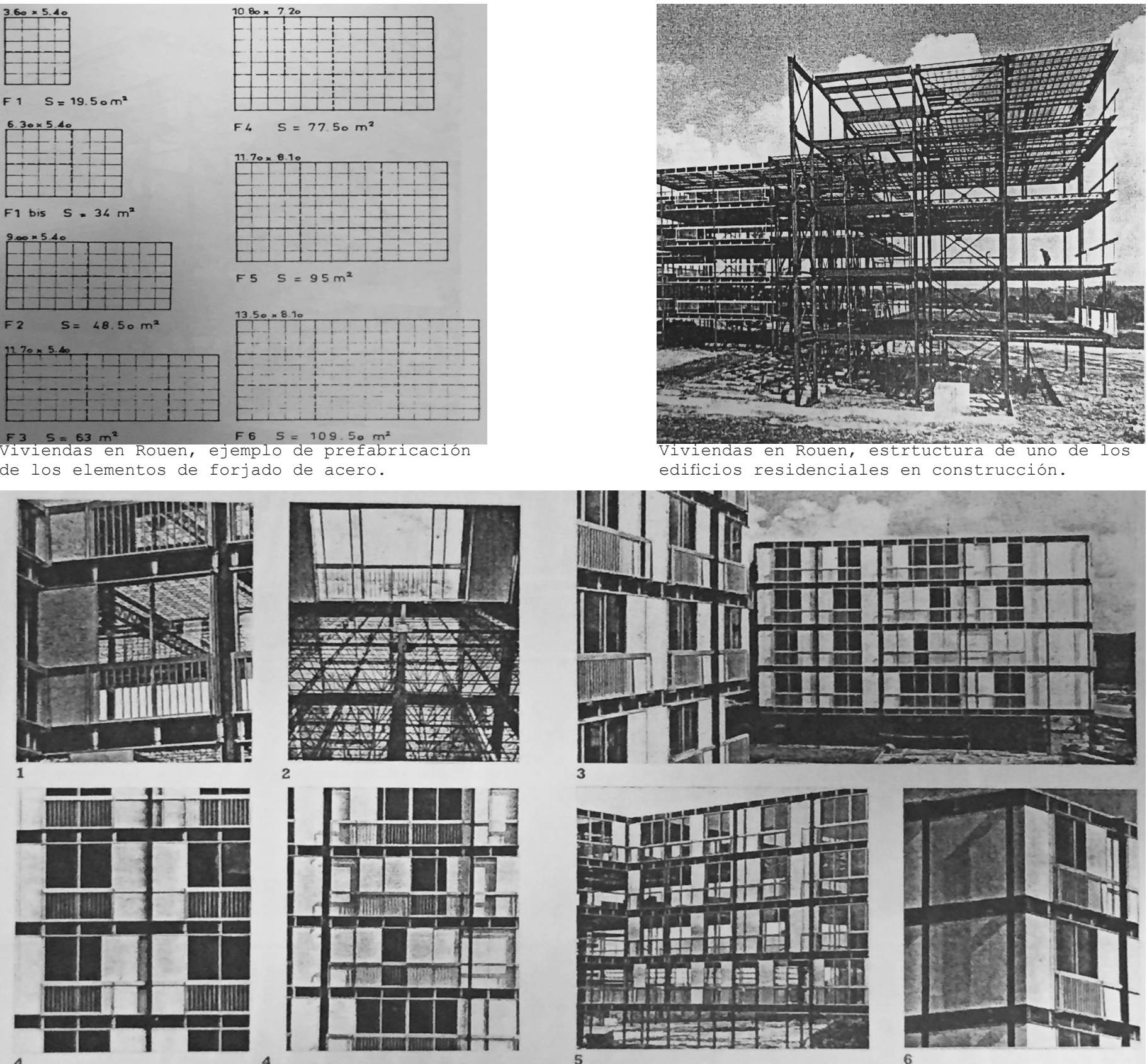

4

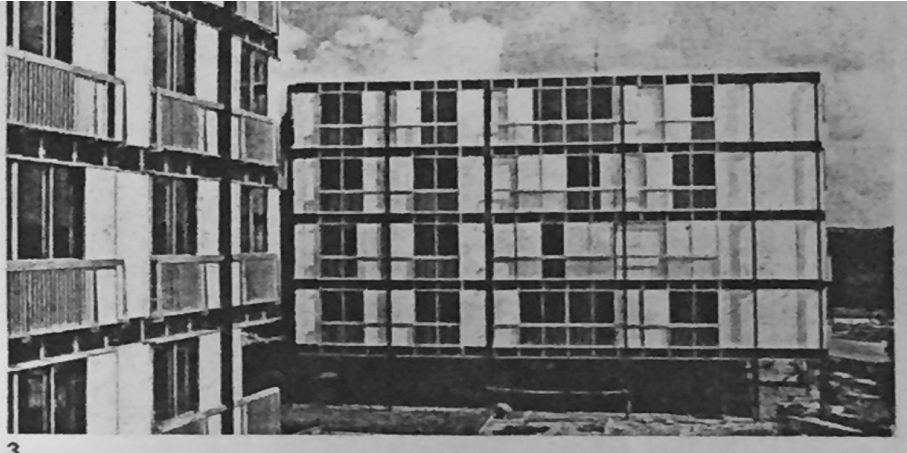

3

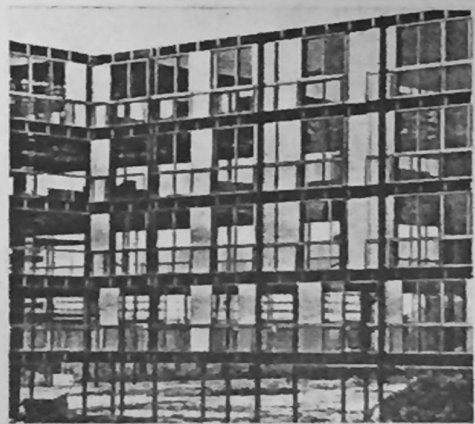

5

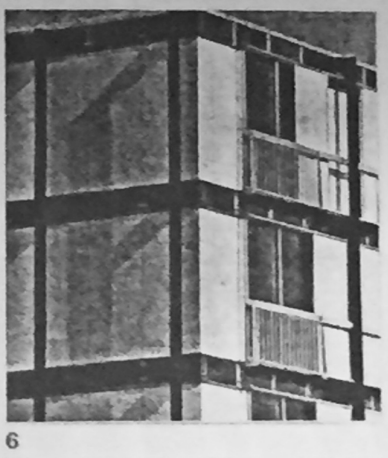

Viviendas en Rouen, fragmentos de los módulos de fachada; esquinas, balcones, o módulos tipo.

Imágenes de Rouen extraídas de la publicación Groupement pour l'etude d'une architecture industrialisée. 


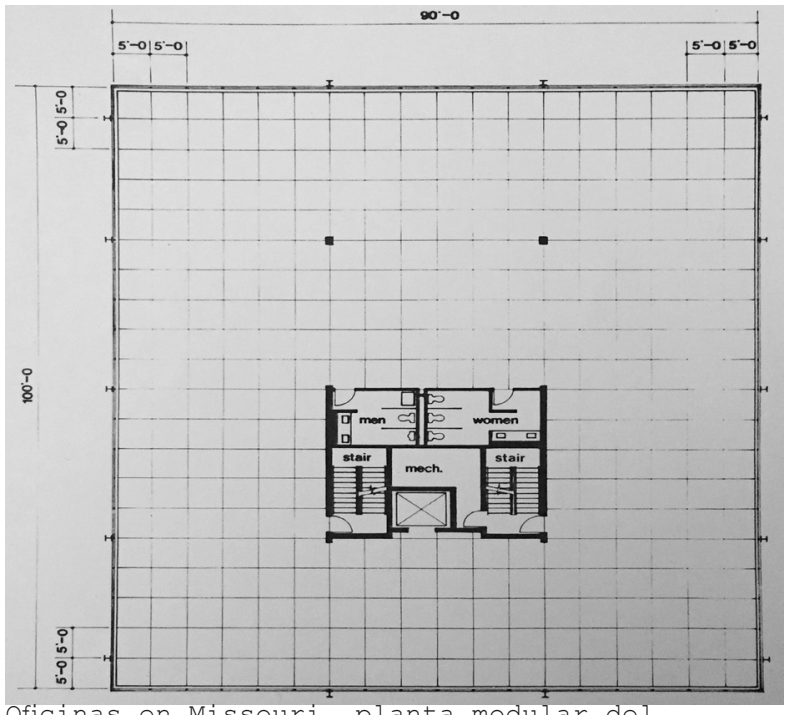

Oficinas en Missouri, planta modular del proyecto.

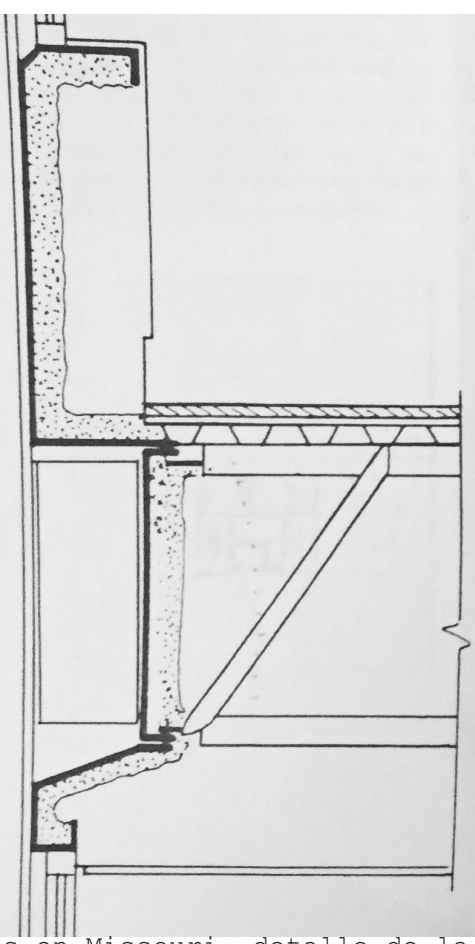

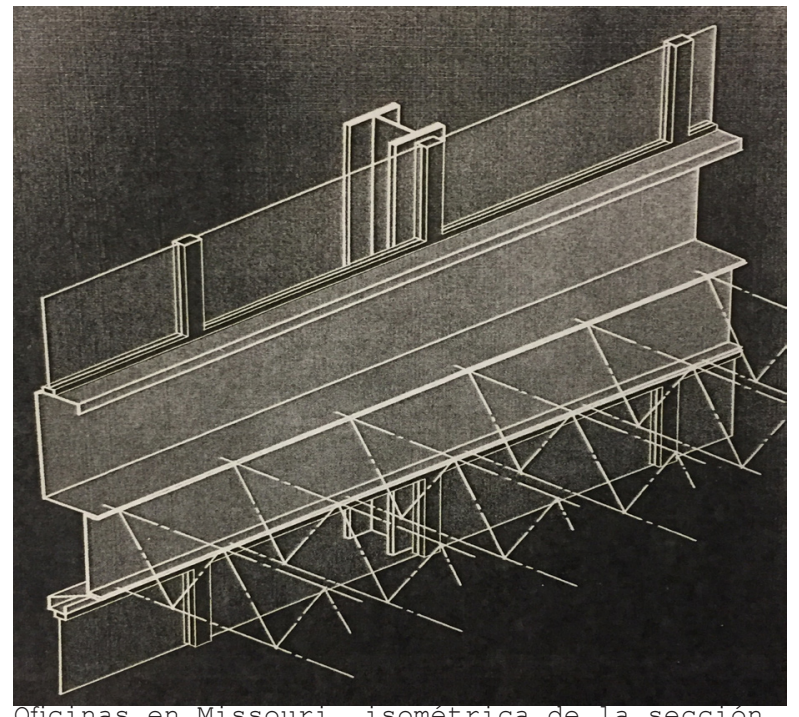
de la fachada.

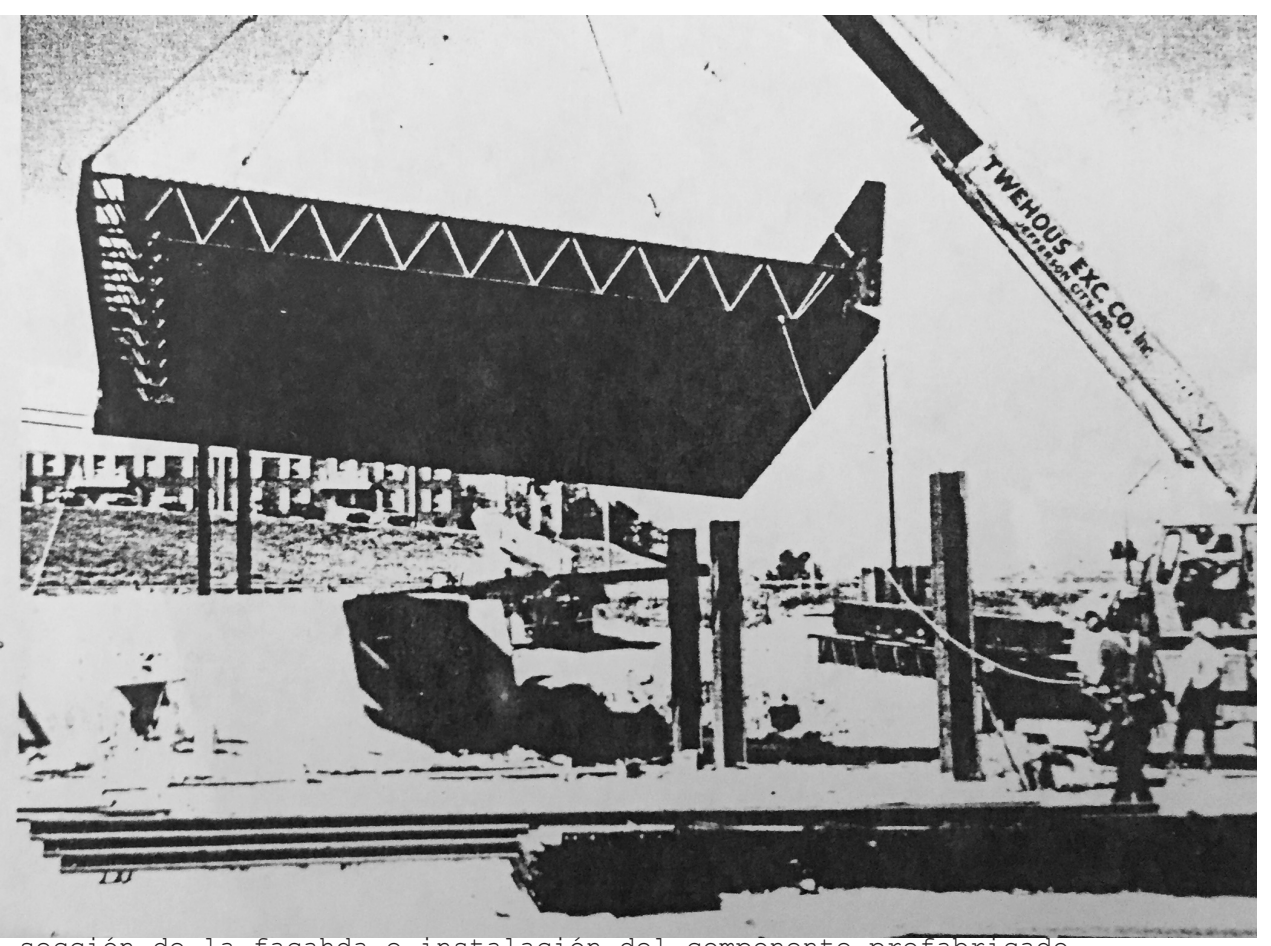

Oficinas en Missouri, detalle de la sección de la facahda e instalación del componente prefabricado.

Imágenes de Missouri extraídas de la publicación del equipo de Architects International (A/I-Chicago). 


\subsubsection{Lake Grove Village. La Arquitectura}

En 1962, DePondt, afincado en Chicago desde que llegó al IIT a estudiar bajo la dirección de Mies van der Rohe, estudió a fondo el concepto de las fachadas ligeras y el uso del vidrio en las mismas. En contra de la corriente predominante en la escuela que dirigía Mies, el arquitecto pareció inclinarse por un uso limitado del vidrio en los muros cortina. Preocupado por los problemas de origen térmico que se desprendían del abuso del vidrio, DePondt optó por estudiar las posibilidades que ofrecía el uso de los muros cortina a base de paneles prefabricados en las fachadas en las que la disposición de los elementos transparentes se organizaban según las necesidades interiores del espacio.

Lake Grove Village es un conjunto de edificios situados en una zona en desarrollo de Chicago donde las viviendas que se proyectaran debían ser de bajo coste. Con "bajo coste", el arquitecto no sólo entendió su construcción, sino también el mantenimiento. Con un presupuesto de 10 millones de dólares, Depondt llevó a cabo 458 viviendas distribuidas en tres edificios de diez plantas cada uno y otros cinco de tres plantas en tan solo doce meses. Lo consiguió gracias a la estandarización e industrialización, dos conceptos que había aprendido y aprehendido de Mies. Sin lugar a duda, la mayor aportación fueron las fachadas, pero la estructura (simple y repetitiva) y las tabiquerías interiores (prefabricadas en seco y desmontables) fueron trabajadas con el mismo empeño y esmero por conseguir un edificio que pudiese ser renovado con el tiempo para acoplarse a las necesidades de los usuarios y a los posibles requerimientos energéticos futuros.

La concordancia entre el diseño y la construcción era impecable, los elementos empleados eran mínimos y estaban estandarizados para facilitar el montaje y reducir errores. De esta manera logró reducir costes y tiempos. Los pilares se montaron en longitudes de dos y tres plantas, los forjados de cerchas metálicas ya venían de serie con el panel que cubriría el frente de los forjados, y los espacios contaban con lo necesario para instalaciones y conductos.

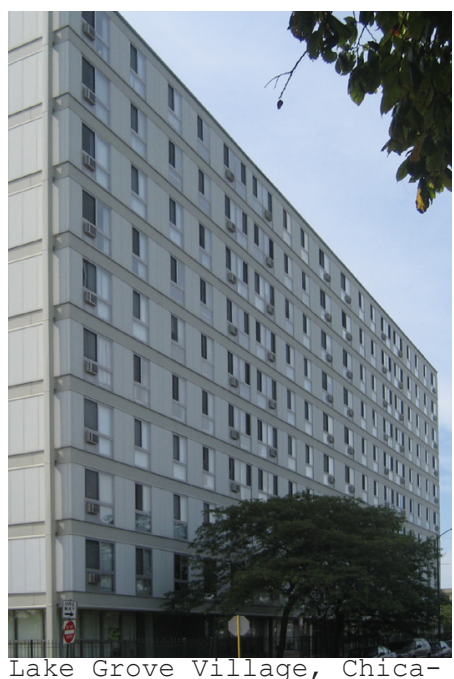

go, 1969, Paul De Pondt. Fotografía año 2009. 
Pero como se ha indicado, lo más novedoso fue el sistema de envolvente del edificio. Los paneles de fachada incluyen un marco de acero, aislamiento térmico y paneles de planchas metálicas en el exterior con un recubrimiento para evitar el deterioro causado por los agentes externos. Los paneles de vidrio, con una altura que iba de suelo a techo, se anclaron a las caras superior e inferior del panel que cubría el frente del forjado. Mediante silicona y gomas que admitían las tolerancias de movimiento de los paneles, la fachada quedaba completamente sellada y hermética. Toda esta experimentación de la fachada se pudo acometer gracias a un análisis de los requerimientos energéticos del lugar, que en el caso de Chicago son especialmente extremos.

Depondt señaló en una entrevista: "...new architectural forms can be reached only through a complete mastery of materials and the only new decisive elements, with respect to the past, come from materials and techniques". "Fue precisamente esta actitud y voluntad por desarrollar técnicas avanzadas de construcción, aun empleando materiales tradicionales, lo que le llevó a experimentar con el concepto de los muros cortina.

Al igual que Mies, se apostó por el acero como material, tanto para la estructura general del edificio como para las estructuras de los sistemas de cerramiento. El acero parecía ser la respuesta que estaba buscando. Debido al reducido peso de los perfiles y cerramientos, los componentes de acero podían ser manejados con mayor facilidad y, por consiguiente, las grúas para elevar las piezas podían ser de menor capacidad. A esto había que añadir la ventaja de la posibilidad de transportar las piezas desde distancias mayores. Además, el arquitecto quiso emplear acero galvanizado para que los efectos de los agentes atmosféricos sobre el material fueran los menos posibles. El acero era también el material empleado en los cerramientos. A diferencia de su maestro, resolvió las fachadas combinando muros cortina de vidrio con otros de paneles sándwich cuya lámina exterior estaba realizada con acero. Las razones, afirmó: la ineficacia del vidrio en aquel momento y las altas posibilidades de materiales aislantes en un muro multicapa. 
Además de las preocupaciones por el traslado, desembalaje y montaje de las piezas -que ya estaban preparadas para ser instaladas- el arquitecto estaba inquieto por el aislamiento acústico de las unidades contiguas. En este caso, debido a la poca inercia o masa de los paneles de la tabiquería interior, sólo podía conseguirse mediante espacios de aire y, para ello, los pilares que separan viviendas contiguas fueron recubiertos por paneles de doble capa creando una cámara de aire que servía de colchón acústico. A ello se añade que, al estar los pilares dentro de la cámara, se resolvía el recubrimiento de protección contra incendios necesarios.

El arquitecto transmitió su voluntad expresa por asegurar un clima interior confortable. A diferencia del hormigón, el acero no tiene la inercia térmica con la que juega el primero, con lo que las pérdidas de calor pueden suponer un grave problema en Chicago. Como en ciudades de estas características, es necesario tener la capacidad de dar una respuesta rápida a los cambios de temperatura, diseñó un sistema de fachadas que asegurasen el intercambio y la renovación de aire por medio de surtidores y extractores incorporados en el cerramiento. Otro elemento que DePondt tuvo en cuenta en sus fachadas fueron las placas solares. Aunque nunca llegaron a incorporarse, el arquitecto francés había proyectado paneles solares en los frentes de forjado de las distintas plantas que, junto con las ideadas para las cubiertas, podían ayudar a alimentar las diferentes unidades.

Al igual que sus coetáneos, el diseño de Lake Grove Village tenía como objeto la flexibilidad de los espacios interiores. En este caso, una de las ventajas que ofrecía el sistema diseñado era que los únicos elementos fijos en los edificios eran la estructura, la instalaciones y los elementos de comunicación vertical como escaleras y ascensores. Por contra, las particiones interiores fueron diseñadas para poder adaptarse a posibles cambios en los tamaños y formas de las estancias, lo que ayudó a la flexibilidad de los espacios dependiendo de las necesidades. Por tanto, el sistema originado en Francia y posteriormente implementado también en Estados Unidos, tiene la capacidad de reducir 
costes y tiempos de ejecución, y ofrecer la posibilidad de la adaptabilidad futura.

Los paneles de la fachada estaban diseñados para ser instalados desde el interior del espacio. Con diferentes recubrimientos de acabado en función de la exposición final, los módulos se inclinaron en la parte superior fijándolos en un canal del alféizar que se encontraba anclado al panel superior. Posteriormente se fija la posición mediante anclajes en la fascia.

El conjunto fue entonces una innovación proyectual y técnica que el arquitecto introdujo en el país de los rascacielos. En el conjunto de viviendas el vidrio empleado era ya un vidrio doble con cámara de aire que, aun sin gas - lámina añadida, tenía un comportamiento frente a su predecesor (vidrio simple) considerablemente mejor. Aun así, sin grandes aspiraciones proyectuales, pero sí una voluntad por ser responsable y coherente en sus decisiones, en una época en la que el vidrio parecía ser el único material para los muros cortina, se demostró que era posible plantear un cerramiento de este tipo combinando vidrio y paneles ligeros. Quizás lo más relevante de la obra fue la estandarización de cada una de sus partes, porque, ¿quién dice que la fachada de Lake Grove Village no pueda cambiarse por una completamente de vidrio sin necesidad de alterar los aspectos generales del proyecto? Lake Grove Village fue diseñado sobre unos pilares arquitectónicos que no difieren tanto de los de hoy día, pero cuya estética lo aleja de los que en la actualidad encontramos. Sin embargo, deja la puerta abierta a posibilidades de adaptación y lo convierte en modelo de modernidad y flexibilidad. Este proyecto ha sido, por tanto, el escenario ideal sobre el que replantear las necesidades de hoy con un sistema de cerramiento que tendrá en cuenta la situación del medio ambiente, así como la percepción del espacio interior sin comprometer las necesidades que las generaciones futuras puedan tener. 


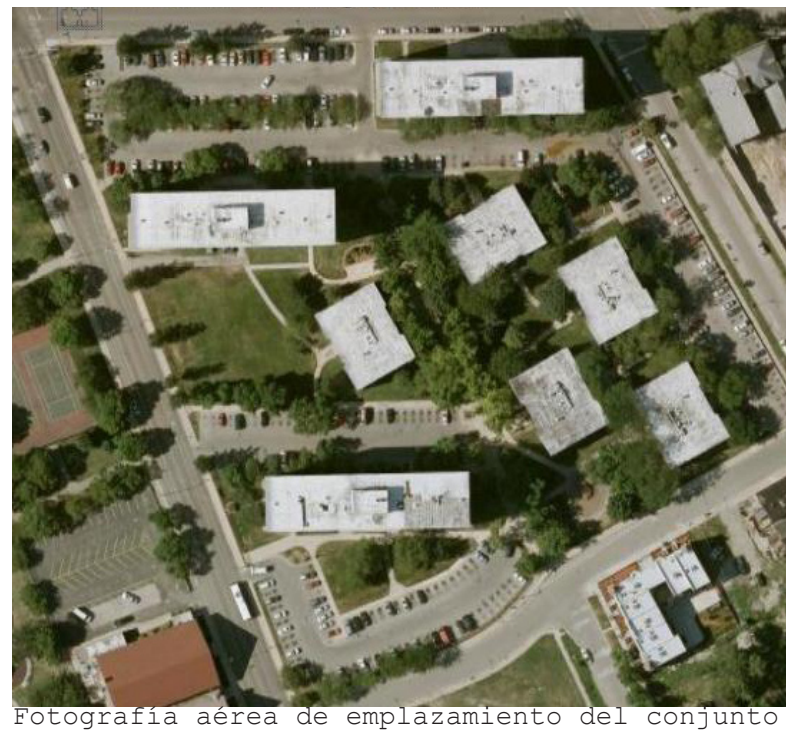
de Lake Grove Village.
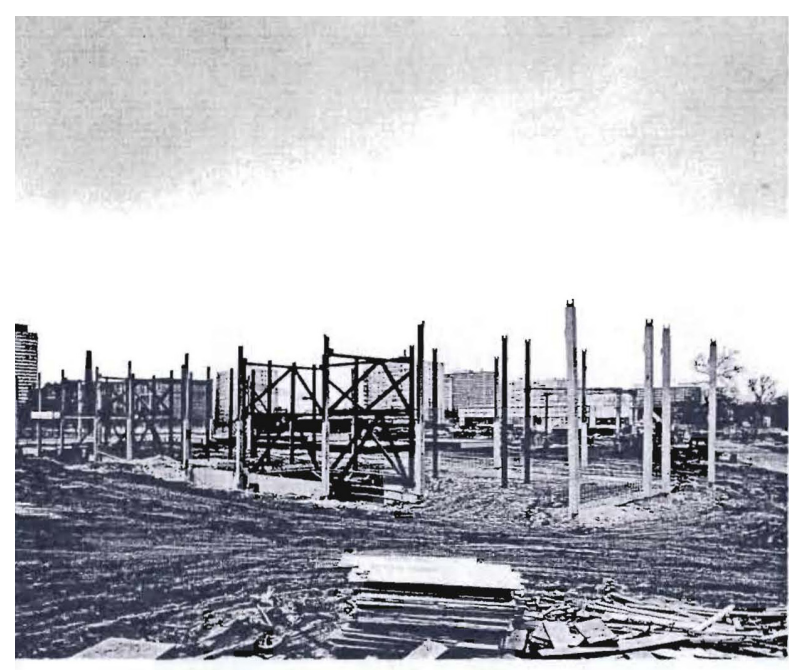

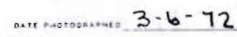

Secuencia constructiva de torre de Lake Grove Village - estructuras verticales, 1972.
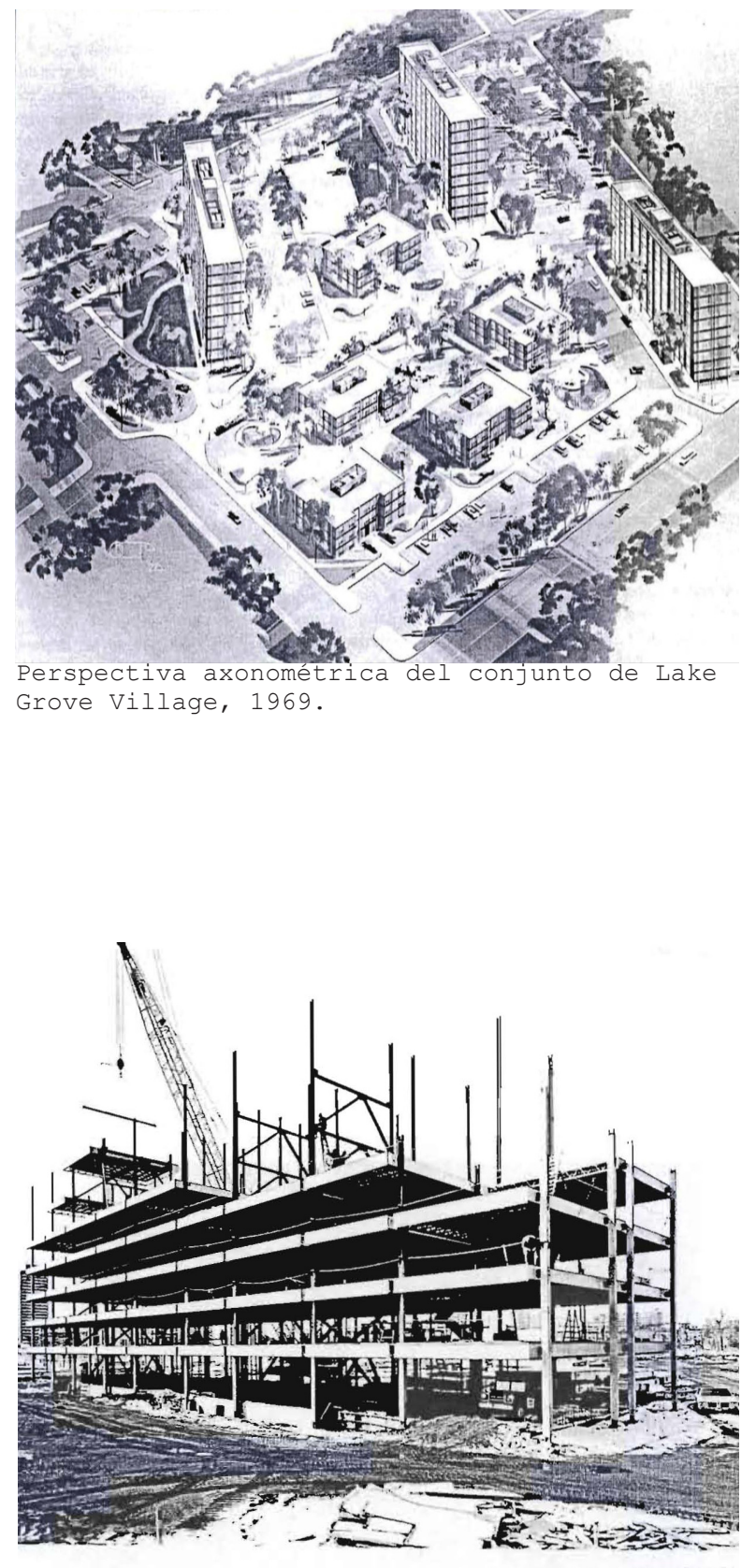

Secuencia constructiva de torre de Lake Grove Village - estructuras horizontales, 1972. 


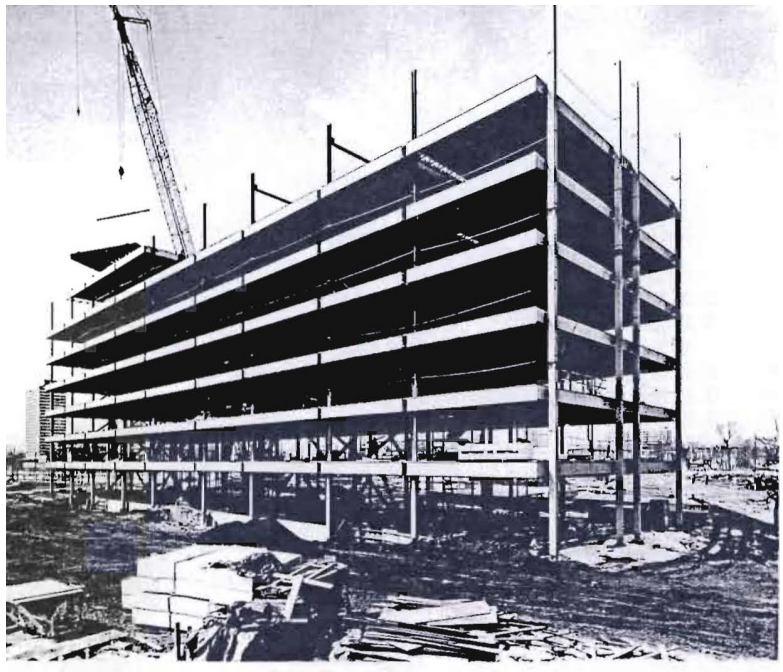

$3-31-72$

Secuencia constructiva de torre de Lake Grove Village - estructuras horizontales, 1972.

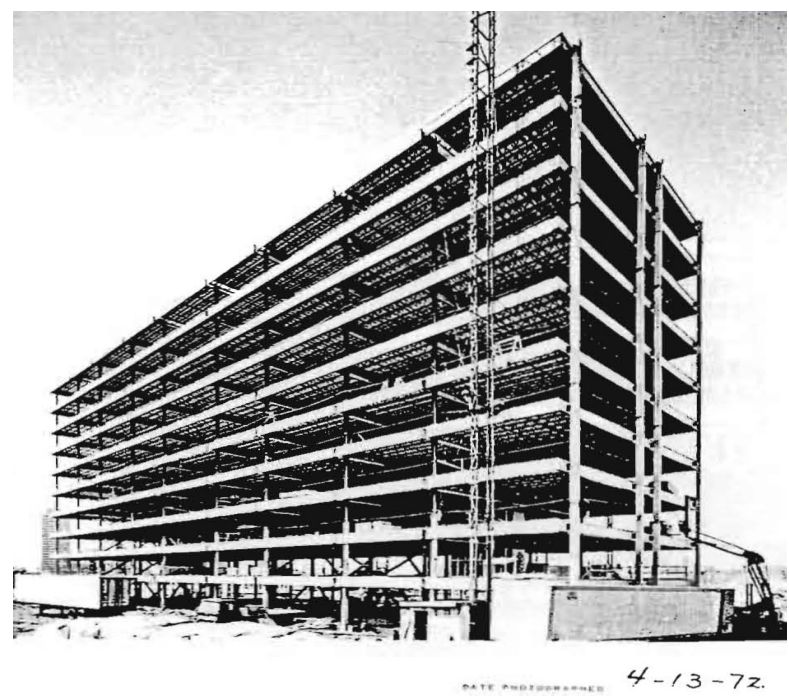

Secuencia constructiva de torre de Lake Grove Village, 1972 .
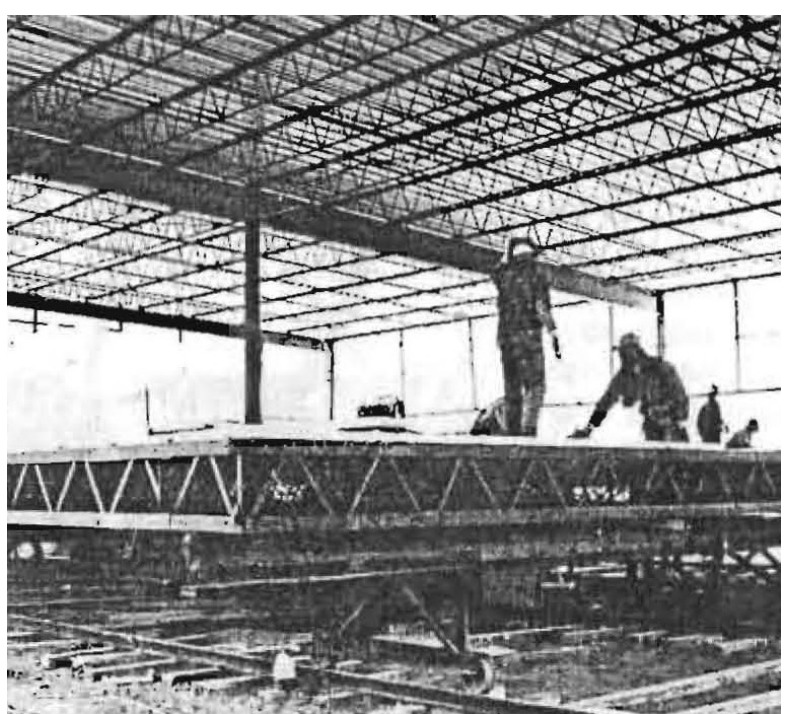
Fotografia de estructuras horizontal prefabricada, 1972 .

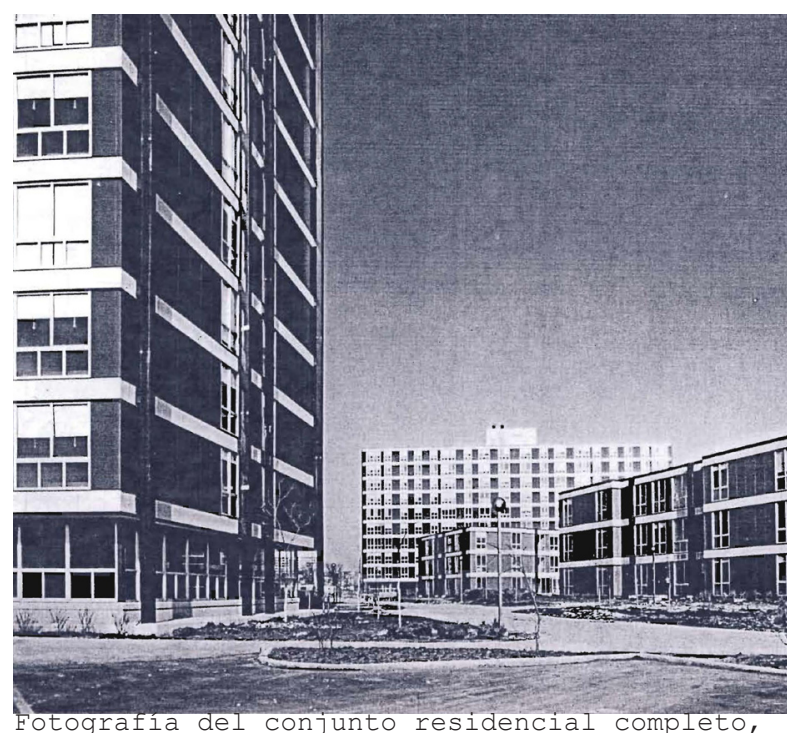

1972 . 


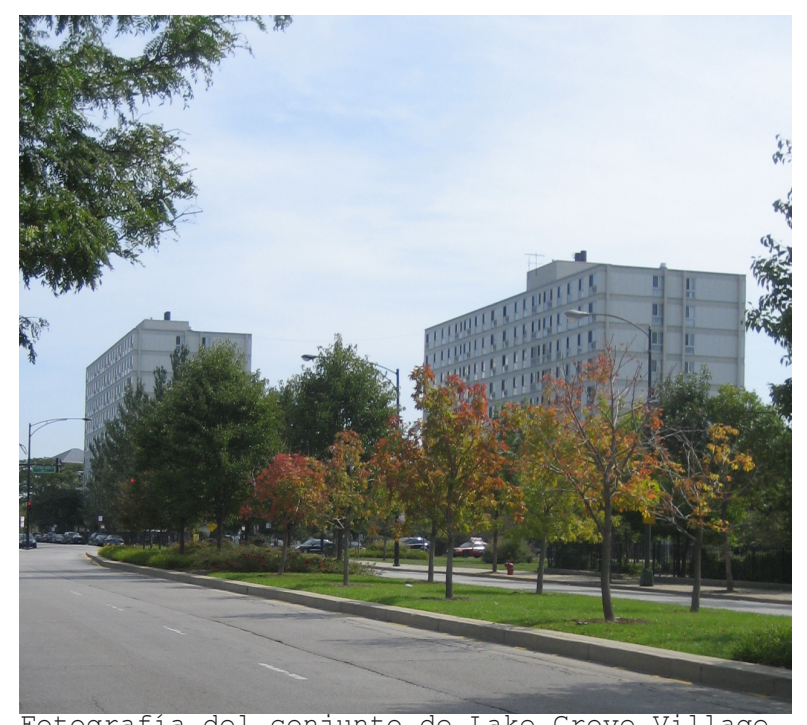

Fotografía del conjunto de Lake Grove Village. Fotografía año 2009.

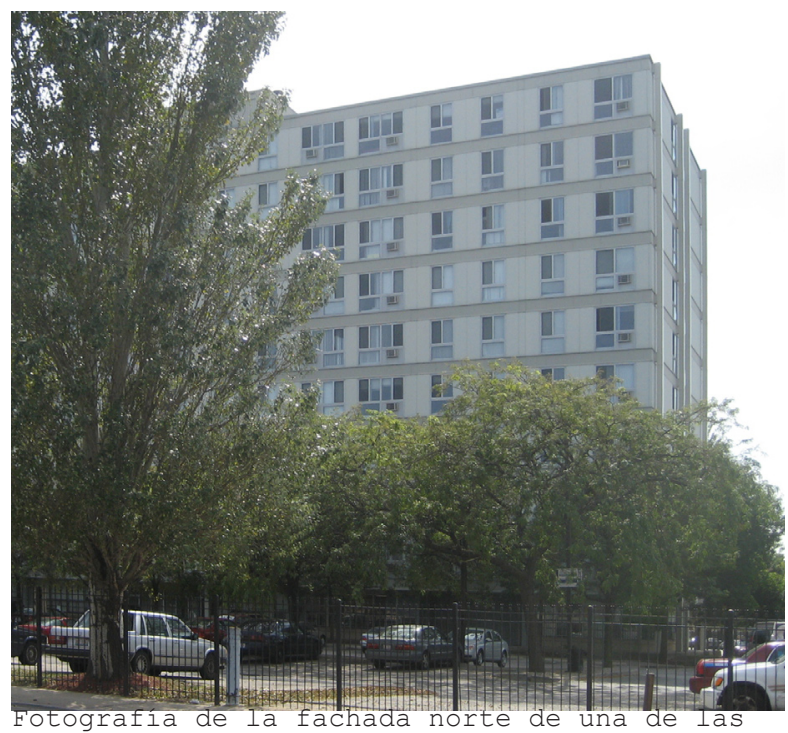

torres del conjunto de Lake Grove Village. Fotografía año 2009 .

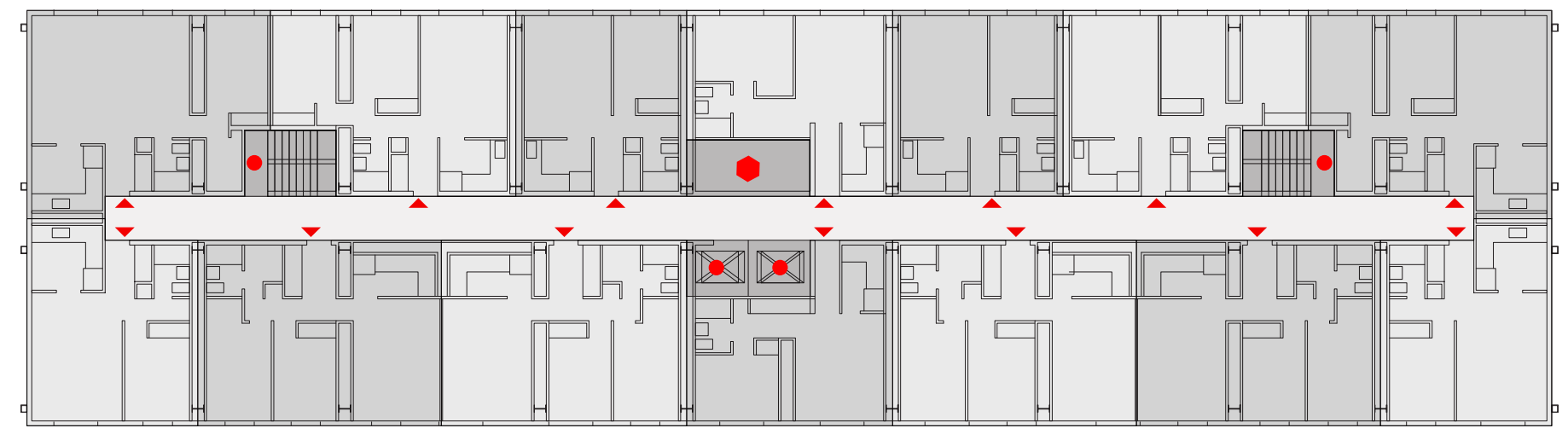

Planta tipo redibjujada de una de las torres residenciales. La orienación norte y sur albergan la mayor parte de los espacios de las viviendas, mientras que la este y oeste comprenden las viviendas en esquina. 

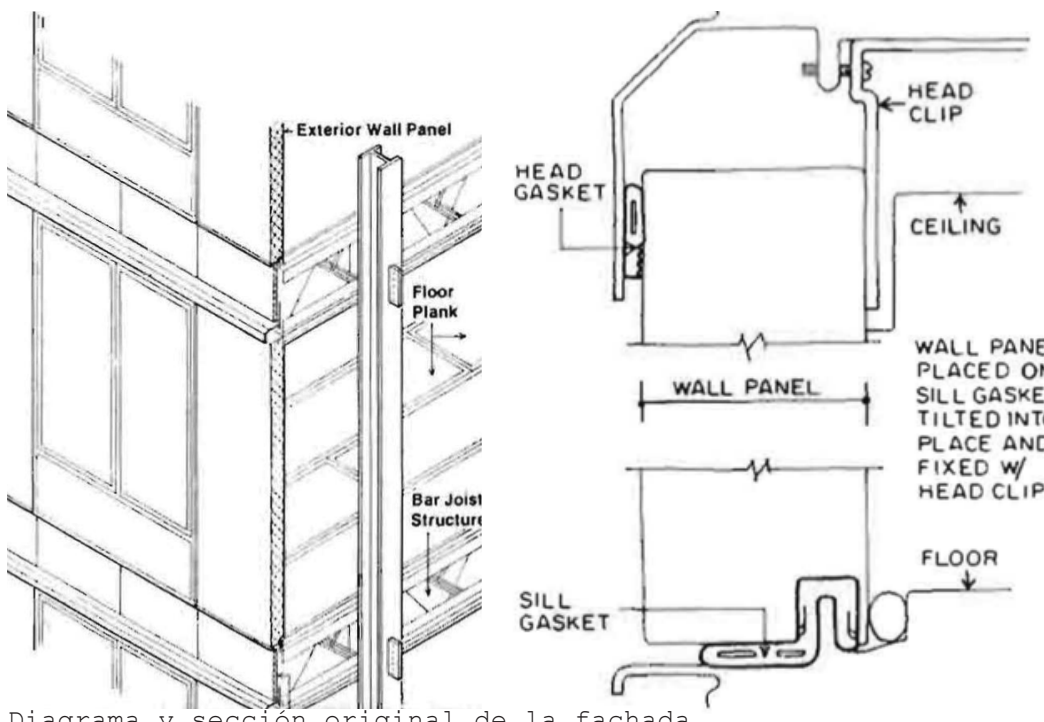

Diagrama y sección original de la fachada.

Diagramas extraídos de la publicación "Steel system building

uses standard parts, familiar materials" Architectural Record, 1972 .

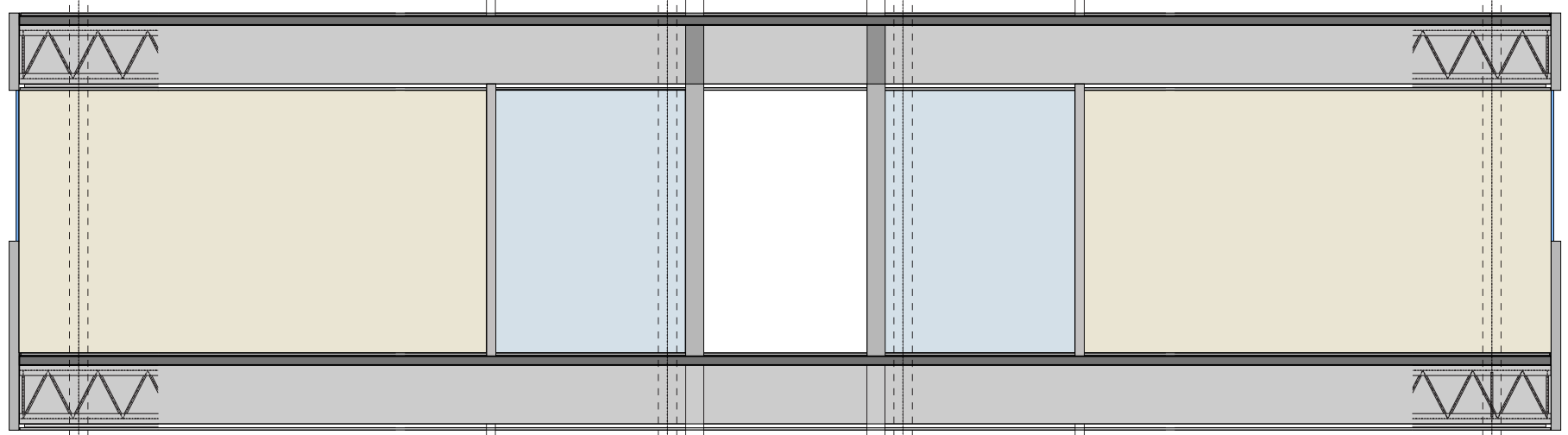

Sección diagramática de la fachada. 

CAPÍTULO 05

5.2 OBJETIVOS DEL DISEÑO Y CAMPO DE TRABAJO.

El alcance de esta investigación incluye el análisis numérico de ciertas decisiones del diseño, así como la evaluación de los efectos que estas decisiones de la envolvente puedan tener en el rendimiento energético de la fachada y/o el edificio, el diseño o el comfort interior. La puesta en práctica de estos estudios se dirigen hacia el proyecto de transformación de la envolvente de Lake Grove Village. Entre otras, es el escenario idóneo para el desarrollo de un proceso que desee enfocarse en las posibilidades de rehabilitación más que de reconstruccion. Con ello, las conclusiones que se extraen de los estudios y análisis numéricos se presentarán dirigidas a la mejora de la envolvente de un edificio ya existente, que en este caso concreto se trata de una fachada prefabricada de paneles sandwich de aluminio. Sin embargo, como antesala a la exposición de los estudios, es pertinente aclarar la intención de que dichos estudios pudiesen ser aplicados a otros proyectos, ya sean estos existentes o de nueva construcción. Además, el interés reside en su adaptabilidad y estudio de sus componentes.

179 
Para ello, se ha establecido un método de estudio con tres variantes.

La primera de estas variantes consiste en evaluar cada orientación de manera independiente y, además, se estudia el efecto que las variantes de la fachada puedan tener en su rendimiento. De esta forma, se lleva a cabo un estudio de cada una de los tipos de fachadas sobre un modelo o prototipo - que se explicará en apartados posteriores - y que servirá para establecer una base común para todos los subsiguientes estudios. La ventaja principal que ofrece este método es la posibilidad de aislar el elemento a estudiar y así poder establecer una comparación relativa de los resultados sin que ello denote que deban ser números absolutos. Además, cada fachada se compone -y descompone- en los distintos elementos que la crean, y estos componentes se convierten en "las piezas del puzzle" que estudiar en términos comparativos. Este método, además de ayudar a la evaluación, establece una conexión directa con la esencia de adaptabilidad que se está presentando en este trabajo, con la consiguiente posibilidad de intercambio de dichos elementos para la obtención de un mejor resultado, ya sea éste definido por el usuario o por el resultado.

La segunda de estas variantes consiste en identificar las combinaciones de los componentes con mayor éxito para las distintas orientaciones. En este caso, y debido a las características de las orientaciones en Chicago, se establecen tres: Norte, Sur, y Este/Oeste. De esta manera, el diseño se extrapola a toda una orientación, permitiendo así al proceso la evaluación en un terreno más amplio: la superficie de fachada. Adicionalmente, y relacionado con la adaptablidad a la que se ha hecho referencia a lo largo de este trabajo, para las fachadas Sur y Este/Oeste se presentan distintas opciones resultado de los análisis. La fachada Norte, que presenta mayores limitaciones en cuanto a posibilidades y requerimientos, se centra en un tipo. Estos conceptos se expondrán y explicarán a lo largo de esta sección.

Finalmente, el estudio lleva al conjunto del edificio los resultados obtenidos. De esta manera, el diseño de cada 
una de las orientaciones Norte, Sur, Este/Oeste se traslada al conjunto del edificio y se evalúa el efecto que dichas combinaciones -y sus componentes- tienen en el cómputo global.

En resumen, los tres campos sobre los que se centra el estudio para demostrar la importancia de evaluar el diseño y la adaptablidad de sus componentes son: el módulo de fachada, la superficie y el edificio. Es aquí donde se establece la tercera dimensión de esta envolvente, creando espacios nuevos o intermedios o formando parte de los mismos. La interacción entre estos tres niveles define el "éxito" de este trabajo. La simplificación inicial de la "piel de vidrio" ha posibilitado el estudio y evaluación de los componentes individuales para poder predecir, y posteriormente lograr, un diseño integrador, adaptable y energéticamente reponsable de la fachada del edificio existente en el sur de Chicago. 



\subsection{ANÁLISIS NUMÉRICO. METODOLOGÍA.}

En esta sección se expone la metodología por la cual el proyecto ha estudiado y analizado los diferentes componentes para una fachada energéticamente responsable y adaptable, dentro de un contexto económicamente sostenible. Se puede anticipar que la evaluación de dichos parámetros está basada en simulaciones informáticas que pueden dar cuantía y métrica a la intención del diseño.

Con el objetivo de aclarar ciertas decisiones que se han ido adoptando a lo largo del proceso de investigación, en primer lugar se explican las hipótesis de los análisis. En segundo lugar, se describe lo que se ha denominado el "prototipo de estudio", así como los diferentes elementos que se han evaluado, con el obejtivo de exponer los posibles efectos que tienen sobre los resultados. En tercer lugar se citan y explican las herramientas que se han empleado. En general, los arquitectos no están familiarizados con muchas de las herramientas existentes para la simulación. La falta de entrenamiento y, en ocasiones, también de conocimientos 


\section{CAPÍTULO 05}

de ciertos componentes mecánicos, dificulta su utilización. Por ello, este trabajo considera de interés establecer una "lista" y puntos que puedan ser de ayuda a quiénes en un futuro puedan estar interesados en realizar un trabajo similar.

Tras explicar las principales herramientas y programas empleados, esta sección expondrá los parámetros que han servido de base para la evaluación y para la interpretación de los resultados. 


\subsubsection{Hipótesis}

Con el fin de evaluar las decisiones de diseño y validar las intenciones de un proyecto desde las primeras etapas del proceso arquitectónico, es importante que el valor de "la métrica" sea reconocido. A efectos de este trabajo, "la métrica" no es otra que poder evaluar numéricamente, mediante una serie de simulaciones informáticas, diferentes conceptos que se tienen en cuenta -en este caso en lo relativo a envolventes - en el proyecto de transofrmación de la envolvente de Lake Grove Village. De esta manera, analizar y sustentar los diferentes elementos que se han ido diseñando y estudiando. La simulación no es el objetivo, tan sólo es un método de apoyo que se ha empleado en el proceso de diseño.

Cuando, ya sea en etapas inciales del proceso de diseño o durante un proceso de rehabilitación, se desea evaluar el comportamiento de una fachada, disponer de la información necesaria puede resultar difícil. A pesar de que el objetivo de este trabajo incluye analizar una propuesta de diseño de una fachada, en un primer estadio se han aislado sus componentes, como por ejemplo el vidrio o los dispositivos de control solar, y se han fijado otros para simplificar el proceso. Esto ha permitido que el estudio se centre sólo en la evaluación de los sistemas que se están diseñando: las envolvente de vidrio.

Para ello se ha escogido una unidad como "prototipo" con el fin de simplificar el estudio. En este caso, una unidad de espacio en Lake Grove Village. Cada espacio en el edificio está relacionado con una unidad de fachada que, al aislarlo, permite entender el comportamiento de las propuestas arquitectónicas que se van desarrollando de manera individual. En términos de simulación energética este sistema simplifica el proceso ya que, entre otros, asume que no hay intercambio energético a través de las paredes, excepto la superficie de fachada que se está estudiando.

El elemento individual aislado como prototipo de estudio es, por tanto, representación de una única zona con las propiedades mostradas a continuación. 


\begin{tabular}{|c|c|c|c|c|}
\hline Área 20'x20' & $\begin{array}{c}\text { Volúmen } \\
20^{\prime} \times 20 \times 11^{\prime}\end{array}$ & $\begin{array}{c}\text { Altura entre } \\
\text { pisos }\end{array}$ & $\begin{array}{c}\text { Suelo a te- } \\
\text { cho máxima } \\
\text { área de ven- } \\
\text { tana }\end{array}$ & $\begin{array}{c}\text { Frente de } \\
\text { Forjado }\end{array}$ \\
\hline 400 & 4400 & $11^{\prime}$ & $8^{\prime}-6^{\prime \prime}$ & $2^{\prime}-6^{\prime \prime}$ \\
\hline
\end{tabular}

Con el fin de centrar el estudio únicamente en el rendimiento energético de aquellos componentes que afectan el diseño, ciertos parámetros se han establecido como base:

\begin{tabular}{|c|c|c|c|}
\hline Cargas Internas & $\begin{array}{l}\text { Ventilación, } \\
\text { Calefacción y } \\
\text { Refrigeración }\end{array}$ & Iluminación & $\begin{array}{l}\text { Propiedades de } \\
\text { los materiales }\end{array}$ \\
\hline $\begin{array}{c}\text { Cargas internas } \\
\text { definidas por los } \\
\text { estándares de } \\
\text { vivienda }\end{array}$ & $\begin{array}{c}\text { Ventilación: } 0.2 \\
\text { intercambios por } \\
\text { hora }\end{array}$ & $\begin{array}{c}\text { Cargas inter- } \\
\text { nas definidas por } \\
\text { estándares de } \\
\text { vivienda }\end{array}$ & $\begin{array}{l}\text { Techo: superficie } \\
\text { adiabática; Uva- } \\
\text { lue: } 0.09 \mathrm{~W} / \mathrm{m} 2 \mathrm{~K}\end{array}$ \\
\hline \multirow[t]{4}{*}{$\begin{array}{l}\text { Grados de acti- } \\
\text { vidad definidos } \\
\text { por DIN1946 }\end{array}$} & $\begin{array}{c}\text { Calefacción: } \\
\text { temperatura am- } \\
\text { biente de } 20^{\circ} \mathrm{C} \text {. } \\
\text { Modo verano de } \\
\text { Abril a Septiem- } \\
\text { bre }\end{array}$ & & $\begin{array}{l}\text { Suelo: superficie } \\
\text { adiabática; Uva- } \\
\text { lue: } 0.09 \mathrm{~W} / \mathrm{m} 2 \mathrm{~K}\end{array}$ \\
\hline & $\begin{array}{l}\text { Refrigeración: } \\
\text { temperatura am- } \\
\text { biente de } 24^{\circ} \mathrm{C}\end{array}$ & & $\begin{array}{c}\text { Particiones: } \\
\text { superficie adia- } \\
\text { bática; Uvalue: } \\
0.09 \mathrm{~W} / \mathrm{m} 2 \mathrm{~K}\end{array}$ \\
\hline & & & $\begin{array}{c}\text { Superficies opa- } \\
\text { cas de la en- } \\
\text { volvente: Rva- } \\
\text { lue: } 26 \text {, Uvalue: } \\
0.2 \mathrm{~W} / \mathrm{m} 2 \mathrm{~K}\end{array}$ \\
\hline & & & $\begin{array}{c}\text { Carpinterías ex- } \\
\text { teriores: alumi- } \\
\text { nio con rotura } \\
\text { de puente tér- } \\
\text { mico }\end{array}$ \\
\hline
\end{tabular}

Propotipo de estudio: una unidad de vivienda de LGV.

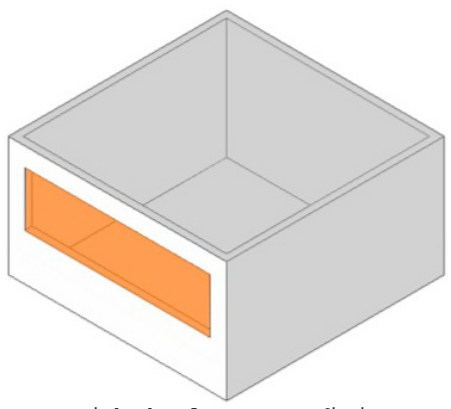

La unidad: la superficie se limita a la envolvente.

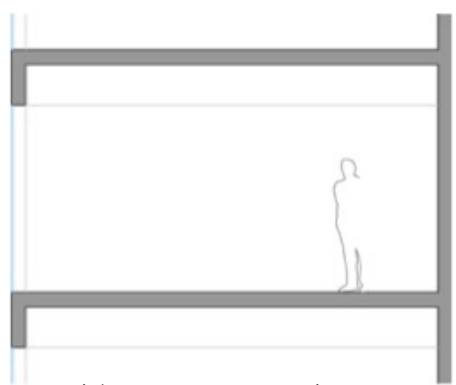

Sección del prototipo de estudio. 


\subsubsection{Características del Prototipo de Estudio}

El prototipo de estudio de lo que se conoce como "singlezone" se ha establecido para poder llevar a cabo el estudio que los diferentes componentes de la fachada tienen en el consumo energético del espacio. Por consumo energético este estudio se centra en el consumo de calefacción y aire acondicionado. Para ello, primero se evalúa el efecto de la orientación de la fachada en la selección del vidrio. En segundo lugar, debido a que el área de superficie transparente en comparación a la opaca tiene consecuencias directas sobre el consumo energético, se lleva a cabo un análisis numérico de dicho parámetro. En tercer lugar, tras estudiar las posibilidades teóricas de los dispositivos de control solar -excepto el efecto de películas o recubrimientos en el vidrio-, ha sido de gran utilidad estudiar cómo el diseño de la pared de vidrio puede variar con la incorporación de dichos dispositivos.

Con ello, los diferentes análisis presentan los datos numéricos para una variedad de fachadas de vidrio que, aunque en este caso corresponden a un escenario específico, pretenden poder ser traslados a otros contextos o diseños. Tras esta breve reseña de los diferentes elementos que deben ser analizados, se presentan las particularidades de cada uno dichos componentes y las propiedades específicas en las que este trabajo ha considerado oportuno prestar mayor atención.

\section{Tipos de Vidrio}

El vidrio en las envolventes de los edificios es uno de los principales materiales utilizados. Dejando a un lado las razones que llevan a su elección, la selección de un tipo de vidrio frente a otro es un factor que debe ser considerado, analizado y evaluado para un uso eficiente de la energía en lo referente al diseño de las fachadas de vidrio. No sólo la selección de un vidrio determinado afecta la imagen de un edificio, sino también influyen en la percepción que tienen los usuarios del mundo exterior. Las películas, gases, número de paneles, tintes o recubrimientos en la unidad, determinan el aspecto y la posibilidad de inte- 
ractuar visualmente con el espacio exterior. Sin embargo, son igualmente importantes otros factores relacionados con el comportamiento de una fachada, y que están directamente relacionados con la selección del vidrio que influyen, por ejemplo, en el espacio interior y en la percepción de confort climático.

Es decir, los componentes de un panel de vidrio determinarán su comportamiento en cuanto a la transmisión de energía -ganancias y pérdidas- o el deslumbramiento y, por consiguiente, influyen en el rendimiento del edificio.

Para este trabajo se han seleccionado una serie de vidrios en función de su posible aplicación en un edificio residencial. Como tal, el diseño de la fachada aspira a ser lo más transparente posible para poder aprovechar la iluminación natural y las ganancias energéticas -especialmente en verano- sin interrumpir las vistas del interior. Por ello, los vidrios escogidos carecen de tintes o coloración, y permiten la mayor entrada de luz posible. La tabla que aparece a continuación especifica los vidrios que han sido seleccionados para el análisis:

\begin{tabular}{|c|c|c|c|c|c|}
\hline $\begin{array}{l}\text { Double } \\
\text { Clear / } \\
\text { Air }\end{array}$ & $\begin{array}{c}\text { Double } \\
\text { Clear } \\
\text { Spectrally } \\
\text { Selective } \\
\text { Low-e (\#2) } \\
\text { / Argon }\end{array}$ & $\begin{array}{c}\text { Triple } \\
\text { Clear } \\
\text { Spectrally } \\
\text { Selective } \\
\text { Low-e (\#2) } \\
\text { / Argon }\end{array}$ & $\begin{array}{c}\text { Triple } \\
\text { Clear } \\
\text { Spectrally } \\
\text { Selective } \\
\text { Low-e (\#5) } \\
\text { / Argon }\end{array}$ & $\begin{array}{c}\text { Triple } \\
\text { Clear } \\
\text { Spectrally } \\
\text { Selective } \\
\text { Low-e (\#2 } \\
\text { \& \#5) / } \\
\text { Krypton }\end{array}$ & $\begin{array}{l}\text { Heat Mi- } \\
\text { rror Quad } \\
\text { Glass ( } 3 \\
\text { films }\end{array}$ \\
\hline $\begin{array}{c}\text { Grosor de } \\
\text { vidrio: } \\
25\end{array}$ & $\begin{array}{c}\text { Grosor de } \\
\text { vidrios: } \\
25\end{array}$ & $\begin{array}{c}\text { Grosor de } \\
\text { vidrios: } \\
44\end{array}$ & $\begin{array}{c}\text { Grosor de } \\
\text { vidrios: } \\
44\end{array}$ & $\begin{array}{c}\text { Grosor de } \\
\text { vidrios: } \\
44\end{array}$ & $\begin{array}{l}\text { Grosor de } \\
\text { vidrios: } \\
51.2\end{array}$ \\
\hline $\begin{array}{c}\text { Uvalue: } \\
2.7\end{array}$ & $\begin{array}{c}\text { Uvalue: } \\
1.4\end{array}$ & $\begin{array}{c}\text { Uvalue: } \\
1.0\end{array}$ & $\begin{array}{c}\text { Uvalue: } \\
1.0\end{array}$ & $\begin{array}{c}\text { Uvalue: } \\
0.7\end{array}$ & $\begin{array}{c}\text { Uvalue: } \\
0.4\end{array}$ \\
\hline $\begin{array}{l}\text { SHGC: } \\
0.701\end{array}$ & $\begin{array}{l}\text { SHGC: } \\
0.374\end{array}$ & $\begin{array}{l}\text { SHGC: } \\
0.342\end{array}$ & $\begin{array}{l}\text { SHGC: } \\
0.419\end{array}$ & $\begin{array}{l}\text { SHGC: } \\
0.403\end{array}$ & $\begin{array}{l}\text { SHGC: } \\
0.282\end{array}$ \\
\hline $\begin{array}{l}\text { Tvis: } \\
0.786\end{array}$ & $\begin{array}{l}\text { Tvis: } \\
0.703\end{array}$ & $\begin{array}{l}\text { Tvis: } \\
0.627\end{array}$ & $\begin{array}{l}\text { Tvis: } \\
0.627\end{array}$ & $\begin{array}{l}\text { Tvis: } \\
0.603\end{array}$ & $\begin{array}{l}\text { Tvis: } \\
0.491\end{array}$ \\
\hline
\end{tabular}




\section{Superficie de Vidrio en Fachada}

La influencia que la relación entre la superficie de vidrio y la superficie opaca tiene en la selección del vidrio es un aspecto que todavía no está resuelto. Tradicionalmente, se ha considerado que cuanto menor fuera el área de la superficie de vidrio mejor sería el rendimiento de la fachada y, por tanto, también sería menor el consumo energético. Sin embargo, a lo largo de este trabajo se ha evaluado el efecto y determinar que la utilización de ciertos vidrios ha beneficiado el consumo energético, incluso cuanto mayor era la superficie acristalada. Para ello han definido una serie de ratios de superficie acristalada frente a superficie opaca para los diferentes vidrios evaluados.

\begin{tabular}{|c|c|c|c|c|c|c|c|}
\hline $\begin{array}{l}\circ \mathrm{V} I- \\
\text { DRTO }\end{array}$ & $100 \%$ & $80 \%$ & $60 \%$ & $50 \%$ & $40 \%$ & $20 \%$ & $18.75 \%$ \\
\hline & $\begin{array}{c}\text { o Es- } \\
\text { cogi- } \\
\text { do por } \\
\text { condi- } \\
\text { cionan- } \\
\text { tes del } \\
\text { diseño }\end{array}$ & & & $\begin{array}{c}\text { Superfi- } \\
\text { cie de } \\
\text { acris- } \\
\text { tala- } \\
\text { miento } \\
\text { por } \\
\text { código }\end{array}$ & & & $\begin{array}{l}\text { Mínima } \\
\text { super- } \\
\text { ficie } \\
\text { acris- } \\
\text { talada } \\
\text { por los } \\
\text { reque- } \\
\text { rimien- } \\
\text { tos del } \\
\text { espacio }\end{array}$ \\
\hline
\end{tabular}

Sin embargo, debido a que una de las premisas del diseño de la fachada de Lake Grove Village es el de una superficie continua de suelo a techo, este aspecto se ha estudiado pero no se considerará como elemento de diseño. Los resultados han servido para entender el comportamiento, pero su aplicación no forma parte de este trabajo. 


\section{Mecanismos de Control Solar}

El tercer grupo de elementos seleccionados para el análisis debido a su indudable efecto sobre el rendimiento de la fachada de vidrio son los dispositivos de control solar. Pese a reconocer que los resultados obtenidos al añadir dispositivos de control solar no definen el comportamiento del vidrio en sí sino que determinan el de la fachada en su conjunto, estos deben ser estudiados para poder entender el comportamiento de la pared de vidrio.

Hoy día, la diversidad de dispositivos de control solar disponible en el mercado es extensa. Sin embargo, para el propósito de este proyecto se ha limitado la selección del vidrio a ciertos tipos, ya que la intención no es validar la idoneidad de un fabricante frente a otro, sino evaluar el efecto de los mismos en el consumo energético de la fachada. Al mismo tiempo, analizar su repercusión en el resto de los componentes. Por ello, los sistemas seleccionados están basados en su idoneidad y uso dependiendo de la orientación de cada fachada.

A continuación se exponen los sistemas de protección solar que se han seleccionado y las razones que han llevado a ello:

Los vidrios de Control Solar han sido analizados para todas las orientaciones. En el proyecto se estudian unidades de vidrio en las que se han incorporado medidas para controlar y regular la entrada de luz solar y de energía a través de la superficie en forma de películas o recubrimientos, gases en la cavidad y número de paneles de vidrio. Ya que los medios de control solar son apropiados y recomendables para todas las orientaciones, la decisión de qué vidrio emplear vendrá dada por la evaluación de cada tipo en las diferentes orientaciones.

Los sistemas de protección solar situados en el interior del espacio no son tan eficaces como los situados en el exterior de la fachada. Sin embargo, su uso es recomendado para todas las orientaciones ya que puede impedir la entrada de ciertas porciones del calor solar sin impedir 
las vistas al exterior. Además, los sistemas situados en el interior ayudan a controlar el deslumbramiento existente en las distintas orientaciones. Para este proyecto la selección de los sistemas de protección solar interiores se ha basado en dos factores: el factor de opacidad o apertura y en el factor de reflexión. La tabla que aparece a continuación detalla los sistemas de control solar estudiados junto con las propiedades de apertura y reflexión.

\begin{tabular}{|c|c|c|c|}
\hline Fachada Norte & Fachada Sur & Fachada Este & Fachada Oeste \\
\hline OF: 15\%, R: 0.63 & OF: 3\%, R: 0.47 & OF: 3\%, R: 0.47 & OF: 3\%, R: 0.47 \\
\hline & $\begin{array}{l}\text { OF: 5\%, R: 0.69 } \\
\text { (for HMQ glass) }\end{array}$ & $\begin{array}{c}\text { OF: 5\%, R: } 0.69 \\
\text { (for HMQ glass) }\end{array}$ & $\begin{array}{l}\text { OF: 5\%, R: 0.69 } \\
\text { (for HMQ glass) }\end{array}$ \\
\hline
\end{tabular}

Los voladizos o proyecciones horizontales como medida de protección solar son beneficiosos para las fachadas orientadas al Sur, ya que el ángulo alto del sol durante el verano se puede bloquear sin que por ello se interfiera con las vistas. Durante el transcurso de este estudio se ha analizado la profundidad óptima de dicha proyección para que no interfiera con la entrada de energía solar durante los meses de invierno y, por otra parte, bloquee la entrada de calor durante los meses con temperaturas más elevadas; en Chicago, el ángulo del sol el 21 de diciembre es de 26 grados y de 72 al mediodía del 21 de junio. Edward Mazria, a quien se ha nombrado con anterioridad y ha servido como referencia para varios de los estudios teóricos llevados a cabo, establece la siguiente directriz: la proyección óptima [P] para la orientación sur es P=Altura/Factor que depende de la latitud. En este proyecto las proyecciones se han estudiado en términos de balcones paredes de doble capa. La tabla siguiente describe las propiedades de la proyección horizontal analizada:

\begin{tabular}{|c|c|c|c|}
\hline Fachada Norte & Fachada Sur & Fachada Este & Fachada Oeste \\
\hline NA & $\begin{array}{c}\mathrm{P}=3.14 \mathrm{~m} / 2.8= \\
1.21 \mathrm{~m} .\end{array}$ & NA & NA \\
\hline & & $\begin{array}{c}\text { El ángulo solar } \\
\text { bajo llevaría } \\
\text { a proyecciones } \\
\text { excesivas }\end{array}$ & $\begin{array}{c}\text { El ángulo solar } \\
\text { a projoyecciones } \\
\text { excesivas }\end{array}$ \\
\hline
\end{tabular}


LOS sistemas de lamas horizontales regulables situadas en el exterior de la fachada se han estudiado en la fachada orientada a Sur, donde se ha comprobado que pueden excluir de la entrada directa de calor al espacio sin tener un efecto negativo sobre las vistas desde el interior. Para ello se han seleccionado el tipo de sistema descrito en la tabla que aparece a continuación:

\begin{tabular}{|c|c|c|c|}
\hline Fachada Norte & Fachada Sur & Fachada Este & Fachada Oeste \\
\hline NA & $\begin{array}{c}\text { Lamas horizon- } \\
\text { tales de vidrio } \\
\text { laminado con } \\
\text { pelicula de baja } \\
\text { emisividad de } \\
\text { espectro selec- } \\
\text { tivo }\end{array}$ & $\begin{array}{c}\text { NA } \\
\text { El ángulo solar } \\
\text { bajo lievaría } \\
\text { cerrar las lamas } \\
\text { para poder blo- } \\
\text { quear el sol }\end{array}$ & $\begin{array}{c}\text { El ángulo solar } \\
\text { cerrar las las lamas } \\
\text { parader blo- } \\
\text { quear el sol }\end{array}$ \\
\hline
\end{tabular}

Los sistemas de lamas verticales regulables situados en el exterior de la fachada se han estudiado para las superficies de vidrio orientadas al Este y Oeste. Debido al bajo ángulo de incidencia del sol, bloquean el exceso de energía solar con una mínima interrupción de las vistas, reduciendo las cargas de aire acondicionado especialmente durante las primeras y últimas horas de sol en ambas orientaciones. A continuación se muestran las características:

\begin{tabular}{|c|c|c|c|}
\hline Fachada Norte & Fachada Sur & Fachada Este & Fachada Oeste \\
\hline NA & NA & $\begin{array}{c}\text { Lamas vertica- } \\
\text { les de vidrio } \\
\text { laminado con } \\
\text { pelicula de baja } \\
\text { emisividad de } \\
\text { espectro selec- } \\
\text { tivo }\end{array}$ & $\begin{array}{c}\text { Lamas vertica- } \\
\text { les de vidrio } \\
\text { laminado con } \\
\text { emisividad de } \\
\text { espectro selec- } \\
\text { tivo }\end{array}$ \\
\hline & $\begin{array}{c}\text { El ángulo solar } \\
\text { bajo llevaria } \\
\text { cerrar las lamas } \\
\text { para poder blo- } \\
\text { quear el sol }\end{array}$ & \\
\hline
\end{tabular}


Por último, este proyecto ha estudiado la posibilidad de diseñar y emplear superficies inclinadas de fachadas de vidrio como un mecanismo integrado y alternativo de protección solar. Esta propuesta se ha aplicado a las fachadas orientadas al sur, aunque los beneficios de la misma en las fachadas orientadas al Este y Oeste también podrían ser aplicados. Las tres orientaciones están expuestas a la radiación directa del sol a lo largo del año, lo que permite inclinar la superficie de vidrio para controlar la entrada de calor. El nivel y grado de inclinación ha sido determinado para aprovechar la entrada en invierno y bloquearla en verano. Debido a la imposibilidad de simular las condiciones en las fachadas Este y Oeste, el estudio se ha limitado a estudiar los beneficios en la fachada sur. A continuación se muestran las propiedades del vidrio inclinado.

\begin{tabular}{|c|c|c|c|}
\hline Fachada Norte & Fachada Sur & Fachada Este & Fachada Oeste \\
\hline $\mathrm{NA}$ & $\begin{array}{c}\text { Inclinación } \\
\text { vertical con un } \\
\text { ángulo de } 20^{\circ} \\
\text { para reducir la } \\
\text { entrada de ener- } \\
\text { gía solar en va- } \\
\text { rano y permitir } \\
\text { las ganancias en } \\
\text { invierno }\end{array}$ & $\begin{array}{c}\text { La inclinación } \\
\text { horizontal hacia } \\
\text { el Norte podría } \\
\text { reducir las ga- } \\
\text { nancias energé- } \\
\text { ticas }\end{array}$ & $\begin{array}{l}\text { La inclinación } \\
\text { horizontal hacia } \\
\text { el Norte podría } \\
\text { reducir las ga- } \\
\text { nancias energé- } \\
\text { ticas }\end{array}$ \\
\hline & & $\begin{array}{c}\text { No se ha estu- } \\
\text { diado }\end{array}$ & $\begin{array}{c}\text { No se ha estu- } \\
\text { diado }\end{array}$ \\
\hline
\end{tabular}




\subsubsection{Herramientas de Análisis}

La evaluación y validación de los componentes del diseño requiere seleccionar las herramientas adecuadas para los análisis. No supone un proceso fácil, y el tiempo dedicado a entender y evaluar cuáles serían las herramientas, es considerable. Teniendo en cuenta el objetivo de este trabajo teórico-práctico, y siendo consciente de, en ocasiones, la falta de familiaridad con este tipo de herramientas, se ha considerado oportuno ofrecer un resumen de los pros y contras encontrados. Para ello, en los siguientes apartados se establece una relación de las características de los instrumentos. El objetivo es que este análisis sirva de introducción a todos aquellos interesados en esta área, y les permita seleccionar de manera más rápida y eficaz cada herramienta.

Casanova (http://nesal.uni-siegen.de/index.htm?/softlab/ casanova e.htm): herramienta gratuita desarrollada por la Universidad de Siegen diseñada para determinar las demandas de calefacción y refrigeración, así como la temperatura ambiental de los espacios. Al tratarse de una herramienta educativa, su interfaz es intuitiva y de variables y opciones sencillas; permite a los usuarios conocer la relación entre los parámetros de la geometría del edificio, las orientaciones, los vidrios y sus propiedades de aislamiento, así como los flujos energéticos a través de los espacios.

Una de las principales ventajas de esta herramienta es que hay una diversidad de parámetros con los que el usuario puede interactuar, y al mismo tiempo son lo suficientemente limitados para no crear confusión e incertidumbre. Las variables permiten ser ajustadas de manera sencilla, intuitiva y gráfica. Al modificar un parámetro aparece el cambio en un gráfico. Sin embargo, los tipos de edificación predeterminados son limitados y, por ejemplo, la localización debe encontrarse dentro de territorio alemán o en ciudades especificadas. De lo contrario se requiere una conversión de zona climática, lo que puede crear cierta incertidumbre de la validez de los resultados. Por otra parte, la demanda de calefacción está basada en normas europeas, por lo que al analizar proyectos en otros territorios podría no ser tan 
útil a no ser que se establezca un factor de conversión. Uno de los inconvenientes radica en que, aunque la representación gráfica y las tablas son de fácil comprensión, los diagramas que explican los flujos energéticos a través de la construcción contienen conceptos que resultan complejos para usuarios inexpertos en sistemas mecánicos.

No obstante, si el proyecto que se está analizando se enmarca en los parámetros que Casanova expone, nos encontramos ante una herramienta muy útil para las primeras etapas del diseño, donde el objetivo se limita a aspectos que se refieren a la orientación y geometría o a la influencia de la relación entre la superficie acristalada y la superficie opaca.

COMFEN (http://windows.lbl.gov/software/comfen/comfen. html) es una herramienta gratuita desarrollada por Lawrence Berkeley National Laboratory (LBNL), diseñada para servir de apoyo a la evaluación de sistemas de vidrio especialmente destinados a los edificios de uso comercial. Como otras herramientas del LBNL, ofrece una precisión y biblioteca de datos validados que se relaciona con el Departamento de Energía de Estados Undios. Vinculado a Energyplus -herramienta que se analiza más adelante en esta sección-, tiene la ventaja de ofrecer una interfaz sencilla y manejable. De esta manera, permite a los usuarios analizar el efecto de parámetros tales como la relación entre la superficie de vidrio y la superficie opaca y, especialmente, el efecto que determinados vidrios tiene en la demanda de calefacción, refrigeración e iluminación. Se trata de una herramienta muy útil para el diseño de fachadas de vidrio para analizar la optimización de la fachada desde las primeras etapas de un proyecto. Dado que el análisis se basa en un prototipo que representa una parte del global, los parámetros mecánicos y sistemas son fijos, con lo que se establece una comparación variable entre los resultados. Esto tiene ventajas y desventajas. Por un lado, si el proyecto en cuestión tiene condiciones similares a los que utiliza COMFEN, los valores de entrada son sencillas y de fácil elección. Por otro lado, el usuario no puede modificar ciertos parámetros, lo cual puede ser una dificultad en determinados casos. Esta herramienta está dirigida a arquitectos e ingenieros, así 
como a fabricantes de ventanas que quieran comprobar la eficacia de sus productos. Esto se debe, en parte, al hecho de que al formar parte del LBNL, CONFEN está directamente vinculada a Window -programa que se analiza más adelante en esta sección-, que permite a los usuarios estudiar casi todos los tipos de vidrio e incluso crear el suyo propio. Otra ventaja reside en que los resultados se presentan en un análisis comparativo, lo que permite no sólo evaluar las decisiones, sino comprar su efecto individualmente.

Por lo tanto, debido a la manejabilidad de su interfaz, su vinculación a una amplia base de datos, y debido también al sofisticado programa de simulación al que está vinculado, COMFEN es una herramienta atractiva que permite una evaluación y comparación sencilla. El mayor inconveniente para este proyecto es que esta herramienta está dirigida al estudio de edificios comerciales. Sin embargo, el LBNL ha creado RESEEN, destinado a los proyectos de uso residencial y que calcula las cargas de calefacción y refrigeración relacionadas con la fachada mediante la definición de tipo de vivienda, condiciones geográficas, orientación, cargas eléctricas y de gas, así como las propiedades del entorno y las relaciones entre la fachada y las superficies horizontales.

Ecotect (http://usa.autodesk.com/) es una herramienta desarrollada por Autodesk destinada a la evaluación de parámetros sostenibles en las fase de diseño de un proyecto. En lo referente a este proyecto, Ecotect tiene dos ventajas principales. En primer lugar, al formar parte del grupo Autodesk es compatible con los principales software de diseño arquitectónico: Autocad, Revit, 3Dmax, etc, lo que hace del paso de una herramienta a otra un proceso sencillo y compatible. En segundo lugar, y debido a su relación con otras herramientas de diseño, la interfaz gráfica de Ecotect -tanto las ventanas de trabajo como las de resultados- resultan gráficamente expresivas; los resultados tienen una variedad de representaciones que no se limitan a gráficos y tablas. Al mismo tiempo, permite que al usuario sacar resultados de datos en forma de tablas y gráficos. A pesar de ofrecer una amplia gama de elementos de análisis -tales como el efecto de la radiación solar, orientación, análisis 
de sombras, etc., los resultados obtenidos son difíciles de verificar ya que las variables de los análisis son complejos para usuarios con poca experiencia. Además, el material de biblioteca es limitado para aquéllos que tengan la intención de analizar parámetros personalizados.

Debido, entre otros, a la dificultad de interpretar sus resultados, el uso que se ha dado de Ecotect en este trabajo queda limitado a la representación gráfica de las condiciones locales, geográficas y de ubicación.

EnergyPlus (http://apps1.eere.energy.gov/buildings/energyplus/) es una herramienta gratuita desarrollada por Departamento de Energía de EE.UU., diseñada para ser un programa de simulación energética para arquitectos e ingenieros. En ella se evalúan, de manera detallada, las demandas de calefacción, refrigeración, iluminación, y ventilación, así como intercambios de energía a través de la construcción que permite, entre otras, medidas de resultados, sistemas modulares y multi-zona, análisis de flujo de aire y evaluación del confort térmico. Una de las principales ventajas de esta herramienta es la seguridad que ofrece; como parte del Departamento de Energía, cada versión está regulada y probada antes de su lanzamiento, por lo que los resultados están prácticamente asegurados. Además, ofrece otras ventajas.

En primer lugar, existe un plug-in para Google Sketchup, que permite a los ingenieros y arquitectos realizar simulaciones de Energyplus desde la interfaz de Google Sketchup. Esto supone una gran ventaja, puesto que uno de los principales inconvenientes de esta herramienta es la manejabilidad de sus parámetros e interfaz. En segundo lugar, Energyplus puede generar un archivo de ejemplo que permite a los usuarios sin excesiva experiencia en sistemas mecánicos emplearlo como base para las simulaciones. El profesional puede decidir si usa el archivo de entrada como base, modificando los parámetros que considere necesarios, o si evalúa los resultados recibidos. Esto puede suponer un ahorro de tiempo al mismo tiempo que ofrece un sistema de aprendizaje. Sin embargo, este proceso puede llevar tiempo, lo que junto a la falta de representación gráfica, hace que 
su uso no sea tan amable como otras herramientas.

Por otra parte, los parámetros que se han de modificar en el archivo de entrada no siempre son accesibles a todos los miembros del equipo de diseño, especialmente durante las primeras etapas de diseño, por lo que Energyplus puede ser más adecuado para las etapas posteriores en las que se suele disponer de mayor información. En conclusión, si se posee la suficiente información que permita identificar con claridad los sistemas mecánicos y otros parámetros así como personal capaz de comprender, esta herramienta es uno de los más acreditados del mercado.

equest (http://doe2.com/equest/) es una herramienta gratuita desarrollada por James J. Hirsch \& Associates en colaboración con el LBNL, realizada en su mayoría con financiación del Departamento de Energía de los Estados Unidos. Sofisticada pero al mismo tiempo fácil de usar, proporciona a los arquitectos e ingenieros la oportunidad de evaluar los proyectos en un plazo razonable de tiempo. La principal ventaja de esta herramienta es que su proceso de aprendizaje resulta menos prolongado y, sin embargo, los resultados de las simulaciones son considerados tan válidos como los obtenidos mediante otras herramientas. equest está dividido en dos interfaces principales: una primera dirigida al diseño inicial y una segunda destinada a un diseño más desarrollado. Ello permite la selección del tipo de proceso que se desee llevar a cabo y de la complejidad de la simulación dependiendo de la información de la que se disponga. Para aquellos proyectos de los que se disponga menos información o de mayor simplicidad, la primera interfaz sería la más apropiada. En ella las variables son sencillas y la simulación asume ciertos parámetros determinados. Una vez seleccionado el tipo de edificación, el programa escoge una serie de valores para crear la base del análisis, que luego servirá para poder establecer una valoración comparativa de los resultados a medida que se van alterando las variables. Esto simplifica el proceso, especialmente para aquellos arquitectos que no están muy familiarizados con ciertas variables o parámetros. eQuest es una herramienta ideal para utilizar en todo tipo de edificios si el proyecto es más complejo que el de una sola zona unidad intuitiva; ofrece 
parámetros variables, representación gráfica de los resultados y una fácil comprensión de los valores numéricos. Sin embargo, uno de los mayores inconvenientes que presenta esta herramienta es que los cambios en la geometría y forma - configuración del edificio no son fáciles de realizar, lo que puede generar errores en el cálculo de la carga.

TRNSYSlite (http://www.transsolar.com/ software/) es una herramienta desarrollada por la empresa Alemana TRANSOLAR. La principal ventaja de esta herramienta es que ofrece una forma fácil, rápida y fiable de simulación de una única zona, en la que evaluar las cargas de calefacción y refrigeración para las orientaciones, analizando también factores de confort, energía y transmisión solar entre superficies. Para ello, TRNSYSlite está dividido en una serie de ventanas en las que se define la geometría del edificio, las propiedades de los materiales y los sistemas de construcción. Las variables que permiten la modificación son limitadas, lo cual simplifica el proceso al mismo tiempo que ofrece la posibilidad de crear diseños o materiales especiales para el estudio, lo que favorece la flexibilidad de los diseños. Otra ventaja es la compatibilidad de los archivos con programas del DOE, de donde pueden obtenerse, por ejemplo, las propiedades de la composiciones de los vidrios. Los archivos de Window pueden ser incorporados en las propiedades del material del vidrio, y añadirse así a la biblioteca en TRNSYSlite. Esto es de gran ayuda, ya que además sugiere e incita a los usuarios o profesionales a experimentar con otros materiales además de los más comunes, lo que resulta especialmente interesante durante las primeras etapas del proyecto.

Además, para el análisis de los dispositivos de control solar, TRNSYSlite permite estudiar diferentes efectos, tales como su influencia en la temperatura interior, la incidencia de radiación solar, su capacidad de crear sombra, el tipo y la posición del dispositivo de control solar y su capacidad de ajuste.

En resumen, esta herramienta simplifica el proceso de evaluación, permitiendo a los usuarios explorar diferentes aspectos y variables del diseño de una manera "rápida" y 
"sencilla". Los resultados originados a partir de los análisis se presentan en forma de informes numéricos, esquemas, gráficos y tablas, y van acompañados de una explicación de los diferentes parámetros energéticos. Para el desarrollo de este trabajo, TRNSYSlite ha resultado ser un instrumento óptimo para estudiar el efecto de las propiedades de los materiales y la geometría del diseño.

THERM (http://windows.lbl.gov/software/therm/therm.html) es una herramienta gratuita desarrollada por LBNL diseñada para evaluar la capacidad de aislamiento y transmisión de energía a través de, por ejemplo, una sección de la fachada. Está diseñada tanto para fabricantes de diferentes elementos de construcción, arquitectos o ingenieros durante las diferentes etapas del proyecto. Permite la evaluación térmica en dos dimensiones de la transferencia de calor, así como las posibilidades de condensación en un vidrio o carpintería de aluminio. El proceso de modelación es sencillo, y tan sólo hace falta conocer los materiales de los elementos en contacto con los diferentes ambientes. Al igual que otras herramientas de LBNL, la compatibilidad entre distintos programas está asegurada, permitiendo así la transferencia de información de uno a otro.

En este caso, los datos extraídos de Window se pueden introducir en el modelo térmico de la sección de la fachada, y el resto de los componentes se definen mediante el establecimiento de las condiciones ambientales limítrofes entre los materiales, así como las propiedades del material en sí y la temperatura atmosférica. Los resultados obtenidos con THERM se pueden importar a Window para definir las propiedades conjuntas del vidrio y de la carpintería. El programa se basa en un método de elementos finitos, que permite el estudio de secciones más o menos sencillas sin mayores consecuencias. Además, permite importar dibujos en 2-D, que son reconocidos para el análisis.

Por tanto, esta herramienta de apoyo es intuitiva y fácil de usar, y permite la evaluación de las transferencias de calor y de la temperatura de manera rápida. 
WINDOW

(http: //windows.lbl.gov/software/window/window . html) es una herramienta gratuita desarrollada por LBNL para calcular el rendimiento térmico, los valores de transmisión de energía, la conductividad, la reflectividad, etc de los vidrios. Existen varias versiones de este programa, y con cada versión se han desarrollado nuevas capacidades. Una de las últimas incorporaciones fue la posibilidad de incorporar elementos de control solar en las superficies de vidrio que se deben estudiar. Window está vinculado a la International Glazing Database, que almacena una gran cantidad de variedades y tipos de vidrios de distintos fabricantes. Los interesados en usar este programa no sólo tienen acceso a los productos de vidrio que ofrece el mercado, sino también a crear sus propios productos definiendo cada capa de la unidad y pudiendo evaluar las consecuencias de sus decisiones en terminos de transmisión de energía. Las variables incluyen: el tipo de vidrio, el material aislante de relleno de cavidades de los vidrios, o el material empleado para separar las distintas láminas de vidrio. Además, se puede añadir sistemas de persianas, cortinas o dispositivos de control solar (que también pueden ser definidos por el usuario). Otra ventaja que inicialmente no parece relevante, es el hecho de que esta herramienta convierte con facilidad unidades del Sistema Imperial (IP) al Sistema Internacional (SI), favoreciendo la compatibilidad entre programas que utilizan distintos sistemas de medidas. Los resultados de los estudios pueden extraerse en archivos que luego son importados en las diferentes herramientas de evaluación.

Por lo tanto, para el desarrollo de esta investigación, el programa Window ha resultado una herramienta imprescindible por su flexibilidad y la utilidad de sus resultados. El uso de esta herramienta fue uno de los primeros pasos en este trabajo debido al interés por evaluar, por ejemplo, el efecto que los componentes del vidrio tienen en su propiedad aislante.

3DMax (http://usa.autodesk.com/) es un programa desarrollado por Autodesk diseñado para la modelación en 3D y la representación en renders y videos. Por tanto, no es una herramienta de simulación. Sin embargo, sí permite un am- 
plio análisis de niveles de iluminación, así como el análisis del efecto de luz solar y la sombra en un edificio. La principal ventaja de esta herramienta reside en que, al pertenecer al grupo Autodesk, es compatible con otros productos como Autcad, Revit o Ecotect (descrito anteriormente. Para este trabajo, la evaluación con esta herramienta no es numérica, sino que se realiza en función de la calidad de las imágenes y la posibilidad de llevar a cabo un análisis cualitativo.

A continuación se comparan las características básicas de las herramientas descritas anteriormente:

\begin{tabular}{|c|c|c|c|c|c|c|c|c|c|}
\hline & 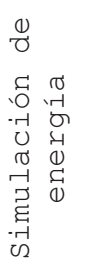 & $\begin{array}{ll}1 & \\
2 & \\
-7 & \\
0 & \\
0 & 2 \\
0 & 0 \\
0 & -1 \\
0 & 0 \\
0 & 0 \\
0 & 0 \\
0 & 0 \\
0 & \\
.-1 & \\
-1-1 & \end{array}$ & 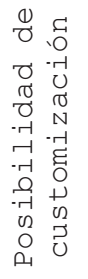 & 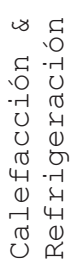 & 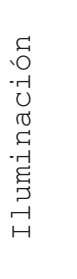 & 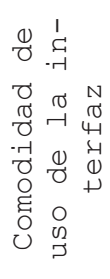 & $\begin{array}{l}-1 \\
-1 \\
0 \\
\text { ro } \\
4-1 \\
0 \\
0 \\
0 \\
0 \\
0 \\
0 \\
0 \\
0 \\
0\end{array}$ & 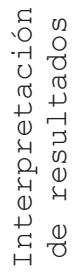 & 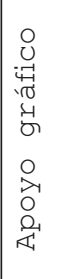 \\
\hline CASAnova & Y & $\mathrm{N}$ & $\mathrm{N}$ & $\mathrm{Y}$ & $\mathrm{N}$ & Y & Y & $\mathrm{N}$ & Y \\
\hline COMFEN & Y & $\mathrm{N}$ & NY & $\mathrm{Y}$ & Y & Y & $\mathrm{Y}$ & Y & Y \\
\hline Ecotect & NY & Y & $\mathrm{N}$ & Y & $\mathrm{N}$ & Y & NY & $\mathrm{N}$ & Y \\
\hline $\begin{array}{l}\text { Energy } \\
\text { Plus }\end{array}$ & Y & $\mathrm{Y}$ & Y & $\mathrm{Y}$ & $\mathrm{Y}$ & $\mathrm{N}$ & $\mathrm{N}$ & NY & $\mathrm{N}$ \\
\hline equest & $\mathrm{Y}$ & $\mathrm{Y}$ & $\mathrm{N}$ & $\mathrm{Y}$ & Y & $\mathrm{NY}$ & Y & NY & Y \\
\hline TRANSYlite & Y & $\mathrm{Y}$ & Y & $\mathrm{Y}$ & $\mathrm{N}$ & Y & $\mathrm{Y}$ & $\mathrm{Y}$ & $\mathrm{Y}$ \\
\hline THERM & $\mathrm{N}$ & - & Y & - & - & Y & Y & Y & Y \\
\hline Window & $\mathrm{N}$ & - & Y & - & - & Y & Y & Y & Y \\
\hline 3D Max & $\mathrm{N}$ & $Y$ & Y & - & - & Y & Y & - & $\mathrm{Y}$ \\
\hline
\end{tabular}

Tras evaluar las caracerísticas de las diferentes herramientas y programas, para el propósito de este trabajo, se tuvo la oportunidad de trabajar con el Sr. Helmut Meyer y el Sr. Christian Frenzel de TRANSOLAR, en el proceso de aprendizaje y comprensión de TRNSYSlite. Este programa se convirtió en la herramienta principal empleada para evaluar no sólo el efecto de la geometría del edificio en, por ejemplo, las cargas de calefacción o aire acondicionado, sino el efecto que pequeñas variaciones en los componentes puedan tener sobre el conjunto. Con TRNSYSlite se evaluaron 
las cargas de calefacción y refrigeración para los vidrios seleccionados y sus componentes, teniendo en cuenta las diferentes orientaciones y las diferentes áreas de vidrio. Para la evaluación de la iluminación se empleó COMFEN, que a pesar de estar destinada a usos comerciales, se aplicó un factor de conversión que permitió su aplicación al uso residencial. Además, el vidrio y sus componentes, así como su selección, se evaluaron en Window (versiones 5 y 6). Por último, los análisis de calidad y cualidad de los espacios se llevaron a cabo con 3D-Max. 


\subsubsection{Descripción del Proceso}

El procedimiento que se ha seguido para la evaluación del diseño se muestra a continuación:

\begin{tabular}{|c|c|c|c|c|}
\hline $\begin{array}{c}\text { Composición } \\
\text { del vidrio }\end{array}$ & $\begin{array}{c}\text { Propiedades } \\
\text { del vidrio }\end{array}$ & \multicolumn{2}{|c|}{ Rendimiento de la fachada diseñada } \\
\hline $\begin{array}{c}\text { IGDB (In- } \\
\text { ternational } \\
\text { Glazing Data } \\
\text { Base) }\end{array}$ & Window & TRNSYSlite & COMFEN & 3D Max \\
\hline $\begin{array}{c}\text { Número de } \\
\text { paneles, } \\
\text { Películas, } \\
\text { Cavidades }\end{array}$ & $\begin{array}{c}\text { SHGC, SC, T- } \\
\text { vis }\end{array}$ & $\begin{array}{c}\text { Calefacción } \\
\text { Refrigera- } \\
\text { ción }\end{array}$ & Electricidad & $\begin{array}{c}\text { Iluminación } \\
\text { natural }\end{array}$ \\
\hline
\end{tabular}

La tabla anterior representa los pasos seguidos por esta investigación, así como los instrumentos empleados para cada uno. En primer lugar, tras revisar la literatura acerca de los componentes de las ventanas y sus propiedades, esta investigación define distintos tipos de vidrio que han de ser analizados. Como se ha expuesto con anterioridad, uno de los requisitos del diseño es proyectar una fachada lo más transparente posible, evitando que los recubrimientos o películas empleados en la superficie del vidrio afecten el color o interfieran con las vistas al exterior. Por tanto, al analizar los componentes de IGDB, la selección de los vidrios se limitó a aquéllos sin tintes ni coloración.

En una primera etapa de selección de vidrio, los estudios se centran en las posibilidades de los revestimientos de baja emisividad, sus propiedades de selección espectral y la posición de las mismas. En segundo lugar, se estudia el número de paneles de vidrio con el objetivo de entender el efecto de agregar paneles -y por lo tanto cavidades- en el rendimiento del vidrio. Es decir, se ha empezado por estudiar vidrios de composiciones de 1, 2, 3 y 4 paneles y, a continuación, se han sustituido por películas para evaluar las diferencias. En tercer lugar se ha estudiado el material de relleno de la cavidad entre los vidrios. Para ello se ha seleccionado aire, argón, kriptón y xenón. 
Los valores extraídos han ayudado a definir la capacidad del vidrio para controlar las transferencias de calor a través de su superficie (U-valor), las capacidad de admitir ganancias de calor (SHGC), y su capacidad para permitir visibilidad exterior (T-vis). Además se han estudiado parámetros tales como el comportamiento de vidrio solar de ciertos ángulos o sus propiedades reflectantes.

Una vez determinado el efecto de modificar ciertos parámetros en el vidrio, y definidos los diferentes diseños de la envolvente atendiendo a la orientación, el uso y, por supuesto, la adaptabilidad, el siguiente paso es evaluar los efectos de éstos en el consumo de energía. Mediante TRNSYSlite han sido evaluados las cargas de calefacción y refrigeración. En primer lugar, los tipos de vidrio han sido evaluados en las diferentes orientaciones. Esto ha permitido comparar el efecto que la orientación de la fachada tiene en el vidrio en sí, obteniendo valores anuales para las cargas de calefacción y refrigeración. Tras ello, se procede a estudiar el efecto que los dispositivos de protección solares tienen en el proceso de selección de vidrio. Para ello, a cada orientación se adjudica uno o varios sistemas de protección, y se evalúa la relación entre sus propiedades y los resultados. En este caso, también las cargas energéticas ayudan a determinar su idoneidad.

Tan relevantes son las cargas energéticas como las de electricidad. Para ello se emplea COMFEN y se analizan los efectos de los diferentes tipos de vidrio en el consumo. El proceso con COMFEN fue algo menos exigente. Ya que esta herramienta se dirige al análisis de edificios comerciales, se aplicó un factor de conversión que permitiera la traslación de los resultados de un uso a otro, estableciendo una relación entre los obtenidos en COMFEN y los que se obtienen en TRNSYSlite.

Por último, se emplea 3D Max para estudiar el efecto del vidrio y los sistemas de fachada en su conjunto en el espacio interior.

Los diferentes análisis llevados a cabo no tienen otro objetivo que evaluar y validar el diseño del proyecto de 
transformación de la envolvente de un edificio en Chicago. Las características de Lake Grove Village, el edificio en cuestión, han ayudado a definir los parámetros explicados a lo largo de esta sección: tipos de vidrio, sistemas de voladizo, terrazas, galerías o vidrios inclinados. Además de ello, y tras haber completado los análisis y estudios, se considera oportuno crear una base de datos de diferentes opciones de fachadas de vidrio y componentes, que puedan ser aplicados con posterioridad en otros proyectos. Y por qué no, que la experiencia obtenida y las conclusiones extraídas puedan ser de aplicación para otros estudios similares. Todo ello, una vez más, sin perder de vista los objetivos iniciales de este estudio.

Tras analizar las condiciones en las que se encuentra el edificio Lake Grove Village y entender las principales características de la construcción de dichos edificios, se propuso la rehabilitación de la fachada. La idoneidad vino dada también por la esencia del diseño de este edificio, que como ya hemos explicado abre las puertas al reciclaje, la rehabilitación y la prefabricación gracias al sistema de construcción empleado. Tras este primer estudio, se llevó a cabo un análisis de las condiciones climatológicas de la ciudad que permitiera seleccionar los requerimientos de las fachadas. Para ello, el proyecto se ha basado también en el estudio de diferentes edificios residenciales de la ciudad, algunos de ellos analizados en apartados anteriores. Todo el trabajo y los estudios teóricos anteriores condujeron a establecer las líneas que el diseño de las nuevas fachadas debían incluir. Así se establecieron los primeros sistemas y escenarios, creando un "catálogo de sistemas de fachadas"

Posteriormente se ha procedido a evaluar y analizar los sistemas inicialmente escogidos. Los análisis se concentran en el consumo de energía. Los resultados han llevado a una mayor definición de los componentes, descartando aquéllos con menores posibilidades de adaptación y estudiando la idoneidad del resto. Por último, se identifica el sistema de fachada adecuado para cada orientación y, reconociendo también la posibilidad de adaptabilidad, se estudian variaciones para así ofrecer diferentes opciones de 
diseño que puedan dar respuesta a cambios de necesidades, usos o hábitos.

Por tanto, el proceso por el que este trabajo ha evaluado y validado las decisiones de diseño ha permitido extraer varias conclusiones. En primer lugar, los profesionales del diseño pueden beneficiarse del conocimiento y uso de herramientas que puedan ayudar a evaluar, validar y refinar las decisiones, especialmente durante las primeras etapas de un proyecto. Las herramientas existentes no siempre son fáciles de usar, por lo que el la industria debe hacer un esfuerzo mayor por facilitar su uso. Entender las condiciones del entorno, la radiación de la energía sobre las fachadas, el viento, la luz o la orientación pueden ayudar a mejorar la percepción del espacio interior y el comportamiento de las fachadas. En segundo lugar, aun cuando la herramienta fuera de fácil uso, el proceso requerirá tiempo y dedicación, y los resultados serán consecuencia de múltiples iteraciones. Por ello, esbozar el plan de estudio y establecer las prioridades desde el principio puede ayudar al proceso, evitando que en etapas finales del diseño se lleguen a conclusiones irrevocables. Por último, los profesionales del diseño deben ser conscientes de que las decisiones de diseño y validación pueden no concluir en números absolutos. En lo referente a este proyecto, los análisis son procesos que permiten la comparación, los números relativos o los porcentajes, sin que ello minimice su importancia.

Todo ello ha permitido llevar a cabo un análisis de los requerimientos de una fachada residencial de vidrio en Chicago, estudiar sus componentes y posibles combinaciones para diseñar un sistema, y evaluar su aplicación en las diferentes orientaciones. 



\subsection{EVALUACIÓN DE LOS COMPONENTES PARA UNA NUEVA ENVOLVENTE DE VIDRIO.}

Esta sección pretende llevar a la práctica los conocimientos que se han adquirido acerca de los requerimientos y las posibilidades en el diseño de fachadas de vidrio energética y económica sostenibles, así como del comportamiento de los parámetros que las conforman. Para ello se han analizado una serie de conceptos.

En primer lugar, se estudia el efecto de las orientaciones en la eficiencia energética de una fachada de vidrio. Como se ha comentado con anterioridad, uno de los requerimientos de esta propuesta es crear una piel transparente, ligera, con capacidad de ser adaptada a diferentes circunstancias y, al mismo tiempo, energéticamente eficiente. Debido al incremento en su uso en la arquitectura, sus ventajas y también sus retos, el vidrio ha sido el material considerado de interés para este proyecto. Su transparencia y claridad permite aprovechar al máximo la luz natural y 
la energía térmica, conceptos valiosos en una ciudad como Chicago. Al mismo tiempo, se deben solucionar aspectos tales como la propiedad aislante del material o el exceso de calor. Debido a que los beneficios de un vidrio dependen de, entre otros elementos, cuál sea la orientación de la superficie, en un primer lugar se analizará el efecto de dichas orientaciones. Para este primer estudio las variables son las orientaciones, y los tipos de vidrio y porcentajes de superficie acristalada se convierten en constantes establecidas.

Una vez comprendido el impacto de las orientaciones en el vidrio, se ha procedido a estudiar una serie de vidrios preseleccionados. Teniendo en cuenta los deseos de transparencia del diseño, los vidrios se han seleccionado primero en función de la apariencia, para posteriormente considerar su viabilidad. En este caso el tipo de vidrio es la variable. Los análisis ayudarán a entender el efecto de incorporar de películas, número de paneles, etc., en el comportamiento energético.

Tras estudiar los diferentes componentes aislados, se procede a incorporar dispositivos de control solar que permiten una evaluación más global de la fachada. En este caso los tres escenarios anteriores se tienen en consideración. 


\subsubsection{Estudio del Vidrio}

La situación geográfica y localización de Lake Grove Village permiten extraer dos premisas a la hora de seleccionar el tipo de vidrio. Por un lado, los fríos inviernos de la Ciudad del Viento convierten en prioridad la entrada de energía solar en los espacios, especialmente durante el invierno. Además, la capacidad aislante de los vidrios debe ser una prioridad. Por otro lado, los veranos son calurosos, por lo que debe existir cierto control y regulación no sólo de entrada de energía solar sino también de iluminación. La localización de los edificios junto al lago Michigan, favorece que el diseño ayude a potenciar las vistas al exterior. Por este motivo, las premisas sobre las que se asienta el proceso de selección del vidrio han venido dadas por la transparencia, las ganancias térmicas y el control solar. Para ello se estudian dos factores principales: la orientación y el tipo de vidrio. Los vidrios definidos en el apartado 5.3.2 se analizan para evaluar su idoneidad en un edificio residencial en Chicago. Como recordatorio, a continuación se especifican los tipos de vidrio y sus propiedades más destacadas:

\begin{tabular}{|c|c|c|c|c|c|}
\hline $\begin{array}{l}\text { Vidrio } \\
\text { Tipo A }\end{array}$ & $\begin{array}{l}\text { Vidrio } \\
\text { Tipo B }\end{array}$ & $\begin{array}{l}\text { Vidrio } \\
\text { Tipo C }\end{array}$ & $\begin{array}{l}\text { Vidrio } \\
\text { Tipo D }\end{array}$ & $\begin{array}{l}\text { Vidrio } \\
\text { Tipo E }\end{array}$ & $\begin{array}{l}\text { Vidrio } \\
\text { Tipo F }\end{array}$ \\
\hline $\begin{array}{l}\text { Double } \\
\text { Clear / } \\
\text { Air }\end{array}$ & $\begin{array}{c}\text { Double } \\
\text { Clear } \\
\text { Spectrally } \\
\text { Selective } \\
\text { Low-e (\#2) } \\
\text { / Argon }\end{array}$ & $\begin{array}{c}\text { Triple } \\
\text { Clear } \\
\text { Spectrally } \\
\text { Selective } \\
\text { Low-e (\#2) } \\
\text { / Argon }\end{array}$ & $\begin{array}{c}\text { Triple } \\
\text { Clear } \\
\text { Spectrally } \\
\text { Selective } \\
\text { Low-e (\#5) } \\
\text { / Argon }\end{array}$ & $\begin{array}{c}\text { Triple } \\
\text { Clear } \\
\text { Spectrally } \\
\text { Selective } \\
\text { Low-e (\#2 } \\
\text { \& \#5) / } \\
\text { Krypton }\end{array}$ & $\begin{array}{l}\text { Heat Mi- } \\
\text { rror Quad } \\
\text { Glass ( } 3 \\
\text { films }\end{array}$ \\
\hline $\begin{array}{c}\text { Uvalue: } \\
2.7\end{array}$ & $\begin{array}{c}\text { Uvalue: } \\
1.4\end{array}$ & $\begin{array}{c}\text { Uvalue: } \\
1.0\end{array}$ & $\begin{array}{c}\text { Uvalue: } \\
1.0\end{array}$ & $\begin{array}{c}\text { Uvalue: } \\
0.7\end{array}$ & $\begin{array}{c}\text { Uvalue: } \\
0.4\end{array}$ \\
\hline $\begin{array}{l}\text { SHGC: } \\
0.701\end{array}$ & $\begin{array}{l}\text { SHGC: } \\
0.374\end{array}$ & $\begin{array}{l}\text { SHGC: } \\
0.342\end{array}$ & $\begin{array}{l}\text { SHGC: } \\
0.419\end{array}$ & $\begin{array}{l}\text { SHGC: } \\
0.403\end{array}$ & $\begin{array}{l}\text { SHGC : } \\
0.282\end{array}$ \\
\hline $\begin{array}{l}\text { TVis: } \\
0.786\end{array}$ & $\begin{array}{l}\text { Tvis: } \\
0.703\end{array}$ & $\begin{array}{l}\text { Tvis: } \\
0.627\end{array}$ & $\begin{array}{l}\text { Tvis: } \\
0.627\end{array}$ & $\begin{array}{l}\text { Tvis: } \\
0.603\end{array}$ & $\begin{array}{l}\text { TVis: } \\
0.491\end{array}$ \\
\hline
\end{tabular}




\section{Orientación de la Superficie de Vidrio}

Los diferentes tipos de vidrio han sido estudiados en las cuatro orientaciones para entender su efecto en el rendimiento energético de la fachada. Los resultados de los análisis y las consideraciones de los mismos se explican a continuación mediante comparaciones relativas entre los valores. Asimismo se detallan las conclusiones extraídas.

Por un lado, en Chicago, las fachadas orientadas al Sur tienen una demanda significativamente menor de calefacción que aquéllas expuestas al resto de orientaciones. Por contra, la orientación Norte exige una demanda mayor de calefacción, y la Este y Oeste se comportan de manera similar. Esto se ha observado al estudiar los distintos tipos de vidrio.

\begin{tabular}{|c|c|c|c|}
\hline \multicolumn{2}{|c|}{ Carga relativa de calefacción en comparación a la orientación Sur } \\
(100\% vidrio - Vidrio Tipo A)
\end{tabular}

\begin{tabular}{|c|c|c|c|}
\hline \multicolumn{2}{|c|}{ Carga relativa de calefacción en comparación a la orientación Sur } \\
$(100 \%$ vidrio - Vidrio Tipo F)
\end{tabular}

Las dos tablas anteriores muestran los resultados en los dos casos más extremos hallados. Al disminuir las ganancias de energía solar en el vidrio -véase vidrio tipo Fla orientación Norte requiere una mayor carga de calefacción, incluso mayor que con un vidrio de menor eficiencia.

Los vidrios situados en posiciones más intermedias presentan valores similares. Los resultados de los estudios del comportamiento de los diferentes vidrios dependiendo de las orientaciones pueden encontrarse en el Anexo. 
Por otro lado, cuando se examinan las demandas de refrigeración, los estudios muestran que, al aislar las orientaciones, las fachadas al Norte presentan una demanda significativamente mayor. Aunque puede resultar obvio, se extrae una consideración interesante: este hecho ha sido resultante tanto para una vidrio común y simple, como en el caso de uno energéticamente eficiente. Esto incide en la importancia de considerar las orientaciones y la situación geográfica en el diseño de las envolventes. Los resultados obtenidos al estudiar los dos tipos de vidrio extremos se plasman en las siguientes tablas.

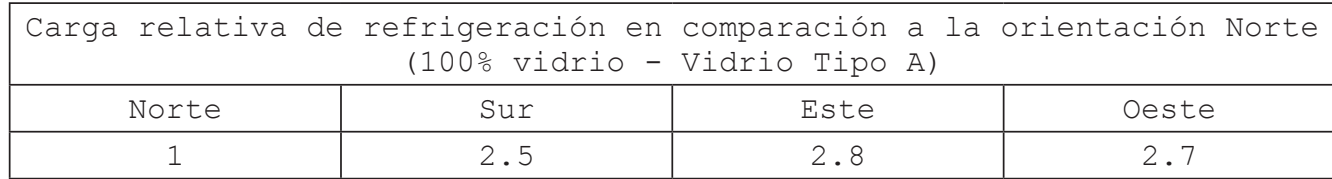

\begin{tabular}{|c|c|c|c|}
\hline Carga relativa de refrigeración en comparación a la orientación Norte \\
(100\% vidrio - Vidrio Tipo F)
\end{tabular}

Los resultados del análisis de los vidrios intermedios en las distintas orientaciones pueden encontrarse en el Anexo.

Por tanto, de este primer estudio se extraen varias conclusiones. Por un lado, dado un tipo de vidrio, las condiciones particulares de cada orientación conllevan comportamientos distintos y demandas de energía también dispares, por lo que éstas deben ser tenidas en cuenta al evaluar el rendimiento de la fachada. Por ejemplo, las fachadas orientadas al Sur en Chicago reciben energía solar directa durante el invierno, con lo que las cargas energéticas de calefacción pueden verse reducidas mediante el uso del vidrio. Esto las hace adecuadas para captar la energía solar durante todo el año. 
Por otro lado, debido a que las fachadas orientadas al Norte reciben menor cantidad de energía solar directa, los espacios se convierten en zonas más susceptibles a demandas de calefacción elevadas. Por su parte, las fachadas orientadas al Este y al Oeste están en un punto más intermedio, y requieren demandas de calefacción y refrigeración similares. Aunque para un edificio en Chicago las cargas de calefacción suelen tener mayor peso que las de refrigeración, éstas también deben considerarse, especialmente para el confort interior de un edificio residencial. Las orientaciones Sur, Este y Oeste son las que deberán prestar más atención a las demandas de aire acondicionado.

En tercer lugar, y como consecuencia de los estudios anteriores, las diferentes orientaciones se han dividido en tres grupos en base a su comportamiento: Norte, Sur y Este/Oeste. Las diferencias entre estas tres exposiciones afectan el consumo de energía de un espacio y, por tanto, requieren estudios independientes.

Por tanto, el proceso de selección del vidrio comienza por el análisis de las condiciones y la determinación de los requerimientos específicos dependiendo de la orientación a la que estén expuesta, ya que cada orientación repercutirá en los requerimientos que se dan al diseño de las envolventes de vidrio. Sin ello se estarán tomando decisiones generalizadas y no se obtendrán los datos específicos necesarios para el diseño de una fachada energéticamente sostenible. 


\section{Tipo de Vidrio}

El análisis de los diferentes tipos de vidrio se ha llevado a cabo en los tres grupos de orientaciones: Norte, Sur y Este/Oeste.

Las fachadas orientadas al Norte están menos expuestas a la radiación solar directa, siendo más susceptibles a las demandas de calefacción. Esto deriva en que el tipo de vidrio seleccionado deba caracterizarse por poseer propiedades aislantes y por minimizar las pérdidas de calor del interior al exterior.

A continuación se exponen los resultados derivados de los análisis y las conclusiones de los estudios para la orientación Norte. Los gráficos que acompañan se presentan en el Anexo.

\begin{tabular}{|c|c|c|c|c|c|}
\hline $\begin{array}{l}\text { Vidrio } \\
\text { Tipo A }\end{array}$ & $\begin{array}{l}\text { Vidrio } \\
\text { Tipo B }\end{array}$ & $\begin{array}{l}\text { Vidrio } \\
\text { Tipo C }\end{array}$ & $\begin{array}{l}\text { Vidrio } \\
\text { Tipo D }\end{array}$ & $\begin{array}{l}\text { Vidrio } \\
\text { Tipo E }\end{array}$ & $\begin{array}{l}\text { Vidrio } \\
\text { Tipo F }\end{array}$ \\
\hline $\begin{array}{l}\text { Double } \\
\text { Clear / } \\
\text { Air }\end{array}$ & $\begin{array}{c}\text { Double } \\
\text { Clear } \\
\text { Spectrally } \\
\text { Selective } \\
\text { Low-e (\#2) } \\
\text { / Argon }\end{array}$ & $\begin{array}{c}\text { Triple } \\
\text { Clear } \\
\text { Spectrally } \\
\text { Selective } \\
\text { Low-e (\#2) } \\
\text { / Argon }\end{array}$ & $\begin{array}{c}\text { Triple } \\
\text { Clear } \\
\text { Spectrally } \\
\text { Selective } \\
\text { Low-e (\#5) } \\
\text { / Argon }\end{array}$ & $\begin{array}{c}\text { Triple } \\
\text { Clear } \\
\text { Spectrally } \\
\text { Selective } \\
\text { Low-e (\#2 } \\
\text { \& \#5) / } \\
\text { Krypton }\end{array}$ & $\begin{array}{l}\text { Heat Mi- } \\
\text { rror Quad } \\
\text { Glass ( } 3 \\
\text { films }\end{array}$ \\
\hline$C: 88.5$ & $C: 49.6$ & NA & $C: 38.4$ & $C: 33.9$ & $C: 30.8$ \\
\hline$R: 28.0$ & $\mathrm{R}: 19.5$ & NA & $R: 24.0$ & $R: 19.9$ & $\mathrm{R}: 17.8$ \\
\hline
\end{tabular}

Mediante la aplicación de láminas de baja emisividad en la superficie de uno de los vidrios, -especialmente en la superficie número 4-, se evita que parte de la energía de calor acumulada en el espacio interior irradie hacia el exterior. Si el revestimiento se coloca en la superficie número 2 -cara interna del panel exterior-, el efecto se ve reducido.

Además de considerar las láminas de baja emisividad, al rellenar la cavidad con un gas inerte y denso como, por ejemplo, el argón, las transferencias de energía se ven reducidas, lo que beneficia al comportamiento del vidrio. 
Ambos parámetros logran reducir el valor de transferencia energética del vidrio.

Otra opción que se ha podido valorar en los análisis, es el beneficio obtenido al añadir un tercer panel de vidrio en la superficie. Al igual que con las otras dos estrategias, esto puede reducir las cargas de calefacción, más aún si ello conlleva añadir una segunda cavidad.

En consecuencia, durante el diseño de una fachada de vidrio expuesta al Norte puede reducirse las cargas de calefacción si se estudia la posibilidad de incorporar láminas de baja emisividad, gases inertes o se incrementa el número de paneles de vidrio. El objetivo principal de estas actuaciones será disminuir las pérdidas energéticas a través de las superficies acristaladas y mantener en el espacio el calor ya acumulado.

Las fachadas orientadas al sur están más sujetas a las ganancias de calor, lo que conlleva mayores cargas de refrigeración que de calefacción. Por ello, los vidrios seleccionados deben estar fundamentalmente destinados a reducir las ganancias de calor en verano y al mismo tiempo permitirlas durante el invierno.

A continuación se exponen los resultados de los análisis y las conclusiones de los estudios para la orientación Sur. Los gráficos que acompañan se presentan en el Anexo.

\begin{tabular}{|c|c|c|c|c|c|}
\hline $\begin{array}{l}\text { Vidrio } \\
\text { Tipo A }\end{array}$ & $\begin{array}{l}\text { Vidrio } \\
\text { Tipo B }\end{array}$ & $\begin{array}{l}\text { Vidrio } \\
\text { Tipo C }\end{array}$ & $\begin{array}{l}\text { Vidrio } \\
\text { Tipo D }\end{array}$ & $\begin{array}{l}\text { Vidrio } \\
\text { Tipo E }\end{array}$ & $\begin{array}{l}\text { Vidrio } \\
\text { Tipo F }\end{array}$ \\
\hline $\begin{array}{l}\text { Double } \\
\text { Clear / } \\
\text { Air }\end{array}$ & $\begin{array}{c}\text { Double } \\
\text { Clear } \\
\text { Spectrally } \\
\text { Selective } \\
\text { Low-e (\#2) } \\
\text { / Argon }\end{array}$ & $\begin{array}{c}\text { Triple } \\
\text { Clear } \\
\text { Spectrally } \\
\text { Selective } \\
\text { Low-e (\#2) } \\
\text { / Argon }\end{array}$ & $\begin{array}{c}\text { Triple } \\
\text { Clear } \\
\text { Spectrally } \\
\text { Selective } \\
\text { Low-e (\#5) } \\
\text { / Argon }\end{array}$ & $\begin{array}{c}\text { Triple } \\
\text { Clear } \\
\text { Spectrally } \\
\text { Selective } \\
\text { Low-e (\#2 } \\
\text { \& \#5) / } \\
\text { Krypton }\end{array}$ & $\begin{array}{l}\text { Heat Mi- } \\
\text { rror Quad } \\
\text { Glass ( } 3 \\
\text { films }\end{array}$ \\
\hline$C: 31.5$ & $C: 15.2$ & NA & $C: 7.4$ & $C: 8.2$ & $C: 8.2$ \\
\hline $\mathrm{R}: 70.5$ & $R: 42.8$ & NA & $R: 57.8$ & $R: 42.9$ & $R: 35.9$ \\
\hline
\end{tabular}


Mediante la aplicación de láminas de baja emisividad en la superficie interna del vidrio exterior -superficie número 2-, la energía proveniente del exterior se ve significativamente reducida. Si estas láminas son selectivas en el espectro, permitirán la entrada de luz natural mientras que evitarán la sobrecarga de calor. En este caso, la posición de la lámina de baja emisividad es crucial para las fachadas orientadas al Sur. Ésta determinará si se bloquea la entrada de calor desde el principio o si, por el contrario, se ha permitido su entrada sin permitir su salida. Esto último ocasionaría un sobrecalentamiento del espacio. El principal objetivo es el bloqueo del exceso de energía.

Por tanto, la consideración principal que hay que tener en cuenta a la hora de diseñar una fachada de vidrio orientada a Sur en Chicago es la posibilidad de establecer medidas de control de las ganancias de calor durante el verano.

Las fachadas orientadas al Este \& Oeste están sujetas tanto a cargas de calefacción como de refrigeración, por lo que son especialmente sensibles a ambas. Para la propuesta de transformación de la envolvente de Lake Grove Village, la distribución de los espacios está principalmente configurada a Norte y al Sur. En principio, las orientaciones Este y Oeste quedan en un segundo plano aunque, como se verá en los planos, las viviendas en esquina organizan los estar-comedor y cocinas parcialmente orientadas a Este y Oeste. Sea como fue, a efectos de este trabajo las cuatro orientaciones se han considerado de igual importancia. Esto permite no sólo dar respuesta al diseño, sino elaborar un guión que pueda aplicarse a diferentes proyectos.

A continuación se exponen los resultados y conclusiones de los estudios de las orientaciones Este y Oeste. Los gráficos que acompañan se presentan en el Anexo. 


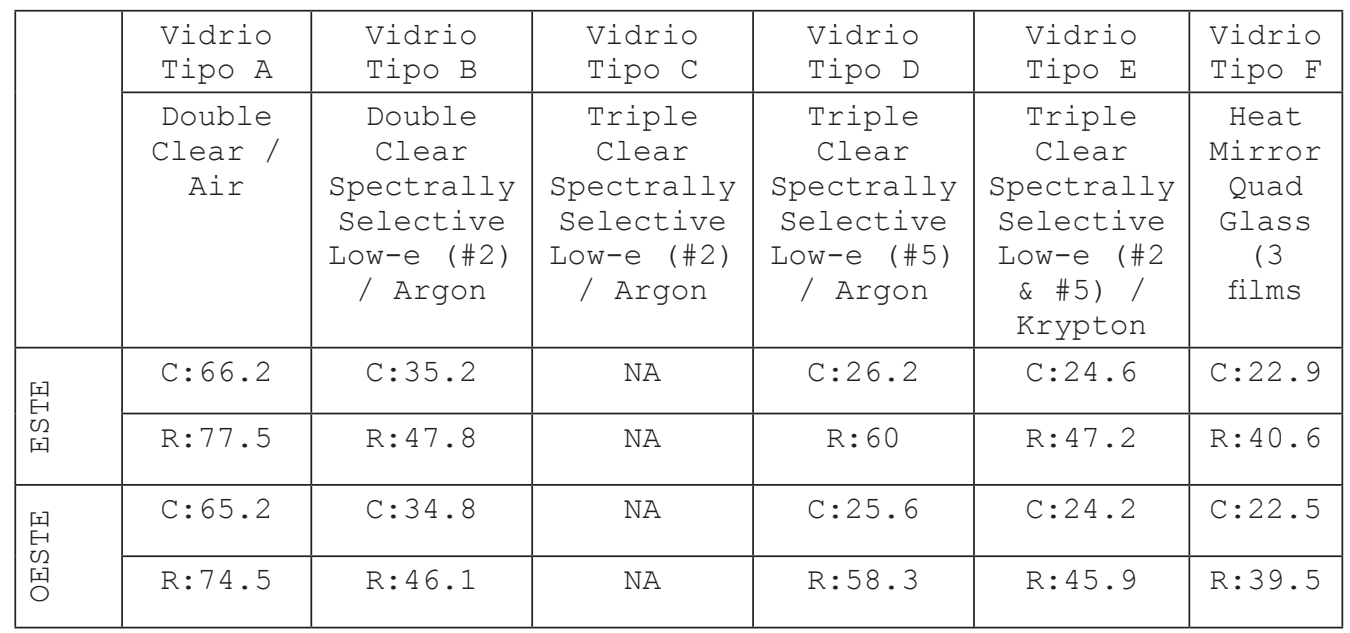

En primer lugar los análisis han permitido observar que el rendimiento de estas fachadas mejora si se controlan los valores de transmisión térmica y las ganancias de energía solar. La combinación de láminas de baja emisividad junto con la mejora de la inercia térmica del material, pueden reducir las cargas energéticas. Esto hace que las orientadas a Este y Oeste sean mas difíciles de controlar, ya que a las fachadas se les exige dos tipos de comportamiento, en ocasiones inverso.

En estas orientaciones, el diseño debe balancear entre los beneficios obtenidos al prevenir la entrada de calor en verano en el Oeste y por otro lado potenciar la entrada $y$ prevenir las pérdidas energéticas en invierno. El objetivo es que estas orientaciones ayuden a equilibrar y controlar las cargas de calefacción y refrigeración.

En conclusión, mejorar el rendimiento de un vidrio en una orientación específica depende, entre otras, de la capacidad de los profesionales de entender y aprehender las ventajas y desventajas de cada una de las decisiones. Existen múltiples factores que determinarán la idoneidad de un vidrio frente a otro, y su uso -o mal uso- tendrán consecuencias directas en el comportamiento de la fachada y, por consiguiente, en el comfort del espacio interior. 


\subsubsection{Estudio de la Envolvente}

Una vez estudiado el comportamiento del vidrio en las diferentes orientaciones, y tras entender el efecto que la composición del mismo puede tener, se ha procedido a estudiar otros componentes que ayuden a mejorar el rendimiento de la envolvente que se está diseñando.

Las envolventes son sistemas complejos compuestos no sólo de vidrios y posiblemente áreas opacas, sino también, en muchos casos, de mecanismos para controlar la entrada y dirección de la energía solar en el espacio. Estos mecanismos son especialmente importantes en determinados climas cuando la piel del edificio es de vidrio, ya que su rendimiento estará directamente relacionado con la incorporación de dichos sistemas. En este caso, los mecanismos de control solar han sido estudiados para evaluar la manera de poder combinarlos con el vidrio para un mejor resultado. Los tipos de dispositivos de control solar analizados se han expuesto en apartados anteriores. Éstos son específicos para cada orientación.

Más aún, para el proyecto de transformación de la envolvente de Lake Grove Viallage, se ha estudiado la posibilidad de incorporar superficie de vidrio inclinado como control solar. Como podrá observarse en apartados siguientes, ofrecen ventajas en el control solar sin bloquear la entrada de luz natural.

En este apartado se expondrán los análisis y las conclusiones obtenidos a raíz de los análisis de los dispositivos de control solar y los sistemas de vidrios propuestos para la nueva envolvente de Lake Grove Village. 


\section{Dispositivos de Control Solar}

Como en los estudios anteriores, los dispositivos de control solar se han estudiado para las orientaciones Norte, Sur y Este/Oeste. A continuación se exponen las conclusiones extraídas de los diferentes análisis.

En las fachadas de orientación Norte, el trabajo se ha limitado a estudiar el efecto de dispositivos situados en el interior del espacio, que ayudan a controlar el deslumbramiento y posibles ganancias de energía solar difusa.

A continuación se exponen los resultados derivados de los análisis y las conclusiones referidos a las cargas de refrigeración para la orientación Norte. Los gráficos que acompañan se presentan en el Anexo.

\begin{tabular}{|c|c|c|c|c|c|}
\hline $\begin{array}{l}\text { Vidrio } \\
\text { Tipo A }\end{array}$ & $\begin{array}{l}\text { Vidrio } \\
\text { Tipo B }\end{array}$ & $\begin{array}{l}\text { Vidrio } \\
\text { Tipo C }\end{array}$ & $\begin{array}{l}\text { Vidrio } \\
\text { Tipo D }\end{array}$ & $\begin{array}{l}\text { Vidrio } \\
\text { Tipo E }\end{array}$ & $\begin{array}{l}\text { Vidrio } \\
\text { Tipo F }\end{array}$ \\
\hline $\begin{array}{l}\text { Double } \\
\text { Clear / } \\
\text { Air }\end{array}$ & $\begin{array}{c}\text { Double } \\
\text { Clear } \\
\text { Spectrally } \\
\text { Selective } \\
\text { Low-e (\#2) } \\
\text { / Argon }\end{array}$ & $\begin{array}{c}\text { Triple } \\
\text { Clear } \\
\text { Spectrally } \\
\text { Selective } \\
\text { Low-e (\#2) } \\
\text { / Argon }\end{array}$ & $\begin{array}{c}\text { Triple } \\
\text { Clear } \\
\text { Spectrally } \\
\text { Selective } \\
\text { Low-e (\#5) } \\
\text { / Argon }\end{array}$ & $\begin{array}{c}\text { Triple } \\
\text { Clear } \\
\text { Spectrally } \\
\text { Selective } \\
\text { Low-e (\#2 } \\
\text { \& \#5) / } \\
\text { Krypton }\end{array}$ & $\begin{array}{l}\text { Heat Mi- } \\
\text { rror Quad } \\
\text { Glass ( } 3 \\
\text { films }\end{array}$ \\
\hline SIN: 28.0 & SIN: 19.5 & NA & SIN : 24.0 & SIN : 19.9 & SIN : 17.8 \\
\hline INT: 26.8 & INT: 18.9 & NA & INT: $: 23.5$ & INT $: 19.5$ & INT: 17.5 \\
\hline
\end{tabular}

Aun a pesar de que el uso de mecanismos de control solar interiores -o persianas- está extendido en casi todas las culturas debido a su capacidad de otorgar privacidad y oscurecer el espacio, los análisis no han demostrado que proporcionen beneficios significativos.

Por un lado, para un tipo de vidrio determinado, el efecto de los dispositivos solares depende del área de la superficie acristalada. A pesar de que inicialmente se pueda pensar que su efecto disminuye a medida que decrece el área de vidrio, los análisis no siempre concuerdan. Es más, los puntos de inflexión de posibles ahorros han variado durante los análisis. 
Por otro lado, establecida una hipótesis de superficie de vidrio, los posibles beneficios vienen determinados por el tipo de vidrio seleccionado. Esto se ha observado tanto para superficies mayores como menores. En general, los resultados han mostrado que cuanto mejor es el rendimiento de un vidrio menor es el efecto del dispositivo sobre el total. De los estudios en las fachadas orientadas a Norte no es posible extraer un valor significativo que permita validar el posible ahorro energético mediante la incorporación de los sistemas de control solar interiores.

A continuación se muestran las reducciones en cargas de refrigeración extraídas de los estudios.

\begin{tabular}{|c|c|c|c|c|c|}
\hline $\begin{array}{l}\text { Vidrio } \\
\text { Tipo A }\end{array}$ & $\begin{array}{l}\text { Vidrio } \\
\text { Tipo B }\end{array}$ & $\begin{array}{l}\text { Vidrio } \\
\text { Tipo C }\end{array}$ & $\begin{array}{l}\text { Vidrio } \\
\text { Tipo D }\end{array}$ & $\begin{array}{l}\text { Vidrio } \\
\text { Tipo E }\end{array}$ & $\begin{array}{l}\text { Vidrio } \\
\text { Tipo F }\end{array}$ \\
\hline $\begin{array}{l}\text { Double } \\
\text { Clear / } \\
\text { Air }\end{array}$ & $\begin{array}{c}\text { Double } \\
\text { Clear } \\
\text { Spectrally } \\
\text { Selective } \\
\text { Low-e (\#2) } \\
\text { / Argon }\end{array}$ & $\begin{array}{c}\text { Triple } \\
\text { Clear } \\
\text { Spectrally } \\
\text { Selective } \\
\text { Low-e (\#2) } \\
\text { / Argon }\end{array}$ & $\begin{array}{c}\text { Triple } \\
\text { Clear } \\
\text { Spectrally } \\
\text { Selective } \\
\text { Low-e (\#5) } \\
\text { / Argon }\end{array}$ & $\begin{array}{c}\text { Triple } \\
\text { Clear } \\
\text { Spectrally } \\
\text { Selective } \\
\text { Low-e (\#2 } \\
\text { \& \#5) / } \\
\text { Krypton }\end{array}$ & $\begin{array}{l}\text { Heat Mi- } \\
\text { rror Quad } \\
\text { Glass ( } 3 \\
\text { films }\end{array}$ \\
\hline $4.29 \%$ & $3.08 \%$ & $\mathrm{NA}$ & $2.08 \%$ & $2.01 \%$ & $1.69 \%$ \\
\hline INT $: 26.8$ & INT: 18.9 & $\mathrm{NA}$ & INT: 23.5 & INT: 19.5 & INT $: 17.5$ \\
\hline
\end{tabular}

Con todo, la reducción existe, y se recomienda la incorporación de estas estrategias para posiblemente reducir la entrada de luz difusa, controlar el deslumbramiento y asegurar la privacidad de los espacios, principalmente en aquéllos de uso residencial.

Los mecanismos de control solar en fachadas orientadas al sur presentan mayores oportunidades de diseño y composición. Como se ha expuesto con anterioridad, para este proyecto se han escogido tres tipos de mecanismos de control solar para las fachadas orientadas al Sur: los dispositivos interiores, las lamas horizontales regulables y las proyecciones horizontales. Cada uno de estos mecanismos se ha estudiado desde el punto de vista de la eficiencia energética con el fin de determinar las ventajas e inconvenientes que presentan. 
A continuación se exponen los resultados y conclusiones derivados del estudio de las cargas de refrigeración para la orientación Sur. Los gráficos que acompañan se presentan en el Anexo.

\begin{tabular}{|c|c|c|c|c|c|}
\hline $\begin{array}{l}\text { Vidrio } \\
\text { Tipo A }\end{array}$ & $\begin{array}{l}\text { Vidrio } \\
\text { Tipo B }\end{array}$ & $\begin{array}{l}\text { Vidrio } \\
\text { Tipo C }\end{array}$ & $\begin{array}{l}\text { Vidrio } \\
\text { Tipo D }\end{array}$ & $\begin{array}{l}\text { Vidrio } \\
\text { Tipo E }\end{array}$ & $\begin{array}{l}\text { Vidrio } \\
\text { Tipo F }\end{array}$ \\
\hline $\begin{array}{l}\text { Double } \\
\text { Clear / } \\
\text { Air }\end{array}$ & $\begin{array}{c}\text { Double } \\
\text { Clear } \\
\text { Spectrally } \\
\text { Selective } \\
\text { Low-e (\#2) } \\
\text { / Argon }\end{array}$ & $\begin{array}{c}\text { Triple } \\
\text { Clear } \\
\text { Spectrally } \\
\text { Selective } \\
\text { Low-e (\#2) } \\
\text { / Argon }\end{array}$ & $\begin{array}{c}\text { Triple } \\
\text { Clear } \\
\text { Spectrally } \\
\text { Selective } \\
\text { Low-e (\#5) } \\
\text { / Argon }\end{array}$ & $\begin{array}{c}\text { Triple } \\
\text { Clear } \\
\text { Spectrally } \\
\text { Selective } \\
\text { Low-e (\#2 } \\
\text { \& \#5) / } \\
\text { Krypton } \\
\end{array}$ & $\begin{array}{l}\text { Heat Mi- } \\
\text { rror Quad } \\
\text { Glass (3 } \\
\text { films }\end{array}$ \\
\hline SIN: 70.5 & SIN: 42.8 & NA & SIN: 57.8 & SIN : 42.9 & SIN : 35.9 \\
\hline INT: 42.7 & INT: 28.3 & NA & INT: 39.6 & INT $: 30.4$ & INT $: 24.4$ \\
\hline PROY : 49.7 & PROY : 31.8 & NA & PROY: 42.3 & PROY: 32.7 & PROY : 28.1 \\
\hline HOR: 10.4 & HOR: 9.2 & $\mathrm{NA}$ & HOR: 11.1 & HOR: 10.1 & HOR : 9.5 \\
\hline
\end{tabular}

En primer lugar, de los resultados obtenidos se puede observar que, de manera similar a lo ocurrido en las fachadas orientadas al Norte, cuanto mejor es el rendimiento del vidrio, menor es el beneficio que se obtiene de la incorporación de sistemas de control solar interiores. Sin embargo, a diferencia de lo que se ha observado en la orientación Norte, en este caso las disminuciones de cargas resultan mayores. Para tratar de mejorar el rendimiento de la envolvente se podría considerar controlar el espacio entre el dispositivo y la cara interna del vidrio. Esto, junto con la posibilidad de controlar la entrada de luz natural y asegurar la privacidad, hace de los dispositivos interiores, elementos complementarios a considerar.

En segundo lugar, las fachadas orientadas al Sur permiten estudiar el efecto que produciría la incorporación de una proyección horizontal o voladizo para controlar la entrada del sol. En este caso, los resultados revelan que, aunque se reducen las cargas de refrigeración, éstas son mayores que las obtenidas mediante los dispositivos de control solar interiores. Además, al tratarse de un elemento fijo, el resultado global se traduce en un aumento de cargas de calefacción durante el invierno. A pesar de que la 
profundidad de la proyección fija se calculó para evitar las ganancias energéticas en verano aun permitiendo la entrada de radiación solar en invierno, los datos están basados en un día y una hora específicos, por lo que hay un espectro amplio de valores que no se consideran y por tanto salen perjudicados.

A continuación se muestran los resultados de los análisis de calefacción para el sistema de proyección horizontal.

\begin{tabular}{|c|c|c|c|c|c|}
\hline $\begin{array}{l}\text { Vidrio } \\
\text { Tipo A }\end{array}$ & $\begin{array}{l}\text { Vidrio } \\
\text { Tipo B }\end{array}$ & $\begin{array}{l}\text { Vidrio } \\
\text { Tipo C }\end{array}$ & $\begin{array}{l}\text { Vidrio } \\
\text { Tipo D }\end{array}$ & $\begin{array}{l}\text { Vidrio } \\
\text { Tipo E }\end{array}$ & $\begin{array}{l}\text { Vidrio } \\
\text { Tipo F }\end{array}$ \\
\hline $\begin{array}{l}\text { Double } \\
\text { Clear / } \\
\text { Air }\end{array}$ & $\begin{array}{c}\text { Double } \\
\text { Clear } \\
\text { Spectrally } \\
\text { Selective } \\
\text { Low-e (\#2) } \\
\text { / Argon }\end{array}$ & $\begin{array}{c}\text { Triple } \\
\text { Clear } \\
\text { Spectrally } \\
\text { Selective } \\
\text { Low-e (\#2) } \\
\text { / Argon }\end{array}$ & $\begin{array}{c}\text { Triple } \\
\text { Clear } \\
\text { Spectrally } \\
\text { Selective } \\
\text { Low-e (\#5) } \\
\text { / Argon }\end{array}$ & $\begin{array}{c}\text { Triple } \\
\text { Clear } \\
\text { Spectrally } \\
\text { Selective } \\
\text { Low-e (\#2 } \\
\text { \& \#5) / } \\
\text { Krypton }\end{array}$ & $\begin{array}{l}\text { Heat Mi- } \\
\text { rror Quad } \\
\text { Glass ( } 3 \\
\text { films }\end{array}$ \\
\hline SIN $: 31.1$ & SIN $: 15.2$ & NA & SIN $: 7.4$ & $\operatorname{SIN}: 8.2$ & $\operatorname{SIN}: 8.2$ \\
\hline PROY : 39.3 & $\operatorname{INT}: 20.0$ & $\mathrm{NA}$ & INT: 10.8 & INT: 11.8 & INT: 11.6 \\
\hline
\end{tabular}

La hipótesis planteada conlleva que, inevitablemente, parte de la energía necesaria en invierno se vea obstruida. De ahí que los valores no reflejen un beneficio significativo ya que, en un clima como el de Chicago, la demanda de calefacción es predominante.

Sin embargo, como se ha mencionado a lo largo de este trabajo, las decisiones de diseño implican poner en una balanza los distintos conceptos. Como premisa destaca la adaptabilidad de los espacios y los diferentes usos que pueda otorgarse a la piel flexible.

Por tanto, si se incorporan otros tipos de medidas de control solar, los voladizos en forma de terrazas o pieles de doble capa pueden conformar espacios que no sólo mejoren sustancialmente el rendimiento de la piel en sí, sino que permitan incluir espacios de transición y estancia que doten de mayor flexibilidad a los espacios interiores. Por ello, éstos se han convertido en una parte imprescindible 
del diseño de este proyecto. La combinación de voladizos con mecanismos de control solar han disminuido las necesidades de refrigeración; y la doble piel ha incrementado el aislamiento térmico de la piel, reduciendo las necesidades de calefacción. Debido a las limitaciones de las herramientas empleadas, este trabajo no ha analizado numéricamente los efectos de dichas combinaciones.

Por último, las fachadas orientadas al sur se benefician de la utilización de dispositivos horizontales móviles - lamas. Los resultados muestran una reducción considerable en la demanda de refrigeración, la cual no se ve significativamente mermada con la mejoría del tipo de vidrio estudiado. Este tipo de sistemas ofrece ventajas en el diseño de una fachada de vidrio ya que, además de suponer un alivio a las cargas en verano, las vistas desde el interior no son obstruidas si los dispositivos son móviles.

A ello se añade el hecho de que al ser regulables no afectan negativamente a la entrada de calor en invierno, con lo que se amoldan a la flexibilidad necesaria en una fachada de vidrio a lo largo de las distintas estaciones.

Por tanto, los análisis llevados a cabo para este
trabajo han contribuido a validar la teoría estudiada,
reforzando la importancia de incorporar medidas de pro-
tección solar en verano en las fachadas orientadas a Sur.

Si se observan las fachadas orientadas al Este \& Oeste, los resultados denotan que su rendimiento vendrá dado, en gran medida, por la incorporación de elementos de protección y control solar. Debido a las particularidades de estas dos orientaciones -en muchos casos con requerimientos variables- el confort del espacio interior estará sujeto a las posibilidades de estos dispositivos. Por tanto, el vidrio no puede ser considerado la única solución para estas orientaciones. Los dispositivos de protección y control solar serán fundamentales para el confort interior. Los análisis llevados a cabo revelan similitudes en el comportamiento de las medidas de control solar, aun a pesar de que los análisis anteriores del vidrio no siempre se asemejan. Con el sistema de protección y control adecuado, las 
fachadas al Este por las mañanas y al Oeste por las tardes, pueden verse aliviadas durante los meses más calurosos.

A continuación A continuación se exponen los resultados y conclusiones derivados del estudio de las cargas de refrigeración para las orientaciones Este y Oeste. Los gráficos que acompañan se presentan en el Anexo.

\begin{tabular}{|c|c|c|c|c|c|c|}
\hline & $\begin{array}{l}\text { Vidrio } \\
\text { Tipo A }\end{array}$ & $\begin{array}{l}\text { Vidrio } \\
\text { Tipo B }\end{array}$ & $\begin{array}{l}\text { Vidrio } \\
\text { Tipo C }\end{array}$ & $\begin{array}{l}\text { Vidrio } \\
\text { Tipo D }\end{array}$ & $\begin{array}{l}\text { Vidrio } \\
\text { Tipo E }\end{array}$ & $\begin{array}{l}\text { Vidrio } \\
\text { Tipo F }\end{array}$ \\
\hline & $\begin{array}{l}\text { Double } \\
\text { Clear / } \\
\text { Air }\end{array}$ & $\begin{array}{c}\text { Double } \\
\text { Clear } \\
\text { Spectrally } \\
\text { Selective } \\
\text { Low-e (\#2) } \\
\text { / Argon }\end{array}$ & $\begin{array}{c}\text { Triple } \\
\text { Clear } \\
\text { Spectra- } \\
\text { lly Se- } \\
\text { lective } \\
\text { Low-e } \\
(\# 2) / \\
\text { Argon }\end{array}$ & $\begin{array}{c}\text { Triple } \\
\text { Clear } \\
\text { Spectrally } \\
\text { Selective } \\
\text { Low-e (\#5) } \\
\text { / Argon }\end{array}$ & $\begin{array}{c}\text { Triple } \\
\text { Clear } \\
\text { Spectrally } \\
\text { Selective } \\
\text { Low-e (\#2 } \\
\text { \& \#5) / } \\
\text { Krypton }\end{array}$ & $\begin{array}{l}\text { Heat Mi- } \\
\text { rror Quad } \\
\text { Glass (3 } \\
\text { films }\end{array}$ \\
\hline \multirow{3}{*}{$\begin{array}{l}\text { 되 } \\
\text { 田 } \\
\text { 되 }\end{array}$} & SIN: 77.5 & SIN : 47.8 & NA & SIN : 60.0 & SIN : 47.2 & SIN : 40.6 \\
\hline & INT: 55.0 & INT: 35.8 & $\mathrm{NA}$ & INT : 49.5 & INT: 38.2 & INT: 30.9 \\
\hline & VERT: 15.4 & VERT: 12.3 & $\mathrm{NA}$ & VERT:15.1 & VERT: 13.3 & VERT $: 12.3$ \\
\hline \multirow{3}{*}{$\begin{array}{l}\text { 되 } \\
\text { 더 } \\
\text { O2 } \\
\text { 됭 }\end{array}$} & SIN: 74.7 & SIN: 46.1 & $\mathrm{NA}$ & SIN: 58.3 & SIN: 45.9 & SIN: 39.5 \\
\hline & INT: 54.4 & INT: 35.1 & NA & INT $: 48.4$ & INT $: 37.4$ & INT: 30.4 \\
\hline & VERT: 17.4 & VERT: 13.5 & $\mathrm{NA}$ & VERT: 16.5 & VERT: 14.4 & VERT $: 13.2$ \\
\hline
\end{tabular}

De manera similar a lo observado en las otras orientaciones, al estudiar el beneficio de incorporar mecanismos de control solar interiores, se comprueba que éstos disminuyen cuánto mayor sea el rendimiento del vidrio. Del mismo modo, las protecciones interiores servirán para proporcionar privacidad y control de la iluminación. Por lo tanto, es una estrategia que, con independencia unas de otras, es recomendable.

Sin embargo, la estrategia que ha demostrado ser más beneficiosa para las orientaciones Este y Oeste, es la incorporación de lamas verticales regulables. Similarmente a lo que se observa en el sur con las lamas horizontales, en este caso la posibilidad de incorporar un sistema de lamas verticales permite controlar la entrada de la energía solar durante las horas críticas -ya sean mañanas o tardes dependiendo de la exposición- y al mismo tiempo posibilita las 
vistas al exterior. La disminución de la demanda de refrigeración mediante esta estrategia es considerable, incluso con vidrios de alto rendimiento. Durante los meses de invierno, éstas se pueden regular, con lo que las demandas de calefacción no se ven alteradas. A medida que disminuye el área de superficie acristalada disminuye también su efecto.

Por tanto, las opciones que deben valorarse para las orientaciones Este y Oeste tendrán la cualidad de bloquear el sol por las mañanas y las tardes, al mismo tiempo que permite la entrada de luz natural sin interponerse a las vistas del exterior. El diseño de lamas verticales, ya sea en combinación con otros sistemas o por sí solos, presentan alternativas atractivas para el diseño. 


\section{Superficies Inclinadas}

Aunque por lo general las envolventes de los edificios han sido descritas en posición vertical, cada vez son más las pieles con una geometría compleja, curvaturas, ángulos e incluso inclinaciones. Durante el desarrollo de este trabajo se han estudiado diferentes casos de envolventes. Una que despertó gran interés fue la inclinación de la superficies de vidrio con el fin de mejorar la calidad del espacio interior y el rendimiento de la fachada. Para ello, se ha llevado a cabo un estudio de cuáles son los beneficios de una fachada de estas características. En este caso, el análisis se ha realizado para la fachada orientada al sur, aunque posiblemente, si la inclinación fuese en el plano horizontal, podrían obtenerse beneficios en las Este y Oeste.

A tal efecto ha sido necesario determinar la posición e inclinación óptima de la envolvente, identificando las condiciones ambientales que se dan en Chicago para una fachada al Sur, y evaluando el ángulo en el que ésta proporcionaría mayores beneficios. Mediante la herramienta SunAngle (www.susdesign.com/sunangle/) desarrollado por Christopher Gronbeck se obtiene la altitud del sol a lo largo del año. Posteriormente se extraen los datos climatológicos de Chicago para definir los meses más calurosos. Así, se definen los meses en los que la demanda de refrigeración sería mayor; para ellos se obtiene la inclinación del sol, con la finalidad de diseñar una envolvente de vidrio que evite la entrada de calor directo durante los meses establecidos y, al mismo tiempo, permita la entrada de energía solar durante los meses más fríos.

El periodo más calurosos comprende entre mayo y agosto, determinando así los ángulos de mayor susceptibilidad. En agosto la altitud del sol es de, aproximadamente, 60 grados. Esto significa que la superficie debería estar diseñada con una inclinación de 30 grados respecto a la vertical. Sin embargo, debido a las dificultades técnicas que ello conllevaría, se ha considerado apropiado seleccionar un ángulo que evite el mayor porcentaje de calor sin comprometer la arquitectura y la construcción. Tras un análisis meticuloso de las diferentes opciones, el ángulo identificado como 
el más apropiado es de 20 grados, ya que bloquea el calor durante el mes más caluroso del año: julio. Una vez determinado el ángulo de inclinación del vidrio, se obtuvieron las propiedades del mismo mediante la herramienta Window y se procedió al análisis del diseño.

A continuación se exponen los resultados y conclusiones derivados del estudio de las cargas de refrigeración del estudio de superficies inclinadas en la orientación Sur. Los gráficos que acompañan se presentan en el Anexo.

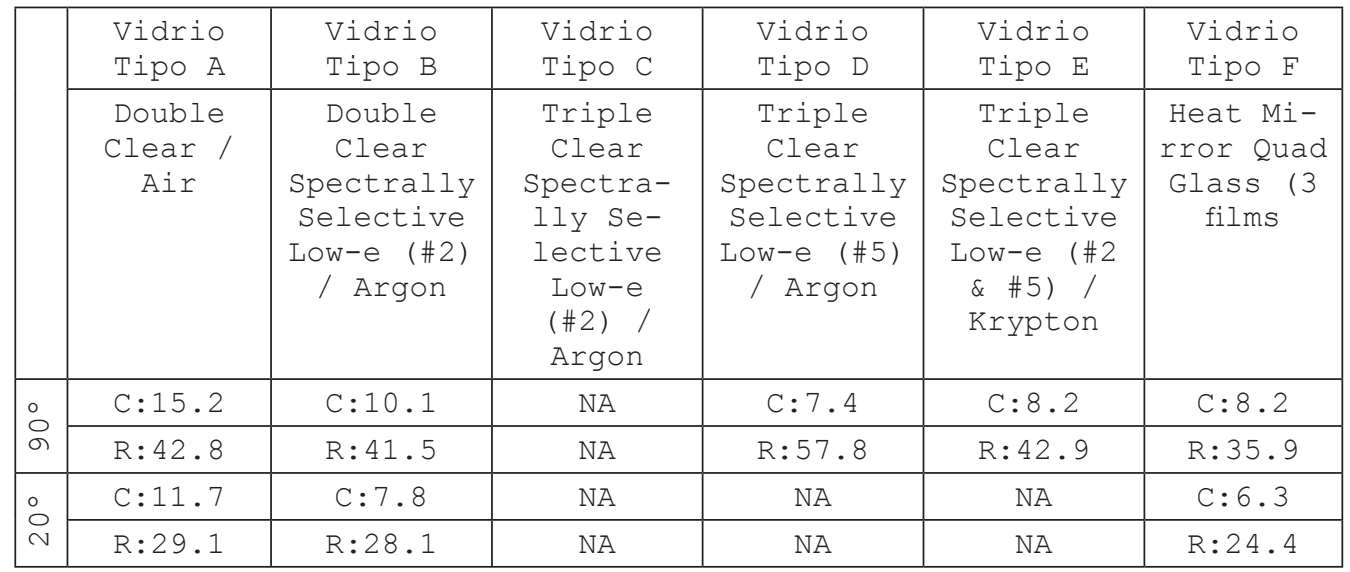

De su evaluación se extrae la posibilidad de controlar la entrada de energía solar durante los meses de verano mediante la inclinación de la superficie de vidrio y reduciendo así las cargas de refrigeración. Sin embargo, de los análisis se ha observado que no todos los vidrios responden de la misma manera. En este caso, dos de los vidrios inicialmente de mayor eficiencia han visto mermada su capacidad cuanto mayor era la inclinación.

Al mismo tiempo, mediante el control del ángulo de inclinación, la fachada de vidrio permite la entrada de calor durante los meses de invierno y no se interrumpen las vistas al exterior.

Por tanto, de los estudios se observa una reducción considerable de las cargas de refrigeración durante los me- 
ses más calurosos, mientras que las de calefacción no se ven alteradas.

En resumen, a pesar de las limitaciones del análisis, se han podido estudiar diferentes tipos, posiciones y relaciones de envolventes hacia un camino energéticamente sostenible. Los mecanismos de control y protección solar analizados han validado lo expuesto en la teoría.

De ellos se concluye lo siguiente: la selección de un tipo de vidrio viene determinado por su localización en la fachada, sus componentes y propiedades, así como por su comportamiento junto con el resto de elementos que componen la envolvente. Mediante el análisis de cada uno de ellos y el estudio del conjunto, el proceso de diseño permite ir comprobando que las decisiones que se toman apuestan por una arquitectura energéticamente eficiente y un control y confort interior. 

9. Anne Lacaton, Jean-Philippe Vassal, "La Libertad estructural, condición del milagro", $2 G$ Lacaton \& Vassal Obra Reciente. (Barcelona: Gustavo Gili, 2010), pág. 162 .

\subsection{PROYECTO DE TRANSFORMACIÓN DE LA ENVOLVENTE. PROPUESTA DE DISEÑO}

"El bienestar, pero también los sueños de una sociedad contemporánea, parecen depender de la manera en la que una situación existente se encuentra con una nueva, dos temporalidades, dos estados de espíritu".9

La transformación del conjunto de Lake Grove Village puede verse resumida, en parte, al resultado de la superposición. Como se ha visto reflejado en alguno de los proyectos de Lacaton \& Vassal estudiados, así como en ciertos de sus escritos, el encuentro entre dos tiempos ha permitido la superposición de un concepto que, sin imponerse a la trama original, ha colaborado en la definición de una nueva realidad.

En este caso, la nueva realidad se ha definido como la superposición de dos situaciones que han creado espacios y usos nuevos, en parte gracias a las diferencias y a las similitudes en las intenciones de ambos. 
Un ejemplo de ello es el respeto al proyecto en sí, su localización y configuración general. Durante el proceso de análisis del lugar, entre otros componentes, el proyecto y las soluciones se han visto influenciadas por el lugar y el entorno inmediato. Así, la trama propuesta es resultado de una perspectiva nueva en un entorno existente.

El diagrama que se muestra a continuación muestra la intención de relación entre el edificio y el contexto:

- las fachadas orientadas al Norte establecen conexiones con el centro de Chicago y el skyline de la ciudad;

- las fachadas orientadas al sur se relacionan con los barrios históricos, mayoritariamente residenciales;

- las fachadas orientadas al Este se aprovechan de la extensión del lago Michigan;

- y finalmente, las fachadas orientadas al Oeste lo hacen de la expansión de la ciudad.

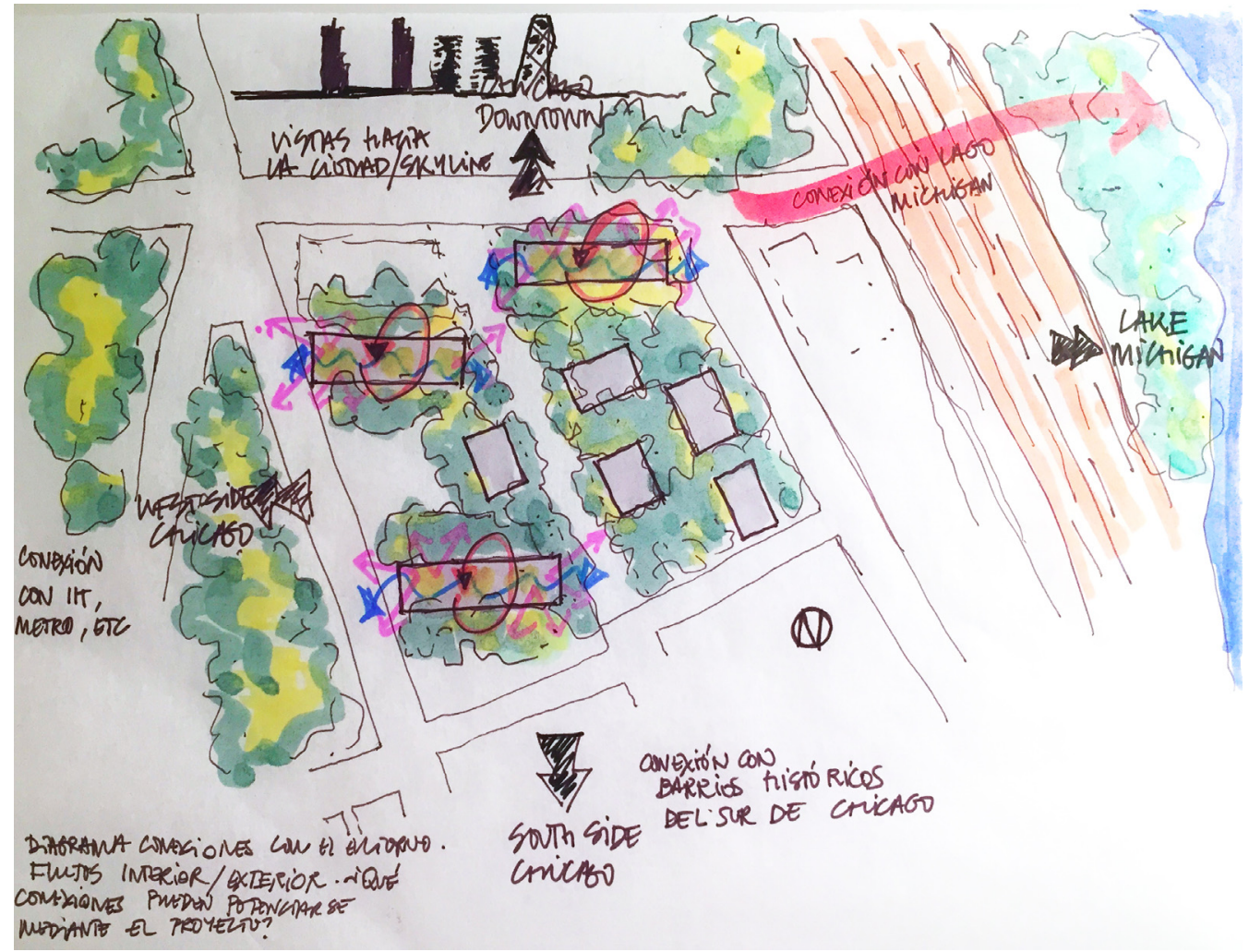


La conexión visual recuerda en parte a la establecida por Mies en los apartamentos de Lake shore Drive, en las que la fachada enmarcaba las vistas de la ciudad y del lago Michigan. En la intervención de Lake Grove Village se abren las envolventes para, además de permitir la entrada de sol, potenciar la conexión visual con el entorno y enmarcar la ciudad como si se tratase de una composición manual. A continuación se muestra la intención del proyecto de enmarcar las vistas de la ciudad, así como una fotografía con lo propio de Lake Shore Drive.
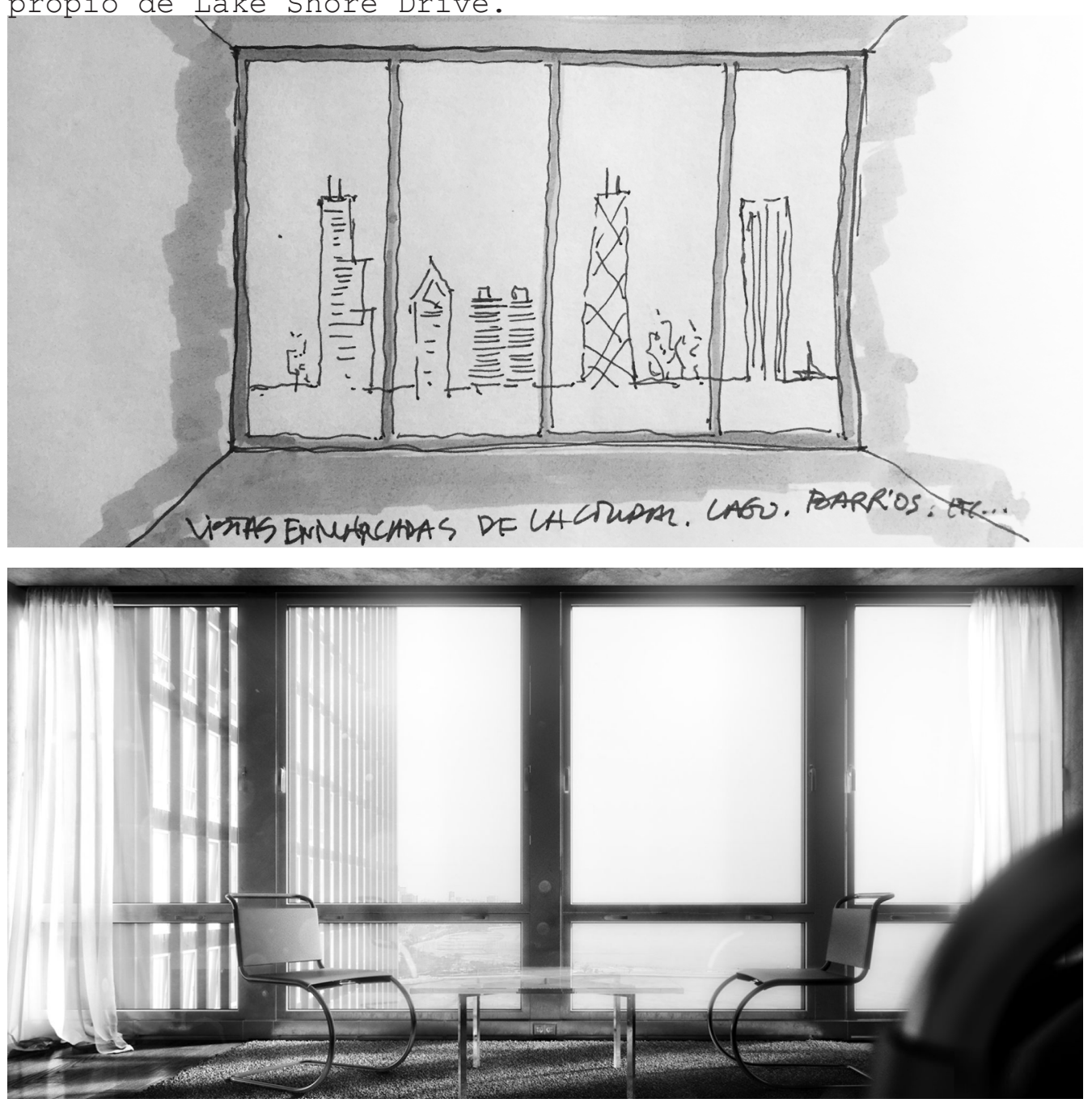
Al mismo tiempo que enmarca las vistas de la ciudad, el conjunto de la fachada propuesta recuerda a la modulación observada en los proyectos estudiados. La fachada original de Lake Grove Village se caracteriza por la combinación de elementos opacos con otros transparentes creando un elemento sólido en la que se insertan los huecos. La lectura parece ser la de una superficie más que el de una retícula. Sin embargo, el proyecto de intervención pretende otorgar una imagen más liviana al edificio, en el que los elementos sólidos puedan leerse mediante el ritmo de los montantes verticales y horizontales de manera similar a lo que se ha visto en, por ejemplo, one IBM Plaza. A continuación se muestra una imagen de ambas fachadas de las que se extrae la lectura de las carpinterías.
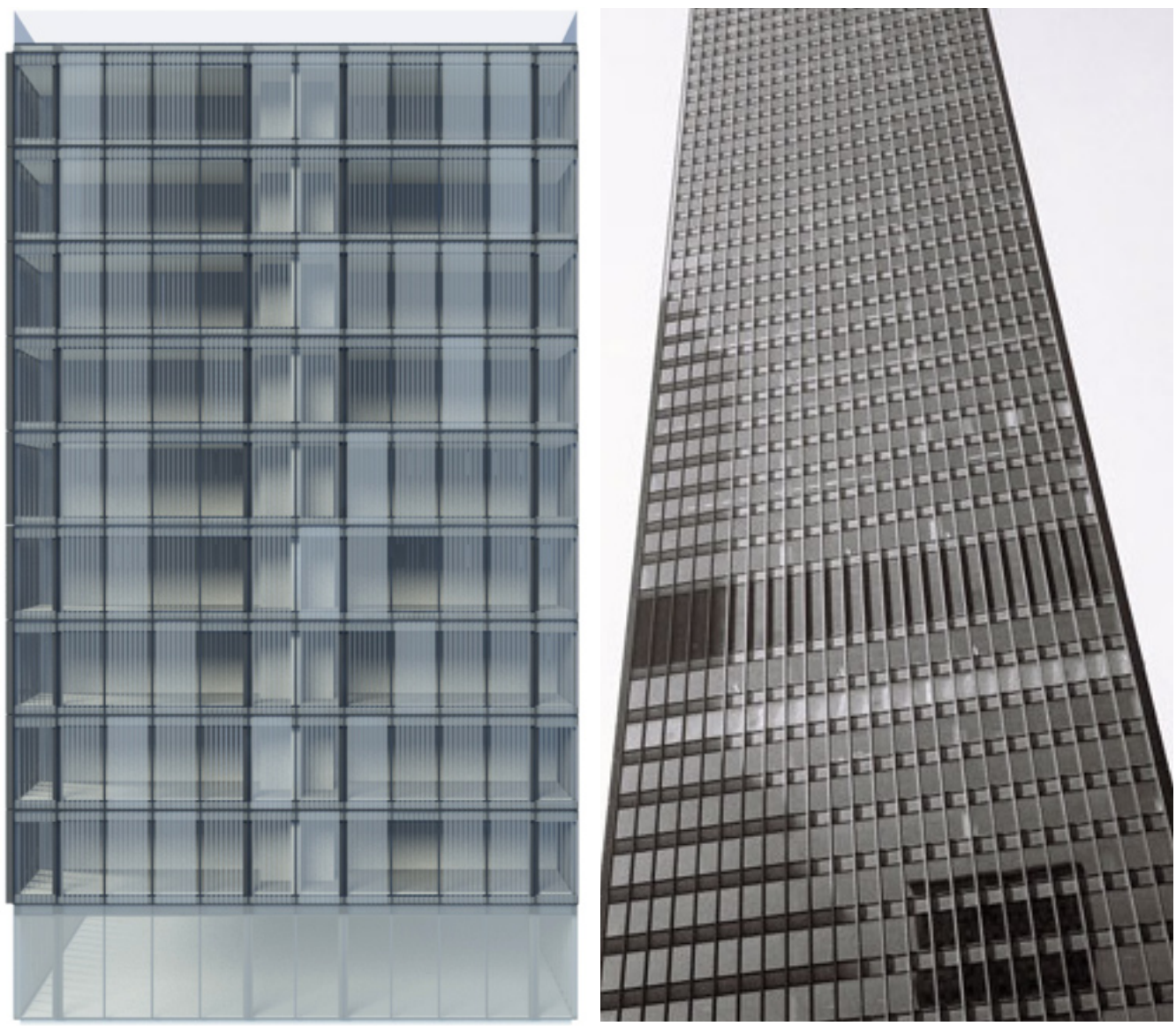
La transformación de una envolvente sólida con huecos puntuales a otra reticular de vidrio es otro ejemplo de superposición; en este caso de dos sistemas. Por un lado, el sistema de estructura prefabricada se mantiene: la estructura vertical y horizontal. Por otro lado, las funciones de la envolvente, aun a pesar de ser similares en ciertos aspectos, se desarrollan de manera diferente. La combinación de ambos crea el nuevo escenario.

En el proyecto original, el aislamiento térmico y acústico viene determinado casi en su totalidad por los paneles metálicos opacos. En la nueva propuesta este viene determinado, entre otras cosas, por el tipo de vidrio. Asimismo, las funciones de ventilación, iluminación y control solar pasan a ser elementos más complejos que simplemente el hueco. Esta situación recuerda a la intervención de Lacaton \& Vassal para la torre Bois-le-Prêtre. A continuación se muestran esquemas de ambas fachadas de transformación: la original de LGV y los esquemas de L\&V.

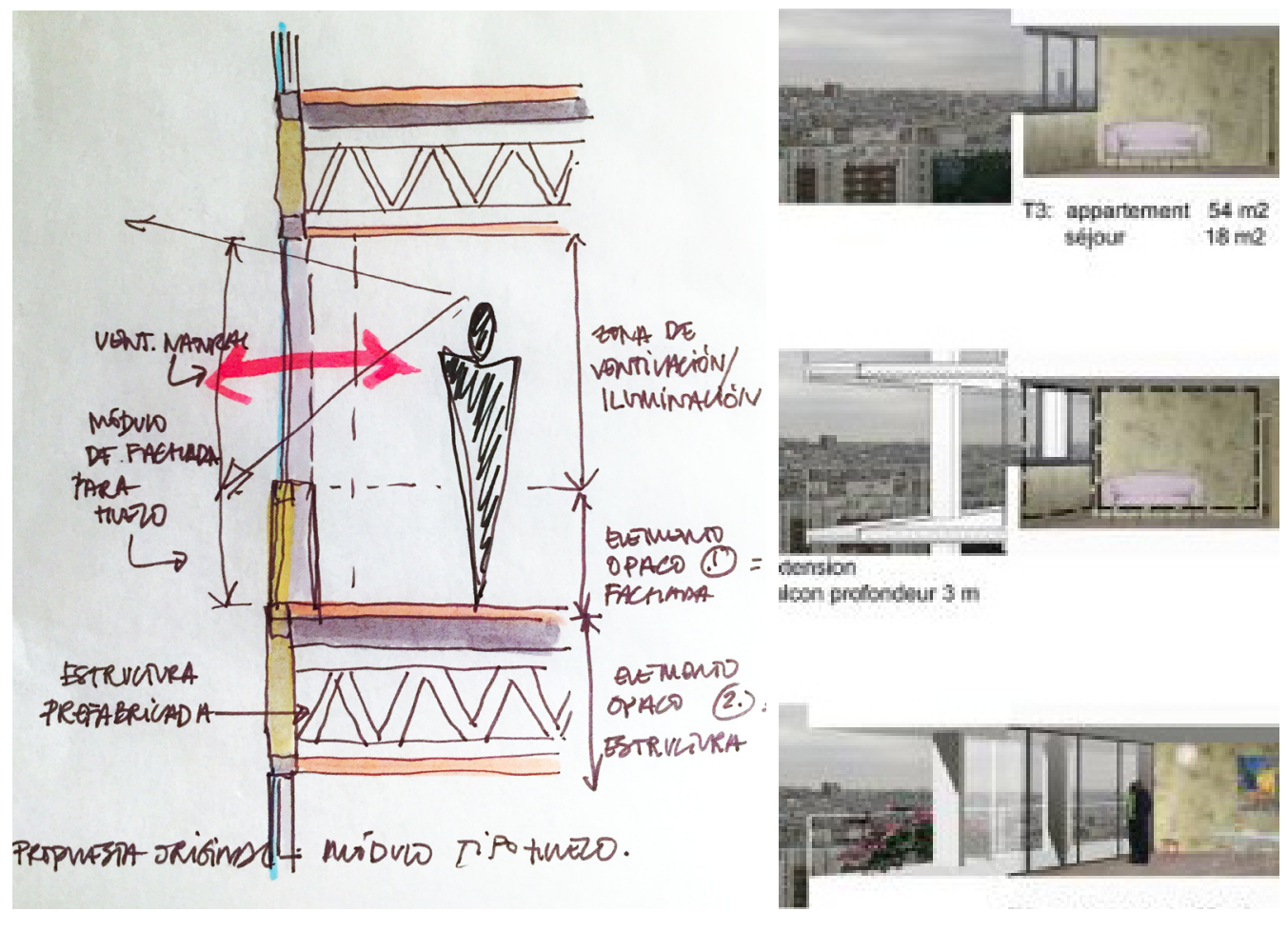


Los cambios en el tratamiento del hueco conllevan una profundización en la envolvente y en sus funciones. La propuesta para LGV se desarrolla partiendo de la posibilidad de que albergue diferentes funciones, permita la adaptabilidad de las mismas y facilite la interacción entre el espacio interior y el exterior. Así, la ventilación natural, el control solar y lumínico, la capacidad aislante o la privacidad, son ejemplos que se estudian desde el inicio del proyecto. De manera similar a lo que Schipporeit diseñó a finales de los años 60 para Lake Point Tower, el proyecto trata la envolvente como la superficie intercambiadora entre diferentes atmósferas. A continuación se muestra uno de los esquemas iniciales que se estudiaron para la piel de LGV el cual, aunque diferente a las propuestas finales, ya apuntaban hacia una intervención en la que las envolventes jugasen un papel activo.
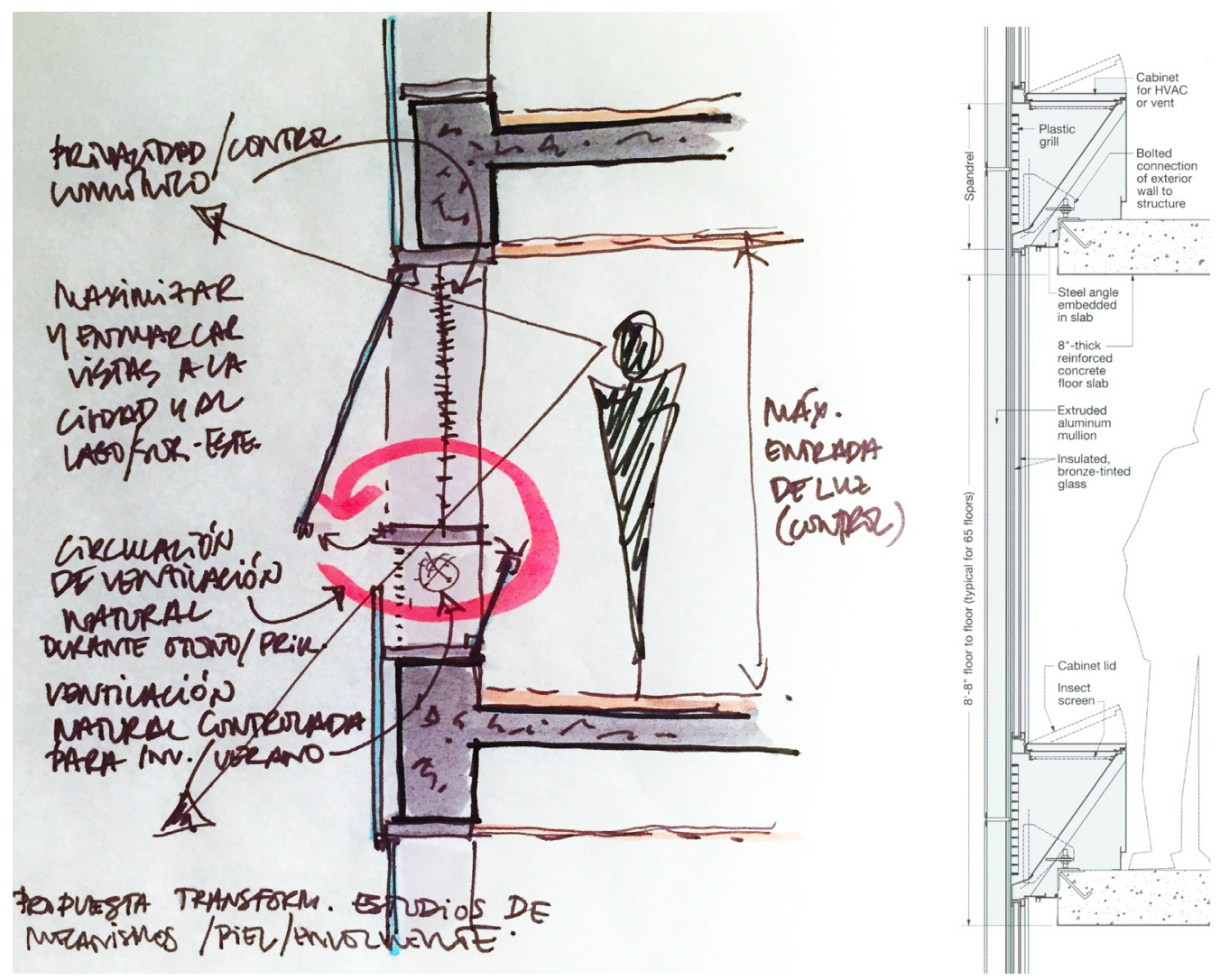
Por último, y como amalgama de los conceptos esbozados en este apartado, la ideación del proyecto traslada la envolvente a la tercera dimensión. La transformación de las viviendas no sólo ha ayudado a alterar y a mejorar la relación entre los espacios interiores y el exterior, sino a crear espacios de transición que permiten a las viviendas la adaptabilidad y singularidad a sus necesidades. De esta manera se crea la nueva realidad a la que se ha hecho referencia con anterioridad. Similarmente al proyecto Lacaton \& Vassal para las viviendas en Saint Nazaire, esta nueva realidad nace de la superposición y permite leer las diferentes capas de los proyectos. Los esquemas que se muestran a continuación son ejemplos de esquemas iniciales de transformación de la envolvente de LGV y el esquema de transformación del proyecto de Lacaton \& Vassal.
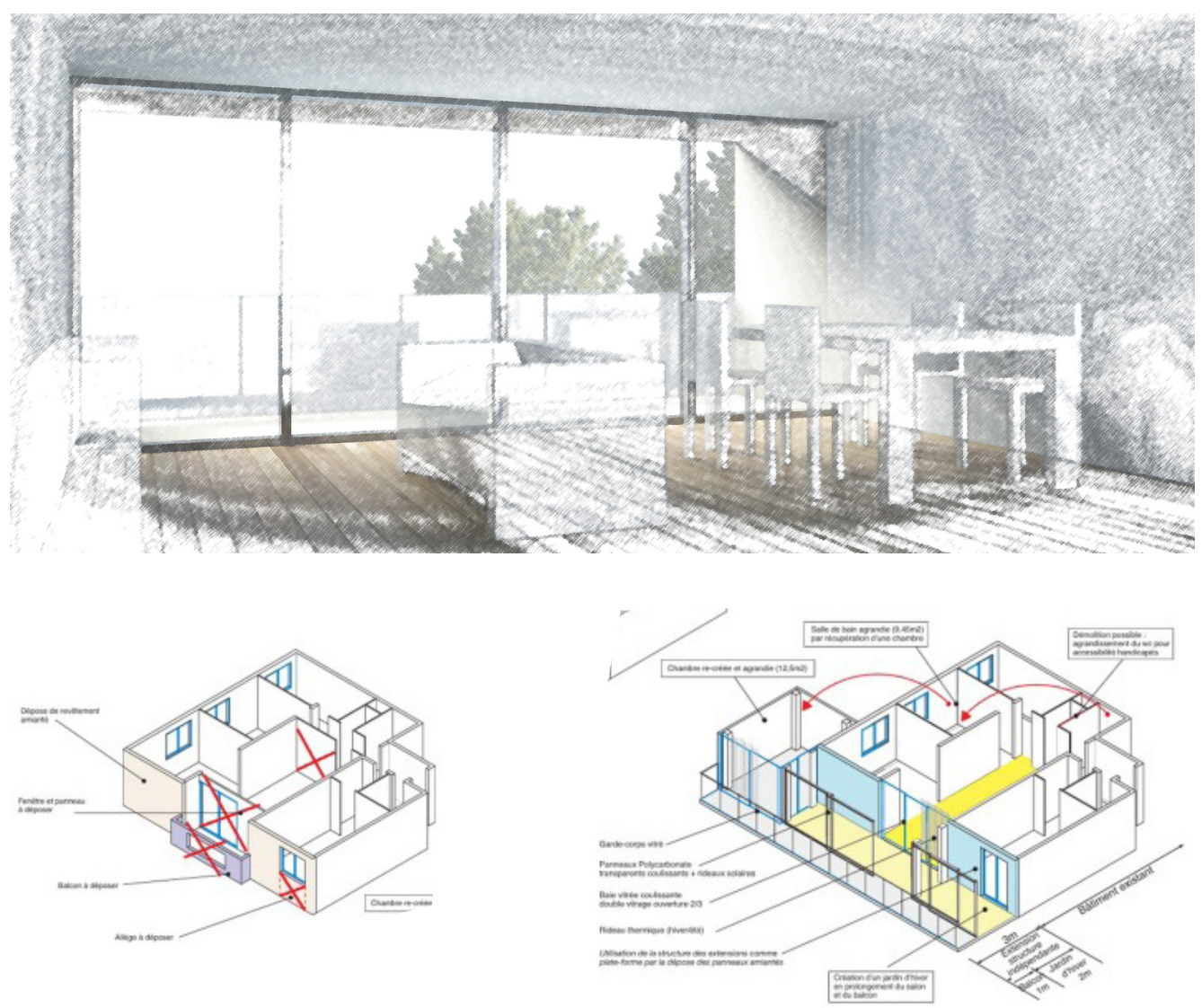



\subsubsection{Propuesta de Diseño}

El proyecto de transformación de la envolvente de Lake Grove Village parte del diseño de un sistema de construcción de los años 60. En él se lleva a cabo un proceso mediante el que se dota a las viviendas de: mayor superficie habitable, mayor superficie de entrada de luz y ventilación natural y mejor eficiencia energética. Todo ello sin modificar el sistema estructural y tratando de minimizar las interferencias con el espacio interior. El proyecto consiste, entre otros elementos, en una envolvente de 1.5 metros de profundidad que, como si de una segunda piel se tratase, va acoplándose a la retícula por delante de los forjados.

Mediante un sistema que recuerda al que los arquitectos Anne Lacaton \& Jean-Phillipe Vassal propusieron para la Torre Bois-le-Pêre, descrito anteriormente, el proyecto se desarrolla mediante módulos de fachada prefabricados y ligeros que permiten una construcción rápida.

En primer lugar, la fachada existente de Lake Grove Village está compuesta por módulos prefabricados que fueron instalados una vez la estructura y demás sistemas del edificio se habían construido. Los edificos se han edificado en un barrio necesitado de vivienda social. Con el tiempo, otros bloques de viviendas fueron construyéndose con objetivos similares. La zona al este del campus del IIT se caracteriza por extensas superficies verdes y grandes bloques de apartamentos de vivienda social. Hoy, transcurridos más de 40 años, las condiciones socioeconómicas de la zona no han mejorado significativamente $y$, en ocasiones, estos apartamentos pueden destinarse a viviendas de renta baja o controlada para aquéllos que no pueden optar a otros inmuebles.

Con ello, se cumple uno de los objetivos originales de este proyecto de transformación, que no supusiese un problema adicional para sus inquilinos. Para ello, el diseño considera el proyecto como una nueva envolvente adicionada frente a los forjados originales que permite la permanencia de los inquilinos durante la ejecución del proyecto. 
La torre en cuestión comprende diez alturas y nueve viviendas por planta que están distribuidas principalmente a lo largo de las orientaciones Norte y Sur. Los espacios orientadas al Este y Oeste forman parte de las viviendas de mayores dimensiones, situadas en esquina. Los dormitorios y espacios de comedor/estar se benefician de la iluminación y la ventilación natural, ya sean a Norte o a Sur. Las zonas húmedas -como cocinas y baños- están localizados en el interior de la crujía. En las viviendas en esquina se produce una excepción: a las cocinas se les otorga superficie de fachada orientada a Este u Oeste, lo que las convierte en las únicas aperturas proyectadas para estas dos orientaciones. Los espacios carecen de toda la iluminación y ventilación natural de la que podrían aprovecharse.

Además, los espacios comunes, como los núcleos de comunicación vertical -escaleras y ascensores-, así como los cuartos de instalaciones y basuras, se concentran en el perímetro ciego del corredor central. A continuación se muestra el esquema de una plata y sección tipo de uno de los edificios de Lake Grove Village. Aun a pesar de que el conjunto incluye un total de 458 viviendas distribuidas en tres edificos de diez alturas, así como cinco edificios de tres, para este trabajo se ha seleccionado uno de los edificios de mayor altura. La planta y sección que se muestran corresponden con uno de ellos.

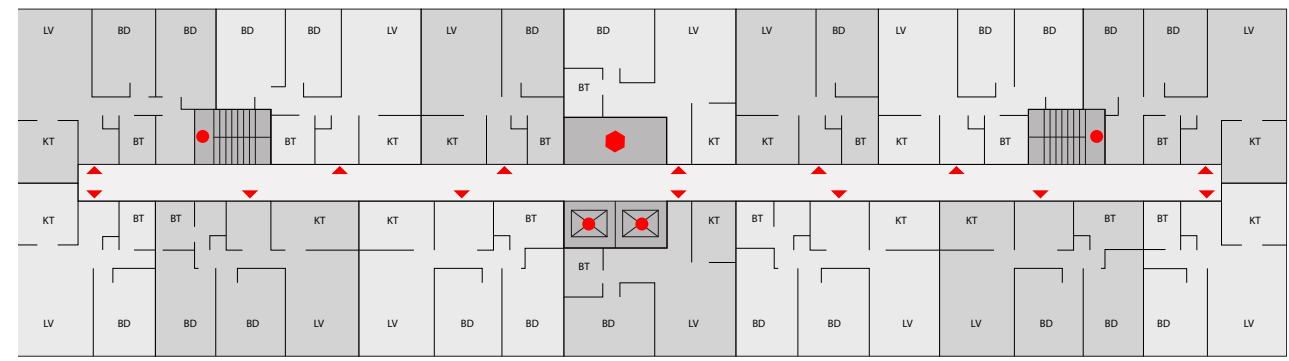

BD: DORMITORIO

LV: COMEDOR / ESTAR

KT: COCINA

BT: CUARTO DE BAÑO ACCESO A VIVIENDAS 
Del diagrama de la sección tipo puede observarse la relación entre la profundidad del espacio y la superficie de acristalamiento. En los módulos de la fachada original el hueco aparece dividido en dos áreas principales. La parte inferior es opaco y se puede destinar, por ejemplo, a albergar los aparatos de aire acondicionado. Este área no permite la entrada de iluminación natural ni la posibilidad de incorporar ventilación natural. Por otro lado, la zona superior es la destinada al "hueco" propiamente dicho. Esta zona es de mayores dimensiones que la anterior y permite la entrada de iluminación y ventilación natural.

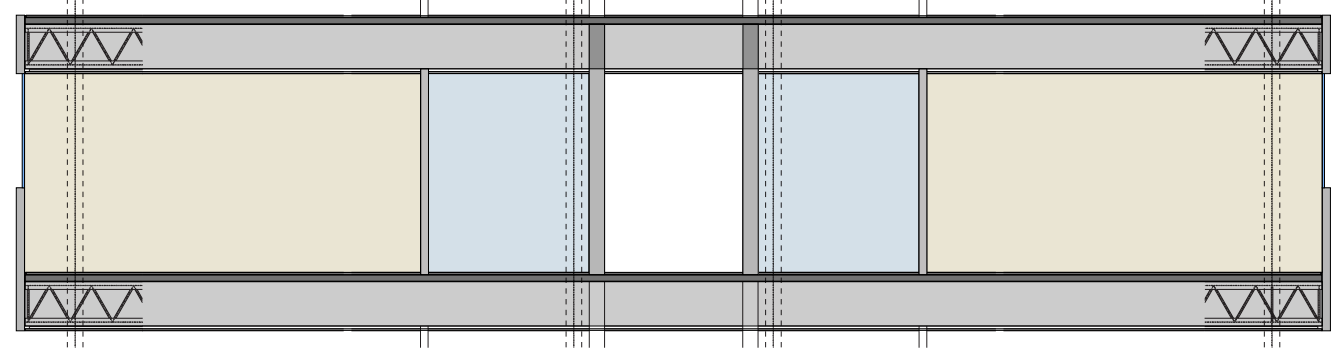

En segundo lugar, uno de los elementos esenciales de la propuesta consiste en aprovechar del diseño original. Además, se pretende trabajar con la idea con la que Paul DuPondt diseñó el conjunto de edificios en los años 60 . Esto es, prever la posibilidad de re-diseño en un futuro.

En tercer lugar, cada módulo de fachada y el espacio que hay tras ella se identifica como una unidad de estudio. La envolvente está sujeta a cambios, pero el espacio interior no. Sin embargo, como se entiende que la envolvente posee la cualidad de la tercera dimensión, el espacio se verá alterado en el sentido del añadido. Del proyecto original se respeta la orientación de las zonas principales de las viviendas, como son los dormitorios y comedor-estar a Norte y a Sur. Las zonas húmedas y núcleos de comunicación se mantienen en el interior. Como en los proyectos de Lacaton \& Vassal, la profundidad de la envolvente y su 
dimensión espacial podrán hacer de los interiores espacios únicos. Esto permite crear espacios de transición entre el interior original y el exterior que, como se podrá observar mas adelante, no sólo tienen un fin espacial, sino que ayudan a mejorar el comportamiento energético de los edificios. Por tanto, contribuyen a crear ambientes habitables y a mejorar la confortabilidad de los espacios.

En cuarto lugar, la propuesta se caracteriza por la posibilidad de intercambiabilidad, que se basa en el concepto que adelantábamos en el primer capítulo: la idea de poder adaptarse a situaciones diferentes. Sin embargo, la propuesta final define un tipo de envolvente para cada orientación debido a una simplificación del proceso. El proyecto entiende el beneficio de ofrecer una solución flexible y adaptable a distintas situaciones. Las diferentes propuestas influirán no sólo en la apariencia del edifico en su conjunto, sino en su rendimiento y eficiencia energética.

En quinto lugar, los diseños desarrollados parten de dos elementos principales: el vidrio y los mecanismos de control solar y las diversas combinaciones de estos dos materiales. Esto ha definido una estética determinada, caracterizada por la transparencia que, como en los edificos de Mies para Lake Shore Drive, pretenden enmarcar en este caso el skyline de la ciudad y establecer la mayor conexión posible con el exterior. Al mismo tiempo ha creado una base sobre la que estudiar las posibilidades del vidrio y los mecanismos solares en el control solar.

Por último tenemos la eficiencia energética. Los diferentes diseños propuestos parten también de la idea de mejorar el rendimiento energético de los espacios, lo que determina, en parte, las medidas que se consideran para las distintas orientaciones. Como se observará posteriormente, el resultado incluye un análisis que permita reducir los consumos energéticos y el aporte de iluminación, y permita la ventilación natural. Como se ha explicado en el edificio de SCB 340 on the Park, cada una de las orientaciones atenderá a unos requerimientos que, en parte, vienen determinados por las orientaciones. Al igual que sucede en Lake Point Tower, de Schipperet, la posibilidad de incorporar 
BD: DORMITORIO

LV: COMEDOR / ESTAR

KT: COCINA

BT: CUARTO DE BAÑO

- ACCESO A VIVIENDAS 1-7: ESTRATEGIAS PROPUESTAS DE DISEÑO DE ENVOLVENTE ventilación natural en un edifico en altura se establece como una premisa. Una vez más, mejora el confort interior de los espacios habitables.

A continuación se muestra el diagrama en planta y sección de la propuesta final. Éste representa la formalización final de una posible solución y, aunque el proceso se explica en apartados posteriores, el objetivo no es otro que situar en contexto los diferentes elementos que se expondrán.
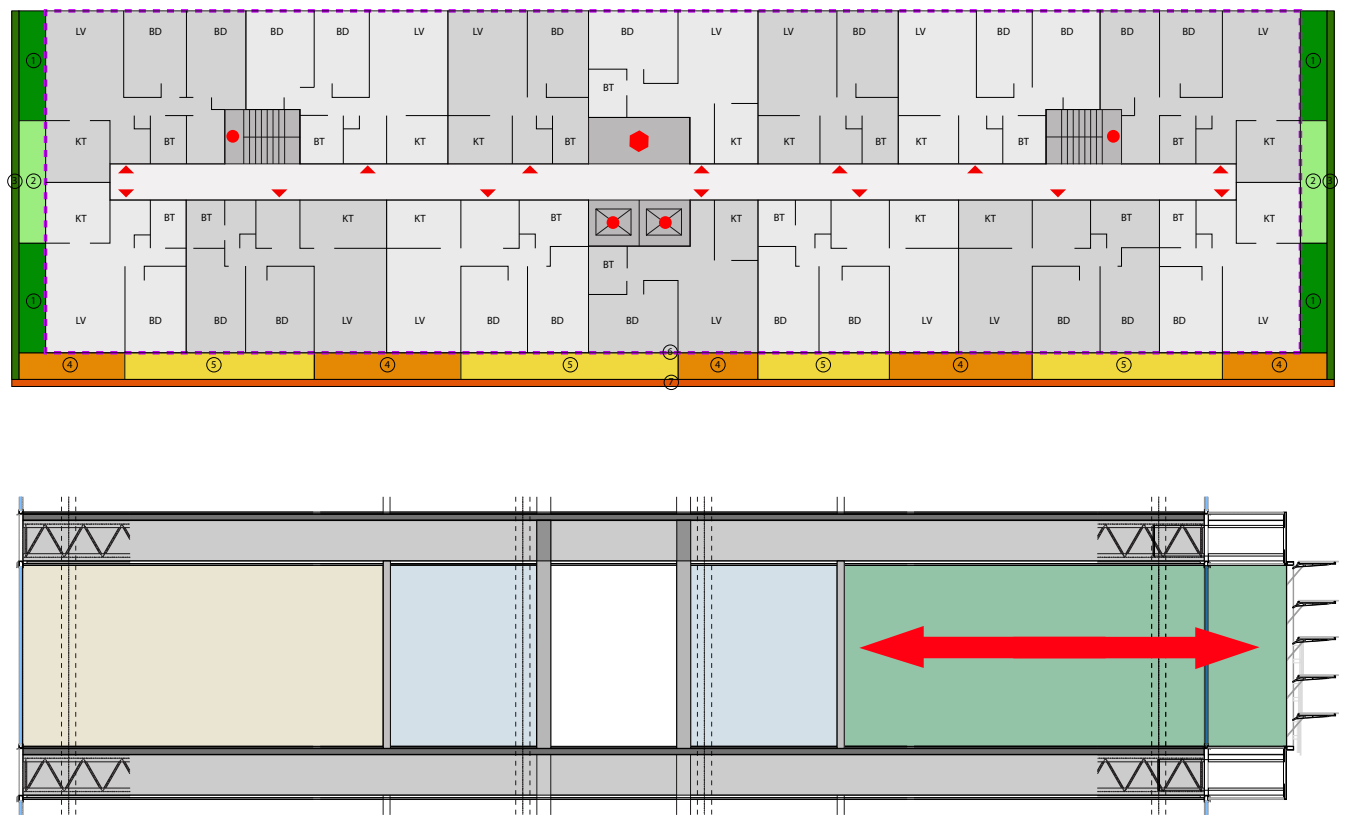

Por tanto, cada propuesta de diseño es resultado, entre otros, de los análisis que persiguen evaluar la eficiencia energética, de las caracteristicas de los espacios interiores y sus posibles mejoras, del estudio de las condiciones climatológicas y sus requerimientos $y$, en este caso, del empleo del vidrio como material principal del diseño. Todas ellas han afectado en cierta medida al resto. Atendiendo a las necesidades particulares del proyecto original, la localización, las premisas de adaptabilidad y 


\section{CAPÍTULO 05}

los espacios interiores, se ha considerado ésta como una opción de mejora de la habitabilidad interior. En última instancia, existe la posibilidades de adaptabilidad, y se ofrecen diferentes opciones.

En los apartados siguientes se presentarán los diferentes tipos de unidades de fachada para luego presentarlos de forma conjunta. De esta manera, el vidrio, los mecanismos de protección solar, los voladizos, las terrazas - las dobles pieles se combinarán para crear una propuesta rítmica y flexible en la que el espacio interior goce de la interacción con el exterior.

También en este caso se desarrollan las tres orientaciones con las que se ha ido trabajando: Norte, Sur y EsteOeste. 


\subsubsection{Propuesta de Diseño para la Fachada Norte}

Como se ha ido viendo, las fachadas orientadas al Norte en Chicago son especialmente sensibles a las pérdidas de calor durante los meses fríos de invierno, lo que las hace susceptibles a las cargas de calefacción para poder alcanzar un confort interior óptimo. Puesto que uno de los objetivos que persigue la propuesta es alcanzar un equilibrio entre el exterior $y$ el interior y lograr un clima interior adecuado, las superficies de vidrio en las fachadas Norte requieren una U-value bajo y un SHGC elevado. De esta forma las pérdidas de energía podrán limitarse y, a la vez, se permitirán las ganancias de energía solar.

Según los análisis, la capacidad de reducir la transmisión de energía -y por tanto las pérdidas- puede llevarse a cabo mediante diferentes métodos: añadiendo más masa o paneles, mediante gases y variando la posición de la película de baja emisividad. En este caso, debido al aumento de sus propiedades aislantes, a la localización de la capa de baja emisividad en la superficie \#5 -que disminuye las pérdidas de calor del espacio al mismo tiempo que permite la entrada de energía solar en verano- el vidrio que ofrece un mayor rendimiento es el que anteriormente se ha definido como el Vidrio Tipo D, cuyas características se definen a continuación.

\begin{tabular}{|c|}
\hline Vidrio Tipo D \\
\hline Triple Clear Spectrally Selective Low-e (\#5) / Argon \\
\hline Grosor de vidrios: \\
44 \\
\hline Uvalue $: 1.0$ \\
\hline SHGC: 0.419 \\
\hline Tvis: 0.627 \\
\hline
\end{tabular}

Adicionalmente, la superficie de fachada se complementa con el diseño de sistemas de protección solar interiores que, como se ha visto, pese a no disminuir significativamente las cargas energéticas, ayudarán a controlar la entrada de luz difusa y a asegurar privacidad y control luminoso en los apartamentos de Lake Grove Village. 
A continuación se exponen los resultados relacionados con las cargas energéticas para la propuesta de Envolvente Tipo NA:

\begin{tabular}{|c|c|c|}
\hline \multicolumn{2}{|c|}{ Envolvente Tipo NA } \\
\hline & Calefacción & Refrigeración \\
\hline Triple Clear Spectra- & 38.4 & 23.5 \\
lly Selective Low-e & & \\
(\#5) with Interior & & \\
Movable Shading with & & \\
Reflective Exterior & & \\
Surface OF:15\%, R:0.63 & & \\
\hline
\end{tabular}

Tan importante es el diseño exterior del edificio, como diseñar para lograr un confort y calidad interior deseado. El vidrio y los mecanismos de control solar contribuyen a ello. Como parte de este trabajo, se ha atendido a la calidad y cualidad luminosa obtenida a través de las pieles propuestas. Respecto a la fachada orientada al Norte, se ha optado por una imagen que simula la luz que penetraría en una tarde de verano; con el sol situado ya en el Oeste, en la que la luz natural difusa aun es capaz de penetrar e iluminar el espacio.

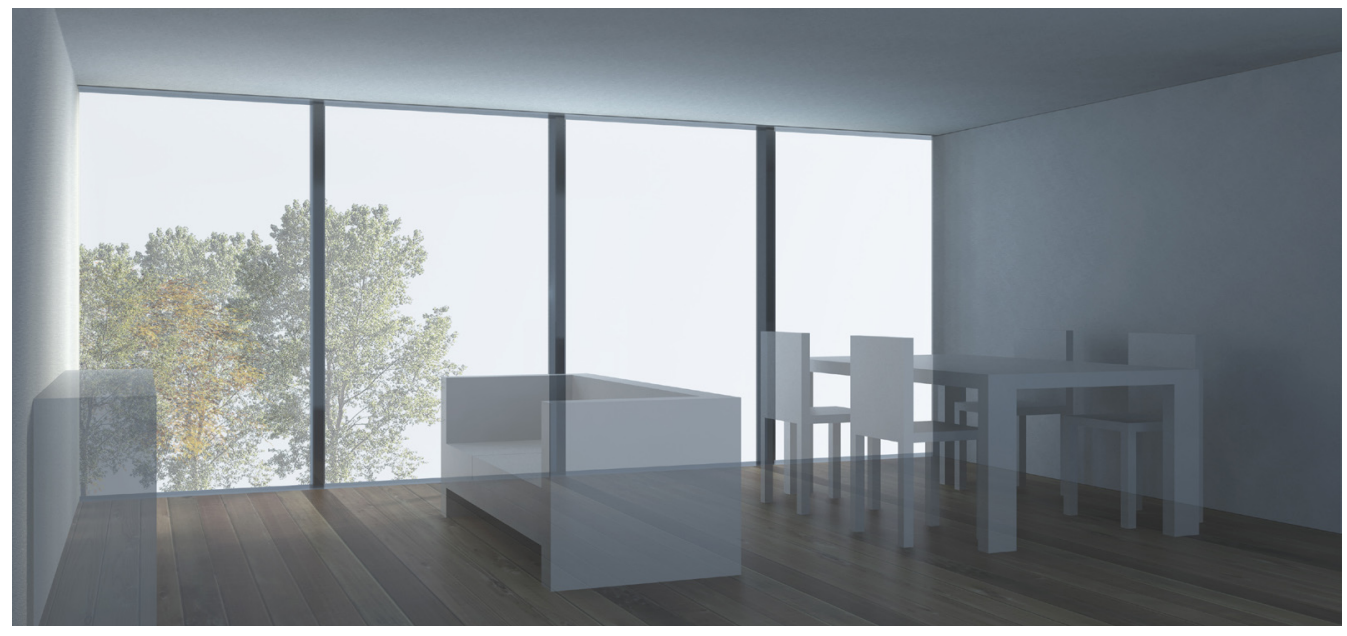


El diseño de las envolventes propuestas para la transformación de Lake Grove Village consideraron, desde el principio, la construcción y método de ensamblaje. No podían obviase los orígenes de estos edificios, concebidos para poder ser adaptados en tiempos futuros. De la misma forma, el diseño de las nuevas pieles debe ser uno que pueda ser prefabricado como, por ejemplo, los muros cortina. La construcción del resto fue en seco, y cada elemento se instaló in-situ.

Con el deseo de respetar los orígenes de los edificios, la instalación de las propuestas se presentan a modo de pasos, lo que permite explicar cada una de las partes. De esta manera, por ejemplo, la propuesta para la envolvente orientada al Norte contempla cuatro pasos, cuyas imágenes se explican a continuación.

En el primero de ellos, se muestra el módulo existente, orientado al Norte, y el lugar en el que la estructura queda expuesta tras retirar del sitio el panel del frente del forjado. En el segundo de ellos, se ancla una estructura auxiliar a los pilares del edificio. Esta estructura es la encargada de trasladar las cargas de la nueva envolvente de vidrio a la estructura principal del edificio. Anclada la sub-estrucura a los pilares, se coloca en su lugar correspondiente el panel que se había retirado con anterioridad. En el cuarto paso se instalan los módulos de carpintería para luego completar la envolvente, colocar los nuevos paneles de recubrimiento y los mecanismos de control solar interiores.

A continuación se exponen las imágenes que gráficamente explican el proceso y componentes de la nueva envolvente, así como los diagramas reflejando el comportamiento de la fachada en verano y en invierno.

En conclusión, la Envolvente Tipo NA propone una piel que limite las pérdidas energéticas en invierno, las ganancias energéticas en verano, aproveche la entrada de iluminación natural y sea capaz de controlar el nivel luminosos y grados de privacidad. 
CAPÍTULO 05

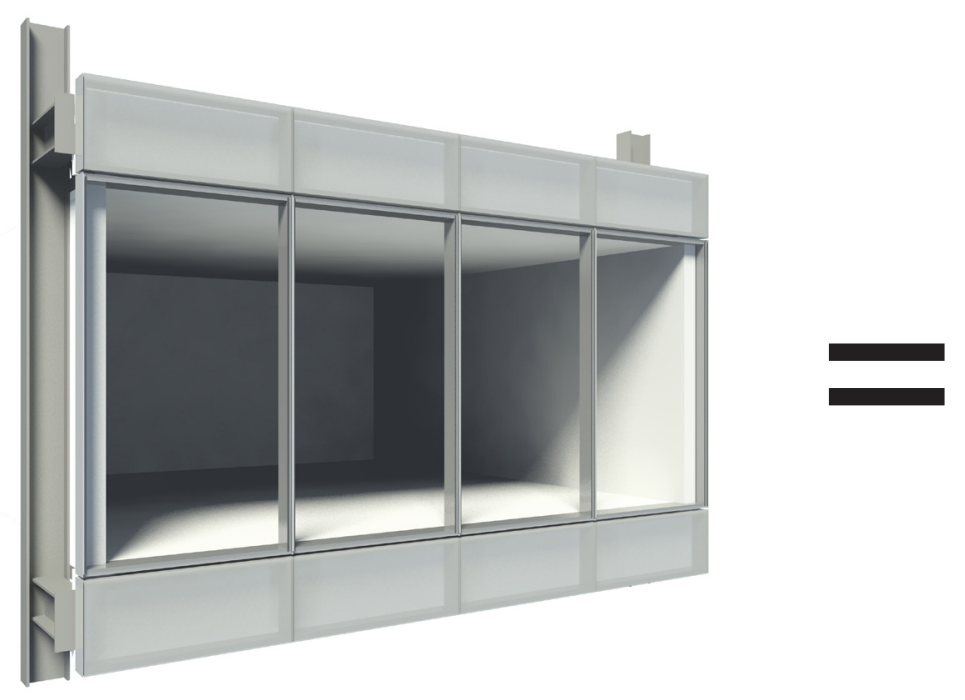

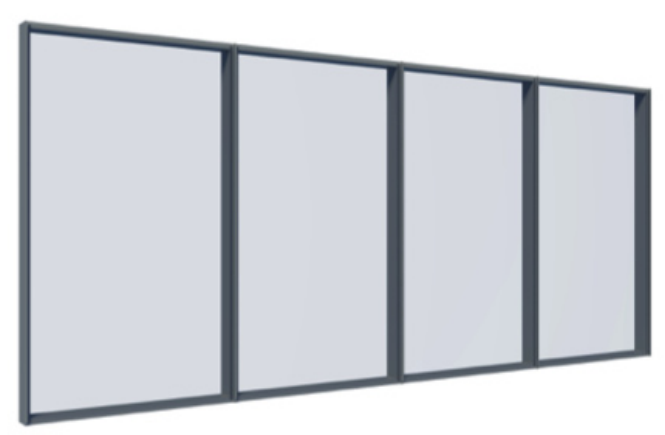

$+$
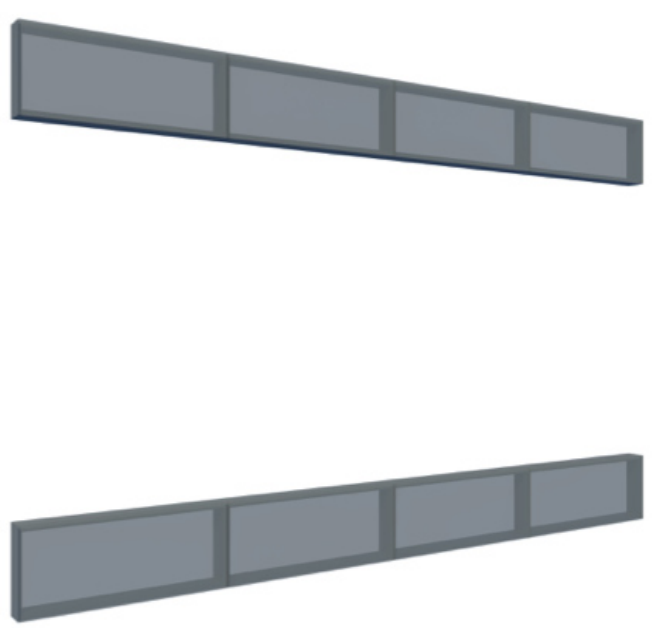
CAPÍTULO 05
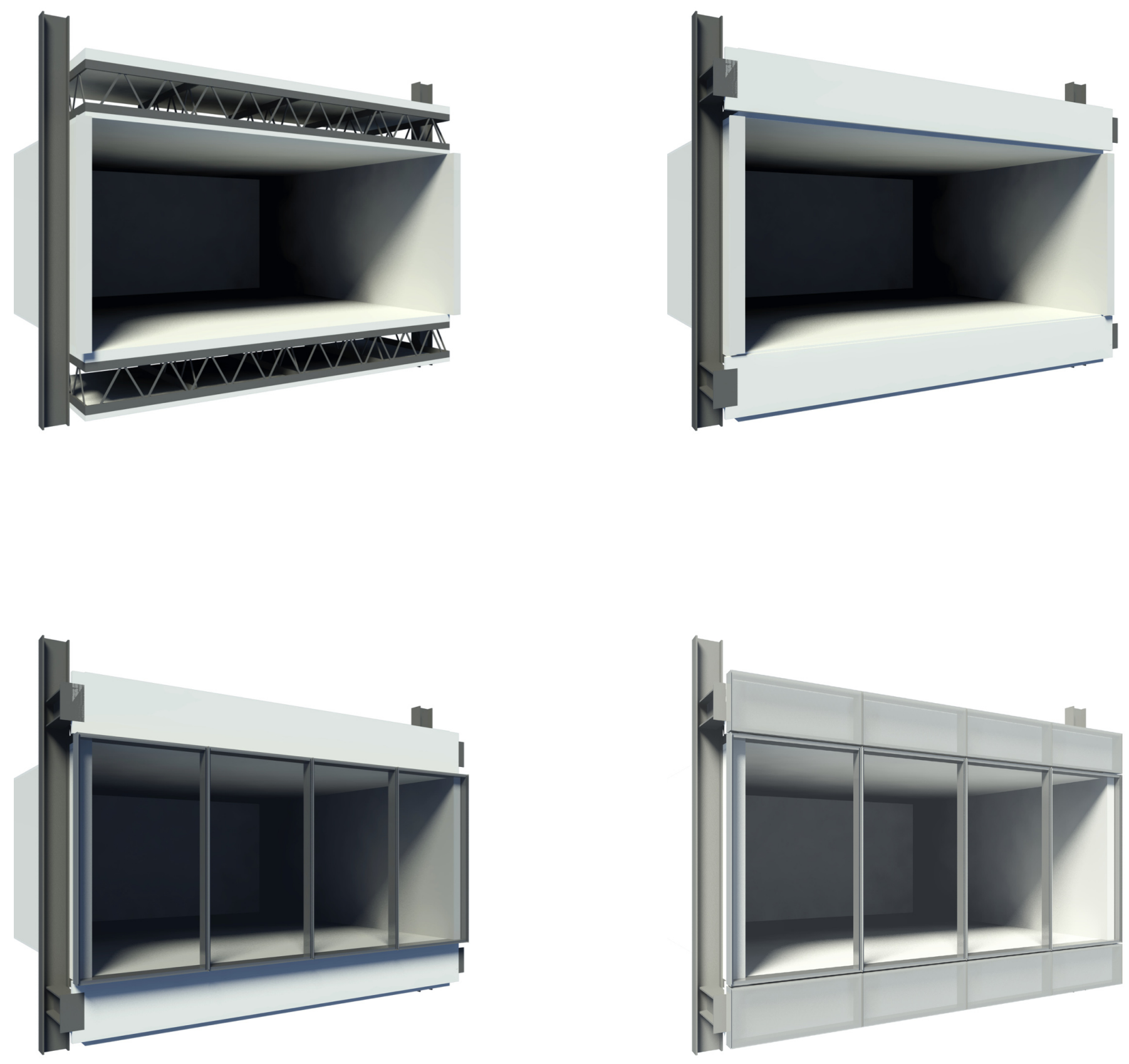


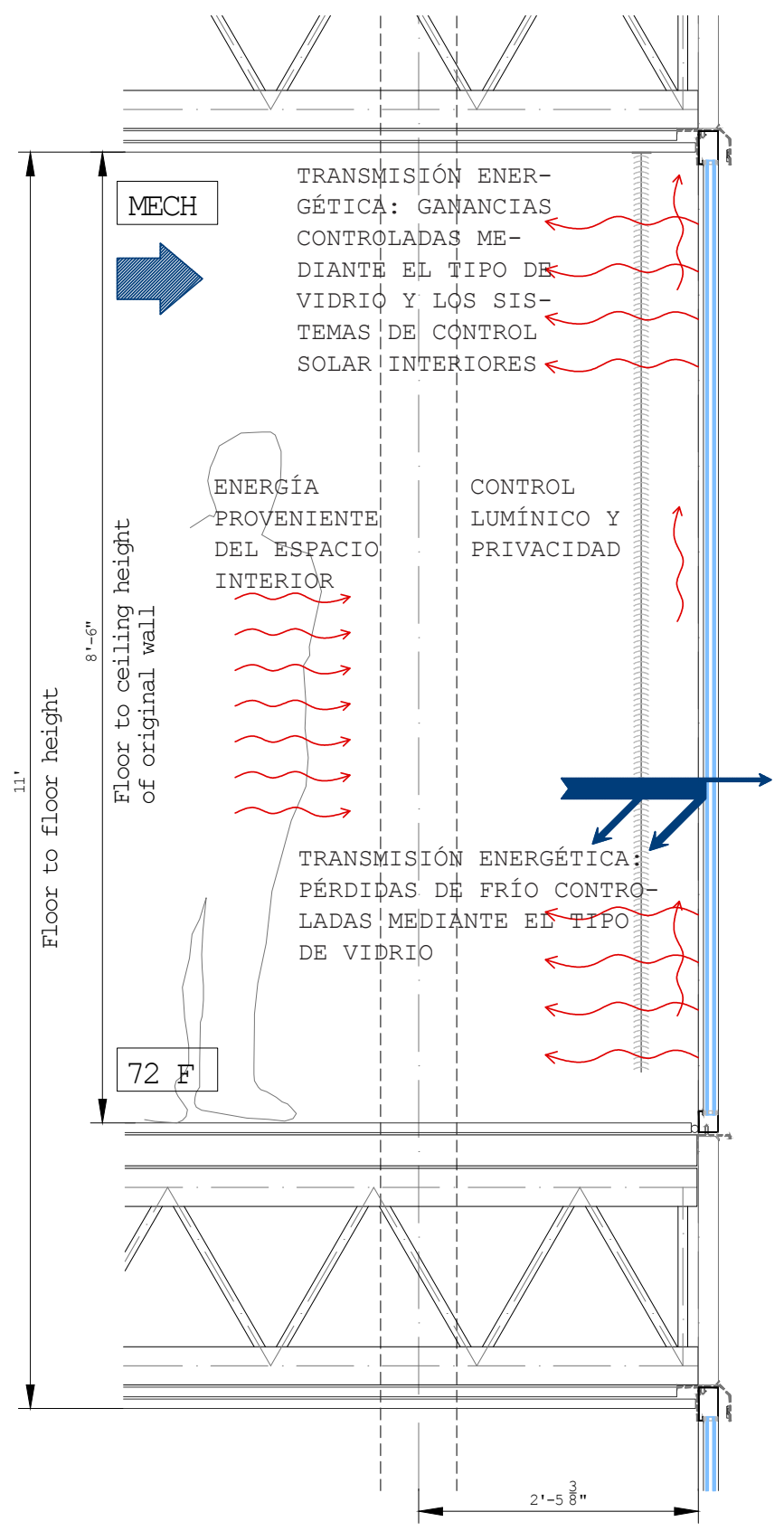

Comportamiento Envolvente Tipo NA modo día-verano

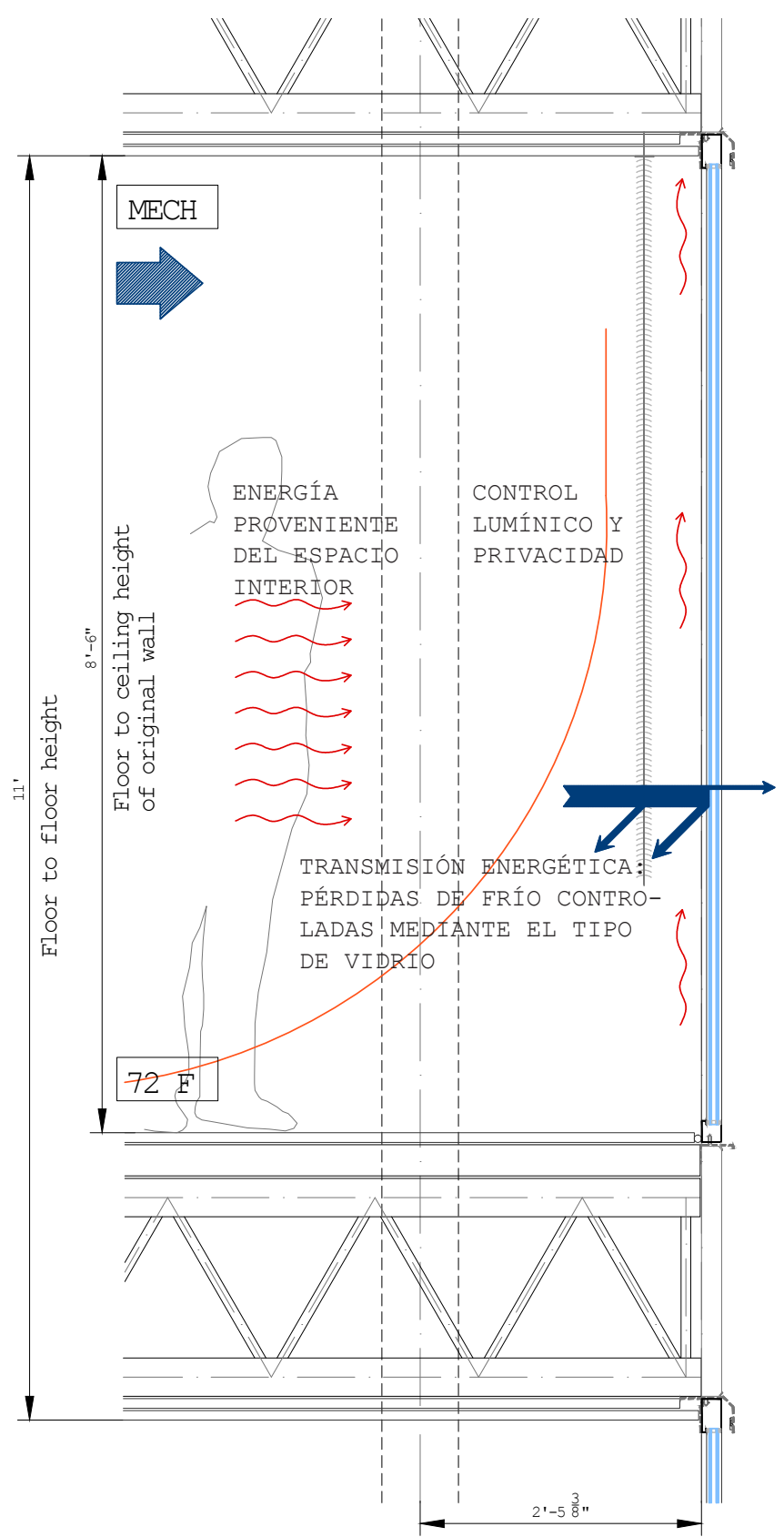

Comportamiento Envolvente Tipo NA modo noche-verano 


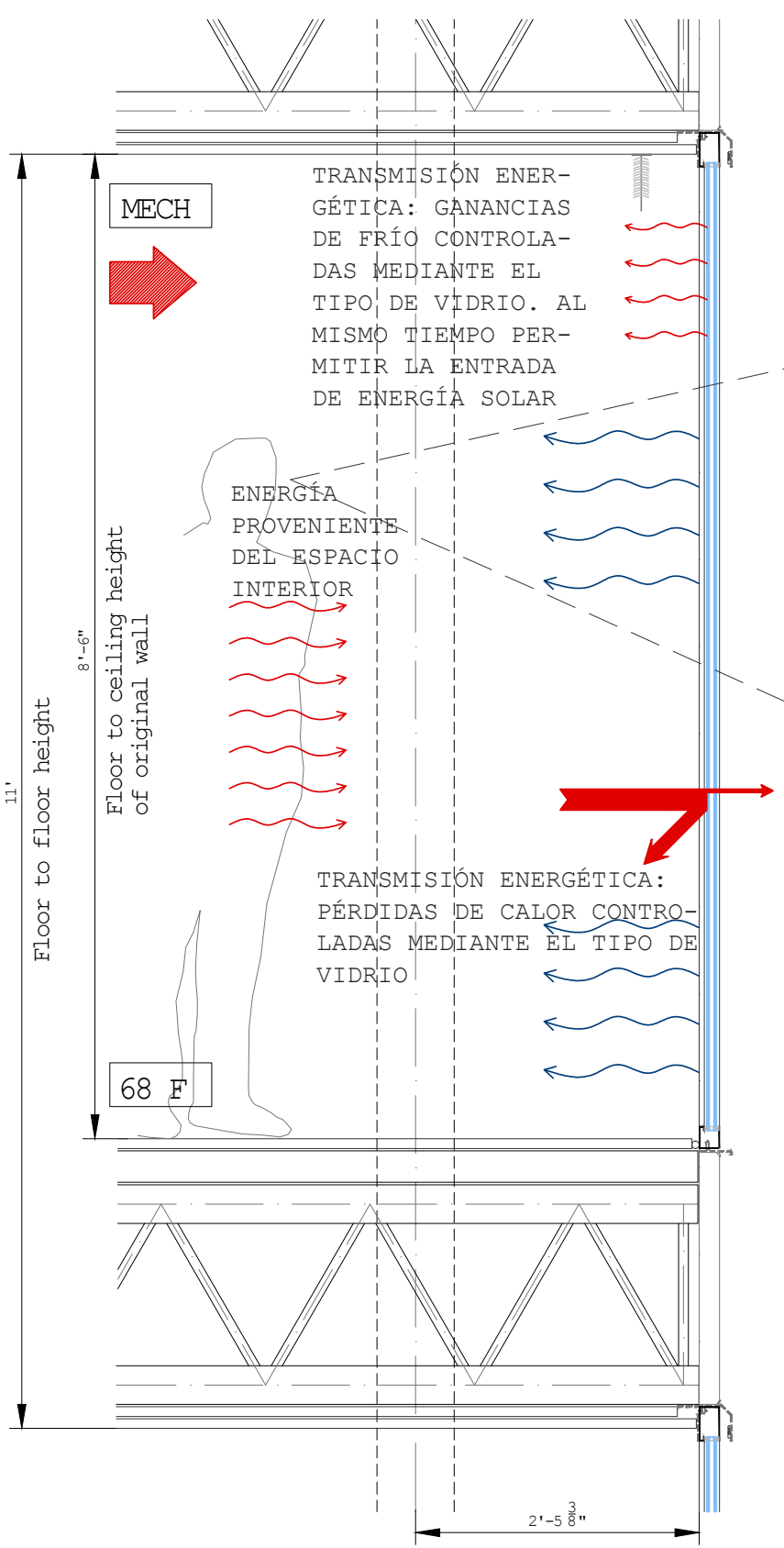

Comportamiento Envolvente Tipo NA modo día-invierno

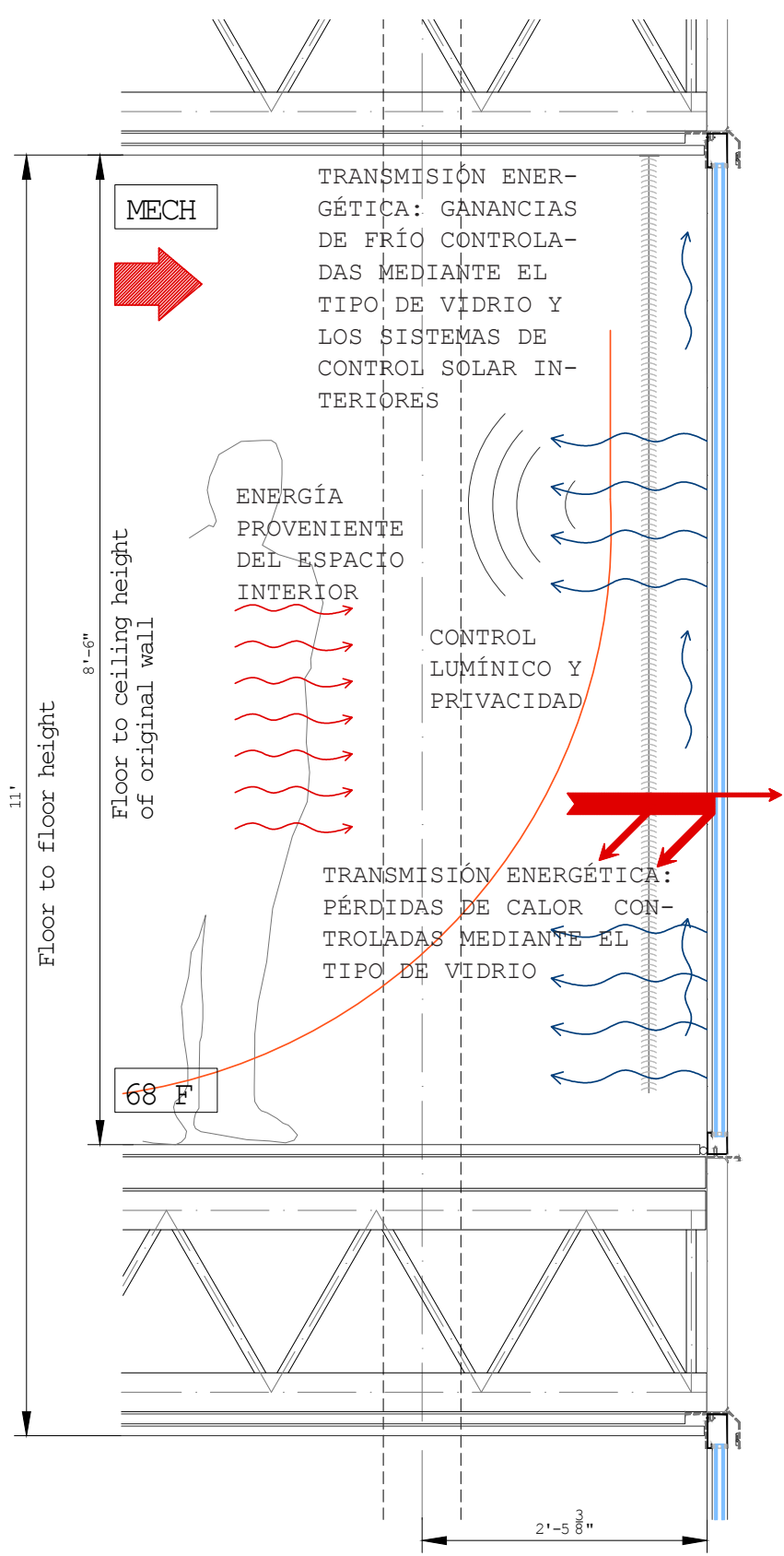

Comportamiento Envolvente Tipo NA modo noche-invierno 
CAPÍTULO 05

Sección constructiva Envolvente Tipo NA

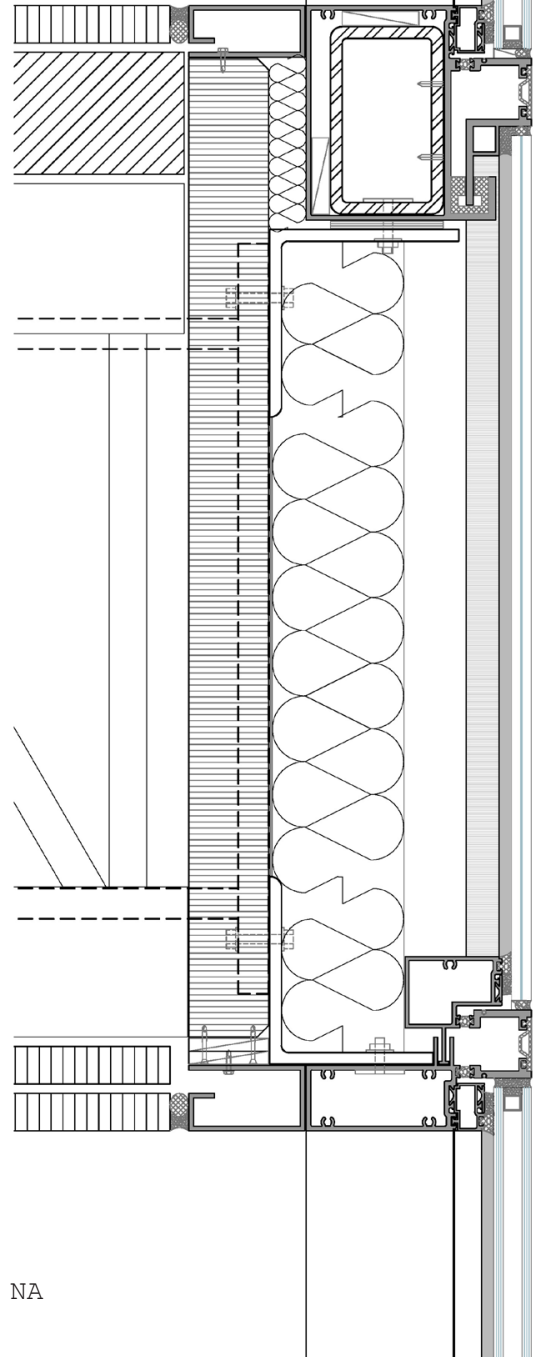

252 




\subsubsection{Propuesta de Diseño para la Fachada Sur}

Al contrario de lo que ocurre en las orientaciones al Norte, las fachadas orientadas al sur son especialmente sensibles a las ganancias energéticas y al sobrecalentamiento durante los meses de calor, por lo que un objetivo será reducir las cargas de refrigeración y conseguir así un confort interior adecuado. El valor que controla la entrada de energía solar es el SHGC, que debe ser cuanto más bajo mejor. Por otro lado, debido a las temperaturas extremas en invierno, la fachada deberá proveer el aislamiento adecuado, con lo que el U-value debe ser igualmente bajo.

En primer lugar, la incorporación de revestimientos de baja emisivididad y espectro selectivo tiene la ventaja de evitar el exceso de ganancias energéticas sin afectar excesivamente la visibilidad exterior. Si el revestimiento se coloca en el la superficie \#2, los beneficios son mayores, ya que el calor se emite al exterior antes de que haya entrado en el espacio.

En segundo lugar, no hay que olvidar las características del clima de Chicago y, por tanto, prevenir las pérdidas energéticas en invierno para disminuir las cargas de calefacción. Igual que en la fachada orientada al Norte, la capacidad de reducir la transmisión de energía -y por tanto las pérdidas- puede realizarse mediante diferentes métodos: añadiendo más masa o paneles, incorporando gases y variando la posición de la película de baja emisividad.

Los vidrios de mayor idoneidad son los anteriormente definidos como el Vidrio Tipo B y Tipo C.

\begin{tabular}{|c|c|}
\hline Vidrio Tipo B & Vidrio Tipo C \\
\hline $\begin{array}{c}\text { Double Clear Spectrally Selective } \\
\text { Low-e (\#2) / Argon }\end{array}$ & $\begin{array}{c}\text { Triple Clear Spectrally Selective } \\
\text { Low-e (\#2) / Argon }\end{array}$ \\
\hline $\begin{array}{c}\text { Grosor de vidrios: } \\
25\end{array}$ & $\begin{array}{c}\text { Grosor de vidrios: } \\
44\end{array}$ \\
\hline Uvalue: 1.4 & Uvalue: 1.0 \\
\hline SHGC: 0.374 & SHGC: 0.342 \\
\hline Tvis: 0.703 & Tvis: 0.627 \\
\hline
\end{tabular}


A diferencia del diseño para la fachada orientada al Norte, para la sur se han propuesto diferentes combinaciones y tipos de envolvente.

La primera opción consiste en combinar el Vidrio Tipo C con un sistema de protección solar interior que, además de disminuir las cargas energéticas, ayudarán a controlar la entrada de luz difusa y a asegurar la privacidad y el control luminoso en los apartamentos de Lake Grove Village.

A continuación se exponen los resultados relacionados con las cargas energéticas para la propuesta de Envolvente Tipo SA:

\begin{tabular}{|c|c|c|}
\hline \multicolumn{2}{|c|}{ Envolvente Tipo SA } \\
\hline & Calefacción & Refrigeración \\
\hline Triple Clear Spectra- & 10.1 & 27.8 \\
ly Selective Low-e & & \\
(\#2) with Interior & & \\
Movable Shading with & & \\
Reflective Exterior & & \\
Surface OF:3, R:0.47 & & \\
\hline
\end{tabular}

El resultado en el interior de la fachada orientada al Sur para la Envolvente Tipo SA se muestra a continuación.

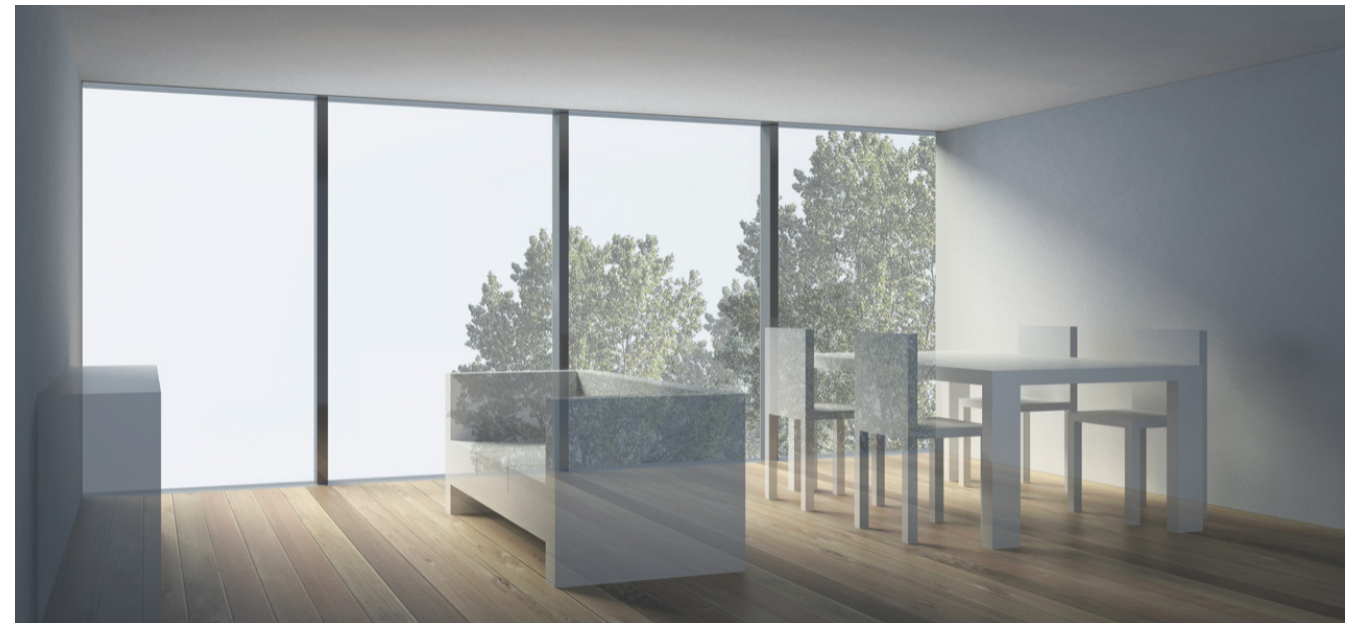


De manera similar al proceso llevado a cabo para la fachada orientada al Norte, el diseño de la Envolvente Tipo SA toma en consideración la voluntad de respetar la esencia del diseño original. Así, la instalación de las propuestas se presentan a modo de pasos, lo que permite explicar cada una de las partes. La Envolvente Tipo SA contempla cuatro pasos, cuyas imágenes se explican a continuación.

En el primero de ellos, se muestra el módulo existente, orientado al sur, y el lugar en el que la estructura queda expuesta tras retirar del sitio el panel del frente del forjado. En el segundo de ellos, se ancla una estructura auxiliar a los pilares principales del edificio; esta estructura es la encargada de trasladar las cargas de la nueva envolvente de vidrio a la estructura principal del edificio. Anclada la sub-estrucura a los pilares, se coloca el panel que se había retirado con anterioridad. En el cuarto paso se instalan los módulos de carpintería para luego completar la envolvente, colocar los nuevos paneles de recubrimiento y los mecanismos de control solar interiores.

A continuación se exponen las imágenes que gráficamente explican el proceso y componentes de la nueva envolvente, así como los mecanismos que se han estudiado acerca del comportamiento de la fachada propuesta en verano y en invierno.

Por tanto, la Envolvente Tipo SA propone una piel que combina las ganancias solares y aislamiento en invierno, al mismo tiempo que limita la entrada solar en verano. En este caso, el vidrio es el principal protagonista; dejando a los sistemas de protección solar interiores a cargo del control de la iluminación o la privacidad. 
CAPÍTULO 05

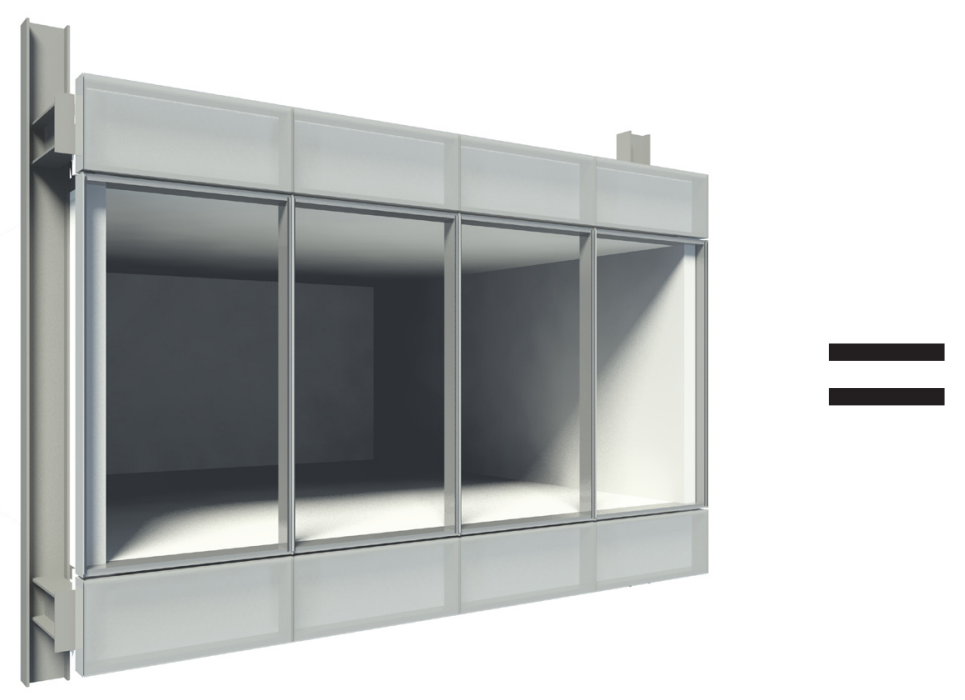

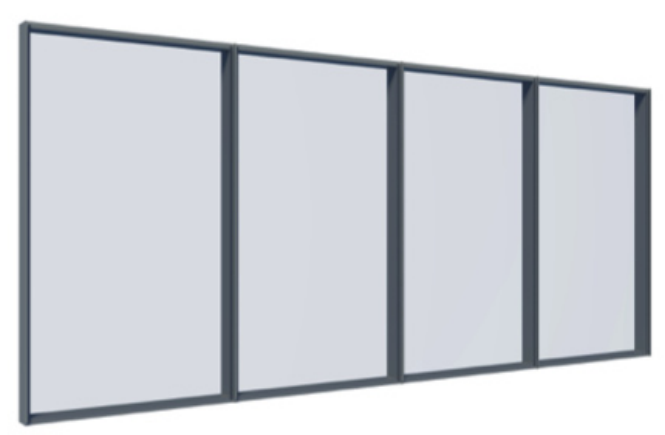

$+$
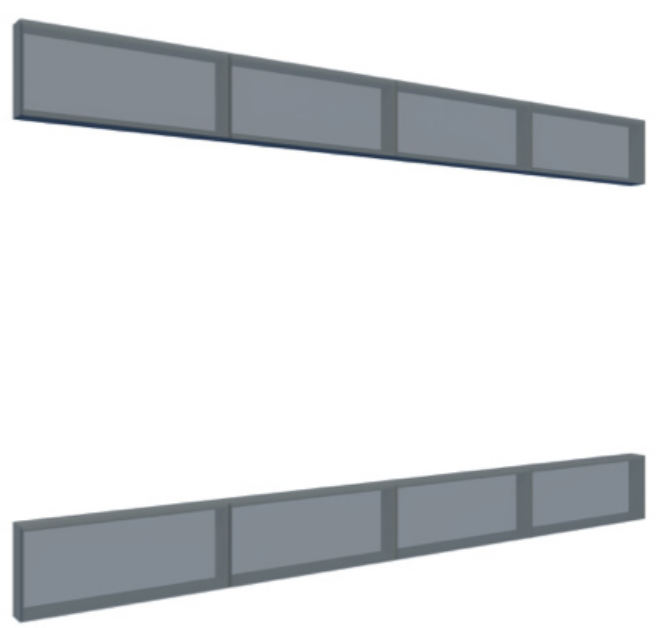
CAPÍTULO 05
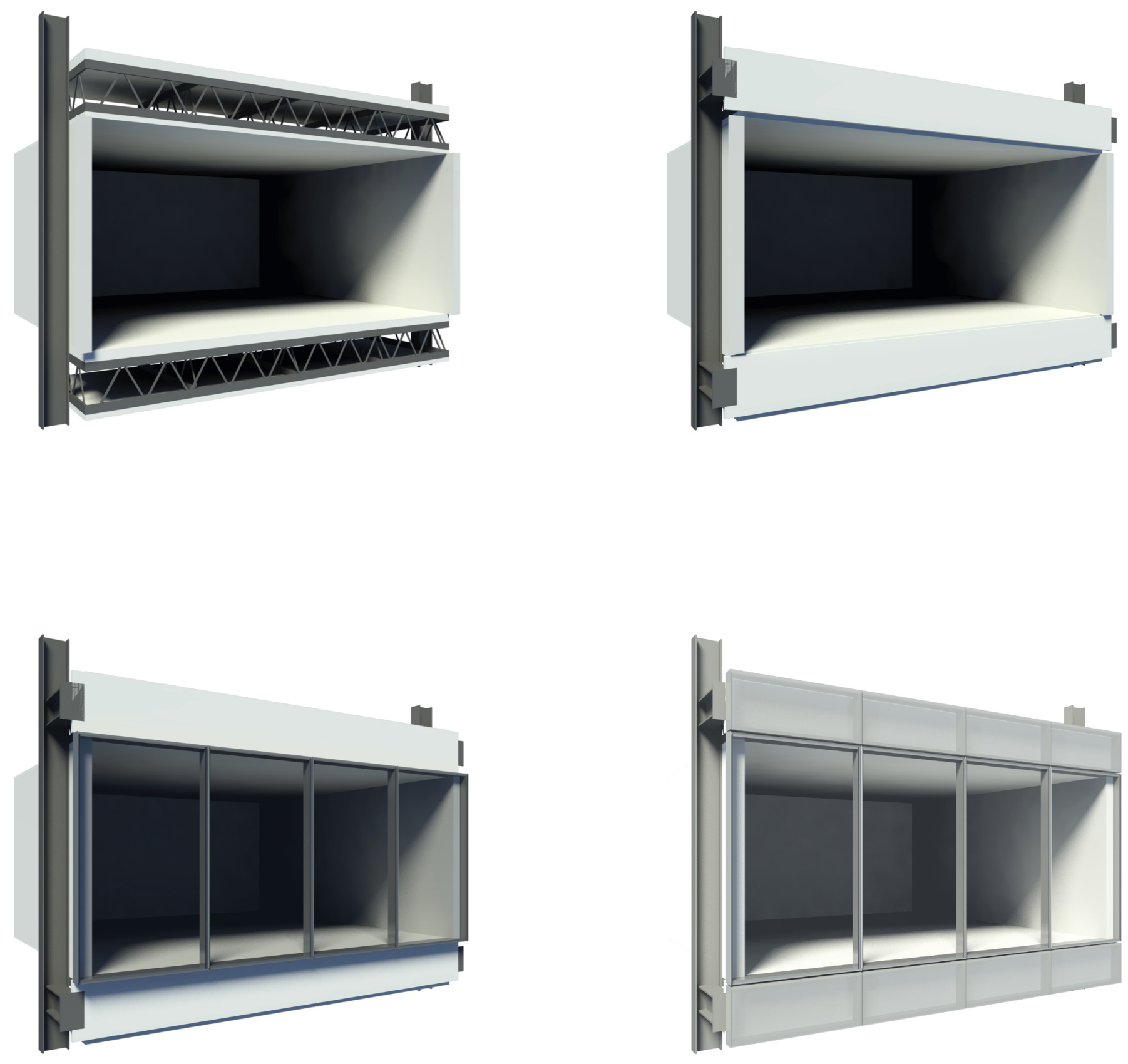


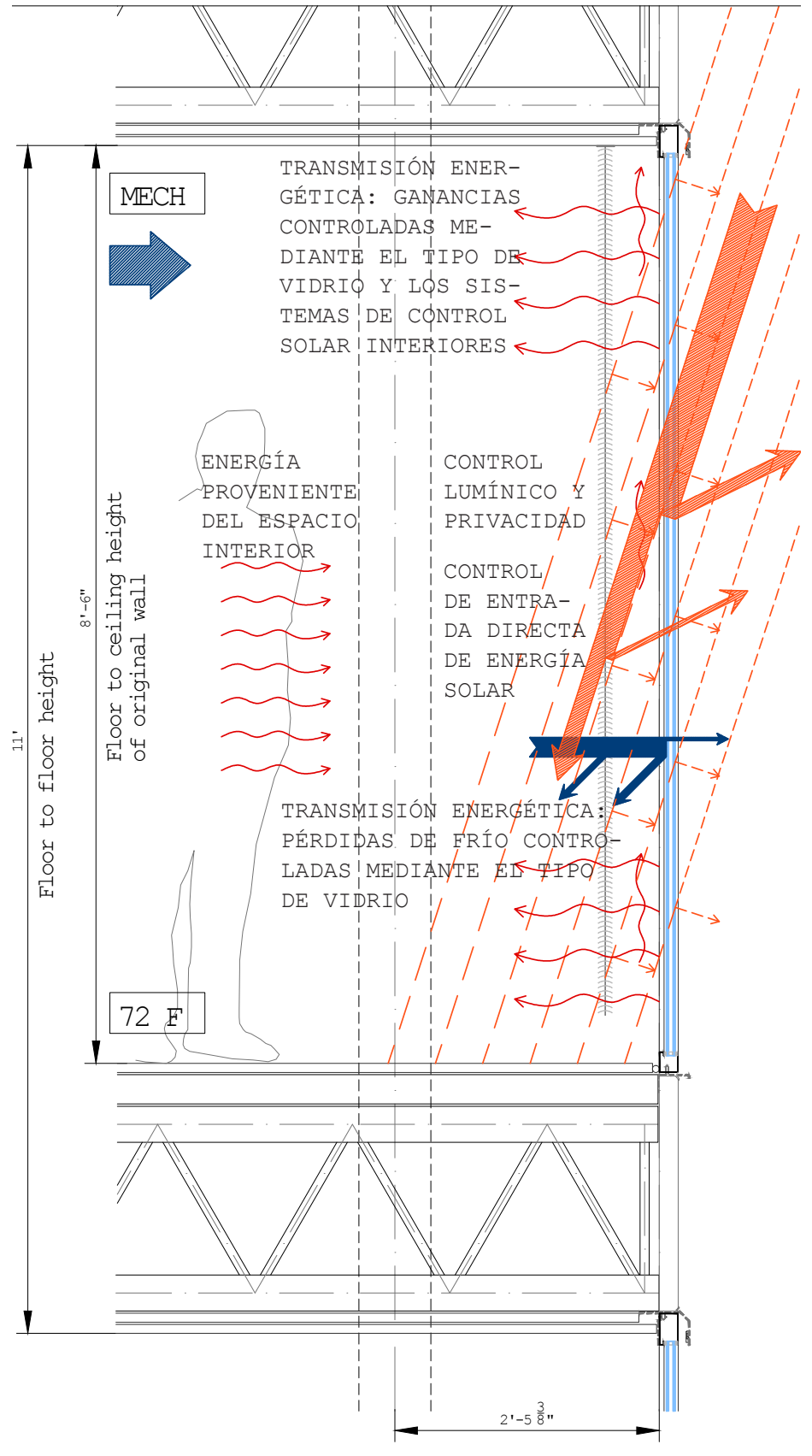

Comportamiento Envolvente Tipo SA modo día-verano

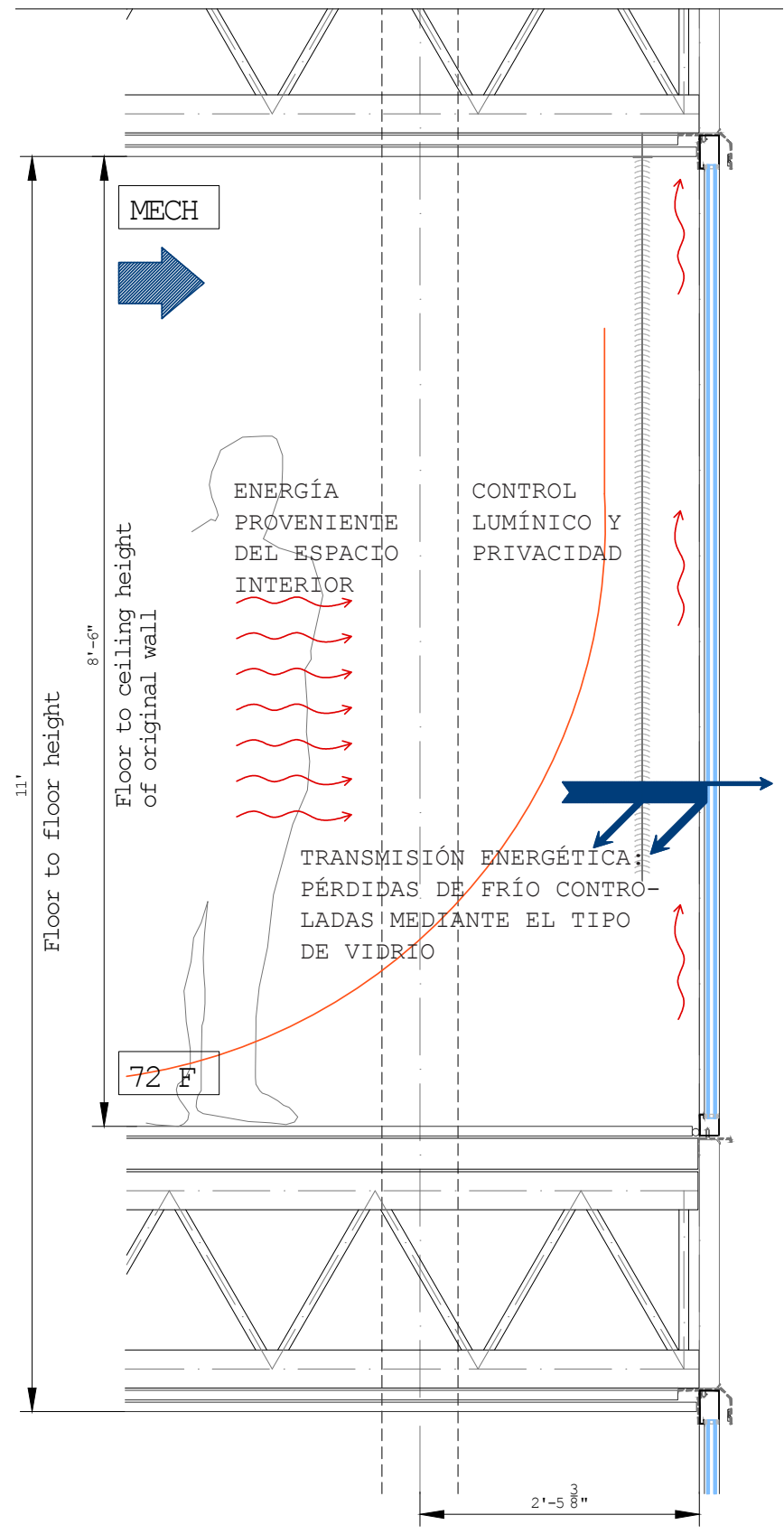

Comportamiento Envolvente Tipo SA modo noche-verano 
CAPÍTULO 05

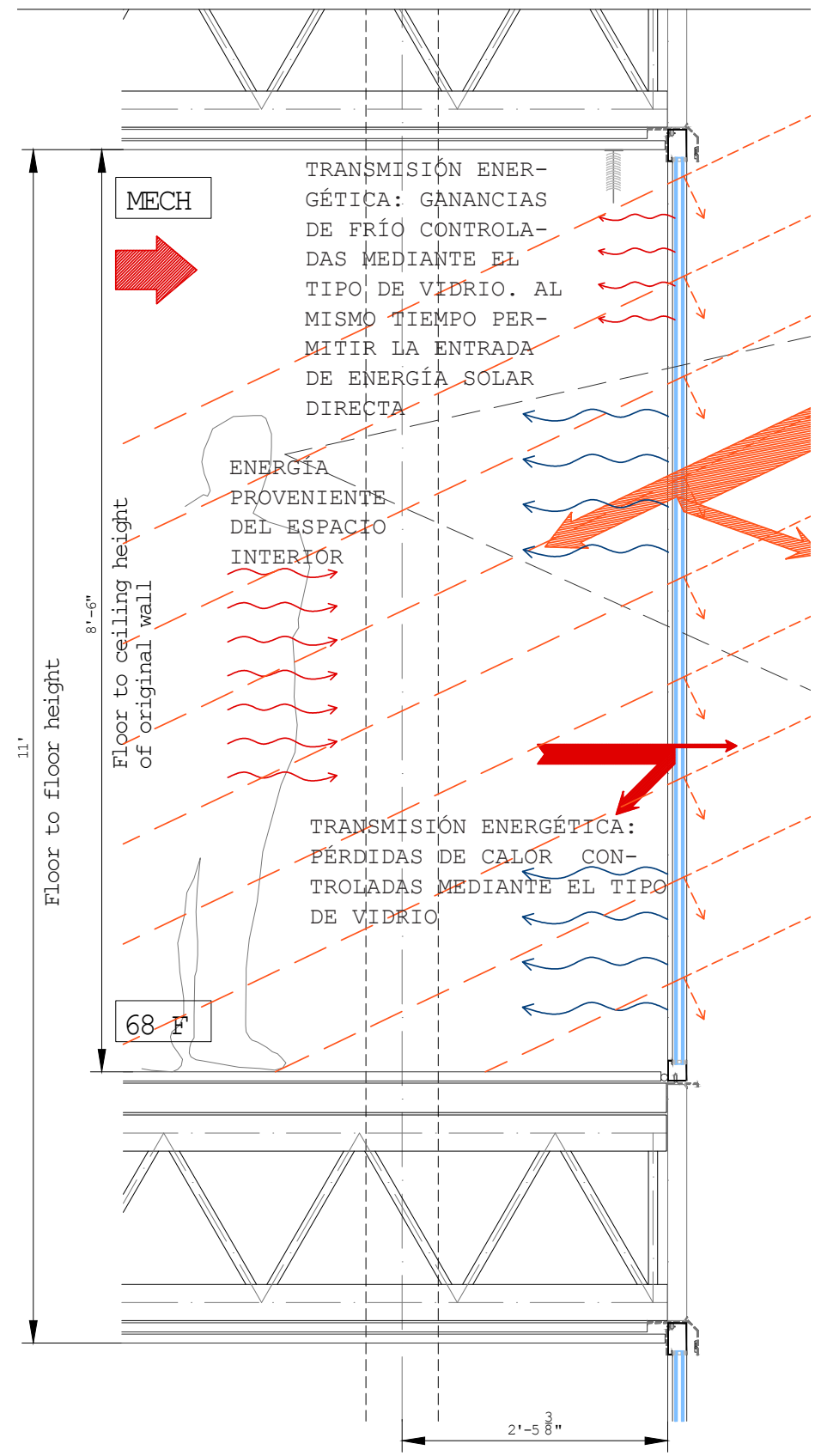

Comportamiento Envolvente Tipo SA modo día-invierno

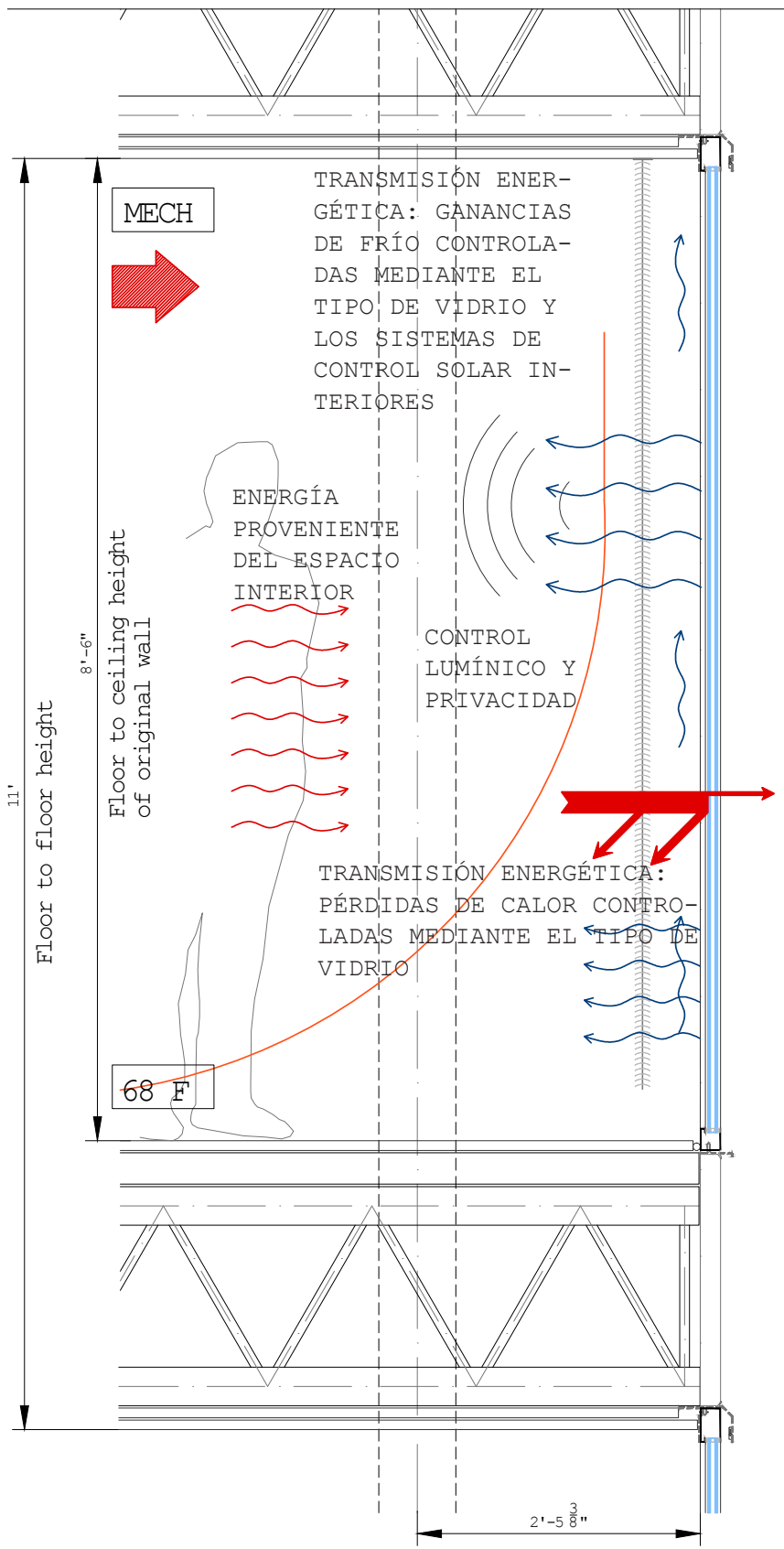

Comportamiento Envolvente Tipo SA modo noche-invierno 
CAPÍTULO 05

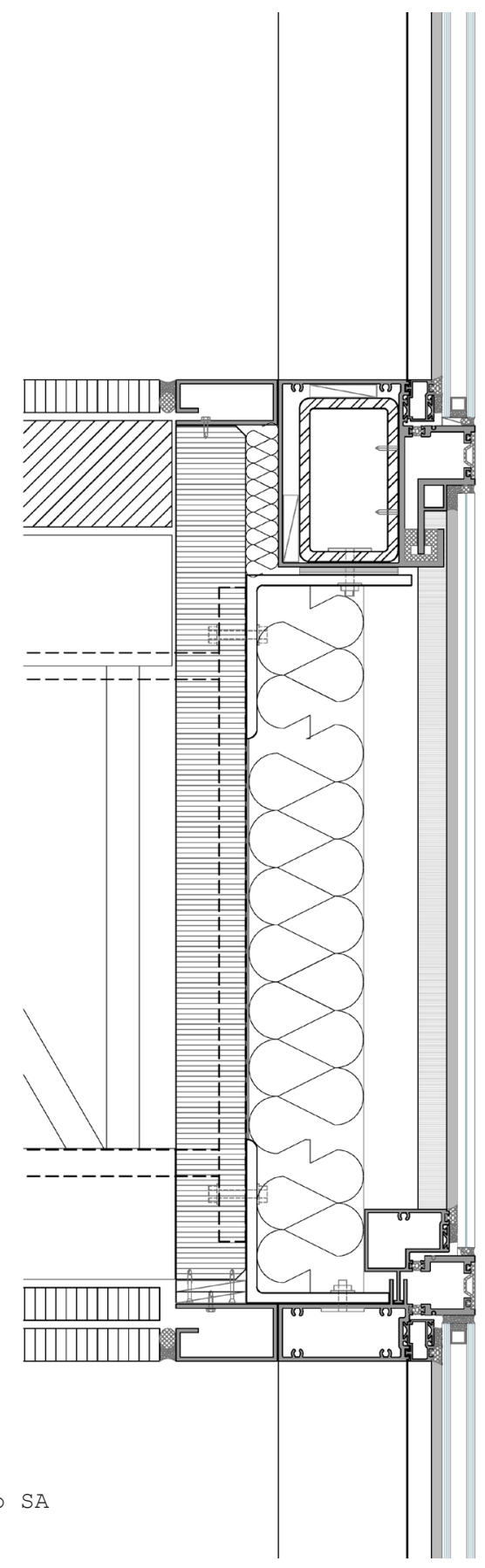

262 

La segunda opción que surge de los resultados obtenidos del análisis de las fachadas orientadas al sur, sugieren la idoneidad de diseñar elementos que prevengan la entrada de energía solar en los espacios antes de entrar en contacto con la superficie de vidrio. Además, este trabajo reconoce las ventajas de diseñar espacios de transición entre los interiores y los exteriores. El diseño que se propone está basado en la combinación del Vidrio Tipo C con una proyección horizontal fija ( $\mathrm{P}: 1,12 \mathrm{~m}$ ) en forma de voladizo que pueda ser disfrutada a modo de terraza o balcón.

A continuación se exponen los resultados relacionados con las cargas energéticas para la propuesta de Envolvente Tipo SB:

\begin{tabular}{|c|c|c|}
\hline \multicolumn{2}{|c|}{ Envolvente Tipo SB } \\
\hline & Calefacción & Refrigeración \\
\hline Triple Clear Spectra- & 13.2 & 31.6 \\
lly Selective Low-e & & \\
(\#2) with Exterior & & \\
Fixed Horizontal pro- & & \\
jection (P: 1.12m) & & \\
\hline
\end{tabular}

El resultado en el interior de la fachada orientada al Sur para la Envolvente Tipo SB se muestra continuación.

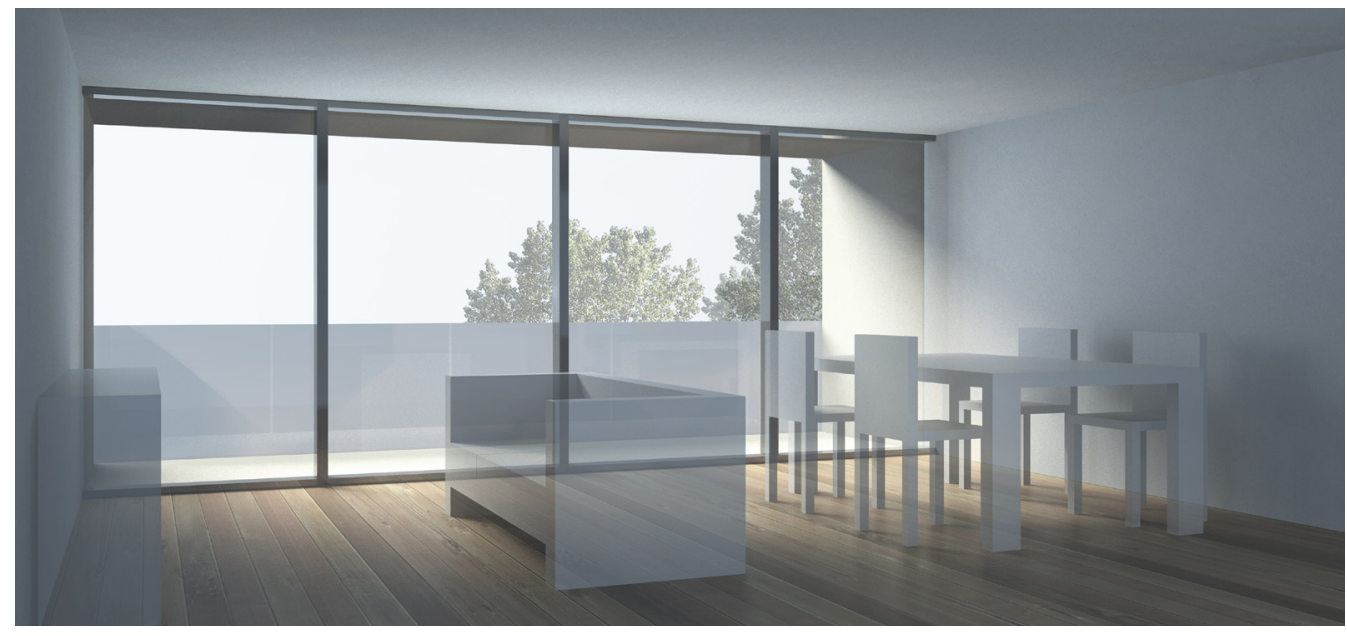


De manera similar al proceso seguido en las propuestas anteriores, la instalación de la Envolvente Tipo SB se presenta a modo de pasos, lo que permite explicar cada una de las partes. La Envolvente Tipo SB contempla los siguientes pasos que se explican a continuación.

En primer lugar se muestra el módulo existente, orientado al sur, donde la estructura queda expuesta tras retirar del sitio el panel del frente del forjado. En segundo lugar se ancla una estructura auxiliar a los pilares principales del edificio. Esta estructura es la encargada de trasladar las cargas de la nueva envolvente de vidrio a la estructura principal del edificio. En tercer lugar, se inserta y ancla una estructura de acero en la que se apoyarán las losas de las proyecciones. Tras colocar las losas se instalan los módulos de carpintería para luego completar la envolvente, acomodando los nuevos paneles de recubrimiento.

A continuación se exponen las imágenes que gráficamente explican el proceso y componentes de la nueva envolvente, así como los mecanismos que se han estudiado acerca del comportamiento de la fachada propuesta en verano y en invierno.

Por tanto, la Envolvente Tipo SB propone una piel que combina el vidrio seleccionado para las fachadas al sur con un elemento de transición. Como se ha comprobado, la proyección horizontal fija tiene el inconveniente de no ser regulable. Sin embargo, y atendiendo a la flexibilidad del programa, se ha considerado para este proyecto debido a su valor espacial y su posibilidad de uso. 
CAPÍTULO 05

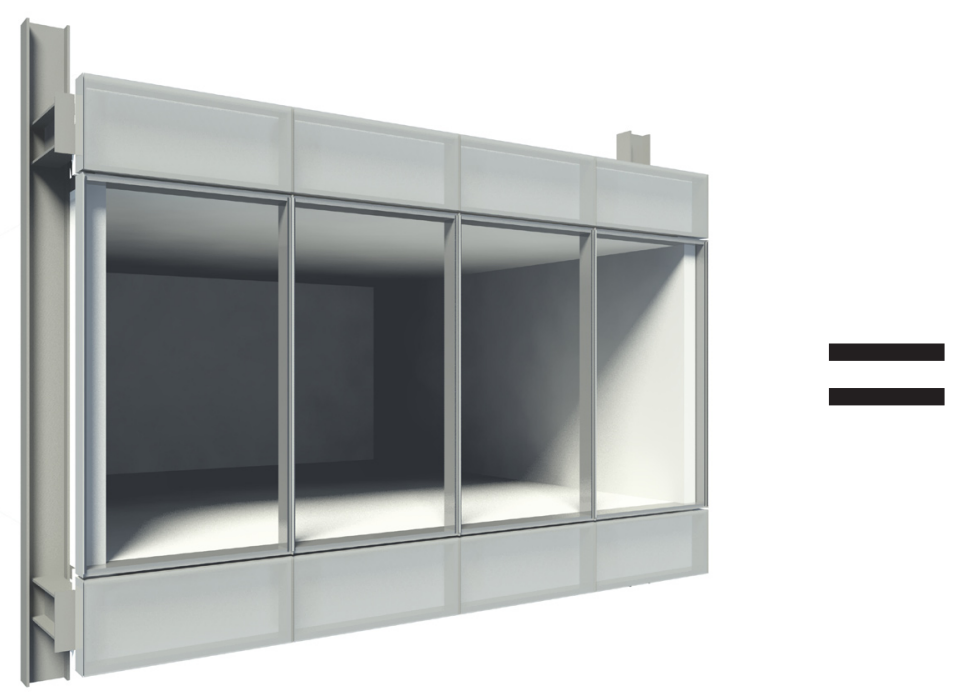

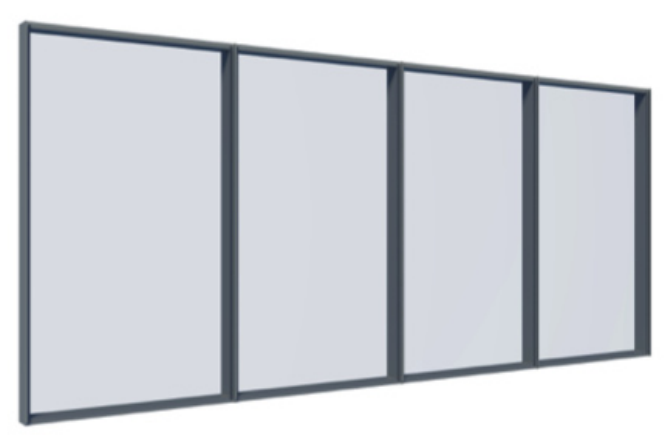

$+$
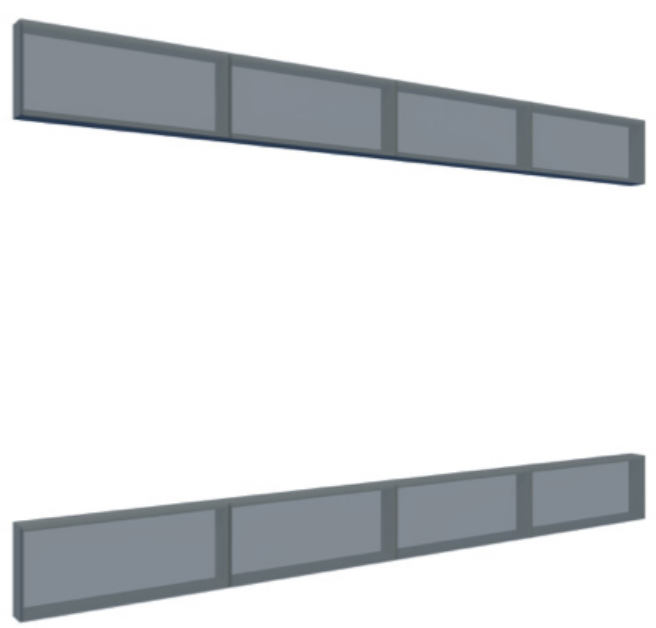
CAPÍTULO 05
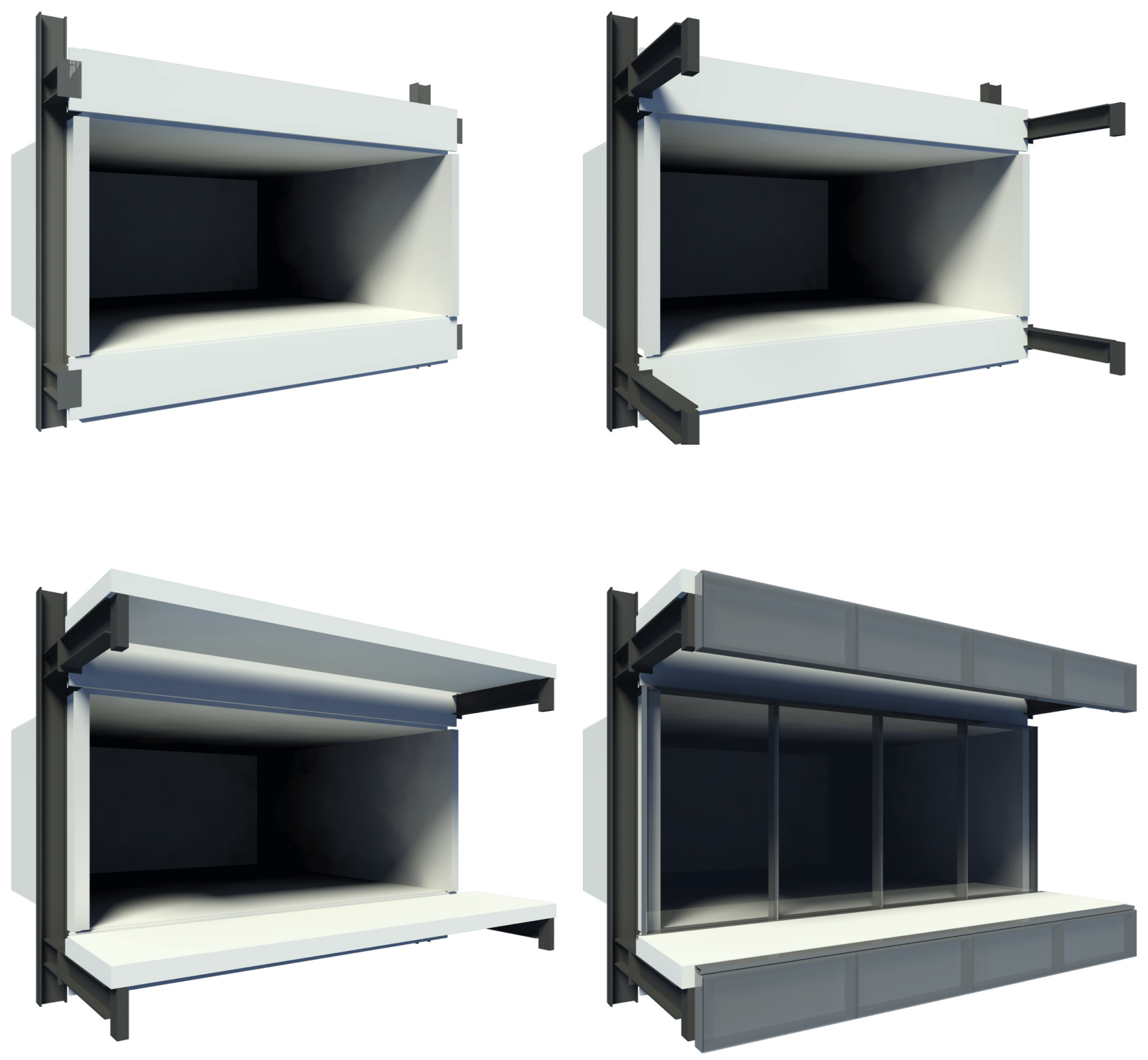
CAPÍTULO 05

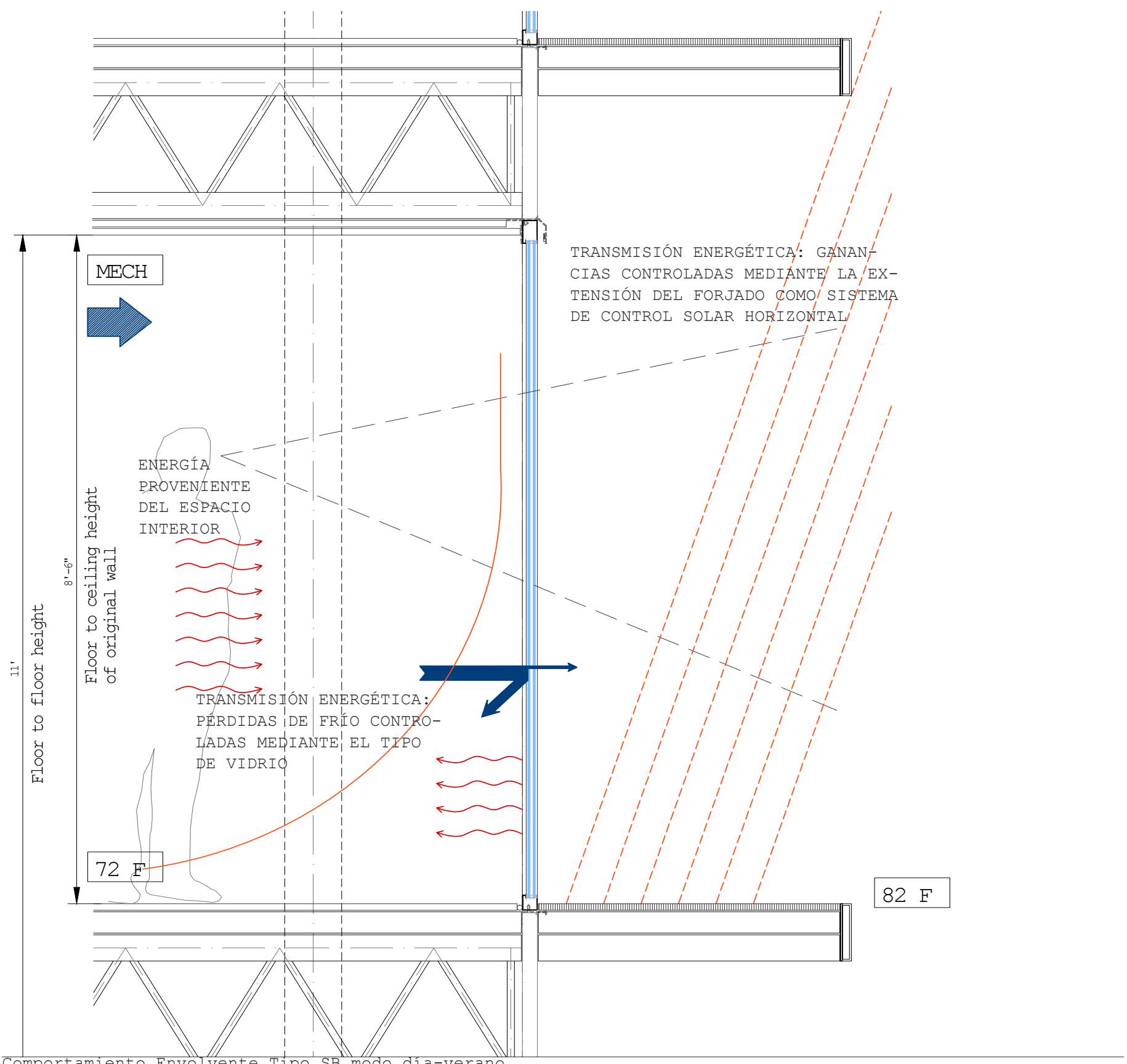


CAPÍTULO 05

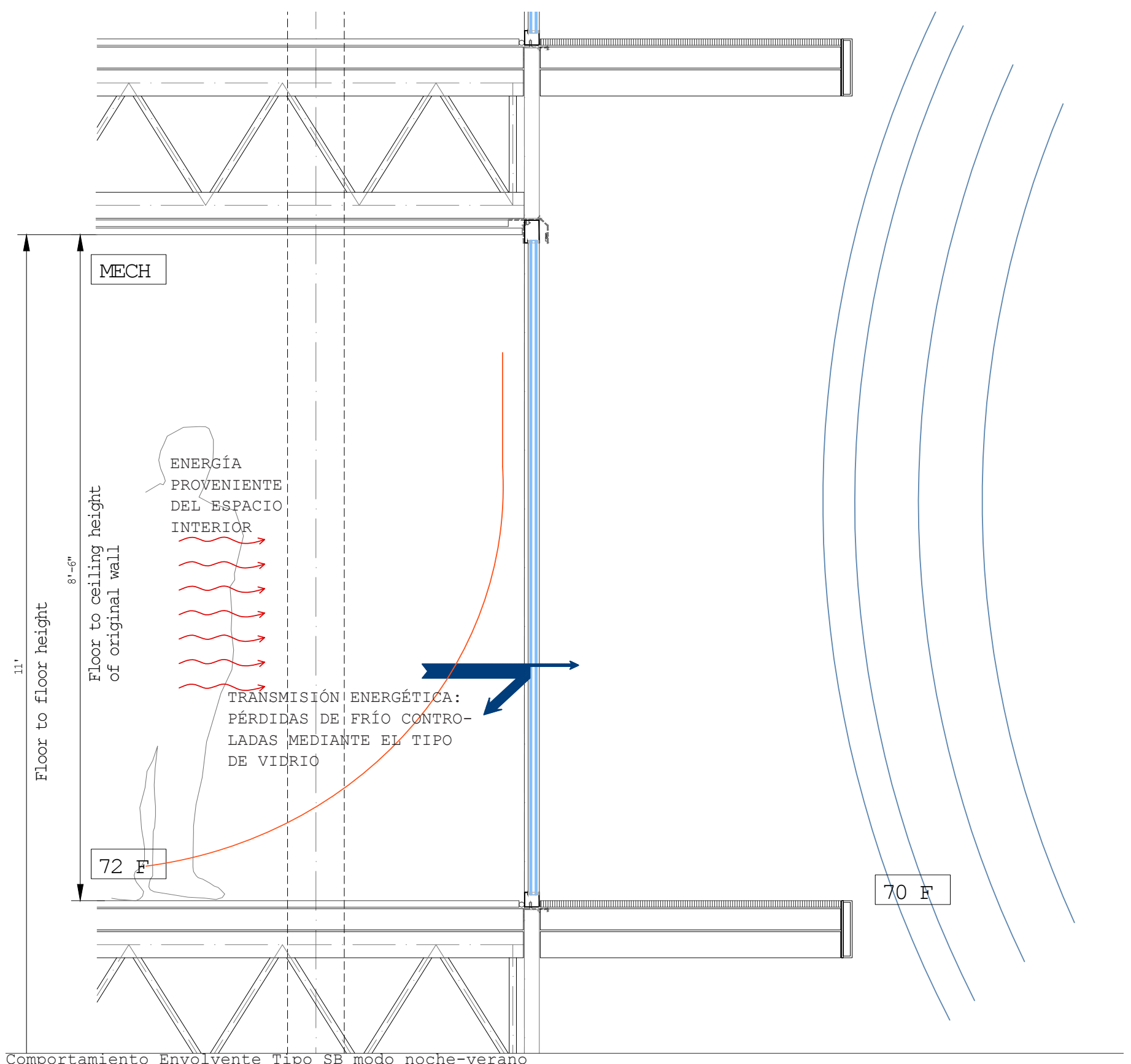




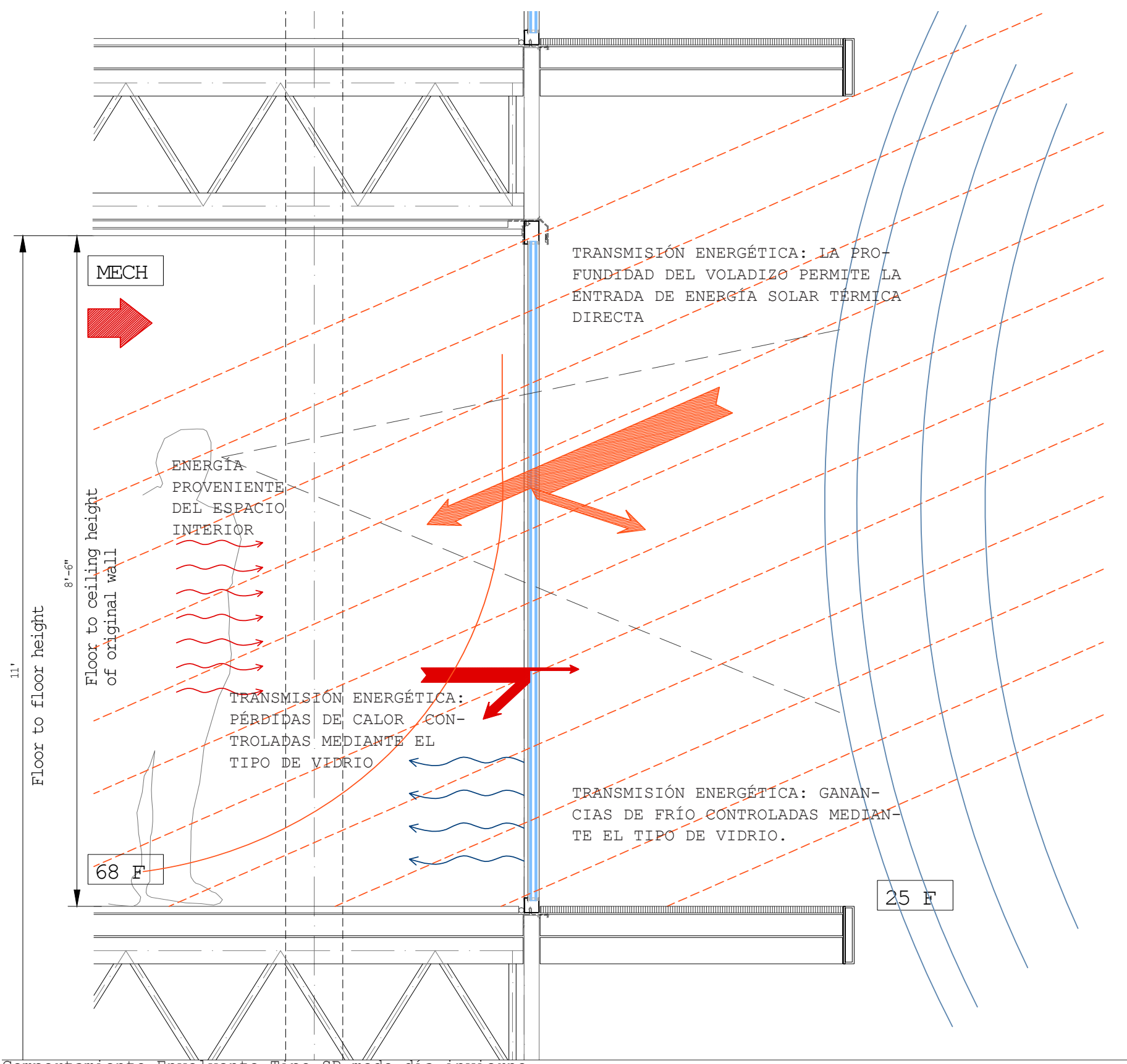


CAPÍTULO 05

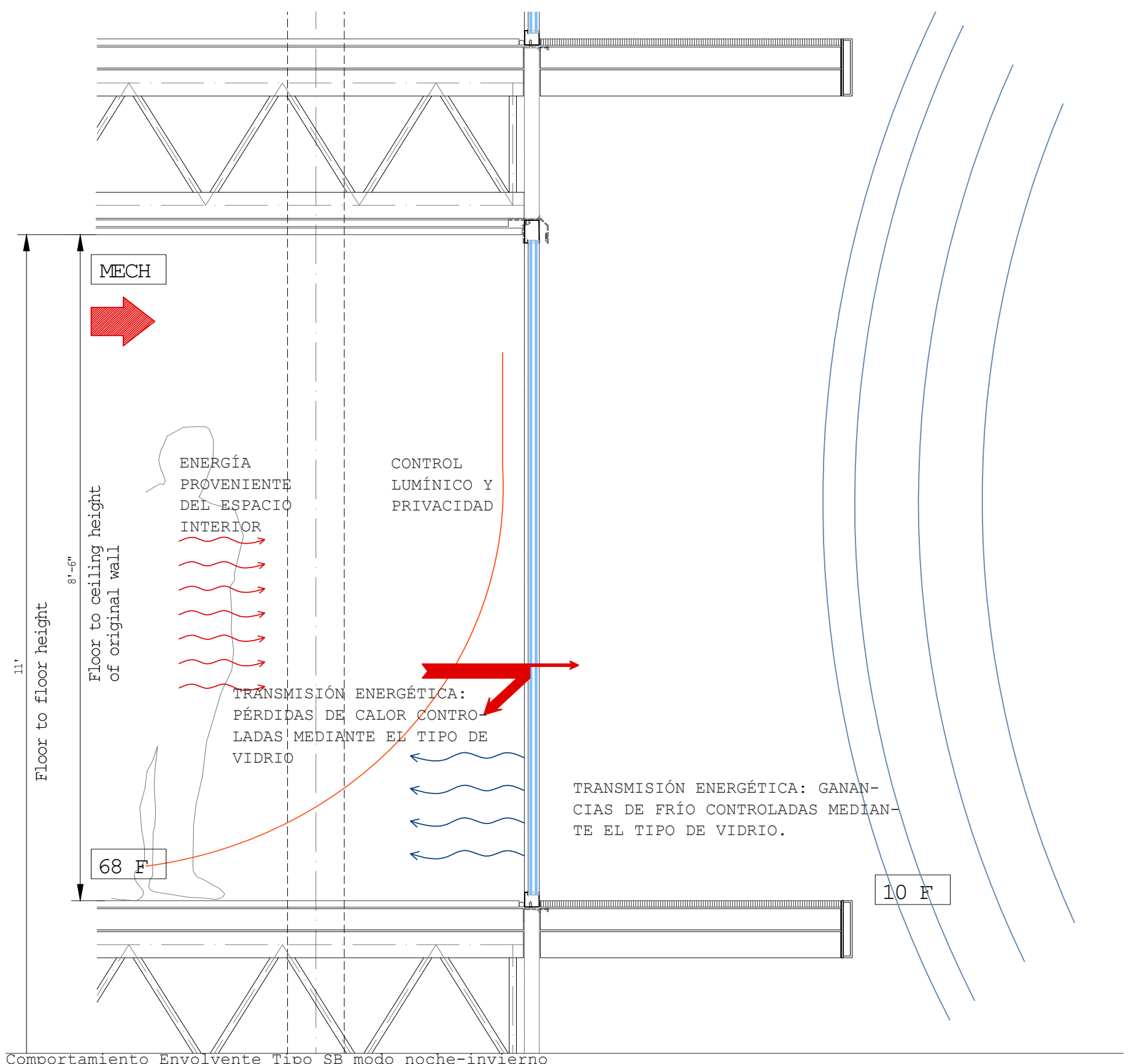




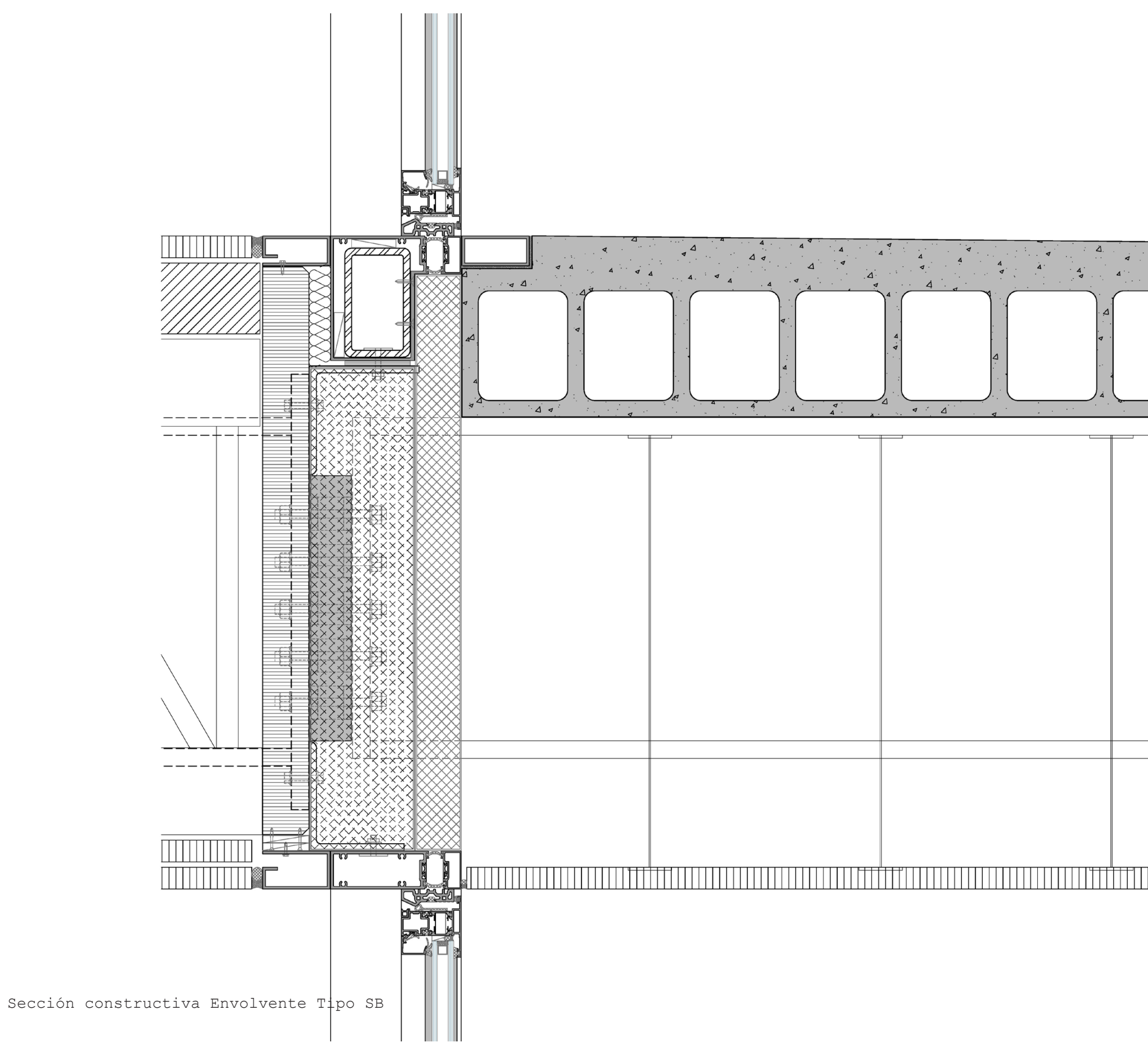


CAPÍTULO 05

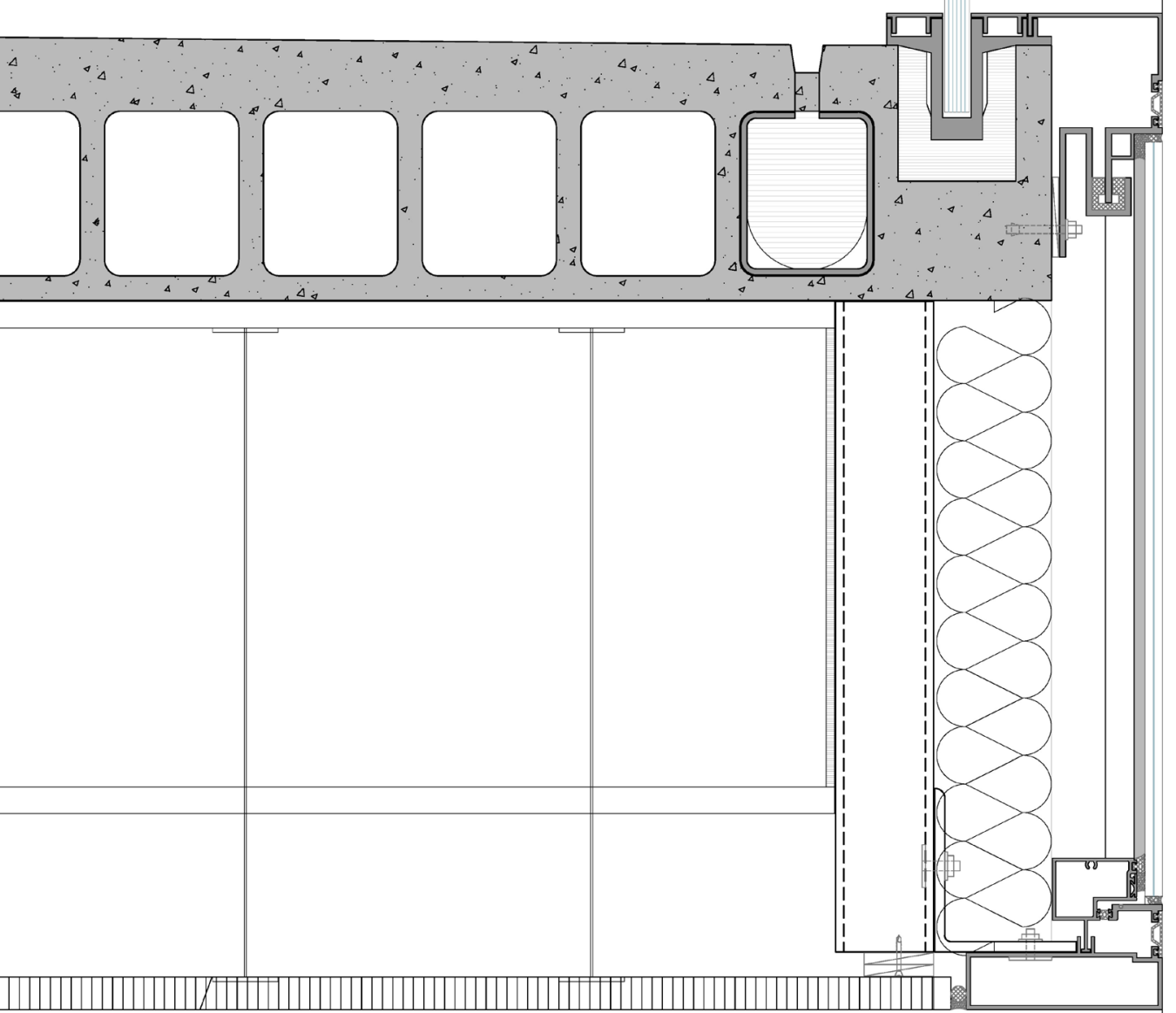


La tercera opción que surge de los resultados obtenidos del análisis de las fachadas orientadas al sur, sugieren que si a la Envolvente Tipo SB se añaden sistemas de protección solar regulables, las demanda de refrigeración se ve reducida. Además, con el material adecuado, estos espacios de transición puedan ser utilizados con mayor flexibilidad. Por ello, el diseño propone la combinación del Vidrio Tipo B con una proyección horizontal fija ( $\mathrm{P}: 1,12 \mathrm{~m}$ ) en forma de voladizo, a la que se añade un sistema de protección solar horizontal regulable.

A continuación se exponen los resultados relacionados con las cargas energéticas para la propuesta de Envolvente Tipo SC:

\begin{tabular}{|c|c|c|}
\hline \multicolumn{2}{|c|}{ Envolvente Tipo SC } \\
\hline & Calefacción & Refrigeración \\
\hline Double Clear Spectra- & 20.0 & 6.83 \\
ly Selective Low-e & & \\
(\#2) with Exterior & & \\
Fixed Horizontal pro- & & \\
jection (P: 1.12m) and & & \\
Exterior Movable Lami- & & \\
nated Horizontal Glass & & \\
Louvers (FC: 0.1) & & \\
\hline
\end{tabular}

El resultado en el interior de la fachada orientada al Sur para la Envolvente Tipo C se muestra continuación.

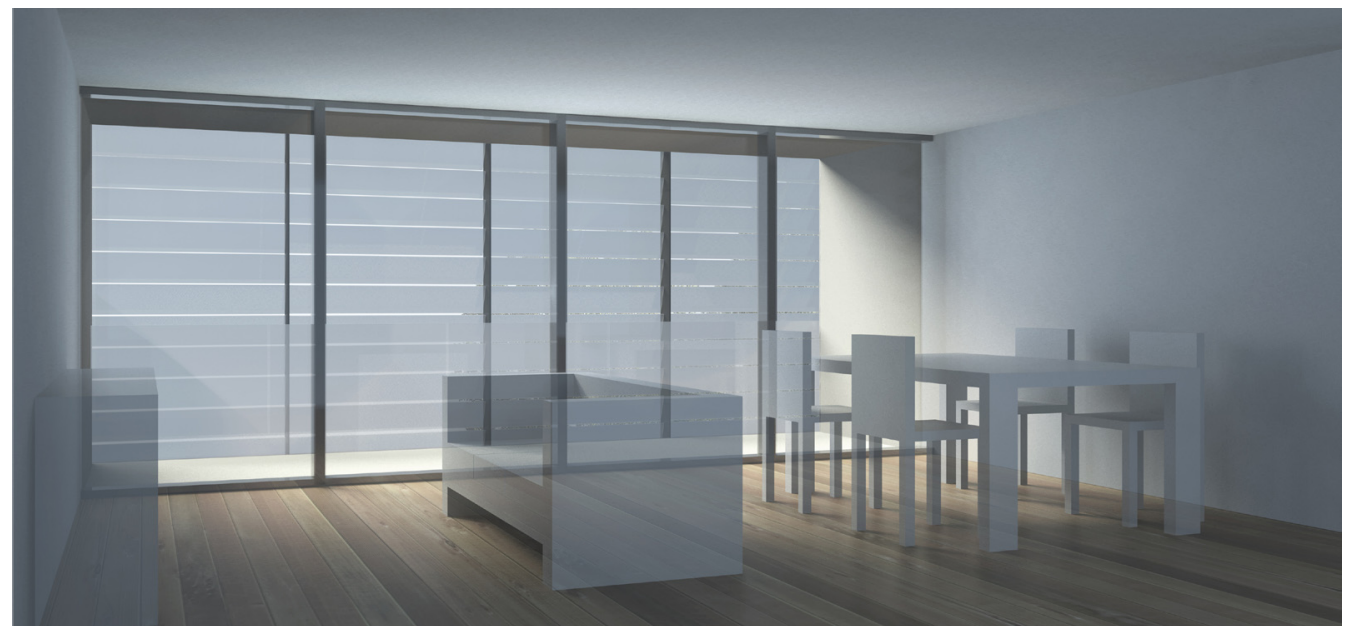


De manera similar al proceso seguido en las propuestas anteriores, el diseño de la Envolvente Tipo SC la instalación se presenta paso a paso para explicar las diferentes partes.

En este caso, a los pasos para la instalación de la Envolvente Tipo SB se añaden los elementos horizontales de protección solar regulables.

A continuación se exponen las imágenes que gráficamente explican el proceso, y el comportamiento del diseño en las estaciones de verano y de invierno.

Por tanto, la Envolvente Tipo SC propone una piel en la que se combina el vidrio seleccionado para las fachadas al Sur con un elemento de transición. Además, este elemento de transición queda completado mediante un sistema de lamas horizontales de vidrio que permiten, entre otras funciones, la utilización del espacio durante un tiempo más prolongado. La flexibilidad que otorga este sistema ofrece la posibilidad de dotar el espacio para distintos usos, además de añadir una segunda piel que mejore las propiedades aislantes de la envolvente. 
CAPÍTULO 05
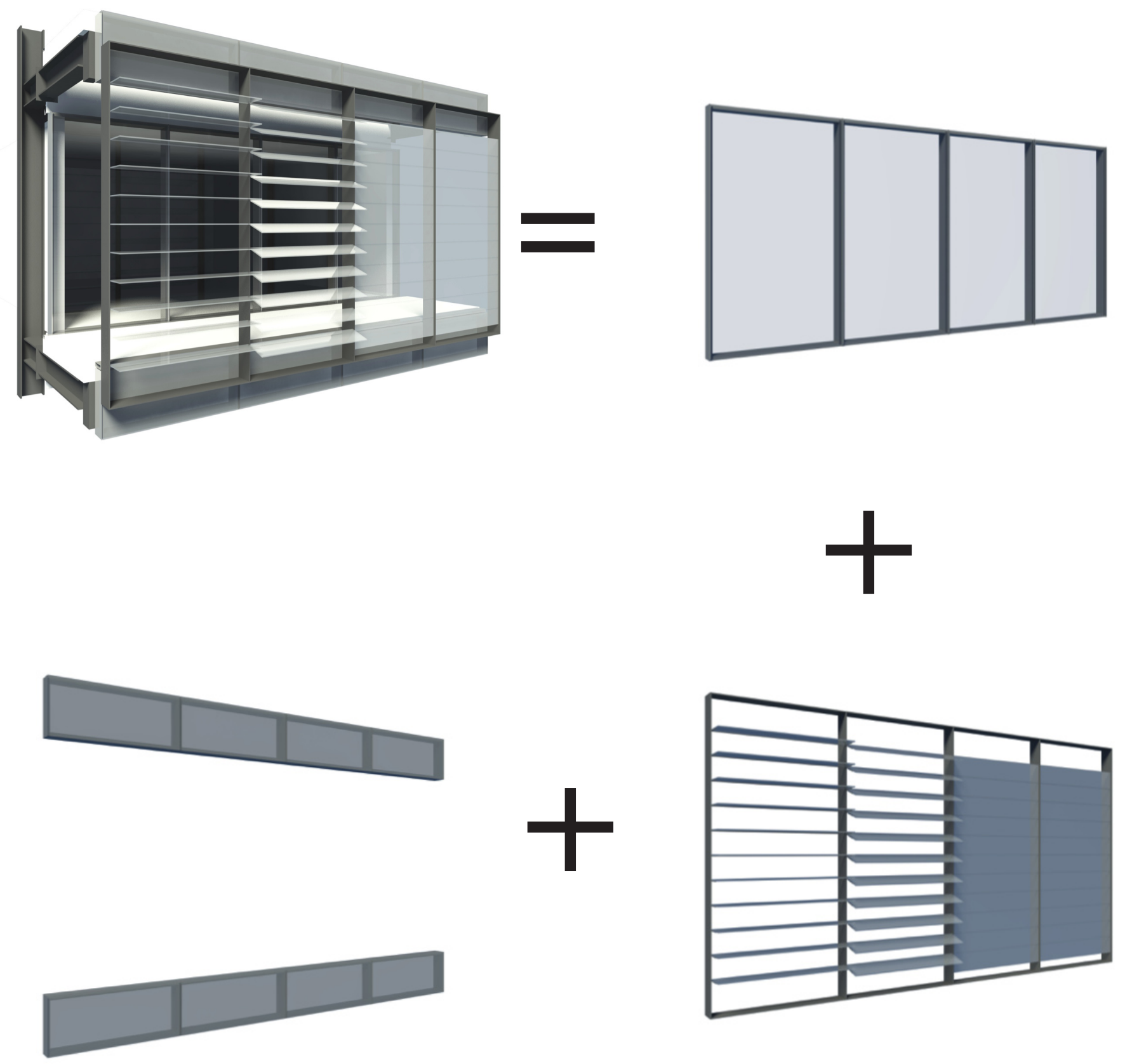
CAPÍTULO 05
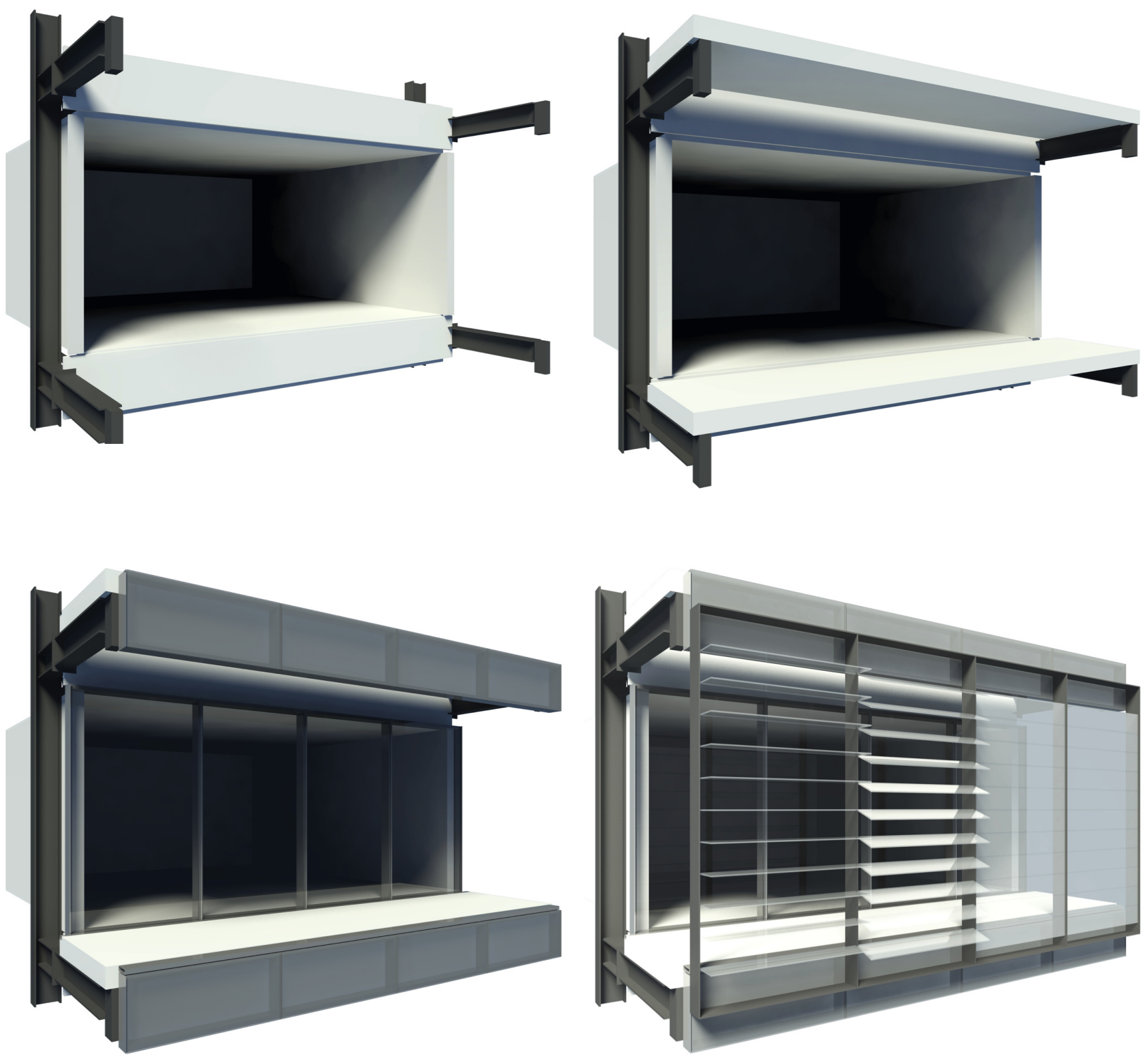
CAPítulO 05

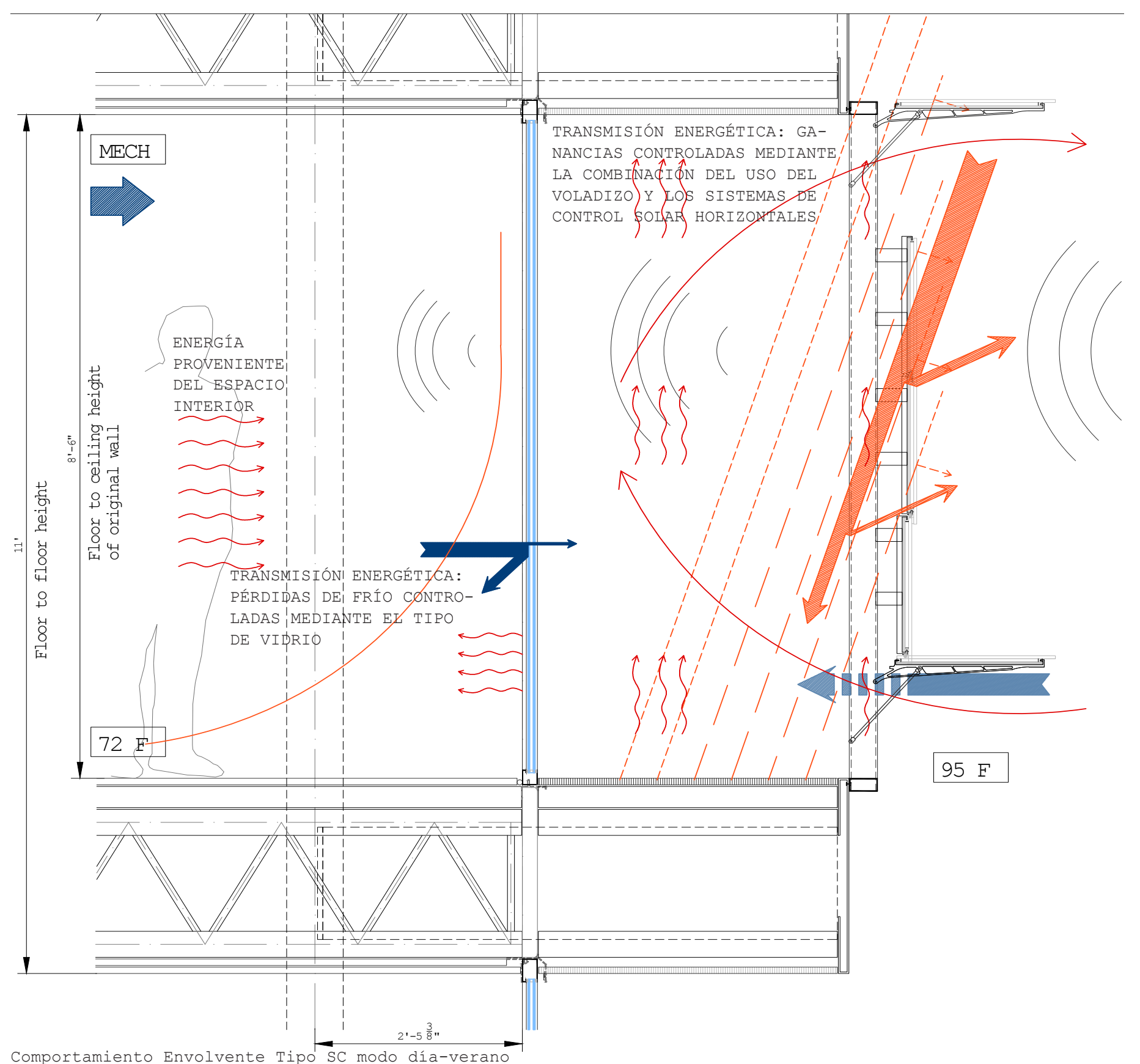


CAPÍTULO 05

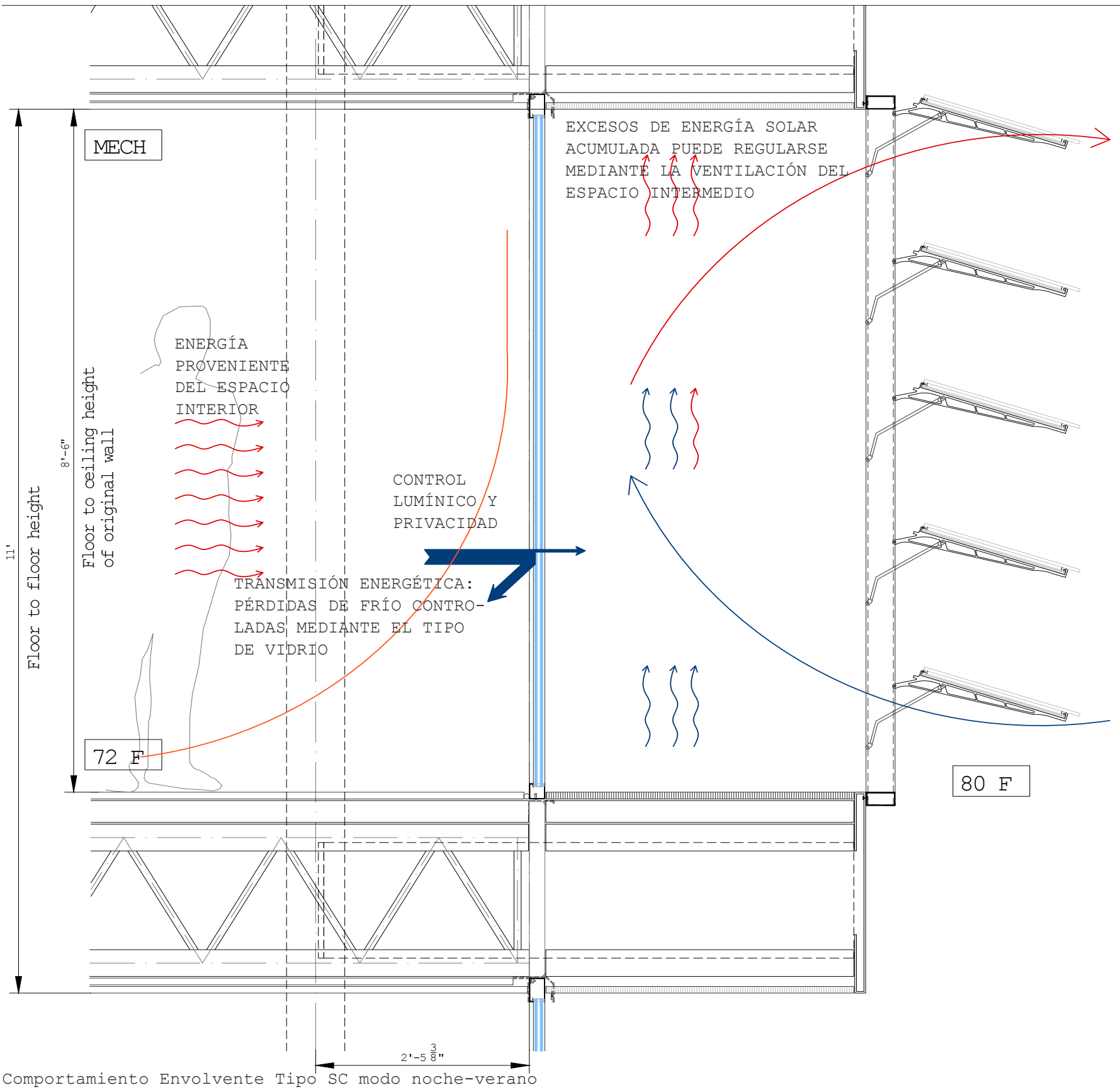


CAPítulO 05

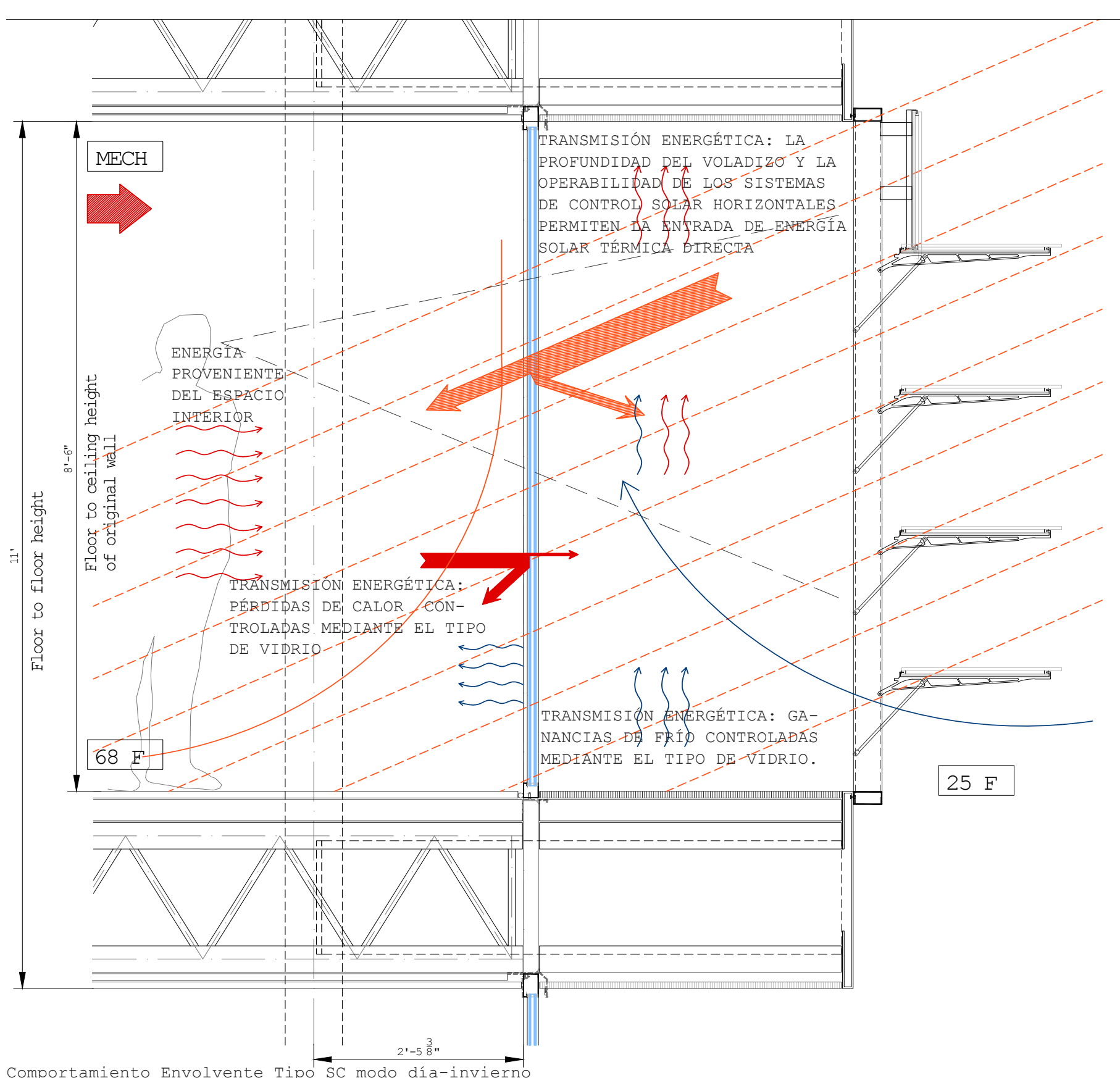


CAPÍTULO 05

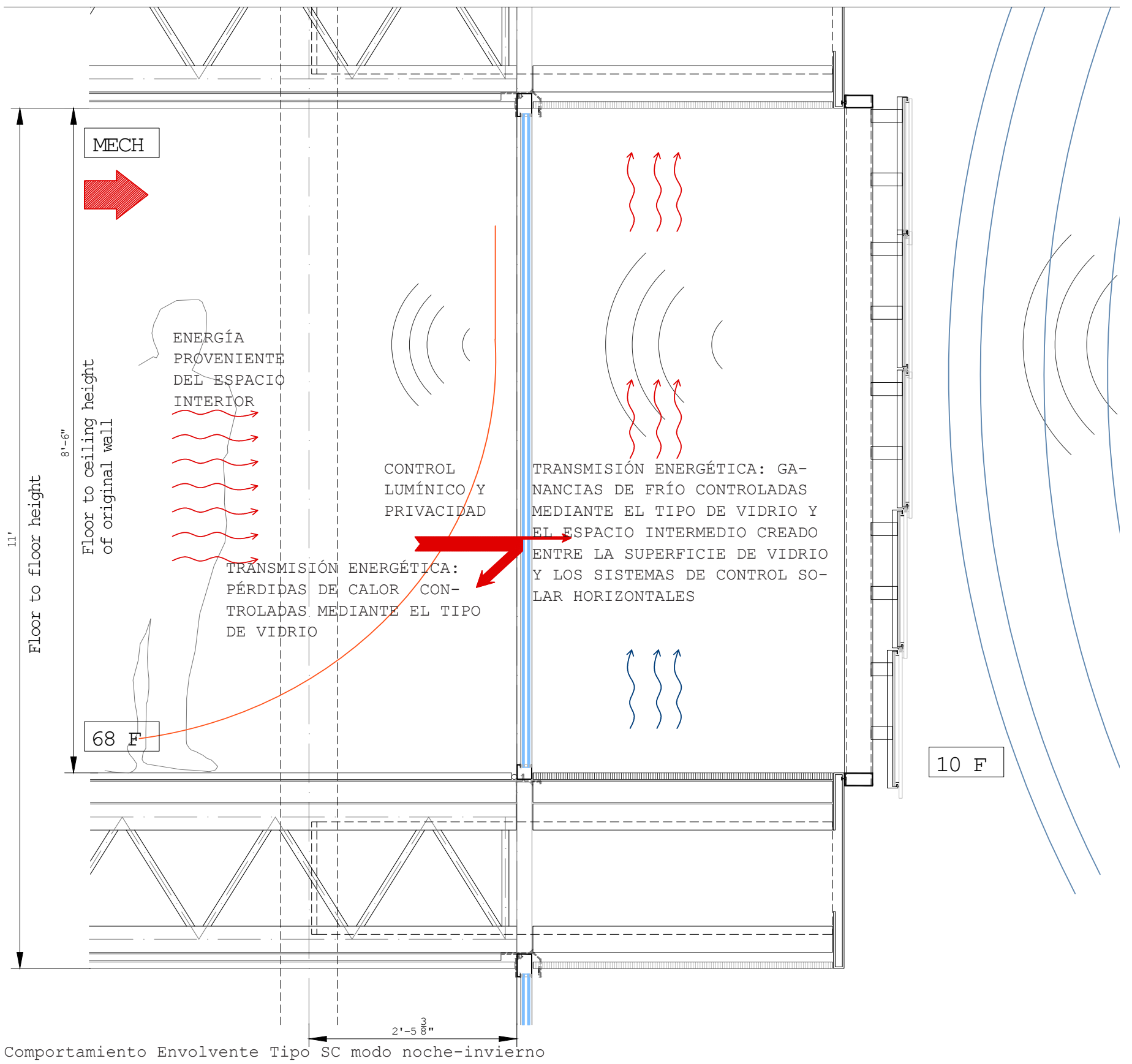




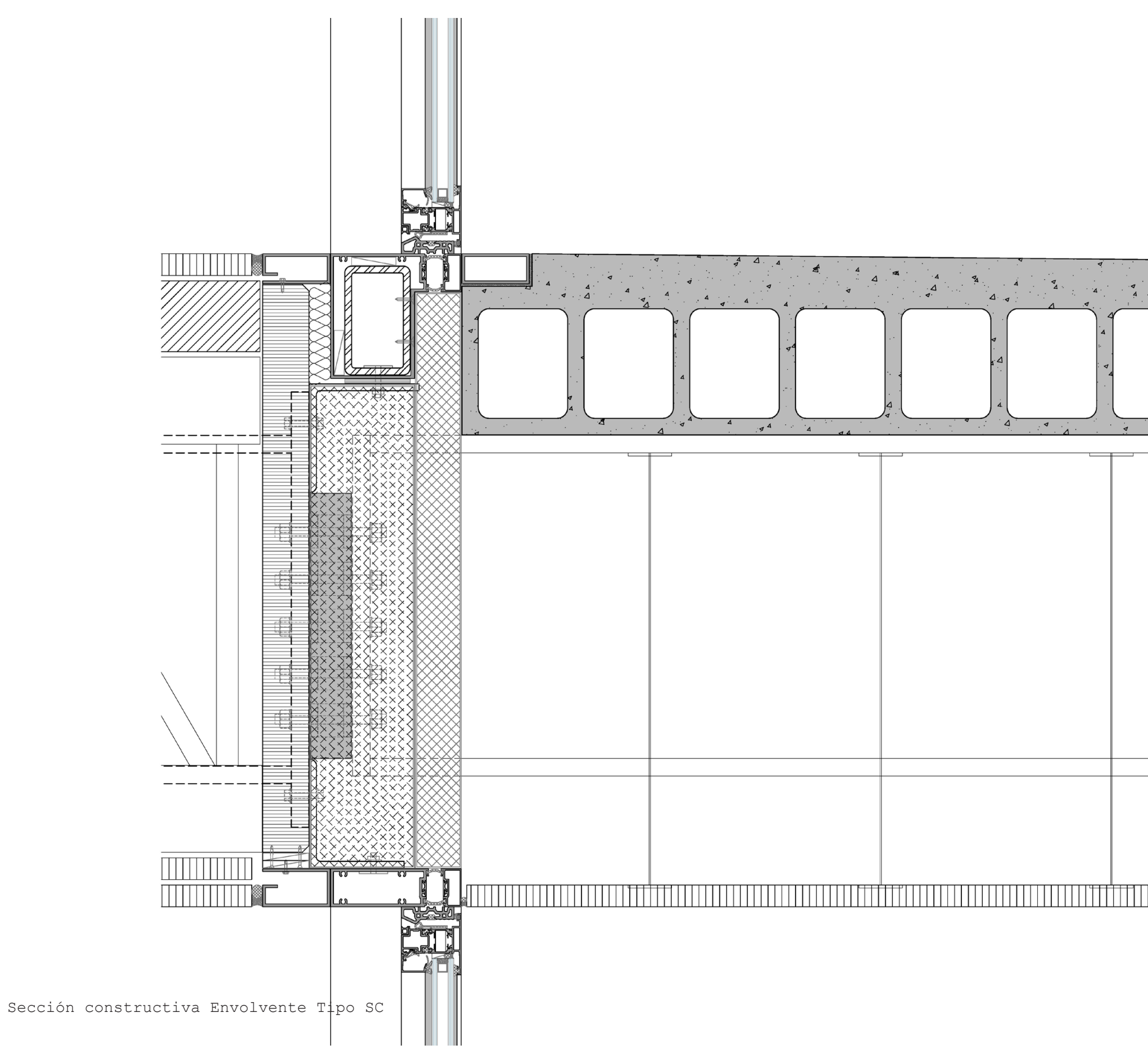


CAPÍTULO 05
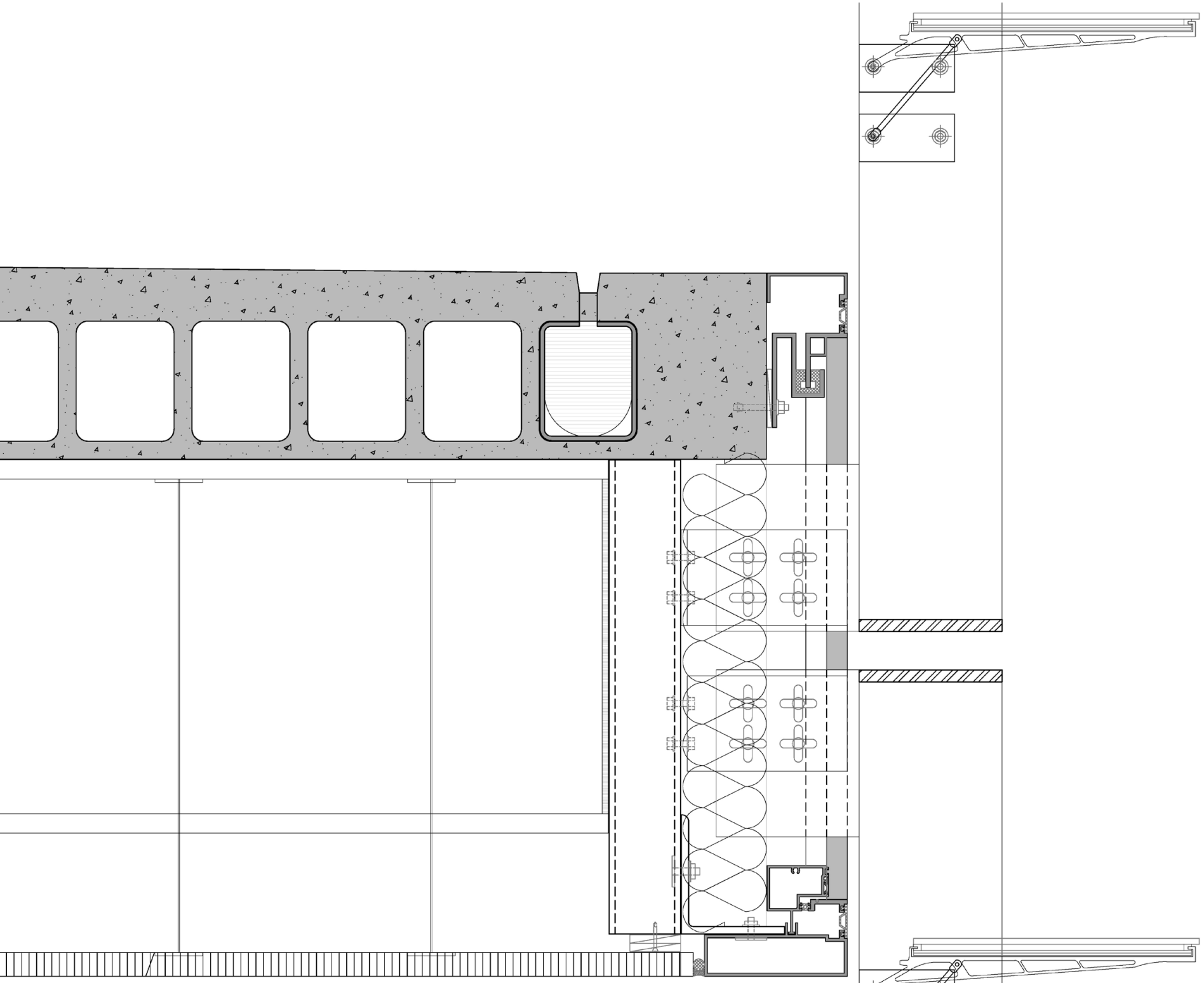

पIIIIIIIII

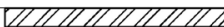

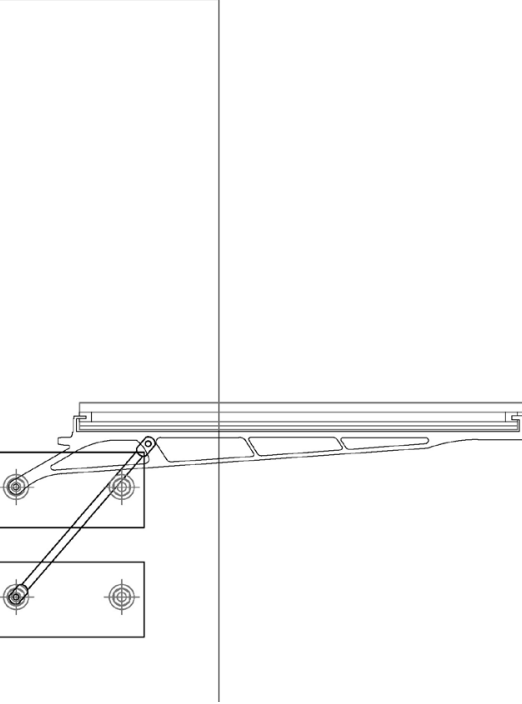




\section{CAPÍTULO 05}

La cuarta opción tiene en consideración la posibilidad de ofrecer una alternativa que no contemple un espacio de transición, y que ofrezca un alternativa a aquéllos que tengan otras preferencias. Por ello, y tras analizar los resultados, se propone la combinación del Vidrio Tipo B con elementos de control solar regulables.

A continuación se exponen los resultados relacionados con las cargas energéticas para la propuesta de Envolvente Tipo SD:

\begin{tabular}{|c|c|c|}
\hline \multicolumn{2}{|c|}{ Envolvente Tipo SD } \\
\hline Double Clear Spectra- & Calefacción & Refrigeración \\
lly Selective Low-e & 20.0 & 6.83 \\
(\#2) with Exterior & & \\
Fixed Horizontal pro- & & \\
jection (P: 1.12m) and & & \\
Exterior Movable Lami- & & \\
nated Horizontal Glass & & \\
Louvers (FC: 0.1) & & \\
\hline
\end{tabular}

El resultado en el interior de la fachada orientada al Sur para la Envolvente Tipo D, se muestra a continuación.

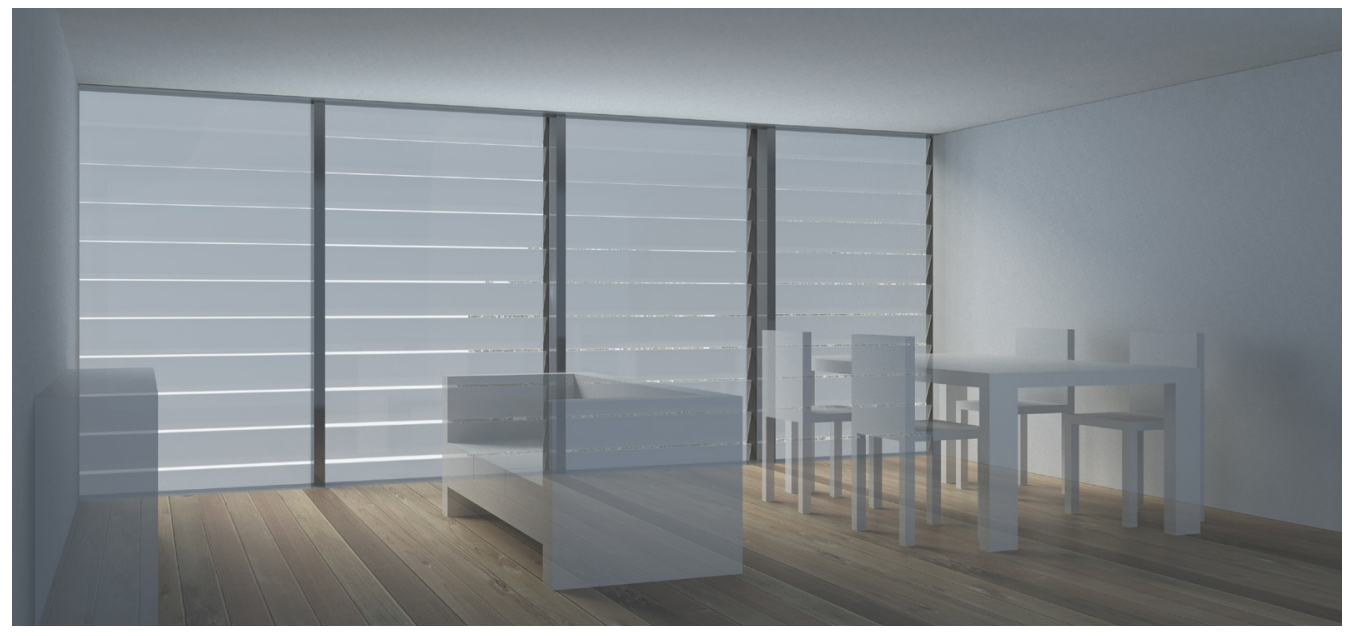


Al igual que en las propuestas anteriores, el diseño de la Envolvente Tipo SD se presenta paso a paso.

En este caso, los pasos que se establecen son los mismos que en la Envolvente Tipo SA, añadiendo al final los sistemas horizontales de protección solar regulables.

A continuación se exponen las imágenes que gráficamente explican el proceso y los componentes de la nueva envolvente, así como su comportamiento en verano y en invierno.

Por tanto, la Envolvente Tipo SD propone una piel en la que se combina el vidrio seleccionado para las fachadas al Sur con un sistema de lamas horizontales de vidrio que permiten, entre otras funciones, controlar la entrada de energía solar antes de que entre en el espacio. Además, al diseñar sistemas regulables, durante los meses de invierno, se permite la entrada de energía solar para calentar el espacio. Si estos sistemas se cierran herméticamente, pueden contribuir a las propiedades térmicas de la piel en su conjunto. 
CAPÍTULO 05
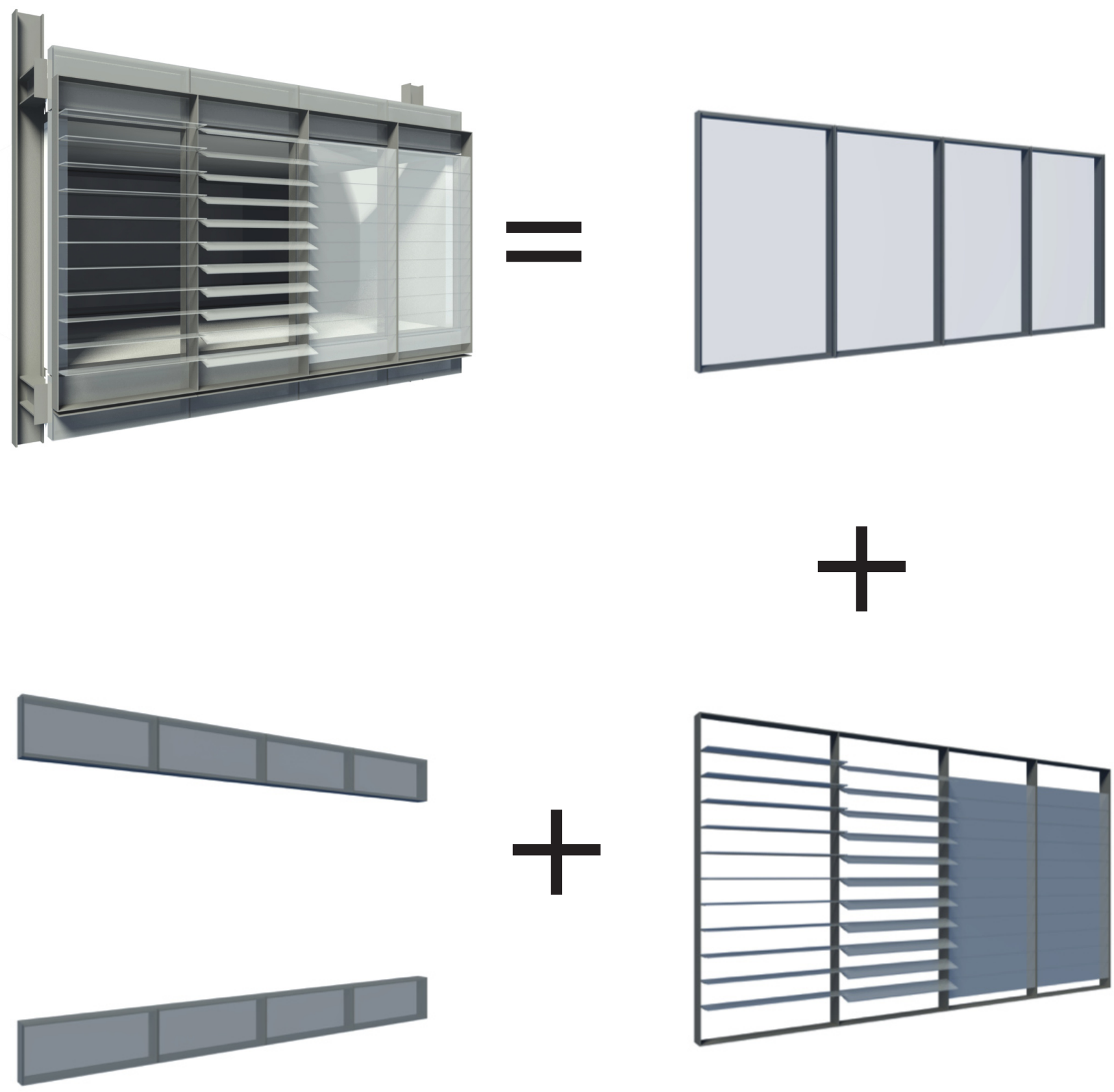
CAPÍTULO 05
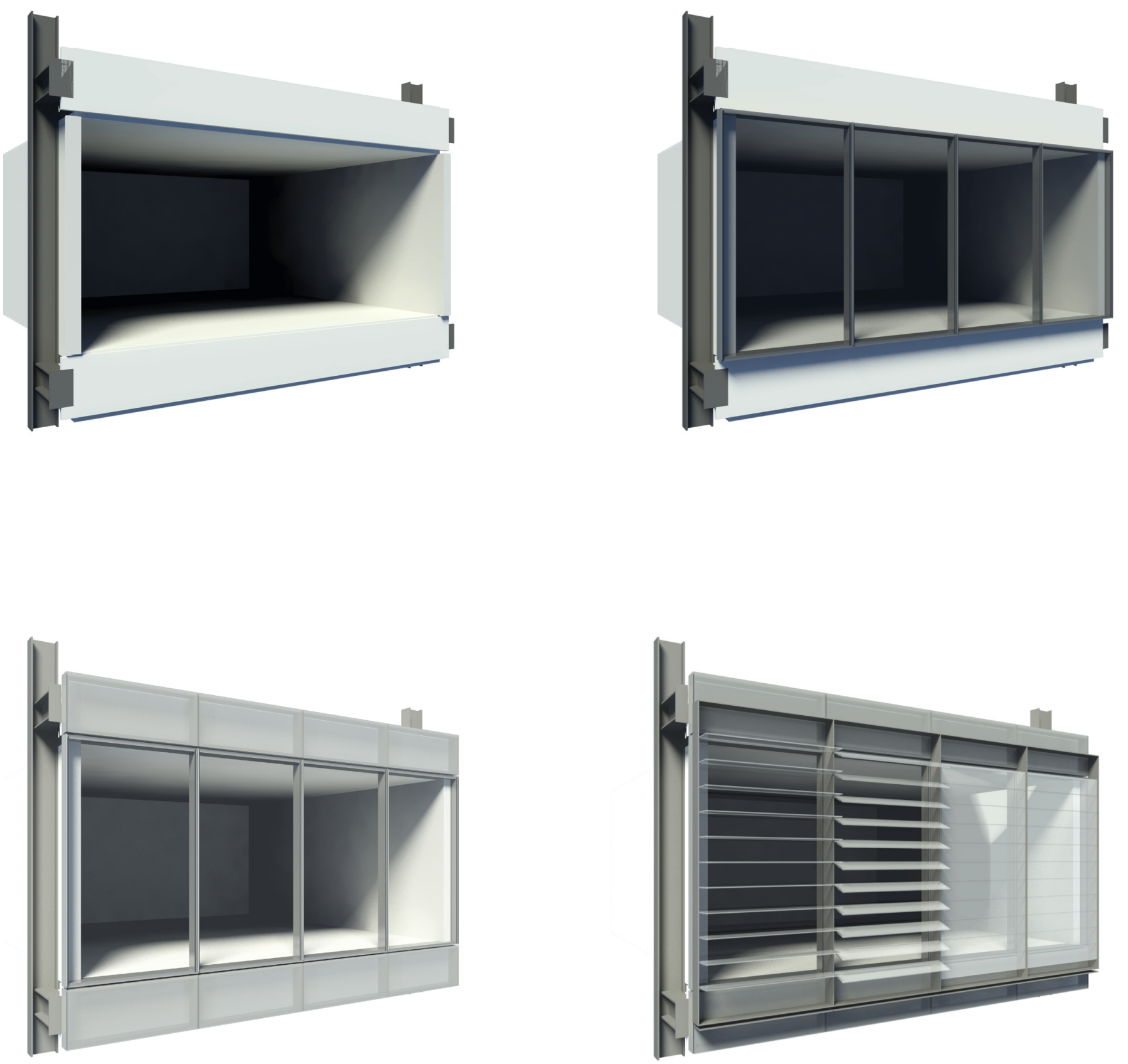
CAPÍTULO 05

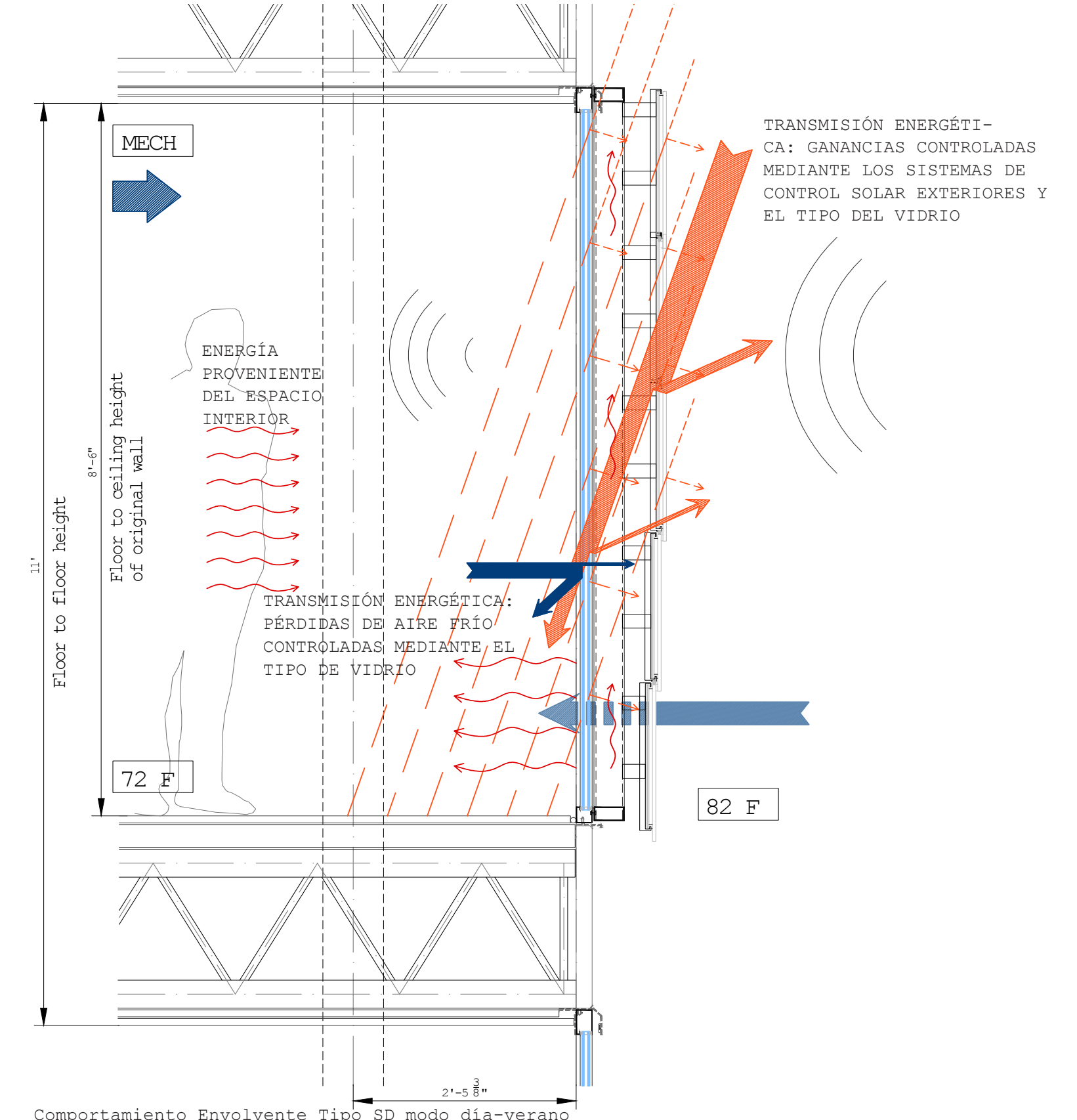


CAPítuLo 05

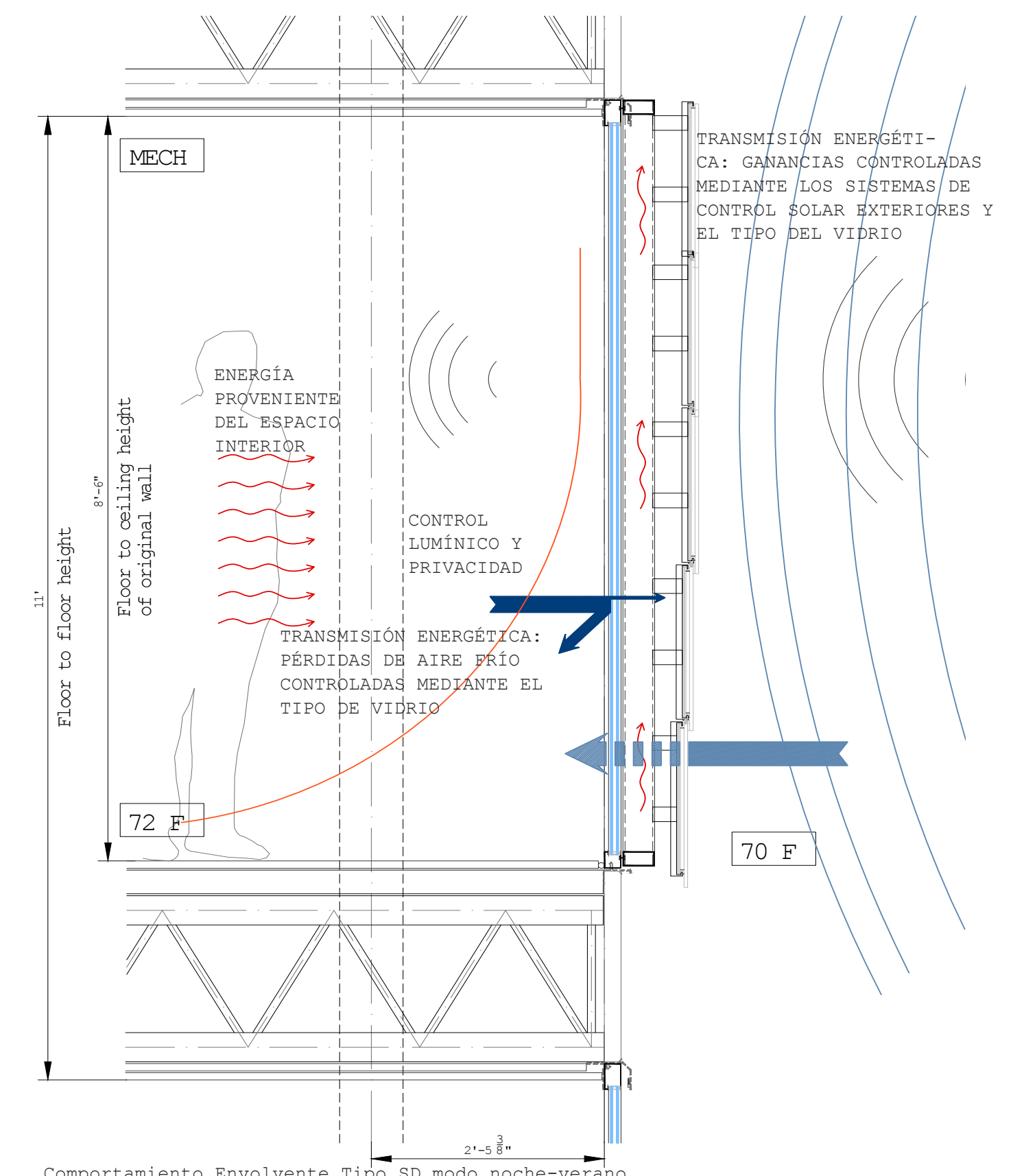


CAPÍTULO 05

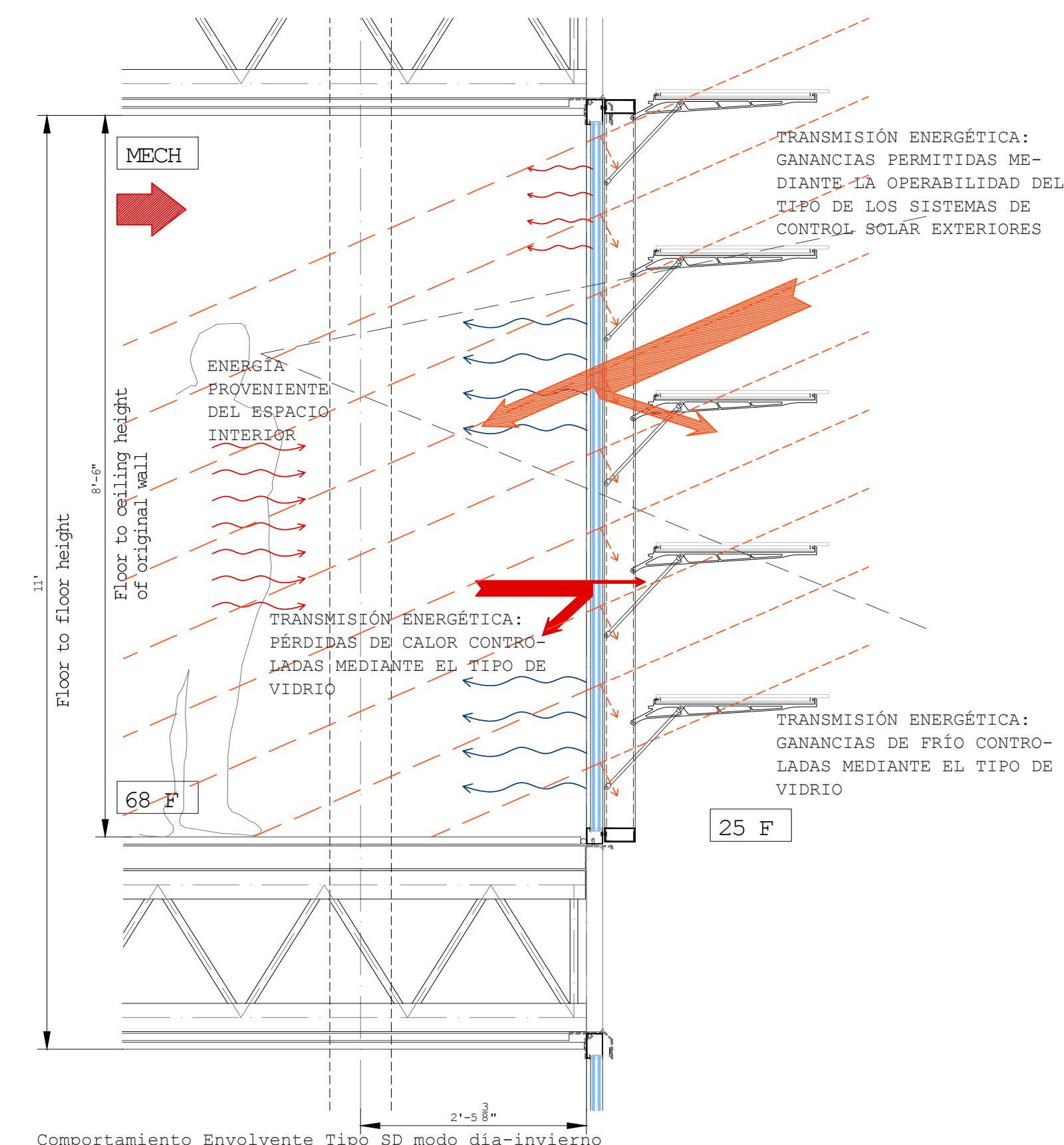




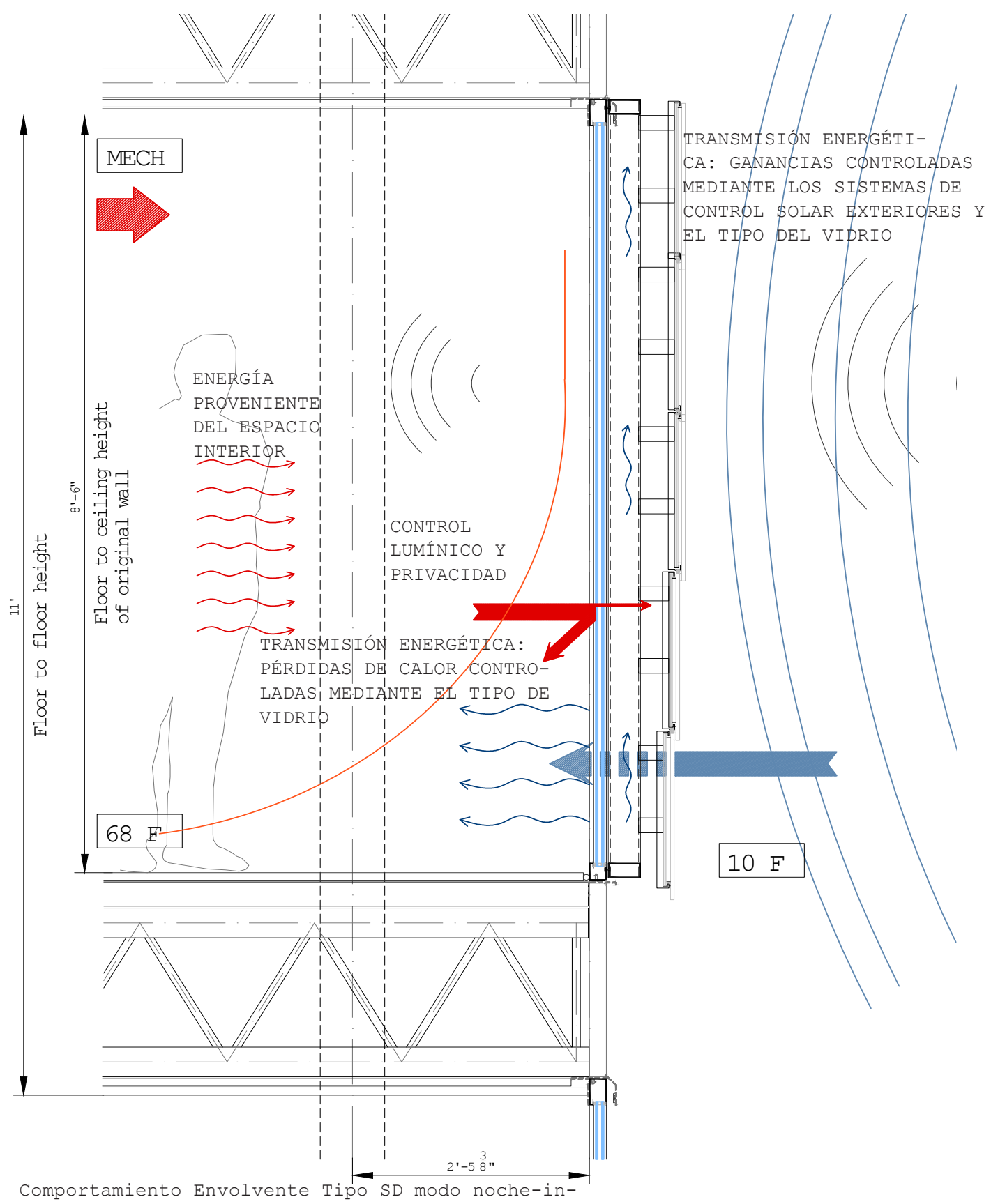

vierno 
CAPÍTULO 05

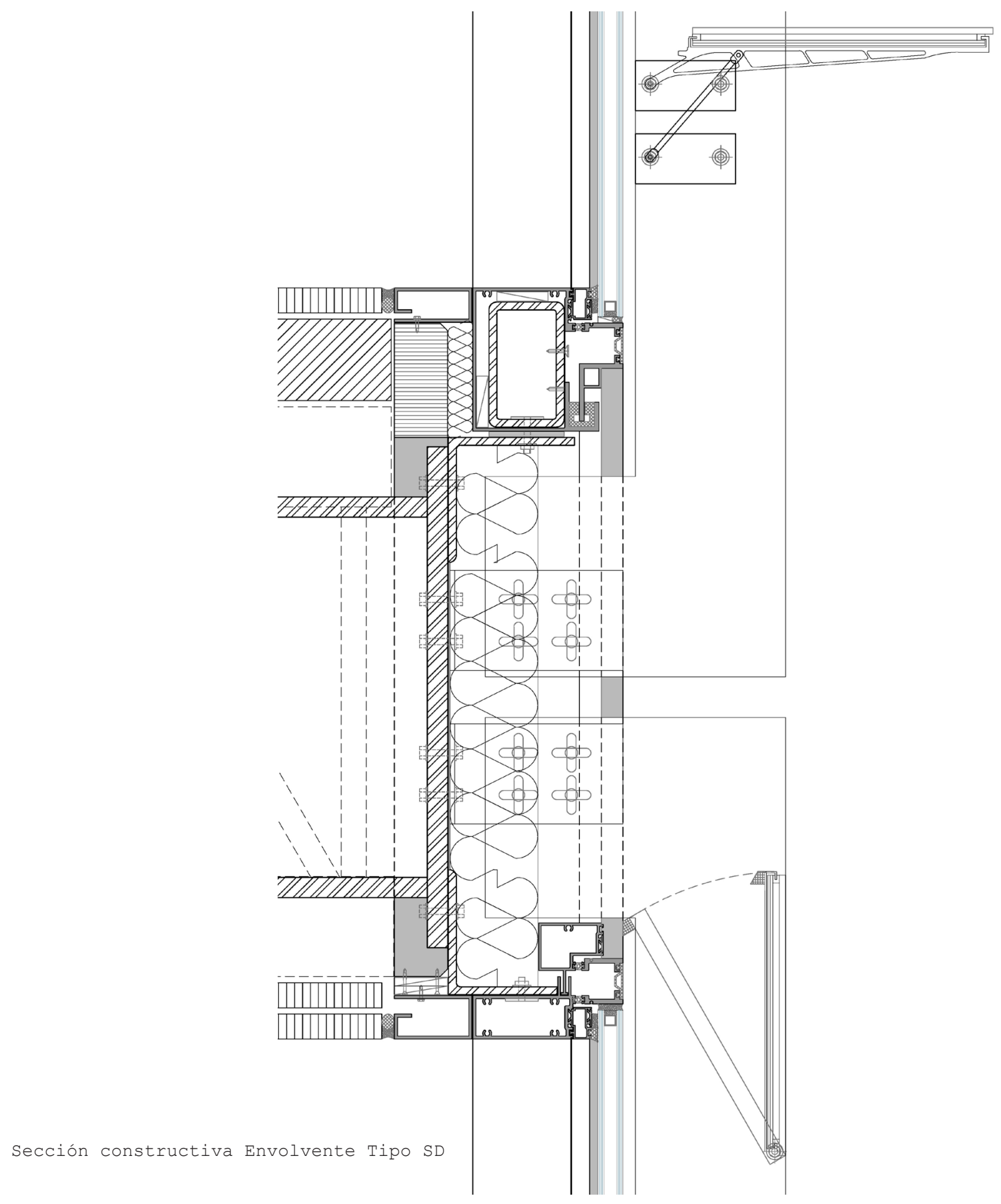



Finalmente, como quinta opción, este estudio propone diseñar una piel en la que, con el menor número de elementos posibles, se logre un rendimiento óptimo. Esta alternativa consiste en la inclinación de la envolvente de vidrio $20^{\circ}$ respecto a la vertical. Los análisis han demostrado que, mediante esta propuesta, los resultados son competitivos, lo que, combinándolo con mecanismos de control luminoso, la convierte en una opción que merece ser considerada. En este caso, el vidrio empleado es el Vidrio Tipo C.

A continuación se exponen los resultados relacionados con las cargas energéticas para la propuesta de Envolvente Tipo SE:

\begin{tabular}{|c|c|c|}
\hline \multicolumn{2}{|c|}{ Envolvente Tipo SE } \\
\hline & Calefacción & Refrigeración \\
\hline Triple Clear Spectra- & 7.7 & 28.5 \\
lly Selective Low-e & & \\
(\#2) tilted at an an- & & \\
gle $\theta: 20^{\circ}$ & & \\
\hline
\end{tabular}

El resultado en el interior de la fachada orientada al Sur para la Envolvente Tipo E se muestra a continuación.

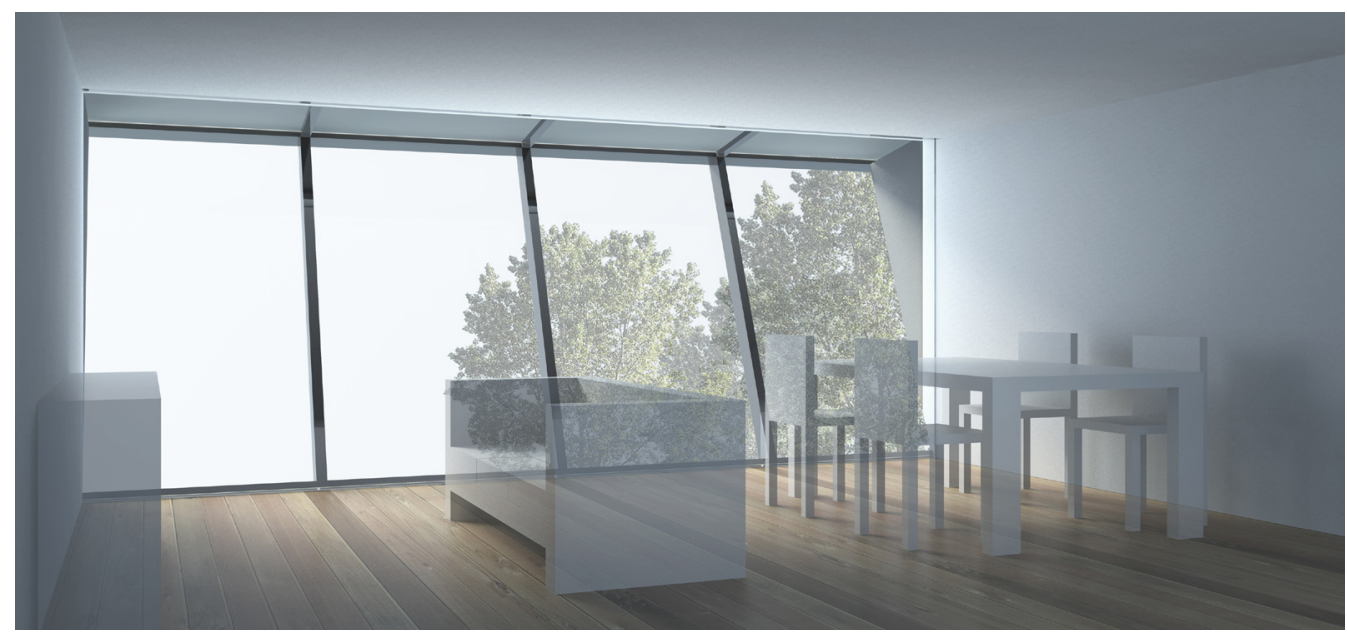


Una vez más, la instalación de la propuesta de la Envolvente Tipo SE se presenta paso a paso para explicar las diferentes partes.

A los pasos de la Envolvente Tipo SA hay que añadir el sistema de vidrio inclinado.

A continuación se exponen las imágenes que gráficamente explican el proceso, así como los gráficos que explican el comportamiento de la propuesta en verano y en invierno.

Por tanto, la Envolvente Tipo SE propone una piel en la que el vidrio seleccionado para las fachadas al sur se inclina $20^{\circ}$ para asegurar las ganancias de energía solar en invierno, y al mismo tiempo disminuir su entrada en verano. Mediante un número reducido de elementos, se ofrece otra alternativa al diseño de la envolvente para la orientación Sur. 
CAPÍTULO 05
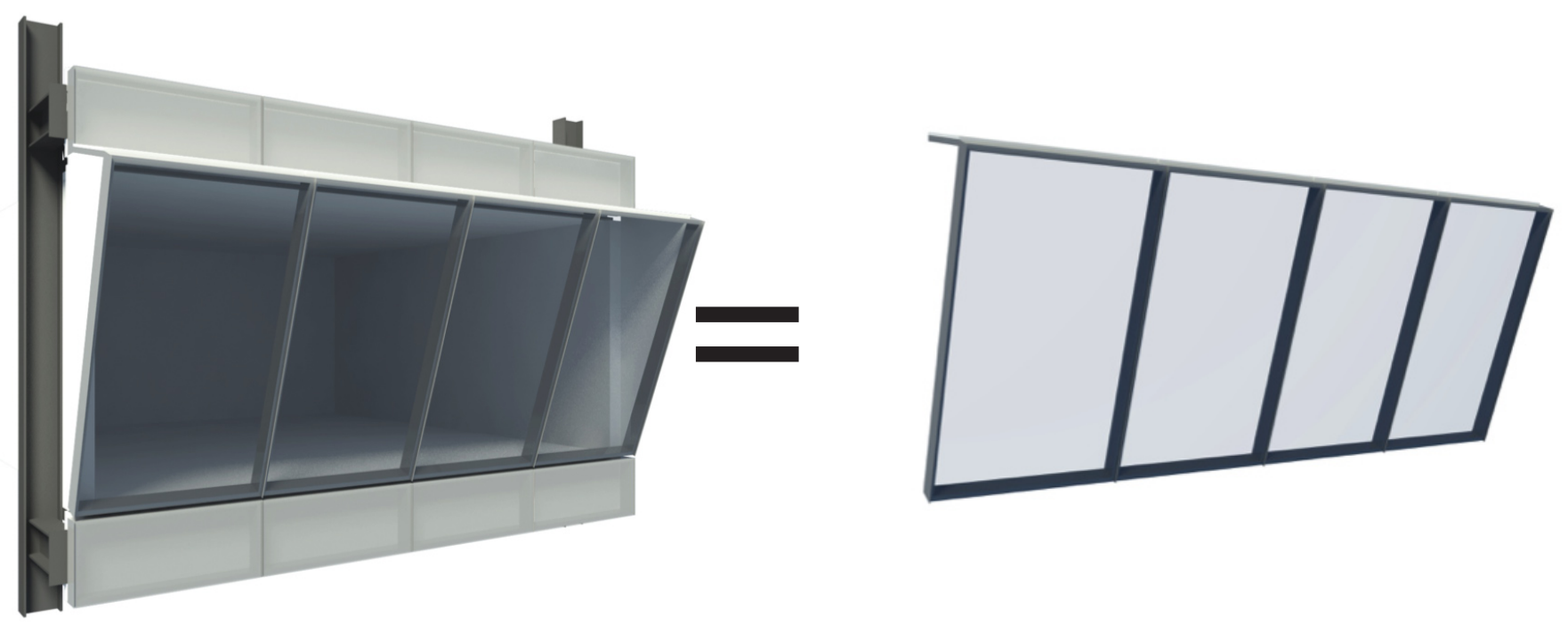

$+$
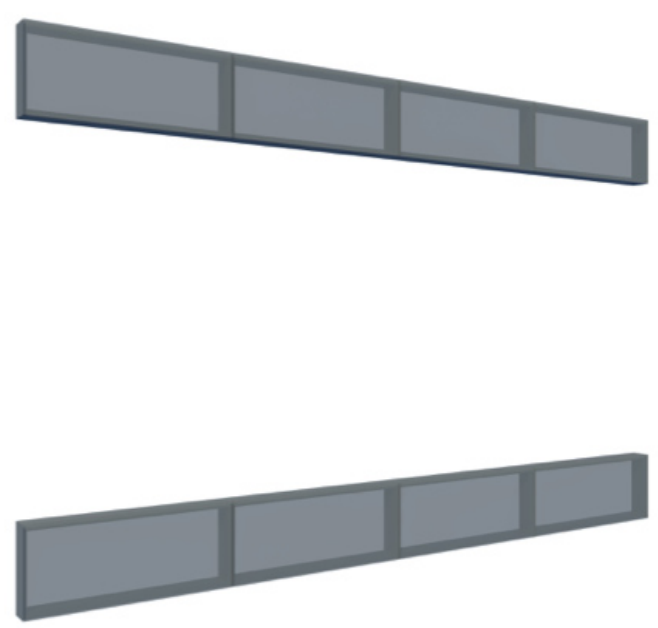
CAPÍTULO 05
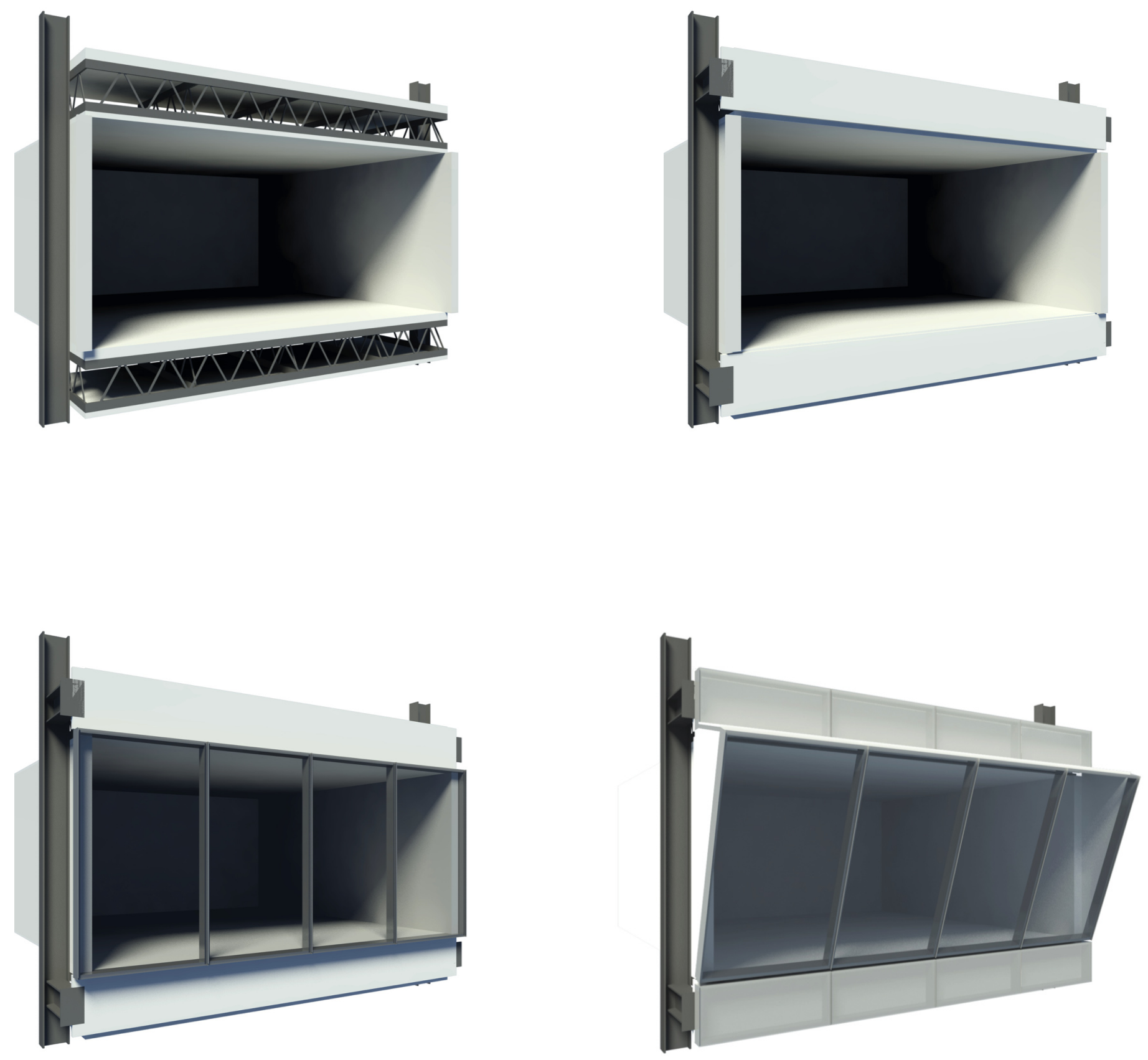


\section{CAPÍTULO 05}

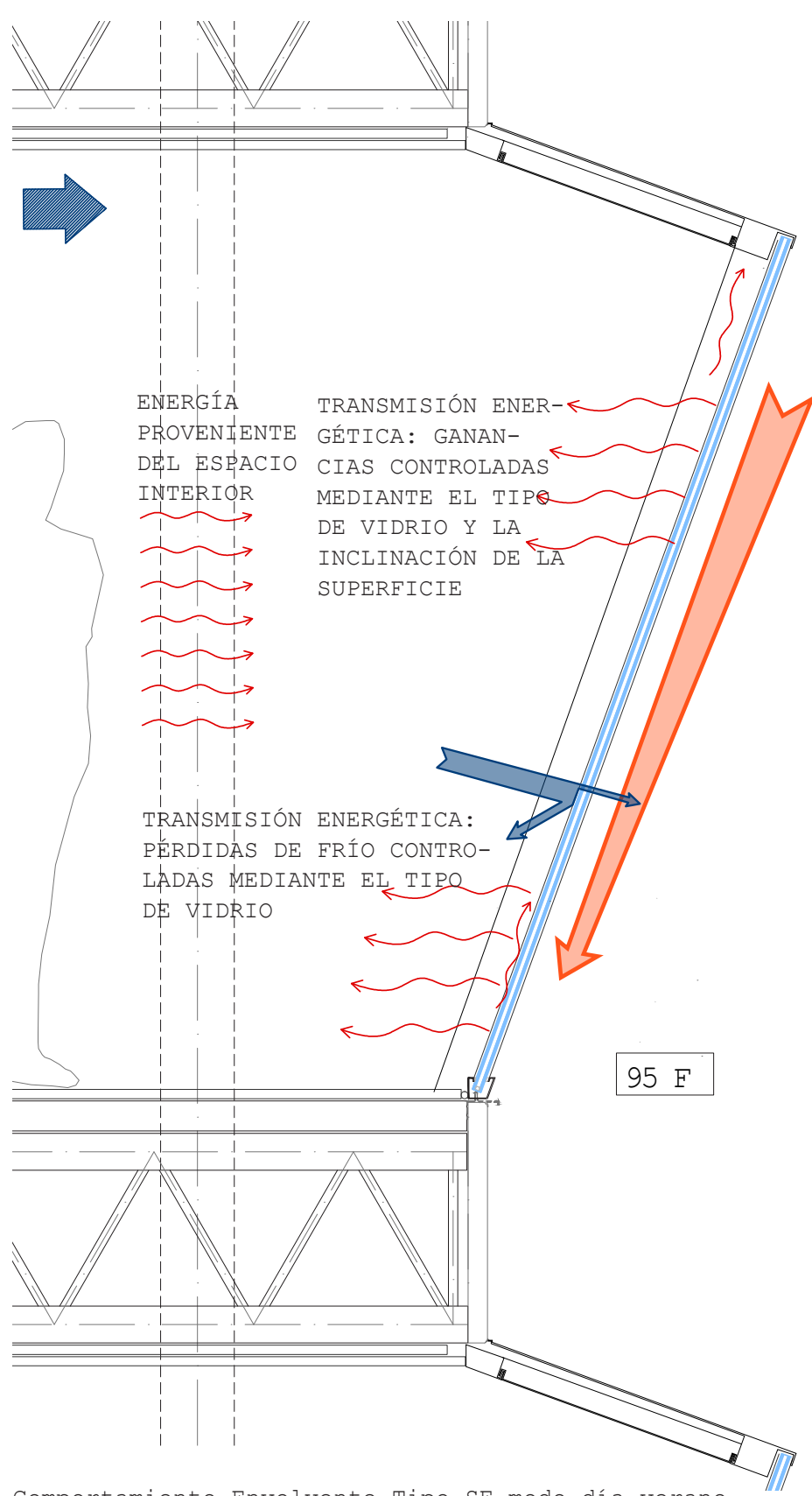

Comportamiento Envolvente Tipo SE modo día-verano
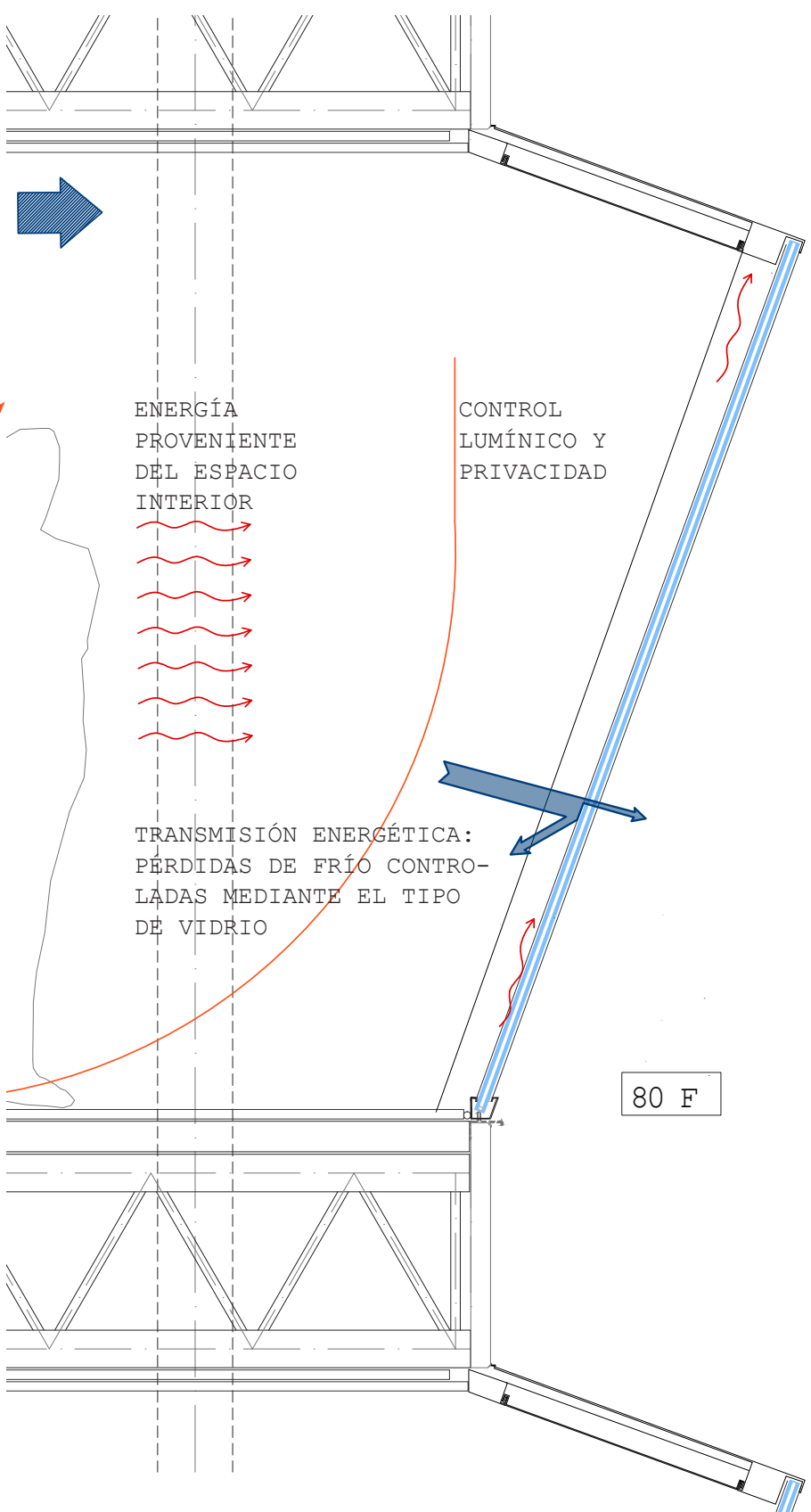

Comportamiento Envolvente Tipo SE modo noche-verano 


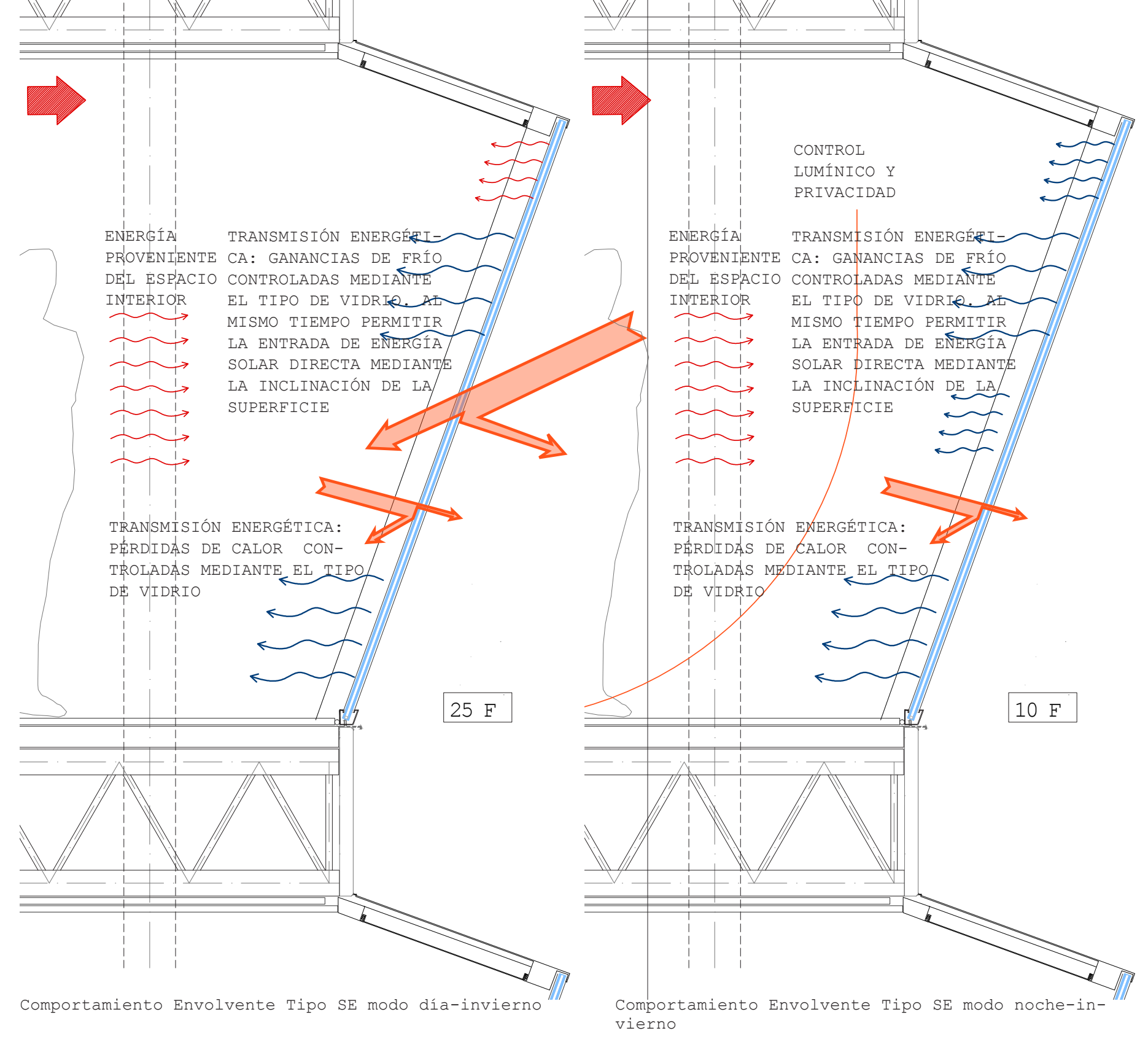


CAPÍTULO 05

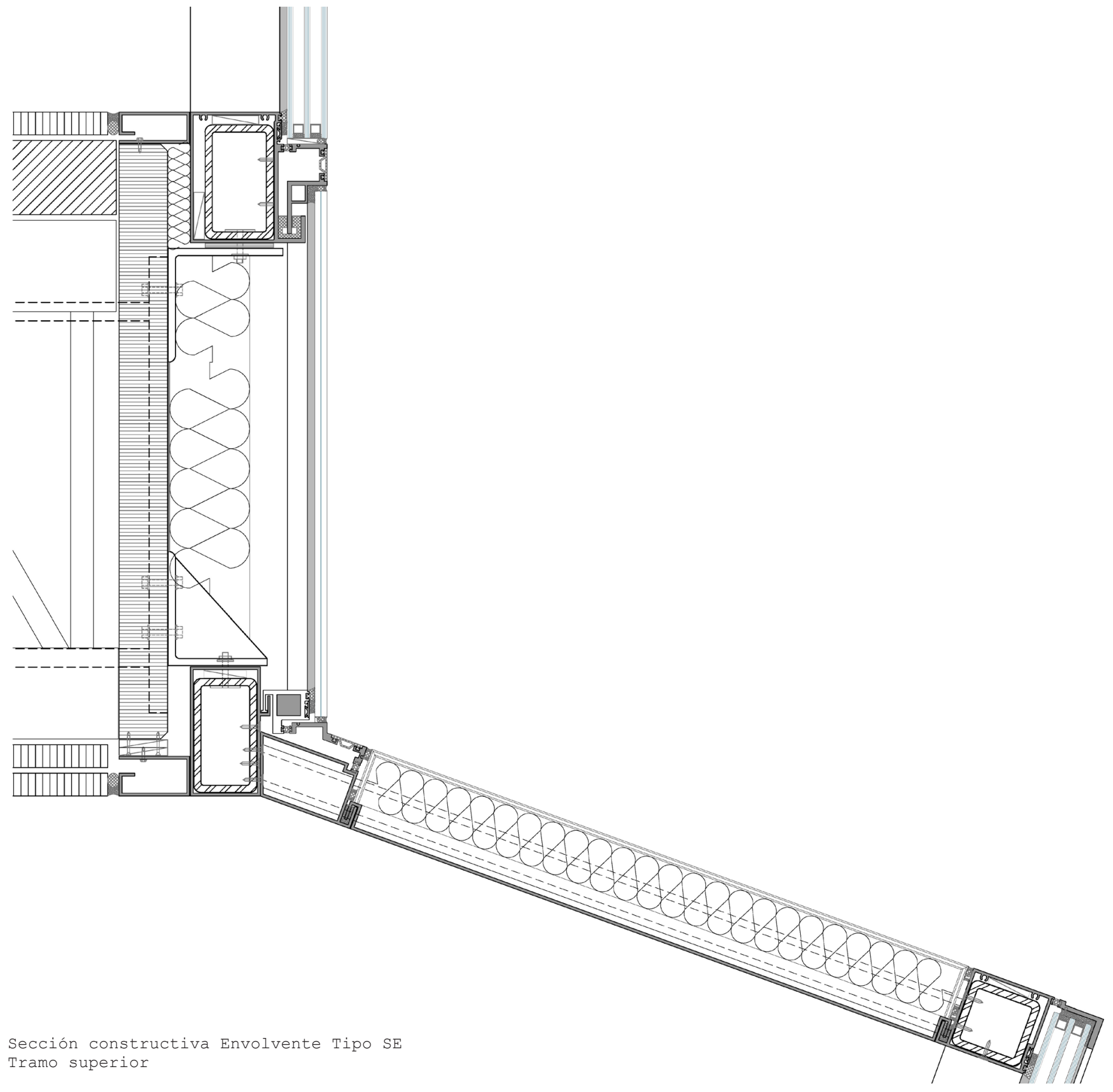


CAPÍTULO 05

Sección constructiva Envolvente Tipo SE Tramo Inferior

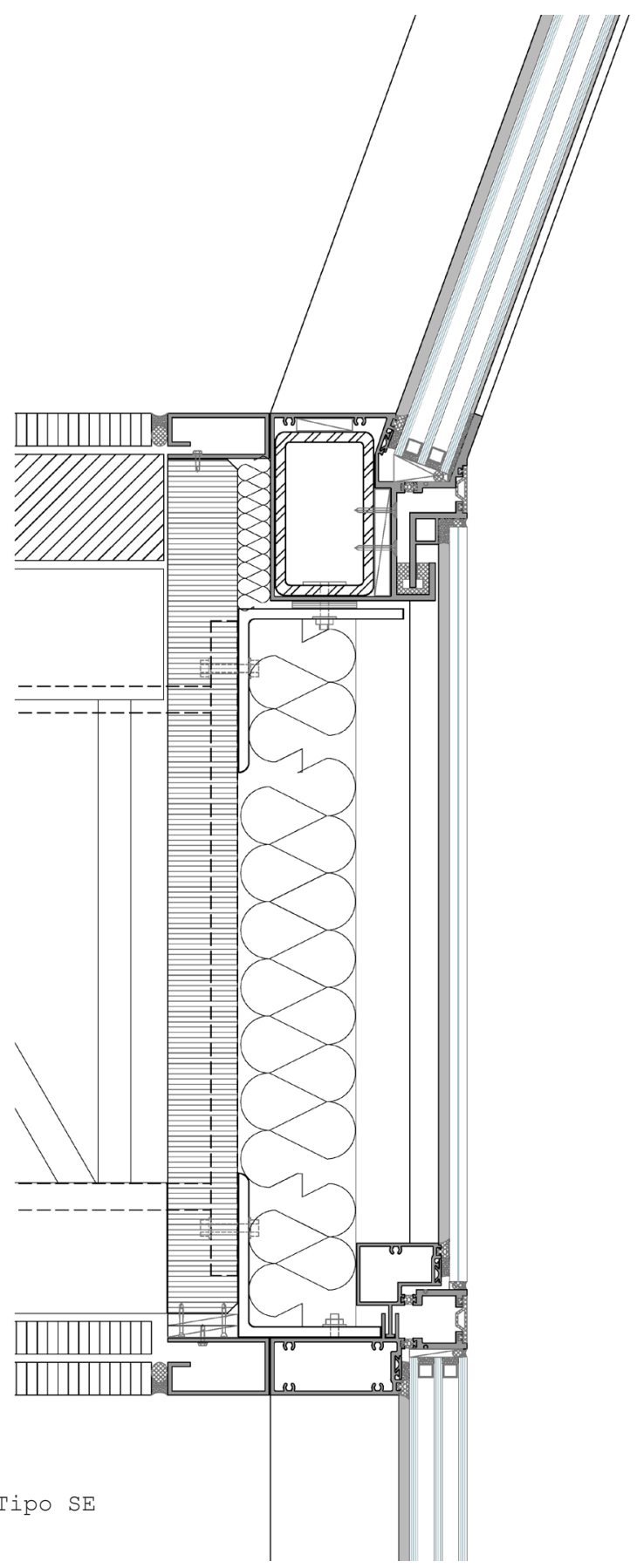





\subsubsection{Propuesta de Diseño para las Fachadas Este y Oeste}

Los análisis llevados a cabo muestran que las fachadas orientadas al Este y Oeste son especialmente sensibles a las ganancias energéticas y al sobrecalentamiento durante los meses de calor, al igual que durante el invierno lo son a las pérdidas energéticas.

Por un lado, estas dos orientaciones requieren vidrios con un bajo SHGC para reducir las ganancias en verano, principalmente durante las primeras horas del día en el Este y por la tarde en el Oeste. Para ello, la incorporación de revestimientos de baja emisivididad y espectro selectivo pueden evitar el exceso de ganancias energéticas sin afectar excesivamente la visibilidad exterior. Si se coloca en la superficie \#2, el calor se emite al exterior antes de que haya penetrado en el espacio.

Por otro lado, y esencialmente durante los meses más fríos, la fachada deberá proveer el aislamiento adecuado, con lo que el U-value debe también ser bajo. En segundo lugar, si el revestimiento de baja emisividad se coloca en la superficie \#5, como ocurría en el Norte, las pérdidas de calor serán menores.

En conclusión, en las fachadas al Este y al Oeste los requerimientos varían y, por ello, presentan mayor dificultad. A ello hay que añadir que debido al ángulo bajo de incidencia del sol, los mecanismos de control solar no siempre funcionan.

Los vidrios de mayor idoneidad son los anteriormente definidos como el Vidrio Tipo C y Tipo E.

\begin{tabular}{|c|c|}
\hline Vidrio Tipo C & Vidrio Tipo E \\
\hline $\begin{array}{c}\text { Triple Clear Spectrally Selective } \\
\text { Low-e (\#2) / Argon }\end{array}$ & $\begin{array}{c}\text { Triple Clear Spectrally Selective } \\
\text { Low-e (\#2 \& \#5) / Krypton }\end{array}$ \\
\hline $\begin{array}{c}\text { Grosor de vidrios: } \\
44\end{array}$ & Grosor de vidrios: \\
44 \\
\hline Uvalue: 1.0 & Uvalue: 0.7 \\
\hline SHGC: 0.342 & THGC: 0.403 \\
\hline Tvis: 0.627 & Tvis: 0.603 \\
\hline
\end{tabular}


También en este caso se han propuesto diferentes combinaciones y tipos de envolventes. La primera de las envolventes que se proponen para las fachadas Este y Oeste sugiere combinar el Vidrio Tipo E con un sistema de protección solar interior que, además de disminuir las cargas energéticas, ayudarán a controlar la entrada de luz difusa y a asegurar privacidad y control luminoso en los apartamentos de Lake Grove Village.

A continuación se exponen los resultados relacionados con las cargas energéticas para la propuesta de Envolvente Tipo E/WA:

\begin{tabular}{|c|c|c|}
\hline \multicolumn{2}{|c|}{ Envolvente Tipo E/WA } \\
\hline & Calefacción & Refrigeración \\
\hline Triple Clear Spectra- & 24.6 & 38.2 \\
lly Selective Low-e & & \\
(\#2, 5) with Interior & & \\
Movable Shading with & & \\
Reflective Exterior & & \\
Surface OF:3\%, R:0.47 & & \\
\hline
\end{tabular}

El resultado en el interior de la fachada orientada al Este / Oeste para la Envolvente Tipo E/WA se muestra a continuación.

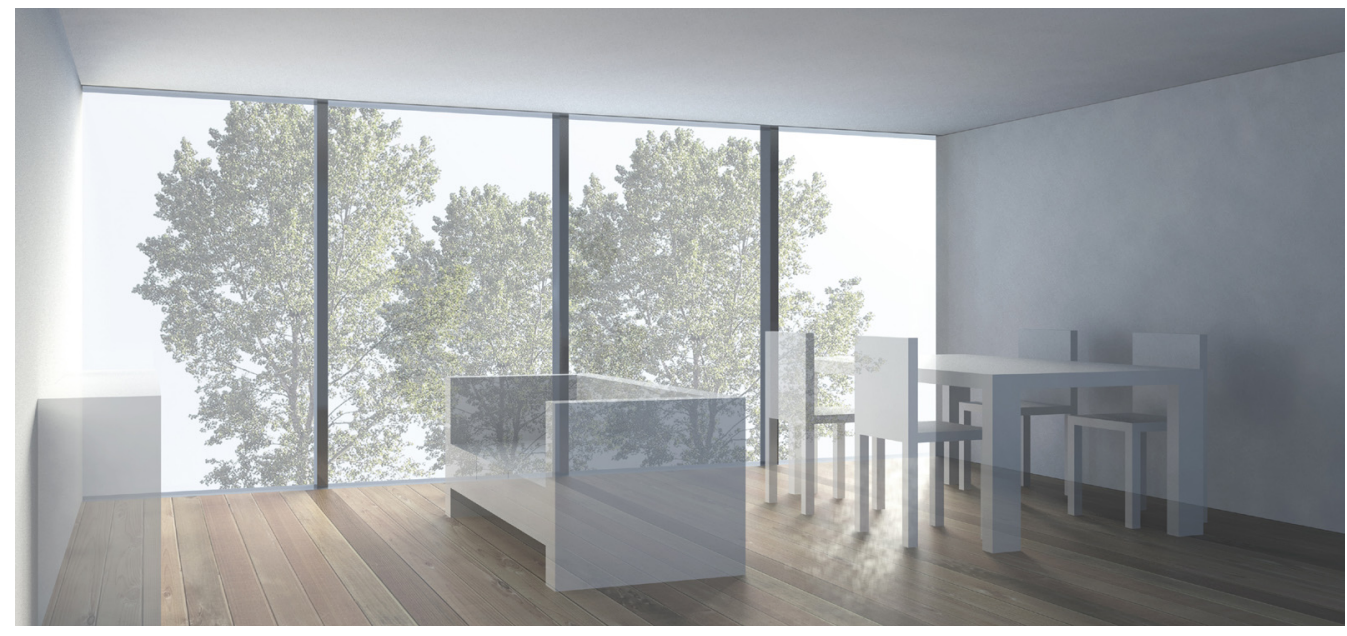


De manera similar a lo explicado para el resto de las fachadas, el diseño de la Envolvente Tipo E/WA toma en consideración la voluntad de respetar el concepto de prefabricación. Así, la instalación de las propuestas se presentan paso a paso. La Envolvente Tipo E/WA consta de cuatro pasos cuyas imágenes se explican a continuación.

En un primer lugar, se muestra el módulo existente, orientado al Este y Oeste, donde la estructura queda expuesta tras retirar del sitio el panel del frente del forjado. En segundo lugar, se ancla una estructura auxiliar a los pilares principales del edificio; esta estructura es la encargada de trasladar las cargas de la nueva envolvente de vidrio a la estructura principal del edificio. El tercer paso consiste en colocar el panel original que anteriormente se había retirado. En cuarto lugar, se instalan los módulos de carpintería para luego completar la envolvente y colocar los nuevos paneles de recubrimiento y los mecanismos de control solar interiores.

A continuación se exponen las imágenes que gráficamente explican el proceso y componentes de la nueva envolvente, así como los mecanismos que se han estudiado acerca del comportamiento de la fachada propuesta en verano y en invierno.

Por tanto, la Envolvente Tipo E/WA propone una piel en la que el vidrio -mediante las dos capas de baja emisividad- ayuda a controlar las ganancias energéticas en verano y a evitar las pérdidas de calor en invierno. Éste se combina con un sistema de protección solar interior que, principalmente, contribuyen al control de los niveles de iluminación, la privacidad y parte de la radiación. 
CAPÍTULO 05

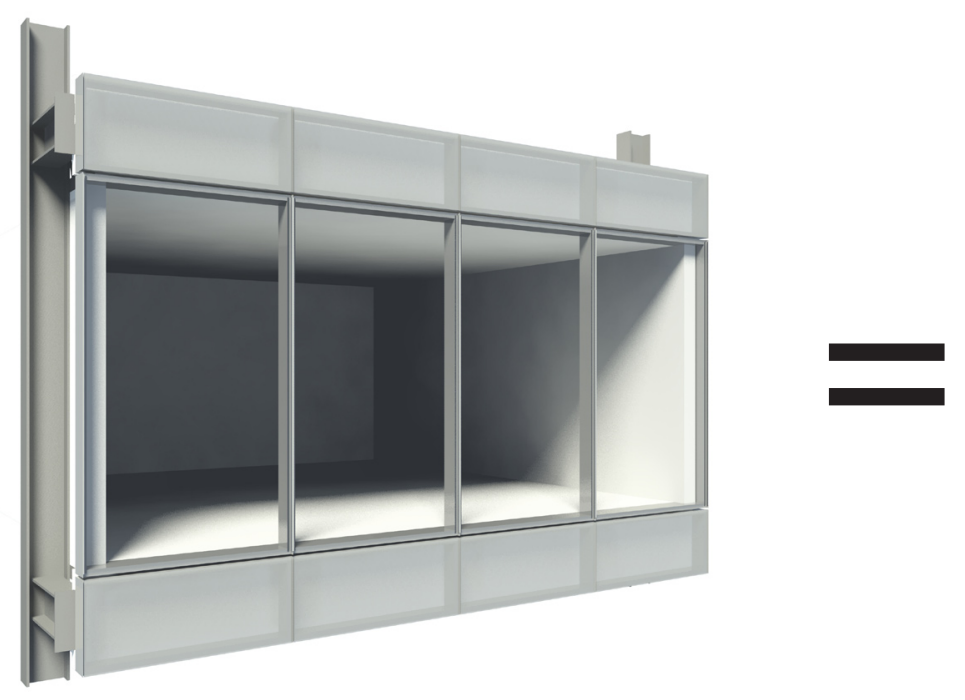

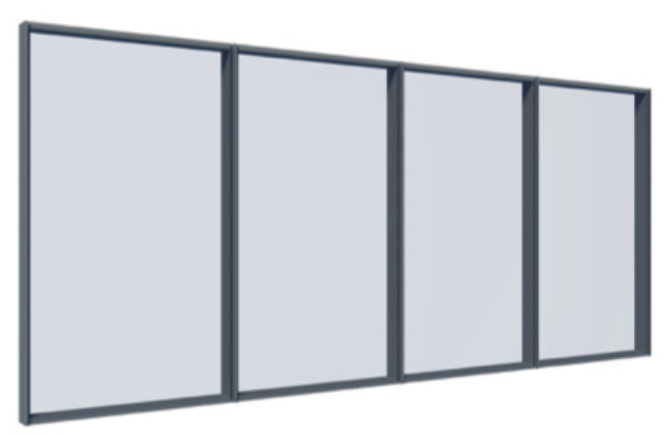

$+$
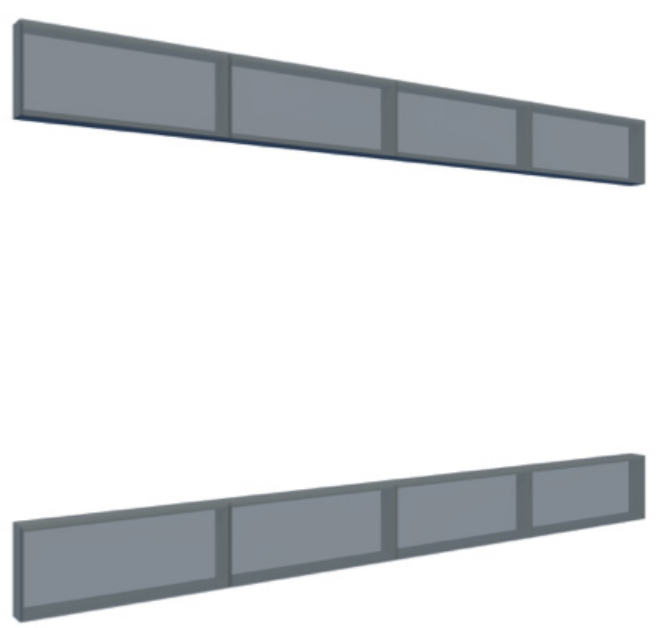
CAPÍTULO 05
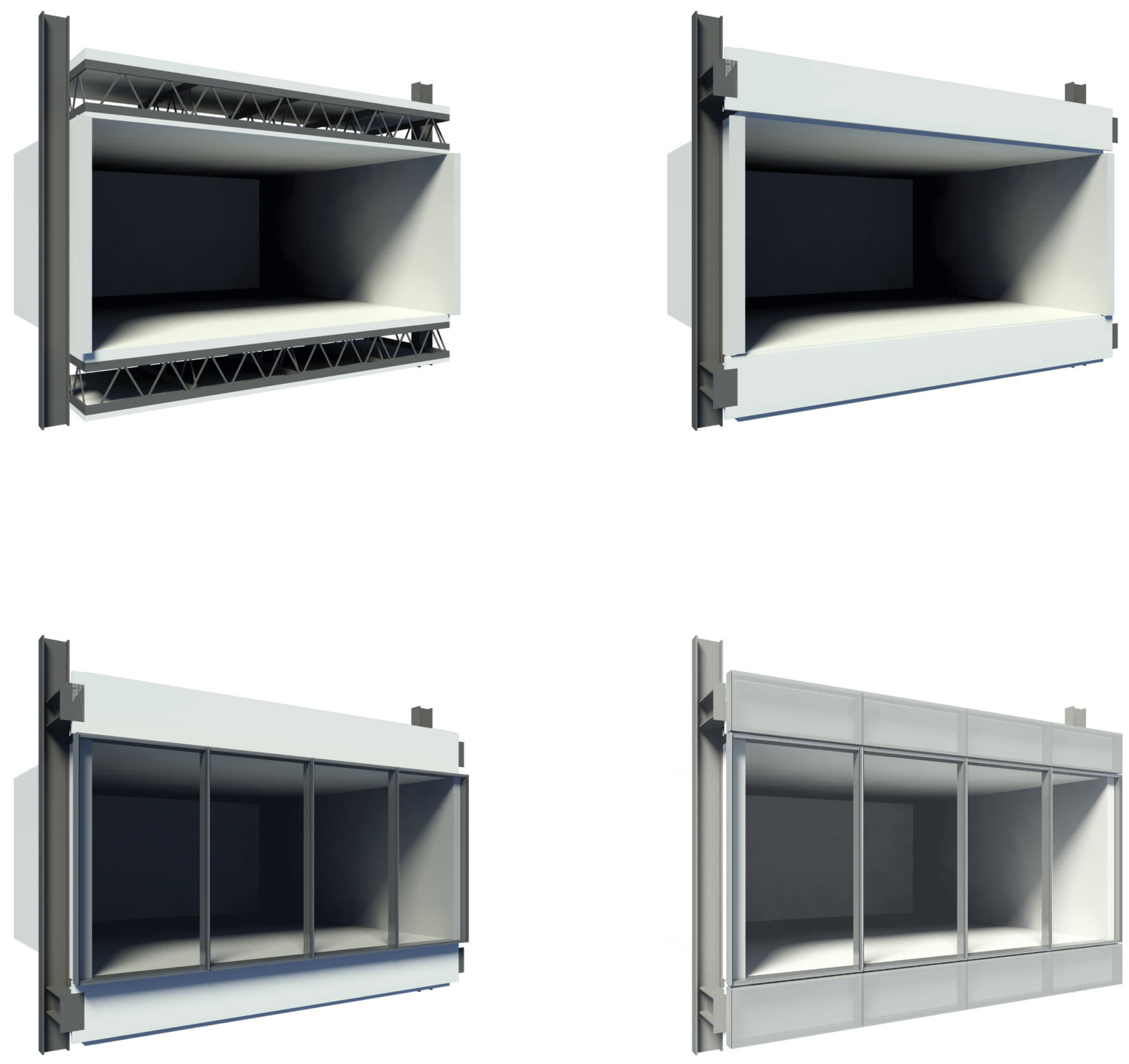


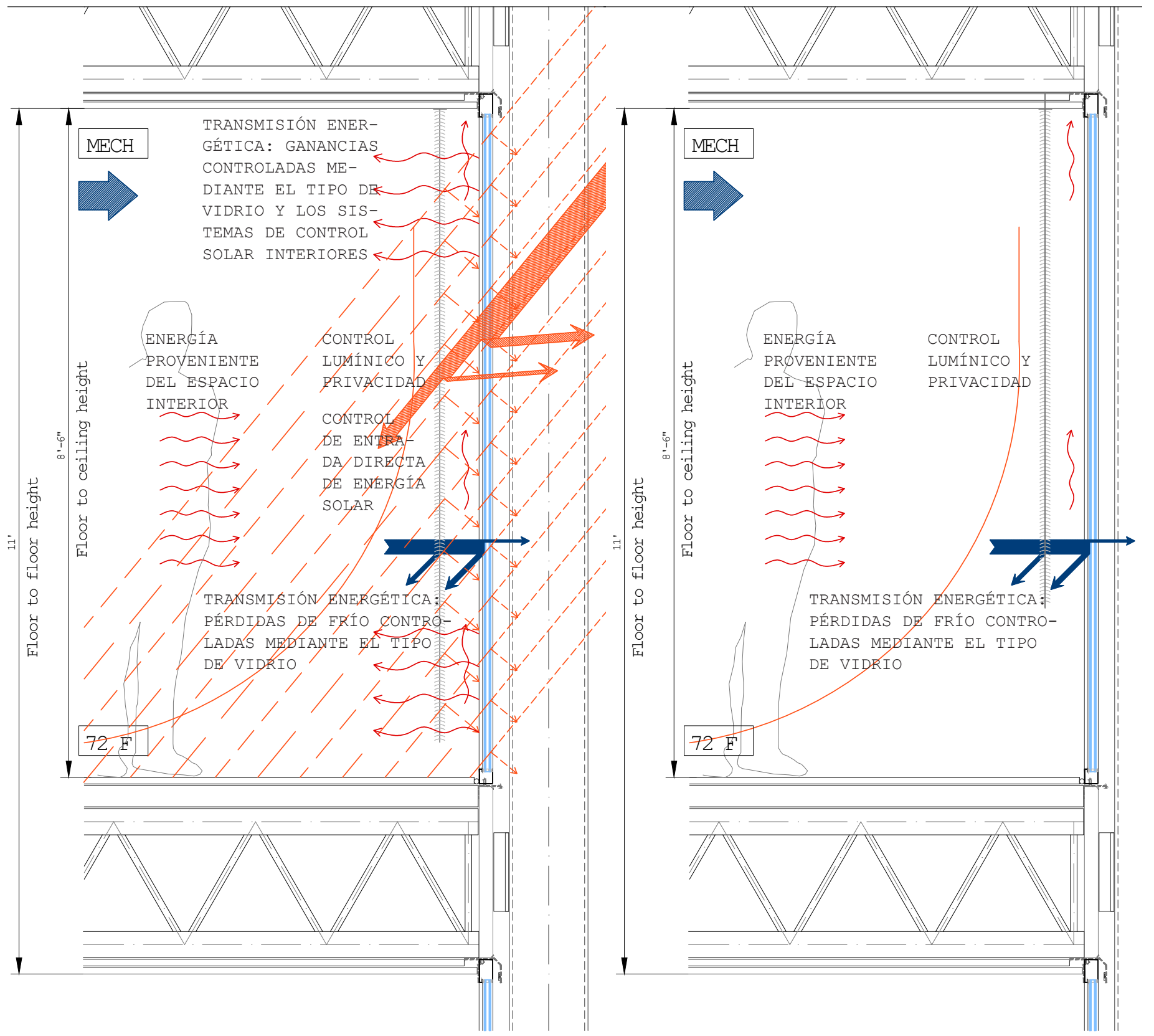


CAPÍTULO 05

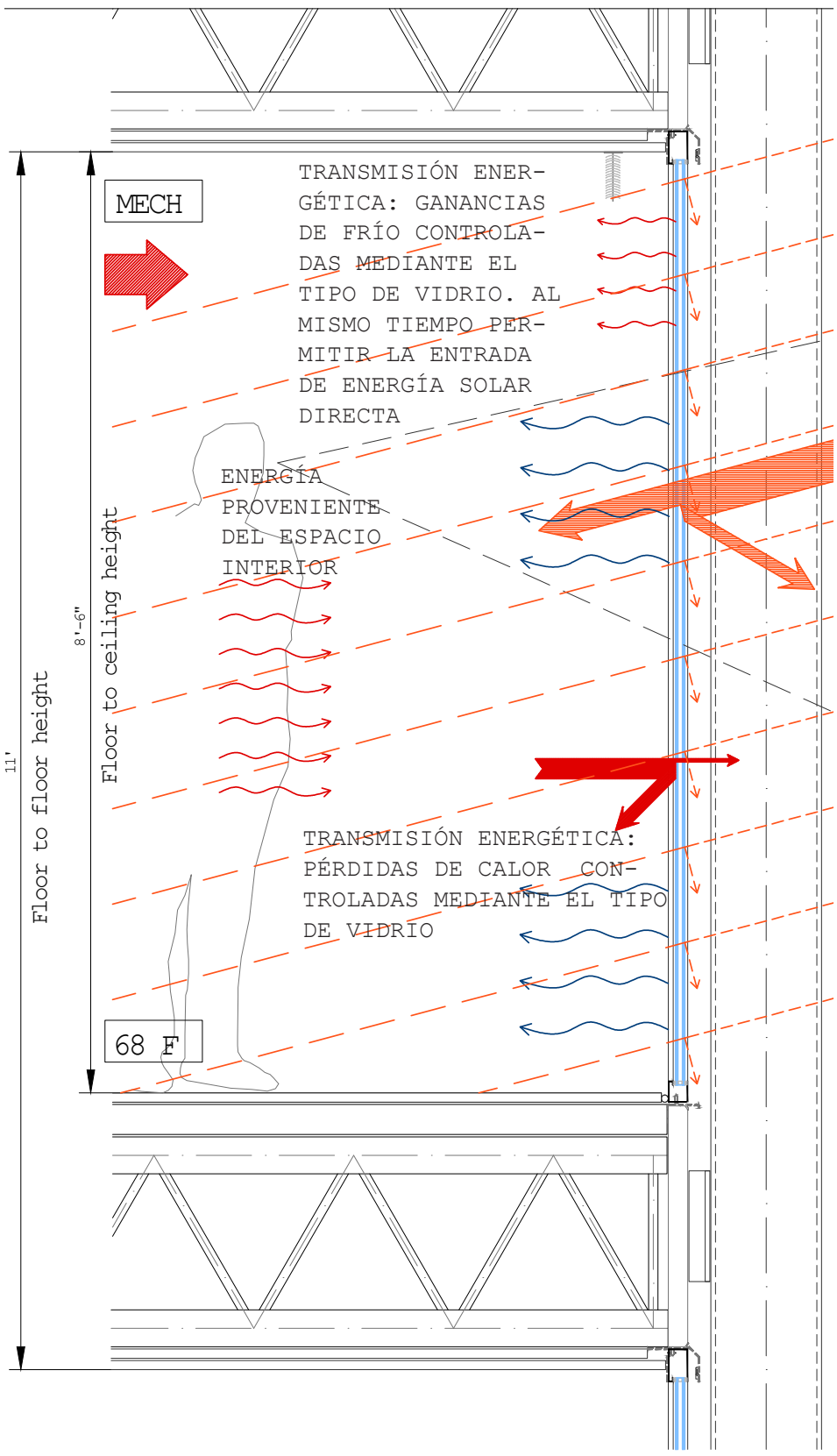

Comportamiento Envolvente Tipo E/WA modo día-invierno

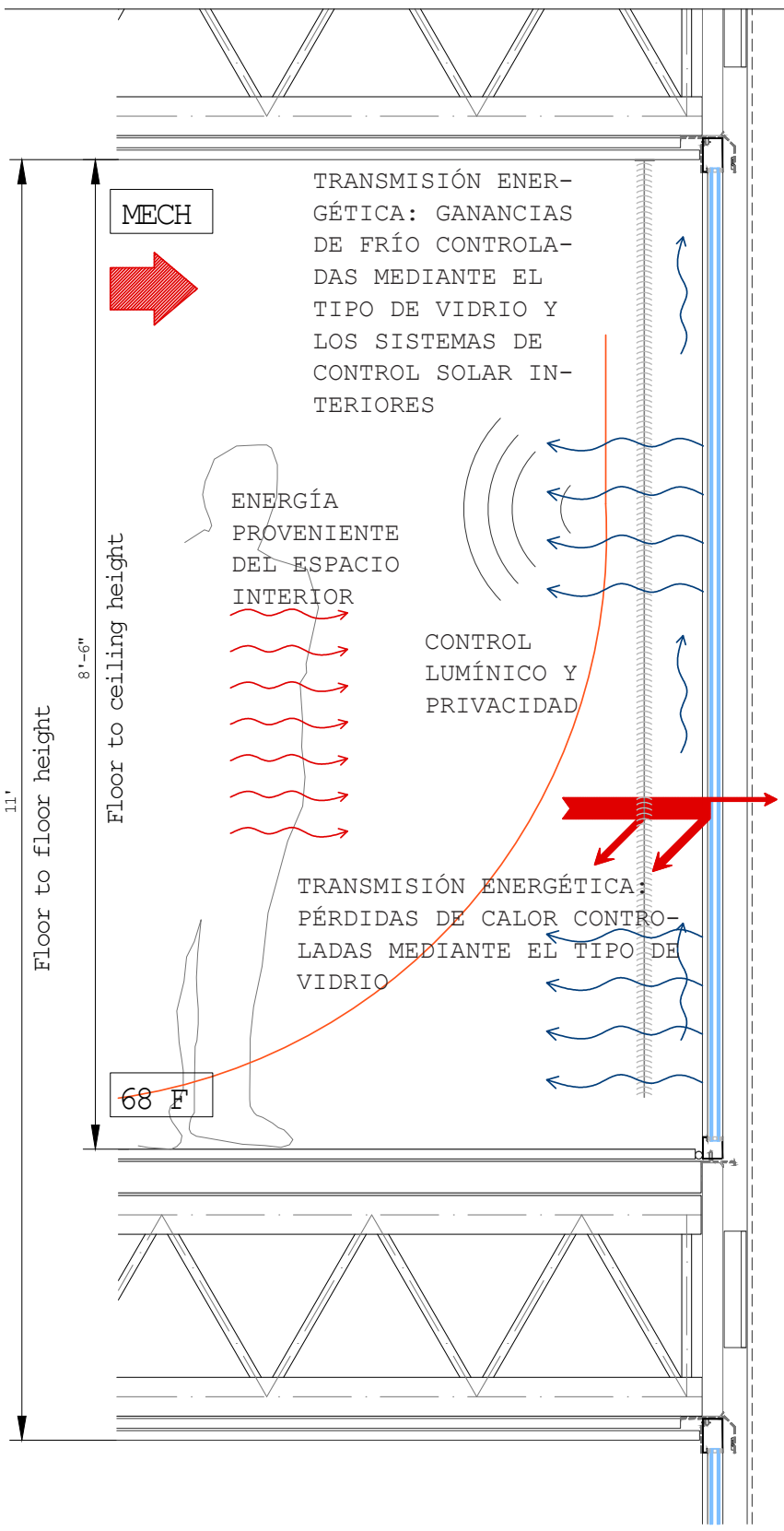

Comportamiento Envolvente Tipo E/WA modo nocheinvierno 
CAPÍTULO 05

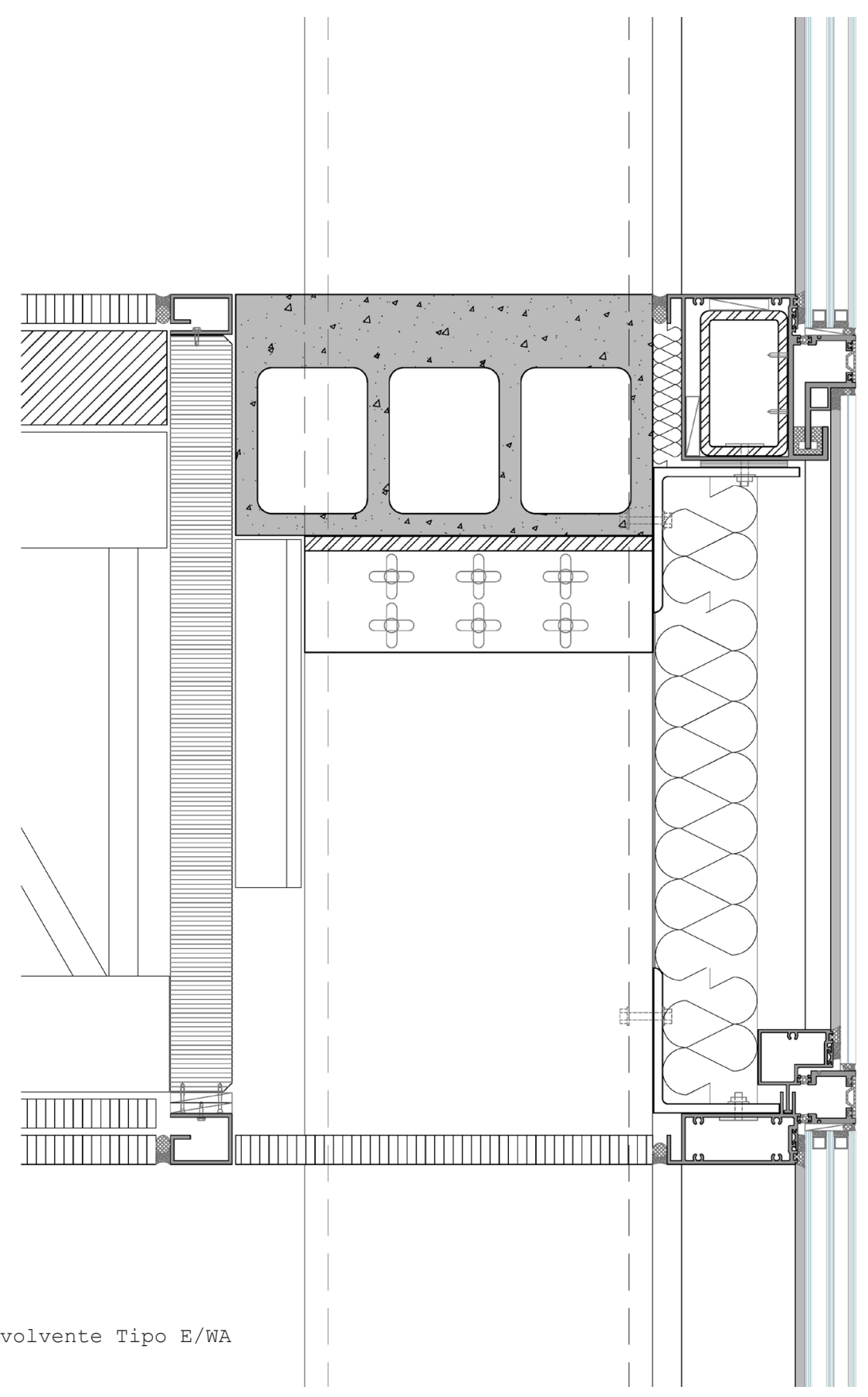



Con el fin de mejorar el rendimiento de la fachada, la segunda opción propone combinare el Vidrio Tipo C con un sistema de lamas verticales exteriores como mecanismos de protección solar. Como se ha explicado con anterioridad, debido al bajo ángulo de incidencia del sol, los sistemas verticales presentan mayores ventajas que los horizontales para ambas orientaciones. De lo contrario, la proyección debería ser excesivamente porlongada para ser efectiva.

A continuación se exponen los resultados relacionados con las cargas energéticas para la propuesta de Envolvente Tipo E/WB:

\begin{tabular}{|c|c|c|}
\hline \multicolumn{2}{|c|}{ Envolvente Tipo E/WB } \\
\hline & Calefacción & Refrigeración \\
\hline $\begin{array}{c}\text { Triple Clear Spectra- } \\
\text { ly Selective Low-e }\end{array}$ & 27.7 & 11.6 \\
(\#2) with Exterior & & \\
Movable Laminated Ho- \\
rizontal Glass Louvers \\
(FC: 0.1)
\end{tabular}

El resultado en el interior de la fachada orientada al Este / Oeste para la Envolvente Tipo E/WB se muestra a continuación.

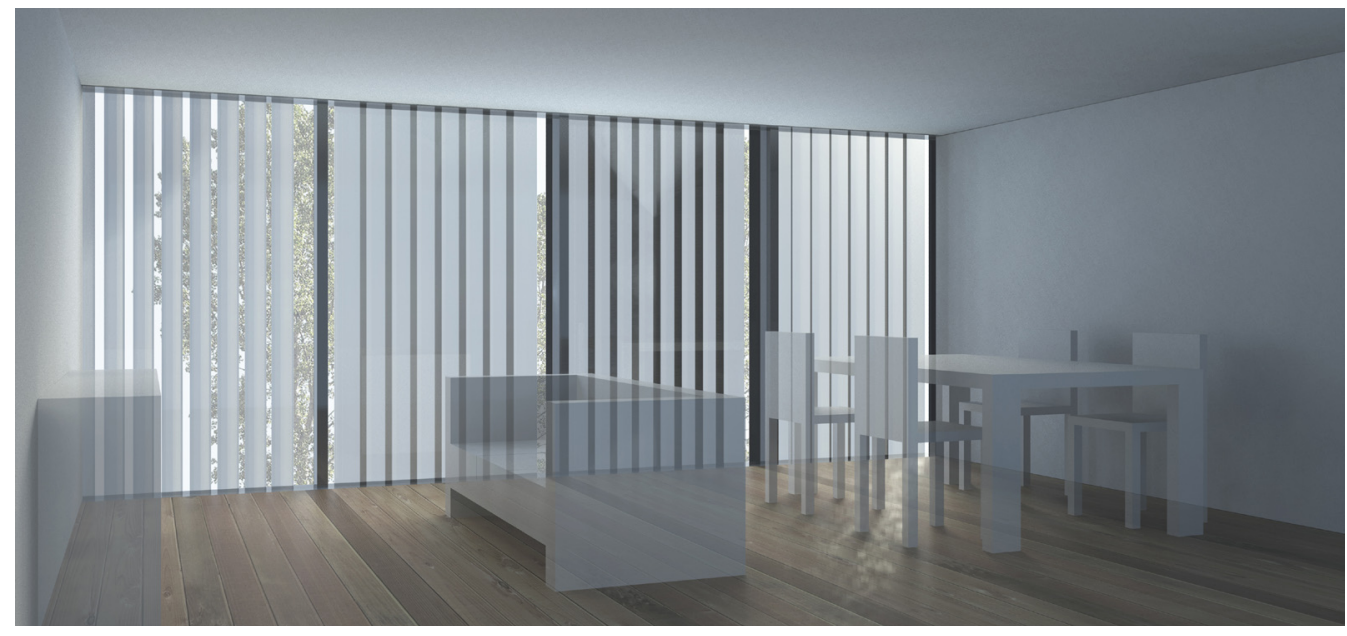


La instalación de la Envolvente Tipo E/WB se presenta en las imágenes que aparecen a continuación paso a paso.

A la Envolvente Tipo E/WA se instalan los sistemas de protección solar verticales para completar la envolvente.

A continuación se exponen las imágenes que gráficamente explican el proceso, así como aquéllas que muestran el comportamiento de la fachada tano en verano como en invierno.

Por tanto, la Envolvente Tipo E/WB crea un sistema de capas en el que la combinación del vidrio de baja emisividad, para evitar la entrada de energía solar en verano, con el cierre hermético de las lamas verticales, mejora las propiedades aislantes del sistema. El sistema permite asímismo controlar la entrada de energía solar antes de entrar en contacto con la superficie del vidrio. En conclusión, el sistema posee una serie de características que permiten dotar de mayor comodidad al espacio interior y mejorar el rendimiento del conjunto. 
CAPÍTULO 05
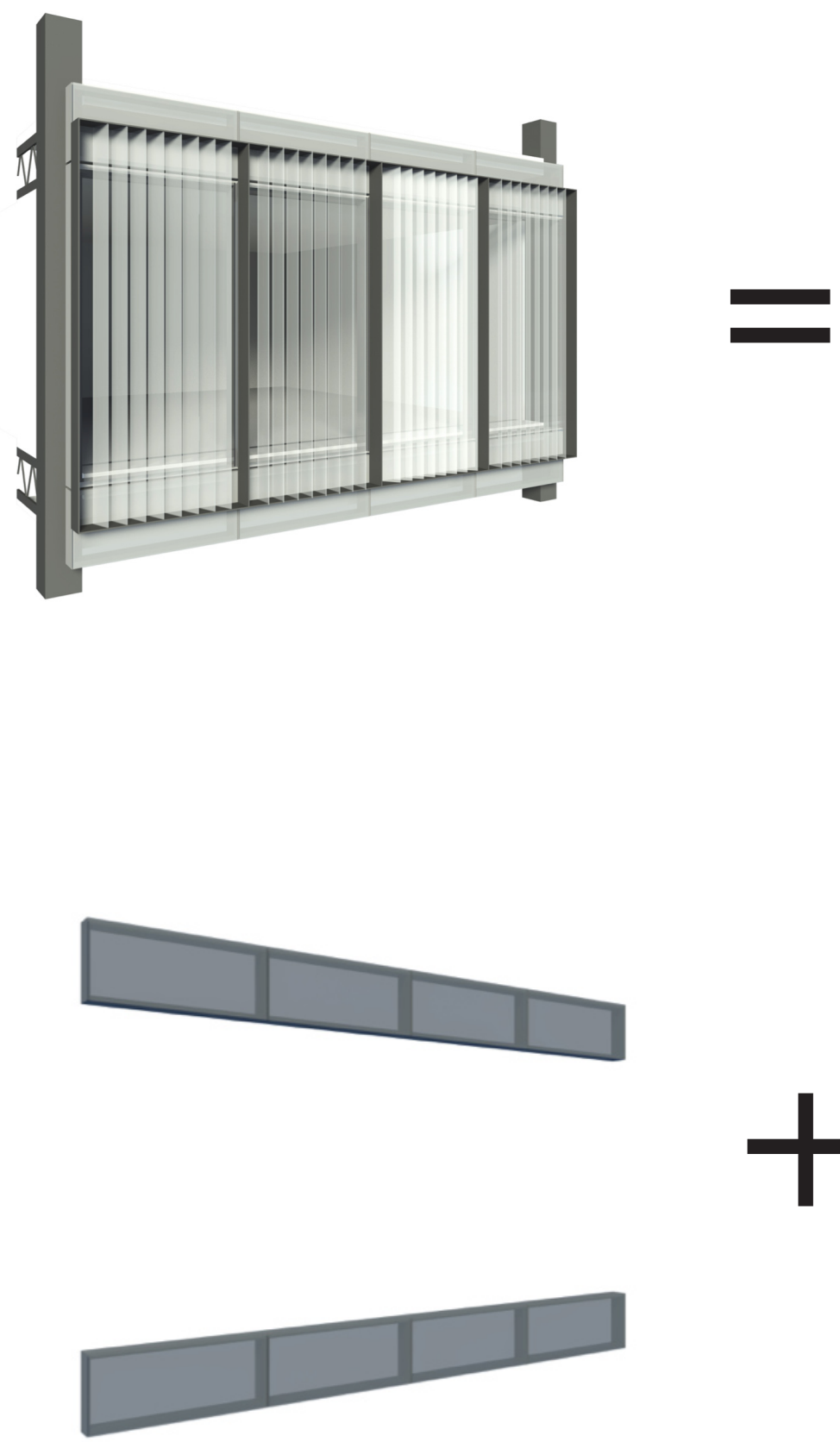

$+$
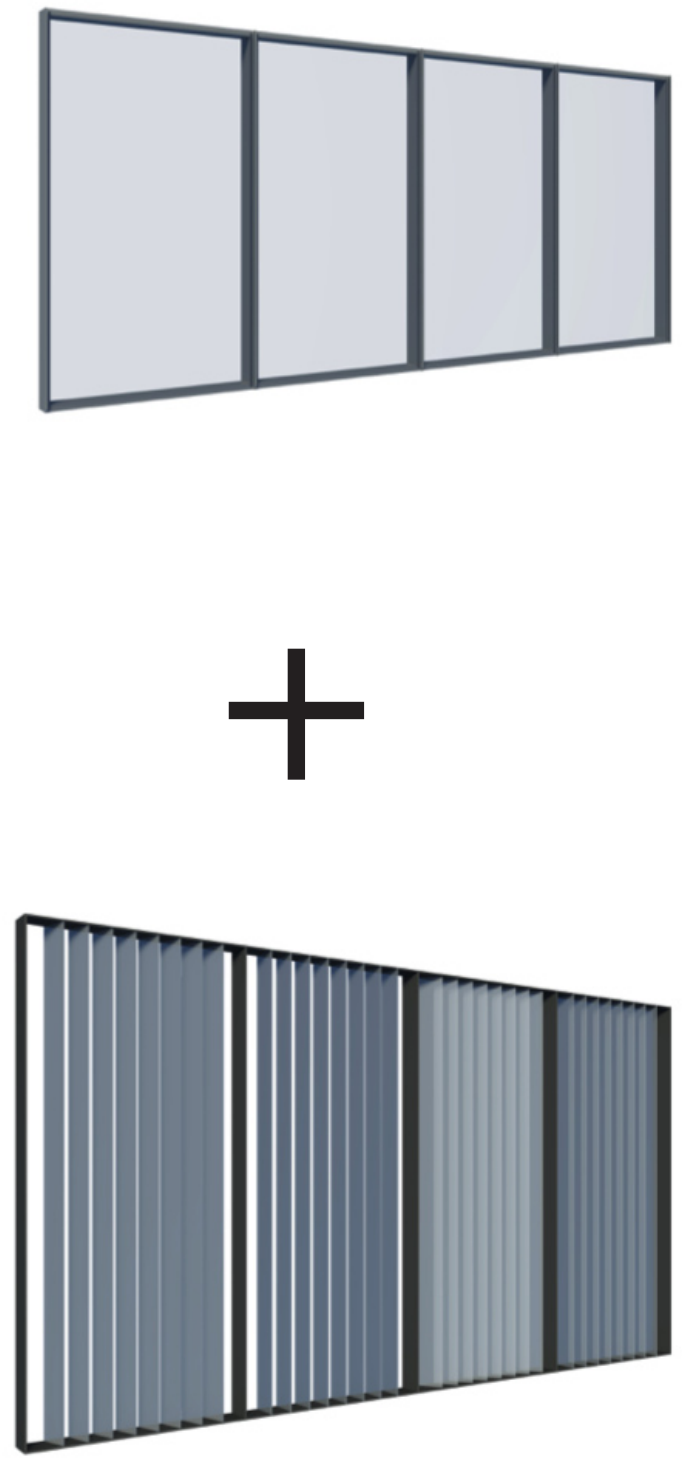
CAPÍTULO 05
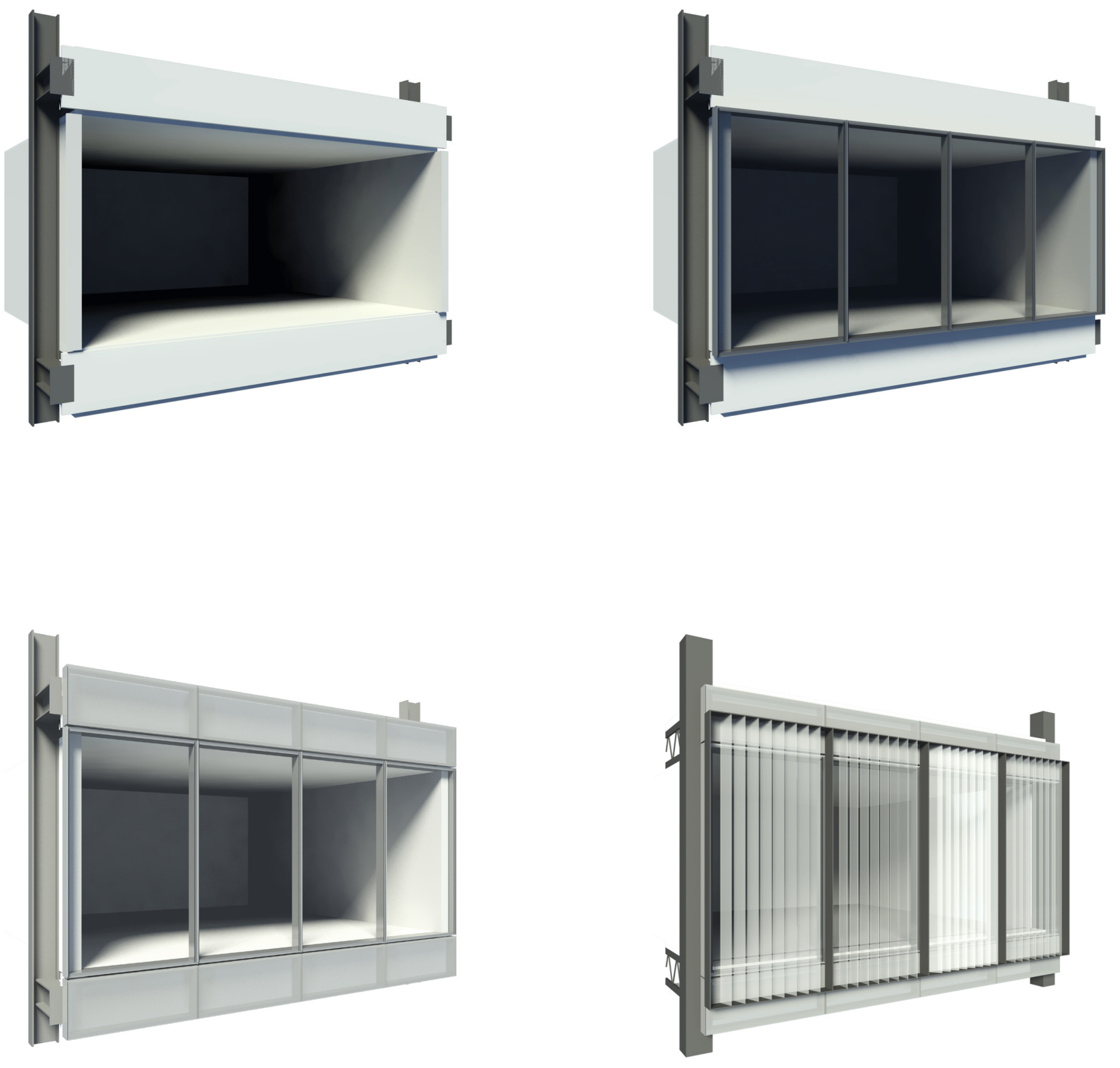


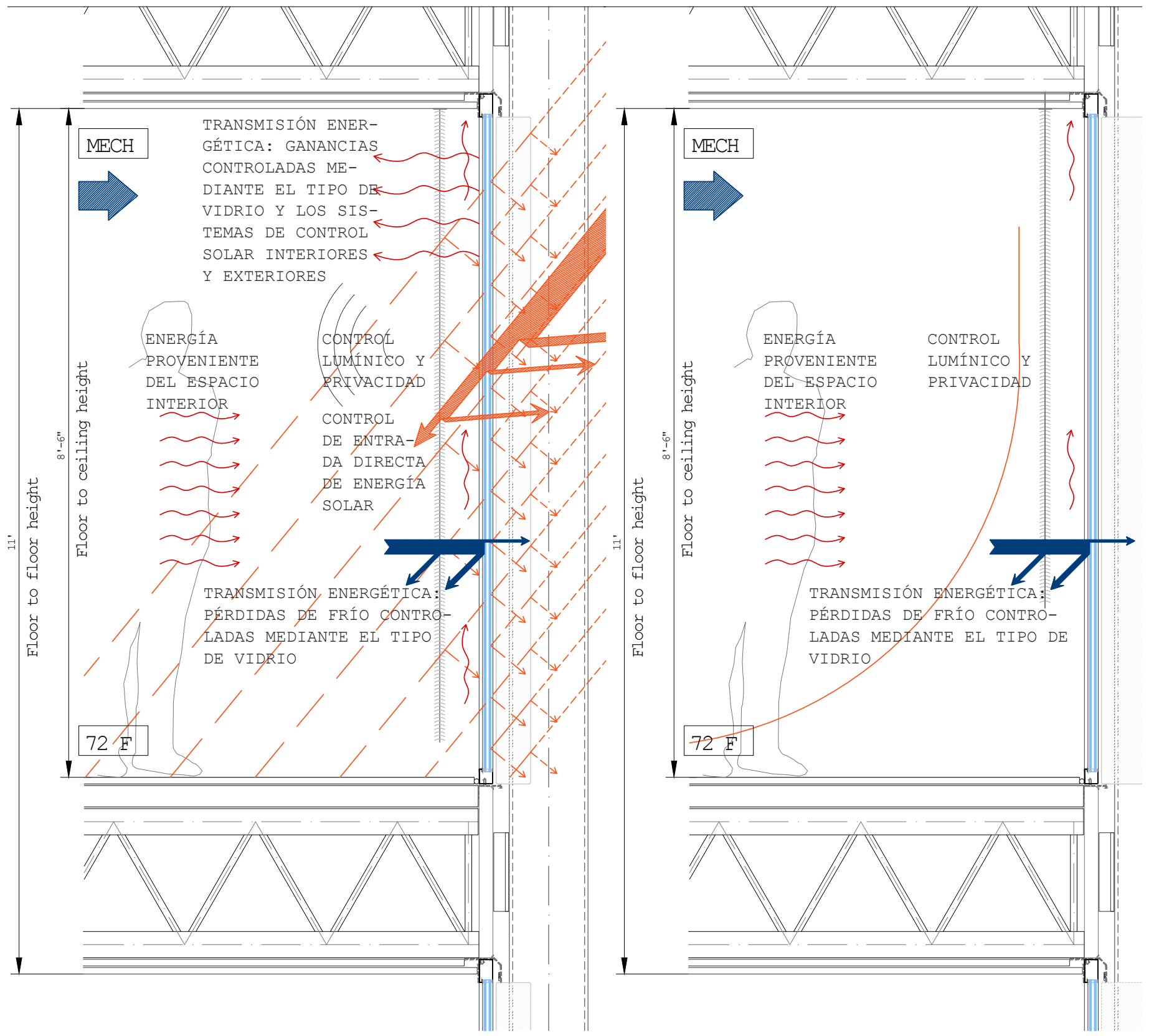


CAPÍTULO 05

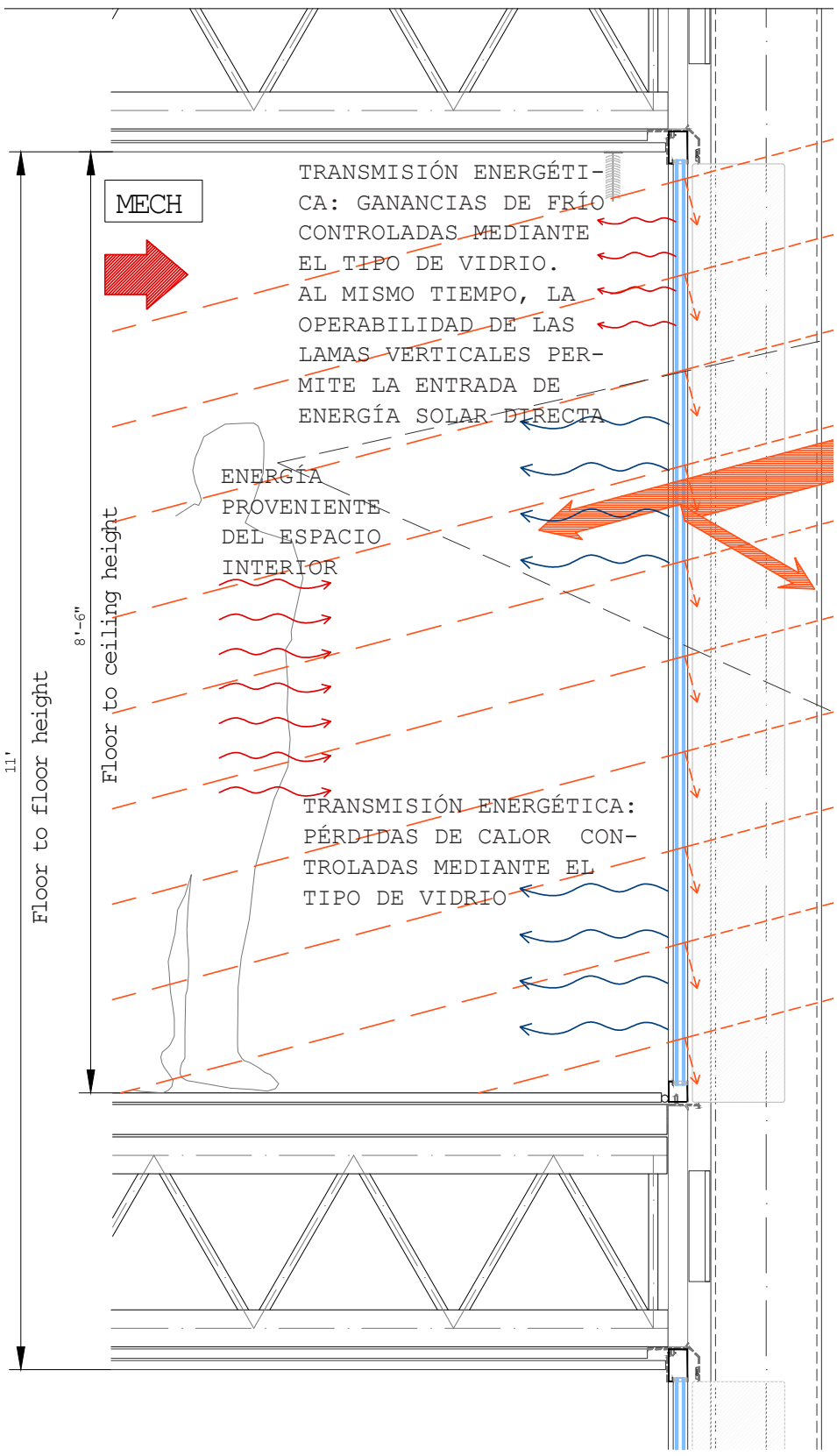

Comportamiento Envolvente Tipo E/WB modo día-invierno

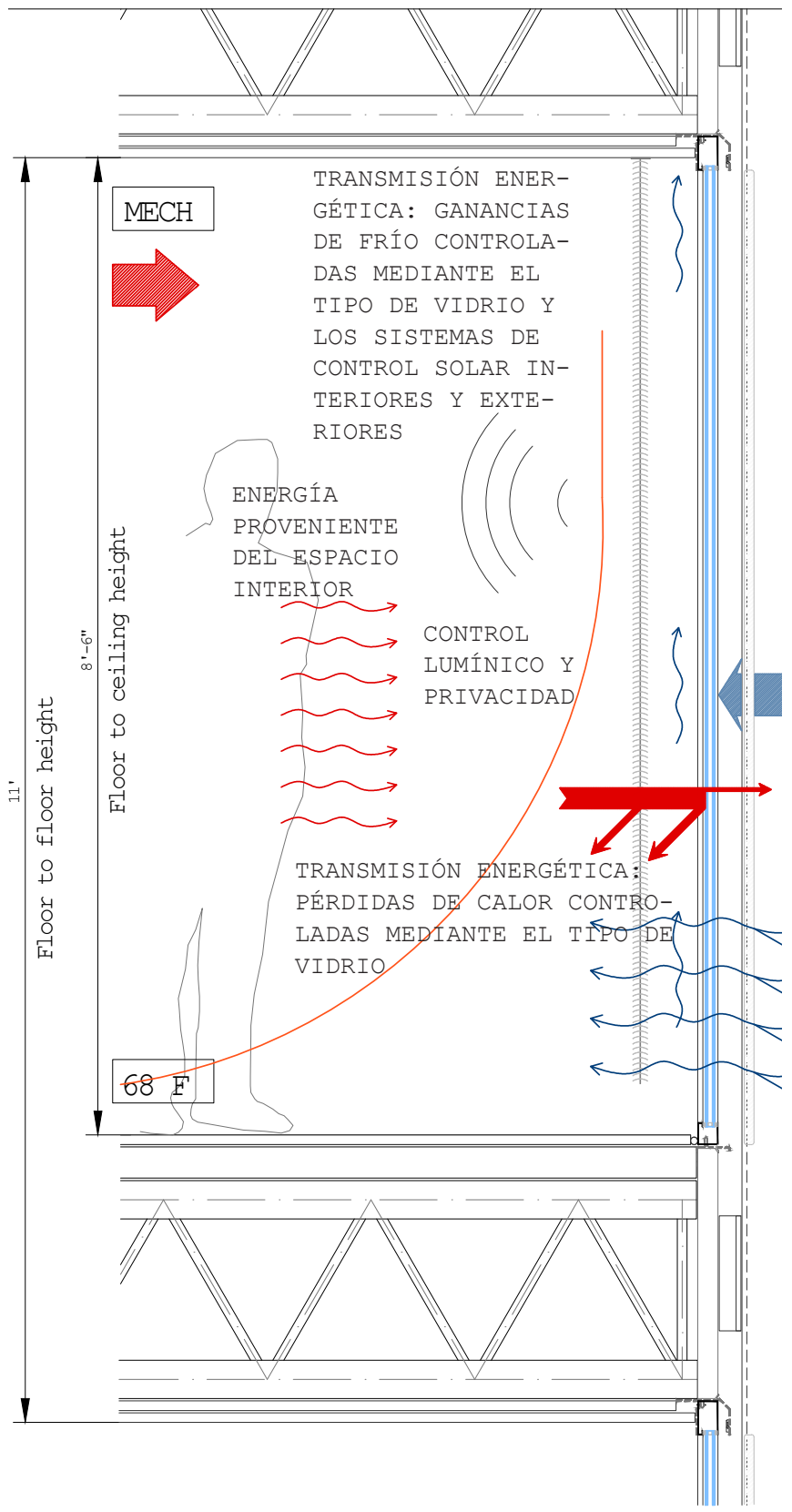

Comportamiento Envolvente Tipo E/WB modo nocheinvierno 
CAPÍTULO 05

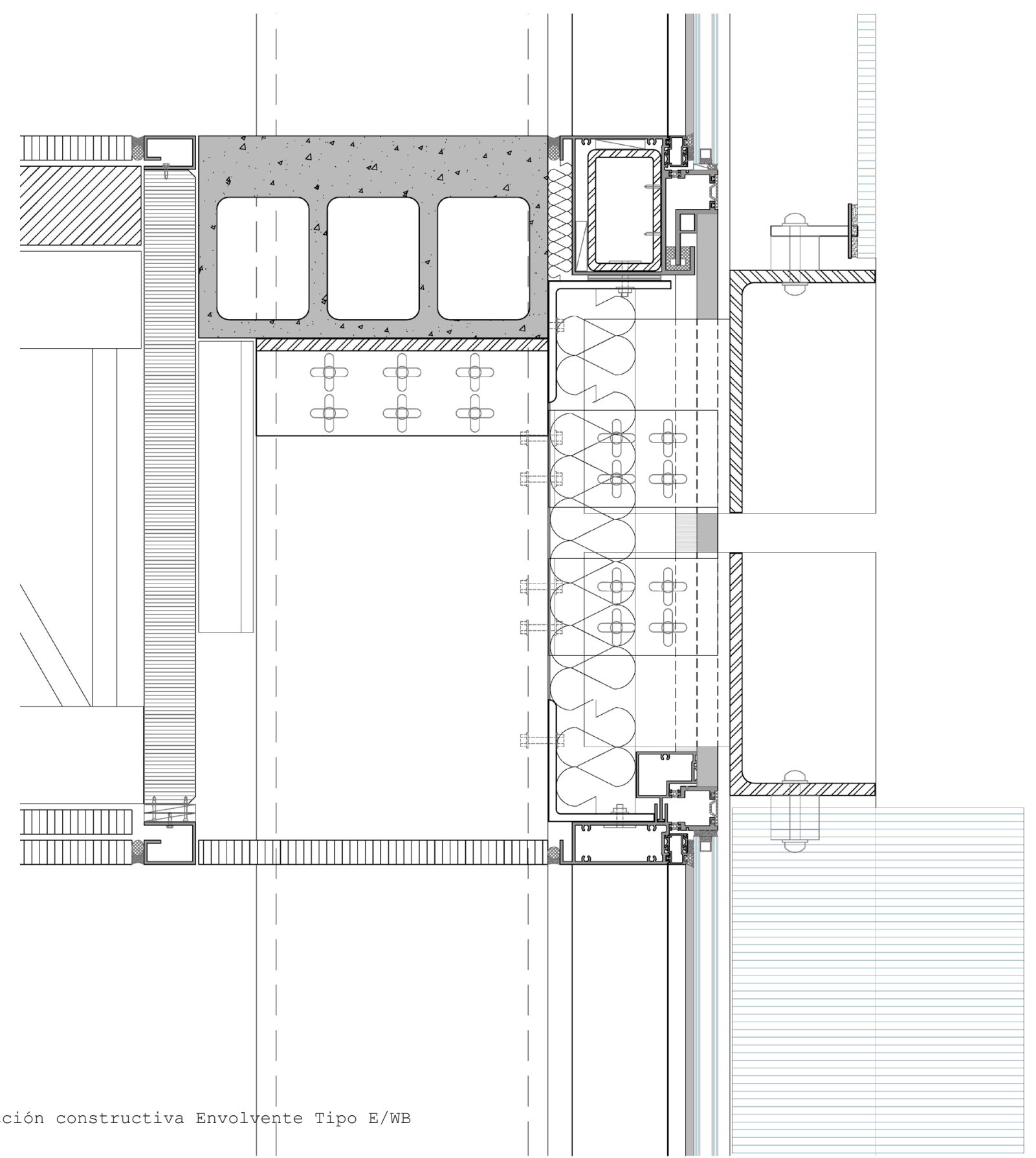





A continuación se muestra una planta tipo del edificio de Lake Grove Village es estado original. De él se puede destacar, especialmente, el ejercicio que Paul DuPondt llevó a cabo para independizar la estructura y los sistemas del edificio de la envolvente.

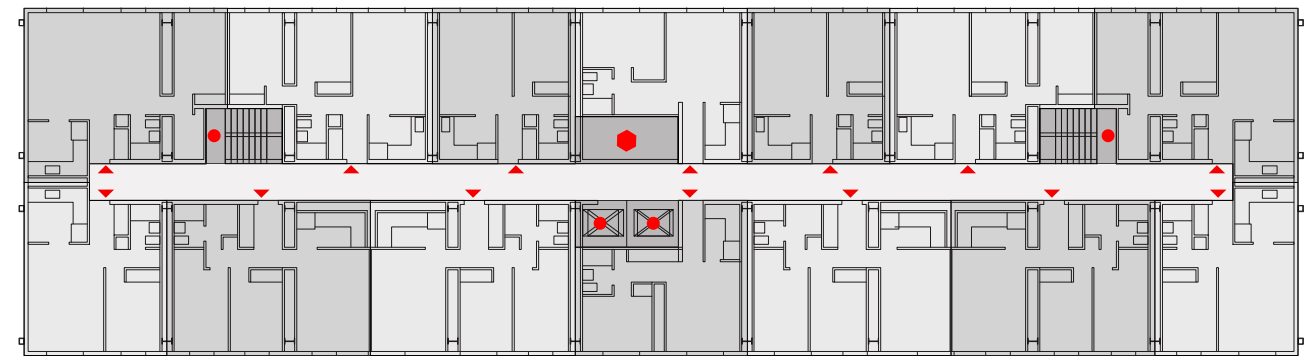

Esto le permitió, entre otras cuestiones, tratar la envolvente como un elemento independiente. Como se ha expuesto con anterioridad, la propuesta actual ha permitido, por un lado, ofrecer a los inquilinos, al igual que en el proyecto de Lacaton \& Vasall, la posibilidad de permanecer en las viviendas durante el proceso tanto de desmontaje de los paneles de la fachada original como de instalación de la nueva envolvente. Por otro lado, mantener la esencia del proyecto de Paul DuPondt en términos de adaptabilidad. Esto permitiría que, si fuese necesario, el edificio sufriese una transformación futura.

"(...) los espacios ya no se repiten de forma idéntica, sino que se reinventan en función de cada uso, de un punto de vista a otro, de un nivel al otro". ${ }^{10}$

Además, la independencia de la estructura ha permitido que las nuevas envolventes puedan instalarse en un tiempo menor que si la estructura tuviera que ser alterada. Por último, los tabiques que albergan la estructura metálica y las bajantes del edificio y de zonas húmedas hace que el espacio restante quede liberado para actividades habitables y para las envolventes. Como en sus viviendas en Rouen, en las que se diseñaron guías que permitiese la movilidad de la tabiquería, la nueva envolvente apuesta por la adaptabilidad de las estancias a las necesidades cambiantes de las familias.
10. Edgar Morin, The Cinema or the Imaginary Man, (Minneapolis: University of Minnesota Pres,2005). 
En segundo lugar, se muestra una planta tipo de Lake Grove Village tras el proceso de transformación de la envolvente. Como se observa, los espacios interiores se respetan y sólo se transforman aquéllos que conviven directamente con la envolvente.

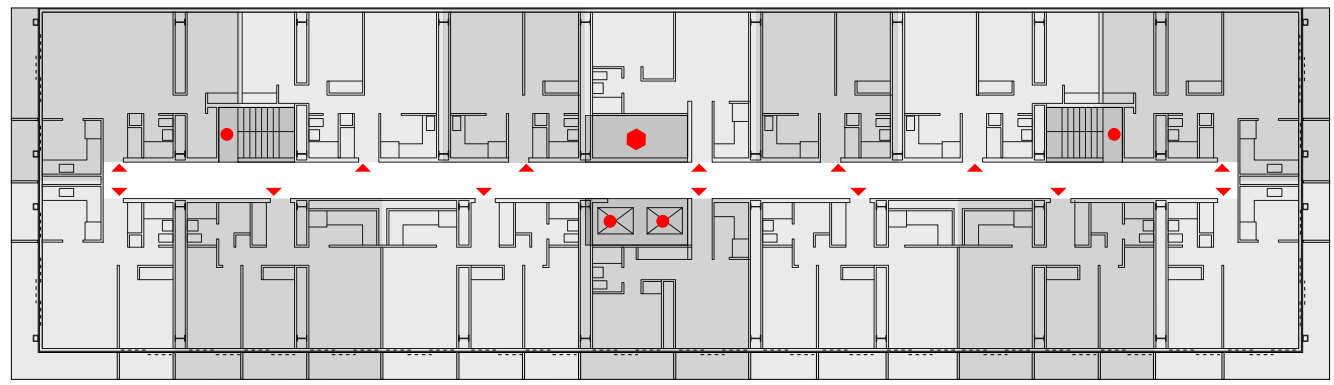

Con respeto a la independencia estructural mencionada anteriormente, del diagrama destaca la nueva envolvente que crea una segunda piel de $1.5 \mathrm{~m}$ de profundidad alrededor del perímetro original. Ésta, que ha sido validada por los análisis cuantitativos, permite, entre otros factores, mejorar el espacio existente mediante elementos de "galería", "balcones" o "añadidos". Estos espacios permitirán a la vivienda gozar de espacios de transición climatizados, espacios de estancia al aire libre sin climatizar, o de mayor superficie dentro de la vivienda.

De manera similar a 340 On the Park, estos espacios no son gratuitos sino que se diseñan en base a dos condicionantes. Por un lado, los espacios responden a un programa interior determinado. El tipo de cerramiento no tiene porqué ser el mismo para espacios de cocina, de dormitorios o para espacios de uso diurno como los comedor-estar. Por otro lado, y no menos importante, por lo que respecta a esta investigación, los espacios vienen justificados por una mejora del comportamiento energético del espacio. Así, por ejemplo y como se ha visto a lo largo del trabajo, las estancias orientadas a Norte se verían afectadas negativamente por el uso de estos espacios, por lo que en estas orientaciones, no se considera la profundidad de la envolvente. 
A continuación se muestra el resumen de la secuencia del proceso de transformación de la envolvente.
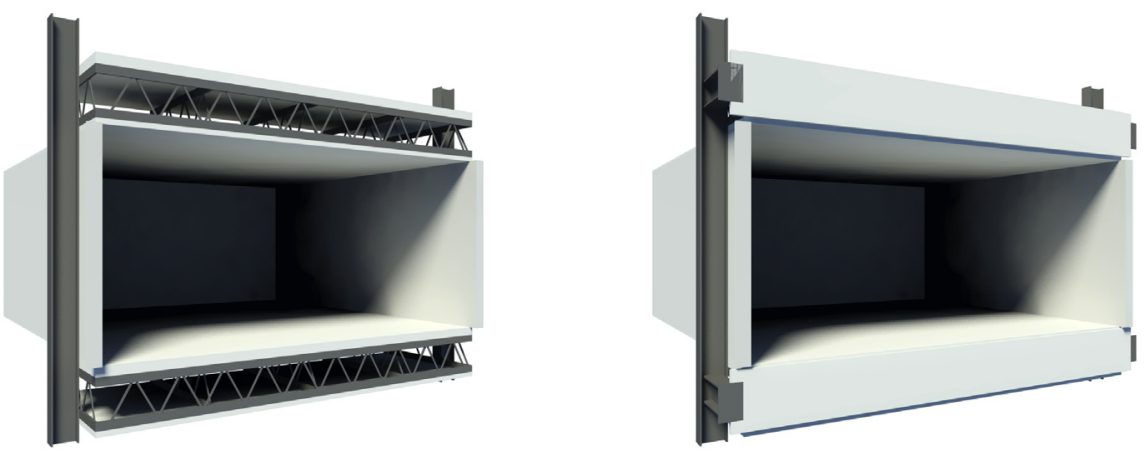

Los paneles originales de la fachada se desmontan dejando al descubierto la estructura original. Ésta prevalece y sirve de anclaje para las nuevas envolventes.
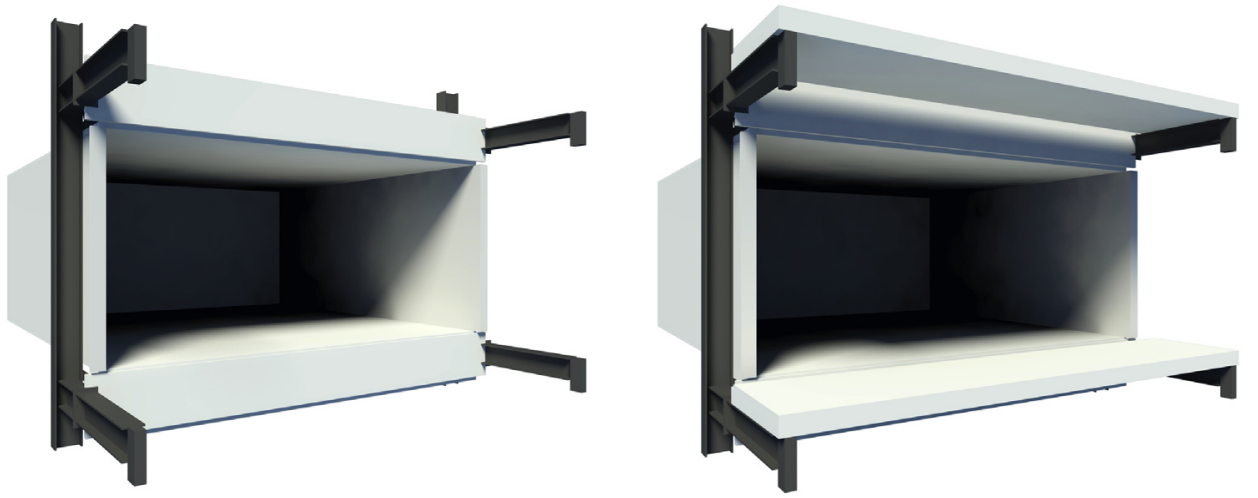

La subestructura de la nueva envolvente y los forjados de los balcones, galerías - espacios añadidos quedan conectados a la estructura original.
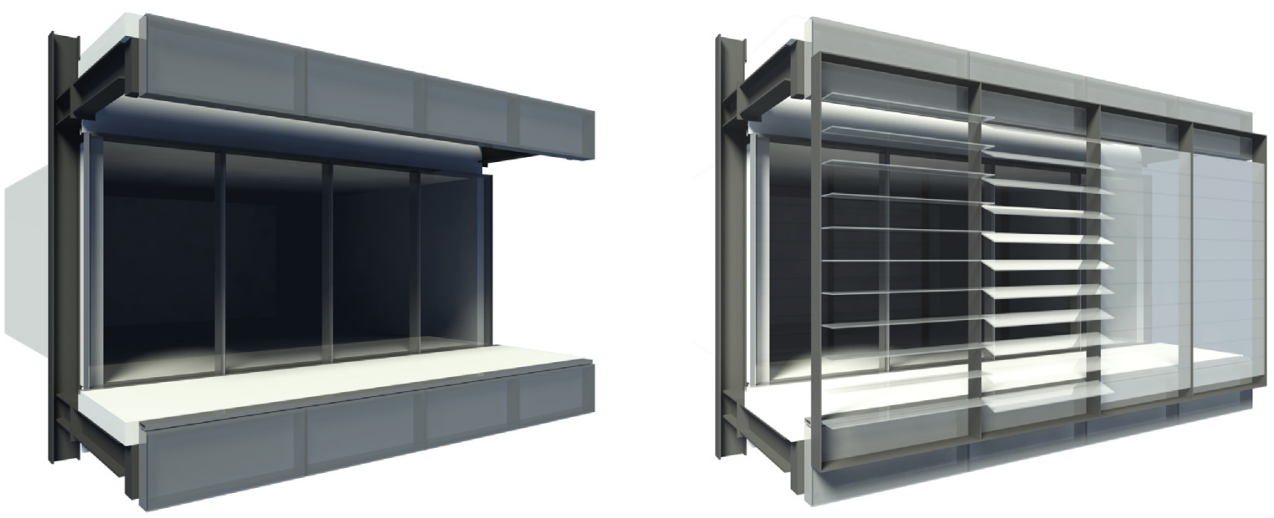

Las envolventes se completan. Primero se cierra el espacio interior en el caso de los balcones o galerías sin climatizar, para después instalar la piel de protección solar. En el caso de las galerías climatizadas, la piel de protección térmica y solar será la misma. 


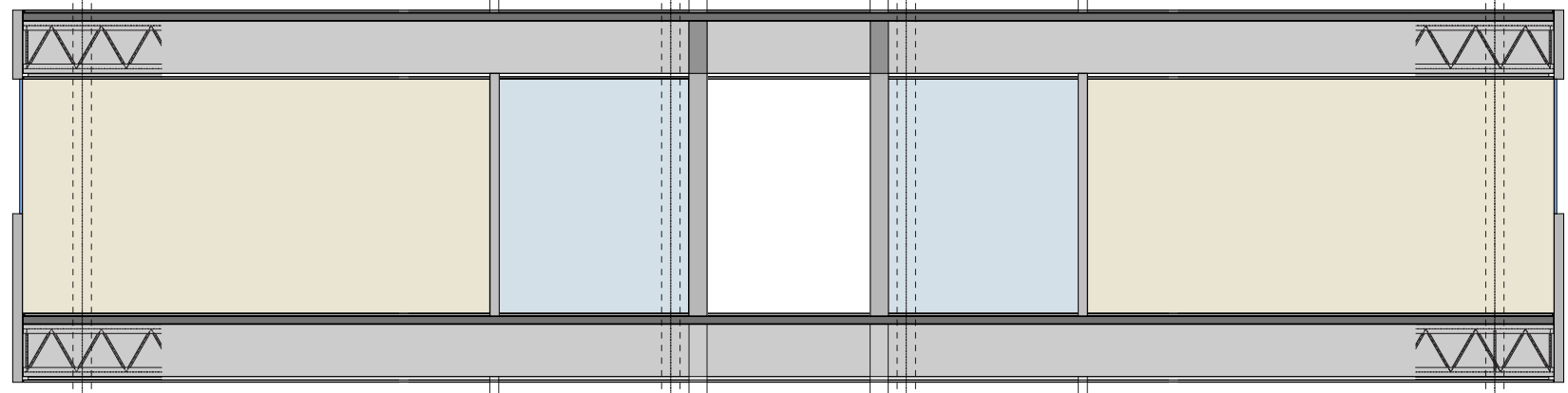

La sección de la fachada original muestra las dos zonas principales de hueco y opaco.

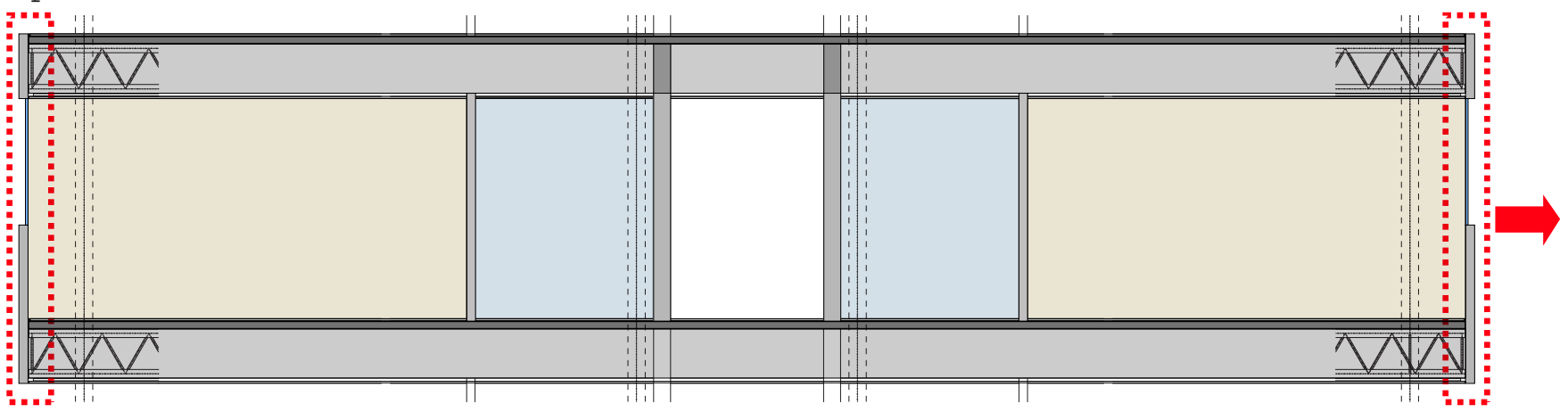

El componente original que se altera durante el proceso de transformación es la fachada de Paul DuPondt.

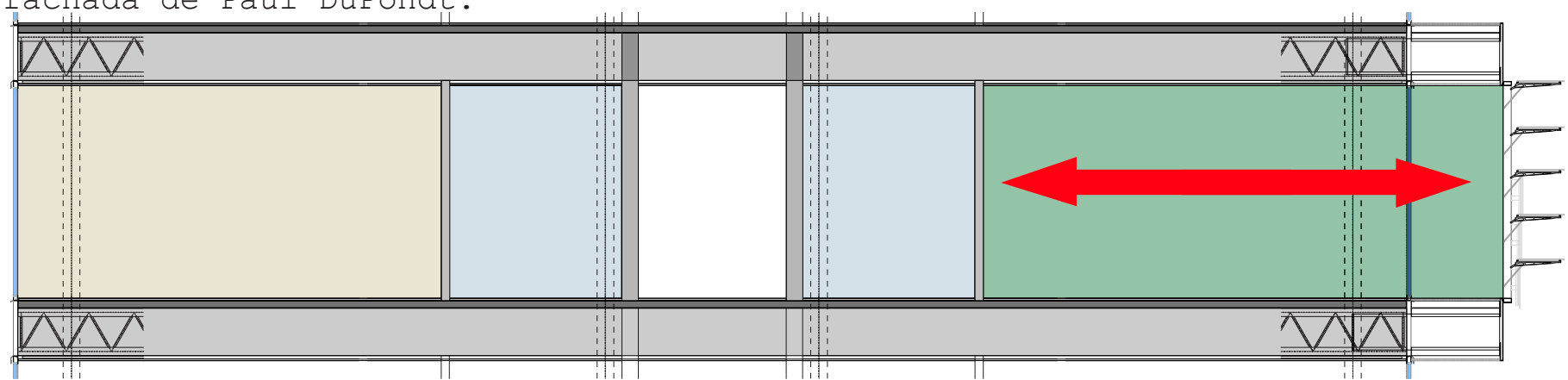

El proyecto, centrado en la envolvente, adquiere la dimensión de profundidad para convertirse en espacio. Como señalábamos en el primer capítulo, la envolvente se define de la sigueinte forma: "...creates an interior and an exterior; it separates but is also permeable, this allowing exchage to take place". ${ }^{11}$

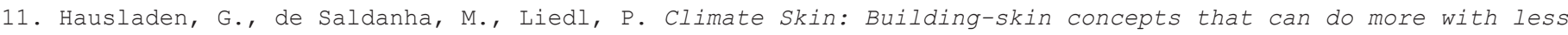
energy. (Basel: Birkhäuser-Publishers for Architecture, 2008), pág. $12 \& 14$. 
En la intervención cabe destacar el diseño de una envolvente que aporta la cualidad tridimensional a la "piel" del edificio. Esta cualidad se plasma en forma de espacios con oportunidad de profundidad. Los espacios se han clasificado en tres tipos, principalmente.

Por un lado, pueden ser incorporados a la estancia interior con la que se relacionan, pasando a formar parte del espacio en sí. Por otro lado, pueden ser elementos que se añaden a modo de espacios de transición. En este caso, la barrera térmica puede colocarse en la primera piel -o misma situación que la fachada original-, o en la envolvente del espacio añadido. En el primer caso, los espacios se diseñan fuera del límite de control térmico propiamente dicho. De cualquier manera, los espacios adicionales pueden ayudar a mejorar el comportamiento energético de la vivienda, y dotan de mayor cualidad y calidad espacial los ya existentes.

Los espacios orientados a Este y Oeste como, por ejemplo, las cocinas de las viviendas en esquina, ganan el tradicional espacio de "galería". Las viviendas pueden aprovecharse de estos espacios, ya sea incorporándolos como parte de la cocina, manteniéndolos como zonas anexas a como espacios climatizados, o simplemente como terrazas exteriores pero cubiertas de las cocinas. Además pueden regular la entrada de energía solar mediante los sistemas de lamas verticales.

De un modo similar, los espacios destinados a los comedor- estar que se encuentran en las orientaciones Este y Oeste pueden beneficiarse. En este caso, el diseño ha considerado dos opciones: mediante la incorporación de la terraza o mediante la ampliación del espacio, ambos protegidos por lamas verticales. El diagrama que aparece a continuación esboza un ejemplo de una de las viviendas orientadas al Este. 


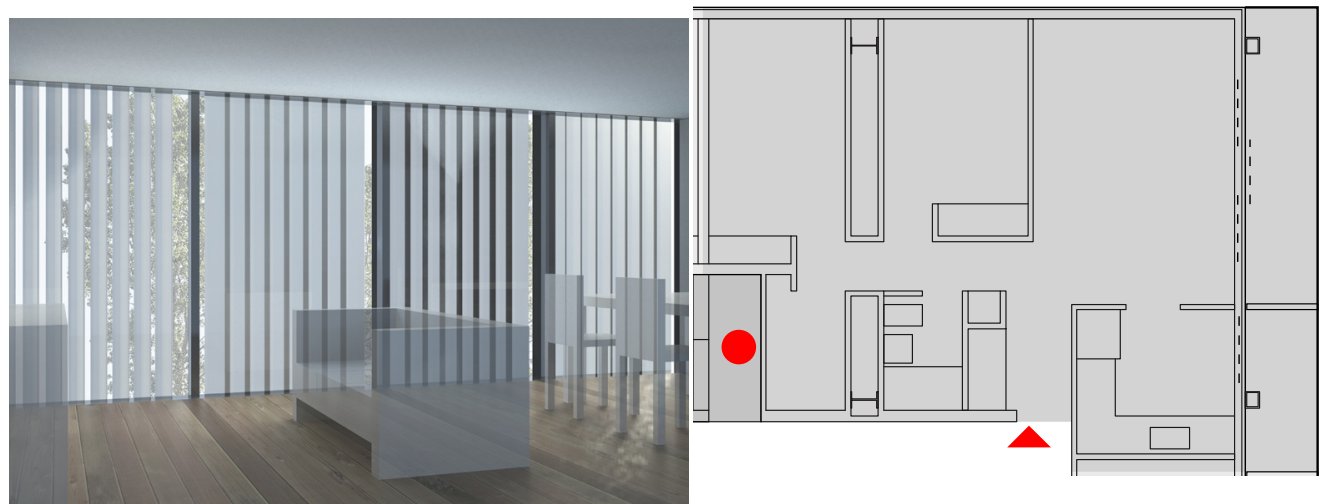

Las viviendas orientadas a Norte y a sur tienen una distribución similar en el edificio original. Sin embargo, como se ha podido comprobar, el diseño de la envolvente que se propone es diferente. En el caso de la fachada orientada al Norte, las viviendas no adquieren esa cualidad tridimensional mediante las envolventes. En este caso, los espacios originales se benefician de la nueva "piel", pero sin añadir una profundidad al espacio. El diagrama incluido a continuación esboza un ejemplo de una de las viviendas orientadas a Norte.
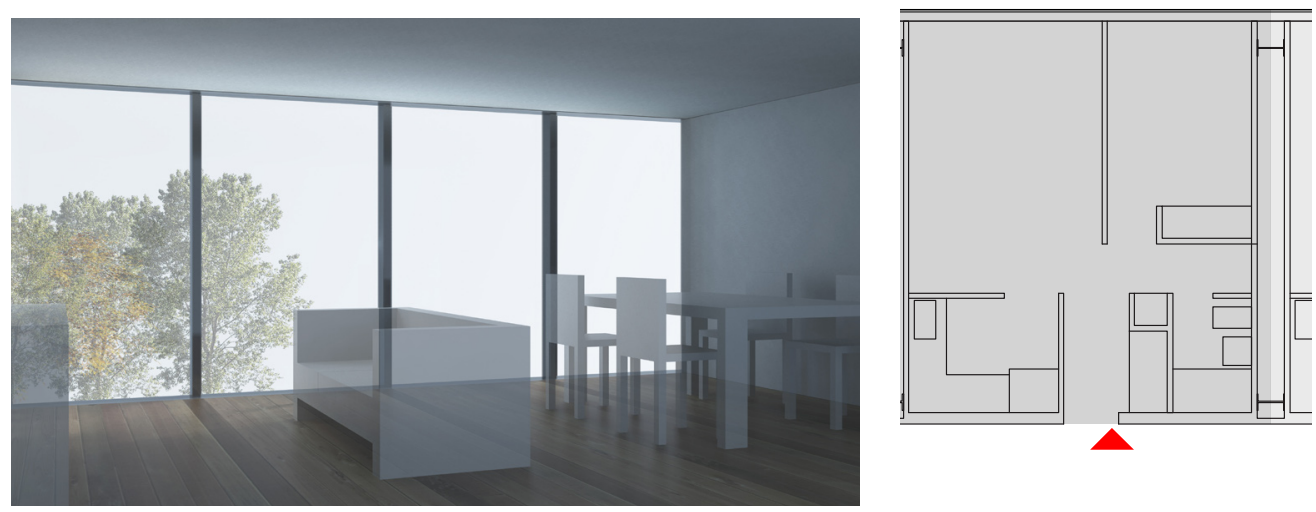
Por último, en el caso de las viviendas orientadas a Sur, aparecen espacios de transición que, de manera similar a los del Este y Oeste, añaden cualidad a los ya existentes mediante la incorporación o la absorción. En este caso, estos espacios se dan en los estares y en los dormitorios. Los baños y las cocinas se encuentran localizados cerca del corredor principal.
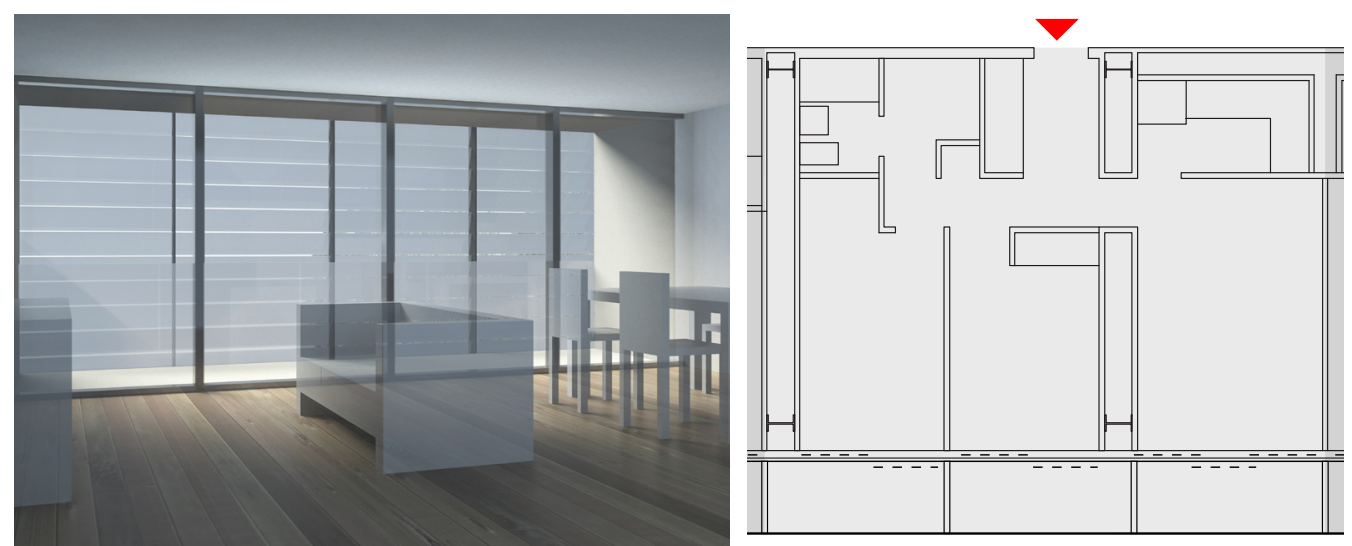

Por tanto, la propuesta supone una tranformación en superficie y en profundicad de espacio, añadiendo a aquéllos donde sea necesario, la tercera dimensión a la "piel". 

CAPÍTULO 05

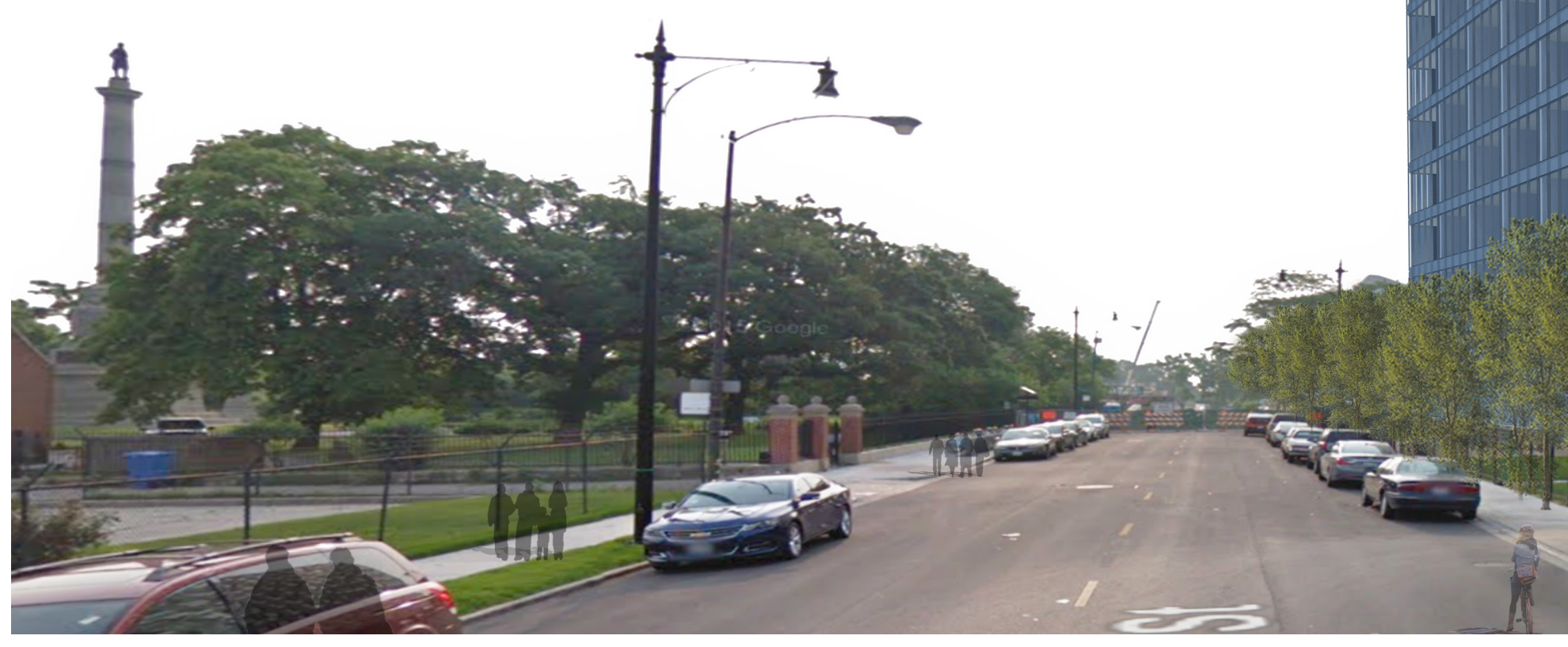




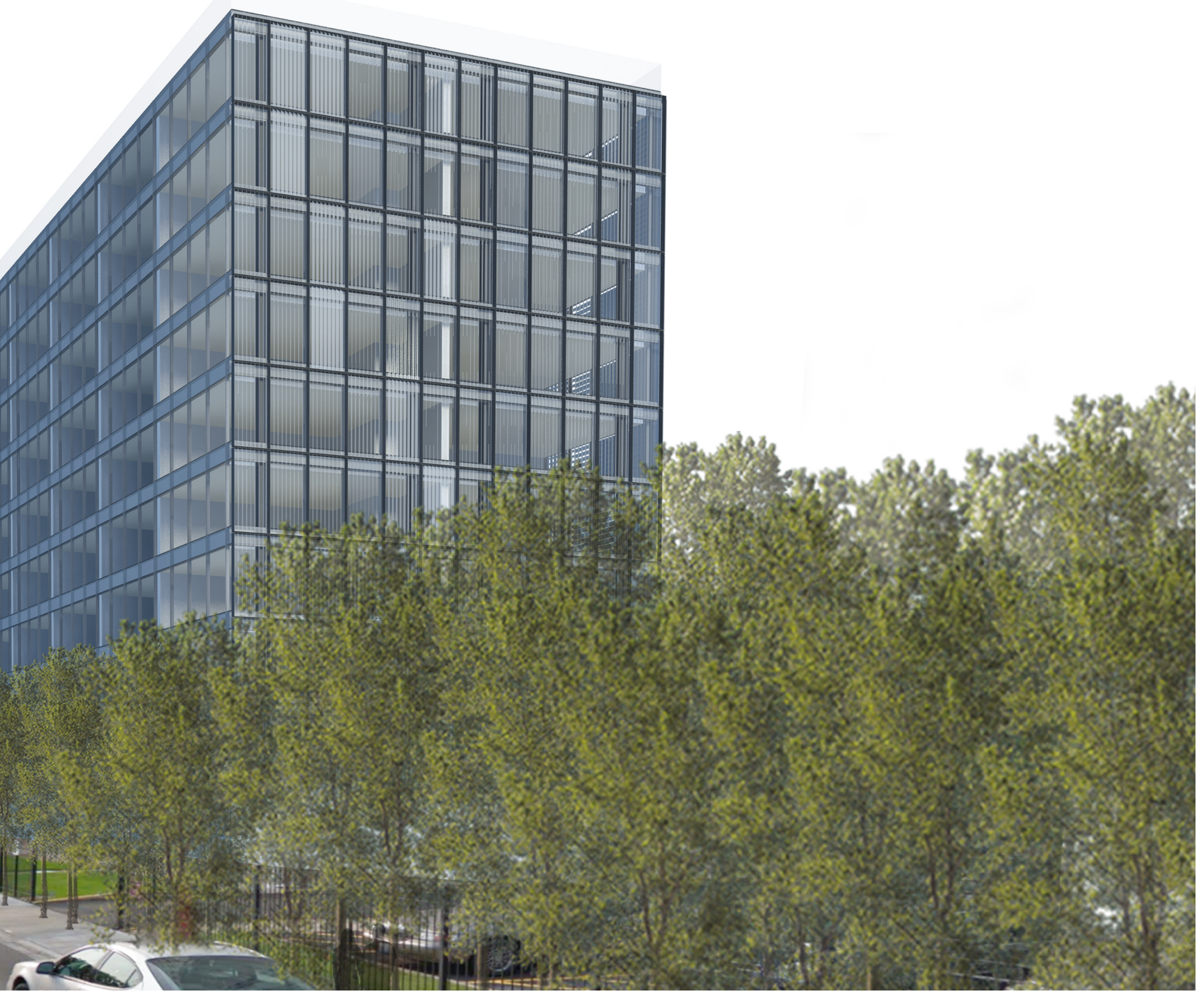




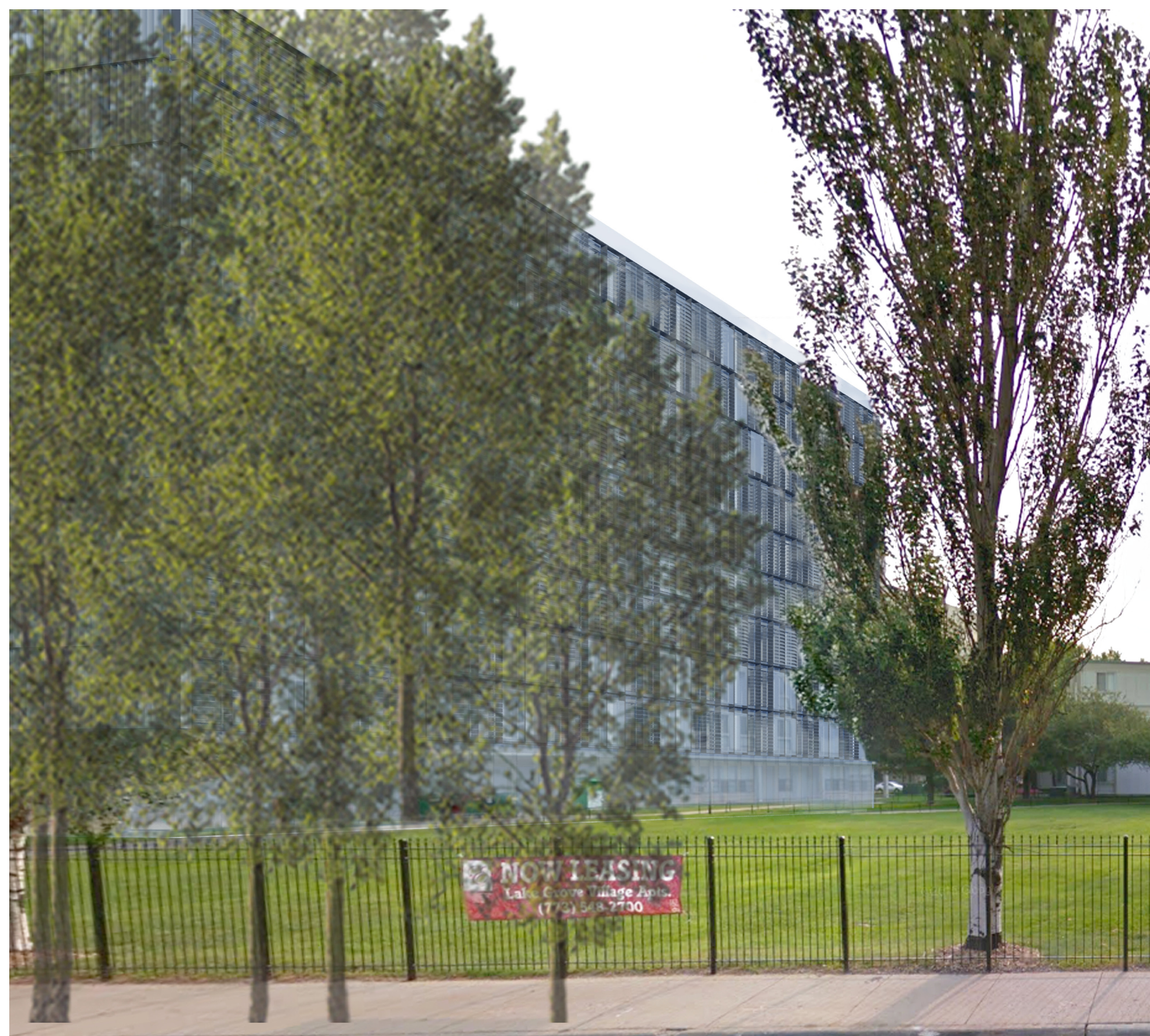




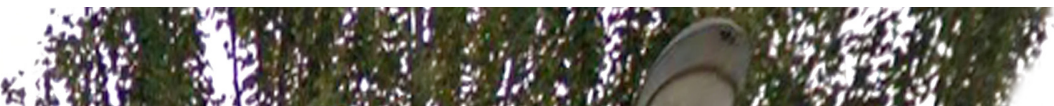

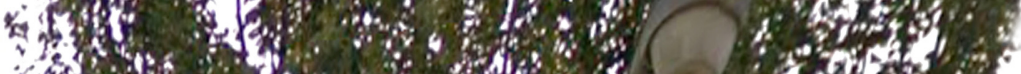

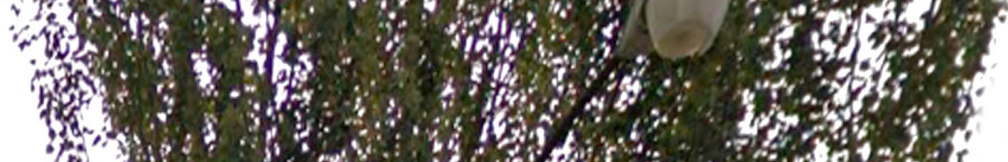

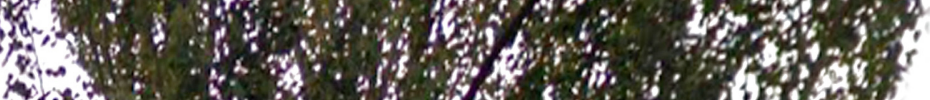
Wos 2. 暴,

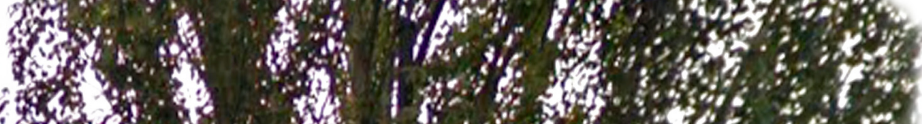

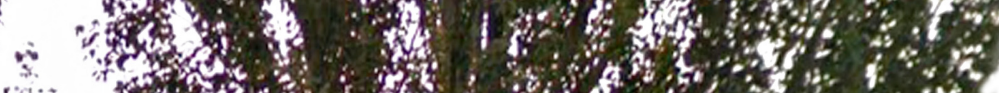

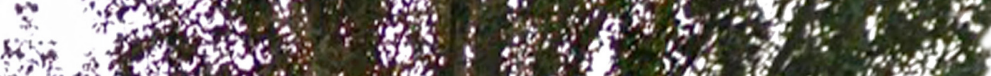
W W (n) W 1 (1) (1) (4) 沗,

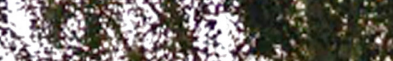
(6) r. , Itome We

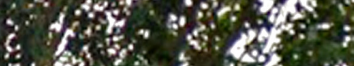
7. $x^{2} \times 2$ (1) 8 , on 2.3. 30 (1) , $5, x$ 9. 1. 35

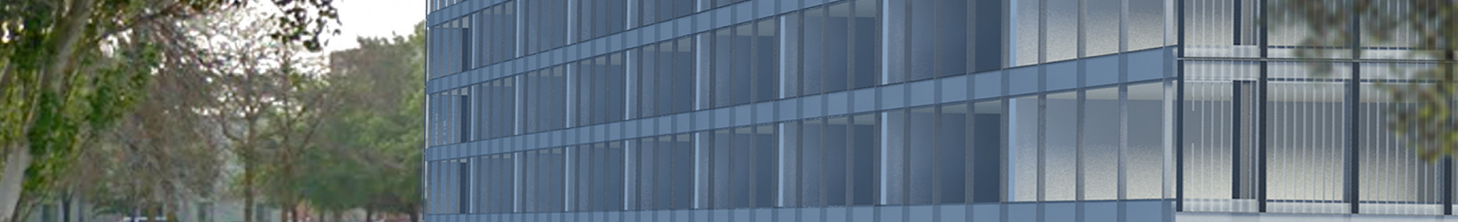

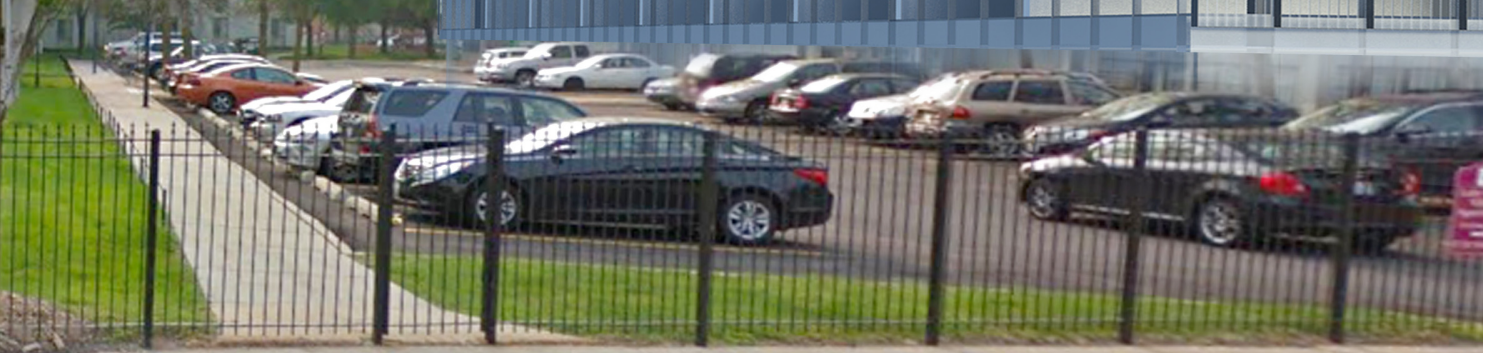




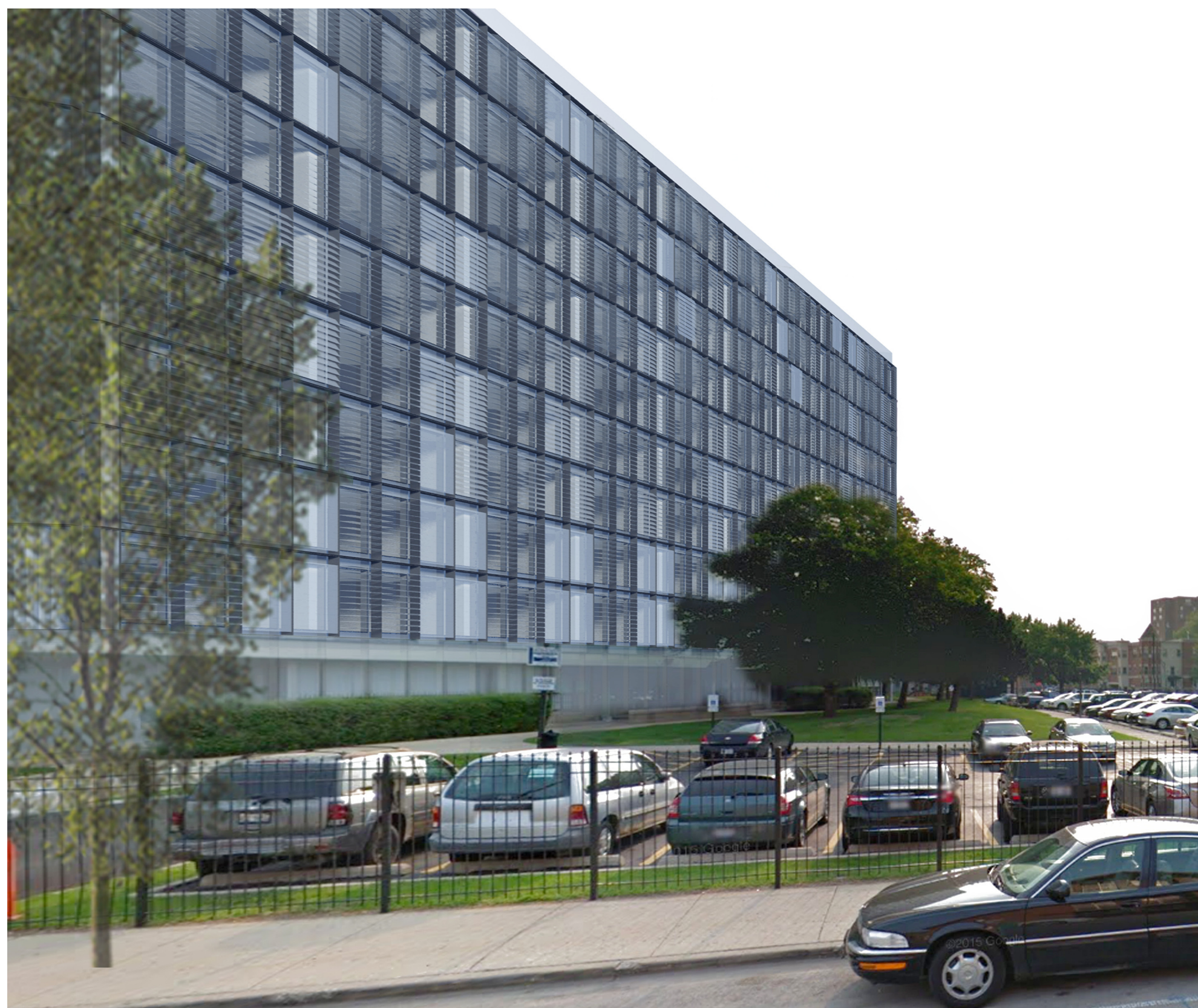




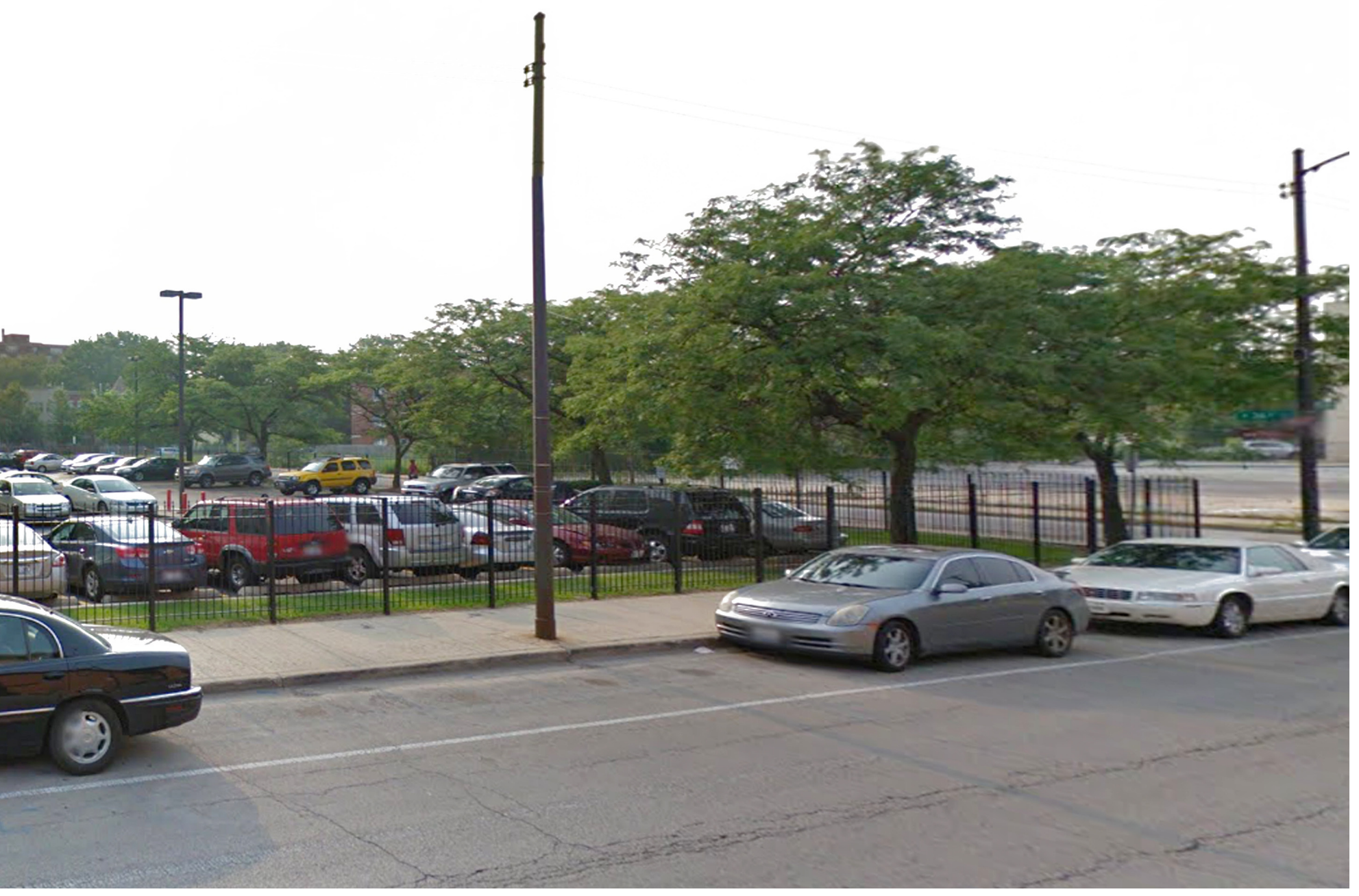




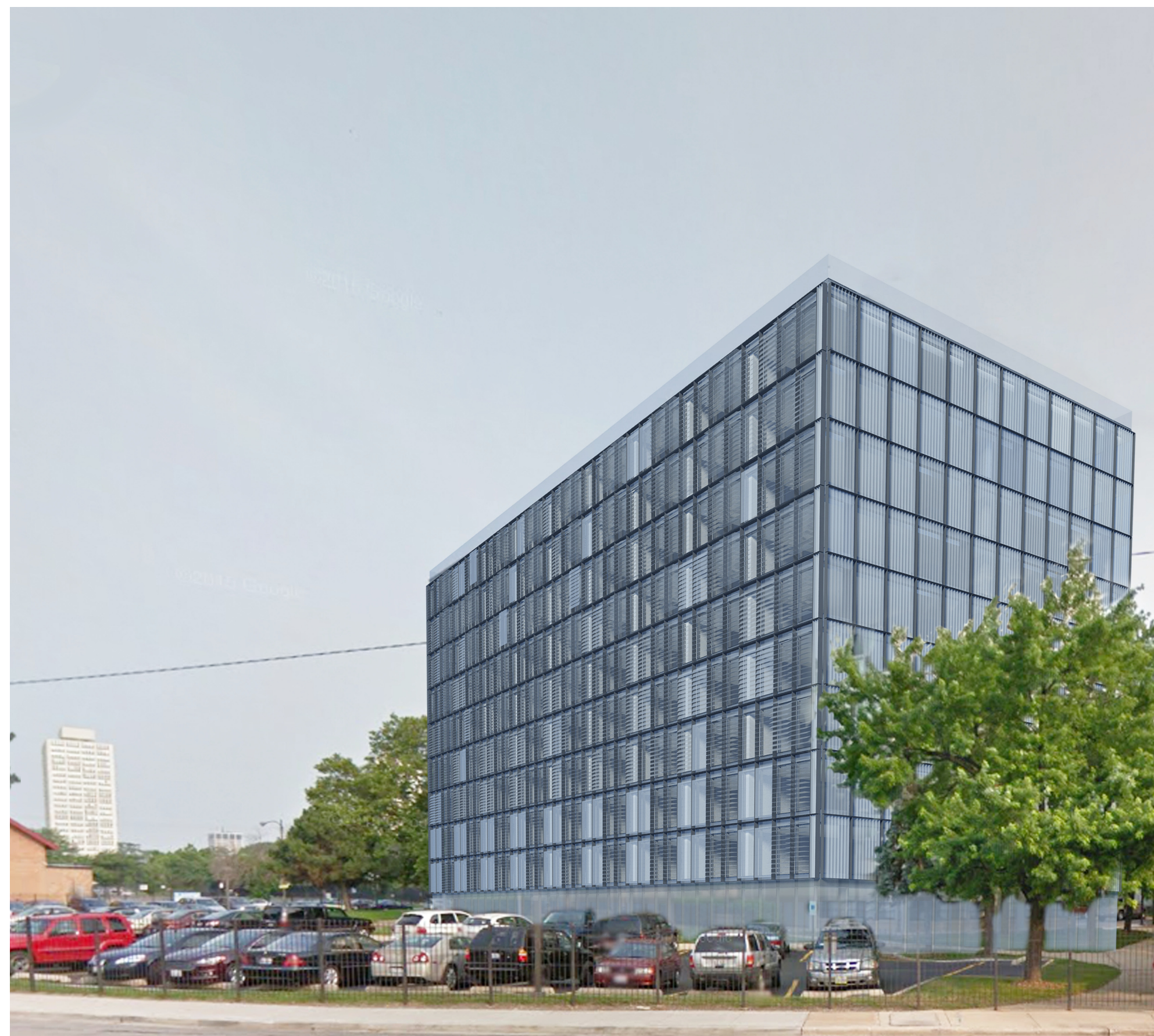




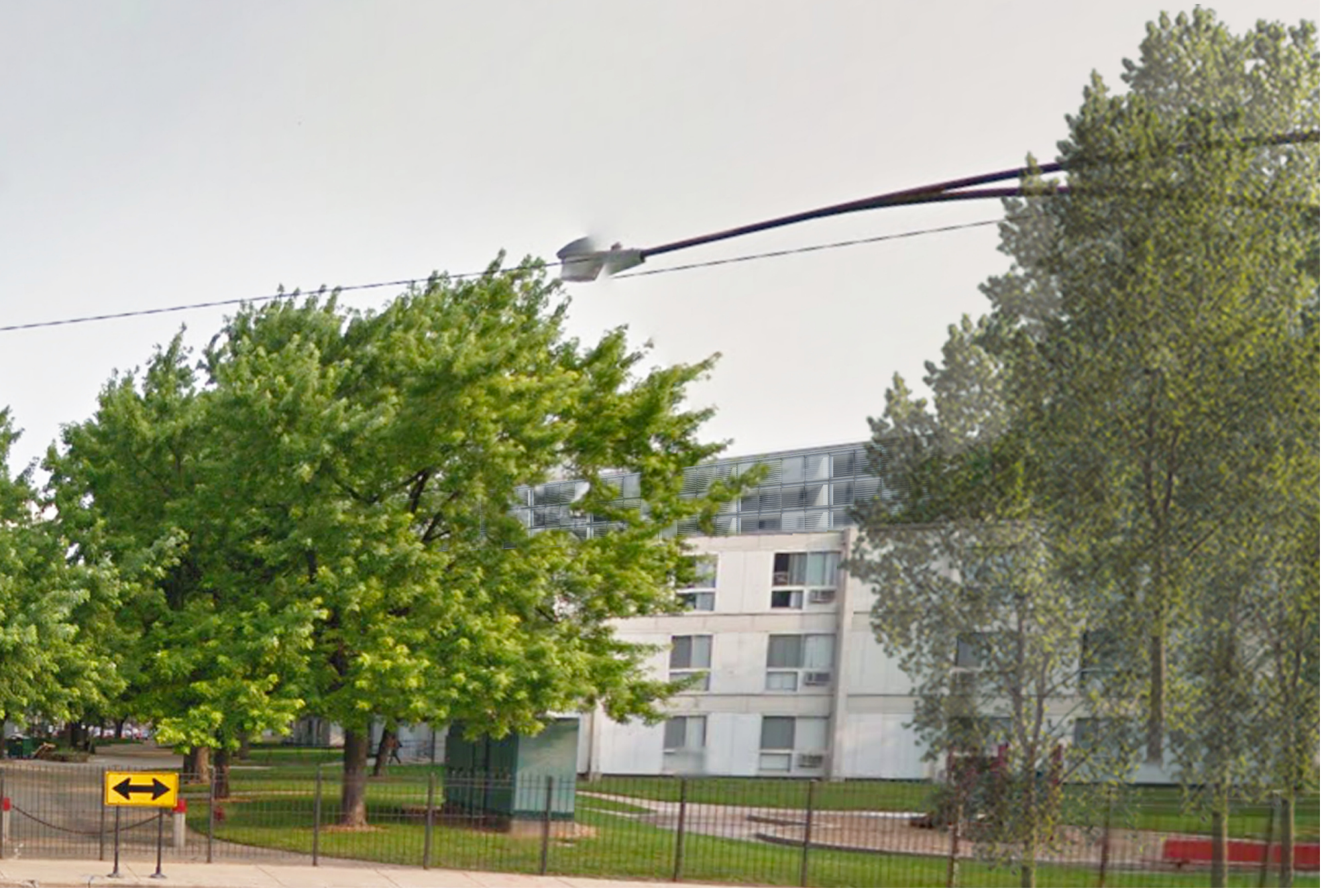



CAPÍTULO 06

CONCLUSIONES. LA ADAPTABILIDAD Y LA ENVOLVENTE

6.1 EPÍLOGO.

Este trabajo comienza a elaborarse en el año 2010 mientras la investigadora cursaba el programa del Master of Science in Architecture en el Illinois Institute of Technology de Chicago. El reto a la hora de seleccionar el tema de la investigación no fue tanto plantear el área de interés, sino ser capaz de acotarla para que ésta permitiese la suficiente libertad, al mismo tiempo que fuese tangible y factible. El área "diseño de fachadas" conlleva tal cantidad de posibilidades que no representaba una hipótesis concreta. Poco a poco ésta se fue acotando y refinando.

Lo primero fue decidir el objeto de estudio o, en este caso, el objeto que dotaría a la investigación del carácter proyectual que pretendía. Para ello se plantearon dos opciones. Por un lado dirigir el proyecto, y por tanto la investigación, hacia uno de "nueva planta" con el que ir desarrollando los conceptos. Esto permitiría asentar una base sobre la que definir los requerimientos y programa del

339 
proyecto para el fin deseado. Por otro lado, llevar a cabo un proyecto de intervención, tomando lo construido como los condicionantes para dar respuesta a una situación existente. Ésta, que en principio se antojaba la opción de menor calibre, resultó la de mayor interés para el tema de investigación por entender inertes, entre otros, los siguientes conceptos:

- Técnica: "...la técnica, que podemos, desde luego, definir, como la reforma que el hombre impone a la naturaleza en vista de la satisfacción de sus necesidades". ${ }^{1}$

- Eficiencia Energética: "...energy efficient architecture must be understood as a combination of minimal energy consumption, optimum indoor climate conditions and architectural quality". ${ }^{2}$

- Envolvente: "...As our third skin, the outside of the building fullfills tasks similar to those of human skin or clothing. It creates an interior and an exterior; it separates but is also permeable, this allowing exchage to take place". ${ }^{3}$

- Adaptabilidad: "dicho de un ser vivo: acomodarse a las condiciones de su entorno". ${ }^{4}$

Así comienza este trabajo de transformación de la envolvente de Lake Grove Village; éstos son los conceptos que han ido apareciendo a lo largo del proyecto, y con ellos concluyen.

"El bienestar, pero también los sueños de una sociedad contemporánea, parecen depender de la manera en la que una situación existente se encuentra con una nueva, dos temporalidades, dos estados de espíritu". 5 Así describen los arquitectos Anne Lacaton \& Jean-Phillippe Vassal el proceso por el que abordan los proyectos de intervención y tratan de llevar a cabo una superposición -que no una imposición de nuevas intenciones sobre una trama existente. Con estas intenciones se leva a cabo el trabajo.
1. José Ortega y Gaset. Meditación de la Técnica. Filosofía Hoy. (Madrid: Edición de la Revista Occidente, 1977), pág.324. 2. Brian Cody, Energía y Arquitectura (Schucco). 3. Hausladen, G., de Saldanha, M., Liedl, P. Climate Skin: Building-skin concepts that can do more with less energy. (Basel: Birkhäuser-Publishers for Architecture, 2008), pág. $12 \& 14$.

4. Real Academia Española. (2001). Diccionario de la lengua española (22.a ed.), Madrid.

5. Anne Lacaton, Jean-Philippe Vassal, "La Libertad estructural, condición del milagro", $2 G$ Lacaton \& Vassal Obra Reciente. (Barcelona: Gustavo Gili, 2010), pág. 162. 
En primer lugar, la técnica. El concepto de técnica ha aparecido en el trabajo como herramienta de estudio y de proyecto. El recorrido a través de una primera arquitectura de fachadas de Chicago, ha pretendido esbozar los elementos más representativos de una ciudad que vio el nacimiento, florecimiento y posterior desarrollo de lo que ha acabado siendo un icono de la vida moderna: el rascacielos. Las nuevas técnicas, la incorporación de materiales como el vidrio y el acero, la arquitectura de Mies van der Rohe, o la interpretación que de ella hicieron sus sucesores, han servido para entender, en cierta medida, las técnicas empleadas y sus condicionantes, pero también sus limitaciones. La técnica aparece como un concepto que permite a la arquitectura cambiar o crear para su propio beneficio. Este concepto se desarrolla a lo largo del trabajo; las envolventes de Le Corbusier, los mecanismos empleados por Schippereit y Hendrich, los perfiles y pieles inertes de Mies Van der Rohe, y su posterior evolución, han sido ejemplos estudiados de cómo los arquitectos han entendido las posibilidades del uso de la técnica (que no necesariamente la tecnología) para sus aportaciones.

El concepto toma especial relevancia al escoger el objeto de estudio. Las premisas a partir de las cuales fue diseñado Lake Grove Village así lo ponen de manifiesto. La estructura metálica y su independencia de la envolvente, la libre disposición de espacios, la unificación de los sistemas, la prefabricación de los paneles de fachada y su diseño y montaje, muestran un interés por parte del arquitecto hacia el uso de herramientas (o técnicas) de las que beneficiarse. Proyectos, como las viviendas de Paul DuPondt también pueden ser tomados como ejemplo de ello.

En las viviendas en Rouen, por ejemplo, el arquitecto se sirve de materiales ligeros como el acero para indagar en la prefabricación y alejarse de otros materiales más pesados o tradicionales. De manera similar, aunque décadas más tarde, encontramos el uso de la técnica en los proyectos de Lacaton \& Vassal. En este caso, entendemos la técnica como la herramienta que les ha permitido estudiar a lo largo de diferentes proyectos y propuestas, la arquitectura de la superposición. 
En segundo lugar, la eficiencia energética. El concepto de eficiencia energética aparece como un objetivo del diseño, entendido como una serie de actitudes que permitan, entre otros, un balance entre el clima interior y el ambiente exterior. Las aportaciones, por ejemplo, de Le Corbusier con respecto a la ventilación e iluminación natural mediante la "fenêtre en longeur", el control solar por medio del "brise soleil", la envolvente inteligente y activa por medio del "mur neutralizant", o la incorporación de aire acondicionado mediante la "respiration exacte", han servido en mayor o menor medida para entender los orígenes de estos conceptos. Asimismo, el vidrio tintado empleado y el sistema de ventilación natural diseñada para la torre Lake Point Tower, pone de manifiesto como Schippereit y Hendrich se preocuparon por la incorporación de la ventilación natural en los espacios.

Este trabajo ha repasado mecanismos arquitectónicos que apuestan por la eficiencia energética, pero siempre desde un punto de vista pasivo. Es decir, aun entendiendo las posibilidades que ofrece la tecnología, esta investigación se ha centrado en entender las posibilidades de mejora del comportamiento del espacio mediante medidas relacionadas con el entorno inmediato, el contexto o la localización del proyecto. Así, tomando como ejemplo el clima y la orientación de las fachadas, se ha podido comprender las oportunidades que brindan así como sus limitaciones. Esta investigación, no obstante, no se ha limitado al plano teórico sino que ha propuesto soluciones prácticas, como el proyecto de transformación de Lake Grove Village en Chicago, en el que se han estudiado diferentes opciones destinadas a incrementar la entrada de luz solar en invierno y controlarla en verano. Mientras que en el diseño original se empleó el mismo tipo fachada para las orientaciones Norte y Sur, en la propuesta de transformación se toma en consideración las oportunidades asociadas a cada exposición. En este caso, la eficiencia energética se ha medido en términos de consumo energético, control y confort, lo que la relaciona a los otros tres apartados propuestos anteriormente: técnica, envolventes y adaptabilidad. 
En tercer lugar, la envolvente. El concepto de la envolvente como superficie intercambiadora se ha visto plasmado en el trabajo. El cerramiento de vidrio inerte como pantalla de exposición, sin otro fin que la transparencia, claridad y ligereza, pasa a dotarse de nuevos cometidos técnicos en el equilibrio energético con el medio ambiente. Esta investigación repasa la evolución de las envolventes, desde los estudios de fachadas cargados de inteligencia de Le Corbusier, los muros cortina puros de Mies en Lake Shore Drive, el guiño a la ventilación natural en edificios en altura que lleva a cabo Schippereit y Heinrich o la sofisticación técnica y energética que sugieren los estudios teóricos de Ken Yeang.

Al mismo tiempo, el trabajo ha examinado algunos de los parámetros que entran en juego en el diseño de las envolvente en Chicago para comprender las posibilidades de los componentes y el conjunto en la transformación de Lake Grove Village; se estudian los mecanismos de las envolventes en las distintas estaciones del año, y se lleva a cabo un análisis de los diferentes modelos de envolvente. Ello permite fijar una base a partir de la cual se puede comenzar a diseñar el proyecto de la envolvente. Por tanto, el concepto de envolvente tal y como se establece al comienzo de este trabajo se ve plasmado en las diferentes etapas del mismo.

En el proyecto desarrollado, la envolvente cobra una tercera dimensión que permite entender el efecto del diseño en el espacio, y relacionarlo así con el concepto de eficiencia y adaptabilidad por medio de la técnica. Se crean envolventes diferenciadas dependiendo de la orientación y, al mismo tiempo, se proponen espacios dependiendo del uso para el que están destinados. La envolvente no cubre sino que crea. A lo largo de esta investigación se han repasado los conceptos básicos de funcionamiento de las envolventes con el fin de ofrecer un marco general en el que poder basarse. Se han estudiado los movimientos a través del vidrio para entender el funcionamiento de las envolventes. Se han analizado los elementos de las fachadas de vidrio que más impacto generan en su rendimiento y comportamiento, ya sea para el confort interior o para la conservación del medio 
ambiente. El vidrio y sus componentes así como los mecanismos diseñados para el control solar en las diferentes posiciones, conformarán las envolventes y definirán su grado de relación con el entorno. Además, se ha hecho hincapié en el comportamiento de las envolventes ante diferentes situaciones climatológicas. La respuesta de las superficies de intercambio de flujos durante los meses fríos no sólo son distintas a las que se producen en los meses de calor, sino que, en ocasiones, son opuestas. Por ello hemos identificado los elementos que se exigen a las envolventes en ambas estaciones del año, concluyendo, una vez más, en la necesidad de adaptarlas para una respuesta óptima. La envolvente se convierte así en la principal protagonista. Para su estudio se han tomado en cuenta referencias bibliográficas y casos de estudio, además de un análisis propio del proyecto de Lake Grove Village.

Así, la envolvente, separadora y permeable, se entiende de manera similar a la piel del cuerpo humano.

Por último, la adaptabilidad. El concepto de adaptabilidad es quizás el que engloba el conjunto de las premisas. La conclusión principal de este trabajo nos remite a esta idea central. La adaptabilidad ante las posibilidades de la técnica, la adaptabilidad ante las situaciones medioambientales o energéticas, ante los cambios en las necesidades de los usuarios, la adaptabilidad en las envolventes, etc. En definitiva: la adaptabilidad de la arquitectura. La relación de los edificios en altura con su entorno ha evolucionado con el tiempo. Mientras que en un primer momento la arquitectura en altura se relacionaba con el exterior desde la distancia, posteriormente precisa de las interacciones entre atmósferas para su funcionamiento. Lo que durante décadas se relegó a los sistemas mecánicos de climatización, hoy en día se intenta solventar sirviéndose de los recursos naturales. Se pasa así de un concepto de fachada como piel inerte dedicada a la contemplación, a otro en la que adquiere una suma de responsabilidades en el comportamiento de un edificio. Las razones de este cambio de mentalidad son diversas, pero no hace falta insistir en que la conciencia en la necesidad de conservar el medio ambiente ha sido uno de los desencadenantes fundamentales. 
La adaptabilidad como herramienta y como objetivo se ha apreciado especialmente en el proyecto de transformación de Lake Grove Village. En la idea original del proyecto se intuye el deseo de crear una arquitectura capaz de adaptarse. En el proyecto de transformación propuesto, las soluciones planteadas están dotadas de la flexibilidad necesaria para permitir la adaptabilidad en tiempos necesarios. Así, por ejemplo, los espacios orientados al sur, que en el diseño original se destinan a galerías o terrazas cubiertas, pueden pasar a formar parte del espacio interior. Por otro lado, se presenta una solución para cada una de las orientaciones como parte de una solución global. Ahora bien, los módulos y tipos de envolventes estudiados y presentados resaltan la posibilidad de alternarlos. El proyecto se fundamenta en las necesidades dispares y cambiantes de los usuarios, incluso las de aquéllos que ocupan una misma unidad. Así pues, la adaptabilidad se traslada al presente, siempre teniendo en cuenta que pueda variar en el futuro. Por tanto, la adaptabilidad que toma esta investigación como referencia está directamente relacionada con la eficiencia de las envolventes. ¿La técnica? Como ya hemos mencionado: una herramienta. 



\subsection{CONSIDERACIONES FINALES.}

La hipótesis principal del trabajo ha explorado la integración de las envolventes en el proceso arquitectónico mediante un proyecto de transformación de la fachada de un edificio en Chicago, con el fin de poder adaptarla a las variaciones de su entorno. Para ello, ha perseguido una serie de objetivos. A continuación se extraen las conclusiones principales de los mismos.

En primer lugar, se han llevado a cabo reflexiones teóricas sobre el uso de la técnica en la construcción de edificios en altura. Las conclusiones extraídas del estudio de la evolución de las envolventes de vidrio en la arquitectura de chicago, han ayudado a construir una base más sólida para el desarrollo del proyecto de transformación.

Los primeros ejemplos de muro cortina se caracterizaban por una separación entre el clima interior y el exterior que trasladaba la mayor parte de la responsabilidad de relación y confort de los espacios, a los suelos y techos 
técnicos. Esto provocaba que la ineficiencia térmica de los cerramientos no afectase en gran medida a la profundidad de los espacios interiores, que podían ser mayores.

La incorporación de mecanismos y materiales que apostaban por un clima de confort interior sin tener que desvincularlo de la composición arquitectónica, fue una de los elementos que permitieron avanzar hacia una arquitectura de mayor optimización.

- La disminución de la conductividad térmica del vidrio permitió evaluar la eficacia tanto del cerramiento como de los sistemas que neutralizasen los intercambios energéticos entre el espacio interior y el exterior

- En este primer apartado han entrado en consideración los conceptos de técnica, eficiencia energética y envolvente.

En segundo lugar, se ha llevado a cabo un estudio del concepto de eficiencia energética en la situación actual. Se han repasado las barreras existentes, así como nuevas propuestas para mejorar el comportamiento energético de las envolventes. De este apartado se extraen las siguientes conclusiones que sirven de contexto para el desarrollo del proyecto de transformación de la envolvente de Lake Grove Village.

- El cambio de actitud de la envolvente del edificio ha ido encaminado a incrementar su relación e integración con otros sistemas del edificio. Con ello, las percepciones y requerimientos del espacio interior se ven modificados.

- La relación entre la envolvente y la eficiencia energética de un edificio está relacionada en cuanto que la primera constituye la superficie por la que ambos medios interactúan. De ahí la creciente percepción de la envolvente sea como elemento activo en la reducción de energía.

- Las barreras existentes en el diseño intentan superarse mediante corrientes, estableciendo objetivos y líneas de mejora a corto, medio y largo plazo.

En tercer lugar, se han estudiado los conceptos y principios de las envolventes de vidrio tras la técnica de las envolventes de vidrio. Lo extraído ha servido de punto de partida para el diseño y desarrollo del proyecto de transformación de la envolvente de Lake Grove Village. 
La transferencia de energía a través del vidrio se produce por mecanismos de conducción, convección y/o radiación. La composición del vidrio determinará, en cierta medida, su transferencia energética -o capacidad aislante.

- La composición de la envolvente y la disposición de las diferentes capas determinará el comportamiento y, por tanto, funciones, de la misma. La piel simple se caracteriza por una distribución de los elementos en un mismo plano. En contraposición, la doble piel de vidrio empieza a disponer los elementos en profundidad y potencia el componente tridimensional de la fachada.

- El comportamiento de la fachada está directamente relacionado con la situación del edificio. Para un clima como el de Chicago, los comportamientos que se deben de tener en cuenta en el desarrollo de un proyecto incluyen: en invierno, minimizar las pérdidas energéticas al mismo tiempo que potenciar la entrada de energía solar; en verano, controlar la entrada de energía solar, y en estaciones intermitentes, permitir la ventilación natural.

Finalmente, se desarrolla la propuesta de transformación de la envolvente de Lake Grove Village, que dota de un enfoque proyectual a esta investigación. Siendo ésta la parte central de este trabajo, consta tanto de un análisis como de una descripción del proyecto en sí y sus componentes. No se entiende que una pudiese existir sin la otra. Del mismo modo, los apartados anteriores tienen como objetivo servir de apoyo y base a lo que se ha desarrollado en este apartado, cuyas conclusiones se resumen a continuación. El proyecto ha supuesto un ejemplo de intervención y superposición de elementos existentes con sistemas nuevos.

Queda probada la posibilidad de intervención en un edificio existente con una actitud de mínimo impacto. El diseño original del edificio plantea una fachada en la que los paneles prefabricados se colocan en serie desde el exterior del espacio, independizando el sistema de envolvente del resto de la estructura. Esto permite que tanto la extracción de los paneles originales como la instalación de los propuestos se lleve a cabo desde el exterior, lo que minimiza los tiempos y posibles interferencias con la vida diaria de los usuarios. La propuesta de transformación sigue pasos similares al entender las unidades como módulos que 
permiten ser instalados independientemente desde el exterior. Del mismo modo, si en un futuro se pretendiese llevar a cabo otro proyecto de transformación, el diseño propuesto permitiría el cambio también minimizando el impacto en el usuario.

- La validación de las diferentes decisiones de diseño permite ir descartando e informando el diseño. Así, los análisis numéricos han permitido informar el proyecto de la conveniencia de un tipo de vidrio frente a otro, su composición, área, orientación, interacción con mecanismos de control solar, etc. Las opciones de todos ellos se han ido reduciendo a medida que ha ido avanzando la evaluación, el diseño y, por tanto, el proyecto.

- La simplificación del prototipo para el análisis ha permitido aislar el componente que era preciso estudiar y, de una manera más o menos sencilla, poder llevar a cabo los análisis.

- El estudio de las herramientas de evaluación ha permitido una decisión informada acerca de cuál emplear para cada caso. El proceso de selección es arduo y no siempre fácil, por lo que el conocimiento por parte de los profesionales de este tipo de técnicas permitiría una mayor facilidad de uso.

- Las envolventes están compuestas por diferentes elementos y materiales cuyo comportamiento, en solitario pero también en su conjunto, tienen un efecto energético en el espacio. A lo largo del proyecto se han estudiado los componentes aislados para, posteriormente, estudiar y evaluar los diferentes tipos de pieles. La posición y tipo de control solar comienza a definir la tercera dimensión de las envolventes y a crear espacios de interacción con la estructura y estancia original.

- No existe una solución única. Esto se ha tenido en consideración desde el comienzo del trabajo mediante el concepto de adaptabilidad. Los análisis han demostrado que, aunque evidentemente unas propuestas son más idóneas que otras, también son intercambiables hacia una solución conjunta.

Las soluciones presentadas no supondrán una solución perfecta. La idoneidad de unas y otras viene determinada por la evaluación de las prioridades. Los resultados demuestran que lo que puede ser idóneo en un momento, puede 
ser contraproducente en otro. Entender las prioridades ayudará a establecer los requisitos. El concepto de adaptabilidad también está presente en este punto.

- Por último, el proyecto permite entender la relación entre el espacio y la piel que lo delimita: la envolvente. La función de ésta no será la misma dependiendo del espacio que recubra y, del mismo modo, la calidad del espacio se verá afectada en gran medida por la envolvente. Los estudios de los diferentes diseños han permitido evaluar numérica y gráficamente dicha interacción.

En conclusión, este trabajo de investigación ha permitido explorar la integración de la envolvente en el proceso arquitectónico mediante un proyecto de transformación de la fachada de un edificio en Chicago. Sin que ello signifique una solución única, sí supone una posible actitud ante el diseño. 



\section{CAPÍTULO 07 \\ BIBLIOGRAFÍA}

-Ábalos, Iñaki, and Juan Herreros. Técnica y Arquitectura en la Ciudad Contemporánea 1950-2000. Guipúzcoa: Editorial Nerea, 1992 .

-Allen, William. Envelope design for buildings. Oxford: Butterworth Heinemann, 1997.

-Baker, N. Energy and Environment in Architecture. A Technical Design Guide. London: Taylor \& Francis Group, 2000.

-Blaser, Werner. Mies van der Rohe Lake Shore Drive Apartments. Basel: Birkhäuser-Publishers for Architecture, 1999.

-Blaser, Werner. Mies van der Rohe : IIT Campus, Illinois Institute of Technology, Chicago. Basel; Birkhäuser, 2002.

-Brock, Linda. Designing the exterior wall. An architectural guide to the vertical envelope. Hoboken, New Jersey: John Wiley \& Sons, Inc., 2005.

-Bucci, Federico. "George Schipporeit, John Heinrich, Alfred Caldwell: Lake Point Tower, Chicago". Casabella 74, no. 790 (2010): 34-46.

-Buchanan, Peter. "Reinventing the Sky-Scraper". A and U. no 329, (1998): 30-67.

-Cody, Brian. "Energía y Arquitectura". Profile Revista sobre Arquitectura, no. 5, Schucco (2009).

-Compagno, Andrea. Intelligent Glass Façades: Material, Practice, Design. 5th ed. Berlin: Brikhäuser Publishers, 2002 .

-Council of Tall Building and Urban Habitat. (Illinois Institute of Technology, EEUU): http://www.ctbuh.org.

-Dell'Isola, K. Life Cycle Costing for Design Professionals. New York: McGraw-Hill, Inc, 1995. 
-Evans, Barrie. "Banking on Ventilation". AJ Building Study. (1997).

- Frampton, Kenneth. Modern architecture: a critical history. London: Thames \& Hudson, 2007.

-Fox Weber, Nicholas. Le Corbusier. A Life. New York: Random House, 2008.

-Greene, AM. "Curtain wall. More than skin deep". Iron Age, no. 207, (1971): 77-79.

- NA. "Lacaton \& Vassal Obra Reciente Recent Work". 2G, n60 (Barcelona: Gustavo Gili, 2010)

-Hausladen, G., de Saldanha, M., Liedl, P. Climate Skin: Building-skin concepts that can do more with less energy. Basel: Birkhäuser-Publishers for Architecture, 2008.

-Herzog, Thomas. Façade Construction Manual. Munich: Birkhäuser Edition Detail, 2004.

-Holt, Glen, Pacyga, Dominic. Chicago: a historical guide to the neighborhoods. The Loop and the south side. Chicago: The Chicago Historical Society, 1979.

- Jayamaha, Lal. Energy-efficient building systems: green strategies for operation and maintenance. New York: McGrawHill Professional Publishing, 2007.

-Kruger, Paul. Alternative energy resources: the quest for sustainable energy. Hoboken, N.J.: 2006.

-Lahey, John. Klemencie, Ron. A Tale of Two Cities: Collaborative Innovations for Sustainable Towers. CTBUH 8th World Congress. Chicago, 2008.

-Lechner, Norbert. Heating, Cooling, Lighting. Sustainable Design Methods for Architects. New Jersey: John Wiley \& Sons, 2009 . 

- Ortega y Gaset, José. Meditación de la Técnica. Filosofía Hoy. Madrid: Edición de la Revista Occidente, 1977.

-Paricio, Ignacio. La piel ligera: maduración de una técnica constructiva. Barcelona: Bisagra, 2000.

-Paricio, Ignacio. El vidrio estructural. Barcelona: Grupo Folcrá Edificación SA, 2010.

-Pomaranc, Joan C. 860-880 Lake Shore Drive. Chicago: Commission on Chicago Historical and Architectural Landmark, 1976 .

-Raymond, Ting. "Functional isolation concept in curtain wall design". Building Integration Solutions. Proceedings of the 2006 Architectural Engineering National Conference, v. 2006, (2006): 13 .

-Richman, R., Pressnail, K. "A more sustainable curtain wall system: Analytical modeling of the solar dynamic buffer zone (SDBZ) curtain wall". Building and Environment, v.44, no.1, (January 2009): 1-10.

-Rimmer, Graham. "Fighting back for curtain walls". Building 248, no. 13, (1985): 32-33

-Rivas, Flor. "Life cycle cost based economic assessment of Active Building Envelope (ABE) systems". Collection of Technical Papers - AIAA/ASME/ASCE/AHS/ASC Structures, Structural Dynamics and Materials Conference, v.8, (2006): 55345548 .

-Rivas, Flor. "Economic viability assessment of active building envelope systems" Collection of Technical Papers AIAA/ASME/ASCE/AHS/ASC Structures, Structural Dynamics and Materials Conference, v.5, (2005): 3235-3251.

-Roth, Kurt. "Double Skin Façades". ASHRAE Journal, v.49, no.10, (October 2007): 70-73.

-Schaal, Rolf. Curtain walls: Design Manual. New York: Reinhold Publishers, 1962. 
-Schulze, Franz. Illinois Institute of Technology [electronic resource]: the campus guide : an architectural tour. New York: Princeton Architectural Press, 2005.

-Sobek, Werner. "Sustainable Tall Buildings. Some Introductory Remarks". CTBUH, 8th World Conference, (2008).

Stout, Randall. Building envelope. Washington DC: NCARB, 2004 .

- Tzemppelikos, A. Integration of Dynamic Façades with other Building Systems. CABA. http://www.caba.org . 2008.

-Vázquez, Fernando. Mies van der Rohe, 1886-1969. Lisboa: Editorial Blau, 1999.

-Wigginton, Michael, Harris, Jude. Intelligent skins. Oxford: Elsevier Ltd, 2002.

-Winderhost, Edward. Lake Point Tower, a design history. Chicago: Chicago Architecture Fondation, 2009.

-Winter, John. 1973. "Follow Mies". Architectural Review 154, (1973): 42-52.

-Yeang, Ken. "The Skyscraper Bioclimatically Considered". Architectural Review, no.202, (August 1997).

-Yeang, Ken. "The Ecological (or Green) Approach to Design." CTBUH, no.1, v.1, (May 2000).

-Yeang, Ken. "Ecoskyscrapers and Ecomimesis: New tall building typologies". CTBUH, 8th World Conference, (March 2008).

- Zukowsky, John. Masterpieces of Chicago architecture. New York: Rizzoli, 2004.

-Zukowsky, John, Mies van der Rohe, su arquitectura y sus discípulos. Madrid: Ministerio de Obras Públicas y Urbanismo, 1987 . 



\section{CAPÍTULO 08}

\section{ANEXOS}

\section{INTRODUCCIÓN}

Las gráficas y resultados que se exponen a continuación son resultado de los análisis llevados a cabo de los diferentes sistemas diseñados. Los resultados no deben extraerse como valores absolutos, sino como conclusiones derivadas de las simulaciones. 

RESULTADOS DE LOS ANÁLISIS DE LA ORIENTACIÓN DEL VIDRIO. 


\section{ANEXOS}

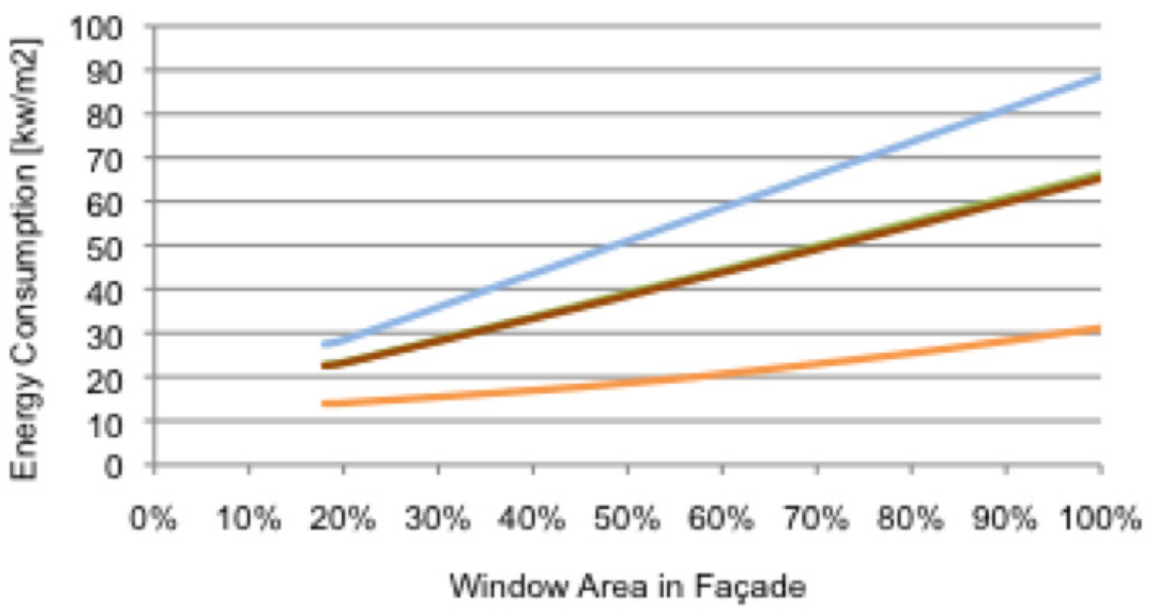

North - South East West

Vidrio Tipo A: Cargas de Calefacción

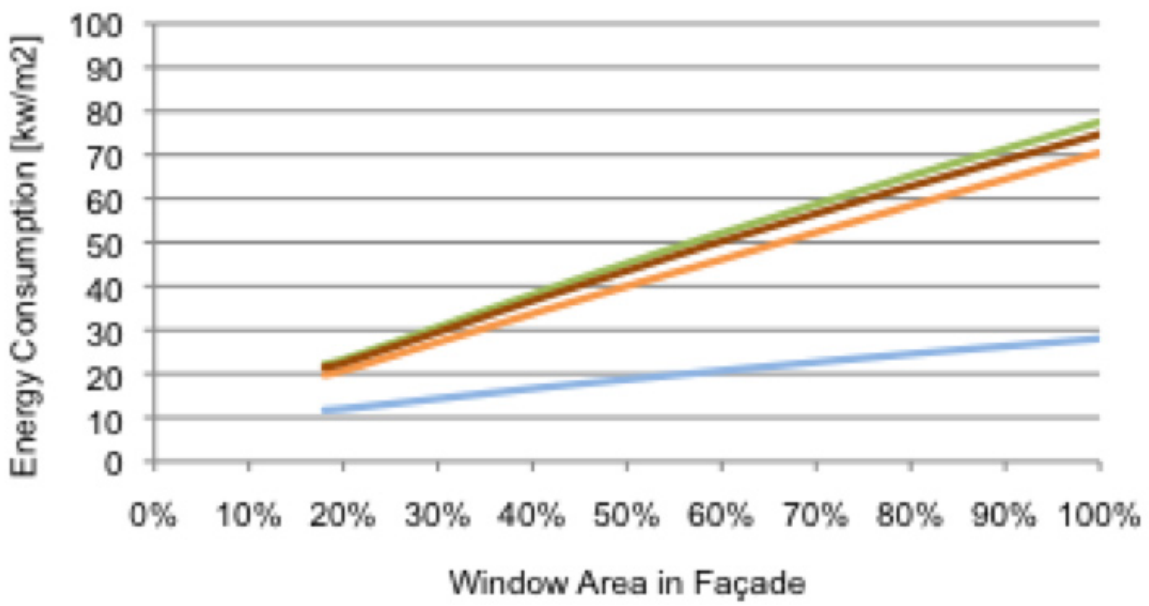

North - South - East West

Vidrio Tipo A: Cargas de Refrigeración 


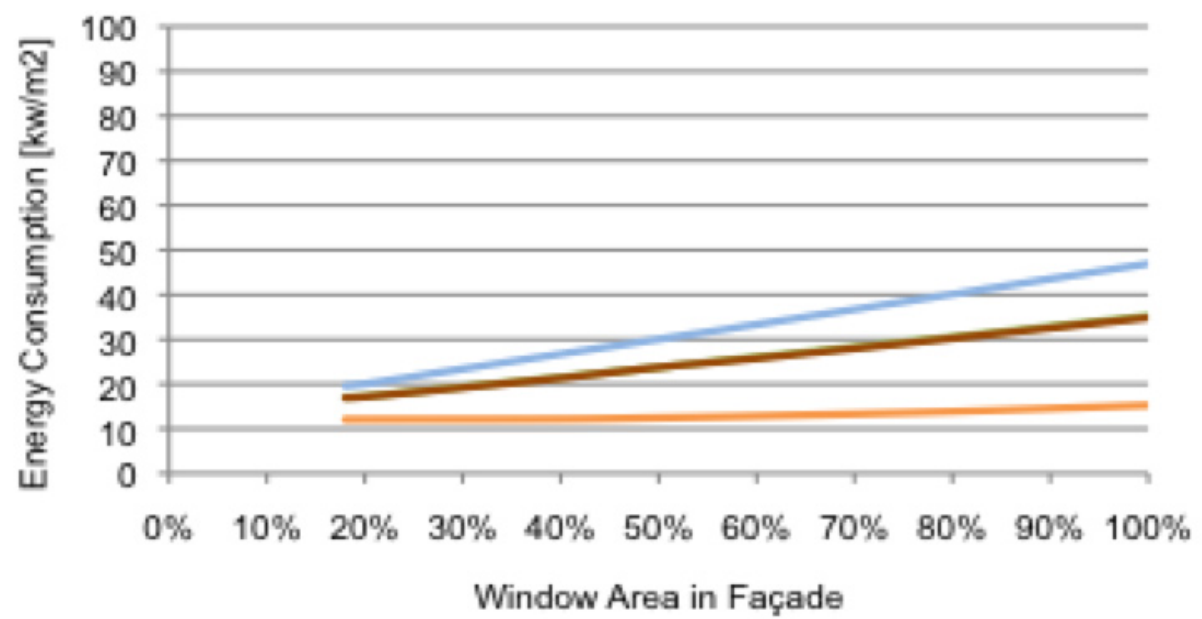

North - South - East West

Vidrio Tipo B: Cargas de Calefacción

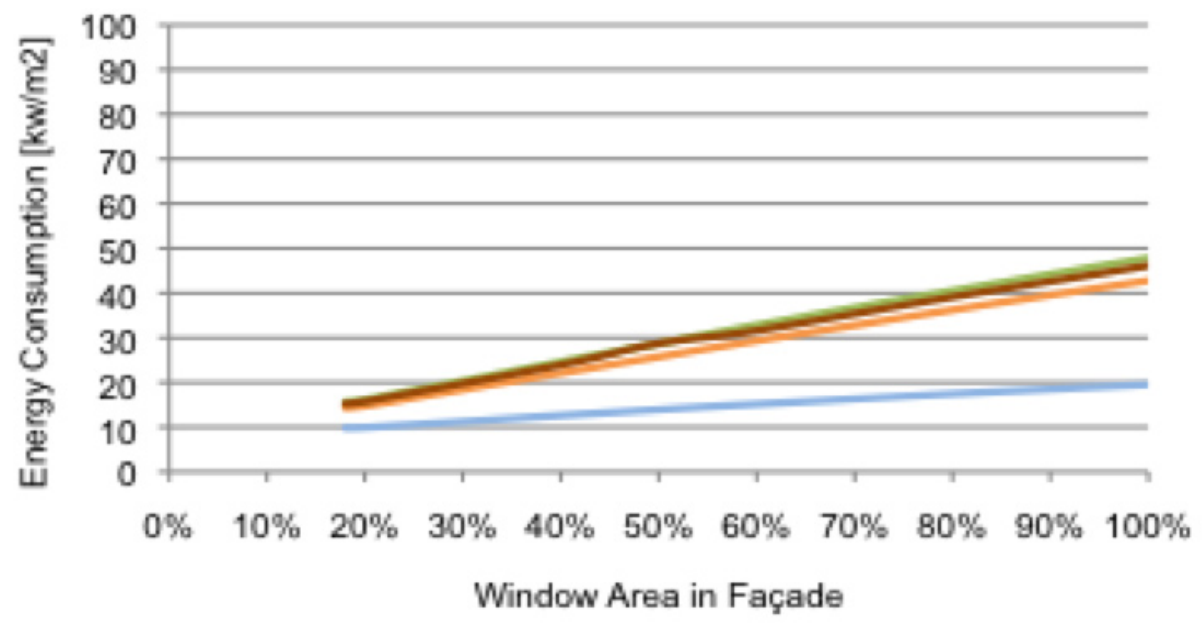

North - South Wast West

Vidrio Tipo B: Cargas de Calefacción 


\section{ANEXOS}

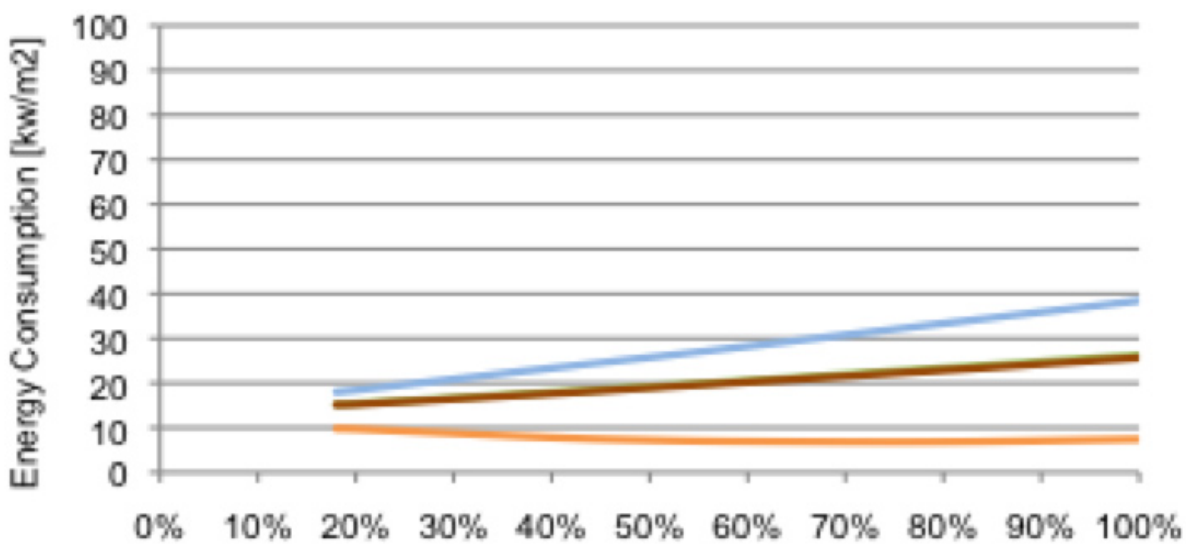

Window Area in Façade

North - South Wast West

Vidrio Tipo D: Cargas de Calefacción

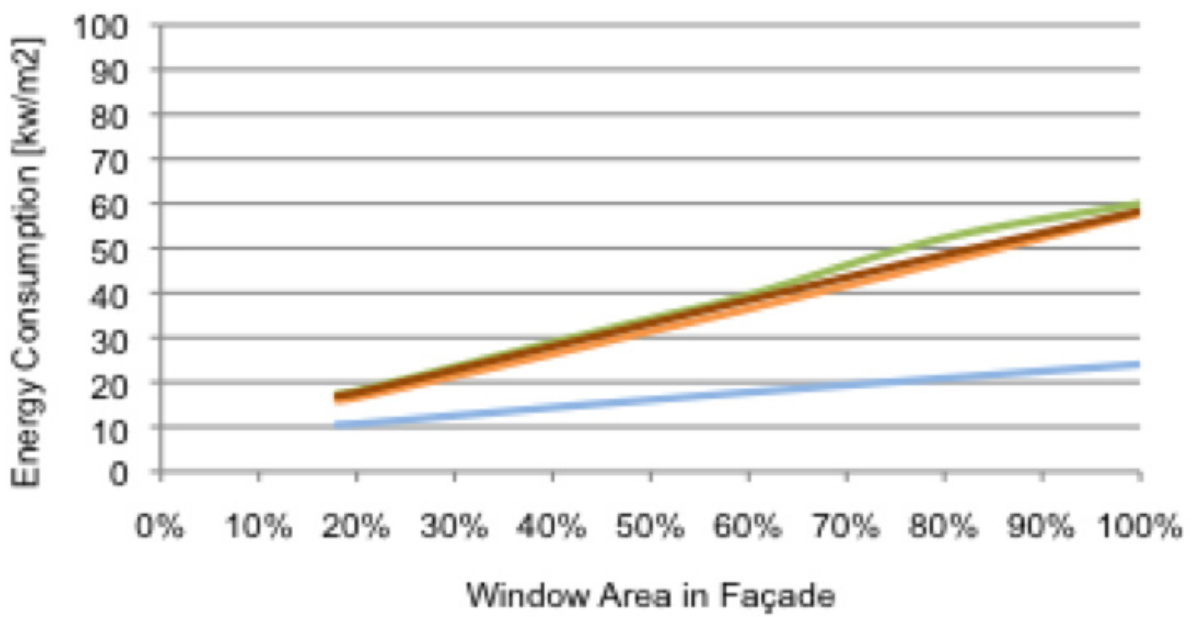

North - South - East West

Vidrio Tipo D: Cargas de Refrigeración 


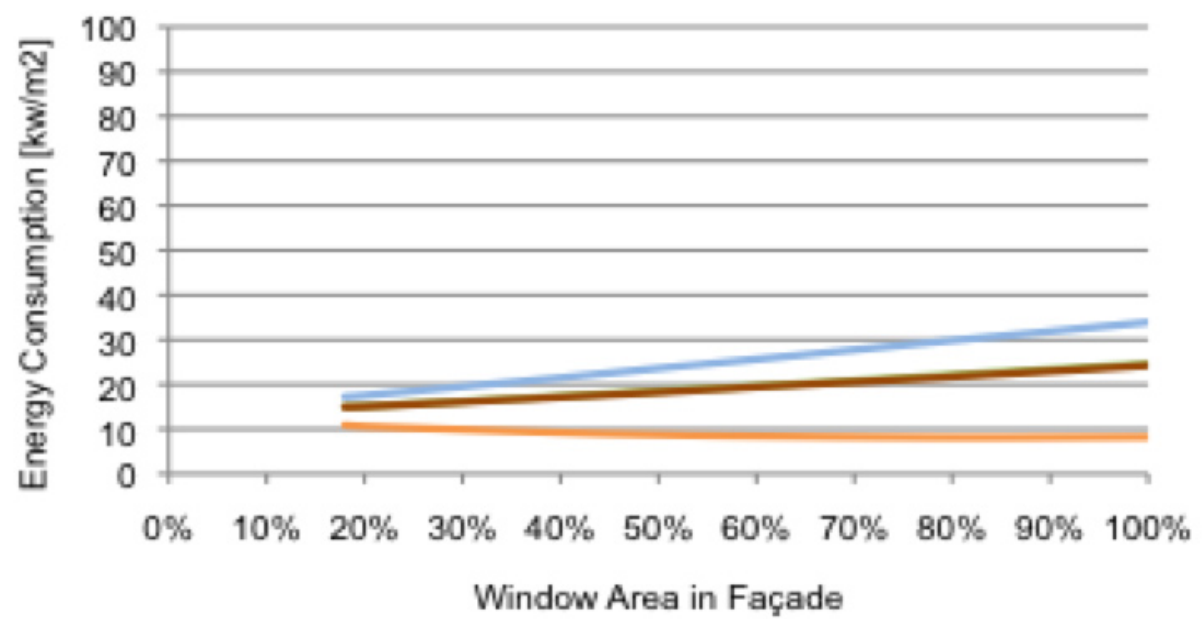

North - South - East West

Vidrio Tipo E: Cargas de Calefacción

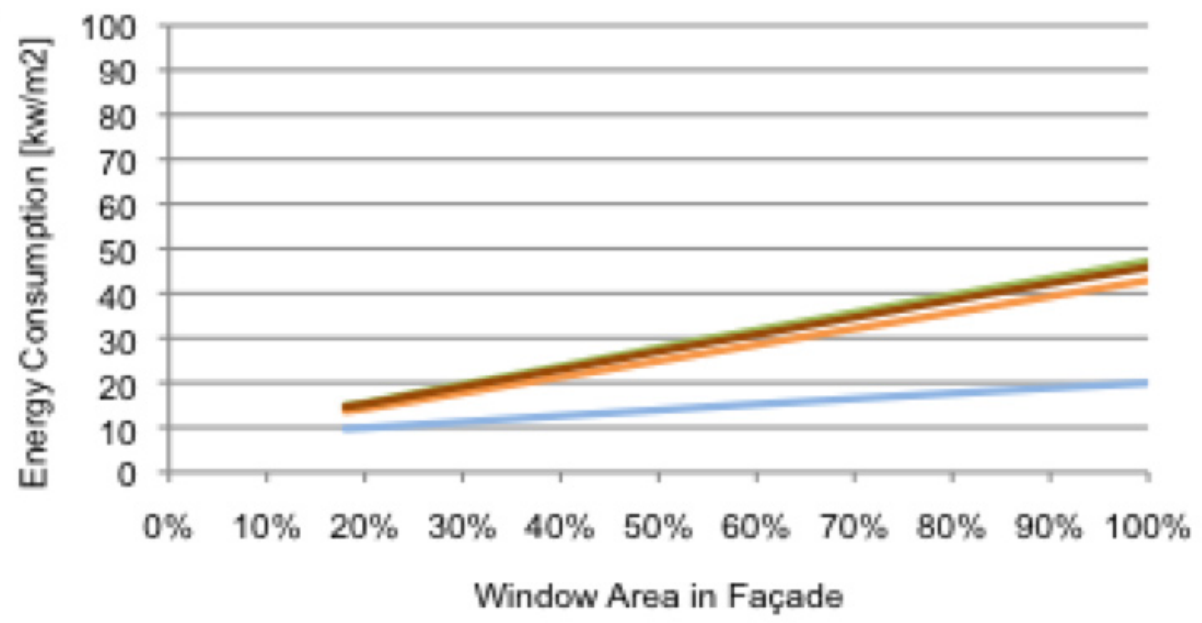

North - South Wast West

Vidrio Tipo E: Cargas de Refrigeración 


\section{ANEXOS}
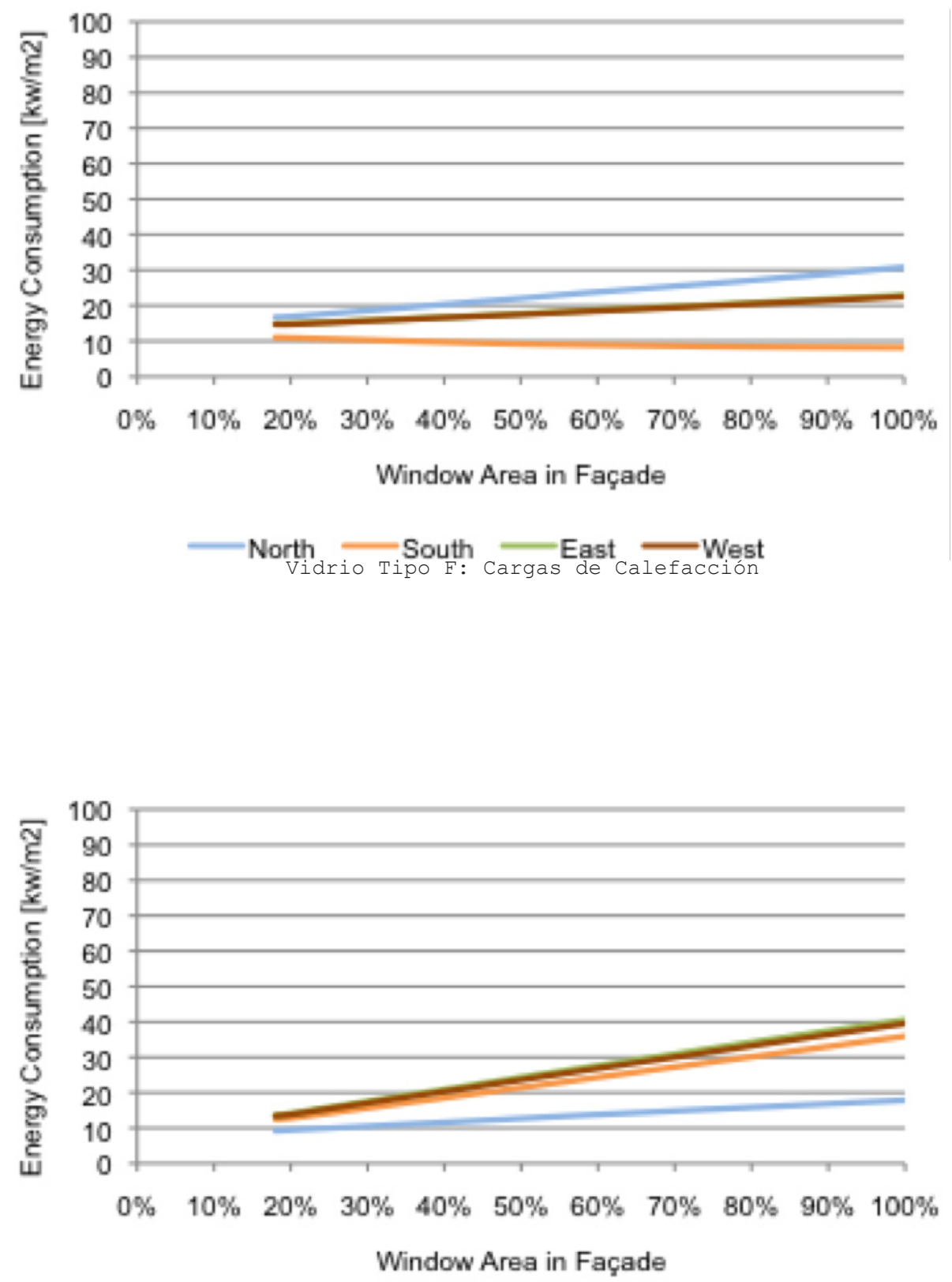

North - South - East 


RESULTADOS DE LOS ANÁLISIS DEL TIPO DE VIDRIO EMPLEADO 


\section{ANEXOS}
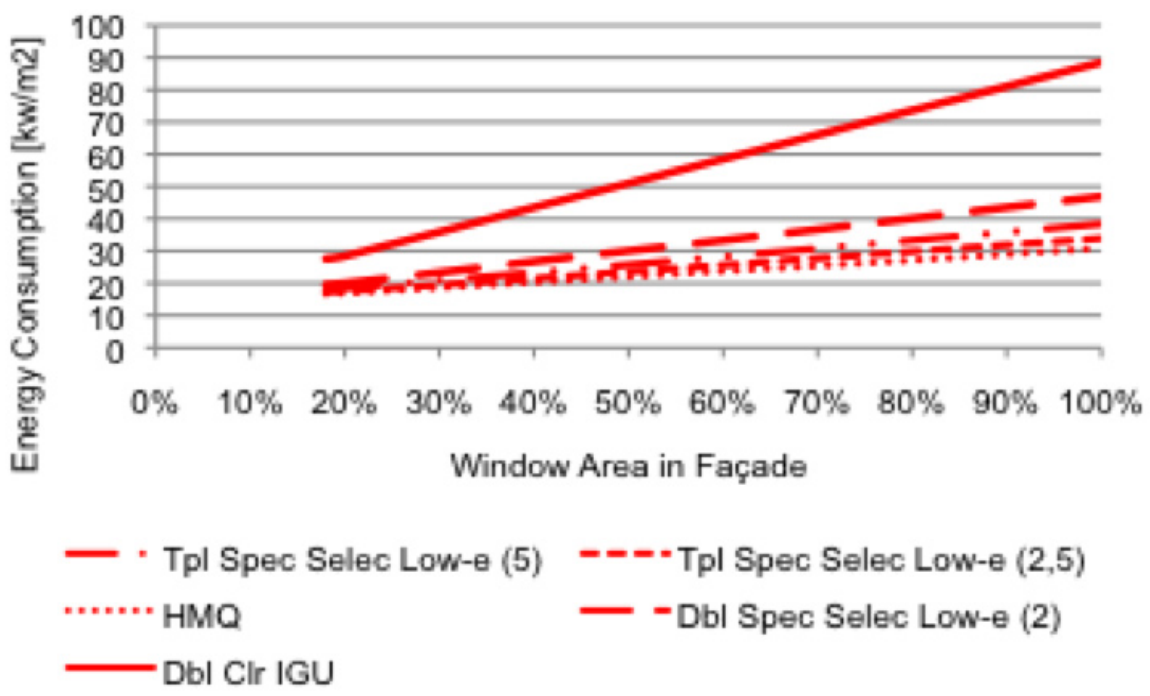

Fachada Norte: Cargas de Calefacción

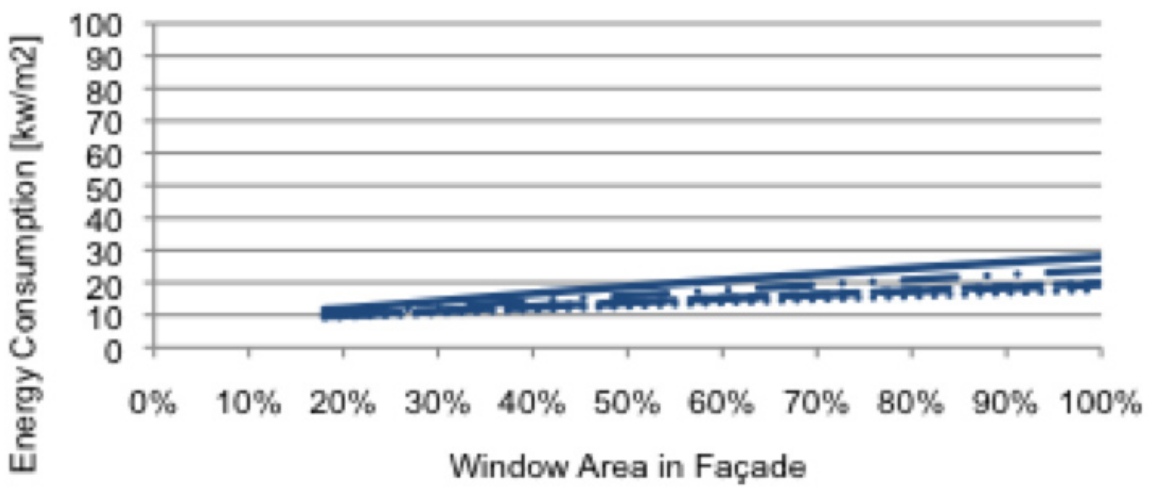

\footnotetext{
- Tpl Spec Selec Low-e (5) - --"Tpl Spec Spec Low-e (2,5)

HMQ

- -Dbl Spec Selec Low-e (2)

Dbl CIr IGU

Fachada Norte: Cargas de Refrigeración
} 

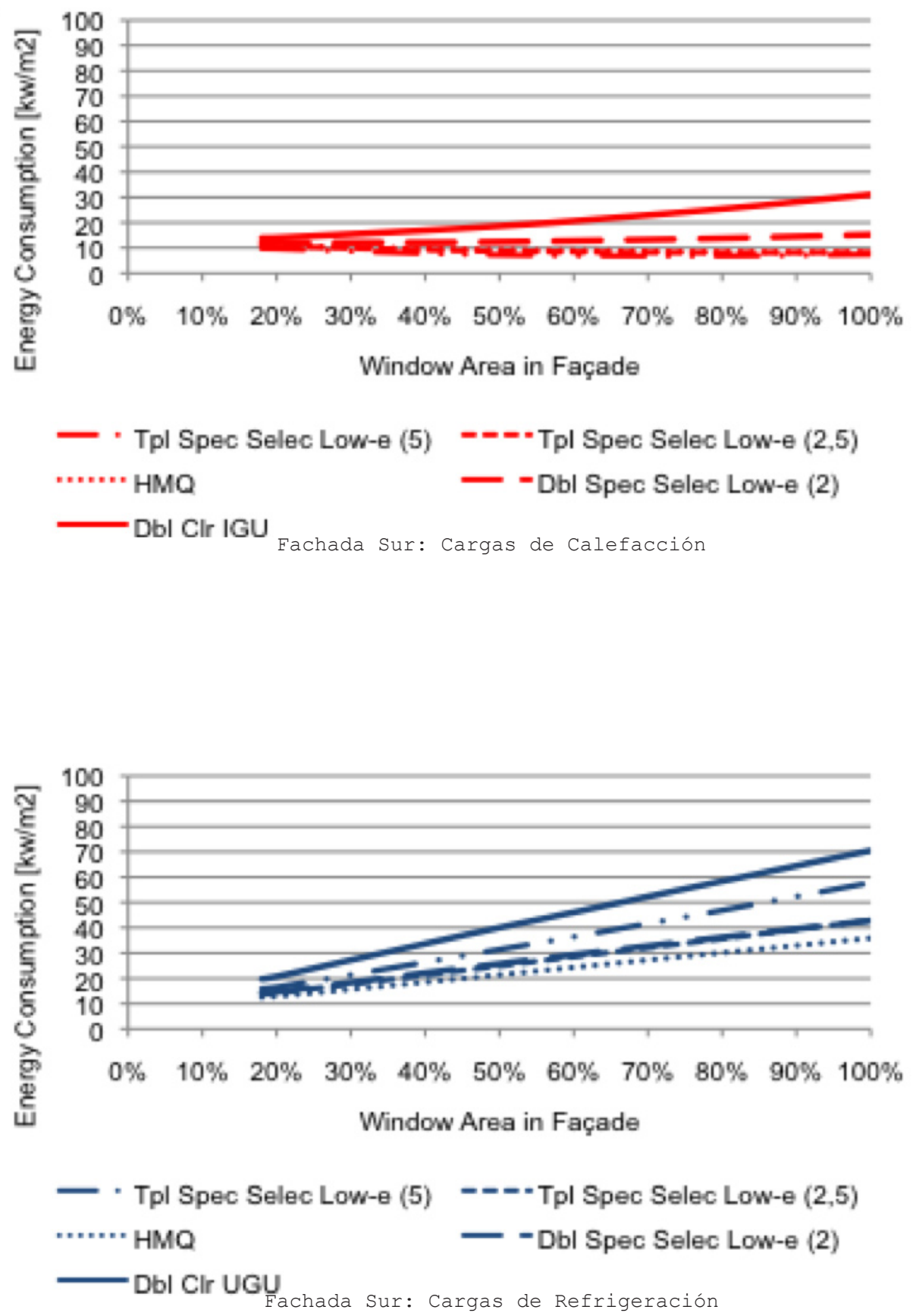


\section{ANEXOS}
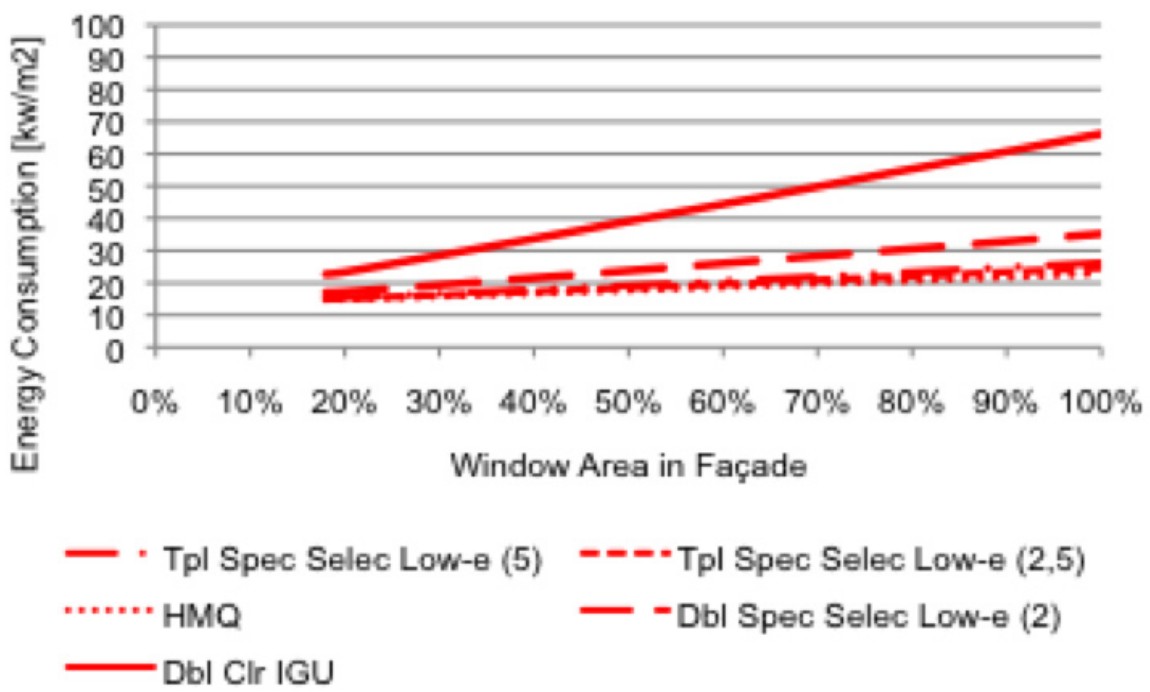

Fachada Este: Cargas de Calefacción

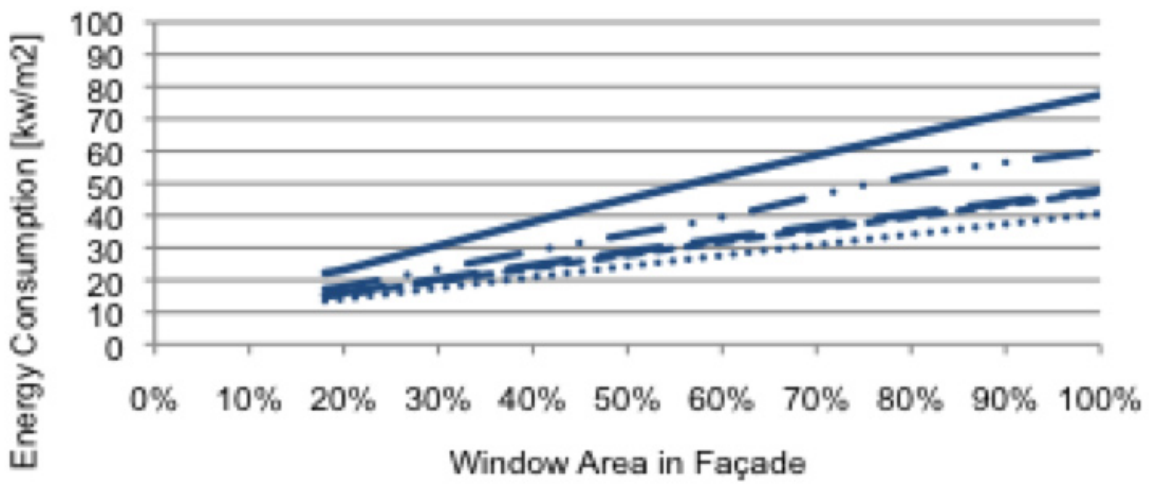

\footnotetext{
- Tpl Spec Selec Low-e (5) - ---Tpl Spec Selec Low-e $(2,5)$

HMO

- -Dbl Spec Selec Low-e (2)

- Dbl Clr IGU

Fachada Este: Cargas de Refrigeración
} 


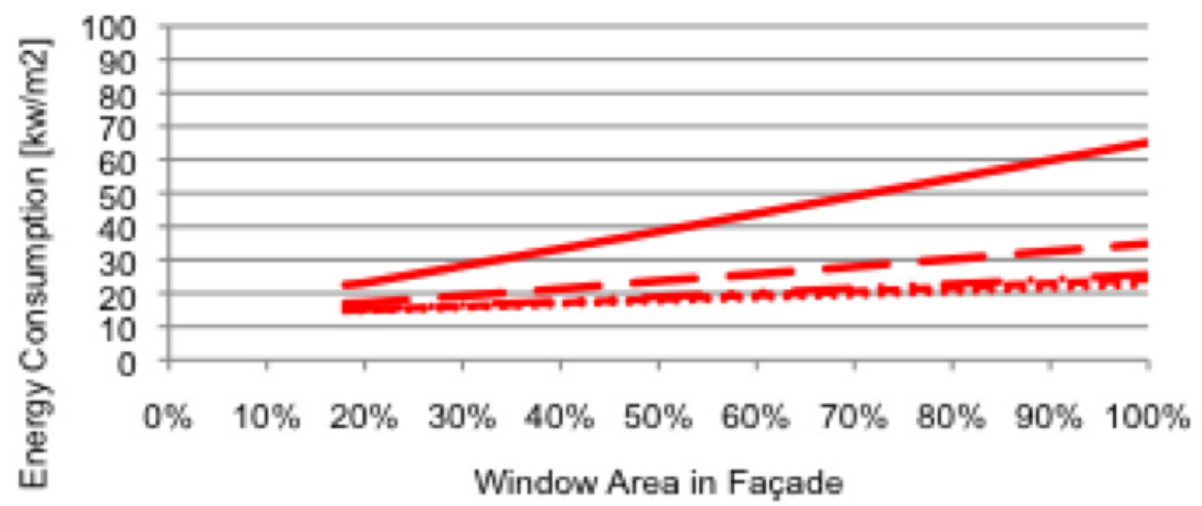

- "Tpl Spec Selec Low-e (5) - --- Tpl Spec Selec Low-e (2,5)

.......HMQ - - Dbl Spec Selec Low-e (2)

- Dbl Clr IGU Fachada Oeste: Cargas de Calefacción

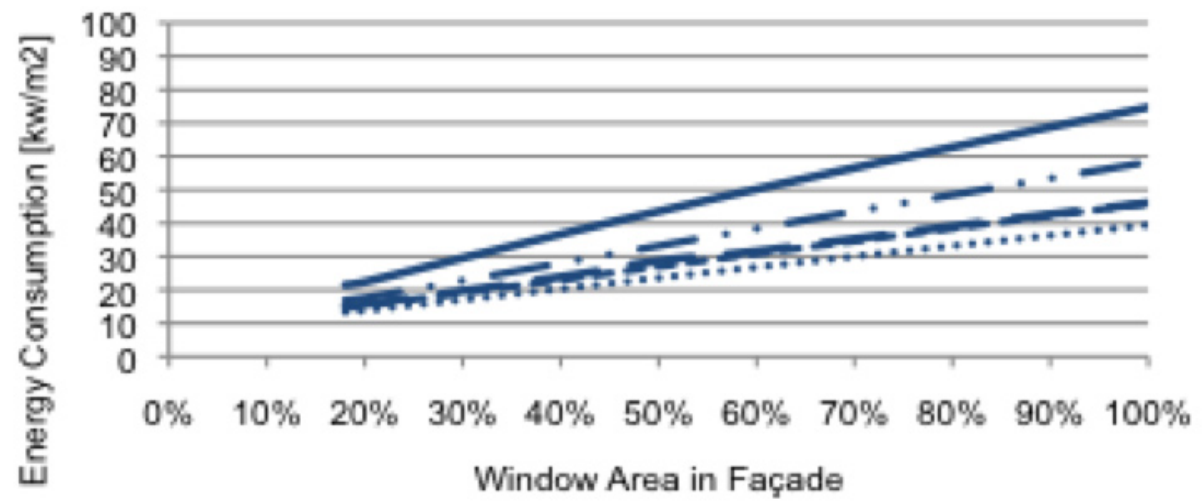

\footnotetext{
- "Tpl Spec Selec Low-e (5) - ---Tpl Spec Selec Low-e (2,5)

$\mathrm{HMQ}$

- -Dbl Spec Selec Low-e (2)

- Dol Clr IGU 

RESULTADOS DE LOS ANÁLISIS DEL TIPO DE MECANISMOS DE CONTROL SOLAR. 
ANEXOS
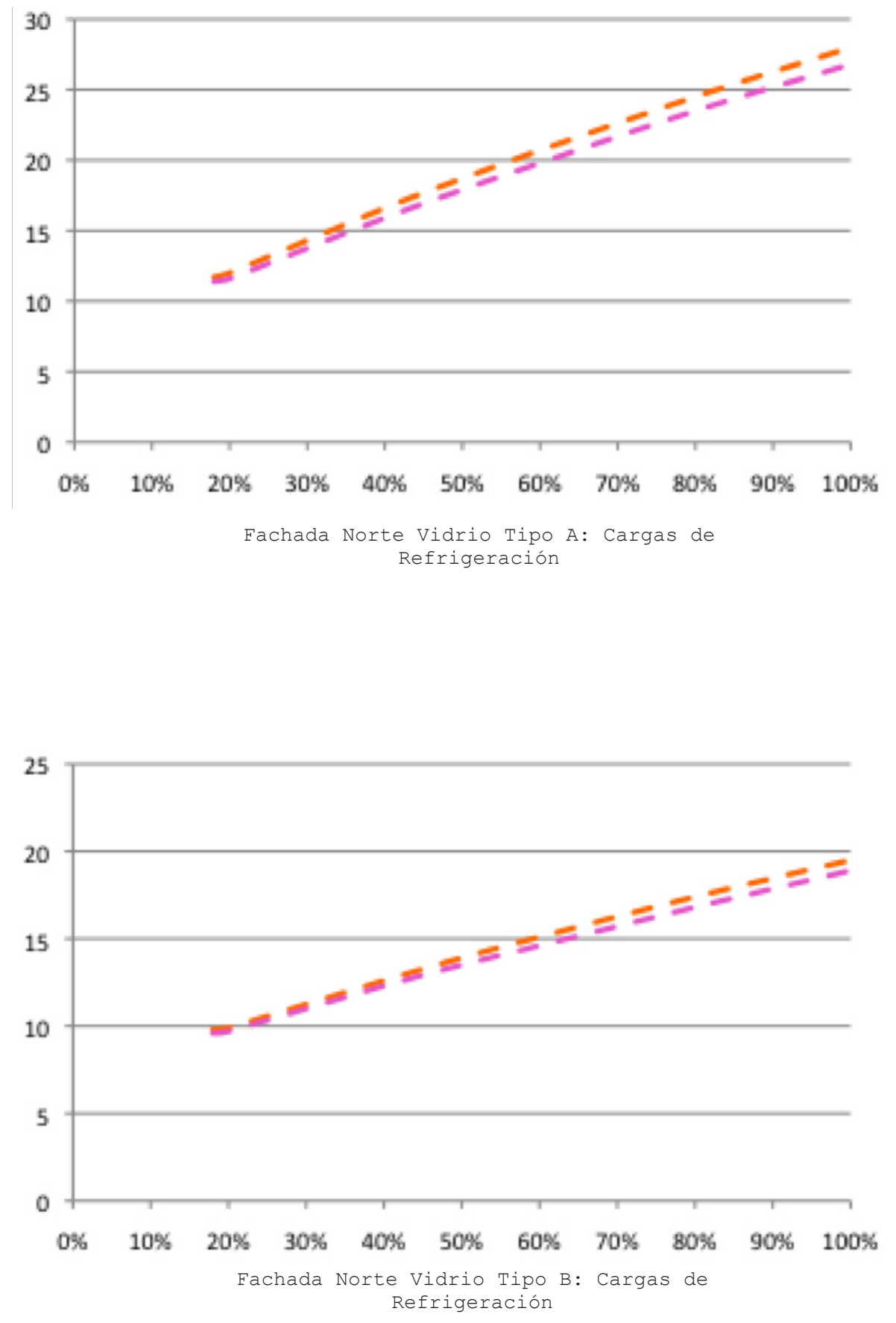

376 
ANEXOS
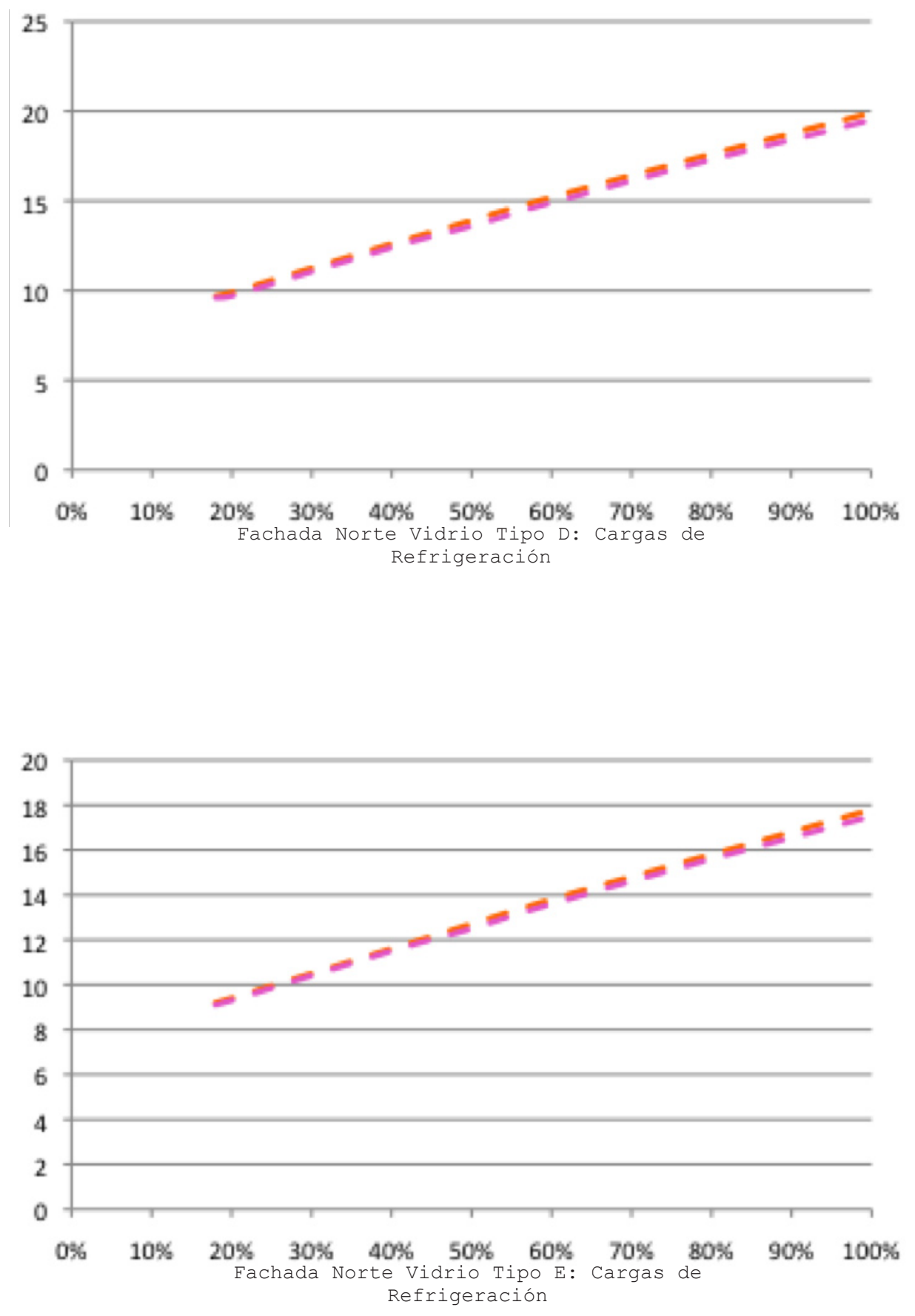

377 
ANEXOS

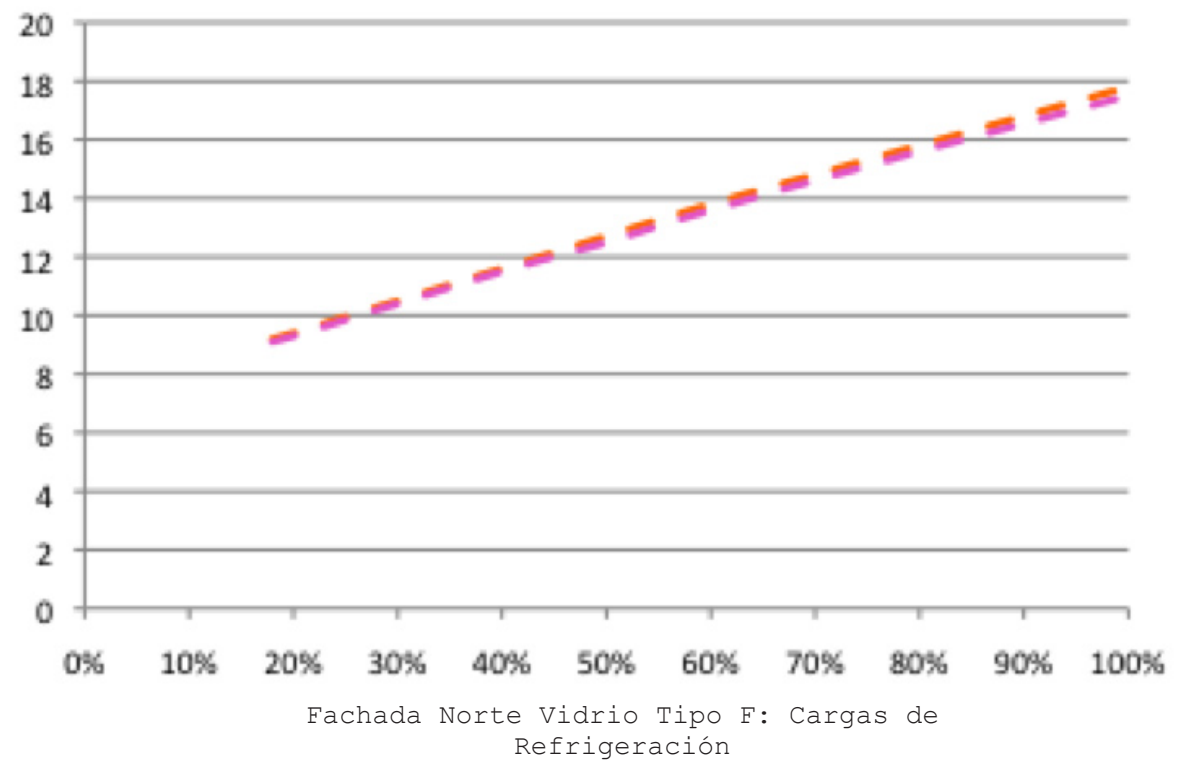

378 



\section{ANEXOS}
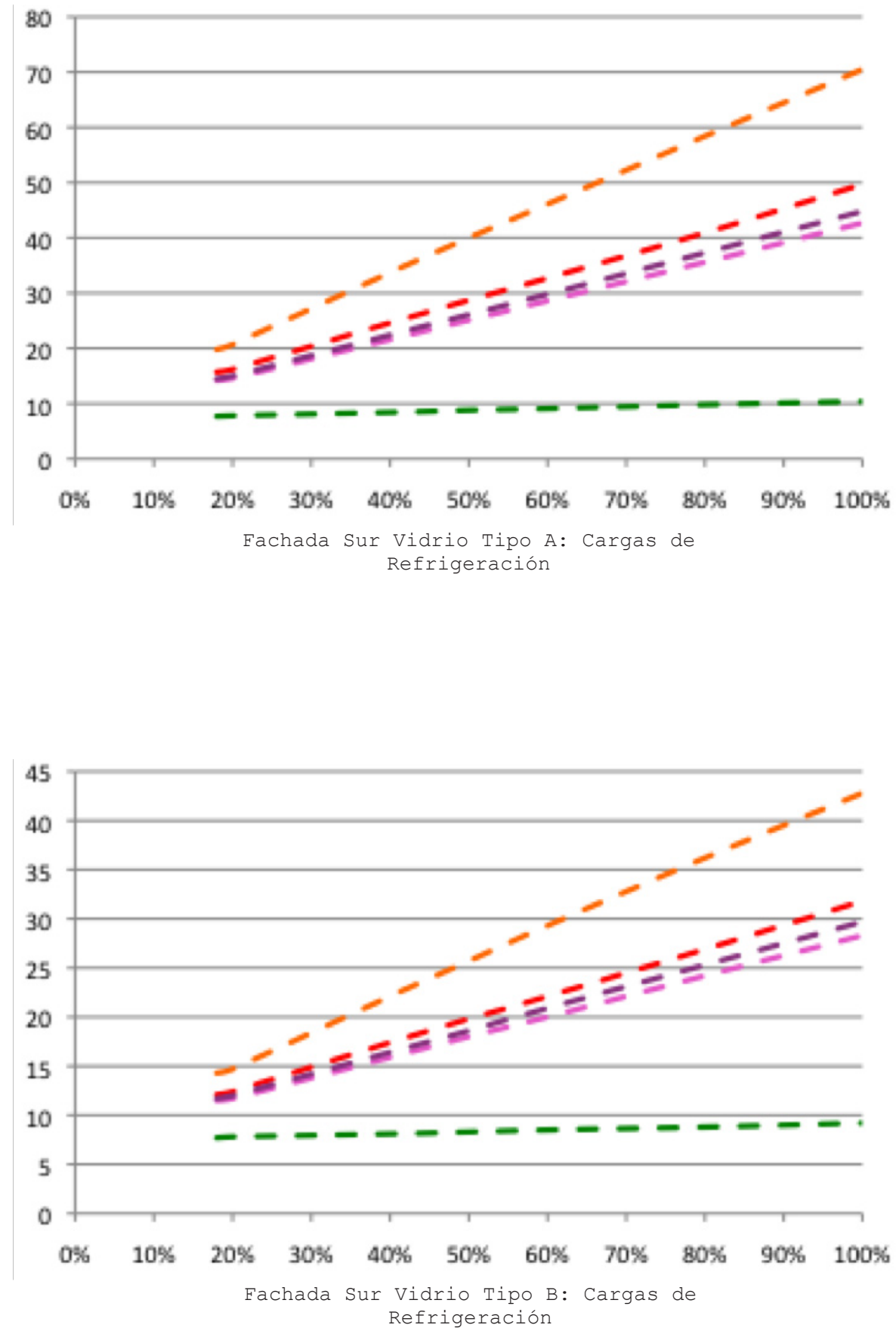
ANEXOS
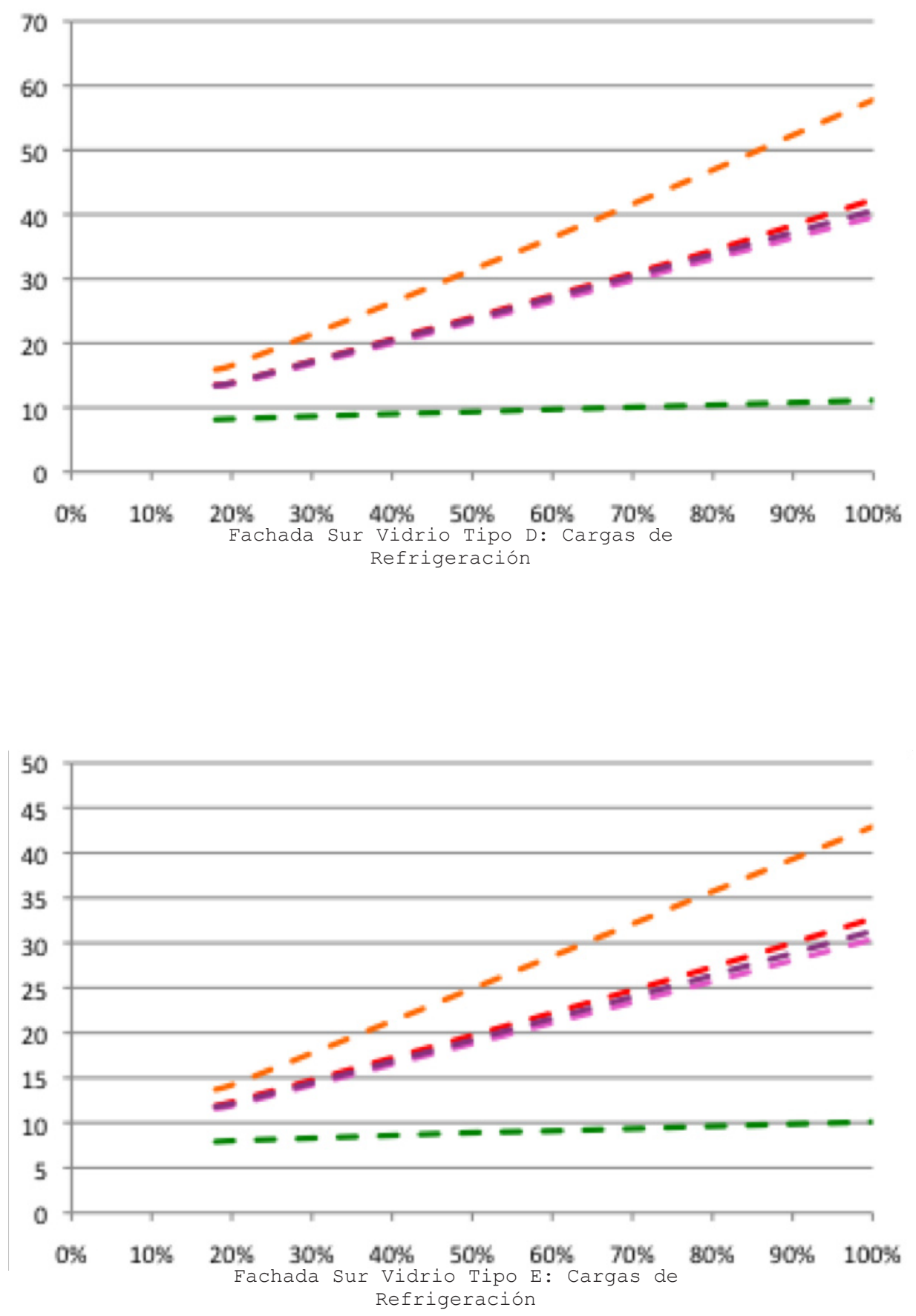

381 
ANEXOS

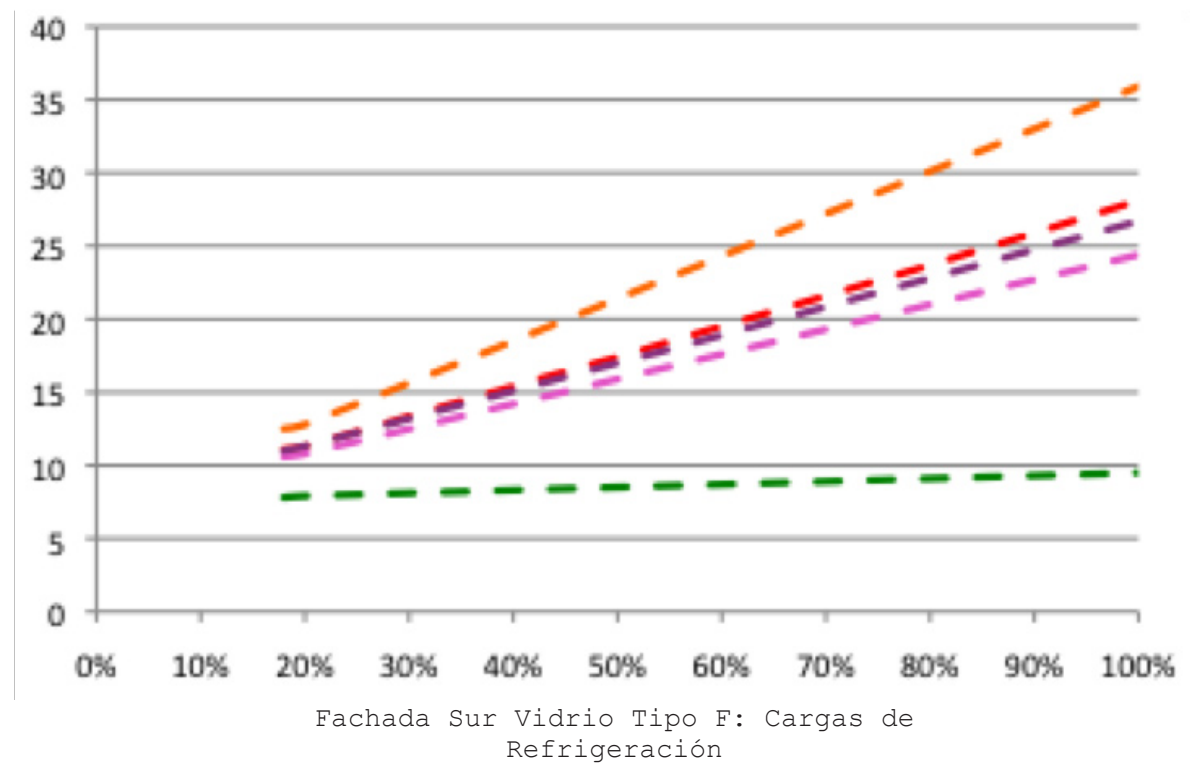

382 

ANEXOS

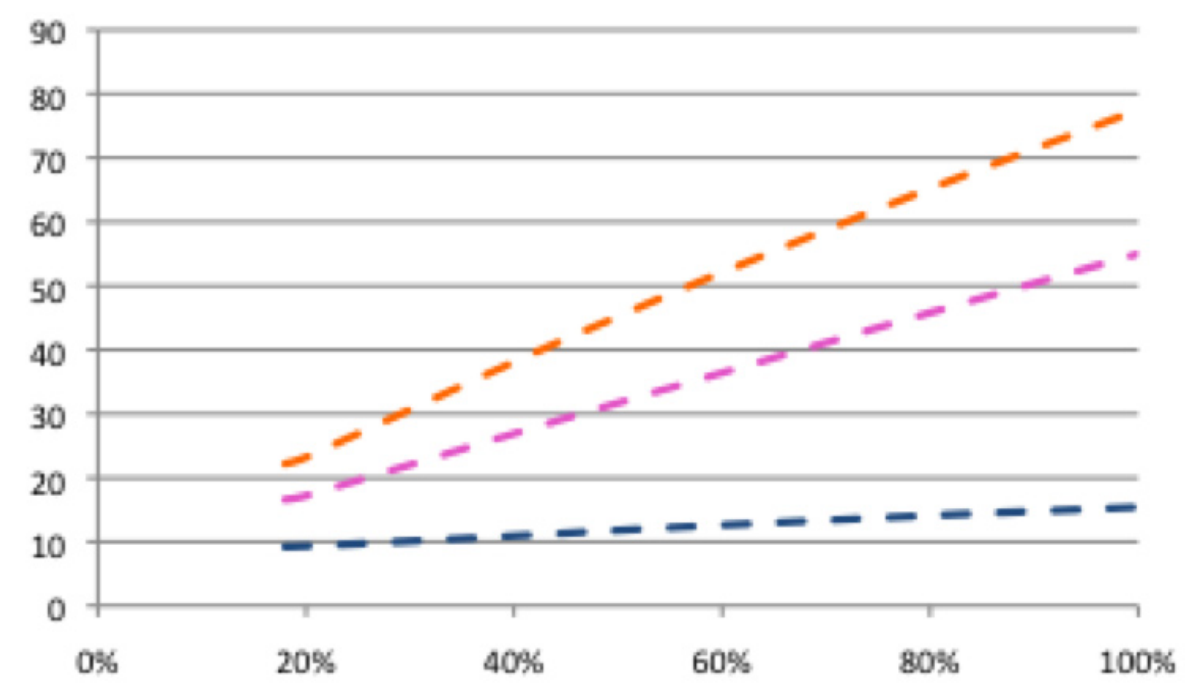

Fachada Este Vidrio Tipo A: Cargas de Refrigeración

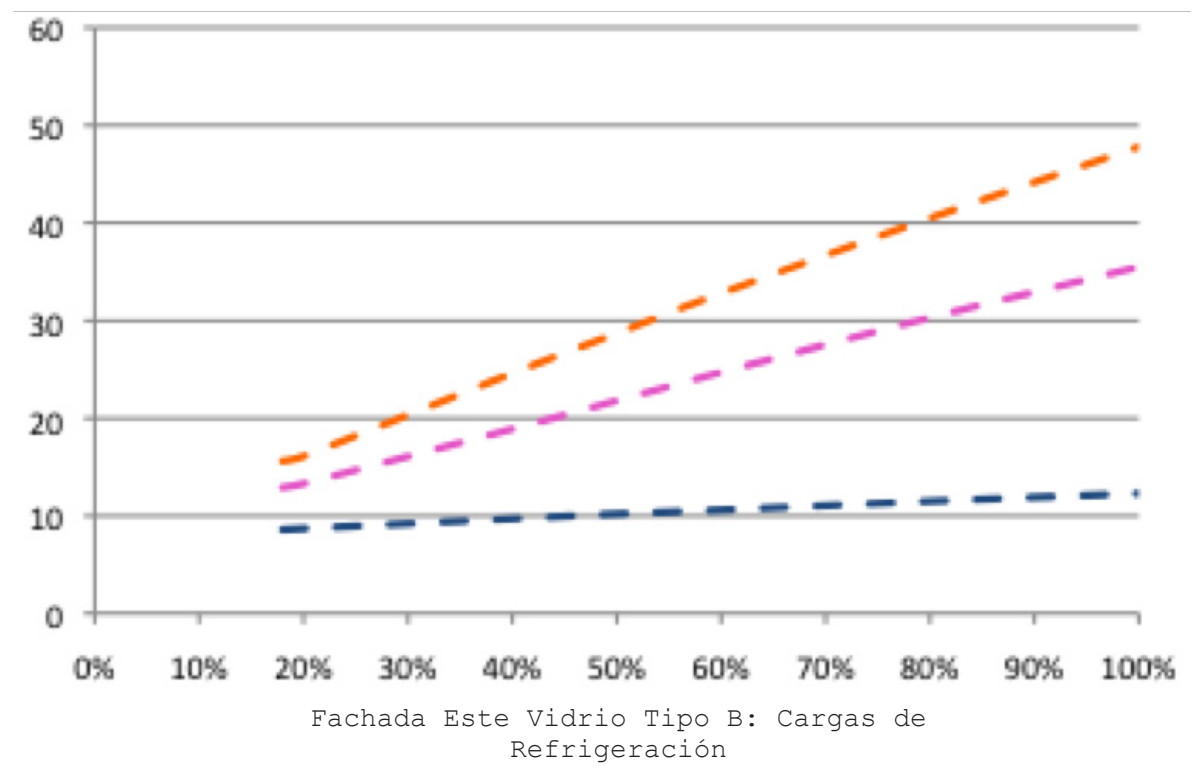

384 
ANEXOS
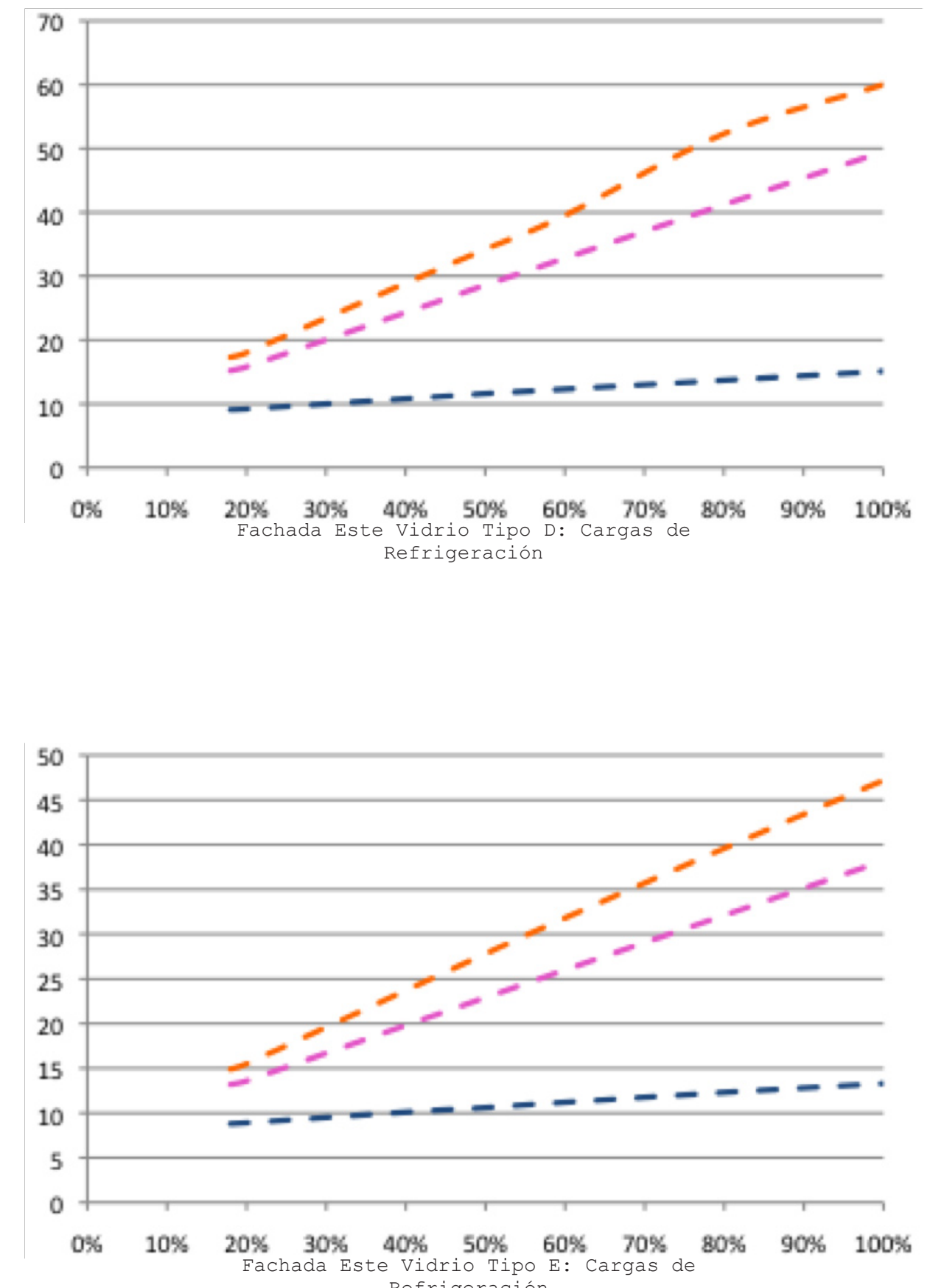

385 
ANEXOS

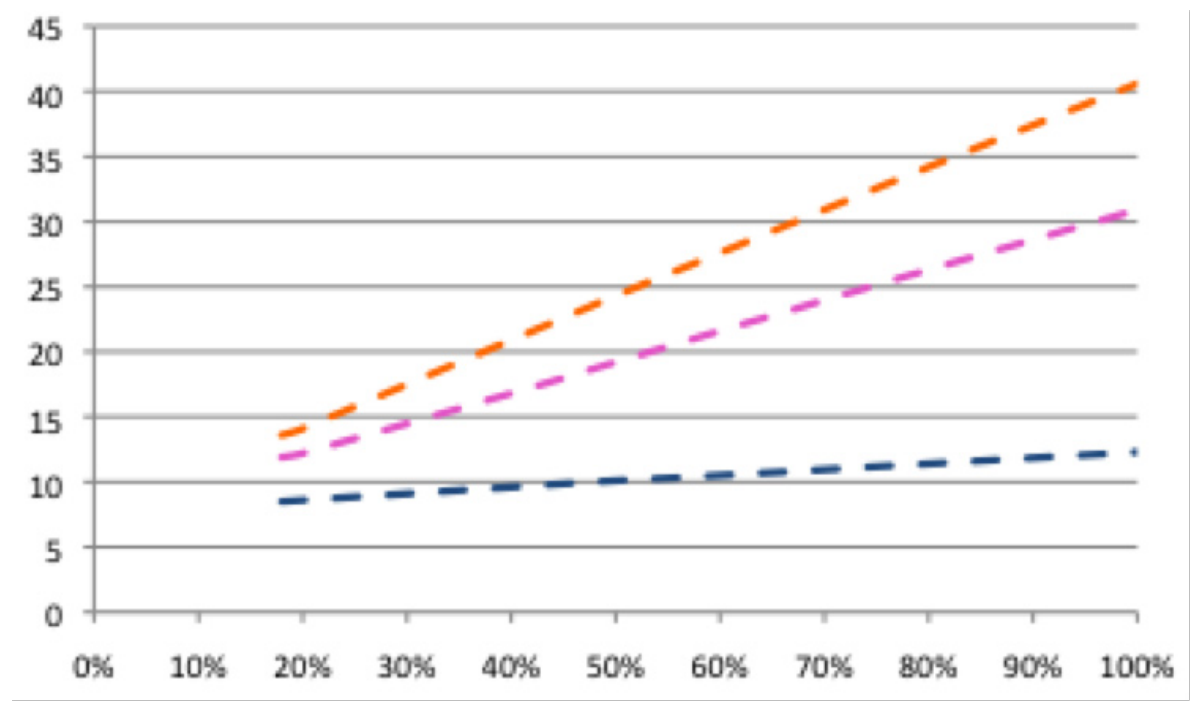

Fachada Este Vidrio Tipo F: Cargas de Refrigeración

386 



\section{ANEXOS}

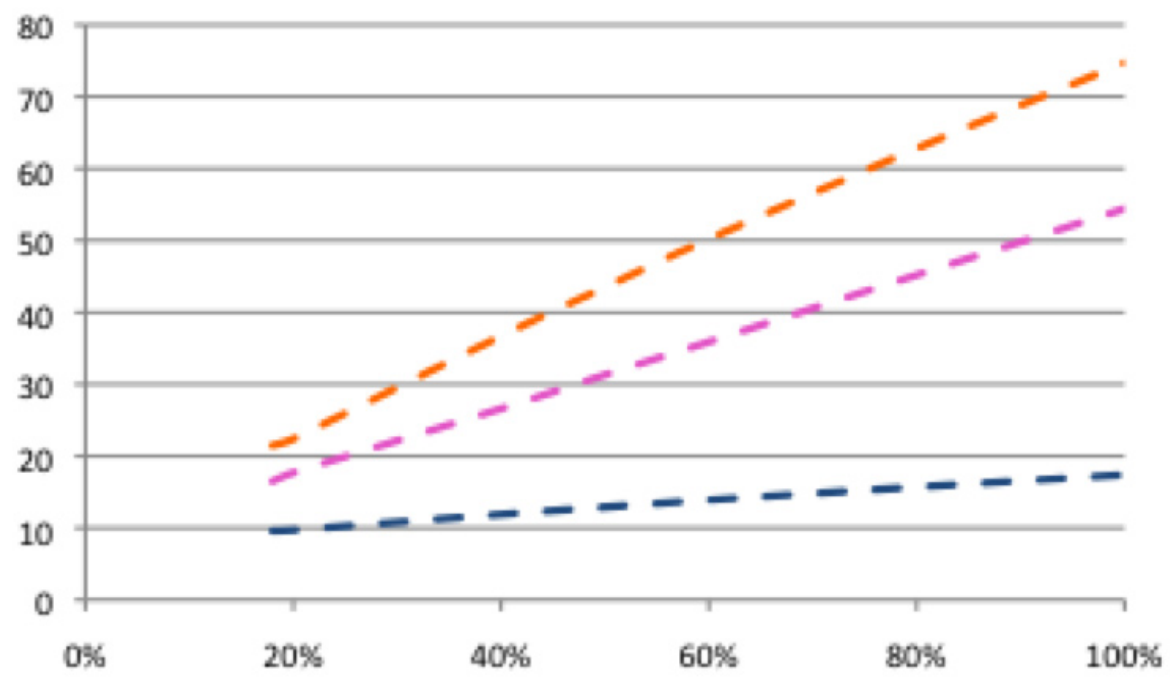

Fachada Oeste Vidrio Tipo A: Cargas de Refrigeración

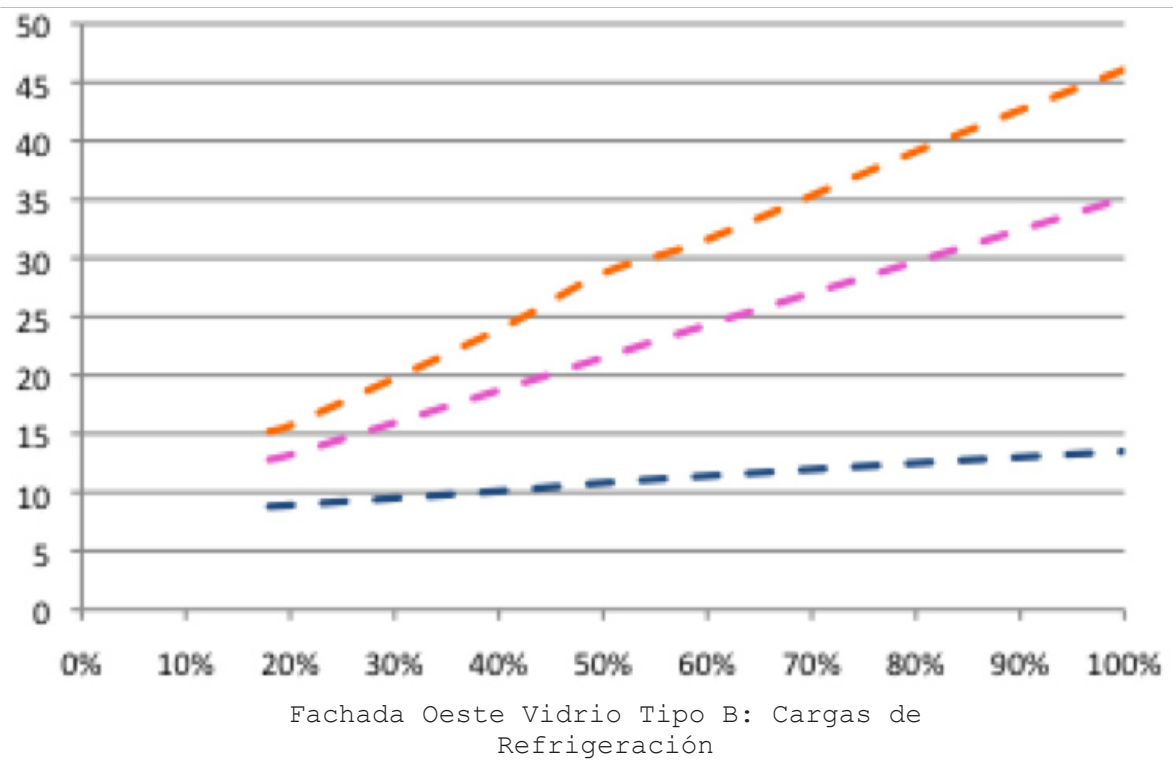


ANEXOS
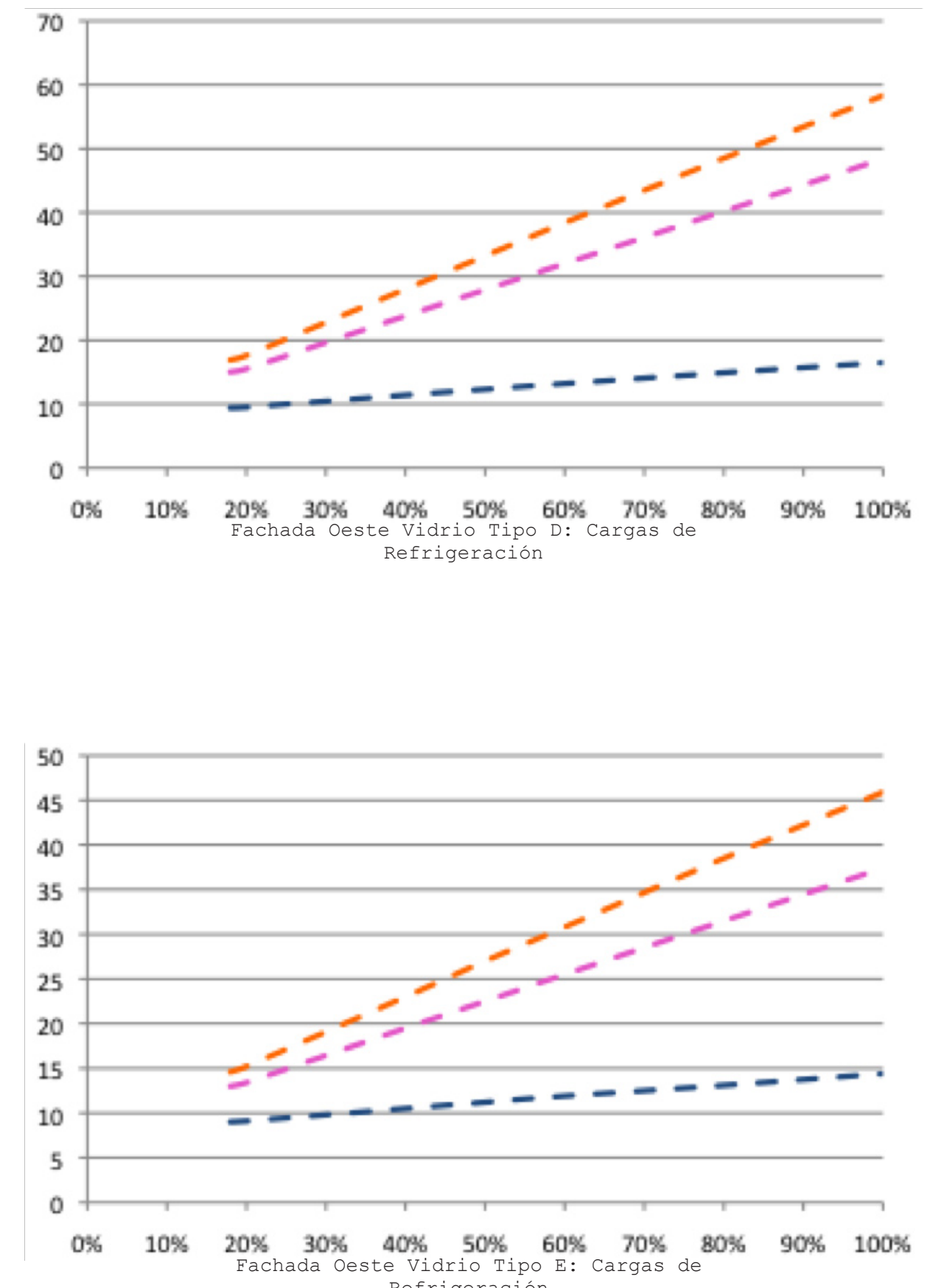

389 
ANEXOS

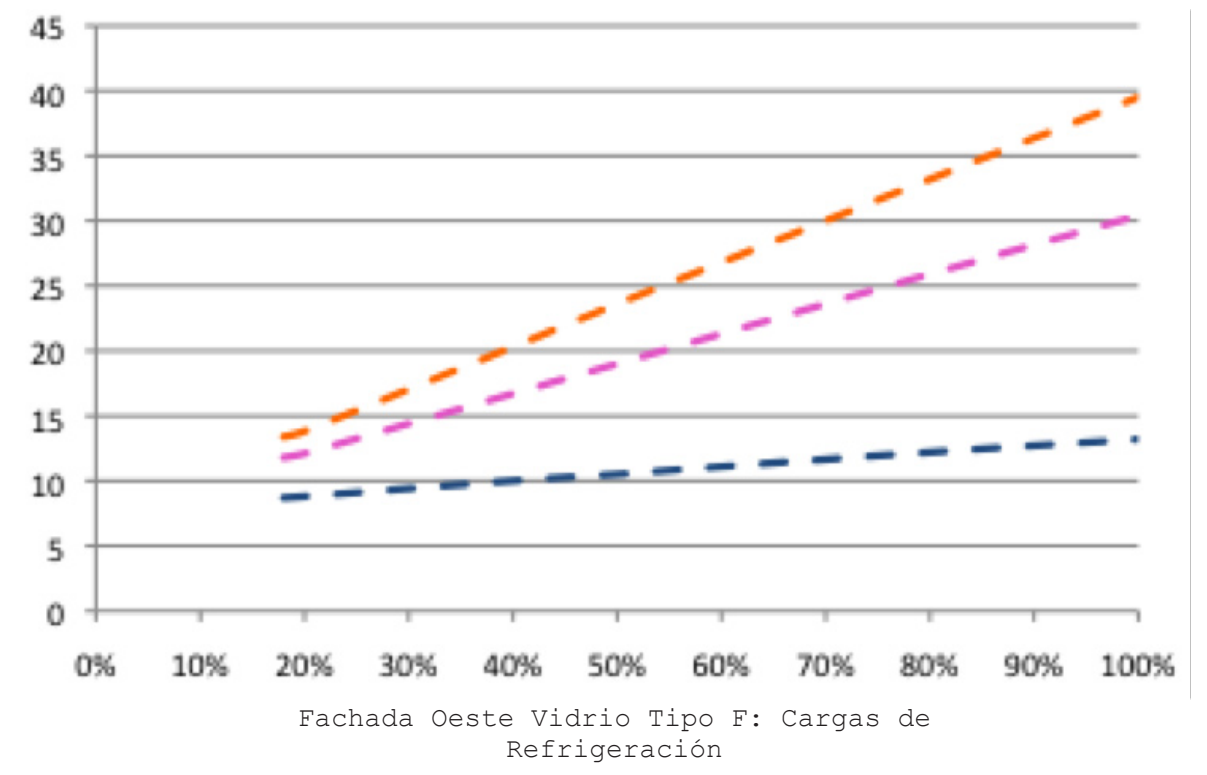

390 


